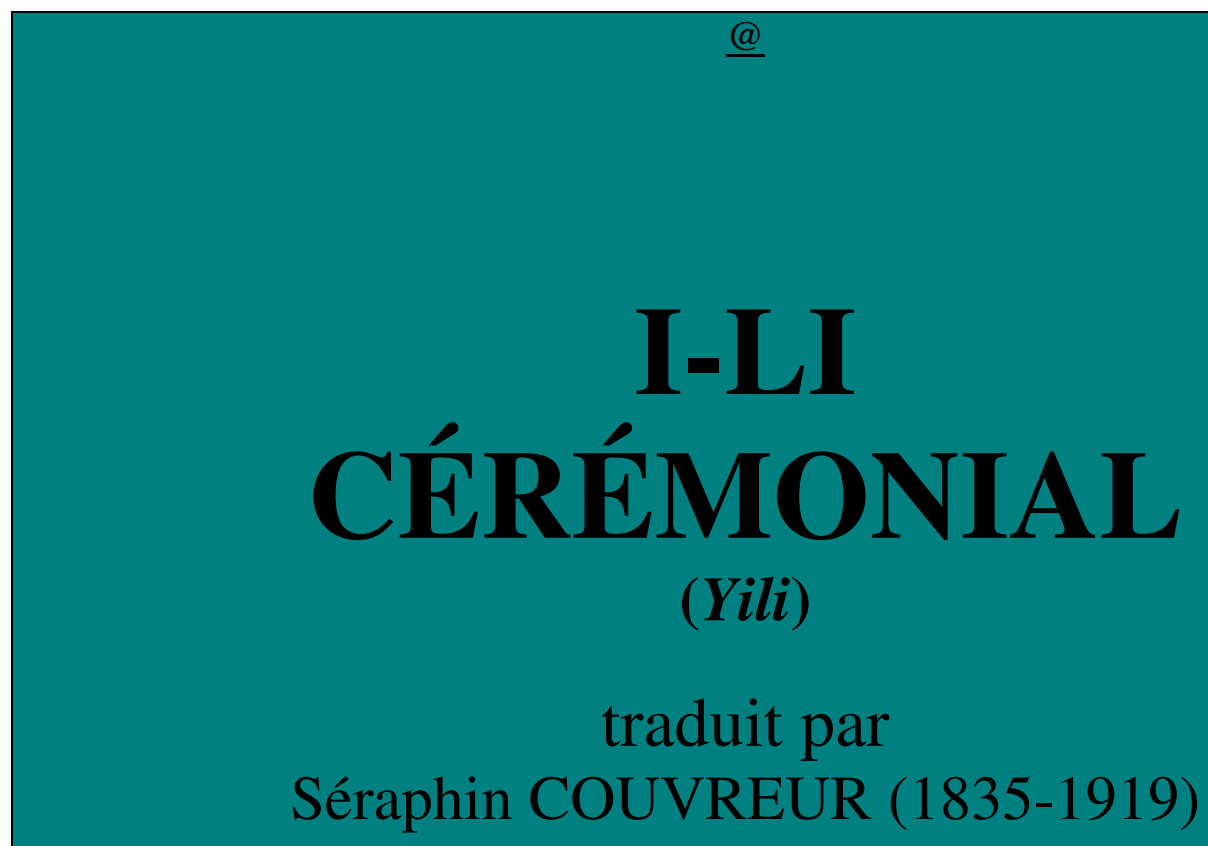

Un document produit en version numérique par Pierre Palpant, collaborateur bénévole

Courriel : pierre.palpant@laposte.net

Dans le cadre de la collection : "Les classiques des sciences sociales" dirigée et fondée par Jean-Marie Tremblay, professeur de sociologie au Cégep de Chicoutimi

Site web : http ://www.uqac.uquebec.ca/zone30/Classiquesdessciencessociales/index.html

Une collection développée en collaboration avec la Bibliothèque Paul-Émile-Boulet de l'Université du Québec à Chicoutimi

Site web : http ://bibliotheque.uqac.uquebec.ca/index.htm 
Un document produit en version numérique par Pierre Palpant, collaborateur bénévole, Courriel : pierre.palpant@laposte.net

à partir de :

\section{I-LI}

CÉRÉMONIAL

\section{traduit par Séraphin COUVREUR (1835-1919)}

Les Humanités d'Extrême-Orient, Cathasia, série culturelle des Hautes Études de Tien-Tsin, LES BELLES LETTRES, Paris, 1951, 668 pages.

Polices de caractères utilisée : Times, 12 points.

Mise en page sur papier format LETTRE (US letter), 8.5' $x$ 11'.

Édition complétée le 30 novembre 2004 à Chicoutimi, Québec. 


\section{T A B LE DES M A T I È R E S}

$\underline{\text { Préface }}$

Chapitre I . $\quad \underline{\text { Imposition du bonnet viril à un futur officier }}$

Chapitre II. $\quad$ Mariage d'un futur officier

Chapitre III. $\quad$ Visite d'un officier à un autre officier

Chapitre IV. $\quad$ Banquet cantonal

Chapitre V. Tir de l'arc dans un canton

Chapitre VI. $\quad$ Banquet à la cour d'un chef d'État

Chapitre VII. $\quad$ Grand tir de l'arc

Chapitre VIII. $\quad \underline{\text { Ambassades }}$

Chapitre IX. $\quad$ Repas donné par un prince à un grand préfet étranger

Chapitre X. $\quad$ Visites des princes à l'empereur

Chapitre XI. $\quad$ Vêtements de deuil

Chapitre XII. $\quad$ Cérémonies funèbres à la mort d'un officier

Chapitre XIII. $\quad$ Après les lamentations du soir

Chapitre XIV. $\quad$ Offrandes présentées au retour de l'enterrement d'un simple officier.

Chapitre XV. $\quad$ Offrandes d'une seule victime.

Chapitre XVI. $\quad$ Offrandes d'un agneau et d'un porc.

Chapitre XVII. Le maître de cérémonie enlève les offrandes 


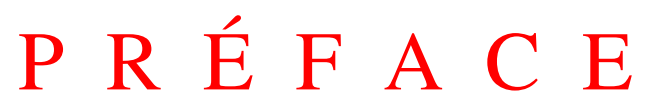

Parmi les ouvrages célèbres de la Chine, les $S \bullet n$ lì tiennent un rang distingué. Le premier, le $L i k i$, a été traduit en anglais par Legge; nous l'avons traduit en français. Le deuxième, le $T c h e \bullet u$ lì, a été traduit en français par Édouard Biot. Le troisième, le $\hat{I}$ lì, a-t-il jamais été traduit en langue européenne? Nous l'ignorons. Sans avoir la même importance que les deux autres, il n'est pas sans intérêt. Mais, pour le bien comprendre, il est nécessaire de recourir aux chapitres correspondants du Li ki. Il aurait été trop long de répéter ici en notes les explications contenues dans le Li ki. Il sera très utile de consulter souvent les gravures qui sont dans cet ouvrage, spécialement celle qui représente le plan du palais impérial. Les grandes maisons, les résidences des officiers étaient disposées à peu près de la même manière.

La préface et l'introduction placées en tête de la traduction du $\mathrm{Li}$ ki fournissent des renseignements sur la formation, la disparition, la réapparition et les commentaires des trois Li.

Hsien hsien, janvier 1916.

[css : pour mémoire, cf. l'article de C. de Harlez du Journal Asiatique, sur Gallica.bnf : I-li, le plus ancien rituel de la Chine, 1889, Sér. 8, T. 13, pp. 229-270] 


\section{CHAPITRE I}

\section{Imposition du bonnet viril à un futur officier}

$[\mathrm{Li} \mathrm{ki} \bullet$

$\mathbf{O} \cdot 1$. - Les sorts sont consultés au moyen de brins d'achillée à la grande porte du temple. Le maître de la maison, portant le bonnet noir, les vêtements de cour, la ceinture noire, les genouillères de cuir blanc, va se placer au côté oriental de la grande porte de celui des temples des ancêtres dans lequel est la tablette de son père défunt. Il tourne le visage vers l'occi dent. (Un chéu jeune homme destiné à remplir une charge recevait le bonnet viril à l'âge de vingt ans, parfois avant cet âge. Le chef de la maison était l'aïeul, le père ou le frère aîné du jeune homme qui devait recevoir le bonnet. Il présidait à la cérémonie. Les sorts étaient consultés sur le choix du jour de l'imposition du bonnet). Les officiers subalternes du maître de la maison, vêtus comme lui, prennent place au côté occidental de la porte et tournent le visage vers l'orient. Ils se $r$ angent du nord au sud, par ordre de dignité, les plus dignes au nord. Les brins d'achillée, la natte du devin, les objets qui serviront à tracer sur le sol les symboles obtenus sont déposés $\bullet_{2}$ près de la salle située au côté occidental de la grande porte du temple. On étend la natte du devin dans l'ouverture de cette porte, à l'ouest du poteau vertical sur lequel se joignent les deux battants et en dehors du seuil. On la tourne vers l'ouest.

Le devin prend l'étui qui contient les brins d'achillée. Il en enlève la partie supérieure. (Cet étui était fait comme nos étuis à aiguilles). Tenant le tout entre ses mains, il va (à l'est) demander les ordres du maître de la maison. (Il lui demande quelles questions il soumettra aux sorts). Lintendant, qui est à la droite du maitre de la maison, se retire un peu en arrière, et l'aide à communiquer les questions au devin. Le devin promet de poser ces questions exactement. Il tourne à droite (vers le nord), et va s'agenouiller sur sa natte, le visage tourné vers l'ouest. Celui qui trace sur le sol les symboles obtenus est au côté gauche du devin. Les sorts consultés (et les symboles tracés sur le sol), le devin transcrit les symboles sur des planchettes, prend ces planchettes et les montre au maître de la maison. Le maître de la maison les reçoit, les regarde et les rend au devin. Le devin va reprendre sa place (à l'ouest), et tourne le visage vers l'est. Avec tous ses subalternes, il interprète le sens des symboles. Cette interprétation terminée, si les sorts ont répondu que le jour proposé serait un jour heureux, il en informe le maître de la maison. Sinon, il consulte de nouveau les sorts sur le choix d'un jour plus éloigné ; cela, de la même manière. (Il a $\bullet \bullet_{3}$ consulté sur un jour de la siûn décade présente de jours du mois. Il consultera sur un jour de la décade suivante) On enlève la natte du devin. Le maitre des cérémonies du temple des ancêtres annonce que ce premier acte est terminé. 
O Le maître de la maison avertit plusieurs étrangers (ses collègues ou ses amis. Il va en personne à leurs maisons et les invite à la grande cérémonie). Ces étrangers s'excusent d'abord, par pure politesse ; puis ils acceptent l'invitation. Le maître de la maison les salue deux fois à genoux. Les invités lui rendent le salut. Le maître de la maison se retire. Les invités le saluent à genoux et le reconduisent.

O L'avant-veille du jour fixé pour l'imposition du bonnet, les sorts sont consultés au moyen des brins d'achillée sur le choix de celui des invités étrangers qui assistera le maître de la maison (et l'aidera à imposer le bonnet). Ils sont consultés de la même manière quills ont été consultés sur le choix du jour.

O Alors le maître de la maison va inviter celui des étrangers qui a été choisi pour être son assistant. (Si• signifie tsú introduire avec respect, inviter à entrer). Cet invité, vêtu comme le maître de la maison, sort de chez lui, se place au côté gauche de sa grande porte, le visage tourné vers l'ouest, et salue deux fois à genoux. Le maître de la maison, le visage tourné vers l'est, lui $\bullet_{4}$ rend son double salut. Ensuite il l'invite à lui servir d'as sistant. Cet étranger accepte l'invitation. Le maître de la mai son le salue deux fois à genoux. Linvité lui rend son double salut. Le maître de la maison se retire. L’invité le salue à genoux et le reconduit. Le maître de la maison va inviter quelqu'un à aider l'assistant étranger. Il l’invite de la même manière qu'il a invité l'assistant.

O Le lendemain du jour de ces invitations, au soir, l'inten dant annonce le moment fixé pour l'imposition du bonnet. Il l'an nonce en dehors de la porte du temple. Le maître de la maison se tient debout au côté oriental de la porte. Ses parents sont à son côté méridional, un peu en arrière, le visage tourné vers l'ouest, Ils son t rangés du nord au sud par ordre d'âge, les plus âgés au nord. Les officiers, vêtus comme au jour des invitations si $i^{\bullet}$, sont tous debout à l'ouest, le visage tourné vers l'est. Ils sont rangés par ordre de dignité, du nord au sud. L'officier chargé par le maître de la maison de traiter avec les hôtes demande quel est le moment fixé pour l'imposition du bonnet. L'intendant répond :

— Juste au lever du jour se fera la cérémonie.

L'hospi talier en donne avis aux parents du maître de la maison et à tous les officiers. Le maître des cérémonies du temple des ancêtres avertit que cette partie de la cérémonie est terminée. L'hospitalier va chez tous les invités annoncer le moment de l'imposition du bonnet.

$\mathbf{O} \cdot{ }_{5}$ Le matin on se lève de bonne heure. On dispose des sì cruches vides le long de l'aile orientale de l'édifice, du sud au nord, dans toute la largeur de la plateforme. (Ces cruches recevront l'eau dont on se sera servi pour se laver les mains ou rincer les coupes). Des jarres pleines d'eau sont placées à l'est de ces cruches. 
Les vêtements destinés au jeune homme sont rangés dans le bâtiment latéral, au pied du mur occidental, le collet tourné vers l'est. Ils sont rangés du nord au sud par ordre de beauté, les plus beaux au nord. Ce sont les vêtements qu'on porte avec le bonnet de peau qui a la forme et la couleur de la tête du moineau ; à savoir, le vêtement inférieur de couleur rouge pâle, la tunique de soie simple, la ceinture noire, les genouillères de cuir couleur garance. Ce sont les vêtements qu'on porte avec le bonnet de peau (de cerf blanc) ; à savoir, le vêtement inférieur de soie blanche plissé à la ceinture, la ceinture noire, les genouillères de cuir blanc. Avec le bonnet de peau blanche on peut aussi porter la longue tunique de couleur noirâtre, le vêtement inférieur noirâtre, le vêtement inférieur jaune, le vêtement inférieur de plusieurs couleurs. On prépare aussi la ceinture noire et les genouillères de cuir de la couleur de la tête du moineau.

Pour le bonnet de toile noire, on prépare le k'ouèi bandeau qui (enveloppe la partie intérieure de la chevelure et) ${ }_{6}$ se lie sur le hiáng derrière du cou. (Ce bonnet n'a pas d'épingles $k^{\bullet}$ ). On prépare les rubans verts qui s'appliquent sur ce bandeau, et une bande de soie noire sì ou chéu, prise dans toute la largeur de la pièce de soie, et longue de six pieds. Les épingles du bonnet de peau de cerf blanc, les épingles du bonnet de peau en forme de tête de moineau, les rubans de soie noire qui lient ces bonnets sous le menton, les bordures rouges qu'on ajoute à ces rubans ; tous ces objets sont dans une même corbeille (avec ceux énumérés plus haut pour le bonnet de toile noire).

Les peignes sont dans un panier. Deux nattes de jonc sont à l'angle méridional de la porte.

Une amphore $t c h \bullet$ unique, contenant du vin non fermenté, est au nord des vêtements. Il y a une corbeille, qui contient une grande cuiller, une grande coupe et une cuiller de corne. Il y a des tranches de viande aromatisées et séchées, de la viande hachée et conservée dans une saumure. Ces objets sont rangés du sud au nord; le plus noble est au sud. (L'amphore tsuøn est au sud; la corbeille est au nord de l'amphore ; les vases de viande sont au nord de la corbeille. L'amphore pour le vin doux n'est pas accompagnée, comme en d'autres cérémonies, de l'amphore pour le hiuên tsiòu vin noir, c'est-à-dire, l'eau pure).

Le bonnet de peau tête de moineau, le bonnet de peau de cerf, le bonnet de toile noire sont chacun dans un panier. Trois officiers subalternes prennent en mains chacun un de ces $\bullet_{7}$ bonnets, et vont attendre la cérémonie au sud de la crédence occidentale (dans la cour). Ils tournent le visage vers le sud. Ils se rangent de l'est à l'ouest ; le plus noble (celui qui tient le bonnet tête de moineau) est le plus à l'est. Quand l'assis tant étranger du maître de la maison monte les degrés de la salle, les trois officiers subalternes tournent le visage (vers lui) vers l'est.

$\mathbf{O}$ Le maître de la maison, portant la longue tunique de couleur noirâtre et les genouillères de cuir couleur moineau, (dans le temple où est la tablette de son père), se tient debout au bas des degrés orientaux de la salle, le dos tourné 
droit au mur oriental, le visage tourné vers l'ouest. Les parents du maître de la maison, $p \bullet$ tous, tchøn entièrement vêtus de hiuên noir, se tiennent debout à l'est des cruches, le visage tourné vers l'ouest. Ils sont rangés du nord au sud par ordre d'âge ou de dignité, les plus dignes au nord. (Tchøn. Vêtement dont la tunique - et la partie inférieure châng sont de la même couleur l'une que l'autre). L'hospitalier, vêtu de la longue tunique noire, a le dos tourné au bâtiment qui est à l'est de la grand'porte. (Son visage est tourné vers le nord). Le jeune homme qui va recevoir le bonnet viril, portant une tunique de toile à bordures, la chevelure liée en forme de chignon, est dans le bâtiment latéral, le visage tourné vers le sud.

O L'assistant étranger, vêtu comme le maître de la maison, et les aides qui l'accompagnent, vêtus de la longue tunique $\bullet_{8}$ noire, se tiennent debout en dehors de la grand'porte de la maison. L'officier chargé de traiter avec les hôtes va annoncer leur arrivée au maître de la maison. Le maître de la maison va les recevoir. Il sort de la grande porte, se place au côté gauche de cette porte, le visage tourné vers l'ouest. Il salue deux fois à genoux l'assistant. Celui-ci lui rend son double salut. Le maître de la maison salue les aides par une inclination profonde. Il fait une inclination profonde à l'assistant, et entre le premier (pour montrer le chemin). A chaque tournant ils se font l'un à l'autre une inclination profonde. Arrivés à la grande porte de celui des temples où est la tablette du père du maître de la maison, ils se saluent par une inclination profonde et entrent. Ils se saluent encore de la même manière dans la cour en trois endroits différents. Arrivés au pied des degrés de la salle, trois fois ils demandent de se céder le pas l'un à l'autre. Le maître de la maison monte les degrés, se tient debout à l'angle du bâtiment situé au côté oriental de la plateforme de la salle, le visage tourné vers l'ouest. L'assistant (monte aussi les degrés), se place près du bâtiment situé au côté occidental, le visage tourné vers l'est.

O Les aides de l'assistant se lavent les mains à l'ouest des cruches, montent les degrés de le salle, se tiennent debout dans le bâtiment latéral, le visage tourné vers l'ouest. Ils sont rangés du sud au nord, par ordre de dignité ; les plus dignes au sud. Les aides du maître de la maison étendent une natte pour le jeune homme auprès du bâtiment situé au côté oriental de la $\bullet_{9}$ plateforme de la salle, un peu au nord de celle du maître de la maison, et de manière que le jeune homme ait le visage tourné vers l'ouest. Celui qui doit recevoir le bonnet sort du bâtiment latéral, tourne le visage vers l'ouest. Les aides de l'assistant mettent la bande de soie noire, les épingles de tête, les peignes à l'angle méridional de la natte du jeune homme. L'assistant salue par une inclination celui qui va recevoir le bonnet. Celui-ci va à sa natte et se met à genoux. Les aides de l'assistant, à genoux, peignent la chevelure du jeune homme et étendent la bande de soie noire sur son cou. L'assistant descend les degrés de la salle (pour aller se laver les mains). Le maître de la maison descend aussi (pour lui faire honneur). L'as sistant décline cet honneur. Le maître de la maison répond à ce refus. Quand l'assistant a fini de se laver les mains, il salue par une seule inclination le maître de la maison, l'invite une 
fois à monter les degrés le premier, puis monte lui-même le premier. Le maître de la maison monte aussi, et va reprendre sa place (à l'angle du mur oriental).

L'assistant se met à genoux sur le devant de la natte du jeune homme, ajuste sur son cou la bande de soie noire, se lève, descend le plus élevé des degrés occidentaux de la salle. L'aide qui tient en mains le bonnet de toile noire monte le plus bas de ces degrés, et, le visage tourné vers l'est, donne le bonnet à l'assistant. (Les marches sont au nombre de trois. ${ }_{10}$ L'assistant descend une marche; l'aide monte une marche. Ils se trouvent tous deux sur la deuxième marche). L'assistant prend de la main droite la partie du bonnet qui sera sur le derrière du cou du jeune homme, et de la main gauche celle qui sera sur le devant de la tête. Il s'avance avec dignité. Alors il exprime des souhaits de bonheur. Il se met à genoux, comme auparavant, sur le devant de la natte du jeune homme; ensuite il lui met le bonnet sur la tête. Il se lève et retourne à sa place (près du mur occidental). Les aides achèvent l'ouvrage, (arrangent et lient le bonnet sur la tête du jeune homme).

Celui qui a reçu le bonnet se lève. L'assistant le salue par une inclination profonde. Le jeune homme entre dans le bâtiment latéral, revêt la longue tunique noire et les genouillères de cuir couleur moineau, sort du bâtiment latéral, et tourne le visage vers le midi. L'assistant le salue par une inclination profonde. Le jeune homme va se mettre à genoux sur sa natte. (Les aides lui ôtent le bonnet de toile noire), lui peignent la chevelure et y mettent des épingles. L'assistant se lave les mains, ajuste la bande de soie noire, comme la première fois.

Il descend deux degrés, reçoit le bonnet de peau de cerf blanc tient de la main droite la partie qui sera sur le derrière du cou, et de $\bullet_{11}$ la main gauche la partie qui sera sur le devant de la tête. Il s'avance, exprime des souhaits de bonheur, et met ce bonnet sur la tête du jeune homme, comme il lui a mis précédemment le bonnet de toile noire. Il retourne à sa place. Les aides achèvent l'ouvrage ; ils lient les cordons du bonnet. Le jeune homme se lève. L'assis tant le salue par une inclination. (On lui ôte le bonnet de peau blanche). Le jeune homme entre dans le bâtiment latéral, revêt la robe blanche plissée à la ceinture et les genouillères de cuir blanc ; puis, avec un air de dignité, il sort du bâtiment latéral et tourne le visage vers le midi. L'assistant descend les trois degrés, reçoit le bonnet de peau qui a la forme et la couleur de la tête du moineau, et le pose sur la tête du jeune homme. Celui-ci met une jupe rougeâtre et des genouillères de cuir rouge. Les autres cérémonies sont semblables à celles qui suivent l'im position du bonnet de peau blanche. Les aides du maître de la maison enlèvent le bonnet de peau blanche, les peignes, la natte, et entrent dans le bâtiment latéral.

$\mathbf{O}$ - Les aides du maître de la maison étendent une natte à l'ouest de la porte de la grande salle pour le jeune homme, de manière qu'il ait le visage tourné vers le sud. Les aides lavent (leurs mains et une coupe) dans le bâtiment latéral, servent $t c h \bullet$ seulement du vin non fermenté. Ils mettent sur 
la coupe une cuiller. Ils tournent cette cuiller à l'envers, de manière que le $i \bullet$ cuilleron est dirigé en avant. L'assis tant salue par une inclination le jeune homme qui a reçu le bonnet. Celui-ci va occuper sa natte. Sa natte est à l'ouest de la porte de la salle. Elle est placée de manière qu'il tourne le visage vers le sud. L'assistant reçoit la coupe de vin $\bullet_{12}$ à l'est de la porte de la salle. Il tourne en avant le manche de la cuiller qui est sur la coupe. Arrivé devant la natte du jeune homme, il tourne le visage vers le nord (et présente la coupe).

Le jeune homme qui a reçu le bonnet, à l'ouest de sa natte, salue à genoux, et reçoit la coupe. L'assistant (retourne à sa place près du mur au côté occidental de la plateforme, et) le visage tourné vers l'est, rend le salut. Les aides apportent des tranches de viande séchées et du hachis de viande conservé dans une saumure. Le jeune homme qui a reçu le bonnet va à sa natte et se met à genoux. De la main gauche il prend la coupe ; de la main droite il offre aux esprits les tranches et le hachis de viande. Avec la cuiller il (puise trois fois du vin dans la coupe et) offre aux esprits trois libations. Il se lève (après chaque libation). A genoux, à l'extrémité de sa natte, il goûte le vin. $T c h$ ' Il met la cuiller dans la coupe, se lève, quitte sa natte, se met à genoux, dépose la coupe, salue à genoux l'assistant, reprend la coupe et se lève. L'assistant lui rend son salut.

$\mathbf{O}$ Celui qui a reçu le bonnet dépose la coupe à l'est de la viande qui lu i a été servie, quitte sa natte, tourne le visage au nord, se met à genoux, prend les tranches de viande, descend par les degrés qui sont à l'ouest, va au bâtiment oriental de la cour, tourne le visage vers le nord, et se présente devant $\bullet_{13}$ sa mère (c'est-à-dire, devant la maîtresse de la maison, qui est sortie et est à la porte des appartements des femmes). Sa mère le salue à genoux et reçoit les tranches de viande. Le fils salue sa mère à genoux, la reconduit chez elle et la salue de nouveau.

O L'assistant descend les degrés de la salle, et va se placer droit à l'angle du bâtiment occidental, le visage tourné vers l'est. Le maître de la maison descend aussi les degrés et retourne à sa première place (à l'angle du bâtiment oriental). Celui qui a reçu le bonnet se tient debout à l'est des degrés occidentaux, le visage tourné vers le sud. L'assistant, lui donne un tsèu nom nouveau. Le jeune homme répond, (il remercie l'assistant).

O L'assistant sort. Le maître de la maison l'accompagne jusqu'au dehors de la grande porte du temple. Il le prie de lui permettre de lui offrir des présents. L'assistant refuse une fois, par pure cérémonie ; puis il accepte. Il se rend à la tente (qui est dressée en dehors de la grande porte du temple. Il y attend les présents).

$\mathbf{O}$ Celui qui a reçu le bonnet se présente devant ses frères. Ses frères le saluent deux fois à genoux. Il leur rend leur double salut. Il se présente devant les aides. Les aides, le visage tourné vers l'ouest, le saluent à genoux. Il leur rend encore leur salut, comme il l'a rendu précédemment. Il entre dans $\bullet_{14}$ le quartier des femmes : il se présente devant ses tantes paternelles, et devant 
celles de ses sœurs qui sont plus âgées que lui, comme il s'est présenté devant sa mère. (Il ne va pas voir ses sœurs puînées).

O Ensuite il change de vêtements. Il prend le bonnet de couleur noirâtre, la longue tunique de couleur noirâtre, les genouillères de cuir couleur moineau. (Il va au palais), dépose un présent (un faisan), et paraît devant le prince. Ensuite, toujours avec un présent (un faisan) en mains, il paraît devant le chef et les anciens grands préfets du canton.

$\mathbf{O}$-: Alors le maître de la maison offre des présents à l'assistant, après un banquet dans lequel le vin n'est offert qu'une fois. Le maître de la maison, pour témoigner sa reconnaissance à l'assist ant, lui donne cinq pièces de soie et deux peaux de cerfs. Tous les aides, c'est-à-dire, tous les $p \bullet n$ étrangers invités, sont présents. Les officiers de rang inférieur qui ont aidé à imposer le bonnet tiennent compagnie à ces nobles invités. L'assistant s'en va. Le maître de la maison l'ac compagne jusqu'au dehors de la grande porte extérieure de la maison. Il le salue deux fois à genoux. Il envoie à la maison de l'assistant la viande qui a été servie à l'assistant sur une petite table.

O Si, (selon l'a ncien usage), le maître de la maison n'offre $\bullet{ }_{15}$ pas de présents à l'assistant, il lui offre une coupe de vin fermenté. Entre le bâtiment latéral et la porte de la salle, on place deux amphores sur des supports. Celle qui contient l'eau pure est à l'ouest de celle qui contient le vin. Sur chaque amphore on met une cuiller, le manche tourné vers le midi. A l'ouest des cruches, on place des corbeilles (qui contiennent des cuillers et des coupes). On les range du nord au sud, les moins distinguées au sud. (chouén, céder, être inférieur).

Après l'imposition du premier bonnet (du bonnet de toile noire), le maître de la maison offre à l'assistant une coupe de vin ; il y ajoute des tranches de viande séchées et du hachis de viande conservé dans la saumure. L'assist ant descend les degrés, prend une coupe dans une corbeille. Il refuse l'honneur que le maître de la maison lui fait de descendre à sa suite, comme précédemment. Après avoir rincé la coupe, il monte les degrés, et offre la coupe pleine de vin au jeune homme qui a reçu le bonnet. Celui-ci salue à genoux et reçoit la coupe. L'assistant lui rend son salut, comme précédemment. Le jeune homme monte sur sa natte et se met à genoux. De la main gauche il tient la coupe. De la main droite il offre aux esprits les tranches de viande et le hachis de viande. Il leur offre le vin. Il se lève, se met à genoux à l'extrémité de sa natte et goûte le vin, Il descend de sa natte et salue l'assistant à genoux. L'assistant lui rend son salut. Le jeune homme $\bullet{ }_{16}$ dépose la coupe à l'est de la viande qui lui a été pré sentée. Il se tient debout à l'ouest de sa natte. Les aides enlèvent les viandes et la coupe. Ils n'enlèvent ni les amphores ni la natte.

L'assistant impose le bonnet de peau avec les mêmes cérémonies que précédemment. Il offre une seconde coupe de vin au jeune homme. Le vin est ch préparé avec soin. Tout le reste, comme précédemment. L'assistant 
impose le bonnet qui a la forme et la couleur de la tête du moineau. Il l'impose avec les mêmes observances que les deux bonnets précédents. Une troisième fois il offre une coupe de vin au jeune homme. On lui sert aussi de la. viande séchée, et sur une petite table, les membres séparés d'un animal (un jeune porc). Le jeune homme goûte ces viandes. Le reste, comme précédemment. Le jeune homme tourne le visage vers le nord, prend les tranches de viande et va se présenter devant sa mère.

O Si l'on tue un animal, c'est un jeune porc, un seul. On le tsái met sur une petite table, $h \bullet$ tout entier, après l'avoir ch॰ng mis et fait cuire tout entier dans une chaudière. On sépare par une incision les deux poumons l'un de l'autre à leur petite extrémité, avant de les mettre dans la chaudière. On dispose un levier avec lequel on porte la chaudière, et une couverture que l'on met dessus. L'assistant offre une première coupe de vin au jeune homme, comme il a été dit précédemment, c'est -à-dire, ${ }^{\bullet}{ }_{17}$ comme quand on n'a pas tué d'animal. La deuxième fois quill lui offre une coupe de vin, il lui s ert deux vases de bois contenant des mauves, des légumes, des escargots hachés et conservés dans une saumure ; et deux vases de bambou contenant des châtaignes et des tranches de viande séchées. Quand la coupe est offerte pour la troisième fois, elle contient un vin bien préparé, comme la deuxième fois, lorsqu'on n'a pas tué de porc. On ajoute une petite table sur laquelle sont les membres séparés du jeune porc. Le jeune homme offre aux esprits ce qui est sur la petite table ; le tout, comme précédemment. Il offre aux esprits les poumons. Lorsque l'assistant a fini d'offrir la coupe, le jeune homme prend les tranches de viande contenues dans les vases de bambou, descend les degrés, (va voir sa mère), comme il a été dit précédemment.

O Si le jeune homme n’a plus ni père ni aïeul paternel, son oncle paternel ou son frère aîné (qui est le maître de la maison) avertit et invite respectueusement les étrangers. Le jour de l’imposition du bonnet, le maître de la maison, les cheveux liés en forme de chignon, va à la grande porte recevoir l'assistant. Il le salue à genoux, se lève, (reçoit le salut qui lui est rendu), salue par une inclination profonde, invite l'étranger à monter les degrés. (Sur le refus de l'étranger, il monte le pre mier, et) se tient debout à l'angle du bâtiment situé au côté oriental de la plateforme. Il agit en tout comme président de l'imposition du bonnet; il préside auprès des degrés orientaux. Chaque $\bullet_{18}$ fois quill salue à genoux l'assistant, c'est le visage tourné vers le nord, au haut des degrés orientaux. L'assistant lui rend son salut, aussi le visage tourné vers le nord, au haut des degrés occidentaux. Si l'on tue un jeune porc, on porte et on dis pose la chaudière en dehors de la grande porte du temple. On la place droit près du bâtiment situé à l'est de la grande porte, en face du nord.

O Si celui qui reçoit le bonnet est le fils d'une femme de second rang, il le reçoit en dehors du bâtiment situé au côté de la plateforme (non au haut des degrés orientaux). Il a le visage tourné au midi. Ensuite une coupe de vin lui est présentée. 
$\mathbf{O}$ Si la mère de celui qui reçoit le bonnet est absente, une personne est chargée de recevoir en sa place les tranches de viande au bas des degrés occidentaux.

$\mathbf{O}$ Le maître de la maison invite les étrangers en ces termes :

- Moi un tel, j’ai un fils nommé N., sur la tête duquel on imposera un bonnet de toile. Je désire que Monseigneur donne à ce fils des enseignements.

L’inv ité répond :

- Moi un tel, je manque dintelligence ; je crains de ne pas savoir remplir cet office, et d'affliger ainsi Monseigneur. Je me permets de décliner cette invitation.

Le maître de la maison reprend :

- Moi un tel, je désire toujours que Monseigneur enfin donne des enseignements à $\bullet{ }_{19}$ mon fils.

L’invité répond :

- Monseigneur m’a réitéré son invitation. Oserais-je ne pas l'accepter?

Le maître de la maison avertit respectueusement chacun des invités, en lui disant :

- Moi un tel, j’imposerai le bo nnet de toile sur la tête d'un tel. Monseigneur voudra bien y assister. Je me permets de l'informer respectueusement.

L'invité répond :

- Moi un tel, oserais-je ne pas me lever de bonne heure pour cette cérémonie ?

Avant la première imposition, c'est-à-dire, avant l'imposition du bonnet de toile noire, l'assistant adresse au jeune homme des souhaits de bonheur en ces termes :

- Le mois est favorable et le jour propice. Je mets sur votre iuên tête un premier f $u$ bonnet. Bannissez vos idées de jeune homme ; suivez les inspirations d'un vertu parfaite. Vivez longtemps. Ouêi $k$ 'î Le ciel vous est favorable. Kiái il augmentera votre kìng grande félicité.

Avant dimposer le deuxième bonnet, l'assistant dit :

- Profitant d'un mois favorable et d'un jour du cycle heureux, je vous donne un deuxième bonnet. Veillez avec soin sur la dignité et la tenue de votre personne. Faites bien attention à cultiver votre vertu. Vous atteindrez une grande vieillesse; vous $\bullet_{20}$ vivrez dix mille ans. Vous jouirez toujours d'une longue prospérité. 
Avant d'imposer le troisième bonnet, l'assistant dit :

- Profitant d'une année heureuse et d'un mois favorable, je vous impose tous vos bonnets l'un après l'autre. Vos frères sont tous présents et montrent leur vertu. Vos cheveux deviendront jaunes et votre visage ridé par l'effet de la vieillesse ; votre vie n'aura pas de fin. Vous recevrez les faveurs du ciel.

En offrant le vin non fermenté au jeune homme, l'assistant lui adresse ces paroles :

- Ce vin doux est un vin généreux. Ces excellents mets qui vous sont présentés ont une odeur agréable. Saluez à genoux, recevez-les et offrez-les aux esprits, afin d'assurer votre bonheur, de recevoir les faveurs du ciel, de vivre longtemps et de n'être jamais oublié.

En offrant le vin fermenté (la première fois) l'assistant dit :

- Ce bon vin a été clarifié. Ces excellents mets sont tout à fait de saison. Quand on vous a mis le premier bonnet sur la iuên tête, vos frères sont tous venus, attirés par votre piété filiale et votre affection fraternelle. Conservez à jamais ces sentiments.

En offrant au jeune homme le vin fermenté, la deuxième fois, l'assistant lui adresse ces paroles :

- Ce bon vin a été ${ }_{21}$ clarifié. Ces excellents mets sont des tranches de viande séchées. Vous avez reçu un deuxième bonnet. Les cérémonies et les observances se continuent. Offrez aux esprits cette coupe d'excellent vin. Vous recevrez les faveurs du ciel.

En offrant le vin la troisième fois l'assistant dit :

- Ce bon vin a une excellente odeur. Ces vases de bambou et de bois sont tch'òu rangés en bon ordre. Vous avez reçu tous les bonnets l'un après l'autre. La chair d'un jeune porc a été mise dans la chaudière. Ses membres séparés sont sur une petite table. Vous recevrez les faveurs du ciel ; vous jouirez d'une félicité sans limite.

Avant de donner un nom nouveau au jeune homme, l'as sistant lui dit :

- Toutes les cérémonies et les observances ont été accomplies. Profitant d'un mois favorable et d'un jour heureux, je vais proclamer votre nom. Ce nom est très beau. Il convient à un mâ̂ chéu homme éminent.

Si le jeune homme est l'aîné de ses frères, l'assistant l'appelle Pe N. fou. Si c'est le deuxième, le troisième, le quatrième de plusieurs frères, l'assistant l'appelle de même Tchoung N. fou, Chou N. fou, Ki N. fou, selon qu'il convient. (Ainsi Confucius fut appelé Tchóung Nî ou Nîfôu). 
O Les chaussures en été sont de chanvre. Avec la longue tunique noire, les chaussures sont noires ; à leur extrémité ${ }_{22}$ elles ont des cordons verts, et, entre la semelle et l'empeigne, un liseret vert. Les bordures de la tunique sont aussi vertes ; elles ont un pouce $(2 \mathrm{~cm})$ de largeur. Avec la tunique blanche plissée, les chaussures sont blanches, recouvertes de chaux d'écailles d'huîtres. Le urs cordons et leurs liserets sont noirs. Les bordures de la tunique sont aussi noires; elles ont un pouce de largeur. Avec le bonnet de peau qui a la forme et la couleur de la tête d'un moineau, les chaussures sont brunes. Leurs cordons et leurs liserets sont noirs. Les bordures de la robe sont aussi noires. Elles ont un pouce de largeur. En hiver, il convient que les chaussures soient de cuir. Les chaussures de souéi toile claire ne sont pas admises (parce que ce sont des chaussures de deuil).

\section{NOTES SUPPLÉMENTAIRES.}

O Signification de l'imposition du bonnet. Le bonnet qu'on impose en premier lieu est le bonnet de toile noire. Dans la haute antiquité, les bonnets ordinaires étaient de toile (blanche). En temps d'abstinence, ils étaient de toile noire. Quant aux rubans des anciens bonnets, Confucius dit : «Je n'en ai pas entendu parler. » Le premier bonnet une fois reçu, il convient de le dédaigner et de le laisser de côté.

Le fils aîné de la femme principale reçoit le bonnet au haut $\bullet{ }_{23}$ des degrés orientaux de la salle, pour montrer qu'il sera le chef de la famille. (Ces degrés sont ceux par lesquels monte le maître de la maison). Il reçoit la coupe de vin à la place destinée aux hôtes, parce que, après avoir reçu le bonnet, il est devenu homme fait. On lui impose en premier lieu le plus vil des trois bonnets, et en dernier lieu, le plus noble, pour signifier que ses aspirations doivent devenir de plus en plus élevées. Après lui avoir imposé les bonnets, on lui donne un nom, qui l'emporte en noblesse sur s on nom d'enfance.

Le bonnet noir appelé ouèi maó a été mis en usage sous la dynastie des Tcheou. Le bonnet noir appelé tchøng fòu était en usage sous les In. Le bonnet noir appelé mê̂u tou॰i était en usage sous la dynastie des Hia. Les Tcheou portaient le bonnet de peau appelé pién; les In, celui appelé hiù ; les Hia, celui appelé che $u$. Sous les trois premières dynasties, avec le p'î pién, on portait la longue tunique noire plissée. (Le mot pién était usité sous les trois dynasties).

Il n'y avait pas de règles particulières pour l'imposition du bonnet aux grands préfets; il y en avait pour leur mariage. Anciennement (avant la dynastie des Tcheou), on n'entrait pas en dignité avant l'âge de cinquante ans. Comment les grands préfets auraient-ils reçu le bonnet à cet âge ? (Mais ils pouvaient se remarier). Il y avait des règles pour limposition du bonnet aux chefs d'État du plus haut rang ; et elles n'avaient pas été $\bullet{ }_{24}$ introduites par les Hia (elles existaient avant la dynastie des Hia. Un jeune prince pouvait succéder à son père avant l'âge de vingt ans, avant d'avoir reçu le bonnet 
viril). Le fils â̂né du fils du ciel reçoit le bonnet comme tout jeune homme destiné aux charges. Dans l'univers il n'est personne qui naisse élevé en dignité. Celui qui succède à ses pères dans la dignité de chef d'État doit imiter leur vertu et leur habileté. La vertu et le talent doivent être en rapport avec la charge et avec la dignité.

L'usage de donner un nom posthume à d'autres qu'aux dignitaires est récent. (Il s'est introduit sous les Tcheou). Anciennement, celui qui n'avait pas été en dignité pendant sa vie ne recevait pas de nom posthume après sa mort. 


\section{CHAPITRE II}

\section{Mariage d'un futur officier}

${ }_{25} \div:-$ Le maître de la maison du jeune homme communique avec le maître de la maison de la jeune fille. (Ses paroles hiá descendent, parce qu'un jeune homme est au dessus d'une fille. Les pourparlers se font par l'intermédiaire d'entremetteurs). Ensuite il envoie des présents ; le porteur tient une oie dans les mains. (L'o ie sait discerner les saisons de l'année •n iâng. Les deux principes •n iâng désignent les deux sexes). Le maître de la maison de la jeune fille fait étendre une natte à l'ouest de la porte de la salle du temple où est la tablette de son père défunt. Cette natte est tournée vers l'ouest. A droite de la natte on place un escabeau. (Cette natte et cet escabeau sont pour les mânes qui viendront assister à la cérémonie). Le messager, vêtu d'une longue tunique noire, arrive à la grande porte de la maison de la jeune fille. L'officier chargé de traiter avec les hôtes sort et lui demande pour quelle affaire il est venu. Cet officier rentre et avertit son maître. Le maître de la maison, vêtu comme cet envoyé étranger, va le recevoir au dehors de la grande porte, et le salue deux fois à genoux. L'é tranger ne rend pas le salut à genoux, (parce quill n'ose pas $\bullet{ }_{26}$ traiter d'égal à égal avec le maître de la maison). Ils se font l'un à l'autre une inclination profonde, et ils entrent.

Arrivés à la grande porte du temple, ils se font l'un à l'autre une inclination profonde et entrent. Ensuite, à trois endroits différents, ils se font une inclination profonde. Arrivés au pied des degrés de la salle, ils s'invitent trois fois l'un l'autre à mon ter (ils veulent se céder le pas). Le maître de la maison monte avec l'étranger. Il (monte lui-même par les degrés orientaux, et) tourne le visage vers l'ouest. L'étranger monte par les degrés occidentaux, va jusque sous la $n g \bullet$ filière du bord du toit de la salle, et, le visage tourné vers l'est, dit l'objet de son message. Le maître de la maison, au haut des degrés orientaux, le visage tourné vers le nord, salue deux fois à genoux. Le messager donne son oie au maître de la maison entre les deux colonnes de la plateforme, le visage tourné vers le midi. Il descend les degrés et s'en va. Le maître de la maison descend aussi, et donne l'oie à son laò intendant.

$\mathbf{O}$ (L'envoyé étranger revient). L'officier chargé de traiter avec les hôtes sort, et demande ce quiil désire. L'envoyé, tenant en mains une oie, demande d’interroger le maître de la maison sur le nom de famille de la jeune fille. Le maître de la maison y consent. L'envoyé entre et donne son oie. Les observances sont les mêmes que précédemment. (La jeune fille peut être une parente par les femmes, et n'avoir pas le même nom de famille que celui chez qui elle demeure. Il faut savoir son nom $\bullet_{27}$ de famille, pour consulter les sorts, comme il sera dit plus loin). 
$\mathbf{O}$ (L'envoyé étranger revient). L'officier chargé de traiter avec les hôtes sort et lui demande ce qu'il désire. L'étranger répond que tout est fini. L'officier rentre, avertit son maître, sort de nouveau et invite l'étranger à recevoir des présents. L'étranger refuse d'ab ord par pure politesse ; ensuite il accepte. Le maître de la maison fait enlever l'escabeau préparé pour les mânes, et étendre une autre natte tournée vers l'est. Une amphore unique contenant du vin non fermenté est dans le bâtiment latéral. (Il n'y a pas d'amphore contenant de l'eau). Le maître de la maison va recevoir l'étranger en dehors de la grande porte du temple. Ils se saluent l'un l'autre par des inclinations, ils veulent se céder le pas, comme précédemment. Il montent les degrés. Le maître de la maison, le visage tourné vers le nord, salue deux fois à genoux. L'étranger, au haut des degrés occidentaux, le visage tourné vers le nord, à son tour salue à genoux. Le maître de la maison essuie (avec la manche de sa tunique) un escabeau, et il en présente le kiaó pied à l'étranger. Ensuite il le salue deux fois à genoux. (Pái sóung. Saluer quelqu'un après lui avoir donné un objet). L'étranger prend l'escabeau, se retire, et, le visage tourné vers le nord, le place sur la natte où il est invité à s'asseoir. Il le place à gauche. Au haut des degrés occidentaux, il $\bullet_{28}$ rend le salut à genoux.

Un aide du maître de la maison verse du vin non fermenté dans une coupe. Sur cette coupe il met une cuiller, qu'il tourne à l'envers, le cuilleron dirigé en avant. Il apporte cette coupe du bâtiment latéral. Le maître de la maison la reçoit, et la tient, le manche de la cuiller dirigé en avant, devant la natte, le visage tourné au nord-ouest. L'étranger salue à genoux, reçoit la coupe de vin non fermenté, et retourne à sa place (au haut des degrés occidentaux). Le maître de la maison, au haut des degrés orientaux, le salue à genoux, après lui avoir donné la coupe. Des aides servent sur la natte des tranches de viande séchées, et de la viande hachée conservée dans une saumure.

L'étranger s'approche de la natte et s'agenouille. De la main gauche il prend la coupe ; (de la main droite) il offre la viande aux mânes ; puis avec la cuiller il leur offre trois fois du vin en libation. Ensuite, au haut des degrés occidentaux, le visage tourné vers le nord, il s'agenouille et goûte le vin. Il met la cuiller dans la coupe, se lève, s'agenouille de nouveau, et dépose la coupe. Ensuite il salue à genoux. Le maître de la maison lui rend son salut. L'étranger va vers la natte, et y dépos e la coupe à gauche des mets qui ont été servis. Il quitte la natte ; le visage tourné $\bullet_{29}$ au nord, il s'agenouille et enlève les tranches de viande (que le maître de la maison lui a fait servir). Le maître de la maison le prie de ne pas emporter lui-même ces tranches de viande, (et de laisser cet office à un serviteur). L'étranger (n'y consent pas), descend les degrés, et donne les tranches de viande à l'un de ses suivants. (De retour à la maison de son maître, il lui présentera ces tranches de viande et lui rendra compte de sa mission). Il s'en va. Le maître de la maison l'accompagne jusqu'en dehors de la grande porte. Il le salue à genoux deux fois.

O Un envoyé du maître de la maison du jeune homme va annoncer au maître de la maison de la jeune fille que, d'après la réponse des sorts, le 
mariage sera heureux; il porte une oie. Les cérémonies sont les mêmes que lorsqu'on offre les présents. Voy. page $\bullet_{25}$.

O Un envoyé du maître de la maison du jeune homme va demander au maître de la maison de la jeune fille de fixer le jour des noces ; il porte une oie. Le maître de la maison décline cet honneur de fixer le jour. L'envoyé se rend à son désir, et lui annonce le jour fixé par le maître de la maison du jeune homme.

$\mathbf{O}$ \# Les présents offerts au père de la jeune fille en signe de consentement irrévocable sont cinq pièces de soie noire unie, cinq pièces de soie brune unie, deux peaux de cerfs. Les cérémonies sont semblables à celles qui ont lieu lorsqu'on annonce la réponse favorable des sorts.

$\mathbf{O} \cdot 30 \mathrm{Au}$ jour fixé, on commence les cérémonies des noces. Trois chaudières sont placées en dehors de la grande porte des appartements particuliers du fiancé, à l'est. Elles regardent le nord, et sont rangées du nord au sud; la plus distinguée est au nord. La plus distinguée contient un jeune porc, qui y a été mis tout entier, sans les orteils. Elle contient deux paires de poumons, qui seront levés et présentés aux nouveaux époux; deux côtes prises sur le dos du porc, et deux paires de poumons qui seront offerts aux mânes. La deuxième chaudière contient quatorze poissons. La troisième contient un lièvre séché tout entier. Les hanches des animaux ne sont pas mises dans les chaudières (elles sont trop viles). Ces viandes, ces poissons sont préparés sur le feu. On dépose les leviers qui servent à porter les chaudières, et les couvertures qui les protègent de la poussière. On met des cruches au sud-est des degrés orientaux. Des mets et des assaisonnements sont dans le bâtiment latéral. Il y a deux vases de bois contenant du vinaigre et de la sauce ; quatre vases de bois contenant des légumes conservés dans le sel et le vinaigre, de la viande hachée et conservée dans le sel et le vinaigre. Ces six vases sont recouverts chacun d'un lin ge. Il y a quatre vases de bois contenant du millet glutineux et du millet non glutineux. Ils ont chacun un couvercle. Le grand ragoût et le jus de viande sont sur le feu du foyer.

Deux amphores sont dans la salle au pied du mur oriental, $\bullet_{31}$ sur des supports. Celle qui contient l'eau est à l'ouest de celle qui contient le vin. Une toile de gros chanvre les couvre. Sur chaque amphore il y a une cuiller, le manche tourné vers le sud. Une amphore de vin est placée à l'est entre le bâtiment latéral et la porte de la salle. Il n'y a pas d'amphore à eau. Une corbeille est au sud. Elle contient quatre coupes, et les deux moitiés d'une calebasse.

$\mathbf{O}$ Le maître (le fiancé) porte un bonnet de peau semblable à la tête du moineau, un vêtement inférieur brun à bordures noires. (Le fiancé est appelé maître, parce que le mari est le maître de sa femme). Ses suivants portent tous la longue tunique noire. Le fiancé monte une voiture enduite de vernis noir. Deux autres voitures la suivent. Des hommes portant des flambeaux marchent devant les chevaux. (Il est soir). La voiture préparée pour la fiancée est 
semblable à celle du fiancé. Les tentures qui couvrent cette voiture ont des bordures pendantes. Le fiancé va à la grande porte de la maison de sa fiancée. Le maître de la maison de la fiancée fait étendre une natte à l'ouest de la porte. La tête ou partie principale de cette natte regarde l'ouest. A droite un escabeau est placé. (Les mânes y descendront).

- La jeune fille, ts'éu parée de cheveux étrangers, vêtue d'une tunique de soie tch'ouên d'une seule couleur à jân bordures brunes, est debout dans le bâtiment latéral, le visage tourné ${ }_{32}$ vers le sud. Sa gouvernante, portant autour de la tête sì ou chèu une bande de soie ajustée avec des épingles, et vêtue d'une tunique à $c h a \bullet$ collet de soie à fleurs, se tient à sa droite. Les compagnes de la jeune fille la suivent, portant toutes des vêtements noirs, une bande de soie ajustée avec des épingles autour de la tête, et k'iòung une tunique sans doublure, sur le collet de laquelle des fòu haches sont brodées en blanc et en noir. (Ces compagnes sont des sœurs puînées et des nièces de la fiancée. Elles vont faire partie du sérail du nouveau marié).

Le maître de la maison du jeune homme, vêtu d'une longue robe noire, va recevoir le jeune époux en dehors de la grande porte de la maison. Le visage tourné vers l'ouest, il le salue deux fois à genoux. Le jeune homme, le visage tourné vers l'est, lui rend son double salut. Le maître de la maison fait une inclination profonde et entre. Le jeune homme le suit, en tenant une oie dans les mains. Arrivés tous deux à la grande porte du temple où est la tablette du père défunt du chef de la maison, ils se font l'un à l'autre une inclination profonde et entrent. A trois reprises différentes, ils se font encore l'un à l'autre une inclination profonde. Arrivés au bas des degrés, trois fois ils veulent se céder le pas l'un à l'autre. Le maître de la maison monte le premier et tourne le visage vers l'ouest. Le jeune homme monte et tourne le visage vers le nord. Il dépose son oie, et salue deux fois à genoux, en frappant du front la terre. (Ce salut ne lui est pas rendu). Il descend les degrés et s'en $\bullet_{33}$ va. Sa jeune épouse descend à sa suite par les degrés occidentaux. Le maître de la maison ne descend pas et n'accompagne pas les nouveaux époux.

Le gendre, c'est-à-dire, le jeune époux, amène la voiture de son épouse, et présente à celle-ci le bout de la corde qui aide à monter en voiture. La gouvernante décline ce service et refuse de recevoir la corde. La nouvelle épouse monte en voiture à l'aide d'un escabeau. La gouvernante met sur la jeune fille un kìng par-dessus (qui la préservera de la poussière). Le jeune époux fait avancer les chevaux. (Quand la voiture a fait trois tours de roues), le conducteur prend la place du jeune époux (et conduit la voiture). Le jeune marié monte sa propre voiture, prend les devants, et attend son épouse devant la grande porte de sa propre maison.

Quand son épouse arrive, il la salue par une inclination profonde et entre. Arrivé à la grande porte des appartements il salue son épouse par une inclination profonde et entre. Il monte avec elle à la salle par les degrés occidentaux. Les ing parentes qui accompagnent la mariée étendent une natte à l'angle sud-ouest de la grande salle. Le jeune époux entre dans cette salle et 
s'approche de la natte. (C'est la place ordinaire du maître de la maison). La jeune épouse se place à l'ouest de l'amphore, le visage tourné vers le midi. - Les compagnes de l'épouse et les iá compagnons de l'époux kia s'échangent et présentent de l'eau aux deux époux, qui se lavent les mains. ${ }_{34}$ Les compagnons de l'époux portent de l'eau à l'épouse, et les compagnes de l'épouse à l'époux).

O Les aides découvrent les amphores. Les porteurs des chaudières se lavent les mains et s'en vont. Ils découvrent les chaudières, les emportent, entrent avec elles et les placent au sud des degrés orientaux. Ils les tournent vers l'ouest et les rangent du nord au sud, la plus distinguée au nord. Des cuillers et des petites tables arrivent à la suite des chaudières, et sont rangées auprès d'elles. Les aides, le visage tourné vers le nord, mettent les viandes sur les petites tables, prennent dans leurs mains ces tables, et attendent que les teóu vases de bois soient placés. Ceux qui ont apporté les cuillers se retirent en ordre inverse. (Les derniers arrivés s'en vont les premiers). Ils retour nent à leurs places à l'est de la grande porte, tournent le visage vers le nord ; ils se rangent de l'ouest à l'est, les plus respec tables à l'ouest.

Les aides mettent la sauce devant la natte du fiancé ; au nord de la sauce ils mettent les légumes conservés dans la saumure, les viandes hachées et conservées dans le sel et le vinaigre. Les petites tables arrivent et sont placées à l'est des vases de bois (qui contiennent les viandes et les légumes conservés dans la saumure). Les poissons viennent ensuite. Un lièvre séché est placé seul au nord des petites tables. Les aides placent du millet glutineux à l'est de la sauce, et du millet $\bullet_{35}$ non glutineux à l'est du millet glutineux. Ils mettent le jus de viande au sud de la sauce.

En face de ces mets servis pour le nouvel époux, les aides placent à l'est un vase de sauce pour l'épouse. Au midi de la sauce ils servent des conserves de légumes et de viande dans le sel et le vinaigre; ils placent la viande au nord des légumes comme étant un mets plus distingué. Ils placent le millet glutineux au nord du lièvre, et le millet non glutineux à l'ouest du millet glutineux. Ils placent le jus de viande au nord de la sauce. Les compagnons de l'époux étendent une natte pour l'épouse en face de la natte de l'époux. Les aides enlèvent les couvercles des vases de millet de l'époux, et les déposent, en les tournant à l'enver s, au sud de ces vases. Les vases de millet de l'épouse sont au nord.

$\mathbf{O}$ Les aides avertissent que tout est prêt. L'époux salue son épouse par une inclination profonde, pour l'inviter à s'approcher de la natte qui lui est préparée. Tous deux se mettent à genoux sur leurs nattes et font des offrandes aux esprits. Ils leur offrent les conserves de légumes et de viande, le millet glutineux, le millet non glutineux, les poumons. Les aides èul placent près des deux époux le millet glutineux sur les nattes. (Les deux époux mangent ce millet). Ensuite les aides leur présentent les poumons et les côtes du dos. Les époux (offrent aux mânes et) mangent ces deux mets avec du jus de viande et de la sauce. Ils les offrent levés et présentés par les aides. Ils $\bullet{ }_{36}$ les mangent 
levés et présentés par les aides. (Le jus de viande se boit; la sauce se prend avec le doigt). Après que les époux ont goûté de trois mets, leur repas est fini.

Un aide rince une coupe, y verse du vin et la présente à l'époux, afin que l'époux boive un peu comme pour se rincer la bouche. L'époux salue à genoux et reçoit la coupe. L'aide, à l'intérieur de la salle, le visage tourné vers le nord, rend le salut. Il présente à boire à l'épouse de la même manière. Les deux époux, avant de boire, offrent le vin aux mânes.

Les aides apportent ensuite un foie à chacun des deux époux. Les deux époux secouent le foie, l'offrent aux esprits, le goûtent du bout des lèvres, puis le mettent dans les vases qui contiennent les conserves de légumes. Après avoir fini de boire, ils saluent à genoux. L'aide leur rend le salut et prend la coupe. Il leur présente à boire une deuxième fois, comme la première fois. Mais ensuite on ne leur sert aucun mets. La troisième fois qu'on leur présente à boire, on se sert des deux moitiés d'une calebasse en guise de coupes. Le tout se passe comme les deux premières fois.

Les aides rincent deux coupes, y versent du vin à l'amphore qui est en dehors de la porte de la salle, entrent dans la salle, $\bullet_{37}$ à l'ouest de cette porte. Le visage tourné vers le nord, ils déposent les coupes et saluent à genoux. Les deux époux leur rendent le salut. Les aides s'agenouillent, offrent le vin aux mânes et le boivent eux-mêmes. Quand ils ont fini de boire, ils saluent à genoux. Les deux époux leur rendent le salut et se lèvent.

L'époux sort de la salle. L'épouse retourne à sa place (à l'ouest de l'amphore). Les aides enlèvent les mets qui sont dans la salle, et les placent dans le bâtiment latéral, dans le même ordre que dans la salle. Il n'y transportent pas l'amphore, (parce que dehors il y a une amphore).

L'époux ôte son vêtement dans le bâtiment latéral. Une des suivantes de l'épouse le reçoit. L'épouse ôte son vêtement dans la salle. Un des suivants de l'époux le reçoit. La gouvernante présente une serv iette à l'épouse (qui se lave les mains et les essuie).

Un des suivants de l'époux étend à l'angle sud -ouest de la salle une natte sur laquelle l'épouse prendra son repos. Une compagne de l'épouse étend à l'est une natte sur laquelle le mari se reposera. (Leâng est le nom qu'une femme donne à son mari). Chaque natte a un oreiller. L'extrémité où seront les pieds est au nord. Le mari entre dans la salle. Il ôte lui-même les rubans qui parent la tête de $\bullet_{38}$ sa femme. Les flambeaux sont emportés.

O Les compagnes de l'épouse mangent les restes de l'époux. Les suivants de l'époux mangent les restes de l'épouse. Pour quils se rincent ensuite la bouche, les aides leur versent du vin à l'amphore qui est dehors. Les compagnes de l'épouse se tiennent près d'elle, de hors à la porte de la salle. Dès que l'épouse les appellera, elles l'entendront.

- Le lendemain les époux se lèvent de bonne heure. L'épouse se lave la chevelure, puis tout le corps. Elle entoure sa chevelure d'une bande de soie 
qu'elle fixe avec des épingles, revêt la tunique à cha collet de soie, et attend le moment de paraître devant le maître et la maîtresse de la maison de son mari. Dès qu'il fait jour tchøu mîng, un aide présente l'épouse au père et à la mère de son mari, ou, s’ils sont morts, au maître et à la maîtresse de la maison de son mari, en leurs appartements particuliers. Une natte est étendue au haut des degrés ; le beau-père y prend place. Une autre natte est étendue en dehors du bâtiment latéral, la tête tournée au sud; la belle-mère y prend place. La jeune épouse, tenant en mains une corbeille qui contient des jujubes et des châtaignes, entre par la grande porte des appartements particuliers, monte par les degrés occidentaux, s'avance et salue à genoux son beau-père. Elle dépose sa corbeille sur la natte du beau-père. Celui-ci, à genoux, pose la main $\bullet_{39}$ sur la corbeille (il ne la prend pas). Il se lève, puis rend le salut à genoux. La jeune épouse retourne (à l'endroit où elle a salué une première fois), et salue de nouveau à genoux. Elle descend les degrés de la salle, reçoit d'un aide une corbeille qui contient si u des tranches de viande aromatisées et séchées, monte les degrés et s'avance. Le visage tourné vers le nord, elle salue à genoux sa belle-mère, et dépose la corbeille sur sa natte. La belle-mère fléchit les genoux, prend la corbeille et se lève. A genoux elle rend le salut. Elle donne la corbeille à un officier.

$\mathbf{O}$ Les aides traitent avec honneur la nouvelle épouse. Une natte est étendue sur la plateforme, entre la porte et la fenêtre de la salle. Une amphore tch $\bullet$ unique, contenant du vin non fermenté, est dans le bâtiment latéral. La nouvelle épouse reste debout • immobile à l'ouest de la natte. Un aide verse dans une coupe du vin non fermenté, met sur la coupe une cuiller, dont il tourne le manche en avant, sort du bâtiment latéral, et se présente devant la natte de l'épouse, le visage tourné vers le nord. L'épouse, le visage tourné vers l'est, salue à genoux et reçoit la coupe. L'aide, au haut des degrés occidentaux, le visage tourné vers le nord, salue à genoux. L'é pouse le salue de nouveau à genoux.

• 40 Un aide sert à l'épouse des tranches de viande séchées et de la viande hachée conservée dans une saumure. L'épouse monte sur la natte, et de la main gauche prend la coupe. De la main droite elle offre les conserves de viande aux esprits, et avec la cuiller elle leur offre trois libations. Elle quitte la natte, tourne le visage vers l'est, s'agenouille, goûte le vin non fermenté, met la cuiller dans la coupe, se lève et salue à genoux. L'aide lui rend ce salut. L'épouse le salue de nouveau à genoux, et dépose la coupe à l'est des viandes qui lui out été servies. Le visage tourné vers le nord, elle fléchit les genoux, prend les tranches de viande, descend les degrés et s'en va. Au sortir de la grande porte, elle donne les tranches de viande à un officier (qui les emporte).

$\boldsymbol{O}$ Le beau-père et la belle-mère entrent dans la salle de leurs appartements particuliers. La nouvelle épouse, après s'être lavé les mains, leur sert à manger. Un jeune porc chøng a été mis dans la chaudière $h \bullet$ tout entier. Tsái il est servi $t c h \bullet$ divisé en deux moitiés. (Le côté droit est servi sur une petite table au beau-père, et le côté gauche à la belle-mère). Il n'y a ni poisson 
ni lièvre séché. Il n’y a pas de millet non glutineux. Pour les différents mets, le midi est la place la plus honorable. Les autres observances sont les mêmes que celles usitées aux noces d'une fille. L'épouse aide son beau -père et sa belle-mère à offrir les mets aux esprits. Le beau-père et la belle-mère, après ${ }_{41}$ avoir mangé, se rincent la bouche une fois avec un peu de vin. Aucun mets n'est servi après cette boisson.

O Une natte est étendue au pied du mur septentrional de la salle. La nouvelle épouse enlève les mets qu'elle a servis à ses beaux -parents, et les dispose sur le devant de cette natte, comme précédemment, de l'ouest à l'est, les plus distingués à l'ouest. Elle mange les restes de son beau -père, excepté la sauce que son beau-père ne lui laisse pas manger, et fait changer pour une autre sauce. (La sauce se mangeait avec les doigts. Un reste de sauce n'était pas propre). Elle mange les restes de sa belle-mère. Un des compagnons de l'époux l'aide et offre pour elle aux esprits le contenu des vases de bois, le millet glutineux et les poumons. Il lève et présente à l'épouse les poumons et les côtes du dos. Elle les mange. Quand elle a fini de manger, sa belle-mère lui offre du vin, pour qu'elle se rince la bouche. La nouvelle épouse salue à genoux et reçoit la coupe. La belle-mère la salue ensuite à genoux. L'épouse à genoux offre ce vin aux esprits. Quand elle a bu, la belle-mère reçoit la coupe et la dépose (dans une corbeille). La jeune femme enlève tout ce qui reste et le porte dans le bâtiment latéral. Les compagnes de la nouvelle épouse mangent les restes du beau-père et les iá compagnons de l'époux mangent les restes de la belle-mère. Ensuite la belle-mère leur offre du vin pour se rincer la bouche. Les compagnes de l'épouse, même quand il n'y a pas parmi elles de sours puînées, (mais seulement des nièces de l'épouse), mangent $\bullet_{42}$ avant les compagnons de l'époux. Alors, comme au commencement du repas du beau-père et de la belle-mère, il y a échange. (Les compagnes de l'épouse servent l'époux ; les compagnons de l'époux servent l'épouse).

$\mathbf{O}$ Le beau-père et la belle-mère offrent à la jeune épouse un repas, dans lequel le vin est offert deux fois (une fois par le beau-père, une deuxième fois par la belle-mère). Le beau-père se lave les mains et rince une coupe près de la cruche qui est au sud. La belle-mère fait de même près de la cruche qui est au nord. Elle dépose sa coupe sur la natte de sa belle-fille, et lui offre à boire pour la deuxième fois. (• hién. Le maître de la maison, après avoir offert à boire à son hôte une première fois, et après avoir bu lui-même le vin que tsó son hôte lui a offert à son tour, tch'eôu offre à boire une deuxième fois à son hôte. Le tout s'appelle - hién). Le beau-père et la belle-mère descendent les premiers par les degrés occidentaux. La nouvelle épouse descend par les degrés orientaux. Le nouvel époux envoie à la chambre de sa femme, par un serviteur de sa femme, la viande de porc qui a été servie sur les petites tables.

$\mathbf{O}$ Le beau-père offre un repas aux officiers qui ont escorté la nouvelle épouse venant pour célébrer ses noces. Le vin y est offert • hién deux fois. La deuxième fois que la coupe est offerte par le beau-père, elle est accompagnée d'un présent de cinq pièces de kìn soie à fleurs de diverses couleurs. (La 
deuxième fois le vin n'est pas bu). La belle -mère offre aussi un festin aux $\bullet_{43}$ officiers qui ont escorté la nouvelle épouse. La deuxième fois que la coupe paraît, elle est accompagnée d'un présent de cinq pièces de soie à fleurs. Si la nouvelle épouse est d'une principauté étrangère ; la belle-mère donne cinq pièces de soie à fleurs aux officiers de ce pays étranger qui ont escorté l'époux amenant sa fiancée.

$\mathbf{O} \mathrm{Si}$ le beau-père et la belle-mère sont déjà morts, la nouvelle épouse, trois mois après son arrivée, dépose des légumes (et les offre à leurs mânes. Ces légumes, appelés kìn, ressemblent au cresson). Une natte est étendue au sud-ouest du temple où sont les tablettes du beau-père et de la belle-mère. Elle est tournée vers l'est. A droite est un escabeau. (Cette natte et cet escabeau sont pour les mânes des deux défunts). Au nord (au pied du iòung mur), on étend une autre natte, qu'on tourne vers le midi. L'invocateur se lave les mains. La jeune femme aussi se lave les mains en dehors de la grande porte. Elle prend la corbeille qui contient les légumes.

L'invocateur la conduit dans la salle du temple et informe les mânes. Il prononce le nom de famille de l'épouse, et dit :

- Une fille de telle famille est venue en qualité d'épouse. Elle se permet de déposer et d'offrir d'excellents légumes à son beau -père défunt, le Seigneur un tel.

L'épouse salue à genoux, les mains appuyées contre terre. (Elle se lève). A genoux, elle dépose les légumes sur la natte, à l'est de l' escabeau. Elle retourne à ${ }_{44}$ l'endroit où elle a fait un salut, et salue de nouveau à genoux, comme la première fois. Elle descend les degrés, prend une corbeille contenant des légumes, (monte de nouveau les degrés et) se présente devant la natte préparée pour les mânes de sa belle-mère. L'invocateur dit :

- Une fille de telle famille est venue en qualité d'épouse. Elle se permet d'en informer sa belle-mère défunte, fille de telle famille.

L'épouse dépose les légumes sur la natte de la belle-mère, comme elle a fait pour le beau-père. Elle sort. L'invocateur fer me la fenêtre et la porte de la salle du temple. L'intendant, le visage tourné au midi, offre des présents à l'épouse, dans le bâtiment latéral, comme un beau -père et une belle-mère le font à leur belle-fille. Le gendre (le nouveau marié) offre un repas et des présents aux hommes mariés et aux femmes mariées qui ont escorté son épouse, quand elle est venue célébrer ses noces; cela, à la manière d'un beau-père et d'une belle-mère.

\section{NOTES SUPPLÉMENTAIRES.}

Toutes les cérémonies requises pour le mariage d'un homme distingué doivent se faire le soir ou le matin au crépuscule. Les messages, les présents 
sont reçus dans le temple où est la tablette du père du maître de la maison. $\bullet_{45}$ Le messager ne dit pas que ses présents sont de peu de valeur. Le maître de la maison ne dit pas que le messager s'est abaissé jusqu'à venir. (Les expressions de pure politesse, les symagrées ne sont pas admises). Le messager n'offre pas un oiseau mort. Les peaux, les pièces de soie doivent pouvoir être taillées et mises en auvre. (Elles doivent être de bon aloi). Le lièvre salé doit être récent. Le poisson doit être une petite carpe (symbole de l'assistance mutuelle fóu des deux époux). Les conserves de légumes ou de viande doivent être parfaites, (il faut que rien n'y manque).

$\mathbf{O}$ - Quand une jeune fille promet de se marier, elle reçoit l'épingle de tête. On lui offre des présents. On lui donne un nouveau nom.

(Quand la jeune fille est de la famille princière), si la tablette de son trisaïeul n’a pas encore été enlevée du temple où elle a été placée primitivement, elle reçoit des instructions dans ce temple pendant trois mois. Si cette tablette a déjà été enlevée, la jeune fille reçoit des instructions dans le est la tablette de celui qui a donné naissance à sa branche de famille.

$\mathbf{O}$ Quand le messager envoyé par le père du prétendant demande quel est le nom de famille de la jeune fille, le maître de la maison reçoit l'oie du messager (entre les deux colonnes de la plateforme), retourne (au haut des degrés orientaux), et, le visage tourné vers l'ouest, répond au messager. Le messager, avant reçu la réponse, descend les $\bullet_{46}$ degrés de la salle. (On lui offre une coupe de vin et des tranches de viande séchées). Une première fois, il puise du vin dans la coupe avec la cuiller et offre une libation aux ancêtres défunts. Il puise de nouveau du vin avec la cuiller et offre une deuxième libation.. Le messager prend les tranches de viande de la main droite, les soutient avec la main gauche, et, s'en retourne chez lui. Il présente ces tranches de viande à celui qui l'a envoyé, et lui rend compte de sa mission.

$\mathbf{O} \bullet$ Lorsque le messager annonce le consentement irrévocable du fiancé, il porte deux peaux de cerfs, le ouên poil tourné à l'intérieur. Il tient les pattes dans les deux mains, tourne les têtes à gauche. Suivi (de deux aides), il entre avec ses présents. Les présents, divisés en trois parts, sont rangés au nord de la cour, de l'ouest à l'est, les plus distingués à l'ouest. Ils regar dent tous le midi. L'envoyé s'acquitte de son message. Il étend en avant les pattes des peaux et laisse voir le poil. Le maître de la maison reçoit les pièces de soie. Les officiers qui doivent recevoir les peaux arrivent dans la cour par l'est, passent derrière le messager, se mettent à sa gauche et reçoivent les peaux. Ensuite ils se mettent à genoux, recueillent les peaux, et se retirent $\bullet$ dans l'ordre inverse. (Les derniers arrivés s'en vont les premiers). Ils vont près du mur oriental.

$\mathbf{O}$ Quand le père donne des présents à sa fille, et attend ${ }_{47}$ qu'on vienne la chercher pour la célébration des noces, la mère, le visage tourné vers le midi, est en dehors du bâtiment latéral. La jeune fille sort et se place à gauche de sa mère. Le père, le visage tourné vers le midi, lui donne des avis. Il ne manque pas de tchéng lui indiquer des objets qui lui rappelleront ces avis, comme sont 
la tunique, l'épingle de tête, qu'elle portera sans cesse sur elle. La mère donne à sa fille des avis au haut des degrés occidentaux. Le père et la mère ne descendent pas de la plateforme.

$\mathbf{O}$ La jeune épouse monte en voiture à l'aide d'un escabeau. Deux de ses suivantes, à genoux, tournées l'une vers l'autre, maintiennent cet escabeau.

O Quand la jeune épouse franchit la grand porte des appartements particuliers du maître de la maison de son époux, un aide enlève la toile qui couvre l'amphore à eau. Trois $t c h \bullet u$ fois il verse de l'eau dans cette amphore, jette le surplus de l'eau entre les deux rangées de degrés, et met une cuiller sur l'amphore.

La corbeille que la jeune femme présente à son beau-père est revêtue de soie noire à l'extérieur et de soie brune à l'inté rieur. Elle est mise sur le buffet. Le beau-père rend à sa belle-fille le salut à genoux. Un intendant enlève la corbeille.

O • ${ }_{48}$ Les tranches de viande séchées et la viande hachée conservée dans une saumure sont d'abord servies sur la natte de l'épouse. Les autres mets sont dans le bâtiment latéral, (et sont servis ensuite).

O Au repas servi à la jeune femme, la belle-mère sert des tranches de viande séchées et de la viande hachée et conservée dans une saumure. La jeune femme rince une coupe sur la partie septentrionale de la plateforme, à l'angle oriental de la salle.

La corbeille est à l'est. La jeune femme se lave les mains, le visage tourné vers le nord. A son tour elle offre il boire à son beau-père (qui lui a servi une coupe de vin). Ensuite elle prend une autre coupe, (se verse du vin et le boit elle-même). Elle prend elle-même et goûte les tranches de viande séchées et le hachis, (et se rince la bouche avec du vin).

Elle n'ose pas prier son beau -père de ne pas rincer la coupe. Quand son beau-père descend, elle se retire dans le bâtiment latéral. Elle ne se permet pas de le saluer après qu'il a rincé la coupe. (Elle n'ose pas lutter de politesse avec lui). Quand une femme offre un festin à une autre femme, ces femmes ne descendent pas les degrés (parce que la cruche à eau et la corbeille qui contient les coupes sont au-dessus des degrés).

$\mathbf{O}$ Une femme, trois mois après son entrée dans la maison de son mari, aide son mari à présenter des offrandes à ses pères défunts (seulement dans le cas où le père du mari est veuf, et dans le cas où le beau-père est mort et la belle-mère âgée de soixante ans ou plus).

$\mathbf{O} \cdot{ }_{49}$ Si la jeune épouse n'est pas la femme du fils aîné de la femme principale, le beau-père et la belle-mère envoient un aide lui présenter une coupe de vin. On ne lui sert pas un jeune porc sur une petite table. (Mais on lui présente des tranches le viande séchées et du hachis). 
$\mathbf{O}$ - L'officier chargé de traiter avec les hôtes dans la maison de la fiancée annonce en ces termes à son maître la demande du mariage :

- Monseigneur, vous êtes bienfaisant. Veuillez donner une fille en mariage à un tel. Un tel (le père du prétendant) est occupé à faire des cérémonies en l'honneur de ses pères. (Il n'a pu venir en personne). Il a envoyé un tel le nom du messager) faire la demande et offrir des présents.

Le père de la jeune fille répond :

— La fille d'un tel (le père de jeune fille) manque d'intelligence et de bon sens. Elle n'est pas même capable de recevoir un peu d'instruction. Monseigneur (le messager) la demande. Moi un tel, je n'ose pas la refuser.

Le messager va s'acquitter de son message auprès du père de la jeune fille. Il lui dit :

— Je me permets de vous apporter des présents.

$\mathbf{O}$ Le messager demande quel est le nom de famille de la jeune fille. (Elle peut n'être pas une fille du maître de la maison, mais une parente). Il dit :

- Moi un tel, après avoir reçu votre assentiment, je consulterai les sorts au moyen de l'écaille de ${ }_{50}$ tortue, pour savoir si le mariage sera heureux. Je me permets de vous demander de quelle famille est cette fille.

Le maître de la maison répond :

- Monseigneur (le messager) a une commission à remplir de la part de celui qui l'a envoyé, et qui a choisi cette fille pour faire nombre dans le sérail. Moi un tel, je ne me permettrai pas de ne pas répondre à sa question.

Le maître de la maison offre des présents à l'envoyé en ces termes :

- Monseigneur est venu à ma maison pour une affaire. Moi un tel, j'ai des objets qui viennent de feu mon père, et sont destinés à être donnés comme présents. Je vous prie de me permettre de les distribuer aux hommes de votre suite.

L'envoyé répond :

- Après que moi N., je suis parvenu à arranger cette affaire, je me permets de refuser les présents.

(Le maître de la maison reprend) :

- Ces objets viennent de feu mon père. Je me permets de vous prier instamment de les accepter.

(L’envoyé réplique) : 
- Moi N, je n'obtiens pas de vous faire accepter mon refus. Oserais-je ne pas suivre votre volonté ?

Le messager, en apportant la réponse favorable des sorts, dit :

- Monseigneur (le maître de la maison de la jeune fille) a eu la bonté de dire le nom de famille de cette fille. $\mathrm{N}$. (le père du prétendant) a consulté les sorts à ce sujet. La réponse des sorts a été favorable. Par son ordre, moi N., je me permets ${ }_{51}$ de vous en informer.

Le maître de la maison répond.

- La fille de N. n’a pas reçu d'éducation. Je crains beaucoup qu'elle soit incapable d'être bonne épouse. Le père du jeune homme a obtenu des sorts une réponse favorable. Moi aussi, j'ai part au bienfait de cet heureux présage. Moi N., je n'ose pas opposer un refus.

Quand l'envoyé apporte les présents et la réponse définitive du maitre de la maison du jeune homme au maître de la maison de la jeune fille, il dit à l'officier chargé de traiter avec les hôtes :

- Monseigneur (le maître de la maison de la jeune fille) a donné une excellente réponse. Il a promis une épouse au fils de N. (qui m'a envoyé). N. (qui m’a envoyé) avait des objets qu'il tenait de feu son père, et qui étaient destinés à être donnés comme présents, deux peaux de cerfs, cinq pièces ale soie. Il m’a chargé, moi N., de les offrir, et vous prie de les accepter comme présents de fiançailles.

En s'acquittant de sa mission, il dit au chef de famille :

- Moi N., je me permets de vous apporter des présents de fiançailles.

Le maître de la maison répond au messager :

— Monseigneur, conformément à l'ancien usage, m’offre de riches présents, à moi N.. Je n'ose pas les refuser. Me permettrais -je de ne pas me conformer à la volonté de celui qui les a envoyés ?

Lorsque l'envoyé interroge sur le jour qui sera fixé pour les noces, il dit à l'officier qui dans la maison de la jeune fille est chargé de traiter avec les hôtes :

- Monseigneur, vous avez la bonté de communiquer les réponses du maitre de la maison. $\bullet_{52}$ Moi N., j'ai plusieurs fois reçu par vous des réponses. Il ne me reste plus qu'à demander quel sera le jour favorable où les noces auront lieu, à moins que, contre toute attente, quelqu'un des trois générations ne vienne à mourir. 
(Ces trois générations sont celles du père, des frères et des fils. En temps de grand deuil, les noces ne peuvent se célébrer). Le maître de la maison répond :

- Moi N., précédemment j'ai reçu vos ordres. A présent, pour ce point spécial du choix du jour, vous n'avez qu'à pa rler, j'obéirai.

L'étranger reprend :

— Un tel qui m'a envoyé m'a commandé, à moi N., de recevoir les ordres de Monseigneur.

Le maître de la maison répète :

- Moi N., je dis de nouveau que j'obéirai, dès que je recevrai un ordre.

L'envoyé répond :

- N. m'a envoyé recevoir des ordres. Monseigneur refuse de donner des ordres. Oserais-je ne pas dire le jour qui a été choisi par celui qui m’a envoyé ?

Le messager dit :

- Tel jour a été choisi.

Le maître de la maison répond :

— Oserais-je n'être pas diligent dans l'attente de ce jour ?

Toutes les fois qu'un messager, de retour chez lui, rend compte de sa mission à celui qui l'a envoyé, il dit :

- Moi N., j'ai pu arranger cette affaire. Je me permets de vous en avertir, et de vous apporter les présents que j'ai reçus.

(Il tient en mains les tranches de viande qui lui ont été données chez la $\bullet_{53}$ fiancée). Le maître de la maison répond :

— J'entends votre rapport.

Quand le père du fiancé offre une coupe de vin à son fils, il lui donne ses avis en ces termes :

- Allez inviter celle qui sera votre aide. Avec elle vous me succéderez dans le service des mânes de nos pères. Efforcez-vous de lui enseigner à devenir, après la mort de votre mère, sa fidèle imitatrice. Si elle l'imite, elle aura constamment une règle de conduite.

Le fils répond :

- Oui. Je crains seulement mon incapacité. Je ne me permettrai pas d'oublier vos recommandations. 
Lorsque l'hôte (le fiancé) arrive à la porte de la maison de la fiancée, l'officier chargé de traiter avec les hôtes lui demande ce qu'il désire. Le fiancé répond :

- Monseigneur, vous avez fait dire à N. (à mon père) que les cérémonies des noces commenceraient $t s \bullet$ en ce moment-ci. Il m'a envoyé, moi N., commencer ces cérémonies, c'est -à-dire, inviter ma fiancée. Je vous prie de me permettre d'exécuter son ordre.

Le maître de la maison répond :

— Moi N., j'ai tout préparé avec soin en attendant ce moment.

Le père accompagne sa fille et lui donne ses avis. Il lui dit :

- Prenez garde ; soyez attentive. Du matin au soir ayez soin de ne pas transgresser les ordres du père et de la mère de votre $\bullet_{54}$ époux.

La mère met un cordon à la robe de sa fille et lui lie un essuie-main à la ceinture. Elle lui dit :

- Soyez diligente et attentive. Du matin au soir gardez-vous de violer les ordres de votre belle-mère dans l'accomplissement des devoirs imposés dans le palais des femmes.

Une femme de second rang du père, près de la grande porte dans la cour, attache un sachet à la ceinture de la fiancée, et lui réitère les avis donnés par le père et la mère. Elle lui dit :

- Suivez avec soin et respect, et $t$ s ung ayez en grand honneur les paroles que votre père et votre mère vous ont adressées. Du matin au soir évitez toute faute. Regardez souvent le cordon de votre robe et le sachet de votre ceinture, (ces deux objets vous rappelleront vos devoirs).

Le gendre (le fiancé) présente à sa fiancée le bout de la corde qui aide à monter en voiture. La gouvernante de la fiancée refuse pour elle ce service. Elle dit :

- Elle n'a pas encore reçu d'éducation.. Elle ne mérite aucun honneur.

O Quand le chef de la branche principale d'une famille (va se marier, s'il) n'a plus de père, sa mère donne les ordres pour son mariage. S'il n'a plus ni père ni mère, il donne lui-même les ordres. (A défaut de père et de mère), un jeune homme qui est d'une branche de famille met en avant le nom du chef de ${ }_{55}$ toute la famille. Un frère puîné met en avant le nom de son frère aîné.

$\mathbf{O}$ - Si le fiancé n'est pas allé en personne au devant de sa fiancée, trois mois après l'arrivée de la fiancée dans la maison du fiancé, celui-ci va faire visite au père et à la mère de sa femme. Il dit : 
- Moi N., parce que j'ai obtenu que ma famille s'unît par le mariage à une famille étrangère (à la famille de ma femme), je demande de faire visite aux parents de ma femme.

(Hou॰n, famille de l'épouse. •n, famille du mari). Le maître de la maison fait répondre :

- Je considère le nombre de jours qui se sont écoulés depuis ce mariage. Ma fille n'a pas encore pu laver les vases sacrés et offrir des mets dans le temple des ancêtres de son mari. C'est pourquoi je n'ose pas encore recevoir la visite de mon gendre. A présent, Monseigneur (mon gendre) s'abaisse à venir me voir. Je le prie de retourner à sa maison. Moi N., j'irai en hâte lui faire visite chez lui.

Le gendre répond :

- Je n'ai pas d'autre motif (je suis venu uniquement à titre de gendre). Je ne suis pas digne que mon beau-père veuille s'abaisser à me faire visite. Je le prie de m'accorder enfin la faveur de me présenter devant lui.

Le beau-père fait répondre :

- Moi N., en considération de l'alliance $\bullet_{55}$ qui unit nos deux familles, je n'ose pas refuser obstinément. Me permettrais -je de ne pas accéder à la demande ?

Le maître de la maison sort, et se tient à gauche de la grande porte de ses appartements, le visage tourné vers l'ouest. Le gendre entre par la grande porte extérieure, (va dans la cour des appartements particuliers), tourne le visage vers l'est, dépose un présent (un faisan), salue deux fois à genoux, sort par la grande porte des appartements particuliers (et attend). L'officier chargé de traiter avec les hôtes prend le faisan, sort par la porte des appartements particuliers, et prie le gendre de prendre le faisan (et d'aller l'offrir à son beau-père). Le gendre refuse d'abord, par pure politesse ; puis il accepte. Il reçoit le faisan et entre. Le beau-père le salue deux fois à genoux et reçoit le faisan. Le gendre salue aussi deux fois à genoux le beau-père qui a reçu le faisan. Il s'en va.

Le gendre va faire visite à la femme du maître de la maison. Celle-ci, l'un des deux battants de sa porte fermé, est debout dans la cour. Le gendre se tient debout en dehors de la cour, le visage tourné vers l'est. La belle-mère le salue une fois à genoux. Le gendre à son tour la salue deux fois à genoux. La ${ }_{57}$ belle-mère le salue une seconde fois à genoux. Le gendre s'en va.

Le beau-père l'invite à boire une coupe de vin. $K^{\bullet}$ Ensemble ou mutuellement, ils se font des salutations profondes, veulent se céder le pas et entrent dans la salle. Le vin est offert avec les cérémonies ordinaires. La belle-mère offre des tranches de viande et du hachis. Elle dépose une deuxième coupe de vin devant son gendre. (Il n'y touc he pas). On ne lui offre 
pas de pièces de soie. Le gendre s'en va. Le beau -père le reconduit et le salue deux fois à genoux. 


\section{CHAPITRE III}

\section{Visite d’un officier à un autre officier}

- ${ }_{58}$ Le visiteur tient dans les mains et offre comme présent, en hiver, un faisan vivant, en été, un faisan tué et séché. Il tient la tête de l'oiseau tournée du côté gauche. Il dit à l'assistant du maître de la maison :

- Moi N., je désire faire visite au maître de la maison. Je n'ai jamais eu de relations avec lui. Je prie le Seigneur N. (l'assistant) de me dire de la part de son maître de me présenter. » (Le chaó kiái sert d'intermédiaire entre le maître de la maison et le visiteur. Il porte les demandes et les réponses de l'un à l'autre).

Le maître de la maison fait répondre :

- Le seigneur N. (l'assistant) m’invite à recevoir un visiteur. Monseigneur le visiteur s'est abaissé à venir me voir. Je le prie de retourner à sa maison. J'irai moi -même lui faire visite.

Le visiteur répond :

- Je ne suis pas digne que le maître de la maison veuille s'abaisser à me faire visite. Je le prie de m'accorder définitivement la faveur de me présenter devant lui.

• ${ }_{59}$ Le maître de la maison répond :

- Je ne me permettrais pas de faire de pures et vaines cérémonies (c'est sincèrement que je parle). Je prie instamment Monseigneur de retourner à sa maison. J'irai moi -même lui faire visite.

Le visiteur répond :

- Je ne me permettrais pas non plus de faire des cérémonies. Je demande instamment la faveur de me présenter.

Le maître de la maison répond :

- J'ai décliné plusieurs fois cet honneur. Je n'ai pas obtenu la faveur d'aller moi -même faire visite. J'apprends que Monseigneur tient en mains un présent (un faisan). Je me permets de refuser tout présent.

Le visiteur répond :

- Je n'oserais pas faire visite sans offrir un présent.

Le maître de la maison répond : 
- Je ne suis pas d'assez grand rang pour recevoir et donner des présents. Je me permets du refuser encore une fois.

Le visiteur répond :

- Sans un présent je n'ose pas me présenter. Je demande instamment de l'offrir.

Le maître de la maison répond :

- J'ai refusé plusieurs fois le présent. Je n'ai pas obtenu le consentement de Monseigneur. Oserais-je ne pas me rendre avec respect à sa volonté ?

Le maître de la maison sort, va au devant du visiteur jusqu'en dehors de la grande porte et le salue deux fois à genoux. Le visiteur lui rend deux saluts. Le maître de la maison fait une inclination profonde, entre et se met à droite de la grande porte. Le visiteur, tenant en mains son faisan, entre et se met au côté gauche de la grande porte. Le maître de la maison salue deux fois à genoux $\bullet_{60}$ et reçoit le faisan, Le visiteur salue deux fois à genoux le maître de la maison pour le remercier d'avoir reçu le faisan, et il s'en va. Le maître de la maison invite le visiteur à lui faire visite dans la salle. Le visiteur retourne sur ses pas et monte à la salle. Quand il se retire, le maître de la maison le reconduit jusqu'à la sortie de la grande porte, et le salue deux fois à genoux.

$\mathbf{O}$ Le maître de la maison (l'officier qui a reçu un autre officier) va lui rendre la visite. Tenant en mains le faisan quill a reçu, il dit :

- Dernièrement Monseigneur a daigné m’inviter, moi N., à le voir dans sa salle. Je demande la permission de rendre son faisan à l'officier qui est sous ses ordres.

Le maître de la maison (l'officier qui le premier a fait visite à l'autre) répond:

- Moi N., après avoir obtenu la faveur de paraître en sa présence, je me permets de refuser l'honneur de sa visite.

L'officier qui vient rendre la visite répond :

- Moi N., je n'ose pas demander d'être admis en sa présence. (On doit craindre de se rendre importun par des visites réitérées). Je demande de rendre son faisan à son employé.

Le maître de la maison répond :

- Après qu’il m’a été donné de me présenter devant $\bullet_{61}$ je me permets de décliner encore (cette marque de respect qu’il me donne, en disant qu'il n'ose pas me faire visite).

Le visiteur répond : 
- Je n'ose pas prêter l'oreille (et me conformer à cette réponse). Je demande de nouveau de remettre le présent aux mains de l'officier qui exécute les ordres du maître de la maison.

Le maître de la maison répond :

- J'ai exprimé plusieurs fois un refus. Je n'ai pas obtenu l'assentiment du visiteur. Oserais -je ne pas céder à sa volonté ?

Le visiteur entre en tenant le faisan dans les mains. Le maître de la maison le salue deux fois à genoux et reçoit le faisan. (Il ne l'invite plus à lui rendre visite dans sa salle). Le visiteur le salue deux fois à genoux pour le remercier d'avoir reçu le faisan, et il s'en va. Le m aître de la maison le reconduit jusqu'au sortir de la grande porte, et le salue deux fois à genoux.

$\mathbf{O}$ Quand un simple officier fait visite à un grand préfet, celui-ci refuse absolument le présent. A l'entrée de l'officier, le préfet le salue une seule fois à genoux pour le remercier de lui faire l'honneur d'une visite. Quand l'officier se retire, le grand préfet le reconduit et le salue deux fois à genoux.

$\mathbf{O} \cdot{ }_{62}$ Lorsqu'on annonce à un officier la visite d'un subalterne qui est constamment à ses ordres, il refuse le présent par pure politesse. (Pressé d'accepter) il dit :

- J'ai refusé, et je n'ai pas obtenu l'assentiment du visiteur. Je n'ose pas refuser de n ouveau.

Le visiteur entre, dépose son présent, salue deux fois à genoux. Le maître de la maison lui rend un seul salut à genoux. Le visiteur s'en va. Le maître de la maison envoie l'officier qui traite avec les hôtes lui rendre son présent au sortir de la grande porte, et lui dire :

- Un tel (le maître de la maison) m’envoie, moi un tel, vous rendre votre présent.

Le visiteur répond :

- J'ai eu la faveur de paraître devant le maître de la maison. Je me permets de refuser.

L'officier du maître de la maison répond :

- Un tel (le maître de la maison) m'a donné un ordre. (C'est sincèrement que je parle). Je n'oserais pas faire de pures cérémonies. Je me permets de vous prier de reprendre votre présent.

Le visiteur répond :

- Moi søu l'humble serviteur de Mons eigneur (føu tsèu le grand préfet), je ne suis pas d'un rang assez élevé pour échanger des présents. Je me permets de refuser de nouveau.

L'officier du maître de la maison répond : 
- Un tel (mon maître) m’a envoyé. Je ne me permettrais pas d'agir par pure ${ }_{63}$ cérémonie. De nouveau je vous prie de reprendre ce présent.

Le visiteur répond :

— J'ai refusé plusieurs fois ; je n'ai pu obtenir l'assentiment de Monseigneur. Oserais-je ne pas me conformer à sa volonté ?

Il salue deux fois à genoux et reçoit le présent.

O Lorsqu'un grand préfet de rang inférieur fait visite à un autre grand préfet de rang inférieur, il porte une oie, dont le corps est paré de toile et les pattes liées ensemble par un cordon. Il agit comme l'officier qui porte un faisan. Lorsqu'un grand préfet de première classe fait visite à un grand préfet de première classe, il présente un agneau, dont le corps est paré de toile, et dont les pattes sont liées ensemble par quatre cordons qui (passent sur le dos et) sont noués sur le devant de l'an imal. Il tourne du côté gauche la tête de l'agneau. Il le tient comme celui qui présente un faon. (En automne, on offre un faon). Les cérémonies sont les mêmes que pour la visite d'un simple officier à un simple officier.

$\mathbf{O}$ Lorsqu'un sujet fait visite à so n prince pour la première fois, tenant son présent entre les mains, il va jusqu'au pied du siège du prince. Il compose son extérieur, s'arrête et marche avec empressement. Lorsqu'un homme qui n'est pas en charge paraît devant le prince, il ne prend pas un air de dignité. En avançant et en se retirant, il marche vite, sans grand empressement. Un simple officier ou un grand préfet qui fait $\bullet_{64}$ visite à son prince, dépose un présent, salue deux fois à genoux en frappant du front la terre. Le prince lui rend un seul salut à genoux.

O Lorsqu'un prince reçoit la visite d'un ministre d'État étranger, il envoie l'officier chargé de traiter avec les hôtes lui rendre son présent, et lui dire :

- Notre prince m'envoie rendre votre présent.

Le visiteur répond :

- Parce que je ne suis pas le sujet de votre prince, mais le sujet d'un autre prince, je n'ose pas refuser de reprendre ce présent.

Il salue deux fois à genoux en frappant du front la terre, et reçoit le présent. (Un prince reçoit le présent offert par un de ses sujets, et ne le lui rend pas).

$\mathbf{O}$ Quiconque fait une visite particulière à un prince, doit avoir soin (de se tourner droit vers le nord) vers le prince qui a le visage tourné vers le midi. S'il ne le peut (parce que le prince n’a pas le visage tourné vers le midi), il doit tourner le visage droit vers un autre des points cardinaux (vers l'est ou vers l'ouest), sans considérer si le visage du prince est tourné exactement vers l'ouest ou vers l'est. Si le prince est sur la plateforme de la salle, le visiteur 
monte et se présente devant lui. Il monte les degrés sans distinction de points cardinaux. Il ne considère que l'endroit où le prince se trouve. (Si le prince est à l'est, il monte par les degrés $\bullet{ }_{65}$ orientaux. Si le prince est à l'ouest, il monte par les degrés occidentaux).

O Quiconque va voir un prince pour lui parler, à moins qu'il n'ait à répondre à une question du prince, attend que le prince t'ouò soit commodément assis ; puis il lui communique ce qu'il a à lui dire. Quiconque converse avec un prince, doit parler de la direction des sujets. Celui qui converse avec un grand personnage (ministre d'État ou grand préfet), doit parler du service dû au prince. Celui qui converse avec un vieux maître doit parler de la direction des élèves. Celui qui converse avec un jeune homme doit parler de la piété filiale envers les parents et du respect fraternel envers les aînés. Celui qui parle à une multitude assemblée doit parler de la loyauté, de la sincérité, de la bienfaisance et de la siàng perfection. Celui qui converse avec un employé qui demeure dans un office doit parler de la loyauté et de la fidélité.

O Quiconque parle à un grand personnage (ministre d'État grand préfet), doit d'abord examiner l'air de son visage (pour savoir ce quil convient de dire). Au milieu de la conversation, il doit tâcher de pénétrer les sentiments paó renfermés en son cour. A la fin, il doit examiner l'air de son visage (pour deviner s'il agrée ce qu'il a entendu). C'est une règle invariable. Elle doit être suivie par tous en toute circonstance. Un fils qui promène ses regards sur la personne de son père doit éviter ${ }_{66}$ de le regarder au dessus du visage ou au dessous de la ceinture. En dehors du temps de la conversation, si le père est debout, le fils doit regarder les pieds du père ; si le père est assis, le fils doit regarder les genoux du père.

O Quiconque fait visite à un homme distingué et est assis auprès de lui, doit demander la permission de se retirer, si cet homme distingué baille, s'étend les membres, demande quelle heure il est, donne ordre de préparer le repas et change de place. Le soir il doit demander la permission de se retirer, si cet homme distingué interroge sur l'heure de la nuit, sur les oignons qui seront servis au souper.

O Lorsqu'un sujet à l'honneur d'être i nvité à la table de son prince, (si le chef de cuisine est absent), l'invité porte la main aux plats, avant que le prince offre quelque chose aux esprits. Il goûte tous les mets et toutes les boissons (comme le fait un chef de cuisine, qui veut s'assurer si tout est bien conditionné) ; ensuite il attend. Il ne mange qu'après y avoir été invité par le prince. S'il y a un chef de cuisine qui règle le repas, (l'invité lui laisse le soin de goûter les mets). Il attend que le prince ait commencé à manger ; ensuite il mange lui-même. Si le prince fait à l'invité l'honneur de lui offrir une coupe de vin, l'invité quitte sa natte, salue deux fois à genoux ${ }_{67}$ en frappant du front la terre, reçoit la coupe, reprend sa place sur sa natte et offre la coupe 
aux esprits. Après avoir vidé sa coupe, il attend que le prince ait aussi vidé la sienne. Ensuite i1 donne sa coupe vide à un officier.

Au sortir de la salle, l'invité, à genoux, prend ses chaus sures. (On laissait les chaussures hors de la salle avant d'y entrer). Il se retire loin de la présence du prince, et ensuite met ses chaussures. Le prince se lève pour le reconduire. Alors l'invité dit :

- Prince, ne vous levez pas pour moi. Votre serviteur n'osera pas décliner l'honneur d'être reconduit par vous. (Un suj et ne se permet pas de lutter de politesse avec son prince, comme un égal le fait avec son égal). Si vous descendez les degrés et me reconduisez, je n'oserai pas penser à décliner cet honneur.

Ensuite l'invité s'en va. (Le prince ne le recon duit pas). Si l'étranger invité est un grand préfet, il décline l'honneur d'être reconduit par le prince. Il se retire, descend les degrés. (Le prince l'accompagne). Arrivé à la porte, trois fois il prie le prince de ne pas le reconduire plus loin (de ne pas sortir de la porte. Le prince ne sort pas).

O Quand un officier d'un âge plus avancé et d'un rang plus élevé (un ministre d'État ou un grand préfet) demande de faire $\bullet_{68}$ visite à un autre officier, le maître de la maison décline cet honneur. S’il n'obtient pas de fai re agréer son refus, il dit:

- Je ne suis pas digne de recevoir sa visite. J'ai refusé ; je n'obtiens pas son assentiment. Je me hâte d'aller le voir.

Le maître de la maison va le premier faire visite au visiteur. (Il va à la porte de sa propre maison, et le premier le salue à genoux, comme si lui-même lui faisait visite).

O Un messager qui n'a pas été envoyé par son prince (et arrive pour une affaire particulière) ne se dit pas l'envoyé de son humble prince. Un messager qui a été envoyé par un grand préfet ou un officier inférieur pour une affaire d'État, dit :

- Moi qui suis le vieux serviteur de mon humble prince.

O Quiconque tient des présents dans les mains évite de marcher avec précipitation. Il compose son extérieur, est calme, $t s i \bullet$ allonge le pas et fait des politesses. Celui qui tient dans les mains une pierre précieuse a soin d'allonger le pas, lève le bout du pied et traîne le talon.

O Quiconque se désigne lui-même en parlant à son prince, s'appelle l'humble sujet du prince, s'il est simple offi cier ou grand préfet. Un officier qui (n'exerce plus de charge et) de meure dans sa maison particulière, s'il vit à la capitale, s'appelle serviteur qui demeure près de la place du marché ; s’il demeure ${ }_{69}$ à la campagne, il s'appelle serviteur qui vit au milieu de l'her be et du chiendent. Un simple particulier s'appelle serviteur qui coupe de l'herbe. 
Un homme qui est en pays étranger, en présence du prince, s'appelle serviteur étranger.

$*$

** 


\section{CHAPITRE IV}

\section{Banquet cantonal}

- ${ }_{70}$ Le maître, c'est-à-dire, le tái føu grand préfet qui est le chef du hiøng canton, va trouver les siøn chøng anciens officiers retraités du canton, et délibère avec eux sur le choix de celui qui sera le principal pøn invité et de celui qui en sera kiái l'as sesseur.

Le chef du canton va avertir celui qui a été choisi pour être le principal invité. Celui-ci le salue à genoux pour le remercier d'avoir daigné lui faire visite. Le chef du canton lui rend son salut à genoux, et l'invite à être le principal héros de la fête. L’invité, par politesse, décline cet honneur. Puis il accepte. Le chef du canton le salue deux fois à genoux. Linvité rend le salut. Le chef du canton se retire. Linvité le salue à genoux pour le remercier d'avoir daigné venir. Le chef du canton avertit de la même manière celui qui a été choisi pour être l'asses seur de l'invité principal.

$\mathbf{O}$ Ensuite on étend des nattes pour le principal invité, pour le chef du canton et pour l'assesseur. (La natte du principal $\bullet_{71}$ invité est placée devant la fenêtre de la salle, de manière quill ait le visage tourné au midi. Celle du chef du canton est placée au haut des degrés orientaux, de manière qu'il ait le visage tourné vers l'ouest. Celle de l'assesseur est placée au haut des degrés occidentaux, de manière qu’il ait le visage tourné vers l'est). Les nattes des autres invités sont toutes (à l'ouest de celle de l'invité principal) séparées les unes des autres. On place deux amphores entre le bâtiment latéral et la porte de la salle, sur des supports qui sont $s \bullet$ sans pieds. L'amphore qui contient le vin noir, c'est-à-dire, l'eau pure est à l'ouest (à la place d'honneur). On dispose des corbeilles au sud des supports ; on les range de l'ouest à l'est, les plus distinguées à l'ou est. On met une cuiller sur chacune des deux amphores. On dispose des cruches vides (dans la cour) au sud-est des degrés orientaux, du sud au nord, dans la largeur de la plateforme, et de l'est à l'ouest, en face de l'extrémité orientale de la crête du toi t de la salle., Les aiguières sont à l'est des cruches. Des corbeilles sont à l'ouest des cruches. Elles sont rangées du nord au sud, les plus distinguées au nord.

$\mathbf{O}$ Le bouillon gras est préparé à point. Le chef du canton va avertir le principal invité de venir vite. Celui-ci le salue à genoux pour le remercier de son obligeance. Le chef du canton lui rend le salut et s'en retourne. L'invité le salue de nouveau à genoux en signe de remerciement. Le chef du canton va appeler de la même manière l'assesseur de l'invité principal. $\bullet_{72}$ Le principal invité et tous les autres invités suivent le chef du canton. 
O Un officier de la maison du chef du canton va recevoir les invités en dehors de la grande porte. Il salue deux fois à genoux le principal invité, qui lui rend son salut. Il salue à genoux l'assesseur, qui lui rend aussi son salut. Il salue par une inclination profonde tous les autres invités. Le chef du canton fait une inclination profonde au principal invité, et entre le premier. Le principal invité salue son assesseur en retirant à soi les mains, et entre au côté gauche de la porte. $(\bullet$, incliner le corps, en portant les mains en avant. $\mathbf{I}$, incliner le corps en retirant à soi les mains). L'assesseur salue tous les autres invités en retirant à soi les mains et entre. Tous les autres invités entrent au côté gauche de la porte, et se rangent du nord au sud, par ordre de dignité, les plus respectables au nord. Le chef du canton fait au principal invité une inclination profonde en trois endroits différents dans la cour. Arrivé au pied des degrés, trois fois il veut lui céder le pas (il l'invi te à monter le premier). Le chef du canton monte le premier ; l’invité monte aussi. Le chef du canton, arrivé au haut des degrés orientaux, sous la poutrelle qui soutient le bord du toit de la plateforme, le visage tourné vers le nord, salue l'invité par deux inclinations profondes. L'invité, au haut des degrés occidentaux, sous la $\bullet_{73}$ poutrelle qui soutient le bord du toit, le visage tourné vers le nord, rend le salut.

O Le chef du canton, à genoux, prend une coupe dans une corbeille, et descend les degrés pour aller rincer cette coupe. Linvité descend (et le prie de ne pas rincer lui-même la coupe). Le chef du canton la dépose devant les degrés, et exprime son refus (de céder au désir de lïnvité). Linvité répond. Le chef du canton, à genoux, reprend la coupe, se lève, va auprès des cruches, tourne le visage vers le sud, fléchit les genoux, dépose la coupe auprès des corbeilles, afin de se laver les mains et de rincer la coupe. L'invité s'avance vers l'est, et, le visage tourné au nord, prie le chef du ca nton de ne pas rincer la coupe. Le chef du canton fléchit les genoux, dépose la coupe dans une corbeille, se lève et répond. L'invité retourne à sa place, auprès du bâtiment occidental, (au bas des degrés), et tourne le visage vers l'est.

Le chef du canton, à genoux, prend une coupe. Un officier chargé de la rincer est à l'ouest, le visage tourné vers le nord. Quand la coupe est rincée, le chef du canton salue linvité par une inclination profonde, linvite une fois à monter le premier ; puis ils montent tous deux. L'invité salue à genoux le chef du canton pour la remercier d'avoir fait rincer la coupe. Le chef du canton, à genoux, dépose la coupe, (se lève), puis salue à $\bullet_{74}$ genoux. Il descend les degrés pour se laver les mains. Linvité descend aussi (pour lui faire honneur). Le grand préfet refuse cet honneur. L'invité lui répond, et va reprendre sa première place auprès du bâtiment occidental.

Le chef du canton, après s'être lavé les mains, salue l'invité par une inclination profonde, et veut lui céder le pas. Ils montent tous deux. L'invité, au haut des degrés occidentaux, reste debout • immobile. Le chef du canton, prend une coupe, y verse du vin devant la natte de l'invité, et, le visage tourné vers le nord-ouest, l'offre à l’invité. L’invité, au haut des degrés occidentaux, 
salue à genoux. Le chef du canton se retire un peu (comme pour éviter cet honneur). L'invité s'avance, reçoit la coupe et retourne à sa place (au haut des degrés occidentaux). Le chef du canton, au haut des degrés orientaux, le salue à genoux pour le remercier d'avoir reçu la coupe. Linvité se retire un peu (comme pour décliner cet honneur).

Un aide sert sur la natte de l'invité des tranches de viande séchées et du hachis, conservé dans une saumure. L'invité monte sur la natte par le côté occidental. On place près de lui une petite table sur laquelle sont les membres découpés d'un quadrupède (un chien). Le chef du ${ }_{75}$ canton, à l'est des degrés orientaux, reste debout immobile. - L'invité, à genoux, prend la coupe de la main gauche, et (de la main droite) offre aux esprits les tranches de viande et le hachis. Il dépose la coupe à l'ouest de la petite table et se lève. De la main droite il prend les poumons par la plus grosse extrémité et fléchit les genoux. Il ne laisse pas pendre les poumons. De la main droite, il en casse la petite extrémité ; puis il les offre aux esprits. Mettant la main gauche au dessus de la main droite, il goûte les poumons, et se levant, les place sur la petite table.

Il fléchit les genoux, essuie ses mains, ensuite il offre le vin aux esprits. Il se lève, s'agenouille à l'extrémité de la natte et goûte le vin. Il quitte la natte, fléchit les genoux, dépose la coupe, salue à genoux, et dit que le vin est délicieux. Il prend la coupe et se lève. Le chef du canton, au haut des degrés orientaux, lui rend le salut à genoux. L'invité, au haut des degrés occidentaux, le visage tourné vers le nord, fléchit les genoux et vide la coupe. Il se lève, fléchit les genoux, dépose la coupe. Ensuite il salue à genoux, prend la coupe et se lève. Le chef du canton, au haut des degrés orientaux, rend le salut à genoux.

$\mathbf{O} \cdot{ }_{76}$ L'invité descend les degrés pour se laver les mains et rincer une coupe (afin d'offrir du vin au chef du canton). Le chef du canton descend aussi (pour lui faire honneur). L'invité fléchit les ge noux, dépose la coupe qu'il a déjà entre les mains, se lève et refuse cet honneur. Le chef du canton lui répond, L’invité, à genoux, reprend la coupe, va au sud des cruches, et tourne le visage au nord. Le chef du canton, à l'est des degrés orientaux, le visage tourné vers le sud, prie linnvité de ne pas rincer lui-même la coupe. Linvité, à genoux, remet la coupe dans la corbeille, se lève et répond. Le chef du canton retourne à l'est des degrés orientaux, et tourne le visage vers l'ouest. L'invité, le vis age tourné vers le nord-est, se lave les mains. Il fléchit les genoux, prend une coupe (et la fait rincer par un aide). Quand elle est rincée, le chef du canton et l'invité se saluent et demandent de se céder le pas l'un à l'autre, comme il a été dit précé demment ; puis ils montent les degrés. Le chef du canton salue à genoux l'invité pour le remercier d'avoir fait laver une coupe. L’invité rend le salut à genoux, se lève, descend les degrés, se lave les mains. Il observe les cérémonies que le chef du canton a observées précédemment.

L'invité verse du vin dans la coupe. Devant la natte du chef du canton, le visage tourné vers le sud-est, il lui offre à boire à son tour. Le chef du canton, 
au haut des degrés orientaux, $\bullet_{77}$ le salue à genoux. L'invité se retire un peu en arrière (comme pour décliner cet honneur). Le chef du canton s'avance, reçoit la coupe et retourne à sa place (au haut des degrés orientaux). L'invité, au haut des degrés occidentaux, le salue à genoux pour le remercier d'avoir reçu la coupe.

On apporte au chef du canton des tranches de viande séchées et du hachis conservé dans une saumure. Le chef du canton monte sur sa natte par le côté septentrional. On lui sert sur une petite table les membres séparés d'un chien. Il les offre aux esprits. Les cérémonies sont les mêmes que celles observées précédemment par l'invité. Il ne dit pas que le vin est excellent. (C'est son propre vin. Par modestie, il évite de le vanter).

Passant devant sa natte, il va au haut des degrés orientaux, tourne le visage vers le nord, fléchit les genoux, vide la coupe, se lève, fléchit les genoux, dépose la coupe; ensuite il salue à genoux. Il prend la coupe et se lève. L'invité, au haut des degrés occidentaux, rend le salut. Le chef du canton fléchit les genoux et dépose la coupe à l'angle du bâtiment latéral. Au haut des degrés orientaux, le visage tourné vers le nord, il salue de nouveau à genoux et dit qu'il a bu son soûl. (Cela signifie qu'il a trouvé le vin mauvais et qu'il ne veut pas en boire davantage). L'invité, au haut des degrés occidentaux, lui rend le salut.

$\mathbf{O} \cdot{ }_{78}$ Le chef du canton fléchit les genoux, prend une coupe dans une corbeille, et descend les degrés pour la rincer. L’invité descend aussi (pour lui faire honneur). Le chef du canton décline l'honneur. Mais il ne le prie pas de ne pas rincer la coupe (parce que le chef du canton la rince pour boire luimême). Il se tient debout près du bâtiment occidental, le visage tourné vers l'est. Quand la coupe est rincée, le chef du canton et l'invité se saluent, veulent se céder le pas l'un à l'autre et montent les d egrés. Linvité au haut des degrés occidentaux reste debout immobile. Le chef du canton emplit la coupe pour (boire lui-même et) engager ainsi l'invité à boire une seconde fois. Au haut des degrés orientaux, le visage tourné vers le nord, il fléchit les genoux, dépose la coupe, puis salue à genoux. Il prend la coupe, se lève. L'invité, au haut des degrés occidentaux, rend le salut à genoux, Le chef du canton fléchit les genoux, offre le vin aux esprits, puis il le boit. Après avoir vidé la coupe, il se lève, fléchit les genoux, dépose la coupe, puis salue à genoux. Il prend la coupe et se lève. Linvité, au haut des degrés occi dentaux, rend le salut.

Le chef du canton descend les degrés pour rincer la coupe (et offrir du vin à l'invité). L'invité descend au ssi, et décline l'honneur que le grand préfet lui fait ; cela, comme la première fois ${ }_{79}$ que le vin lui a été offert. Tous deux montent les degrés. L’invité ne salue pas pour remercier de ce que la coupe a été rincée.

L'invité, au haut des degrés occidentaux, se tient debout. Le chef du canton remplit la coupe devant la natte de l'invité, et tourne le visage vers le nord. Linvité, au haut des degrés occi dentaux, salue à genoux. Le chef du 
canton se retire un peu. Quand l'invité a fini de saluer, le chef du canton s'avance, fléchit les genoux et dépose la coupe à l'ouest des conserves de viande de l'invité. L'invité remercie, fléchit les genoux, prend la coupe et retourne à sa place. Le chef du canton, au haut des degrés orientaux, salue à genoux l'invité qui a reçu la coupe. L'invité, le visage tourné vers le nord, fléchit les genoux, dépose la coupe à l'est des conserves de viande et retourne à sa place. (Il ne boit pas).

Le chef du canton salue par une inclination profonde et descend les degrés. Linvité principal descend aussi. Il reste debout à l'ouest des degrés, près du bâtiment latéral, le visage tourné vers l'est. Le chef du canton et l'assesseur de l'invité principal se saluent l'un l'autre par une inclination profonde, demandent de se céder le pas l'un à l'autre et montent les de grés. Ils se saluent à genoux. Les cérémonies sont les mêmes qu'à • ${ }_{80}$ l'entrée du principal invité. Le chef du canton, à genoux, prend une coupe à l'angle du bâtiment oriental. Il descend les degrés pour aller la rincer. L'assesseur descend pour lui faire honneur. Le chef du canton refuse cet honneur. L'assesseur refuse l'hon neur que le chef du canton veut lui faire en rinçant lui-même la coupe. Les cérémonies sont les mêmes que celles qui ont été faites pour le premier invité. L'assesseur monte les degrés avec le chef du canton. Il ne le salue pas pour le remercier d'avoir fait rincer la coupe. Au haut des degrés occidentaux, il se tient debout. Le chef du canton emplit la coupe devant la natte de l'assesseur. Il la lui offre, le visage tourné vers le sud-ouest. L'assesseur, au haut des degrés occidentaux, le visage tourné vers le nord, salue à genoux. Le chef du canton se retire un peu en arrière. L'assesseur s'avance, le visage tourné vers le nord, reçoit la coupe et retourne à sa place. Le chef du canton à la droite de l'assesseur, le visage tourné vers le nord, salue à genoux, après lui avoir donné la coupe. L'assesseur se retire un peu en arrière.

Le chef du canton se tient debout à l'est des degrés occidentaux. On présente des conserves de viande à l'assesseur. L'as sesseur monte sur sa natte par le côté septentrional. On lui apporte une petite table sur laquelle sont les membres séparés d'un animal (un chien). L'assesseur offre les mets aux esprits, comme l'a fait le principal invité. Il ne goûte pas les poumons. Il $\bullet_{81}$ ne porte pas la coupe à ses lèvres. Il ne dit pas que le vin est savoureux. Il descend de la natte par le côté méridional, tourne le visage vers le nord, fléchit les genoux, boit le vin et se lève. Il fléchit les genoux, dépose la coupe, puis salue à genoux. Il prend la coupe et se lève. Le chef du canton, à la droite de l'assesseur, rend le salut à genoux.

L'assistant descend les degrés pour rincer une coupe. Le chef du canton retourne vers les degrés orientaux. Il descend, et refuse l'honneur qui lui est préparé, comme il l'a fait précé demment à l'égard de l'invité principal. Quand la coupe est rincée, le chef du canton se lave les mains. L'assesseur salue le chef du canton par une inclination profonde, lui cède le pas et monte avec lui. La coupe est présentée vide au chef du canton entre les deux colonnes de la plateforme. L'assesseur se tient debout au haut des degrés occidentaux. Le chef du canton remplit la coupe (pour boire lui-même, après avoir offert à 
boire à l'assesseur). Au haut des degrés oc cidentaux, à la droite de l'assesseur, il fléchit les genoux, dépose la coupe, puis salue à genoux. Il reprend la coupe et se lève. L'assesseur lui rend le salut à genoux. Le chef du canton, à genoux, offre le vin aux esprits, puis boit.

Après avoir vidé la coupe, il se lève. Il se met à genoux, ${ }_{82}$ dépose la coupe, puis salue à genoux. Il reprend la coupe et se lève. L'assesseur lui rend le salut. Le chef du canton, à genoux, dépose la coupe au sud de la colonne occidentale, à la droite de l'assesseur, sal ue encore une fois à genoux et se dit rassasié de vin. L'assesseur lui rend le salut. Le chef du canton retourne vers les degrés orientaux, fait une inclination profonde et descend les degrés. L'assesseur descend aussi, et se tient debout au sud du princip al invité.

$\mathbf{O}$ Le chef du canton, le visage tourné vers le sud-ouest, salue trois fois à genoux toute la foule des invités. Les invités lui rendent tous ensemble un seul salut à genoux. Le chef du canton fait une inclination profonde et monte les degrés. Il fléchit les genoux et prend une coupe au pied de la colonne occidentale. Il descend les degrés et fait rincer cette coupe. Il monte les degrés, emplit la coupe au haut des degrés occidentaux, et l'offre à la troupe des invités. Les trois les plus respectables d'entre eux, (un à un, l'un après l'autre), montent les degrés, saluent à genoux et reçoivent la coupe. Le chef du canton les salue à genoux, après quills ont reçu la coupe. Les trois invités fléchissent les genoux, offrent le vin aux esprits, se lèvent, boivent, et ne saluent pas, après avoir vidé la coupe. Ils la donnent au chef du canton, descendent et retournent à leur place. La coupe est offerte à tous les autres invités. Ils ne saluent pas à genoux. Ils reçoivent la coupe, fléchissent les $\bullet_{83}$ genoux, offrent le vin aux esprits, se lèvent et boivent debout. Après avoir offert le vin à chacun des trois invités les plus respectables, on leur sert des conserves de viande sur leurs nattes (au haut des degrés). Les autres invités ont aussi chacun des conserves de viande (au bas des degrés). Le chef du canton descend avec la coupe et la dépose dans une corbeille.

Le chef du canton fait une inclination profonde au premier invité, veut lui céder le pas, et monte les degrés. Le premier invité salue son assesseur par une inclination profonde, en retirant à soi les mains, et monte les degrés. L'assesseur salue de la même manière la foule des autres invités et monte aussi. Tous les autres invités montent par ordre d'âge et vont à leurs nattes. Un officier du grand préfet rince une coupe de corne et monte les degrés, afin de (boire lui-même d'abord et de) porter cette coupe à l'invité principal. Il emplit la coupe au haut des degrés occidentaux, fléchit les genoux, dépose la coupe, puis salue à genoux. Il prend la coupe et se lève. Le principal invité, à genoux à l'extrémité (occidentale) de sa natte, lui rend le salut à genoux. L'officier fléchit les genoux, offre le vin aux esprits, puis boit. Après avoir vidé la coupe, il se lève. Il fléchit les genoux et dépose la coupe. Ensuite il salue à genoux, $\bullet_{84}$ prend la coupe et se lève. Le premier invité lui rend le salut à genoux. 
L'officier descend les degrés, rince la coupe, monte les degrés, emplit la coupe et se tient debout au haut des degrés occidentaux. Le premier invité le salue à genoux. L'officie $r$ s'avance et dépose la coupe à l'ouest des conserves de viande de l'invité. Celui -ci, après avoir décliné cet honneur, fléchit les genoux, prend la coupe et se lève. L'officier qui a apporté la coupe, au haut des degrés occidentaux, salue à genoux le premier invité qui retourne à sa natte. Le premier invité fléchit les genoux et dépose la coupe à la place où elle doit être (à l'ouest des conserves de viande). L'officier qui a apporté la coupe descend les degrés.

O Des nattes sont étendues sur la plateforme à l'angle occidental, de l'est à l'ouest ; l'est est le côté le plus honorable. Ces nattes sont pour quatre musiciens (aveugles, dont deux chanteurs et) deux joueurs de guitare. Les joueurs de guitare arrivent les premiers. Leurs deux conducteurs hò portent chacun sur le bras gauche une guitare, dont ils tiennent la cheòu tête en arrière. Leur main gauche $k$ '•u est enfoncée dans l'ouverture $i u^{\bullet}$ pratiquée à la partie inférieure de la table dharmonie, et touche les cordes qui sont à l'intérieur. De la main droite ils conduisent les deux aveugles.

- ${ }_{85}$ Le préfet de musique monte le premier sur la plateforme, et se tient debout à l'est des degrés occidentaux. Les autres musiciens entrent dans la cour, montent par les degrés occidentaux, tournent le visage vers le nord et fléchissent les genoux. Les conducteurs de ces musiciens aveugles tournent le visage vers l'e st, fléchissent les genoux, puis présentent les guitares aux musiciens. Ensuite ils descendent les degrés. Les musiciens exécutent (trois chants du Siao ia, Livre I, Chants I, II et III) Les cerfs brament, Les quatre coursiers, Les fleurs brillantes.

Les chants terminés, le chef du canton offre à boire aux quatre musiciens. Le plus âgé d'entre eux, tenant son instrument de la main gauche (sil est joueur de guitare), salue à genoux et sans se lever, reçoit la coupe à figure d'oiseau. Le chef du canton, au haut des degrés orientaux, salue à genoux le musicien qui a reçu la coupe. Des conserves de viande sont servies à ce musicien. Un officier est chargé de l'aider à offrir aux esprits le vin et la viande. Ce musicien boit, et ne salue pas à genoux, après avoir vidé la coupe ; il la donne au chef du canton.

Alors les trois autres musiciens, sans saluer à genoux, reçoivent la coupe, offrent le vin aux esprits et boivent. On leur sert, pién à tous, des conserves de viande. Ils ne les offrent $\bullet_{86}$ pas aux esprits. Quant au grand chef de musique, (s'il y en a un, le chef du canton descend les degrés et) fait rincer la coupe pour lui. (La coupe n'avait pas été rincée avant d'être offerte aux tro is musiciens précédents). Le chef des invités et son assesseur descendent (pour faire honneur au chef du canton). Le chef du canton refuse cet honneur. Le chef de musique ne refuse pas que la coupe soit rincée pour lui.

Les joueurs d'orgue à bouche entrent et vont se tenir debout au bas de la plateforme, au sud des pierres musicales, le visage tourné vers le nord. (Ils sont quatre). Ils exécutent (trois chants du Siao ia) Les degrés méridionaux, La 
fleur blanche, Le millet en fleur. Le chef du canton leur offre à boire au haut des degrés occidentaux. L'un d'entre eux (le plus âgé) monte tous les degrés, mais ne s'avance pas sur la plateforme. Il reçoit la coupe. Le chef du canton le salue à genoux, après lui avoir donné la coupe. Le musicien (descend les degrés), fléchit les genoux devant les degrés, offre le vin aux esprits, se lève et boit étant debout. Il ne salue pas, après avoir vidé la coupe ; il monte les degrés et donne la coupe au chef du canton. Les trois autres joueurs d'orgue à bouche, sans saluer, reçoivent la coupe (au haut des degrés occidentaux, descendent), fléchissent les genoux, offrent le vin aux esprits, se lèvent et boivent debout. Tous reçoivent des $\bullet_{87}$ conserves de viande. Ils ne les offrent pas aux esprits.

Ensuite les chanteurs et les joueurs d'orgue à bouche exécu tent kiøn alternativement six chants du Siao ia, Livre II, Chants III, IV, V, VI, VII et VIII. Les chanteurs chantent Les poissons passent dans la nasse. Les orgues jouent Iôu køng (Ce chant n'existe plus). Les chanteurs chantent Au midi il y a des barbeaux. Les orgues jouent La haute colline (Ce chant n'existe plus). Les chanteurs chantent Sur les montagnes du midi crô̂t la plante t'âi. Les orgues jouent Iôu î. (Ce chant n'existe plus).

Alors les chanteurs et les joueurs d'instruments réunis exécu tent ensemble trois chants du Tcheou nan, Chants I, II et III : Les oiseaux aquatiques crient, Le dolic rampe, La lampourde. Puis ils exécutent trois chants du Chao nan, Chants I, II et IV : Le nid de pie, Elle cueille l'armoise blanche, Elle cueille des lentilles d'eau. Le chef des musiciens dit au préfet de musique :

— Les chants réglementaires sont terminés.

Le préfet de musique avertit le principal invité, et descend les degrés.

$\mathbf{O}$ Le chef du canton quitte sa natte par le côté méridional. Il descend les degrés tch $\bullet$, seul (sans être accompagné par le principal invité ni par l'assesseur). Il charge quelqu'un de l'aider et de faire l'office de maître des cérémonies. Celui à qui il offre cet office décline d'abord cet honneur par pure - 88 politesse. Puis il l'accepte. Le chef du canton le salue à genoux. Le maître des cérémonies lui rend le salut à genoux.

Le chef du canton monte les degrés et retourne à sa natte. Le maître des cérémonies rince une coupe de corne, et monte par les degrés occidentaux. Au haut des degrés orientaux, le visage tourné vers le nord, il reçoit les ordres du chef du canton. Celui-ci lui dit :

- Priez le principal invité (de ne pas s'en retourner à présent chez lui, mais) de rester encore ici.

Le maître des cérémonies en parle au principal invité. Celui-ci refuse d'abord par politesse ; puis il accepte. Le maître des cérémonies le dit au chef du canton. Le chef du canton, au haut des degrés orientaux, salue deux fois à genoux le principal invité. Le principal invité, au haut des degrés occidentaux, rend le salut à genoux. 
Le maître des cérémonies se tient debout entre les deux colonnes, pendant que le chef du canton et le principal invité se saluent l'un l'autre à genoux. Ensuite le chef du canton et le principal invité se saluent debout par une inclination profonde, et chacun d'eux retourne à sa natte. Le maître des cérémonies emplit la coupe et descend par les degrés occidentaux. Entre les deux rangés, le visage tourné vers le nord, il fléchit les genoux $\bullet_{89}$ et dépose la coupe. Il se retire en arrière, kòung joint les mains devant la poitrine et demeure quelque temps debout. Il fléchit les genoux, prend la coupe, n'offre pas le vin aux esprits et le boit. Après avoir vidé la coupe, il se lève ; il se met à genoux, dépose la coupe et salue à genoux. Il prend la coupe, se lève et rince la coupe. (Il l'emporte, puis) le visage tourné vers le nord, et à g enoux, il la dépose à la place où elle était d'abord. Il se retire en arrière, et se tient debout au sud de la coupe.

O Le principal invité, le visage tourné vers le nord, et à genoux, prend une coupe de corne placée à l'ouest de la petite table. Au haut des degrés orientaux, le visage tourné vers le nord, il invite le chef du canton à boire une seconde fois. Le chef du canton quitte sa natte et se tient debout à l'est du principal invité. Le principal invité, à genoux, dépose la coupe, puis salue à genoux. Il prend la coupe et se lève. Le chef du canton lui rend le salut à genoux. Le principal invité n'offre pas le vin aux esprits; il le boit étant debout. Il ne salue pas. Après avoir vidé la coupe, il ne la rince pas. Il la remplit, et, le visage tourné vers le sud-est, il la présente au chef du canton. Le chef du canton, au haut des degrés orientaux, salue à genoux. ${ }_{90}$ Le principal invité se retire un peu en arrière. Le chef du canton reçoit la coupe. Le principal invité salue à genoux le chef du canton, et l'accompagne en se tenant à l'ouest de sa per sonne. Il le salue par une inclination profonde et retourne à sa natte.

Le chef du canton, au haut des degrés occidentaux, présente à boire à l'assesseur pour la deuxième fois. L'assesseur quitte sa natte par le côté méridional, et se tient debout au côté occidental du chef du canton. Le chef du canton lui offre à boire comme le principal invité lui a offert à boire à luimême pour la deuxième fois. Ensuite il le salue par une inclination profonde et retourne à sa natte.

Le maître des cérémonies monte les degrés, et fait boire à la ronde la foule des invités. Chacun d'eux, après avoir bu, offre la coupe au suivant, en disant :

- Monseigneur N., recevez la coupe pour la deuxième fois.

Celui qui reçoit la coupe quitte sa natte. Le maître des cérémonies se retire. Il se tient debout à l'angle du bâtiment latéral, le visage tourné vers l'est. Le pre mier qui reçoit la coupe, (la reçoit des mains de l'assistant), au côté droit de l'assistant. Chacun des autres, pour la recevoir, se met au côté gauche de celui qui la lui présente. Chacun d'eux salue à genoux, se lève et boit. Pour tous, les cérémonies sont les mêmes que quand le premier invité offre à boire pour $\bullet_{91}$ la deuxième fois au chef du canton. Ils boivent tous. Celui qui reçoit la coupe le dernier descend les degrés avec elle. A genoux, il 
le remet dans la corbeille. Le maître des cérémonies descend les degrés et retourne à sa place.

Le chef du canton envoie deux officiers présenter des coupes au principal irrité et à l'assesseur. Ces deux officiers rincent deux coupes et montent les degrés. Ils emplissent les coupes au haut des degrés occidentaux. Tous deux fléchissent les genoux, déposent les coupes, puis saluent à genoux. Ils prennent les coupes et se lèvent. Le principal invité et son assesseur, à l'extrémité de leurs nattes, rendent le salut. Les deux officiers fléchissent les genoux, offrent le vin aux esprits, puis ils le boivent. Après avoir vidé les coupes, ils se lèvent, fléchissent les genoux, déposent les coupes, puis ils saluent à genoux. Ils prennent les coupes et se lèvent. Le principal invité et son assesseur, à l'extrémité de leurs nattes, leur rendent le salut.

Les deux officiers descendent les degrés, • inversement, c'est-à-dire, celui qui est monté le dernier descend le premier. Ils rincent les coupes, montent les degrés, emplissent les coupes, et se tiennent debout tous deux au haut des degrés occidentaux. Le principal $\bullet_{92}$ invité et son assesseur les saluent à genoux tous les deux. Les deux officiers s'avancent. L'un deux dépose une coupe à l'ouest des conserves de viande du principal invité. Le principal invité, après des paroles d'excuse, se met à genoux, prend la coupe et se lève. La coupe de l'ass esseur est déposée au sud des conserves de viande. L'assesseur fléchit les genoux, prend la coupe et se lève. Les deux officiers se retirent en arrière, et saluent à genoux les deux invités qui ont pris les coupes. Ils descendent les degrés. Les deux invités déposent les coupes dans l'endroit où elles doivent être.

O Le maître des cérémonies monte par les degrés occidentaux, et va recevoir les ordres du chef du canton. Le chef du canton lui dit :

- Invitez le principal invité à s'asseoir.

Le principal invité refuse de s'asseoir par respect pour la petite table (qui est sur chaque natte. Sur cette table sont les membres séparés d'un chien. Il faut les respecter; ils ont été offerts aux esprits). Le chef du canton lui propose de faire enlever les petites tables. Le principal invité donne son assentiment. Le maître des cérémonies descend, et, debout devant les degrés occidentaux, dit aux invités les plus jeunes d'aider à enlever les petites tables. Il monte les degrés et se tient debout à l'angle du bâtiment latéral. Le principal invité quitte sa natte et tourne le visage vers le nord. Le chef du canton quitte sa natte, et se tient au $\bullet_{93}$ haut des degrés orientaux, le visage tourné vers le nord. L'asses seur quitte sa natte, et se tient au haut des degrés occidentaux. (Les ministres ou les grands préfets, s'il y en a), qui tsuén assistent à la fête, quittent leurs nattes, et se tiennent à l'est de ces nattes, le visage tourné vers le midi.

Le principal invité prend sa petite table, et se retournant, la donne au maître des cérémonies. Le maître des cérémonies descend avec cette table. Le principal invité le suit. Le chef du canton prend sa petite table, et se tournant, 
la donne à l'un des plus jeunes invités. Celui -ci descend avec la table par les degrés occidentaux. Le chef du canton descend par les degrés orientaux. L'assesseur prend sa petite table, et se tournant, la donne à l'un des plus jeunes invités. Cet homme descend avec cette table. L'assesseur le suit. S'il y a un ministre d'État ou un grand préfet, il donne sa petite table à quelqu'un, comme le principal invité. Les invités descendent tous.

$\mathbf{O}$ Le chef du canton et ses convives ôtent et laissent leurs chaussures dans la cour (pour être assis plus commodément sur les nattes). Ils se font des inclinations profondes, veulent se céder le pas les uns aux autres, comme précédemment. Ils montent et s'assiéent. On leur sert un ragoût exquis (de la viande de chien hachée et conservée dans une saumure). Le $\bullet_{94}$ nombre des coupes de vin qu'ils boivent n'est pas limité, ni le nombre des morceaux de musique qui sont exécutés.

A la sortie du principal invité, on chante $K \bullet i$ (l'un des neuf morceaux de musique des Hià). Le chef du canton le reconduit jusqu'au dehors de la grande porte, et le salue deux fois à genoux. (Linvité ne rend pas le salut).

Si un ministre d'État ou un grand préfet d'un pays étranger veut assister à la fête, il entre quand un officier a présenté une coupe de corne pour boire la seconde fois. (Il n'est pas admis à boire le vin la première fois). On lui disp ose plusieurs nattes l'une sur l'autre à l'est du principal invité, trois, si c'est un ministre, deux, si c'est un grand préfet. A l'entrée d'un ministre ou d'un grand préfet, le chef du canton descend les degrés. Le principal invité et son assesseur descendent. Tous les autres invités descendent aussi, et vont reprendre les places qu'ils occupaient d'abord. Le chef du canton va au devant du nouveau venu, lui fait des inclinations profondes, lui offre de lui céder le pas et monte.

Un ministre d'État monte e t est traité de la même manière que le principal invité. Il refuse l'une des trois nattes qu'on lui a préparées ; il la fait enlever par quelqu'un, (il veut n'en avoir que deux l'une sur l'autre, comme un grand préfet). Un grand $\bullet_{95}$ préfet agit et est traité de la même manière que l'assesseur. S'il y a un ministre d'État, un grand préfet refuse la seconde natte mise sur la première ; il la place à l'extrémité de la natte infé rieure. Le chef du canton ne la fait pas emporter. S’il n'y a pas de ministre d'État, un grand préfet demande d'enlever la natte supérieure. Le chef du canton s'y oppose. La natte supérieure n'est pas retirée.

$\mathbf{O}$ Le lendemain de la fête, le principal invité, vêtu d'habits semblables à ceux qu'il portait le jour du banquet du canton, va saluer à genoux le chef du canton pour le remercier de sa faveur. Le chef du canton, vêtu comme le principal invité, le salue à genoux et le remercie d'avoir daigné venir. (Ces salutations se font en dehors de la grande porte de la maison. Le visiteur n'entre pas).

$\mathbf{O}$ Le chef du canton ôte son beau vêtement, (revêt une longue tunique noire), puis il félicite et fête le maître des cérémonies. Il ne lui donne pas 
d'assesseur. Il ne fait pas tuer d'animal (il ne lui sert pas de viande de chien sur une petite table). Il lui fait servir des conserves de viande. En fait de ragoût, (il n'achète rien), il ne sert rien qu’il n'ait déjà. Il n’invite que ceux qu’il veut bien inviter. Il convient qu'il invite des hom mes d'un âge mûr, des hommes d'un grand mérite. Le principal in vité du jour précédent et son assesseur n'assistent pas à ce repas. En fait de chants des cantons, le chef ne fait exécuter que ceux qu'il veut.

\section{NOTES SUPPLÉMENTAIRES.}

O • ${ }_{96}$ Le chef du canton, en habits de cour, délibère sur le choix du principal invité et de l'assesseur. Il choisit deux hom mes capables. Il ne va pas les appeler chez eux deux fois (mais une seule fois).

$\mathbf{O}$ La natte est de jonc, avec bordure de toile noire. L'am phore a une couverture de toile de dolic de seconde qualité, qu'on enlève à l'arrivée du principal invité.

O L'animal immolé (et servi sur chaque petite table) est un chien, (parce que le chien sait discerner les hommes, qualité qu'un officier doit avoir). On le fait cuire au nord-est de la plateforme.

Pour offrir le vin la première fois, on se sert d'une coupe en forme d'oiseau, (elle est très distinguée). Les autres fois, on se sert d'une coupe de corne (coupe d'un usage ordinaire).

$\mathbf{O}$ On sert cinq tranches de viande aromatisées et séchées, et par dessus, une sixième tranche placée en travers, et destinée à être offerte aux esprits. On les apporte du bâtiment qui est à gauche.

Des aides, partant du mur oriental de la cour et montant par les degrés occidentaux, apportent trois petites tables (sur lesquelles il y a de la viande de chien). Sur la petite table du principal invité, il y a une côte prise sur le dos de l'animal, $\bullet_{97}$ une côte prise sur le devant du corps, une épaule et des poumons. Sur la petite table du chef du canton, il y a une côte prise sur le dos, une côte prise sur le devant du corps, la partie inférieure d'un membre antérieur et des poumons. Sur la petite table de l'assesseur, il y a une côte prise sur le dos, une côte prise sur le devant du corps, la partie inférieure d'un mem bre postérieur et des poumons. Les deux poumons d'un animal sont tous séparés l'un de l'autre à leur petite extrémité par une incision. Les parties des membres sont toujours placées à droite sur les petites tables, la plus grosse extrémité dirigée en avant.

O Linvité qui, après avoir vidé la coupe en forme d'oiseau a salué à genoux le chef du canton, ne reste pas à ne rien faire, après s'être levé. (Il offre à boire au chef du canton). 
$\mathbf{O}$ Celui qui a vidé la coupe en forme d'oiseau étant à genoux, salue à genoux celui qui la lui a présentée. Celui qui l'a vidée étant debout, ne salue pas à genoux celui qui la lui a présentée.

O L'invité dépose toujours la coupe à sa gauche, pour que celui qui l'enlèvera l'ait à sa droite (et la prenne de la main droite).

$\mathbf{O}$ Quand le chef du canton va offrir à boire à la foule des invités, le plus âgé d'entre eux, à l'exemple du principal invité, prie le chef du canton de ne pas rincer lui-même la coupe.

Lorsque les invités sont debout, le visage tourné vers l'est, ils sont ran gés du nord au sud, par ordre de dignité, les $\bullet_{98}$ plus dignes au nord. Lorsquils sont debout, le visage tourné vers le nord, ils sont rangés de l'est à l'ouest, par ordre de dignité, les plus dignes à l'est.

O On sert des tranches de viande (avec le vin) au directeur de musique, ainsi qu'à tous les musiciens, par ordre d'âge. Ils se tiennent debout.

Chaque fois que la coupe en forme d'oiseau est offerte à l'une des trois classes de personnes, (invités, chef du canton, musiciens), elle n'est pas offerte seule (elle est accompagnée de tranches de viande).

$\mathbf{O}$ Quand la musique commence à se faire entendre, le chef du canton n'entre pas encore.

O Pour offrir le vin la première fois aux chanteurs et aux joueurs d'orgue à bouche, le chef du canton prend une coupe dans une corbeille sur la plateforme. Après leur avoir offert le vin, il dépose la coupe dans une corbeille au bas de la plateforme. Aux joueurs de flûte à bouche, il offre le vin au haut des degrés occidentaux.

$\mathbf{O}$ Les pierres musicales sont disposées en ligne entre les deux rangées de degrés, le long des gouttières du toit (de l'est à l'ouest). Ceux qui les battent ont le visage tourné vers le nord.

O • 99 Quand le chef du canton ou l'assesseur monte sur sa natte, c'est toujours par le côté septentrional. Quand il la quitte, c'est toujours par le côté méridional.

$\mathbf{O}$ Le maître des cérémonies reste à sa place, après que la coupe de corne lui a été présentée et que les tranches de viande lui ont été servies (il ne change pas de place).

Quand tous boivent à la ronde, on ne rince pas la coupe (tous boivent à la même coupe sans qu'on la rince). Quand on ne rince pas la coupe, le vin n'est pas offert aux esprits, (la coupe est impure). 
O Après que tous ont bu à la ronde, (il n'y a plus de règle, chacun boit à sa guise), les hommes distingués n'entrent plus.

$\mathbf{O}$ Quand on enlève les petites tables, ceux qui reçoivent celles du principal invité, de son assesseur, d'un ministre d'État ou d'un grand préfet qui tsuén assiste à la fête, descendent les degrés avec ces tables; puis en sortant, ils les donnent aux suivants de ces dignitaires. Celle du chef du canton est portée à l'est (dans la cour).

O Quand le directeur de la musique donne ordre d'exécuter le chant $K \bullet i$ Prenez garde, les invités sortent (pour ne pas s'enivrer), Quand ils sont arrivés au bas des degrés, le chant $K \bullet i$ commence.

- ${ }_{100}$ S’il y a un ministre d'État (et un grand préfet), le grand préfet se place au nord du chef du canton, le visage tourné vers l'ouest.

Les aides du chef du canton ont le visage tourné vers l'ouest, et sont rangés du nord au sud, par ordre de dignité. Ils ne sont pas de ceux à qui l'on offre le vin. Mais ensuite ils sont de ceux qui boivent un nombre de coupes non limité. (Ce sont des hommes de bas étage). 


\section{CHAPITRE V}

\section{Tir de l'arc dans un canton}

- 101 - Le chef du canton va avertir celui qui sera le principal invité (et comme le premier ou le chef des invités. Il va à sa maison). Cet officier sort et va à la rencontre du chef du canton (à l'extérieur, devant la grande porte de sa propre maison) ; il le salue deux fois à genoux. Le chef du canton lui rend ce double salut. (Dehors, sans entrer dans la maison), il l’invite à tenir la pre mière place à l'exercice du tir. L'invité, par modestie, décline d'a bord cet honneur; puis il l'accepte. Le chef du canton le salue deux fois à genoux. Linvité lui rend ce double salut. Le chef du canton se retire. (Il retourne au gymnase). A son départ, l'in vité le salue deux fois à genoux. Le principal invité n'aura pas d'assesseur.

Une natte est étendue (entre la porte et la fenêtre de la salle du gymnase) pour le principal invité. Elle est tournée de telle sorte qu'il regardera le sud. Son côté le plus honorable sera son côté oriental (son côté gauche). Les nattes de tous les autres invités sont placées à la suite, à l'ouest de celle du princi pal invité. On étend la natte du chef du canton au haut des $\bullet_{102}$ degrés orientaux, de manière qu'il ait le visage tourné vers l'ouest. Deux amphores (pour l'eau et le vin) sont à l'est de la natte du principal invité. Toutes deux sont sur des supports sans pieds. Celle qui contient l'eau est à gauche (à la place d'honneur). Sur chacune d'elles on met une cuiller. Des corbeil les contenant les coupes sont placées au sud des amphores. Elles sont rangées de l'est à l'ouest, les plus distinguées à l'ouest.

On dispose des cruches vides au sud-est des degrés orientaux. Elle sont rangées, les unes du sud au nord, dans toute la largeur de la plateforme; les autres de l'est à l'ouest, vis à vis de l'extrémité orientale du faîte du toit. Des aiguières sont à l'est des cruches, et des corbeilles à l'ouest des cruches. Les corbeilles sont rangées du nord au sud, les plus distinguées au nord. Les pierres musicales suspendues sont au nord-est des cruches; elles regardent l'ouest.

O Ensuite on déploie la cible. Les cordes qui lient les $c h \bullet$ langues ou bandes latérales de la cible au bas des poteaux sont à un òu (la longueur du pied de l'homme, $22 \mathrm{~cm}$ ) au dessus du sol. (Avant le tir) on ne lie pas celle de ces cordes qui est à gauche (au côté occidental). On relève le bas de la bande latérale qui est à gauche et on la lie en son milieu. Une cloison $f \bullet$ derrière laquelle s'abritera celui qui signalera les flèches qui frapperont le centre de la cible, est placée loin de la cible à une distance égale au tiers de celle qui sépare l'archer de la cible. Elle décline sur le tàng côté occidental de la cible à 
une distance de cinq рóu pas. (Le póu était de $\bullet_{103} 1 \mathrm{~m}, 20 \mathrm{~cm}$ L’archer qui tirait à la cible était à une distance de cinquante póu).

$\mathbf{O}$ Quand le bouillon gras (fait avec de la viande de chien) est préparé à point, le chef du canton, en habits de cour, va à la maison du principal invité, pour l'avertir d'arriver vite au gymnase. Le principal invité, en habits de cour, sort et va au devant du chef du canton jusque hors de la grande porte de sa maison. Il le salue deux fois à genoux. Le chef du canton lui rend ce double salut et se retire. L'invité l'accompagne et le salue deux fois à genoux. Puis l'invité principal et tous les autres invités suivent (à distance, et vont rejoindre au gymnase) le chef du canton.

Quand ils arrivent à la grande porte du gymnase, l'un des aides du chef du canton sort et les reçoit en dehors de la grande porte. Il salue deux fois à genoux le principal invité. Le principal invité lui rend ce double salut. L'aide salue tous les autres invités par une inclination profonde. Le chef du canton salue le principal invité par une inclination profonde, et entre le premier (pour montrer le chemin). Le principal invité $i \bullet$ salue tous les autres invités par une inclination profonde en retirant à soi les mains. Les invités entrent tous par le côté gauche (par le côté occidental) de la porte, tournent le visage vers l'est, et se rangent du nord au sud par ordre de dignité, les plus dignes au nord. $\bullet_{104} \mathrm{Le}$ principal invité avance un peu (et les autres aussi). Le chef du canton et le principal invité se saluent l'un l'autre trois fois par une inclination profonde (en trois endroits de la cour); ils marchent tous deux (suivis de tous les invités). Arrivés au bas des degrés, trois fois ils offrent de se céder le pas l'un à l'autre. Le chef du canton (monte le premier ; quand il) a monté un degré, le principal invité en monte aussi un. Le chef du canton, au haut des degrés orientaux, vis-à-vis du linteau de la porte, le visage tourné vers le nord, salue deux fois à genoux. Le principal invité, au haut des degrés occidentaux, vis-à-vis du linteau de la fenêtre, le visage tourné vers le nord, rend ce double salut.

$\mathbf{O}$ Le chef du canton prend une coupe à figure d'oiseau dans une corbeille sur la plateforme et descend les degrés. Le principal invité descend aussi. Le chef du canton, devant les degrés, le visage tourné vers l'ouest, fléchit les genoux, dépose la coupe, se lève, et refuse l'honneur que l'invité lui fait en descendant à sa suite. L'invité lui répond. Le chef du canton fléchit les genoux, prend la coupe, et se levant, va pour la rincer. Le visage tourné vers le sud, il fléchit les genoux, dépose la coupe auprès des corbeilles, et se lave les mains, pour rincer ensuite la coupe. L'invité s'avance, et, le visage tourné vers le nord-est, prie le chef du canton de ne pas rincer lui-même la $\bullet{ }_{105}$ coupe. Le chef du canton (consent à faire rincer la coupe par un autre. Il fléchit les genoux, dépose la coupe dans une corbeille, se lève et répond. Linvité retourne à sa place.

Quand la coupe a été rincée (par un officier), le chef du canton salue une fois l'invité par une inclination profonde, offre une fois de lui céder le pas et monte le premier avec lui. L'invité au haut des degrés occidentaux, le visage 
tourné vers le nord, le salue à genoux, pour le remercier d'avoir fait rincer la coupe. Le chef du canton, au haut des degrés orientaux, le visage tourné vers le nord, dépose la coupe, puis rend le salut. Alors il descend les degrés (pour se laver les mains de nouveau). Linvité descend aussi (pour lui faire honneur). Le chef du canton refuse cet honneur. L'invité lui répond. Le chef du canton, après s'être lavé les mains, salue une fois l'invité par une inclination profonde, offre une fois de lui céder le pas, et monte les degrés. Linvité monte aussi. Au haut des degrés occidentaux, il se tient debout • immobile. Le chef du canton fléchit les genoux, prend la coupe, la remplit. devant la natte de l'invité, et, le visage tourné vers le nord -ouest, il la lui offre. Linvité, au haut des degrés occidentaux, le visage tourné vers ${ }_{106}$ le nord, salue à genoux. Le chef du canton se retire un peu en arrière. Linvité s'avance, reçoit la coupe devant sa natte et retourne à sa place (sur sa natte). Le chef du canton, au haut des degrés orientaux, salue à genoux l'invité qui a reçu la coupe. L’invité se retire un peu en arrière, (comme pour décliner ce salut).

On sert des conserves de viande à l'invité. Il monte sur sa natte par le côté occidental. Alors on lui apporte sur une petite table les membres séparés d'un animal (un chien). Le chef du canton, à l'est des degrés orientaux, se tient debout • immobile. L'invité fléchit les genoux ; de la main gauche il prend la coupe, et de la main droite offre aux esprits les conserves de viande. Il dépose la coupe à l'ouest des conserves de viande, se lève, prend les poumons, fléchit les genoux, retranche la petite extrémité des poumons et les offre aux esprits. Ayant la main gauche au dessus de la main droite, (la gauche tient la grosse extrémité des poumons, et la droite l'autre extrémité), il goûte les poumons. Il se lève et remet les poumons sur la petite table.

Il fléchit les genoux, s'essuie les mains, prend la coupe et offre le vin aux esprits. II se lève, se met à genoux à l'extrémité de sa natte et goûte le vin. Il quitte sa natte, fléchit les genoux, $\bullet_{107}$ dépose la coupe, salue à genoux et loue la saveur du vin. Il prend la coupe et se lève. Le chef du canton, au haut des degrés orientaux, lui rend le salut. L'invité, au haut des degrés occidentaux, le visage tourné vers le nord, fléchit les genoux et vide la coupe (boit tout le vin). Il se lève, fléchit les genoux, dépose la coupe, puis salue à genoux. Il prend la coupe et se lève. Le chef du canton, au haut des degrés orientaux, lui rend le salut.

O Linvité descend les degrés avec la coupe vide (afin d'offrir à boire au chef du canton). Le chef du canton descend aussi (pour lui faire honneur). L'invité, devant les degrés occidentaux, le visage tourné vers l'est, fléchit les genoux, dépose la coupe, se lève et refuse cet honneur. Le chef du canton lui répond. L'invité fléchit les genoux, prend la coupe et va auprès des cruches. Le visage tourné vers le nord, il fléchit les genoux et dépose la coupe à côté des corbeilles. Il se lave les mains et se prépare à rincer la coupe. Le chef du canton, à l'est des degrés orientaux, le visage tourné vers le midi, le prie de ne pas rincer la coupe lui-même. L'invité fléchit les genoux et dépose la coupe dans une corbeille. (Il consent à ne pas la rincer lui-même). Il se lève et 
répond. Le chef du canton retourne à sa place. Après que la coupe a été rincée - 108 (par un officier subalterne), l'invité salue le chef du canton une fois par une inclination profonde, et offre une fois de lui céder le pas, comme précédemment; puis il monte.

O Le chef du canton salue l'invité par une inclination profonde, pour le remercier d'avoir fait rincer la coupe. L'invité lui rend son salut à genoux, se lève, descend et se lave les mains, comme le chef du canton l'a fait précédemment. Il monte, emplit la coupe devant la natte du chef du canton, et, le visage tourné vers le sud-est, lui rendant la pareille, il lui présente à boire. Le chef du canton, au haut des degrés orientaux, salue à genoux. Linvité se retire un peu en arrière (comme pour décliner le salut). Le chef du canton avance, reçoit la coupe et retourne à sa place. L'invité, au haut des degrés occidentaux, salue à genoux le chef du canton qui a reçu la coupe.

On sert des conserves de viande au chef du canton. Il monte sur sa natte par le côté septentrional. Alors on lui apporte sur une petite table les membres séparés d'un animal (un chien). Il offre aux esprits la viande et le vin, comme l'invité l'a fait précédemment. Il ne loue pas la bonté du vin. (c'est son • 109 propre vin). Passant devant la partie antérieure de sa natte, il va au haut des degrés orientaux. Le visage tourné vers le nord, il fléchit les genoux et vide la coupe. Il se lève, fléchit les genoux, dépose la coupe, puis il salue à genoux. Il prend la coupe et se lève. L'invité, au haut des degrés occidentaux, le visage tourné vers le nord, lui rend son salut. Le chef du canton fléchit les genoux, et dépose la coupe à l'extrémité du bâtiment latéral qui est à l'est. Au haut des degrés orientaux, il salue deux fois à genoux et se dit rassasié de vin. (Cela signifie qu'il a trouvé le vin mauvais et n'en veut pas boire davantage. Il le dit par humilité ; c'est son propre vin). L’invité, au haut des degrés occidentaux, lui rend ses deux saluts.

O Le chef du canton fléchit les genoux, prend une coupe de corne ou en forme de corne dans une corbeille et descend les degrés (pour offrir à boire une seconde fois). Linvité principal descend aussi (pour lui faire honneur). Le chef du canton dépose la coupe et refuse cet honneur. Linvité répond. Le visage tourné vers l'est, il se tient debout. Le chef du canton fléchit les genoux, prend la coupe pour la rincer lui-même. (L'invité ne s'oppose pas à ce qu'il la rince, parce qu'il la rince pour boire lui -même le premier). Le chef du canton, après avoir rincé la coupe, salue l'invité par une inclination profonde, demande de lui céder le pas, et monte le premier. L’invité, au haut des degrés occidentaux, se tient debout $\bullet$ immobile.

Le chef du canton emplit la coupe, pour (boire lui-même, $\bullet_{110}$ et ensuite) offrir à boire une seconde fois à l'invité. Au haut des degrés orientaux, le visage tourné vers le nord, il fléchit les genoux, dépose la coupe, puis il salue à genoux. Il prend la coupe et se lève. L'invité, au haut des degrés occidentaux, le visage tourné vers le nord, lui rend son salut. Le chef du canton fléchit les genoux, offre le vin aux esprits, ensuite il boit. Après avoir fini de boire, il se lève, fléchit les genoux, dépose la coupe, puis il salue à 
genoux. Il prend la coupe et se lève. L’invité, du haut des degrés occidentaux, le visage tourné vers le nord, lui rend son salut.

Le chef du canton descend les degrés pour rincer la coupe (et offrir à boire à l'invité). L'invité descend aussi et s'oppose à ce qu'il rince lui-même la coupe. Les cérémonies sont les mêmes que pour offrir à boire la première fois. Le chef du canton et l'invité montent les degrés. L'invité ne salue pas pour remercier d'avoir fait rincer la coupe. Au haut des degrés occidentaux, il se tient debout. Le chef du canton emplit la coupe devant la natte de l'invité, le visage tourné vers le nord. Linvité, au haut des degrés occidentaux, le salue à genoux. Le chef du canton fléchit les genoux et dépose la coupe à l'ouest des conserves de viande, L’invité refuse d'abord ; puis il fléchit les genoux, prend - ${ }_{111}$ la coupe, et se levant, l'emporte à sa place. Le chef du canton, au haut des degrés orientaux, le salue à genoux à son départ. Linvité, le visage tourné vers le nord, fléchit les genoux, dépose la coupe à l'est des conserves de viande, et retourne à sa place. (Il ne boit pas). Le chef du canton le salue par une inclination profonde et descend les degrés. L'invité descend aussi, et, le visage tourné vers l'est, se tient debout à l'ouest des d egrés occidentaux, près du bâtiment situé au côté occidental.

$\mathbf{O}$ Le chef du canton, le visage tourné vers le sud-ouest, salue trois fois à genoux la foule des invités. Ceux-ci lui rendent tous un seul salut à genoux. Le chef du canton les salue tous ensemble par une inclination profonde et monte les degrés. Il fléchit les genoux, et prend une coupe à figure d'oiseau, à l'extrémité du bâtiment latéral. Il descend et rince la coupe. Il monte les degrés, emplit la coupe et, au haut des degrés occidentaux, l'off re à la foule des invités. Les trois les plus âgés des invités montent les degrés, saluent à genoux et reçoivent la coupe. Le chef du canton les salue à genoux à leur départ. Ces trois vieillards (au haut des degrés occidentaux) fléchissent les genoux et offrent le vin aux esprits. Ils (se lèvent), boivent debout, et ne saluent pas à genoux, après avoir vidé la coupe. Ils la donnent au chef du canton, descendent et retournent à leurs places. Tous les autres invités, (au bas des degrés), sans saluer à genoux, reçoivent la coupe, fléchissent les genoux et offrent le vin aux esprits. Ils (se lèvent $\bullet_{112}$ et) boivent debout. On sert des conserves de viande sur la natte de chacun de ceux à qui l'on a offert à boire. Tous les invités pién sans exception ont des tranches de viande séchée, et de la viande conservée dans le sel et le vinaigre. Le chef du canton descend les degrés avec la coupe vide et la dépose dans une corbeille.

O Le chef du canton salue par une inclination profonde l'invité principal, l'invite à monter les degrés et monte le premier. Le principal invité salue tous les autres invités par une inclination profonde en retirant à soi les mains. Il monte les degrés. Les (trois les plus âgés des) autres invités montent aussi et vont à leurs nattes. Un officier du chef du canton rince une coupe de corne, pour (boire lui-même et ensuite) présenter à boire au principal invité. Il monte les degrés, emplit la coupe au haut des degrés occidentaux, fléchit les genoux, dépose la coupe et salue à genoux. Il prend la coupe et se lève. Le principal 
invité, à l'extrémité de sa natte, lui rend son salut. L'of ficier qui tient la coupe fléchit les genoux et offre le vin aux esprits ; ensuite il le boit.

Après avoir vidé la coupe, il se lève, fléchit les genoux, dépose la coupe et salue à genoux. Il prend la coupe et se $\bullet_{113}$ lève. Le principal invité lui rend son salut. L'officier descend et rince la coupe. Il monte et emplit la coupe au haut des degrés occidentaux, le visage tourné vers le nord. Le principal invité le salue à genoux. L'officier qui apporte la coupe s'ava nce, fléchit les genoux et dépose la coupe à l'ouest des conserves de viande de l'invité. (Il n'est pas d'assez haut rang pour la donner de main à main). Le principal invité s'excuse ; puis il fléchit les genoux, prend la coupe et se lève. L'officier qui a apporté la coupe, à genoux au haut des degrés occidentaux, salue l'invité qui s'en va. L'invité remet la coupe à la place où elle doit être, (à l'ouest des conserves de viande). L'officier qui a emporté la coupe descend.

O Si un grand préfet vient assister à l'exercice du tir, il entre par le côté gauche de la grande porte. Le chef du canton descend les degrés. Le principal invité descend; les autres invités descendent aussi, et retournent à leur première place près de la grande porte). Le chef du canton salue le grand préfet par une inclination profonde, l'invite à monter les degrés et monte avec lui. Il le salue à genoux pour le remercier de sa venue. Le grand préfet lui rend le salut. Le chef du canton prend une coupe à figure d'oiseau et descend les degrés. Le grand préfet descend aussi (pour lui faire honneur). Le chef du canton refuse cet honneur. Le grand préfet le prie de ne pas rincer $\bullet_{114}$ luimême la coupe. Les cérémonies sont les mêmes que celles faites quand le vin est offert au principal invité.

Une natte est étendue à l'est des amphores pour le grand préfet. Le grand préfet monte les degrés. Il ne salue pas à genoux pour remercier le chef du canton de lui avoir fait rincer une coupe. Le chef du canton emplit la coupe devant la natte du grand préfet et la lui présente. Le grand préfet, au haut des degrés occidentaux, salue à genoux. Il s'avance, reçoit la coupe et retourne à sa place. Le chef du canton, à la droite du grand préfet, le salue à genoux à son départ. Le grand préfet refuse la seconde natte qu'on lui a placée sur la première. (Un grand préfet s'assied sur deux nattes placées l'une sur l'autre). Le chef du canton lui répond. La seconde natte n'est pas enlevée. Alors on sert des conserves de viande au grand préfet. Il monte sur sa natte. On lui apporte une petite table sur laquelle sont les membres séparés d'un animal (un chien). Il les offre aux esprits. Les cérémonies sont les mêmes que pour le principal invité. Il ne goûte pas les poumons ni le vin. Il ne loue pas la bonté du vin. Au haut des degrés occidentaux, il vide la coupe et salue à genoux. Le chef du canton lui rend son salut.

$\mathbf{O} \cdot{ }_{115}$ Le grand préfet descend les degrés pour rincer la coupe (et offrir à boire au chef du canton). Le chef du canton retourne aux degrés orientaux, descend et prie le grand préfet de ne pas rincer lui-même la coupe; cela comme précédemment. Après que la coupe a été rincée (par un officier), le chef du canton se lave les mains. Il salue le grand préfet par une inclination 
profonde, l'invite à monter le premier et monte avec lui. Le grand préfet lui donne la coupe entre les deux colonnes de la plateforme, et retourne à sa place. Le chef du canton emplit la coupe pour (boire lui-même, et ensuite) offrir à boire une seconde fois au grand préfet, au haut des degrés occidentaux. Il fléchit les genoux. Le grand préfet lui rend son salut. Le chef du canton fléchit les genoux, offre le vin aux esprits, le boit entièrement et salue à genoux. Le grand préfet lui rend son salut. Le chef du canton fléchit les genoux, et dépose la coupe au midi de le colonne occidentale. Il salue une seconde fois à genoux. Il dit qu'il est rassasié de vin, (par humilité, il dit qu'il ne veut pas boire davantage, parce que son vin n'est pas bon), Le grand préfet lui rend son salut.

Le chef du canton retourne aux degrés orientaux, salue par une inclination profonde et descend. Le grand préfet descend aussi et se tient debout au midi du principal invité. Le chef du canton salue par une inclination profonde le principal invité, $\bullet{ }_{116}$ le prie de monter le premier et monte avec lui. Le grand préfet et (les trois les plus âgés de) la foule des invités montent les degrés et vont à leurs nattes.

O Des nattes sont étendues pour les musiciens au haut des degrés occidentaux, un peu à l'est. Le dire cteur de la musique monte le premier, tourne le visage vers le nord et se tient debout à l'ouest des nattes des musiciens. Les musiciens sont quatre, dont (deux chantent et) deux pincent la guitare. (Ils sont aveugles tous les quatre). Les joueurs de guitare arrivent les premiers. Les conducteurs de ces aveugles portent chacun sur le bras gauche une guitare, la plus grosse extrémité dirigée en avant. Leur main gauche tient les cordes à travers l'ouverture $i u^{\bullet}$ percée dans la caisse d'harmonie. De la main droite ils conduisent les deux musiciens. Ils entrent et montent avec eux par les degrés occidentaux. Ils tournent le visage vers le nord ; le plus âgé est à l'est de l'autre. Les musiciens fléchis sent les genoux. leurs conducteurs fléchissent aussi les genoux, leur donnent leurs guitares et descendent. Les joueurs d'orgue à bouche entrent. Ils se tiennent debout au milieu des pierres musicales suspendues ; ils ont le visage tourné vers l'ouest.

Alors tous les musiciens exécutent ensemble trois chants $d u \cdot{ }_{117}$ Tcheou nan, Chants I, II et III : Les oiseaux aquatiques crient, Le dolic rampe, La lampourde [cf. p. ${ }_{87}$ ]. Puis ils exécutent trois chants du Chao nan, Chants I, II et IV Le nid de pie, Elle cueille l'armoise blanche, Elle cueille des lentille s d'eau [cf. p. ${ }_{87}$ ]. Les musiciens, sans se lever, disent au directeur de la musique :

- Les chants réglementaires sont terminés.

Le directeur de la musique avertit le principal invité, puis il descend. Le chef du canton prend une coupe à figure d'oisea $u$ dans une corbeille sur la plateforme, pour offrir à boire aux artistes.

Pour le chef de musique (ou pour le plus âgé des musiciens) la coupe est rincée. (Le chef du canton descend pour la rincer). Le principal invité descend 
aussi (pour lui faire honneur). Le chef du canton refuse cet honneur. Les musiciens ne prient pas le chef du canton de ne pas rincer la coupe. Quand la coupe est rincée, le chef du canton monte les degrés et emplit la coupe. Les musiciens ne se lèvent pas. Les joueurs de guitare sont à gauche. Un des musiciens (le chef ou le plus âgé) salue à genoux et reçoit la coupe. Le chef du canton, au haut des degrés orientaux, le salue à genoux à son départ avec la coupe.

Des conserves de viande sont servies au principal musicien. Un homme est chargé de l'aider à les offrir aux esprits, ainsi que le vin. Le musicien boit. Il ne salue pas à genoux après $\bullet_{118}$ avoir bu ; il donne la coupe au chef du canton. Tous les autres musiciens, sans saluer, reçoivent la coupe, offrent le vin aux esprits et boivent. On sert à chacun d'eux des conserves de viande. Ils ne les offrent pas aux esprits.

Le chef du canton, sans rincer la coupe, offre à boire aux joueurs d'orgue à bouche au haut des degrés occidentaux. (La coupe n'est pas rincée, parce qu'ils sont de bas étage). Le principal joueur d'orgue salue à genoux au bas de la plateforme, monte tous les degrés, n'avance pas sur la plateforme, et reçoit la coupe. Le chef du canton le salue à genoux à son départ avec la coupe. Le joueur d'orgue (descend), fléchit les genoux devant les degrés, offre le vin aux esprits, se lève et boit debout. Il ne salue pas après avoir vidé la coupe ; il monte et donne la coupe au chef du canton. Les autres joueurs d'orgue, sans saluer, reçoivent la coupe, fléchissent les genoux et offrent le vin aux esprits ; ils se lèvent et boivent debout. On sert des conserves de viande à chacun d'eux. Ils ne les offrent pas aux esprits. Le chef du canton descend avec la coupe et la dépose dans une corbeille. Il retourne vers les degrés orientaux, monte et va à sa natte.

O Le chef du canton quitte sa natte par le côté méridional. Il descend, tch $\bullet$ seul, sans être accompagné ou suivi (par le $\bullet_{119}$ principal invité). Il constitue un aide qui sera directeur des cérémonies. Celui qui est désigné pour être directeur des cérémonies décline d'abord cet office par politesse ; puis il accepte. Le chef du canton le salue deux fois à genoux. Le directeur des cérémonies lui rend son salut. Le chef du canton monte les degrés et retourne à sa natte.

$\mathbf{O}$ Le directeur des cérémonies rince une coupe de corne, monte par les degrés occidentaux, passe par le côté intérieur (au nord) de la colonne, va au haut des degrés orientaux, et, le visage tourné vers le nord, reçoit les ordres du chef du canton. (Par ordre de celui-ci), il va au haut des degrés occidentaux, et, le visage tourné vers le nord, il prie le principal invité de demeurer (de ne pas s'en retourner chez lui de suite). Le principal invité refuse d'abord par politesse; puis il accepte. Le directeur des cérémonies en avertit le chef du canton. Puis il se tient debout entre les deux colonnes pour diriger les salutations. Le chef du canton, au haut des degrés orientaux, salue deux fois à genoux l'invité. L'invité, au haut des degrés occidentaux, lui rend deux saluts 
à genoux. Ils se saluent mutuellement par une inclination profonde et retournent à leurs nattes.

- ${ }_{120}$ Le directeur des cérémonies emplit une coupe de corne. Il descend par les degrés occidentaux. Dans la cour, le visage tourné vers le nord, il fléchit les genoux et dépose la coupe. Il se lève, se retire en arrière et reste debout un peu de temps. Il s'avance, fléchit les genoux, reprend la coupe, se lève, retourne à sa place, fléchit les genoux, et, sans offrir le vin aux esprits, il vide la coupe. Il se lève, fléchit les genoux, dépose la coupe et salue à genoux. Il prend la coupe, se lève, la rince ; puis, le visage tourné vers le nord et à genoux, il la dépose à la place où elle doit être. Il se lève, se retire un peu en arrière, et, le visage tourné vers le nord, il reste debout au midi de la coupe. On ne boit pas encore à la ronde. (Ce sera après le tir).

Six archers qui tireront de l'arc deux à deux attendent à l'ouest de la plateforme, le visage tourné vers le sud. (Ils sont rangés de l'est à l'ouest), l'est est le côté le plus honorable. Le directeur du tir (un officier du chef du canton) va à l'ouest de la plateforme, se découvre le bras gauche, met un doigtier au pouce de sa main droite, puis (une manche de cuir sur son bras gauche).

Tán. Ouvrir la tunique de dessus $s^{\bullet}$ et laisser voir la tunique de dessous $s^{\bullet}$; ou bien, ouvrir à la fois les deux tuniques. L'archer, après avoir découvert son bras gauche, y $\bullet_{121}$ mettait une manche de cuir rouge keóu ou ch $\bullet$, contre laquelle il appuyait son arc. Le doigtier kiu• était d'os ou d'ivoire. Mis au pouce de la main droite, il servait à tirer la corde de l'arc pour lancer les flèches.

Le directeur du tir prend un arc à l'ouest des degrés, et quatre flèches, qu'il $h i \bullet$ tient des deux mains entre l'index et le doigt du milieu, ave c son arc. Il monte par les degrés occidentaux. Au haut des degrés, le visage tourné vers le nord, il avertit le principal invité en ces termes :

- Les arcs et les flèches sont préparés. Le directeur invite à commencer le tir.

Le principal invité répond :

- Moi N., je manque d'habileté. J'accepte l’invi tation pour mes quelques jeunes compagnons (les autres invités).

Le directeur du tir va au haut des degrés orientaux, et, le visage tourné vers le nord-est, il avertit le chef du canton en ces termes:

- J'ai demandé au principal invité de faire commencer le tir. Il y consent.

O Le directeur du tir descend par les degrés occidentaux. Devant les degrés, le visage tourné vers l'ouest, il dit aux plus jeunes des archers de porter les instruments de tir (arcs, flèches, doigtiers,...); ces jeunes gens portent tous ces instruments à l'ouest de la plateforme. Les arcs du principal invité et du grand préfet, (s'il y a un grand préfet), sont adossés contre le 
bâtiment latéral qui est à l'ouest. Leurs flèches sont en deçà de leurs arcs, la coche tournée vers le nord. Les arcs de tous les autres ${ }_{122}$ invités sont adossés à l'ouest de la plateforme. Leurs flèches sont sur la plateforme. L'arc et les flèches du chef du canton sont à l'est du bâtiment latéral qui est à l'est.

$\mathbf{O}$ Le directeur du tir ne dépose pas son arc ni ses flèches. Au sud de la plateforme, il s'occupe de former trois paires d'archers, composées chacune de deux archers d'égale habileté. (Il choisit six jeunes gens parmi les invités). $\mathrm{Au}$ sud de ces trois paires d'archers, le visage tourné vers le nord, il dit au premier de chaque paire :

— Un tel sera votre compagnon de tir, Seigneur.

Il dit au second :

— Seigneur, vous tirerez de l'arc avec le Seigneur N.

$\mathbf{O}$ Le directeur des cérémonies fait l'office de c ommandant. Il ordonne de déployer entièrement la cible. Les jeunes invités délient le noud (qui fixe en son milieu le bas de la bande latérale gauche de la cible, voy. plus haut, page - ${ }_{102)}$; puis ils attachent le bas de cette bande au poteau avec la corde inférieure. Le commandant ordonne à celui qui signalera les victoires d'adosser son guidon de plumes ou son petit drapeau contre le milieu de la cible (derrière la cible). (Houé. Obtenir, réussir, atteindre le but, frapper le milieu de la cible, succès, victoire, signaler un succès ou une victoire). Cet homme (l'un $\bullet_{123}$ des jeunes invités) arrive du côté occidental, fléchit les genoux, prend son drapeau et l'appuie contre le milieu de la cible. Puis il se retire.

$\mathbf{O}$ Le directeur de la musique va à l'ouest, et dit aux jeunes invités d'aider les artistes à se transporter avec leurs instruments au bas de la plateforme. Les jeunes invités aident les musiciens comme ils les ont aidés à leur entrée. Les musiciens descendent par les degrés occidentaux. Ils vont au sud-est, au bas des degrés orientaux, devant la plateforme, loin de la plateforme à la distance de trois fois la longueur du bois d'une flèche (en tout $1 \mathrm{~m} 80 \mathrm{~cm}$ ). Le visage tourné vers l'ouest, ils se rangent du nord au sud ; le nord est le côté le plus honorable. Ils fléchissent les genoux. Le directeur de la musique, le visage tourné vers le nord, se tient debout au sud des musiciens.

Le directeur du tir, tenant encore en mains quatre flèches, avec son arc, donne ses ordres aux trois paires d'archers. Chacun des archers offre à son compagnon de lui céder la priorité ; puis il prend un arc, prend quatre flèches une à une, $k i \bullet$ alternativement avec son compagnon. (Quand le premier en a pris une, le second en prend une). - Les six archers se découvrent le bras gauche, mettent un doigtier au pouce de la main droite, puis (couvrent d'une manche de cuir le bras gauche). Un iôu séu officier (un des jeunes invités) présente à chaque archer son $\bullet_{124}$ arc, dont il tient un bras de la main gauche et la corde de la main droite. Ensuite il lui présente ses flèches.

- Chacun des six archers prend son arc. (Il tient l'une des extrémités de l'arc de la main gauche et la corde de la main droite). Il enfonce trois flèches 
sous sa ceinture. Il tient une quatrième flèche des deux mains sur son arc; il la tient entre l'index et le doigt du milieu. Le directeur du tir, le visage tourné vers l'est, se tient d'abord debout au sud -ouest de l'endroit où l'on dépose les tchôung récipients qui contiennent les fiches qui servent à marquer les victoires. Les six archers s'avancent, passent à l'ouest du directeur du tir, et se tiennent debout au sud-ouest de sa personne, le visage tourné vers l'est. Ils sont rangés du nord au sud; le nord est le côté le plus honorable. Ils attendent.

$\mathbf{O}$ Le directeur du tir, le visage tourné vers l'est, se tient debout au nord des six archers, enfonce trois flèches sous sa ceinture, et en tient une des deux mains, ainsi que son arc. Il salue par une inclination profonde et s'avance. En face des degrés, le visage tourné vers le nord, il salue par une inclination profonde. Arrivé près des degrés, il salue encore par une inclination profonde. Il monte sur la plateforme et fait une inclination profonde. Il keôu tourne à l'intérieur (à l' est de la colonne de $\bullet_{125}$ la Sié ou siú salle du tir, et passe en dehors (au sud) de la colonne qui est sur la plateforme. En face de $\boldsymbol{u}$ la place délimitée dans laquelle l'archer de gauche se tient quand il tire de l'arc, le visage tourné vers le nord, il salue par une inclination profonde. Arrivé à cette place, il fait encore une inclination profonde. Son pied gauche foule cette place. Ses deux pieds ne sont pas føng à côté l'un de l'autre sur la même ligne, (l'un est en avant, l'autre en arrière). Il se tourne; il considère la cible et les récipients des fiches. Il incline le corps; ses deux pieds sont à côté l'un de l'autre sur la même ligne. On n'enlève pas le guidon, (on le laisse auprès de la cible, parce qu'il n'y aura pas encore de victoires à sig naler ; le directeur du tir ne fera que stimuler l'ardeur des archers et les exercer). • Le directeur du tir invite à commencer. Il lance quatre flèches, une vers chacun des quatre points cardinaux. - Il tient le bois de son arc de la main gauche et la corde de la main droite. Il ne tient pas de flèche. Le visage tourné vers le sud, il salue par une inclination profonde. Il salue et monte comme pour tirer de l'arc. Il des cend et passe au sud de sa place ordinaire. Il va à l'ouest de la plateforme, et change d'attitude. Prenant une flèche, il la tient des deux mains entre l'index et le doigt du milieu, transversalement sur son arc. - Ensuite il va à l'ouest des degrés, prend sa baguette (pour châtier les délinquants), l'enfonce sous sa ceinture et retourne à sa place.

$\mathbf{O} \cdot{ }_{126}$ Le commandant dit à celui qui doit signaler les victoires de prendre en main le guidon et de se tenir derrière la cible. Cet homme va à la cible, prend le guidon, se place derrière la cible et attend. Le directeur du tir se tourne. En face de la première paire d'archers, le visage regardant l'ouest, il leur ordonne de tirer de l'arc. Puis il retourne à sa place. Ces deux archers saluent par une inclination profonde et avancent. Le premier de la paire est à gauche du second. Ils marchent à côté l'un de l'autre.

En face des degrés, le visage tourné vers le nord, ils saluent par une inclination profonde; arrivés aux degrés, il font encore une inclination profonde. Le premier des deux monte le premier les trois degrés. Le second le suit à un degré d'intervalle. Le premier monte sur la plateforme ; il se tient un peu à gauche. Le second (il est à droite) y monte aussi. Le premier fait au 
second une inclination profonde. Tous deux marchent côte à côte. En face de l'endroit où ils doivent se tenir pour tirer de l'arc, le visage tourné vers le nord, ils font tous deux une inclination profonde. Arrivés auprès de cet endroit, ils font encore une inclination profonde. Tous deux foulent du pied gauche cet endroit, se retournent et considèrent la cible et les récipients des fiches. Ils mettent les deux pieds à côté l'un de l'autre et $\bullet_{127}$ attendent. (On appelle $\bullet$ deux places contiguës, limitées par des lignes. Les deux archers s'y tiennent, le premier à gauche, le second à droite, quand ils tirent à la cible).

$\mathbf{O}$ Le commandant va à l'ouest de la plateforme. Il n'a ni doig tier au pouce de la main droite ni manche de cuir au bras gauche. Il a le bras gauche découvert et tient en mains son arc. Il passe au sud du directeur du tir, monte par les degrés occidentaux, tourne à l'ouest de la colonne occidentale, passe derrière le premier des deux archers, et, le visage regardant le sud-ouest, il se tient debout entre les deux $u$ places assignées aux deux archers. De la main droite, tenant son arc par une extrémité, il l'agite vers le midi et avertit tous les assistants de s'éloigner de la cible (de peur d'être frappés par les flèches) . Celui qui doit signaler les victoires (et qui est derrière la cible) prend son guidon, et répond qu'il $n \bullet$ obéit. Il ne cesse de crier $n \bullet$ jusqu'à ce qu'il arrive à la cloison qui lui sert d'abri contre les flèches. Il fléchit les genoux, et, le visage tourné vers l'est, il couche à terre son guidon. Il se lève et attend.

Le commandant s'en va, passe au sud du second archer, tourne derrière lui, descend par les degrés occidentaux, passe au sud du directeur du tir, retourne à l'ouest de la plateforme ${ }_{128}$ et dépose son arc. Il se couvre le bras gauche des manches de ses deux tuniques, retourne à sa place et se tient debout au sud du directeur du tir.

Le directeur du tir s'avance, se croise avec le commandant devant les degrés ; tous deux passent à gauche l'un de l'autre. Le directeur du tir, au bas de la plateforme, à l'est des degrés occidentaux, le visage tourné vers le nord, avertit le premier des deux archers en ces termes :

- Prenez garde que vos flèches ne frappent, ni en ligne droite ni $l i \bullet$ par ricochet, celui qui est chargé de signaler les victoires.

Le premier archer le salue par une inclination profonde. Le directeur du tir s'en va et retourne à sa place.

Alors commence le tir. Après que le premier archer a décoché la flèche qu'il tenait des deux mains sur son arc, le second archer lance la sienne. Tous deux décochent et envoient alternativement quatre flèches. Celui qui est chargé de signaler les flèches qui frappent le milieu de la cible, fléchit les genoux et avertit quand une flèche atteint le centre de la cible. Il lève son guidon en faisant entendre la note $k \bullet$ ung (la première note de la gamme). Il couche son guidon en faisant entendre la note chøng (la deuxième note de la gamme. Il chante Hou - ${ }_{129}$ mais on ne pose pas encore de fiches (parce que ce tir n'a été qu'un essai, un exercice préliminaire). 
Quand les deux archers ont fini de tirer, tenant en mains leurs arcs, mais pas de flèche, le visage tourné vers le sud, ils saluent par une inclination profonde. Ils saluent ainsi comme ils l'ont fait avant de monter pour aller tirer de l'arc. Le premier des deux descend les trois degrés. Le second, un peu à droite, le suit à un degré d'intervalle (il descend un degré quand son compagnon en a descendu un). Tous deux marchent côte à côte, le premier à gauche. Ils passent à gauche des deux autres archers qui vont monter et tirer de l'arc. Ils se croisent avec eux devant les degrés ; ils les saluent par une inclination profonde, et réciproquement. Ils passent au sud du commandant et vont à l'ouest de la plateforme. Ils déposent leurs arcs, ôtent leurs doigtiers et leurs manches de cuir, se couvrent le bras gauche des manches de leurs deux tuniques, et attendent à l'ouest de la pla teforme, le visage tourné vers le sud, le premier archer à l'est du second. Les trois paires d'archers agissent ainsi du commencement à la fin.

$\mathbf{O}$ Le directeur du tir enlève la baguette qui est à sa ceinture, et la dépose à l'ouest des degrés occidentaux. Il monte sur $\bullet_{130}$ la plateforme, le visage tourné vers le nord, il avertit le principal invité en ces termes :

\section{— Les trois paires d'archers ont fini de lancer leurs flèches.}

Le principal invité le salue par une inclination profonde. Le directeur du tir descend, enfonce sa baguette sous sa ceinture et retourne à sa place.

$\mathbf{O}$ Le commandant va à l'ouest de la plateforme, se découvre le bras gauche, prend son arc, passe au midi de sa place ordinaire, s'avance, se croise avec le directeur du tir devant les degrés, l'un passant à gauche de l'autre. Il monte par les degrés occidentaux, tourne la colonne, passe derrière l'espace tracé à l'archer de droite, et se tient debout entre les deux espaces tracés aux deux archers. Le vissage tourné vers le sud-ouest, il s’incline avec son arc dans les mains, et ordonne aux archers de prendre des flèches.

Celui qui signale les victoires prend son guidon et se met aux ordres du commandant. Sans cesser de crier $n \bullet$, il va avec son guidon se placer derrière la cible, et il attend. Le commandant s'en va, passe au sud de l'espace tracé à l'archer de gauche, tourne derrière et descend par les degrés occidentaux. Puis il va devant la plateforme, et, le visage tourné vers le nord, il se tient debout au sud de la place où l'on met les $\bullet_{131}$ récipients des flèches. Il ordonne aux plus jeunes des invités de disposer ces récipients. Alors ces jeunes invités disposent les récipients des flèches au sud de la cour centrale, en face des cruches, la moins belle extrémité tournée vers l'est. Le com mandant passe au sud du directeur du tir et s'en va. Il dépose son arc à l'ouest de la plateforme, couvre son bras gauche des manches de ses deux tuniques et retourne à sa place.

Les jeunes invités prennent des flèches, et, le visage tourné vers le nord, à genoux, ils les déposent dans les récipients, la coche tournée vers le nord. Puis ils se retirent. Le commandant se couvre le bras gauche des manches de ses tuniques et s'avance en face du côté méridional des récipients, le visage 
tourné vers le nord, il fléchit les genoux, met les deux mains sur les flèches et les compte quatre par quatre. Si les flèches ne sont pas en nombre suffisant, le commandant se découvre de nouveau le bras gauche, prend son arc et monte les degrés, comme précédemment. Il donne ses ordres en disant :

— Les flèches ne sont pas sou• en nombre suffisant.

Les jeunes invités qui sont à l'ouest répondent :

— Nous sommes à vos ordres.

Aussitôt il vont de nouveau chercher des flèches et les mettent dans les récipients.

$\mathbf{O} \cdot{ }_{132}$ Le directeur du tir adosse sa baguette à l'ouest des degrés, m onte, et propose au principal invité, comme précédemment, de faire commencer le tir. Le principal invité accepte la proposition.

$\mathbf{O}$ Le principal invité, le chef du canton, le grand préfet (quand il y en a un), tous les autres invités prennent part au tir, $j \bullet$ s’ils le veulent. Alors le directeur du tir avertit le principal invité. Il va au haut des degrés orientaux. avertir le chef du canton. Le chef du canton et le principal invité forment ensemble une paire d'archers. Ensuite le directeur du tir avertit les grands préfets (s'il y en a). Un grand préfet peut avoir pour compagnon de tir même un simple officier de la foule des invités. Le directeur du tir avertit un grand préfet en lui disant :

— Un tel sera votre compagnon de tir, Seigneur.

Le directeur du tir, au haut des degrés occidentaux, le visage tourné vers le nord, dit à tous les invités de commencer le tir. Il descend les degrés, enfonce sa baguette sous sa ceinture, passe au sud du commandant, va à l'ouest de la plateforme, se tient debout et associe tous les archers deux à deux. Les invités qui désirent prendre part au tir descendent tous, passent au $\bullet_{133}$ midi $d u$ commandant, vont à l'ouest de la plateforme, se mettent à la suite des trois premières paires d'archers, et se tiennent debout, rangés de l' est à l'ouest ; l'est est le côté le plus honorable. Les paires où il entre un grand préfet sont les plus honorables. Si, à cause du grand nombre, il est des archers qui soient obligés de se placer à l'est (du nord au sud), les plus honorables sont au nord . Le principal invité, le chef du canton, les grands préfets seuls ne descendent pas encore. Alors le chef du tir associe par paires tous ceux qui désirent tirer de l'arc et ne sont pas descendus à la première invitation.

$\mathbf{O}$ Ensuite il ordonne aux archers des trois premières paires de prendre des flèches une à une alternativement, et il retourne à sa place. Ces six archers deux à deux prennent des flèches une à une alternativement. Tous se découvrent le bras gauche, mettent un doigtier au pouce de la main droite et une manche de cuir au bras gauche. Puis ils prennent leurs arcs, s'avancent, et restent debout au sud-ouest du commandant. 
Le directeur du tir dit aux deux archers de la première paire de prendre des flèches. Il retourne à sa place. Ces deux archers saluent par une inclination profonde, et s'avancent. En face des récipients des flèches, le visage tourné vers le nord, ils s’inclinent $\bullet_{134}$ profondément ; arrivés près des récipients, ils font encore une inclination profonde. Le premier des deux archers tourne le visage vers l'est ; le second vers l'ouest. Le premier salue par une inclination profonde, s'avance, fléchit les genoux, tient son arc transversalement, le bois de l'arc en haut et la corde en bas). Il $k$ ' passe la main droite entre le bois et la corde de l'arc et prend une flèche. Il la tient de la main gauche, ainsi que le bras de son arc. Il passe la main droite le long des plumes de la flèche dans le sens des barbes (et saisit la corde de son arc). Alors il se lève ; tenant la corde de son arc, il tourne à gauche, se retire, retourne à sa place, et, le visage regardant l'est, il salue par une inclination profonde. Le second des deux archers s'avance, fléchit les genoux, tient son arc transversale ment, passe la main droite par dessus le bois de son arc, prend une flèche et se lève. Ensuite il fait ce qu'a fait le premier.

Quand les deux archers ont pris chacun quatre flèches, une à une alternativement, ils font une inclination profonde, tournent tous deux à gauche, et, le visage regardant le midi, saluent par une inclination profonde. Tous deux s'avancent un peu. Au sud des récipients des flèches, ils tournent tous deux à gauche. Le visage regardant le nord, ils enfoncent chacun trois flèches sous la ceinture, et en tiennent une des deux mains entre l'index et ${ }_{135}$ le doigt du milieu sur leurs arcs. Après une salutation profonde, ils tournent tous deux à gauche ; le premier se tient à la droite du second. Ces deux archers se croisent avec les deux qui leur succèdent, passent à leur gauche, échangent avec eux une inclination profonde et retournent à leurs places premières. Les trois paires d'archers prennent des flèches de cette manière, une à une, alternativement. Le dernier prend ensuite une cinquième flèche, qu'il donnera au directeur du tir, et dont le directeur du tir se servira en invitant les archers. Il la prend en sus des quatre flèches réglementaires. Il la donne au directeur du tir qui est à l'ouest. Puis il retourne à sa place.

O Ceux des invités qui n'ont pas encore pris de flèches alternativement deux à deux, se découvrent tous le bras gauche, mettent le doigtier au pouce de la main droite, puis (la manche de cuir au bras gauche). Ensuite ils prennent leurs arcs, enfoncent chacun trois flèches sous la ceinture et en tiennent une des deux mains entre l'index et le doigt du milieu. Ils passent à l'ouest de la plateforme, s'avancent et se tiennent debout au sud à la suite des trois premières paires d'archers. Ils tournent le visage vers l'est. Ils sont rangés du nord au sud. Le côté le plus honorable est le nord. Les plus honorables des archers sont les grands préfets et ceux qui leur sont associés pour le tir.

$\mathbf{O} \cdot{ }_{136}$ Le directeur du tir donne ordre de lancer les flèches, comme précédemment. Les deux archers qui forment la première paire, saluent par une inclination profonde, montent les degrés, comme l'ont fait les précédents. 
Le commandant ordonne à tous de s'éloigner de la cible (pour éviter les flèches). Celui qui signale les victoires répond qu'il obéit. (Il s'éloigne de la cible). Le commandant descend, dépose son arc et retourne à sa place. Le directeur du tir tient encore des deux mains son arc et une flèche. Il enlève la baguette qui est à sa ceinture, croise le commandant devant les degrés, monte, et demande au principal invité qu'on pose une fiche, chaque fois qu'une flèche frappera le centre de la cible. Le principal invité y consent.

Le directeur du tir descend, enfonce sa baguette sous sa ceinture, et, le visage tourné vers l'ouest, se tient debout à l'est de l'endroit où l' on placera le récipient des fiches. Le visage tourné vers le nord, il ordonne à celui qui pose les fiches de placer le récipient des fiches. Ensuite il lui adresse des recommandations. Celui qui doit poser les fiches prend le récipient orné d'une figure de cerf. Un homme prend les fiches et le suit. Celui qui est chargé de poser les fiches $\bullet_{137}$ fléchit les genoux, et dispose le récipient des fiches, au midi en face des récipients des flèches, à l'ouest en face du bâtiment latéral situé à l'ouest. Le visage tourne vers l'est il se lève, reçoit les fiches. Il fléchit les genoux, met huit fiches dans le récipient, place transversalement le reste des fiches à l'ouest du récipient, les extrémités tournées vers le midi. Il se lève, kòung tient les mains réunies devant la poitrine et attend.

Ensuite le directeur du tir s'avance, passe au bas de la plate forme, tourne le visage vers le nord, et parle en ces termes :

- Une flèche qui ne perce pas la cible, n'obtient pas de fiche.

(La cible est de toile). Le premier des deux archers salue par une inclination profonde. Le directeur du tir se retire et retourne à sa place. Celui qui pose les fiches fléchit les genoux et prend les huit fiches qui sont dans le récipient. Il met huit autres fiches dans ce récipient. Il se lève, tenant dans les mains les huit fiches quill a prises, et attend.

Alors les archers tirent de l'arc. Quand une flèche frappe le milieu de la cible celui qui marque les victoires fléchit les genoux et pose une fiche. Pour chacune des flèches qui frappent le but, il pose une fiche. Il met à droite les fiches du premier des $\bullet_{138}$ deux archers de chaque paire, et à gauche celles du second. S’il reste des fiches qui n'aient pas été employées (parce que les huit flèches n'ont pas toutes frappé le but) ; il retourne et les dépose (à l'ouest du récipient). Il prend de nouveau huit fiches dans le récipient, en met huit autres dans ce récipient, se lève, et tenant en mains les huit fiches quil a prises, il attend. Les trois premières paires d'archers lancent chacune toutes leurs flèches.

O Le principal invité, le chef du canton et le grand préfet (s’il y en a) saluent par une inclination profonde, descendent chacun par leurs degrés respectifs (le chef du canton par les degrés orientaux, les deux autres par les degrés occidentaux) ; ils saluent encore par une inclination profonde. Le chef du canton, à l'est de la plateforme, se découvre le bras gauche, met un doigtier au pouce de la main droite, puis (une manche de cuir sur le bras gauche). 
Ensuite il prend son arc de la main gauche, enfonce trois flèches sous sa ceinture, et en tient une des deux mains, ainsi que son arc. Le principal invité, à l'ouest de la plateforme, fait la même chose. Tous deux montent et des cendent par leurs degrés respectifs. Au bas des degrés, ils saluent par une inclination profonde. Ils montent sur la plateforme et saluent par une inclination profonde. Le chef du canton est le second de la paire, (il cède au principal invité l'honneur d'être le premier). Tous deux, en face de l'espace limité où ils doivent se tenir en tirant de l'arc, le visage tourné vers le nord, ils - ${ }_{139}$ saluent par une inclination profonde. Arrivés à cet espace, ils font encore une inclination profonde. Ensuite ils lancent leurs flèches. Quand ils les ont lancées toutes, le visage tourné vers le sud, ils saluent de nouveau par une inclination profonde.

Tous deux montent et descendent par leurs degrés respectifs. Au haut des degrés, ils saluent par une inclination profonde. Après avoir descendu les degrés, ils saluent par une inclination profonde. Le principal invité, à l'ouest de la salle du tir et le chef du canton à l'est, déposent tous deux leurs arcs. (La salle du tir est située à l'ouest de la plateforme et de la salle centrale, au même niveau que la plateforme). Ils ôtent leurs doigtiers, leurs manches de cuir, se couvrent le bras gauche des manches de leurs deux tuniques. Ils retournent à leurs places. Ils montent. Arrivés aux degrés, ils saluent par une inclination profonde, s'avancent sur la plateforme, saluent par une inclination profonde et retournent à la salle du tir.

$\mathbf{O}$ Le grand préfet se découvre le bras gauche, se met un doigtier au pouce de la main droite et (une manche de cuir au bras gauche). Puis il prend son arc, enfonce trois flèches sous sa ceinture, et tient son arc et une quatrième flèche des deux mains. Il part de l'ouest de la s alle, sort à l'ouest du directeur du tir et va auprès de son compagnon de tir (dans la cour). Le grand préfet est le second archer de la paire, (il cède à son compagnon l'honneur d'être le premier). Il salue par une inclination profonde et s'avance. Son co mpagnon marche un $\bullet_{140}$ peu en arrière (par respect). Ils font des inclinations profondes à plusieurs reprises comme les trois premières paires d'archers.

Quand ils sont arrivés au bas des degrés, le compagnon monte le premier. Quand ils ont fini de lancer leurs flèches, ils saluent par une inclination profonde, comme quand ils ont monté pour tirer de l'arc. Le compagnon descend le premier. Quand ils ont descendu les degrés, le compagnon se retire un peu en arrière (et le grand préfet marche le premier). Tous deux déposent leurs arcs à l'ouest de la plateforme et se couvrent le bras gauche des manches de leurs tuniques. Ensuite le compagnon reste à gauche de la plateforme. Le grand préfet monte les degrés et va à sa natte. Les autres invités tirent de l'arc à la suite les uns des autres, deux à deux. A chaque flèche qui frappe la cible, on pose une fiche comme précédemment. Ceux à qui le directeur du tir commande de tirer de l'arc, ce sont seulement les deux premiers archers, c-à-d., les compagnons du principal invité et du chef du canton. (Il ne le commande pas au principal invité ni au chef du canton). 
(Les archers forment deux partis. Les premiers archers des différentes paires forment ensemble le premier parti ; les seconds archers forment le parti opposé),

Quand le tir est terminé, celui qui a posé les fiches, monte par les degrés occidentaux avec celles qui lui restent entre les mains. Il monte trois degrés, mais n'avance pas sur la plateforme. $\bullet_{141}$ Il avertit le principal invité en ces termes :

- Les archers de gauche, c'est-à-dire, les seconds archers de chaque paire, et les archers de droite, c'est-à-dire, les premiers de chaque paire, ont tous lancé leurs quatre flèches.

Il descend et retourne à sa place. Il fléchit les genoux et dépose les fiches restantes à gauche du récipient. Il se lève, joint les mains devant la poitrine et attend.

O Le commandant, le bras gauche découvert, le doigtier au pouce de la main droite et l'arc dans la main gauche, monte et ordonne de recueillir les flèches (celles qui ont été lancées et celles qui restent). Il donne cet ordre comme les précédents. Celui qui a signalé les victoires répond qu'on va lui obéir. Avec son guidon il se place derrière la cible, comme précédemment. Le commandant descend, dépose son arc et retourne à sa place. Les jeunes invités (recueillent et) déposent les flèches à la place où elles étaient d'abord. Quant aux flèches du grand préfet, on les lie ensemble par un lien de chiendent appliqué en leur milieu. Les quatre flèches du commandant sont remises à leur première place.

O Ensuite le directeur du tir va à l'ouest des degrés occi dentaux, dépose son arc, enlève sa baguette, recouvre son bras $\bullet_{142}$ gauche, s'avance, passe à l'est du récipient des fiches, se tient debout au sud de ce récipient, et, le visage tourné vers le nord, examine les fiches. Celui qui a placé les fiches, le visage tourné vers l'est, à l'ouest du récipient des fiches, fléchit les genoux, et compte d'abord les fiches de droite (obtenues par les premiers archers des différentes paires). Deux fiches font un tout, une paire). Celui qui a posé les fiches, après en avoir pris une paire avec la main droite, la passe dans la main gauche. Quand il en a dix paires dans la main gauche, il les dépose $c h \bullet u$ en long devant lui. Chaque fois qu'il en dépose une dizaine, il la place en sens contraire de le dizaine précédente. (Il la place de l'est à l'ouest, si la dizaine précédente est placée du nord au sud). S'il reste des paires qui soient moins de dix, il les dépose transversalement, en deçà des autres, (près de lui). S’il reste une fiche unique qui n'ait pas sa compagne, il la place encore en long devant lui, en deçà des paires de fiches.

Celui qui a posé et compte les fiches se lève. Devant les fiches, il s'écarte de droite à gauche, (afin de compter les fiches qui sont à sa gauche). Il tourne le visage vers l'est. Il fléchit les genoux, prend toutes les fiches de gauche ensemble et les tient de la main gauche. Il les dépose à terre deux par deux. Il les traite autrement que les fiches de droite, dont il déposait à terre dix paires à 
la fois. S’il reste des fiches en sus des dizaines de paires, il les dépose comme il a déposé celles de droite. Le $\bullet_{143}$ directeur du tir retourne à sa place.

Ensuite celui qui a posé les fiches s'avance, prend les fiches du parti vainqueur, et les tenant dans les mains, monte par les degrés occidentaux. Il monte tous les degrés, mais n'avance pas sur la plateforme. Il informe le principal invité du résultat final. Si les archers de droite (les premiers des différentes paires) sont victorieux, il dit :

- Les archers de droite ont été plus habiles que les archers de gauche (les seconds des différentes paires).

Si les archers de gauche sont victorieux, il dit :

— Les archers de gauche ont été plus habiles que les archers de droite.

Il dit combien de paires de fiches chacun des deux partis a obtenues. Si, outre les paires, il y a des unités, il le dit aussi. Si les fiches de gauche et celles de droite sont en nombre égal, il prend de la main gauche une fiche de gauche et de la main droite une fiche de droite, et dit :

— Les fiches de gauche et celles de droite sont en nombre égal.

Il descend et retourne à sa place. Il fléchit les genoux, prend toutes les fiches à la fois dans les mains, en place huit dans le récipient et dépose le reste à l'ouest du récipient. Il se lève, joint les mains devant la poitrine et attend.

$\mathbf{O} \cdot{ }_{144}$ Le directeur du tir va à l'ouest de la plateforme, et dit aux plus jeunes des invités de disposer les cuvettes sur lesquelles on placera les coupes. Les jeunes invités prennent les cuvettes, montent les degrés et placent les cuvettes, à l'ouest de la colonne occidentale ; ensuite ils descendent. (Ces cuvettes ont la forme d'un boisseau peu élevé). Un jeune invité du parti des vainqueurs rince une coupe de corne (ou en forme de corne), et monte pour offrir à boire aux vaincus. (Les vaincus boivent dans une corne. C'est une humiliation. Les vainqueurs boivent dans une coupe à forme d'oiseau. C'est un honneur). Le jeune invité, le visage tourné vers le midi, fléchit les genoux, et place la coupe sur la cuvette. Il descend, se découvre le bras gauche, prend son arc et retourne à sa place.

Ensuite le directeur du tir se découvre le bras gauche, prend son arc, tient des deux mains son arc et une flèche, enfonce sa baguette sous sa ceinture, et, le visage tourné vers le nord, va se placer au midi des trois premières paires d'archers. Il donne ses ordres à ces six archers et à tous les autres. - Tous les vainqueurs se découvrent le bras gauche, mettent le doigtier au pouce de la main droite et la manche de cuir au bras gauche, et tiennent en mains leurs arcs bandés. Tous les vaincus se couvrent le bras gauche, ôtent le doigtier et la manche de cuir. Ils tournent en bas la main gauche, qui tient le $\bullet_{145}$ bois de l'arc, tournent en haut la main droite et délient la corde de l'arc. Ensuite ils tiennent des deux mains les deux bras de l'arc débandé. 
Le directeur du tir retourne le premier à sa place. Les archers des trois premières paires et tous les autres archers, divisés par paires, s'avancent et se tiennent debout chacun à la place qui lui a été assignée avant le tir. Ils sont rangés du nord au sud; le nord est la place d'hon neur. Le directeur du tir les fait monter pour boire, comme il les a fait monter pour tirer de l'arc. La première paire s'avance et salue par une inclination profonde, comme avant de monter pour le tir. Quand ils arrivent près des degrés, le vainqueur monte le premier à la plateforme et s'écarte un peu à droite. Le vaincu s'avance. Le visage tourné vers le nord, il fléchit les genoux et prend la coupe qui est sur la cuvette. Il se lève, se retire un peu, et debout, vide la coupe. Il s'avance, fléchit les genoux et dépose la coupe en deçà de la cuvette (entre lui et la cuvette). Il se lève et salue par une inclination profonde. Le vaincu descend le premier. Il se croise devant les degrés avec celui qui monte pour boire après lui. Tous deux passent à gauche l'un de l'autre, et se saluent réciproqueraient par une inclination profonde. $\bullet_{146}$ Le vaincu se retire en passant au midi $d u$ commandant. Ensuite il va à l'ouest de la plateforme. Il dépose son arc, se couvre le bras gauche et attend.

Il y a un homme (un officier du chef du canton) qui est chargé d'apporter la coupe à figure d'oiseau (pour les vain queurs). Cet homme fléchit les genoux, prend la coupe de corne, la remplit, s'en retourne et la dépose sur la cuvette. Les archers montent, et les vaincus boivent, comme il a été dit précédemment.

Quand les vaincus des trois premières paires ont fini de boire, le principal invité, le chef du canton et le grand préfet, s’ils ont été vaincus, ne prennent pas leurs arcs. Celui qui est chargé de présenter la coupe à figure d'oiseau, prend la coupe de corne, descend, la rince, monte, la remplit et la présente successivement à chacun de ces nobles vaincus devant leurs nattes. Chacun d'eux reçoit cette coupe de corne, va au haut des degrés occiden taux, et boit debout, le visage tourné vers le nord. Après avoir vidé la coupe de corne, il la donne à celui qui est chargé de présenter la coupe à figure d'oiseau, s'en retourne et va à sa natte. Quand un grand préfet va boire le vin des vaincus, son compagnon de tir ne monte pas les degrés avec lui. Si le $\bullet_{147}$ compagnon de tir du grand préfet n'a pas été vainqueur, lui aussi, tenant son arc débandé, monte seul et boit. Tous les vaincus boivent ensuite. Alors tous les vainqueurs sans exception boivent dans la coupe à figure d'oisea $\mathrm{u}$. On enlève la cuvette et la coupe de corne.

$\mathbf{O}$ Le commandant rince une coupe à figure d'oiseau, monte, la remplit, descend et offre à boire à celui qui a signalé les victoires, et qui est derrière la cible. Il lui fait servir des conserves de viande, et une petite table sur laquelle sont les membres séparés d'un animal (un chien). Celui qui a signalé les victoires offre aux esprits trois fois (en trois endroits différents) la chair de l'animal et les conserves de viande. Le dos tourné à la cible et le visage regardant le nord, il salue à genoux et reçoit la coupe. Le commandant, le visage tourné vers l'ouest, accompagne d'un salut le départ de la coupe. 
Celui qui signale les victoires prend la coupe. Des aides prennent les conserves de viande et la petite table, et vont à sa suite les déposer au kò bâtiment latéral situé à droite. Celui qui a signalé les victoires, le visage tourné vers le midi, fléchit $\bullet{ }_{148}$ les genoux, de la main gauche tient la coupe, et de la main droite offre aux esprits les conserves de viande. Tenant en main la coupe, il se lève, prend les poumons, et fléchissant les genoux, il les offre aux esprits. Ensuite il offre le vin aux esprits. Il se lève, va au récipient des fiches placé derrière le bâtiment latéral qui est à gauche, et de la même manière (il offre aux esprits le vin et la viande). Les aides au nord-ouest du bâtiment latéral de gauche, à trois póu $(3 \mathrm{~m}, 60 \mathrm{~cm})$ de ce bâtiment, le visage tourné vers l'est, déposent les conserves de viande et la petite table. Celui qui a signalé les victoires, à droite des conserves de viande, le visage tourné vers l'est, de bout, boit le vin. Il ne salue pas à genoux après avoir vidé la coupe.

Le commandant reçoit la coupe, la dépose dans une corbeille et retourne à sa place. Celui qui a signalé les victoires prend les conserves de viande. Un aide prend la petite table et le suit. Tous deux s'écartent de la direction de la cible, et vont placer ces mets au sud de la cloison qui sert d'abri contre les flèches. Celui qui a signalé les victoires retourne se placer derrière la cible, et attend.

$\mathbf{O}$ Le directeur du tir va à l'ouest des degrés occidentaux, dépose son arc et ses flèches, enlève sa baguette, ôte son doigtier et sa manche de cuir, se couvre le bras gauche des manches de ses tuniques, et va auprès des cruches. Il rince une coupe à $\bullet_{149}$ figure d'oiseau, monte avec elle, l'emplit, descend avec elle, et l'offre à celui qui a posé les fiches. Il la lui présente un peu au sud de la place ordinaire de cet homme. Il lui fait servir des conserves de viande, une petite table sur laquelle est un animal (un chien) dont les membres sont séparés, et de plus, des poumons qui devront être offerts aux esprits. Celui qui a posé les fiches, à droite des conserves de viande, le visage tourné vers l'est, salue à genoux et reçoit la coupe. Le directeur du tir, le visage tourné au nord, salue à genoux son départ avec la coupe. Celui qui a posé les fiches va auprès de ses conserves de viande et fléchit les genoux. De la main gauche tenant la coupe, il offre aux esprits les conserves de viande. Il se lève, prend les poumons, et à genoux, les offre aux esprits. Puis il leur offre le vin. Il se lève. A l'ouest du di recteur du tir, le visage tourné vers le nord, debout, il boit le vin. Il ne salue pas à genoux après avoir vidé la coupe. Le directeur du tir reçoit la coupe et la dépose dans une corbeille. Celui qui a posé les fiches, s'écarte un peu à l'ouest loin des conserves de viande, et retourne à sa place.

$\mathbf{O}$ Le directeur du tir va à l'ouest de la plateforme, se décou vre le bras gauche, met son doigtier au pouce de la main droite, puis (sa manche de cuir au bras gauche). Il prend son arc à l'ouest des degrés, tien t des deux mains une flèche ainsi que $\bullet_{150}$ son arc, enfonce sa baguette sous sa ceinture et retourne à sa place. Il enlève sa baguette, la place à l'ouest des degrés, monte les degrés, et demande au principal invité son agrément pour faire tirer de l'arc ; cela, comme précédemment. Le principal invité donne son assentiment. 
O Le directeur du tir descend, enfonce sa baguette sous sa ceinture, passe au sud du commandant, va à l'ouest de la plateforme, et dit aux archers des trois premières paires et à tous les autres archers de se découvrir le bras gauche, de mettre le doigtier au pouce de la main droite, la manche de cuir au bras gauche, de prendre leurs arcs et d'aller à leurs places. Le directeur du tir le premier retourne à sa place. Les archers des trois premières paires et les autres invités se découvrent le bras gauche, mettent le doigtier au pouce de la main droite et la manche de cuir au bras gauche. Ils prennent leurs arcs, s'avancent divisés par paires et retournent à leurs places. Le directeur du tir leur ordonne d'aller deux à deux prendre des flèches une à une alternativement. Les archers des trois premières paires prennent des flèches une à une alternativement, comme précédemment, et retournent à leurs places.

$\mathbf{O} \cdot{ }_{151}$ Le principal invité, le chef du canton et le grand préfet descendent et saluent par une inclination profonde, comme précédemment. Le chef du canton, à l'est de la plateforme, et le principal invité, à l'ouest de la plateforme se découvrent tous deux le bras gauche, mettent le doigtier au pouce de la main droite et la manche de cuir au bras gauche, prennent leurs arcs, s'avancent, et devant les degrés, se saluent par une inclination profonde. Arrivés aux récipients des flèches, ils se saluent par une inclination profonde, et prennent des flèches alternativement, comme les archers des trois premières paires. Cela fini, le visage tourné vers le nord, chacun d'eux enfonce trois flèches sous sa ceinture, et des deux mains tient une quatrième flèche, ainsi que son arc. Ils se saluent par une inclination profonde et se retirent. Le principal invité, à l'ouest de la plateforme, et le chef du canton, à l'est de la plate. forme, déposent tous deux leurs arcs et leurs flèches et se couvrent le bras gauche. Arrivés au pied des degrés, ils se saluent par une inclination profonde, montent à la plateforme, se saluent par une inclination profonde et vont à leurs nattes.

Le grand préfet se découvre le bras gauche, se met le doigtier au pouce de la main droite et la manche de cuir au bras gauche, prend son arc, et va trouver son compagnon de tir. Il le salue par une inclination profonde. Tous deux s'avancent, comme les archers des trois premières paires. Le compagnon ${ }_{152}$ tourne le visage vers l'est et le grand préfet vers l'ouest. Le grand préfet s'avance, fléchit les genoux et enlève le cordon qui tient ses flèches liées ensemble. Il se lève et retourne à sa place. Ensuite son compagnon salue par une inclination profonde, s'a vance, fléchit les genoux, prend à la fois quatre flèches, passe la main le long des plumes dans le sens des barbes, et se lève. Il retourne à sa place et salue par une inclination profonde.

Le grand préfet s'avance, fléchit les genoux, et prend aussi à la fois quatre flèches, comme son compagnon. Le visage tourné vers le nord, il enfonce trois flèches sous sa ceinture, et des deux mains tient une flèche, ainsi que son arc. Il salue son compagnon par une inclination profonde et se retire. Le compagnon retourne à sa place. Ensuite le grand préfet va à l'ouest du bâti ment latéral, dépose son arc et ses flèches, recouvre son bras gauche, monte et va à sa natte. Tous les invités, deux à deux, à la suite les uns des autres, 
prennent des flèches une à une alternativement, comme les six premiers archers, et retournent à leurs places avec ces flèches.

$\mathbf{O}$ Le directeur du tir, tenant encore une flèche des deux mains, ainsi que son arc, engage les premiers archers de chaque paire à tirer de l'arc, comme au commencement. Une paire d'archers salue par une inclinati on profonde, et monte, comme précédemment. Le commandant monte et ordonne qu'on $\bullet_{153}$ s'éloigne de la cible, de peur d'être frappé par une flèche. Celui qui signale les victoires lui répond qu'il obéit. Le commandant descend, dépose son arc et retourne à sa place. Le directeur du tir et le commandant se croisent en passant devant les degrés. Le directeur du tir enlève sa baguette, couvre son bras gauche et monte les degrés.

Il demande au principal invité son agrément pour réjouir l'assemblée par des airs de musique. Le principal invité y consent. Le directeur du tir descend, enfonce sa baguette sous sa ceinture, et, le visage tourné vers l'est, donne ses ordres au directeur de la musique en ces termes :

- J'ai demandé au principal invité son agrément pour réjouir l'assemblée par des airs de musique. Il y consent.

Ensuite le chef du tir va se placer entre les deux rangées de degrés, au bas de la plateforme, et, le visage tourné vers le nord, proclame cette prescription :

- Toute flèche qui n'aura pas été lancée au temps marqué par le son des instruments n'obtiendra pas de fiche.

Le premier archer de chaque paire salue par une inclination profonde. Le directeur du tir se retire et retourne à sa place.

• ${ }_{154}$ Le directeur de la musique, le visage tourné vers l'est, avertit le chef de musique en ces termes:

- Exécutez le chant Tche $\underline{\text { iû }}$ (Chao nan, Ch. XIV). Entre les strophes, que la pause soit toujours égale.

Le chef de musique, sans se lever, promet d'obéir. Le directeur de la musique se retire et retourne à sa place. Alors les musiciens exécutent le chant Tche $u$ îu, pendant lequel les archers tirent de l'arc. Quand les six premiers archers ont fini de tirer, le principal invité, le chef du canton, le grand préfet et tous les invités continuent le tir. Les fiches sont posées comme précédemment. Le tir terminé, les archers descendent (à l'exception du principal invité, du chef du canton et du grand préfet). Celui qui a posé les fiches, tenant en main les fiches restantes, monte, et avertit, comme précédemment, que les deux archers de chaque paire ont fini de lancer leurs flèches.

$\mathbf{O}$ Le commandant monte et donne ordre de prendre des flèches. Celui qui signale les victoires lui répond quîl sera obéi. Le commandant descend, dépose son arc et retourne à sa place. Les plus jeunes invités (apportent et) déposent des flèches. Le commandant les divise quatre par quatre, comme 
précédemment. Le directeur du tir dépose son arc et examine les fiches, comme précédemment. Celui qui a posé les fiches annonce que $\bullet_{155}$ tel parti est vainqueur ou que les deux partis ont un nombre égal de victoires ; cela, comme précédemment. Il descend et retourne à sa place.

$\mathbf{O}$ Le directeur du tir ordonne de placer la cuvette sur laquelle sera la coupe de corne. On place la cuvette et on emplit la coupe de corne, comme précédemment. Ensuite le directeur du tir ordonne aux vainqueurs de tenir en mains leurs arcs bandés, et aux vaincus de tenir en mains leurs arcs débandés. Il les fait monter et boire, comme précédemment.

O Le directeur du tir se découvre de nouveau le bras gauche, met le doigtier au pouce de la main droite et la manche de cuir au bras gauche. De la main gauche il tient le bras de son arc; de la main droite il tient la corde de son arc, et en même temps une flèche, dont la pointe est dirigée en avant. Il va à l'ouest de la plateforme, et ordonne aux archers de prendre des flèches une à une alternativement, comme auparavant. Le directeur du tir retourne à sa place. Les archers des trois premières paires, le principal invité, le chef du canton et les autres invités se découvrent le bras gauche, mettent le doigtier au pouce de la main droite et la manche de cuir au bras gauche. Puis, deux à deux, $\bullet_{156}$ alternativement, ils prennent des flèches, une à une ; comme précédemment, ils ne tiennent pas une flèche des deux mains, entre le pouce et l'index de chaque main ; mais de la main droite ils tiennent une flèche et la corde de l'arc, et de la main gau che ils tiennent trois flèches et le bras de l'arc. Ils se retirent avec ces flèches, mais ne retournent pas à leurs places. Ensuite ils donnent leurs flèches au directeur du tir, à l'ouest de la plateforme. Tous les archers, deux à deux, prennent des flèches, une à une, alternativement. Ils saluent par une inclination profonde, montent tous et vont à leurs nattes.

$\mathbf{O}$ Le directeur du tir va à l'ouest de la plateforme, dépose son arc, enlève sa baguette, ôte son doigtier et sa manche de cuir, couvre son bras gauche des manches de ses tuniques et retourne à sa place. Le commandant ordonne aux jeunes invités de délier et de déposer la corde qui tient déployé le coin inférieur du côté gauche de la cible. Il ordonne à celui qui a signalé les victoires de prendre son guidon et de se retirer. Il ordonne aux jeunes invités d'éloigner les récipients des flèches. Le directeur du tir ordonne à celui qui a posé les fiches d'éloigner les fiches et leur récipient, et d'attendre.

Le commandant reprend l'office de maître des cérémonies. $\bullet_{157}$ Il se retire, retourne au sud de la coupe de corne et reste debout. Le directeur de la musique ordonne aux jeunes invités d'aider les musiciens, et retourne à sa place. Les jeunes invités aident les musiciens. Ils descendent comme ils sont descendus la première fois que les musiciens sont entrés. Les musiciens montent par les degrés occidentaux, et retournent s'asseoir à leurs places.

$\mathbf{O}$ Le principal invité, le visage tourné vers le nord, fléchit les genoux et prend une coupe de corne à l'ouest des petites tables. Il se lève. Au haut des degrés orientaux, le visage tourné vers le nord, il offre à boire au chef du 
canton. Le chef du canton quitte sa natte et se tient debout à l'est du principal invité. Le principal invité fléchit les genoux, dépose la coupe, salue à genoux, prend la coupe et se lève. Le chef du canton lui rend le salut à genoux. Le principal invité, sans offrir le vin aux esprits, le boit lui-même entièrement. (Il boit le premier, pour encourager le maître du canton à boire ensuite. Après avoir bu), il ne salue pas à genoux. Il ne rince pas la coupe. Il la remplit, et s'avance, le visage tourné vers le sud-est. Le chef du canton, au haut des degrés orientaux, le visage tourné vers le nord, salue à genoux. Le principal invité se retire un peu en arrière. Le chef du canton avance, et reçoit la coupe. Le principal invité, à l'ouest du chef du canton, le visage tourné au nord, lui donne à genoux le salut du départ. Le principal $\bullet_{158}$ invité salue par une inclination profonde et va à sa natte.

Le chef du canton, tenant la coupe, va au haut des degrés occidentaux offrir à boire au grand préfet. Le grand préfet quitte sa natte et se tient debout à l'ouest du chef du canton. Les cérémonies sont les mêmes que quand le principal invité offre à boire au chef du canton. Le chef du canton salue le grand préfet par une inclination profonde et va à sa natte. S'il n'y a pas de grand préfet, le plus âgé des invités reçoit la coupe comme le ferait un grand préfet.

Le directeur des cérémonies monte par les degrés occidentaux; par ses soins, tous les invités se passent la coupe les uns aux autres. A chacun de ceux qu'il avertit de la recevoir, il dit :

— Un tel vous offre à boire, Seigneur un tel.

Celui à qui la coupe est offerte quitte sa natte. Le directeur des cérémonies se retire, et se tient debout à l'angle du bâtiment occidental, le visage tourné vers l'orient. (Il attend que la coupe passe au suivant). Chacun de ceux qui reçoivent la coupe salue à genoux, se lève et boit debout. Chaque fois les cérémonies sont les mêmes que quand le principal invité offre à boire au chef du canton. Lorsque les invités ont tous bu, la coupe est présentée aux officiers subalternes (aux aides du principal $\bullet_{159}$ invité et du chef du canton). Ces officiers, l'un après l'autre, montent tous, et reçoivent la coupe au haut des degrés occidentaux. Celui qui la reçoit le dernier descend avec elle et la dépose dans une corbeille. Le directeur des cérémonies descend et retourne à sa place.

O Le chef du canton envoie deux hommes présenter une coupe de corne au principal invité, et une autre coupe de corne au grand préfet (s'il y a un grand préfet). Ces deux hommes rincent deux coupes, montent et les emplissent. Au haut des degrés occidentaux, le visage tourné vers le nord, tous deux fléchissent les genoux, déposent les coupes, saluent à genoux, prennent les coupes et se lèvent. Le principal invité et le grand préfet, tous deux à l'extrémité de leurs nattes, rendent le salut à genoux. Les deux hommes qui portent les coupes fléchissent les genoux, offrent le vin aux esprits, puis le boivent eux-mêmes. Après avoir vidé les coupes, ils se lèvent, fléchissent les 
genoux, déposent les coupes, saluent à genoux, prennent les coupes et se lèvent. Le principal invité et le grand préfet leur rendent le salut à genoux.

- ${ }_{160}$ Ces deux officiers qui portent les coupes descendent; celui qui est monté le second, descend le premier. Ils rincent les coupes, montent, remplissent les coupes, et tous deux se tiennent debout au haut des degrés occidentaux, le visage tourné vers le nord, le plus âgé à l'est de l'autre. Le principal invité et le grand préfet saluent à genoux. Les deux hommes qui portent les coupes s'avancent, fléchissent les genoux et déposent les coupes à droite des conserves de viande qui ont été servies au principal invité et au grand préfet. (Les deux officiers, par respect pour les deux dignitaires, ne leur donnent pas les coupes de main à main ; ils les déposent devant ces grands personnages). Le principal invité et le grand préfet réclament contre cet honneur. Ils fléchissent les genoux, et, prenant les coupes, ils se lèvent. Ceux qui ont apporté les coupes se retirent et retournent à leurs places. Tous deux saluent à genoux les deux dignitaires qui ont reçu les coupes. Puis ils descendent. Le principal invité et le grand préfet reportent les coupes, et (fléchissant les genoux) les déposent dans l'endroit qui leur est propre. Ils se lèvent. S’il n’y a pas de grand préfet, on ne porte de coupe qu'au principal invité.

Le directeur des cérémonies monte par les degrés occidentaux, et au haut des degrés orientaux, prend les ordres du chef $\bullet_{161}$ du canton. Il va au haut des degrés occidentaux, et le visage tourné vers le nord, prie le principal invité de s'asseoir. Le principal invité refuse de s'asseoir par respect pour les petites tables (sur chacune desquelles est la chair d'un chien qui a été offerte aux esprits). Le directeur des cérémonies donne avis de ce refus au chef du canton. Le chef du canton dit :

- Demandez-lui de consentir à ce que les petites tables soient enlevées.

Le principal invité y consent. Le directeur des cérémonies descend par les degrés occidentaux. Devant les degrés, il dit aux jeunes invités de s'occuper à enlever les petites tables.

Le directeur des cérémonies monte et se tient debout à l'an gle du bâtiment situé au côté occidental. Le principal invité quitte sa natte et tourne le visage vers le nord. Le chef du canton quitte sa natte par le côté méridional. Au haut des degrés orientaux, il tourne le visage vers le nord. Le grand préfet quitte sa natte, il se tient à l'est de sa natte, le visage tourné vers le sud. Le principal invité prend sa petite table, et se tournant, la donne au directeur des cérémonies. Le directeur des cérémonies descend avec cette table par les degrés occidentaux. Le principal invité descend à sa suite; puis il se tient debout à l'ouest des degrés, le visage tourné vers l'est. Le directeur des cérémonies emporte la petite table dehors et la donne à l'un des hommes de la suite du principal invité. 
- ${ }_{162}$ Le chef du canton prend sa petite table, et se tournant, la donne à l'un des jeunes invités. Celui-ci reçoit cette table, descend par les degrés occidentaux et porte la table vers l'est (pour la donner à un serviteur du chef du canton). Le chef du canton descend par les degrés orientaux, et le visage tourné vers l'ouest, reste debout. Le grand préfet prend sa petite table, et se tournant, la donne à l'un des jeunes invités. Celui -ci descend avec la table par les degrés occidentaux ; puis il la porte dehors et la donne à l'un des hommes de la suite du grand préfet. Le grand préfet descend après lui, et se tient debout au sud du principal invité. Les invités descendent tous, et se tiennent debout au sud du grand préfet, un peu en arrière, rangés du nord au sud; le nord est le côté le plus honorable.

O Le chef du canton salue le principal invité par une inclination profonde, l'invite à monter le premier. Ils ôtent tous deux leurs chaussures, (les laissent dans la cour), puis montent. Le grand préfet et tous les invités quittent leurs chaussures, montent et s'assiéent. (L'usage était d'ôter les chaussures, pour ne pas salir la salle).

O Alors on sert à chacun des mets, (un chien sur une petite table et des conserves de viande). Le nombre des coupes qu'on $\bullet_{163}$ boit n'est pas limité. Le directeur des cérémonies charge deux hommes de présenter deux coupes de corne. Le principal invité et le grand préfet, sans se lever, prennent les coupes, les déposent, puis ils boivent. Après avoir bu tout le vin, ils ne saluent pas à genoux.

Les deux aides qui sont chargés du soin des coupes les reçoivent, puis les remplissent. La coupe du principal invité est présentée au chef du canton, et celle du grand préfet au plus âgé des invités. Elles sont échangées. Ceux à qui elles sont présentées ne saluent pas à genoux. Elles sont présentées successivement à tous les invités. Ceux qui les reçoivent en dernier lieu se lèvent, et vont avec ces coupes au haut des degrés occidentaux, offrir à boire aux aides, aux subalternes. Le plus âgé de ces subalternes reçoit la coupe. Il la reçoit sans saluer. Puis il boit. Quand il a vidé la coupe, on la remplit pour le suivant. Celui qui reçoit la coupe ne salue pas en signe de remerciement. Tous la reçoivent. Personne ne salue.

O Ceux qui présentent les coupes ont aussi part à l'honneur de boire. Ceux qui les reçoivent les derniers descendent avec ces coupes vides, et les déposent dans les corbeilles. Ceux qui présentent à boire rincent deux coupes, montent et les $\bullet_{164}$ emplissent. Ils retournent les déposer devant le principal invité et devant le grand préfet. Le nombre des chants exécutés n'est pas limité.

O Quand le principal invité se lève, le directeur de la musique donne ordre d'exécuter le chant $K \bullet i$ (chant de la dynastie des Hià). Quand le principal invité quitte la salle et arrive au haut des degrés, le chant $K \bullet i$ commence à se faire entendre. Le principal invité sort ; tous les autres invités sortent aussi. Le chef du canton les accompagne jusque hors de la grande 
porte du gymnase. Il les salue deux fois à genoux. (Les invités ne lui rendent pas le salut).

O Le lendemain, le principal invité, en habits de cour, se présente à la grande porte du gymnase, et (devant la porte), salue à genoux pour remercier le chef du canton de la faveur de la veille. Le chef du canton ne le voit pas. Mais, vêtu d'habits semblables aux siens, il le suit de loin, va à la grande porte de sa maison, et (sans le voir) salue à genoux, pour le remercier d'avoir daigné aller le saluer. Ensuite il se retire.

$\mathbf{O}$ Le chef du canton dépose ses habits de cour, puis fête le directeur des cérémonies comme pour le délasser de sa fatigue. Il ne lui donne pas d'assesseur. Il ne fait pas tuer de chien. (Il ne lui fait pas servir de viande de chien). Il envoie un officier l'appeler. Il va le recevoir jusque hors de la grande porte du gymnase. Il ne le salue pas à genoux. Il entre et monte les ${ }_{165}$ degrés avec lui. Il ne le salue pas pour le remercier de son arrivée. Il ne le salue pas après que la coupe a été rincée. Il lui fait servir des conserves de viande ; mais pas de viande de chien sur une petite table.

Lorsque l'invité (le directeur des cérémonies de la veille) à son tour présente la coupe au chef du canton, le chef du canton ne se dit pas rassasié de vin. Il ne salue pas à genoux la foule des invités. Après que le vin a été offert une première fois à tous les invités, un officier apporte une coupe de corne. Puis le nombre des coupes qu'on boit n'est pas limité. Personne n'est constitué directeur des cérémonies. Le principal invité (le directeur des cérémonies de la veille) n'assiste pas à cette partie de la fête. (Elle ne convient pas à son rang). Le chef du canton n'y invite que ceux qu'il veut y inviter. Il convient qu'il y invite les vieillards du canton et les offic iers qui se sont démis de leurs charges. Il ne fait servir que les mets qu'il a déjà (il n'en fait pas préparer de nouveaux). Parmi les chants des cantons, il fait exécuter ceux qu’il veut, et pas d'autres. (Ces chants sont tous tirés du Tcheou nan et du Chao nan).

\section{NOTES SUPPLÉMENTAIRES.}

Lorsqu'un grand préfet assiste aux cérémonies du tir, un officier en charge est constitué invité principal. (Un simple particulier ne peut pas être mis au dessus d'un grand préfet). ${ }_{166}$ On choisit pour principal invité un homme capable (intelligent et diligent). On n'a pas besoin d'aller deux fois l'avertir de venir.

L'animal servi sur chaque petite table est un chien, (parce que le chien sait discerner les hommes. Un officier doit avoir ce discernement). On fait cuire le chien au nord-est de la plateforme.

Sur chaque amphore il y a une couverture faite de grosse toile de dolic. On l'enlève à l'arrivée du principal invité. 
Les nattes sont faites de jonc et bordées de toile noire.

Le côté le plus honorable des nattes placées près du bâtiment occidental est le côté septentrional.

Pour offrir le vin la première fois, on se sert d'une coupe à figure d'oiseau. Les autres fois on se sert d'une coupe de corne ou faite en forme de corne. (La coupe à figure d'oiseau, étant très noble, doit être rarement employée).

Le principal invité salue à genoux après avoir reçu la coupe. Il ne reste pas sans rien faire, quand il s'est levé, (il offre à boire au chef du canton).

On sert sur chaque natte des tranches de viande séchées, dans un vase de bambou. On y met cinq tranches; au dessus, en travers, on ajoute la moitié d'une tranche qui sera offerte aux esprits. La viande hachée et conservée dans une saumure est servie dans un vase de bois. Ces viandes sont apportées du - ${ }_{167}$ bâtiment oriental. Une tranche de viande est longue de un pied et deux dixièmes $(24 \mathrm{~cm})$.

Les porteurs des petites tables, partant du mur oriental, montent par les degrés occidentaux. Sur la petite table du principal invité il y a une côte prise sur le dos du chien, une côte prise sur le devant du corps, une épaule, les poumons. Sur la petite table du chef du canton, il y a une côte prise sur le dos du chien, une côte prise sur le devant du corps, la partie inférieure d'un membre antérieur, les poumons. Les poumons sont toujours séparés l'un de l'autre par une incision à leur petite extrémité. Les os sont toujours placés à droite sur les petites tables, les muscles dirigés en avant.

La coupe à figure d'oiseau est présentée à trois reprises différentes. Elle n'est jamais prése ntée seule, (elle est toujours accompagnée de conserves de viande). Celui qui dépose une coupe qui lui a été présentée, la dépose toujours à sa gauche. Celui qui présente une coupe, la place à la droite de celui qui doit la prendre. Le plus âgé des invités refuse que la coupe soit rincée par le chef du canton, de la même manière que le principal invité.

S’il y a un ministre d’État, il agit et est traité comme le principal invité ; le grand préfet agit et est traité comme l'assesseur du principal invité. S' il n'y a pas de ministre d'État, le grand préfet agit et est traité comme le principal invité.

Quand la musique se fait entendre, un grand préfet n'entre pas (il attend).

- ${ }_{168}$ Le directeur de la musique se tient debout parmi les autres invités au rang que lui donne son âge. Trois orgues à bouche jouent ensemble; un quatrième orgue à bouche plus petit les accompagne et complète l'accord. Pour offrir à boire une première fois aux chanteurs et aux joueurs d'orgue, on prend une coupe à figure d'oiseau dans une corbeille au haut des degrés. Quand ils ont bu, la coupe est déposée dans une autre corbeille au bas des degrés. On offre à boire aux joueurs d'orgue au haut des degrés o ccidentaux. 
(Les parents et les amis du principal invité) se tiennent debout, le visage tourné vers l'est, (rangés du nord au sud, au bas des degrés) ; le nord est le côté le plus honorable.

Après avoir présenté la coupe de corne au directeur des cérémonies, on lui sert des conserves de viande à sa place (au nord de la coupe).

Les archers des trois premières paires sont choisis parmi les jeunes parents ou amis du principal invité. Le directeur du tir les encourage et les exerce.

L'arc, les flèches et la ba guette du directeur du tir sont adossés à l'ouest des degrés occidentaux.

- ${ }_{169}$ Le directeur du tir, après s'être découvert le bras gauche, après avoir mis le doigtier au pouce de la main droite et la manche de cuir au bras gauche, s'avance et monte les degrés. Le commandant, devant les degrés, ordonne de déployer la cible ; ensuite il ordonne d'adosser le guidon contre la cible.

Ordinairement, la cible du fils du ciel (en son centre) porte un ours sur un fond blanc ; celle d'un prince, un grand cerf sur un fond rouge vif. La cible d'un grand préfet est de toile ; elle porte en son centre un tigre ou un léopard en peinture. La cible d'un simple officier est de toile ; elle porte en son centre un cerf ou un sanglier en peinture. Généralement ces peintures sont sur un fond rouge-cinabre.

Les archers lancent leurs flèches du milieu des deux colonnes de la salle du tir. L'espace $\bullet$ dans lequel chacun d'eux fait cet office, c'est -à-dire, tire de l'arc, est de la longueur d'une flèche $(60 \mathrm{~cm})$. Entre les deux espaces il y a la distance nécessaire pour leurs arcs $(1 \mathrm{~m}, 20 \mathrm{~cm})$. Un archer tient les deux pieds l'un derrière l'autre à la distance de la trace d'un pied $(24 \mathrm{~cm})$. Les deux espaces dans lesquels les deux archers se tiennent en tirant de l'arc sont dans la ligne de la poutre faîtière de la salle du tir, et en face de la poutre qui soutient le bord du toit de la plateforme de la salle centrale.

- ${ }_{170}$ Quand le commandant donne un ordre à celui qui se tient derrière la cible (et signale les victoires), il donne cet ordre de sa place, (il ne quitte pas sa place, parce que celui à qui il donne cet ordre est d'un rang peu élevé).

Ceux qui vont à l'oues t de la plateforme, en allant et en venant, passent ordinairement au sud du commandant. Mais, quand le principal invité ou un grand préfet a descendu les degrés, on passe à l'ouest pour aller chercher un arc ou des flèches (par respect pour ces personnages).

En fait de drapeaux, tout officier d'une grande principauté a une bannière composée de bandes de soie de diverses couleurs. Les officiers des petites principautés qui n'ont pas cette sorte de bannière ont un guidon, qui est formé de plumes blanches et de plumes rouges jeóu mêlées ensemble, et dont la hampe, longue de trois jén (4 m, 80), a une enveloppe longue de deux sîn $(3 \mathrm{~m}, 20 \mathrm{~cm})$, et terminée à la partie supérieure en forme de cou de grue. 
Celui qui tient des deux mains une flèche et son arc, tient entre deux doigts (entre l'index et le doigt du milieu) de chaque main la flèche placée transversalement sur son arc (sur la corde et le bois de l'arc).

Le directeur du tir se tient au nord du commandant. Le commandant, lorsqu’il n'a rien à faire, n'a pas son arc entre les mains.

• ${ }_{171}$ La première fois que les archers tirent de l'arc, on signale les victoires, mais on ne pose pas encore de fiches. (Ce n'est qu'un essai). La seconde fois, on pose des fiches. La troisième fois, la musique règle le tir.

Le premier des deux archers de chaque paire se met à la droite du second.

Les récipients des flèches sont de la longueur d'une flèche. Ils ont trois ts'uén $(6 \mathrm{~cm})$ de largeur, un ts'uén et demi $(3 \mathrm{~cm})$ de profondeur. A chaque extrémité est une figure de dragon; au milieu sont des figures de serpents qui se croisent. Ces récipients ont une enveloppe de cuir. Ils sont enduits de vernis. Ceux qui les portent les tiennent des deux mains transversalement, c'est-à-dire, par les deux extrémités. Le visage tourné vers le sud, ils fléchissent les genoux et les déposent. Ils les rangent du sud au nord, en face des cruches.

Un archer qui par maladresse blesse un homme avec sa flèche est puni de coups de verge.

Ceux des invités qui ne prennent pas part au tir ne descendent pas les degrés. (Ils ne feraient que gêner les autres).

Celui qui est chargé de prendre des flèches pour le directeur $\bullet_{172}$ du tir avant l'exercice préliminaire, après avoir pris pour lui -même quatre flèches alternativement avec son compagnon, (retourne à sa place); puis il (revient et) prend à la fois quatre flèches pour le directeur du tir.

Quand le principal invité et le chef du canton tirent de l'arc, c'est le directeur du tir (et non le commandant) qui monte et descend pour transmettre leurs ordres, (à cause de leur dignité). Quand ils ont fini de lancer leurs flèches, le directeur du tir retourne vers sa natte et reprend sa place. Son office est terminé.

Le récipient en forme de cerf dans lequel sont les fiches est enduit de vernis. Le cerf a les genoux en terre. Sur son dos est une ouverture qui contient huit fiches. Celui qui pose les fiches porte le récipient des deux mains, la tête du cerf en avant.

Quand le grand préfet est descendu (pour tirer de l'arc), il se tient debout à l'ouest de la plateforme et attend le moment de tirer de l'arc. Lorsqu'un grand préfet tire de l'arc avec un simple officier, il se découvr e le bras gauche, (mais ne le dénude pas entièrement). Il conserve sur ce bras la manche de sa tunique intérieure qui est de couleur brune. Son compagnon se met un peu en arrière (par respect), dans l'espace où ils doivent se tenir en lançant leurs flèches . 
Le directeur du tir dépose son arc et ses flèches, avant $\bullet_{173}$ d'examiner les fiches et avant d'offrir à boire, (il les dépose seulement dans deux circonstances). Celui qui pose les fiches dépose aussi son arc et ses flèches, (quand il doit rincer la coupe, la présenter et saluer à genoux).

D'après les règles, l'archer doit éviter de transpercer le cuir de la cible (quand elle est de cuir). L'archer qui transperce le cuir de la cible, s'il est vainqueur (s’il a frappé le centre de la cible), est encore ad mis à tirer. S'il n'est pas vainqueur, il descend (il ne lui est plus permis de tirer).

Le chef du canton lui-même boit au haut des degrés occidentaux (le vin des vaincus, s'il n'a pas été vainqueur).

Sur la petite table de celui qui signale les victoires il y a une côte prise sur le dos du chien, une côte prise sur le devant du corps et les poumons. Le côté oriental ici mentionné est le bâtiment latéral situé à droite. Sur la petite table de celui qui pose les fiches il y a une côte prise sur le dos du chien, une côte prise sur le devant du corps et les poumons. Celui qui signale les victoires et celui qui pose les fiches reçoivent tous deux des poumons qu'ils offrent aux esprits.

Le grand préfet détache le cordon qui lie ensemble ses flèches. Il le détache à genoux.

${ }_{174}$ Les chants Tcheøu iû et Ts'ài prîn [Chao nan, Ch. IV] sont exécutés tous deux cinq fois en entier, (pendant que chaque paire d'archers tire de l'arc), quel que soit le nombre des archers.

Les anciens conversaient pendant que la coupe passait à tous les invités. Quand la coupe passe à tous les invités, elle n'est pas rincée chaque fois qu'un invité a bu. Quand elle n'est pas rincée, elle n'est pas offerte aux esprits, (elle n'est pas pure).

Après que la coupe a passé à tous les invités, (a lieu le banquet), un officier n'entre pas, (parce qu'il se trouverait mêlé et rangé d'après son âge parmi les simples particuliers du canton).

Le grand préfet sort le dernier. Le chef du canton l'accom pagne jusque hors de la grande porte du gymnase, et le salue deux fois à genoux.

La largeur de la cible du district, à la partie supérieure cháng kó, est de cinq $\sin (8 \mathrm{~m})$. Au milieu, elle est de dix tch' $\bullet$ ( $2 \mathrm{~m})$. La distance, à laquelle l'archer se place de la cible est de cinquante $k \bullet u n g(60 \mathrm{~m})$. Un $k \bullet u n g$ et deux ts'uén $(1 \mathrm{~m}, 40 \mathrm{~cm})$ est la longueur du centre de la cible. Deux fois la longueur du centre est la longueur du corps de la cible. Deux fois la longueur du corps de la cible est la longueur des langues ou bandes de toile qui pendent, l'une à droite, l'autre à gauche de la cible. La partie inférieure de ces langues (la partie qui pend plus bas que le corps de la cible) $\bullet_{175}$ est moitié moins longue que la partie supérieure. 
Les fiches sont au nombre de quatre-vingts. Elles ont un tch' $u(20 \mathrm{~cm}) \mathrm{de}$ longueur. Elles ont une poignée. La poignée est nue (dépouillée de son écorce).

La verge du directeur du tir est une baguette d'un arbuste épineux. Elle est de la longueur d'une flèche. La plus grosse extrémité est dépouillée de son écorce à la longueur d'un pi ed (c'est la poignée).

Lorsqu'un prince tire de l'arc, il est le second de sa paire (il s'humilie). Le premier archer de sa paire (son compagnon de tir) se met en arrière du prince à la distance de la longueur d'une flèche, sur l'espace limité sur lequel i 1 se tient en tirant de l'arc. Après avoir lancé ses flèches, il se tourne vers le prince, et attend que le prince ait fini de lancer ses flèches. Le prince ne se rend à la place où il doit tirer de l'arc, qu'après que la musique a commencé à se faire entendre. Quand il se découvre le bras gauche pour tirer de l'arc, il garde sur le bras gauche la manche de sa tunique inférieure de couleur rouge. (Il ne prend pas quatre flèches, comme les autres archers). Un petit officier (prend, essuie et) tient avec une serviette des flèches pour le prince, et les lui donne. Quand le principal invité présente à boire à un prince (qui n'est pas du nombre des vainqueurs), il faut deux coupes, comme à un festin, (le prince, après avoir vidé la coupe qui lui est présentée, offre lui-même à boire au principal invité).

• ${ }_{176}$ Quand un prince tire de l'arc dans sa capitale, le récipient des fiches a la forme d’un animal appelé pî̀ chóu. Le guidon qui sert à signaler les victoires porte un taó bouquet de plumes, les unes blanches, les autres rouges, mêlées ensemble. Quand un prince tire de l'arc dans la campagne près de sa capitale, le récipient des fiches a la forme d'une liù licorne. Un guidon de plumes signale les victoires.

Quand un prince tire de l'arc aux frontières de ses États (avec un prince voisin), le récipient des fiches a la forme d'un tigre. Le guidon est de soie et porte l'image d'un dragon.

Quand un grand préfet tire de l'arc, le récipient des fiches a la forme d'un rhinocéros. Chaque grand préfet a un guidon particulier pour signaler les victoires, d'après so n degré de dignité.

Quand un officier ordinaire tire de l'arc, le récipient des fiches a la forme d'un cerf. Le guidon qui sert à signaler les vic toires porte un bouquet de plumes.

Un prince seul peut tirer de l'arc dans la capitale. Les autres officiers n'en ont pas le droit.

En présence d'un prince, un grand préfet, pour tirer, de l'arc, se dénude le bras gauche jusqu'à laisser voir la peau. 


\section{CHAPITRE VI}

\section{Banquet à la cour d'un chef d'État}

$\mathbf{O} \cdot{ }_{177}$ Un petit officier avertit (et invite de la part du prince) ceux qui prendront part au banquet.

L’intendant de la cuisine du prince prépare à l'est des appar tements particuliers du prince les viandes et les vins qui sont de son office. Les musiciens suspendent leurs instruments (tambours, cloches, pierres musicales). On dispose des cruches vides et des corbeilles au sud-est des degrés orientaux, en face des gouttières orientales. (Dans les cruches on versera l'eau qui aura servi à laver les mains ou à rincer les coupes. Dans les corbeilles sont déposées les coupes). Des vases pleins d'eau sont à l'est. Les corbeilles sont à l'ouest des cruches. Elles sont rangées du sud au nord ; le côté méridional est moins honorable que le côté septentrional. Celles qui contiennent les chán bonnes ou belles coupes du prince sont placées au nord des autres. Elles font face à l'ouest.

Les amphores de lintendant du palais sont à l'ouest de la colonne orientale. Ce sont deux vases carrés. Celle qui contient l'eau pure est à gauche (au sud) de celle qui contient le vin. $\bullet_{178}$ Le côté méridional est le plus honorable. Les amphores du prince sont deux grands vases d'argile. Elles sont placées sur des cuvettes. Leurs couvertures sont de grosse toile de dolic ou de fine toile de chanvre. Elles sont au sud des autres amphores. Le côté méridional est le plus honorable. Les amphores des simples officiers qui vivent à la cour sont à l'ouest de la grande porte. Ce sont deux vases ronds. Lintendant du palais place la natte du principal invité à l'ouest de la porte de la salle; il la tourne vers l'est. Il ne met pas deux nattes l'une sur l'autre, (mais une simple natte).

O Le chef des archers avertit le prince que tout est prêt. Un petit officier dispose la natte du prince au haut des degrés orientaux, le devant tourné vers l'ouest. Il place deux nattes l'une sur l'autre. Le prince monte, et va prendre place sur sa natte, le visage tourné vers l'ouest.

Un petit officier introduit les ministres d'État et les grands préfets. Ceux -ci entrent par le côté droit de la grande porte, tournent le visage vers le nord, et se rangent de l'est à l'ouest par ordre de dignité, les plus respectables à l'est. Les simples officiers se tiennent debout à l'ouest, le visage tourné vers l'est. Ils sont rangés du nord au sud par ordre de dignité. L'invocateu r et l'annaliste sont debout à l'est de la grande porte, le visage $\bullet_{179}$ tourné vers le nord ; le plus honorable des deux est à l'est de l'autre. Un chef de petits officiers est seul au bas de la partie orientale de la plateforme, le visage tourné vers le sud. 
Tous les simples officiers qui vivent à la cour sont debout à l'ouest de la grande porte, rangés de l'est à l'ouest par ordre de dignité, les plus dignes à l'est.

Le prince descend, et se tient debout au sud-est des degrés orientaux, le visage tourné vers le sud. Près de lui sont les ministres d'État. Ils ont le visage tourné vers l'ouest. Ils sont rangés du nord au sud par ordre de dignité, les plus dignes au nord. Près des ministres sont les grands préfets ; ils se mettent un peu en avant.

$\mathbf{O}$ Le chef des archers prie le prince de désigner celui qui sera le principal invité. Le prince répond :

- Dites à un tel (un grand préfet) de faire l'office de principal invité.

Le chef des archers avertit celui que le prince a désigné pour être principal invité. Celui-ci s'avance un peu, et par politesse décline cet honneur. Le chef des archers fait son rapport au prince. Le prince de nouveau désigne ce même officier pour être le principal invité. Cet officier salue deux fois à genoux et incline le front jusqu'à terre. Il consent. Le chef des archers en informe le prince. Le principal invité sort du palais, et se tient debout $\bullet_{180}$ en dehors de la grande porte, le visage tourné vers l'est.

Le prince salue par une inclination profonde les ministres d'État et les grands préfets, monte et va prendre place sur sa natte.

$\mathbf{O}$ Un petit officier, au bas des degrés orientaux, le visage tourné vers le nord, demande au prince l'autorisation d'appeler les officiers qui ont charge des couvertures des amphores, et ceux qui présentent les ragoûts et les mets exquis. Par ordre du prince, les officiers qui ont charge des couvertures des amphores montent par les degrés occidentaux, et se tiennent debout au sud des amphores, le visage tourné vers le nord. Ils sont rangés de l'est à l'oues t par ordre de dignité, les plus dignes à l'est. L'intendant de la cuisine demande au prince l'autorisation de lui présenter des ragoûts, à lui et aux ministres d'État.

O Le chef des archers introduit le principal invité. Celui-ci entre. Quand il est arrivé dans la cour, le prince descend un degré et salue l'invité par une inclination profonde. Il monte et retourne à sa natte.

L'invité monte par les degrés occidentaux. Le maître d'hôtel monte aussi par les degrés occidentaux. A la droite de l'invité principal, le visage tourné vers le nord, il le salue deux fois à $\bullet_{181}$ genoux pour le remercier de son arrivée. L’invité lui rend deux saluts à genoux.

Le maître d'hôtel descend, pour rincer une coupe, au sud des cruches, le visage tourné vers le nord-ouest. L'hô te descend à l'ouest des degrés pour lui faire honneur, et tourne le visage vers l'est. Le maître d'hôtel refuse cet honneur. L'invité lui ré pond. Le maître d'hôtel, le visage tourné vers le nord, se lave les mains. Il fléchit les genoux, prend une coupe de corne et la veut rincer. L'hôte avance un peu, et prie le maître d'hôtel de ne pas rincer la 
coupe lui-même. Le maître d'hôtel, à genoux, dépose la coupe dans une corbeille. Il se lève et répond. L'hôte retourne à sa place.

Après que le maître d'hôtel a fait rincer une coupe par un subalterne, l'invité le salue par une inclination profonde et monte les degrés. Le maître d'hôtel monte aussi. Linvité salue à genoux le maître d'hôtel pour le remercier d'avoir fait rincer la coupe. Le maître d'hôtel dépose la coupe à la droite de l'invité, et lui rend le salut à genoux. Il descend et se lave les mains. L'invité descend aussi pour lui faire honneur. Le maître d'hôtel refuse cet honneur. L'invité répond. Après que le maître d'hôtel s'est lavé les mains, l'invi té le salue par une inclination profonde $\bullet_{182}$ et monte les degrés. Le maître d'hôtel monte, fléchit les genoux et prend une coupe. La couverture de l'amphore du prince est enlevée par un aide chargé de cet office. Le maître d'hôtel (qui représente la perso nne du prince) verse du vin dans une coupe du prince pour l’invité. L'aide remet la couverture sur l'amphore.

Le maître d'hôtel présente la coupe à l'invité devant sa natte : L'invité, au haut des degrés occidentaux le salue à genoux. Il reçoit la coupe devant sa natte et retourne à sa place. Le maître d'hôtel, à la droite de l’invité, salue à genoux l'invité qui a reçu la coupe. L'intendant de la cuisine sert des conserves de viande à l'invité. L'invité prend place sur sa natte. L'intendant de la cuisine place devant lui une petite table sur laquelle sont les membres séparés d'un chien.

L'invité fléchit les genoux ; de la main gauche il prend la coupe, et de la main droite il offre aux esprits les conserves de viande. Il dépose la coupe à droite des conserves de viande. Il se lève et prend les poumons. Il fléchit les genoux, retranche la petite extrémité des poumons et les offre aux esprits. Il les goûte; et se levant, les replace sur la petite table. Il fléchit les genoux, s'essuie les mains, prend la cou pe et offre le vin aux $\bullet_{183}$ esprits. Il se lève, s'agenouille à l'extrémité de sa natte et goûte le vin. Il quitte sa natte, fléchit les genoux, dépose la coupe, salue à genoux, et loue la qualité du vin. Il prend la coupe et se lève. Le maître d'hôtel lui rend le salut à genoux. L’invité, au haut des degrés occidentaux, le visage tourné vers le nord, fléchit les genoux et vide la coupe. Il se lève, fléchit les genoux et dépose la coupe. Ensuite il salue à genoux. Le maître d'hôtel lui rend son salut.

L'invité descend avec la coupe vide. Le maître d'hôtel descend aussi. L’invité, au sud des cruches, fléchit les genoux et dépose la coupe. Il s'avance un peu et refuse l'honneur que le maître d'hôtel lui fait en descendant. Le maître d'hôtel lui répond, le visage tourné vers l'est. L'invité fléchit les genoux, prend la coupe et la dépose en deçà des corbeilles. Il se lave les mains et se prépare à rincer la coupe. Le maître d'hôtel le prie de ne pas rincer la coupe lui-même. L'invité, à genoux, dépose la coupe dans une corbeille. Il se lève et répond. Quand la coupe a été rincée par un aide, il s'avance. Arrivé auprès des degrés, il salue par une inclination profonde et monte. Le maître d'hôtel monte aussi, salue l'invité pour le remercier d'avoir fait rincer la coupe. Il fait comme l'invité a fait précédemment. 
• ${ }_{184}$ L’invité descend pour se laver les mains. Le maître d'hôtel descend aussi pour lui faire honneur. L'invité décline cet hon neur. Après s'être lavé les mains, il salue par une inclination profonde et monte les degrés. Il verse du vin dans une coupe du prince pour le maître d'hôtel. Un aide qui a charge des couvertures des amphores agit comme précédemment. L'invité va offrir à boire au maître d'hôtel au haut des degrés occiden taux. Le maître d'hôtel, le visage tourné vers le nord, salue à genoux et reçoit la coupe. Linvité, à la gauche du maître d'hôtel, le salue à genoux après lui avoir donné la coupe. Le maître d'hôtel fléchit les genoux, offre le vin aux esprits, mais ne le goûte pas. Il ne remercie pas en saluant à genoux celui qui lui a offert du vin. Il ne loue pas la qualité du vin. Ensuite il vide la coupe. Il se lève, fléchit les genoux, dépose la coupe, salue à genoux. Il prend la coupe et se lève. L’invité lui rend le salut à genoux.

Le maître d'hôtel ne se dit pas rassasié de vin. Il descend avec la coupe vide et la dépose dans une corbeille. L'invité descend et se tient debout à l'ouest des degrés occidentaux. Le chef des archers dit à l'invité de monter. Linvité monte et se tient debout dans la salle latérale, le visage tourné vers l'est.

$\mathbf{O} \cdot{ }_{185}$ Le maître d'hôtel se lave les mains et rince une coupe ornée d'ivoire. Il monte, emplit la coupe, et, le visage tourné vers le nord-est, il la présente au chef d'État. Le prince salue à genoux et reç oit la coupe. Le maître d'hôtel descend par les degrés occidentaux. Au bas des degrés orientaux, le visage tourné vers le nord, il salue à genoux le prince qui a reçu la coupe. Un officier sert au prince des conserves de viande. Lintendant de la cuisine place devant lui une petite table sur laquelle sont les membres séparés d'un animal. Il monte par les degrés occidentaux. Le prince offre ces mets aux esprits, comme a fait l'invité. Un aide de l'intendant de la cuisine présente au prince les poumons. Le prince ne remercie pas en saluant à genoux celui qui lui a offert du vin. Debout, il vide la coupe. Il fléchit les genoux, dépose la coupe et salue à genoux. Il prend la coupe et se lève. Le maître d'hôtel lui rend son salut à genoux. Il monte, reçoit la coupe, descend avec elle et la dépose dans une des corbeilles du prince.

$\mathbf{O}$ Le maître d'hôtel prend une autre coupe et la rince. Il monte les degrés, verse dans le coupe du vin du prince, et descend, pour boire lui-même le vin au bas des degrés orientaux (et offrir ensuite à boire au principal invité). Le visage tourné ${ }_{186}$ vers le nord, il fléchit les genoux, dépose la coupe, et salue deux fois à genoux, inclinant le front jusqu'à terre, Le prince lui rend un double salut à genoux. Le maître d'hôtel fléchit les genoux, offre le vin aux esprits, puis vide la coupe. Il salue deux fois à genoux, inclinant le front jusqu'à terre. Le prince lui rend deux fois le salut à genoux. Le maître d'hôtel dépose la coupe dans une corbeille.

$\mathbf{O}$ Le maître d'hôtel se lave les mains et rince une coupe. Il monte les degrés, afin de íng présenter cette coupe au principal invité. Il y verse du vin d'une jarre ordinaire. Au haut des de grés occidentaux, il fléchit les genoux, 
dépose la coupe, et salue à genoux l'invité. L'invité q uitte sa natte, et, le visage tourné vers le nord, lui rend le salut à genoux. Le maître d'hôtel fléchit les genoux, offre le vin aux esprits, puis le boit. Linvité ré clame. (Il dit que le maître d'hôtel, représentant la personne du prince, doit boire de bout). Le maître d'hôtel, après avoir vidé la coupe, salue à genoux l'invité. L'invité lui rend le salut à genoux.

Le maître d'hôtel descend pour rincer une coupe. L’invité descend aussi pour lui faire honneur. Le maître d'hôtel refuse cet honneur. L'invit é prie le maître d'hôtel de ne pas rincer la $\bullet_{187}$ coupe lui-même. Après que la coupe a été rincée par un aide, le maître d'hôtel salue par une inclination profonde et monte les degrés. L'invité ne salue pas le maître d'hôtel pour le remer cier d'avoir fait rincer la coupe. Le maître d'hôtel verse dans la coupe du vin du prince. L'invité, au haut des degrés occi dentaux, le salue à genoux, reçoit la coupe devant sa natte et retourne à sa place. Le maître d'hôtel salue à genoux l'invité qui emporte la coupe. L'invité monte, sur sa natte, fléchit les genoux, offre le vin aux esprits, puis dépose la coupe à l'est des conserves de viande. Le maître d'hôtel descend et retourne à sa place. Linvité quitte sa natte par le côté occidental, et se tient debout, le visage tourné au sud-est.

$\mathbf{O}$ Un petit officier, au bas des degrés orientaux, demande au prince de charger deux officiers d'offrir la coupe pour la deuxième fois. Le prince désigne le plus honorable de ces deux officiers. Le petit officier avertit deux grands préfets du dernier rang de présenter la coupe pour la deuxième fois. Ceux qui présenteront la coupe, auprès des degrés orientaux, le visage tourné vers le nord, saluent deux fois le prince à genoux, inclinant le front jusqu'à terre. Le prince leur rend deux fois le salut à genoux. Ceux qui présenteront la coupe se tiennent debout au midi des cruches, le visage tourné vers l'ouest. Le plus respectable des deux est au sud de l'autre. $\bullet_{188}$

Ils s'avancent l'un à la suite de l'autre, se lavent les mains, rincent deux coupes de corne, montent par les degrés occidentaux, s'avancent l'un à la suite de l'autre, versent dans les coupes du vin d'une jarre, se croisent au nord de la colonne (occidentale), descendent au bas des degrés orientaux, déposent tous deux leurs coupes, et saluent deux fois à genoux, inclinant le front jusqu'à terre. Ils prennent leurs coupes et se lèvent. Le prince leur rend deux fois le salut à genoux. Ces deux grands préfets fléchissent les genoux, offrent le vin aux esprits, puis le boivent entièrement. Ils se lèvent, fléchissent les genoux, déposent les coupes, et saluent deux fois à genoux, inclinant le front jusqu’à terre. Ils prennent les coupes et se lèvent. Le prince leur rend deux fois le salut genoux. Les deux grands préfets, tenant les coupes dans les mains, attendent les ordres du prince au sud des cruches.

Un petit officier demande au prince si ces grands préfets offriront à boire tous deux simultanément, on si l'un d'eux seu lement le fera. Si le prince ordonne que tous les deux remplissent cet office, tous les deux s'avancent l'un à la suite de l'autre et déposent leurs coupes dans les corbeilles. Au bas des degrés orientaux, ils saluent deux fois à genoux, inclinant le front jusqu’à $\bullet{ }_{189}$ 
terre. Le prince leur rend deux fois le salut à genoux. Les deux grands préfets rincent une coupe divoire, montent les degrés et emplissent la coupe. Ils s'avancent l'un à la suite de l'autre, fléchissent les genoux, et déposent la coupe au sud des conserves de viande. Le plus respectable des deux se tient au nord de l'autre. Ils descendent. Au bas des degrés orientaux, ils saluent deux fois à genoux, inclinant le front jusqu'à terre devant le prince qui a reçu la coupe. Le prince leur rend deux fois le salut à genoux.

Le prince, à genoux, prend la coupe que les deux grands préfets lui ont présentée. Il se lève pour offrir à boire une deuxième fois au principal invité. Le principal invité descend. Au bas des degrés occidentaux, il se prépare à saluer deux fois à genoux, inclinant le front jusqu'à te rre. Le prince envoie un petit officier lui dire de ne pas saluer au bas des degrés. Lin vité monte et fait les salutations à genoux. Le prince fléchit les genoux, dépose la coupe, et rend deux fois le salut à genoux. Il prend la coupe et se lève. Debout, il vide la coupe. L'invité des cend pour saluer à genoux. Un petit officier s'y oppose au nom du prince. Linvité monte, et salue deux fois à genoux, inclinant le front jusqu’à terre. Le prince fléchit les genoux, dépose la $\bullet_{190}$ coupe et rend deux fois le salut à genoux. Il prend la coupe et se lève. L’invité s'avance, reçoit la coupe vide, descend et dépose la coupe dans une corbeille. Il prend une autre coupe et la rince.

Si le prince l'ordonne, l'invité ne change ni ne rince la coupe. De nouveau, il monte les degrés. Il verse du vin dans la belle coupe du prince, descend et se prépare à saluer à genoux. Un petit officier s'y oppose au nom du prince. L'invité monte, et salue deux fois à genoux, inclinant le front jusqu'à terre. Le prince lui rend deux fois le salut à genoux.

$\mathbf{O}$ Linvité se sert de cette coupe pour offrir à boire une deuxième fois à tous les officiers au haut des degrés occidentaux. Le chef des archers invite les grands préfets. Le plus vénérable d'entre eux monte les degrés pour recevoir la coupe. Le principal invité, à la droite de ce grand préfet, fléchit les genoux, dépose la coupe, et salue par une inclination profonde. Il prend la coupe et se lève. Le grand préfet lui rend le salut à genoux. L'invité fléchit les genoux, offre le vin aux esprits, et étant debout, le boit. Après avoir vidé la coupe, il ne salue pas à genoux. Si c'est la coupe du prince, il descend, prend une $\bullet{ }_{191}$ autre coupe et la rince. Il monte les degrés et emplit la coupe à une jarre. Le grand préfet salue à genoux et reçoit la coupe. Linvité salue à genoux le grand préfet qui a reçu la coupe. Les grands préfets reçoivent tous la coupe pour la deuxième fois, avec les mêmes cérémonies que le plus vénérable d'entre eux l'a reçue des mains du principal invité. Ils n'of frent pas le vin aux esprits. Celui qui reçoit la coupe le dernier descend avec cette coupe vide et la dépose dans une corbeille.

$\mathbf{O}$ Le maître d'hôtel rince une coupe, monte et remplit la coupe à une jarre. Il va offrir à boire aux ministres d'État au haut des degrés occidentaux. L'intendant du palais enroule des nattes deux à deux et va les placer à gauche du principal invité ; le côté oriental est le plus honorable. (Deux nattes sont 
placées l'une sur l'autre pour chaque ministre. L'un des ministres monte, salue à genoux et reçoit la coupe. Le maître d'hôtel salue à genoux le ministre qui s'en va avec la coupe. Le ministre refuse d'avoir deux nattes. Lintendant du palais enlève la deuxième natte.

On sert des conserves de viande au ministre. Le ministre monte sur sa natte, fléchit les genoux; de la main gauche il prend la coupe, et de la main droite il offre aux esprits les conserves de viande. Ensuite il leur offre le vin. Il ne goûte ${ }_{192}$ pas le vin. Il quitte sa natte. Au haut des degrés occidentaux, le visage tourné vers le nord, il fléchit les genoux et vide la coupe. Il se lève, fléchit les genoux, dépose la coupe et salue à genoux. Il prend la coupe et se lève. Le maître d'hôtel lui rend le salut à genoux et reçoit la coupe. Le ministre descend et retourne à sa place. Le maître d'hôtel offre à boire à tous les ministres. Puis il descend avec la coupe vide et la dépose dans une corbeille.

$\mathbf{O}$ Le chef des archers invite tous les ministres d'État à monter les degrés. Tous les ministres montent et vont à leurs nattes. S’il y a un ministre d'une grande principauté étrangère, on lui offre à boire avant de l'offrir aux ministres du pays, avec les mêmes cérémonies. Sa natte est à l'ouest des degrés orientaux. Il a le visage tourné vers le nord. Son côté oriental est le plus honorable. Il n'a pas deux nattes placées l'une sur l'autre.

$\mathbf{O}$ Un petit officier demande de nouveau au prince de permettre que les deux grands préfets qui ont déjà offert la coupe pour la seconde fois l'offrent encore comme précédemment. Il lui demande si chacun d'eux aura une coupe, ou si un $\bullet{ }_{193}$ seul aura une coupe. Si le prince ordonne que le plus vénérable seul ait une coupe, l'autre dépose sa coupe dans une corbeille. Il attend seul au sud des cruches. Le plus respectable qui est chargé de présenter la coupe, au bas des degrés orientaux, salue deux fois à genoux, inclinant le front jusqu'à terre. Le prince lui rend deux fois le salut à genoux.

Le grand préfet rince une coupe d'ivoire, monte les degrés, emplit la coupe, fléchit les genoux et dépose la coupe au sud des conserves de viande du prince. Lui et l'autre grand préfet qui est debout au sud des cruches, saluent ensemble deux fois à genoux, inclinant le front jusqu'à terre devant le prince qui a reçu la coupe. Le prince leur rend deux fois le salut à genoux.

$\mathbf{O}$ Le prince fait de nouveau circuler une coupe. Le principal invité et le ministre d'une grande principauté étrangère, sỉl y en a, sont les seuls à qui il offre lui-même à boire pour la seconde fois. Les grands préfets reçoivent la coupe l'un après l'autre au haut des degrés occidentaux, comme précé demment. Celui qui la reçoit le dernier, descend avec cette coupe vide et la dépose dans une corbeille.

$\mathbf{O} \cdot{ }_{194}$ Le maître d'hôtel rince une coupe, monte et offre à boire aux grands préfets au haut des degrés occidentaux. Chacun des grands préfets monte les degrés, salue à genoux et reçoit la coupe. Le maître d'hôtel salue à genoux le grand préfet qui a reçu la coupe. Le grand préfet fléchit les genoux, 
offre le vin aux esprits ; debout, il boit tout le vin. Il ne salue pas à genoux, après avoir vidé la coupe. Le maître d'hôtel reçoit la coupe. Le grand préfet descend et retourne à sa place.

O Un aide de l'intend ant de la cuisine du prince sert des conserves de viande au maître d'hôtel, au nord des cruches. Le maître d'hôtel a le visage tourné vers l'ouest. Avec les conserves de viande, on ne lui sert pas la chair d'un animal sur une petite table. On offre à boire à tous les grands préfets. Ensuite on leur sert des conserves de viande. Ils sont à la suite du principal invité, rangés de l'est à l'ouest par ordre de dignité ; le côté oriental est le plus honorable. Quand ils ont fini de boire et de manger, le chef des archers les fait monter. Ils vont tous prendre place sur leurs nattes.

Les nattes des musiciens sont placées au haut des degrés occidentaux, un peu à l'est. Le directeur de la musique monte $\bullet{ }_{195}$ le premier ; le visage tourné vers le nord, il se tient debout à l'ouest des degrés. De petits officiers introduisent les musiciens. Les musiciens sont quatre; deux d'entre eux pincent de la guitare. Deux petits officiers portent chacun sur le bras gauche une guitare, la table d'harmonie en avant. Leur main gauche tient les cordes à travers l'ouverture percée dans la table d'harmonie. De la main droite ils conduisent et introduisent les deux musiciens aveugles. Les deux musiciens montent par les degrés occidentaux. Le visage tourné vers le nord, le premier à l'est du second, ils fléchissent les genoux. Les deux petits officiers fléchissent aussi les genoux, donnent aux musiciens les guitares, puis descendent.

Les musiciens exécutent les trois premiers chants du Cheu Siao ià : Les cerfs brament, Les quatre coursiers mâles, Les fleurs brillantes [cf. p. ${ }_{85}$ ]. Quand ils ont fini, le maître d'hôtel rince une coupe, monte et leur offre à boire. Les musiciens ne se lèvent pas. Le premier des joueurs de guitare, tenant son instrument de la main gauche, salue à genoux et reçoit la coupe. Le maître d'hôtel, au haut des degrés occidentaux, salue à genoux le musicien qui a reçu la coupe. Il lui sert des conserves de viande. Il charge quelqu'un de l'aider à offrir aux esprits le vin et la viande. Le musicien, après avoir vidé la coupe, ne salue pas à genoux.

• ${ }_{196}$ Le maître d'hôtel reçoit la coupe. Tous les musiciens la reçoivent sans saluer; à genoux ils offrent le vin aux esprits, puis le boivent. On leur sert à tous des conserves de viande. Ils ne les offrent pas aux esprits. Le maître d'hôtel reçoit la cou pe, descend, et la dépose dans une corbeille.

$\mathbf{O}$ Le prince prend encore une coupe et la dépose, en vue d'offrir à boire seulement à ceux qu'il veut récompenser. Tous reçoivent la coupe au haut des degrés occidentaux, comme précédemment. On a fini de boire.

$\mathbf{O}$ Les joueurs d'orgue à bouche entrent, et se tiennent debout au milieu des tambours, des cloches et des pierres musicales suspendues. Ils exécutent le dixième chant du premier Livre et les deux premiers chants du deuxième Livre du Cheu Siaô ià : Les degrés du midi, La fleur blanche, Le millet en 
fleur. Le maître d'hôtel rince une coupe, et monte les degrés, pour offrir à boire aux joueurs d'orgue à bouche, au haut des degrés occidentaux. L'un des joueurs d'orgue à bouche salue à genoux, monte tous les degrés, ne s'avance pas sur la plateforme, reçoit la coupe et descend. Le maître d'hôtel le salue à genoux après lui avoir donné la coupe. Le musicien, devant les degrés, fléchit les genoux et offre le vin aux esprits. Il les boit étant debout. Il ne salue pas après avoir vidé la coupe.

- ${ }_{197}$ Il monte et donne la coupe au maître d'hôtel.

Les autres joueurs d'orgue à bouche, sans saluer, reçoivent la coupe, descendent, fléchissent les genoux, offrent le vin aux esprits, se lèvent et boivent debout. Ils ont tous des conserves de viande. Ils ne les offrent pas aux esprits.

Ensuite les musiciens alternent (et exécutent six chants du Cheu Siaô ià, Livre II, [cf. p. $\left.{ }_{87}\right]$ ). Les chanteurs chantent Les poissons passent dans la nasse. Les orgues à bouche jouent Iôu $k \bullet n g$. Les chanteurs chantent Au midi est un excellent poisson. Les orgues à bouche jouent La haute colline. Les chanteurs chantent Sur les montagnes du midi crôt la plante tâi. Les orgues à bouche jouent Iôu $\hat{\imath}$.

Ensuite les musiciens chantent des chants des cantons [cf. p.• ${ }_{87}$ ]. C'est à savoir, trois chants du Tcheou nan. Les deux tsi $\bullet k^{\bullet} \boldsymbol{u}$ chantent alternativement, Le dolic se propage, La lampourde; et trois chants du Chao nan : Le nid de pie, Elle cueille l'armoise blanche, Elle cueille la marsilea. Le premier des musiciens avertit le directeur de la musique, en disant :

— Les chants réglementaires sont tous terminés.

Le directeur passe au-delà (au nord) de la $\bullet{ }_{198}$ colonne occidentale. Arrivé à l'est de la colonne orientale, il avertit le prince. Ensuite il descend et retourne à sa place.

$\mathbf{O}$ Le chef des archers demande au prince la permission de constituer un directeur des cérémonies. Le prince le permet, Le chef des archers nomme un directeur des cérémonies. Le directeur des cérémonies rince une coupe de corne. Le visage tourné vers le sud, il fléchit les genoux, et dépose la coupe au milieu de la cour. Il monte les degrés ; à l'est de la colonne orientale, il prend les ordres du prince. Au haut des degrés occidentaux, le visage tourné vers le nord, il communique aux ministres d'État et aux grands préfets le désir du prince, en ces termes. :

— Le prince m'a dit de vous faire (asseoir et) reposer.

Les ministres et les grands préfets répondent :

— Oui ; oserions-nous ne pas nous reposer?

Le directeur des cérémonies descend par les degrés occidentaux. Le visage tourné vers le midi, il fléchit les genoux, prend une coupe, monte, emplit la coupe à une jarre et descend, Le visage tourné vers le sud, il fléchit les genoux 
et dépose la coupe. Il se tourne à droite, et le visage regardant le nord, il $\bullet{ }_{199}$ reste debout un peu de temps. Il fléchit les genoux, prend la coupe, se lève, fléchit les genoux ; sans offrir le vin aux esprits, il vide la coupe et la dépose. Il se lève, salue deux fois à genoux, inclinant le front jusqu'à ter re. Il se tourne à gauche. Le visage tourné vers le midi, il fléchit les genoux, prend la coupe et la rince. Le visage tourné vers le sud, il remet la coupe à la place qui lui est propre.

Il monte par les degrés occidentaux ; à l'est de la colonne orientale, il demande au prince la permission d'enlever les petites tables, et descend. Le prince permet. Le directeur des cérémonies avertit le principal invité. Celui-ci, le visage tourné vers le nord, prend sa petite table et s'en va avec elle. L'inten dant de la cuisine du prince enlève la petite table du prince, descend par les degrés orientaux et va à l'est. Les ministres d'État et les grands préfets descendent tous. Le visage tourné vers l'est, ils se rangent du nord au sud par ordre de dignité, les plus respectables au nord.

Le principal invité rentre. Lui, les ministres et les grands préfets ôtent tous leurs chaussures (pour être assis commodément), montent et vont à leurs nattes. Le prince, le principal $\bullet_{200}$ invité, les ministres et les grands préfets s'assiéent tous à leur aise. On leur sert plusieurs sortes de viandes. Les grands préfets offrent aux esprits les conserves de viande. Le directeur des cérémonies monte et prend les ordres du prince. Il avertit tous ces dignitaires en ces termes :

— Le prince dit que chacun doit boire tout son soûl.

Le principal invité, les ministres d’État et les grands préfets se lèvent tous et répondent :

— Oui. Oserions-nous ne pas boire notre soûl ?

Ils s'assiéent tous de nouveau.

Le maître d'hôtel rince une coupe, et monte pour offrir à boire aux simples officiers au haut des degrés occidentaux. Le plus respectable de ces officiers monte, salue à genoux et reçoit la coupe. Le maître d'hôtel salue à genoux l'officier qui s'en va avec la coupe. L'officier fléchit les genoux, offre le vin aux esprits, se lève et boit debout. Il ne salue pas après avoir vidé la coupe. Les autres officiers ne saluent pas. Ils fléchissent les genoux, offrent le vin aux esprits, se lèvent et boivent debout. Ensuite on sert des conserves de viande au directeur des cérémonies, au chef des archers, au chef des officiers et aux deux officiers qui ont charge des couvertures des amphores. Ils se tiennent debout au sud de la coupe, rangés de l'est à l'ouest par ordre de dignité, les plus dignes à l'est. On offre à boire à tous les officiers sans exception. Quand ils ont tous bu, ils se tiennent $\bullet_{201}$ debout à l'est, le visage tourné vers l'ouest ; ils sont rangés du nord au sud par ordre de dignité, les plus dignes au nord. Ensuite on leur sert des conserves de viande. 
L'invocateur, l'annaliste et le chef des petits officiers vont aussi à leurs places, et on leur sert des conserves de viande. Le maître d'hôtel va à l'amphore des officiers qui vivent à la cour, et il leur offre à boire. Ces officiers, sans saluer, reçoivent la coupe, fléchissent les genoux, offrent le vin aux esprits, se lèvent et boivent debout.

Si l'on tire de l'arc, le grand chef des archers est le directeur du tir. Les règles sont les mêmes que celles du tir dans un canton.

$\mathbf{O}$ Le principal invité descend, rince une coupe, et monte pour offrir à boire une deuxième fois au prince. Il emplit la coupe à une jarre, descend et se prépare à saluer à genoux. Le prince descend un degré, Un petit officier, de la part du prince, s'oppose à ce que l'invité salue au bas des degrés. L'invité monte, et salue deux fois à genoux, inclinant la tête jusqu'à terre. Le prince lui rend deux saluts à genoux. L'invité fléchit les genoux, offre le vin aux esprit s, le boit entièrement, et salue deux fois à genoux, inclinant le front jusqu'à terre. Le prince lui rend $\bullet_{202}$ deux saluts à genoux. Linvité descend, rince une coupe ornée d'ivoire, monte, emplit la coupe du vin du prince, fléchit les genoux et dépose la coupe au sud des conserves de viande du prince. Il descend pour saluer à genoux. Un petit officier, de la part du prince, s'oppose à ce qu'il salue au bas des degrés. L'invité monte et fait deux saluts à genoux. Le prince lui rend deux saluts à genoux. Liinvité retourne à sa place.

Le prince fléchit les genoux et prend la coupe que l'invité lui a présentée. Il se lève, et offre à boire seulement à ceux qu'il veut récompenser. Ceux qui reçoivent cet honneur observent les mêmes règles que l'invité quand il a bu la deuxième fois. Linvité descend, prend une autre coupe et la rince. Il monte, emplit la coupe du vin du prince, descend et veut saluer à genoux. Un petit officier, de la part du prince, s'oppose à ce qu'il salue au bas des degrés. L'invité monte et fait les salutations à genoux. Le prince les lui rend. L'invité retourne à sa natte. Il s'assied et fait circuler la coupe. Il y a des officiers qui la présentent. Ceux-là seuls saluent à genoux, qui la reçoivent du prince. Le directeur des cérémonies ordonne à ceux qui présentent la coupe de l'offrir à tous les grands préfets. Celui qui la reçoit le dernier se lève, et s'en sert pour offrir à boire aux simples officiers.

$\mathbf{O} \cdot{ }_{203}$ Celui des grands préfets qui reçoit la coupe le dernier se lève en la tenant dans les mains. Il offre à boire aux simples officiers au haut des degrés occidentaux. Chacun d'eux monte. Le grand préfet dépose la coupe et salue à genoux. L'officier lui rend le salut à genoux. Le grand préfet debout boit tout le vin de la coupe. Il ne salue pas. Il remplit la coupe. L'officier salue à genoux et reçoit la coupe. Le grand préfet salue à genoux l'officier qui a reçu la coupe. Les simples officiers, au haut des degrés occidentaux, reçoivent tous la coupe. Quand ils l'ont tous reçue, la cérém onie est finie.

$\mathbf{O}$ Lintendant des hôtes rince une coupe, monte par les degrés occidentaux. Il offre à boire aux fils aînés du prince et des hauts dignitaires, de la même manière qu'il a offert à boire aux simples officiers. Tous reçoivent la 
coupe. Le maître d'hôtel descend, rince une coupe, et offre à boire à tous les chefs d'offices qui sont auprès de lui et aux petits officiers du palais, au haut des degrés orientaux, de la même manière qu'il a offert à boire aux fils aînés du prince et des dignitaires.

Le nombre des coupes qu'on boit n'est pas limité. Un • ${ }_{204}$ officier présente du vin de l'amphore du prince ; un autre présente du vin d'une jarre. Celui qui présente du vin de l'amphore du prince emplit sa coupe et l'offre au prince. Le prince la reçoit sans saluer. Celui qui offre le vin d'une jarre emplit sa coupe, et va trouver le prince, qui lui désigne ceux qu'il veut récompenser. Ceux à qui le prince fait offrir à boire en récompense se lèvent, reçoivent la coupe et descendent. Ils déposent la coupe auprès de leurs nattes, et saluent deux fois à genou, inclinant la tête jusqu'à terre. Le prince leur rend le salut à genoux. Ceux qui sont ainsi récompensés vont à leurs nattes avec la coupe et fléchissent les genoux. Ils ne boivent que quand le prince a vidé sa coupe. L'officier qui offre le vin de l'amphore du prince reçoit la coupe du prince, la remplit de nouveau, et retourne la déposer devant le prince.

Celui qui a reçu le dernier la coupe en récompense, se lève et donne la coupe à l'officier qui puise du vin à la jarre. Cet officier remplit la coupe et l'offre successivement à tous les grands préfets. Ceux-là seuls saluent à genoux qui reçoivent la coupe en récompense du prince. Le grand préfet qui reçoit la coupe le dernier se lève avec elle et va offrir à boire aux simples officiers au haut des degrés occidentaux. Chacun des simples $\bullet_{205}$ officiers monte. Le grand préfet, sans saluer, boit tout le vin de la coupe (pour encourager par son exemple les simples officiers). Il remplit la coupe. Le simple officier la reçoit sans saluer. Le grand préfet retourne à sa natte. Les simples officiers, l'un après l'autre, remplissent la coupe et imitent le grand préfet.

Quand le prince ordonne de découvrir les amphores, les ministres d'État et les grands préfets descendent tous. Au bas des degrés occidentaux, le visage tourné vers le nord, ils se rangent de l'est à l'ouest par ordre de dignité, les plus respectables à l'est. Ils saluent le prince deux fois à genoux, inclinant le front jusqu'à terre. Le prince envoie un petit officier leur dire qu'ils ne doi vent pas saluer au bas des degrés. Il leur rend deux fois le salut à genoux. Tous les grands préfets s'écartent (comme pour décliner cet honneur). Ensuite ils montent et retournent s'as seoir sur leurs nattes. Les simples officiers reçoivent tous la coupe, comme précédemment.

Le nombre des morceaux de musique qu'on exécute n'est pas limité. Le soir, le fils aîné d'un dignitaire tient un flambeau au haut des degrés orientaux, et l'intendant du palais au haut des de grés occidentaux. le directeur des laboureurs tient un $\bullet_{206}$ grand flambeau dans la cour, et le portier en dehors de la grande porte.

Le principal invité a bu tout son soûl. Le visage tourné vers le nord, il fléchit les genoux, prend les tranches de viande qu'on lui a servies et descend. Les musiciens exécutent le chant $K \bullet$. Le principal invité fait don de ses 
tranches de viande à ceux qui battent le tambour, sous les gouttières intérieures près de la grande porte; puis il s'en va. Les ministres d'État et 1 es grands préfets s'en vont tous. Le prince ne les reconduit pas.

$\mathbf{O}$ Le prince offre un banquet aux hôtes venus des pays étrangers. Son envoyé dit si chacun d'eux :

- Notre prince a de mauvais vin. Il vous invite, Monseigneur, à en boire et à passer quelque temps avec lui. Il m'envoie, moi N., vous inviter.

L'étranger répond :

- Mon prince est le serviteur de votre prince. Il n'y a pas de raison pour que votre prince s'abaisse à me faire cette faveur, à moi simple messager. J'ose décliner cet honneur.

(L’en voyé du prince va avertir son maître. Il revient et dit) :

- Notre prince persiste à vous offrir son mauvais vin. Il m'envoie vous inviter de nouveau.

(L'étranger répond) :

- Mon prince est le serviteur de votre prince. Il n'y a pas de raison pour que votre prince s'abaisse à me faire cette faveur. J'ose persister $\bullet_{207}$ dans mon refus.

(L’envoyé avertit son maître, revient et dit) :

- Notre prince persiste à dire qu'il a du mauvais vin à vous offrir. Il m'envoie vous inviter de nouveau.

(L'étranger répond) :

- J'ai refusé plusieurs fois ; je n'ai pas obtenu l'agré ment du prince. Oserais-je ne pas suivre son désir?

L'officier qui exécute les ordres du prince répète :

- Notre prince m'a envoyé, moi N., vous dire qu'il a du mauvais vin, et vous inviter à le boire et à passer quelques moments avec lui.

(L'étranger répo nd) :

— Votre prince a été très obligeant envers mon prince. De plus, il a daigné me faire une faveur. Je me permets de le saluer à genoux pour le remercier de sa bonté.

NOTES SUPPLÉMENTAIRES. 
Avant le banquet, le prince revêt ses habits de cour dans ses appartements particuliers.

On fait cuire les mets en dehors de la grande porte, à l'est du palais.

- 208 Quand le prince offre un banquet à un hôte d'un pays étran ger, un officier va recevoir l'hôte à la grande porte du palais, le salue par une inclination profonde, offre de lui céder le pas et monte avec lui. L'hôte est traité avec respect. Sa natte est à l'ouest des degrés orientaux : elle regarde le nord. On lui sert la chair d'un animal (un chien) sur une petite table. Il ne goûte ni les poumons ni le vin. Son compagnon est traité comme le principal invité. L’hôte n'a ni belle amphore d'argile ni belle coupe d'ivoire.

Quand un prince donne un banquet à un ministre d'État ou à un grand préfet, un grand préfet fait l'office de principal invité.

L'intendan t de la cuisine du prince et ceux qui ont charge des couvertures des amphores sont toujours de simples officiers. Celui qui prépare les mets d'un ministre d'État est un aide de l'intendant de la cuisine du prince.

Si un invité est introduit au son de la musique, à son entrée dans la cour, on exécute le chant Séu hià. L'invité salue à ge noux, quand on lui offre du vin. Le maître d'hôtel rend le salut $\bullet_{209}$ à genoux, et la musique cesse. Quand le prince salue à genoux et reçoit la coupe, on exécute le chant Séu hià. Quand le prince a vidé la coupe, le maître d'hôtel monte, reçoit la coupe et descend avec elle. Alors la musique cesse. Les chanteurs montent et chantent Les cerfs brament (Siao ia). Au bas des degrés, les flûtes jouent Le nouveau palais (Siao ia). Les orgues à bouche entrent et jouent trois morceaux. Ensuite tous les musiciens exécutent ensemble des chants des cantons. (Ils exécutent six chants tirés du Tcheou nan et du Chao nan). S'il y a des repré sentations mimiques, on exécute le chant $T c h \bullet$.

Seuls le prince et le principal invité ont une petite table.

Celui qui offre à boire au prince dit :

- Je me permets de vous offrir la coupe, prêt à me soumettre à votre volonté,

(c'est -à-dire, acceptez ou n'acceptez pas, ce sera comme il vous plaira).

Chaque fois que le prince appelle un officier, l'officier ne prend pas le temps de mettre les deux pieds l'un après l'autre sur chaque marche. Ce sont seulement les deux dernières marches qu'il monte sans mettre les deux pieds l'un après l'autre sur chac une d'elles.

Quand un officier offre à boire au prince pour la deuxième fois, après l'avoir salué à genoux, il lui demande toujours la permission d'offrir à boire à tous les officiers qui sont au service du prince.

- ${ }_{210}$ Celui qui fournit les conserves de viande et celui qui fournit les mets exquis sont toujours des aides de l'intendant de la cuisine du prince. 
Les mets exquis sont préparés à l’intérieur du palais.

Quand un prince prend part au tir à l'arc, il est le second archer de sa paire. Il se découvre le bras gauche, mais il garde sur ce bras la manche de sa tunique rouge (qu'il porte sur la peau sous deux autres tuniques). Il ne se rend à la place d'où il lancera ses flèches, que quand la musique a commencé à se faire entendre. Un petit officier (essuie et) tient avec un linge les flèches du prince, et les présente à l'instant où elles doivent être lancées. Le prince ne les lance pas comme les autres archers, en mesure, d'accord avec la musique. Après qu'il les a lancées, le petit officier reçoit l'arc du prince et le donne à celui qui a soin des arcs. Le premier archer, dans l'espace qui lui est assigné pour tirer de l'arc, se tient en arrière du prince à la distance de la longueur d'une flèche. Après avoir lan cé ses flèches, il se tourne vers le prince et attend qu'il ait aussi lancé ses flèches. Si l'on offre à boire au prince, au banquet il faut deux coupes. En présence du prince, si un grand préfet tire de l'arc, il se dénude entièrement le bras gauche.

Quand le prince donne un festin à un l'hôte d'une contrée $\bullet{ }_{211}$ étrangère, la deuxième fois que la coupe est présentée, l'hôte dit :

- Votre serviteur (l'hôte) reçoit une faveur. Permettez-lui d'aider l'officier qui présente la coupe.

Cet officier répond :

- Monseigneur, ne vous abaissez pas à faire ce service.

Dans un bâtiment latéral, la princesse fait de la musique (pour réjouir son mari). 


\section{CHAPITRE VII}

\section{Grand tir de l'arc}

O $212 \ldots$ Le prince ordonne d'avertir les archers. Le premier minis tre avertit tous les officiers que les archers auront un exercice. Le directeur du tir avertit les ministres de première et de deuxième classe et les grands préfets. Le chef des simples officiers avertit les simples officiers et les aides. Trois jours avant le tir, le principal intendant du premier ministre avertit les autres intendants et le commandant. (La veille du tir) le chef du tir si • avertit une seconde fois, et examine si l'on a bien nettoyé (le terrain, les vases et les instruments).

$\mathbf{O}$ Le commandant ordonne au mesureur de mesurer la distance qui séparent la cible de l'archer, et la distance qui séparera l'abri ou cloison de la cible ; cela, avec l'instrument appelé lî póu double pas qui porte l'image d'un renard. (Il valait six $6 t c^{\bullet} u, 1 \mathrm{~m}, 20 \mathrm{~cm}$ ). La grande cible se place à la distance de quatre-vingt dix lî póu. La cible qui porte les images ou sàn mêlées de plusieurs animaux se place à la distance de soixante-dix lî póu. La cible qui porte l'image d'un ngán chien de garde se place à la distance de cinquante lî póu. Chaque $\bullet_{213}$ cloison ou abri contre les flèches se place loin de la cible à la distance de dix lî póu à l'ouest et de dix lî póu au nord.

$\mathbf{O}$ Ensuite le commandant ordonne au mesureur et à l'in tendant des voitures de déployer trois cibles : la grande cible est tch'ôung haute ; son $k \bullet u$ centre apparaît au dessus de la cible moyenne. Le centre de la cible moyenne apparaît au dessus de la petite cible. La petite cible est au dessus du sol à la hauteur de óu la trace du pied de l'homme $(24 \mathrm{~cm})$. (Avant le tir) on ne lie pas la corde destinée à attacher au bas du poteau la bordure gauche de la cible. Voyez page $\cdot{ }_{102}$. L'abri contre les flèches se place loin de la cible, à la distance de dix lî póu à l'ouest et de dix lî póu au nord.

$\mathbf{O}$ - La veille du tir $s^{\bullet}$, on suspend pour les musiciens, à l'est des degrés orientaux, les pierres musicales, les cloches, et les clochettes, Les pierres musicales qui accompagnent les orgues à bouche font face à l'ouest. Au sud de ces pierres musicales sont les cloches qui accompagnent les orgues à bouche. Au sud des cloches sont les clochettes. Ces instruments sont tous rangés du sud au nord. A l'ouest des degrés orientaux, on fixe un tambour sur un poteau ; le côté sur lequel on frappe regarde le midi. A l'est de ce tambour, est le tambour $p$ ̂̀ qui lui répond ; le côté sur lequel on frappe regarde le midi.

- ${ }_{214}$ A l'ouest des degrés occidentaux sont les pierres musicales dont le son accompagne les chants élogieux; elles regardent l'est. Au sud de ces pierres musicales sont des cloches. Au sud des cloches sont des clochettes, Les 
cloches et les clochettes sont rangées du sud au nord. Au sud des clochettes, on fixe un tambour sur un poteau; le côté sur lequel on frappe regarde l'est. Au nord de ce tambour est un tambour $p \hat{\imath}$ qu'on frappe chou d'abord (avant de frapper le tambour ordinaire). A l'est des degrés occidentaux on fixe un tambour sur un poteau; le côté sur lequel on frappe regarde le midi. Entre les tambours placés sur des poteaux sont des instruments de bambou (flûtes, orgues à bouche). Le tambourin à manche est à l'ouest des pierres musicales dont le son accompagne les chants élogieux; il repose contre les cordes auxquelles ces pierres sont suspendues.

O Le matin du jour du tir, les amphores de l'intendant du palais sont placées à l'ouest de la colonne orientale ; ce sont deux vases carrés. Au sud de ces deux amphores sont les amphores du prince; ce sont deux jarres dont le goulot est étroit et le ventre large. Elles reposent sur des cuvettes. Leurs couvertures sont de fine toile de chanvre ou de dolic. Elles sont cousues de petits bâtonnets. Ou en relève les bords pour couvrir la cuiller qui est sur chaque amphore. Il y a toujours $\bullet_{215}$ une amphore pour l'eau ; l'amphore pour le vin est au nord de celle qui contient l'eau.

Les amphores de tous les simples officiers qui vivent à la cour sont au sud des clochettes occidentales; elles regardent le nord ; ce sont deux vases ronds. On place aussi des amphores au nord-est de l'abri contre les flèches de la grande cible. Ce sont deux vases qui servent pour offrir du vin (à celui qui signale les victoires).

O On dispose des cruches au sud-est des degrés orientaux, (les vases pleins d'eau à 1 'est de ces cruches et des corbeilles à l'ouest. On range ces objets du sud au nord. Au nord de ces corbeilles on place les corbeilles du prince ; on les tourne vers l'ouest. On place aussi des cruches au nord-ouest des amphores de celui qui signale les victoires. On place de l'eau au nord des cruches, et des corbeilles au sud. On range ces objets de l'est à l'ouest.

O Un petit officier dispose la natte du prince au haut des degrés orientaux ; il la tourne vers l'ouest. L'intendant du palais dispose la nat te du principal invité à l'ouest de la porte de la salle, le devant tourné vers le sud. Le principal invité a deux nattes placées l'une sur l'autre. Les nattes des ministres sont à l'est de $\bullet_{216}$ celle du principal invité ; elles sont rangées de l'est à l'ouest ; le côté oriental est le plus honorable. Les ministres des petits États sont à l'ouest du principal invité ; ils sont rangés de l'est à l'ouest par ordre de dignité ; le côté oriental est le plus honorable.

Les grands préfets sont placés à la suite des ministres; ils sont rangés de l'est à l'ouest ; le côté oriental est le plus honorable. S'il en est qui (à cause du nombre) aient le visage tourné vers l'est, ils sont rangés du nord au sud; le côté septentrional est le plus honorable. Les nattes des musiciens sont à l'est des degrés occidentaux ; elles regardent le nord. Elles sont rangées de l'est à l'ouest ; le côté oriental est le plus honorable. Les officiers fournissent des vivres. 
O Quand le bouillon gras est préparé à point, le grand archer avertit le prince que tout est prêt. Le prince monte et prend place sur sa natte. Un chef de petits officiers introduit les ministres des grands États, les autres ministres et les grands préfets. Tous ces hauts dignitaires entrent et se placent à droite de la grande porte, le visage tourné vers le nord, rangés de l'est à l'ouest, les plus honorables à l'est. Les simples officiers se placent à l'ouest, le visage tourné vers l'est, rangés du nord au $\bullet_{217}$ sud, les plus honorables au nord. (Au milieu de la cour), les grands préfets se placent au nord-est de la cible au chien de garde, le visage tourné vers le nord, rangés de l'est à l'ouest, les plus honorables à l'est. Les simples officiers qui vive nt à la cour se placent au sud des autres simples officiers, le visage tourné vers le nord, rangés de l'est à l'ouest, les plus honorables à l'est. Les suivants du chef des petits serviteurs se placent au bas de la partie orientale de la plateforme, le visage tourné vers le midi, rangés de l'ouest à l'est, les plus honorables à l'ouest.

Le prince descend, et se tient debout au sud-est des degrés orientaux, le visage tourné vers le midi. Le chef des petits serviteurs l'avertit de saluer par une inclination profonde les ministres des grands États, les autres ministres et les grands préfets. Tous ces dignitaires ont le visage tourné vers l'ouest. Ils sont rangés du nord au sud, les plus honorables au nord. Le prince salue les grands préfets (et les ministres) par une inclination profonde. Tous les ministres et les grands préfets avancent un peu.

O Le grand chef des archers porte les ordres du prince aux étrangers et lui rapporte leurs réponses. Il prie le prince de désigner celui qui fera l'office de principal invité. Le prince dit :

- Je nomme un tel pour cet office.

Le chef des archers avertit $\bullet_{218}$ le grand préfet qui est désigné pour être le principal invité. Celui-ci s'avance un peu et s'excuse par politesse. Le chef des archers fait son rapport au prince. Le prince désigne de nouveau le même grand préfet. Ce grand préfet salue deux fois à genoux en inclinant le front jusquà terre, et accepte cet office. Le chef des archers en avertit le prince. Le principal invité sort du palais, et se tient dehors en dehors de la grande porte, le visage tourné vers le nord. Le prince salue par une inclination profonde les ministres et les grands préfets, monte et va à sa natte.

O Un petit officier, au bas des degrés orientaux, le visage tourné vers le nord, demande au prince l'autorisation d'appeler les officiers qui mettent les couvertures sur les amphores et ceux qui présentent des mets exquis. Il communique l'ordre du prince aux officiers qui mettent les couvertures sur les amphores. Ceux-ci montent par les degrés occidentaux. Il se tiennent debout au sud des amphores, le visage tourné vers le nord; le plus âgé est à la droite de l'autre. L'intendant de la cuisine demande au prince l'autorisation de servir des mets aux ministres des grands États et aux autres ministres.

O Le grand chef des archers, qui fait l'office d'hôtelier, introduit le principal invité. Quand celui-ci est arrivé dans la cour, le prince descend une 
marche et le salue par une inclination profonde. Linvité se retire de côté (comme pour $\bullet_{219}$ décliner cet honneur). Le prince monte et va à sa natte. La musique exécute le chant Séu hià. L’invité monte par les degrés occidentaux. Le mâtre d'hôtel le suit ; il est à sa droite. Il a le visage tourné vers le nord. Quand l'invité arrive à sa place, le maître d'hôtel le salue deux fois à genoux. L’invité rend deux fois ce salut.

O Le maître d'hôtel descend, et s'apprête à rincer une coupe, au sud des cruches, le visage tourné vers le nord-ouest. L’invité, pour lui faire honneur, descend par les degrés occidentaux et tourne le visage vers l'est. Le maître d'hôtel décline cet honneur. L'invité lui répond. Le maître d'hôtel, le visage tourné vers le nord, se lave les mains, fléchit les genoux, prend une coupe et veut la rincer. L'invité s'avance un peu et prie le maître d'hôtel de ne pas rincer la coupe lui-même. Le maître d'hôtel fléchit les genoux et dépose la coupe dans une corbeille. Il se lève et répond. Linvité retourne à sa place.

Après que le maître d'hôtel a fait rincer une coupe par un aide, l'invité le salue par une inclination profonde et monte. Le maître d'hôtel monte aussi. L'invité le salue à genoux pour le remercier d'avoir fait rincer la coupe. Le maître d'hôtel, à la droite de l'invité, dépose la coupe et lui rend le salut à $\bullet 220$ genoux. Il descend et se lave les mains. L’invité descend aussi pour lui faire honneur. Le maître d'hôtel refuse cet honneur. L’invité répond. Après s'être lavé les mains, il salue par une inclination profonde et monte. Le maître d'hôtel monte aussi, fléchit les genoux et prend la coupe. L'officier qui met la couverture sur l'amphore enlève cette couverture.

Le maître d'hôtel emplit la coupe à l'amphore du prince. L'officier qui a soin de la couverture de l'amphore la remet sur l'amphore. Il en relève les bords pour couvrir la cuiller placée sur l'amphore par le maître d'hôtel. Celui ci offre la coupe à l'invité devant sa natte. L'invité, au haut des degrés occidentaux, salue à genoux. Il reçoit la coupe devant sa natte et reprend sa place. Le maître d'hôtel, à la droite de l'invité, le salue à genoux après lui avoir donné la coupe. Un officier du chef de cuisine sert à l'invité des conserves de viande. L'invité monte sur sa natte. Un aide du commandant lui sert une petite table sur laquelle sont les membres séparés d'un ch ien.

L'invité fléchit les genoux, de la main gauche prend la coupe et de la main droite offre les conserves de viande aux $\bullet_{221}$ esprits. Il dépose la coupe à droite des conserves de viande et se lève. Il prend les poumons, fléchit les genoux, retranche la petite extrémité des poumons, les offre aux esprits, les goûte, se lève et les place sur la petite table. Il fléchit les genoux, s'essuie les mains, prend la coupe et offre le vin aux esprits. Il se lève. A l'extrémité de sa natte, il fléchit les genoux et goûte le vin. Il quitte sa natte, fléchit les genoux, dépose la coupe, salue à genoux. Il loue la qualité du vin. Il prend la coupe et se lève. Le maître d'hôtel lui rend le salut à genoux. La musique cesse. L'invité, au haut des degrés occidentaux, le vis age tourné vers le nord, fléchit les genoux, vide la coupe et se lève. Il fléchit les genoux, dépose la coupe et 
salue à genoux. Il prend la coupe et se lève. Le maître d'hôtel lui rend le salut à genoux.

L'invité descend avec la coupe vide. Le maître d'h ôtel descend aussi pour lui faire honneur. L'invité au sud des cruches, le visage tourné vers le nord-ouest, fléchit les genoux, dépose la coupe, s'avance un peu et décline cet honneur. Le maître d'hôtel, à l'ouest des degrés occidentaux, le visage tourné vers l'est, s'avance un peu et répond. L'invité fléchit les genoux, prend la coupe et la dépose en deçà des corbeilles. Il • ${ }_{222}$ veut se laver les mains et rincer la coupe. Le maître d'hôtel prie l'invité de ne pas rincer la coupe. Linvité, à genoux, dépos e la coupe dans une corbeille. Il se lève et répond.

L'invité, après avoir fait rincer une coupe, arrivé aux degrés, salue par une inclination profonde et monte. Le maître d'hôtel monte aussi et salue à genoux pour remercier d'avoir fait rincer la coupe. Il fait les mêmes cérémonies que l'invité. L’invité descend et se lave les mains. Le maître d'hôtel descend aussi. L'invité décline cet honneur. Après s'être lavé les mains, il salue par une inclination profonde et monte. Il verse dans la coupe du vin de l'amphore du prince. L'officier qui place la couverture sur l'amphore agit comme précédemment. L'invité offre à boire au maître d'hôtel au haut des degrés occidentaux. Celui-ci, le visage tourné vers le nord, salue à genoux et reçoit la coupe. Linvité, à la gauche du maître d'hôtel, le salue s'en allant avec la coupe.

Le maître d'hôtel, à genoux, offre le vin aux esprits. Il ne le goûte pas. Ensuite il le boit tout entier et se lève. Il fléchit les genoux, dépose la coupe et salue à genoux. L’invité lui rend le salut à genoux. Le maître d'hôtel ne se dit pas rassasié de vin. Il descend avec la coupe vide et la dépose dans une corbeille. ${ }_{223}$ L'invité descend et se tient debout à l'ouest des degrés occiden taux, le visage tourné vers l'est. L'officier qui port e les ordres du prince dit à l'invité de monter. L’invité monte, et se tient debout près de la salle latérale qui est à l'ouest, le visage tourné vers l'est.

$\mathbf{O}$ Le maître d'hôtel se lave les mains et rince une coupe d'ivoire. Il monte et emplit la coupe à l'amphore du prince. Le visage tourné vers le nord-est, il offre la coupe au prince. Le prince salue à genoux et reçoit la coupe. On exécute le chant Séu hià. Le maître d'hôtel descend par les degrés occidentaux. Au bas des degrés orientaux, le visage tourné vers le nord, il salue à genoux le prince qui tient la coupe.

Un aide de l'intendant de la cuisine sert au prince des con serves de viande, qu'il apporte du bâtiment qui est à gauche. Un officier monte par les degrés occidentaux, et place devant le prince une petite table sur laquelle sont les membres séparés d'un chien. Le prince offre le vin et la viande aux esprits, comme a fait l'invité. Un officier aide le prince et lui présente les pou mons. Le prince ne salue pas pour remercier du vin qu'il a reçu. Debout, il vide la coupe ; à genoux, il la dépose et salue. ${ }_{224}$ Il prend la coupe et se lève. Le maître d'hôtel lui rend le salut à genoux. La musique cesse. Le maître d'hôtel monte, reçoit la coupe, descend et dépose la coupe dans une corbeille. 
O Le maître d'hôtel prend une autre coupe et la rince. Il monte, emplit la coupe a une jarre et descend avec elle, pour offrir à boire au prince à son tour. Au bas des degrés orientaux, le visage tourné vers le nord, il fléchit les genoux, dépose la coupe, et salue deux fois à genoux, inclinant le front jusqu'à terre. Le prince lui rend le salut à genoux. Le maître d'hôtel fléchit les genoux, offre le vin aux esprits ; puis il le boit tout entier et se lève. Il fléchit les genoux, dépose la coupe, et salue deux fois à genoux, inclinant le front jusqu'à terre. Le prince lui rend le salut à genoux. Le maître d'hôtel dépose la coupe dans une corbeille.

O Le maitre d'hôtel se lave les mains et rince une coupe pour (boire lui même et) offrir à boire à l'invité. Il empli t la coupe à une jarre. Au haut des degrés occidentaux, il fléchit les genoux, dépose la coupe et salue à genoux. L'invité, au haut des degrés occidentaux, le visage tourné vers le nord, lui rend le salut à genoux. Le maître d'hôtel fléchit les genoux, off re le yin aux esprits, puis le boit. L'invité refuse l'honneur de ${ }_{225}$ recevoir encore une fois la coupe. Le maître d'hôtel, après avoir vidé la coupe, se lève, fléchit les genoux, dépose la coupe et salue à genoux. Il prend la coupe et se lève. Linvité l ui rend le salut à genoux.

Le maitre d'hôtel descend pour rincer une coupe. L'invité descend aussi. Le maître d'hôtel refuse cet honneur. Linvité prie le maitre d'hôtel de ne pas rincer lui-même la coupe. Après qu'une coupe a été rincée par un aide, linnv ité salue par une inclination profonde et monte. Il ne salue pas pour remercier le maitre d'hôtel d'avoir fait rincer la coupe. Le maître d'hôtel emplit la coupe à l'amphore du prince. L'invité, au haut des degrés occidentaux, salue à genoux. Il reçoit la coupe devant sa natte et retourne à sa place. Le maître d'hôtel le salue à genoux après lui avoir donné la coupe. L’invité monte sur sa natte, fléchit les genoux, offre le vin aux esprits ; puis il dépose la coupe à l'est des conserves de viande. Le maitre d'hôtel descend et retourne à sa place. L'invité descend aussi. Il se tient debout à l'ouest de sa natte, le visage tourné au sud-est.

O Un petit officier, au bas des degrés orientaux, prie le prince de désigner les officiers qui offriront la coupe pour la deuxième fois. Le prince désigne celui qui sera le premier. Le petit $\bullet_{226}$ officier avertit deux grands préfets de second ordre de remplir cet office. Les deux grands préfets, au bas des degrés orientaux, le visage tourné vers le nord, saluent deux fois à genoux, inclinant le front jusqu'à terre. Le prince leur rend le salut à genoux. Les deux grands préfets se tiennent debout au sud des cruches, le visage tourné à l'ouest, le plus respectable au nord. Ils s'avancent l'un après l'autre, se lavent les mains , rincent des coupes de corne, montent par les degrés occidentaux, s'avan cent l'un à la suite de l'autre, et emplissent leurs coupes à une jarre. Ils se croisent en passant au nord de la colonne, descendent et vont au bas des degrés orientaux. Ils déposent tous deux leurs coupes, et saluent deux fois à genoux, inclinant le front jusqu'à terre. Ils prennent les coupes et se lèvent. Le prince leur rend le salut à genoux. 
Les deux grands préfets qui portent les coupes, fléchissent les genoux et offrent le vin aux esprits; puis ils le boivent entièrement, et se lèvent. Ils fléchissent les genoux, déposent les coupes, et saluent deux fois à genoux, inclinant le front jusqu'à terre. Ils prennent les coupes et se lèvent. Le prince leur rend deux fois le salut à genoux. Les deux officiers, tenant $\bullet_{227}$ en mains les coupes, attendent au midi des cruches.

Un petit officier demande au prince lequel de ces deux grands préfets lui offrira la coupe. Si le prince veut que tous les deux la lui offrent, tous deux s'avancent l'un à la suite de l'autre, et déposent leurs coupes dans les corbeilles. Tous deux, au bas des degrés orientaux, le visage tourné vers le nord, saluent deux fois à genoux, inclinant le front jusqu’à terre. Le prince leur rend le salut à genoux. Ces deux hommes rincent une coupe d'ivoire, montent et la remplissent. Ils s'avancent l'un à la suite de l'autre, fléchissent les genoux, et déposent la coupe au sud des conserves de viande du prince, le plus honorable se tenant au nord de l'autre. Ils descendent, vont au bas des degrés orientaux, et tous deux à genoux, inclinant le front jusqu'à terre, saluent deux fois le prince qui a reçu la coupe. Le prince leur rend le salut à genoux. Les grands préfets s'éloi gnent tous deux et retournent à leurs places.

Le prince fléchit les genoux, prend la coupe qui lui a été offerte par les deux grands préfets, et se levant, s'en sert pour offrir à boire une deuxième fois au principal invité. Celui-ci descend. Au bas des degrés occidentaux, il se prépare à saluer deux fois à genoux, inclinant le front jusqu'à terre. Un • 228 chef de petits officiers lui dit de la part du prince de ne pas saluer au bas des degrés. L'invité monte et fait ses salutations.

Le prince fléchit les genoux, dépose la coupe et rend le salut à genoux. Il prend la coupe et se lève. Il vide la coupe. L'invité veut le saluer au bas des degrés. Un chef de petits officiers s'y oppose. Linvité monte, et salue deux fois à genoux, inclinant le front jusqu'à terre. Le prince fléchit les genoux, dépose la coupe, rend le salut à genoux, prend la coupe et se lève. Linvité s'avance, reçoit la coupe vide, descend et dépose la coupe dans une corbeille.

Il prend une autre coupe, se lève et la rince. Si le prince l'ordonne, l'invité ne change pas la coupe, et ne la rince pas. Il monte de nouveau, emplit la coupe à l'amphore du prince, descend et se prépare à saluer à genoux. Un chef de petits officiers lui dit de ne pas saluer au bas des degrés. Linvité monte, et salue deux fois à genoux, inclinant le front jusqu'à terre. Le prince lui rend le salut à genoux.

O Linvité avertit celui qui porte les ordres du prince de demander au prince l'autorisation d'offrir à boire à tous les $\bullet_{229}$ officiers. Celui qui porte les ordres du prince avertit le prince. Le prince permet.

En conséquence, le principal invité offre à boire à tous les grands préfets au haut des degrés occidentaux. L'officier qui communique les ordres du prince dit au plus vénérable des grands préfets de monter et de recevoir la coupe. Le principal invité, à la droite de ce grand préfet, fléchit les genoux, 
dépose la coupe, salue à genoux, prend la coupe et se lève. Le grand préfet lui rend le salut à genoux. L'invité fléch it les genoux, offre le vin aux esprits, et debout, vide la coupe. Il ne salue pas en signe de remerciement. Si la coupe est celle du prince, l'invité descend, prend une autre coupe, la rince, monte et la remplit à une jarre.

Le grand préfet salue à genoux et reçoit la coupe, L'invité le salue à genoux après lui avoir donné la coupe; ensuite il va à sa natte. Tous les grands préfets reçoivent la coupe de la même manière que le premier. Ils n'offrent pas le vin aux esprits. Celui qui reçoit la coupe le dernier descend avec cette coupe vide, la dépose dans une corbeille et retourne à sa place.

$\mathbf{O} \cdot{ }_{230}$ Le maître d'hôtel rince une coupe, monte, la remplit à une jarre, et offre à boire aux ministres d’État, au haut des degrés occidentaux. L'intendant du palais enroule des nattes deux à deux, et va les placer à la gauche du principal invité pour les ministres. Il les range de l'est à l'ouest, les plus honorables à l'est. Les ministres montent, saluent à genoux et reçoivent la coupe. Le maître d'hôtel salue à genoux chacun d'eux après lui avoir donné la coupe. Les ministres refusent l'honneur d'avoir deu x nattes l'une sur l'autre. Lintendant du palais fait enlever les secondes nattes.

On sert aux ministres des conserves de viande. Les ministres montent sur leurs nattes. Des officiers placent devant chacun d'eux une petite table sur laquelle sont les membres séparés d'un chien. Chaque ministre fléchit les genoux. De la main gauche il prend la coupe ; de la main droite il offre aux esprits les conserves de viande. Il dépose la coupe à droite des conserves de viande et se lève. Il prend les poumons; à genoux, il en retranche la plus petite extrémité et les offre aux esprits. Il ne goûte pas les poumons. Il se lève et les met sur la petite table. Il fléchit les genoux, s'essuie les mains, prend la coupe et offre le vin aux esprits. Tenant la coupe, il se lève et quitte $\bullet_{231}$ sa natte. Au haut des degrés occidentaux, le visage tourné vers le nord, il fléchit les genoux, vide la coupe et se lève. Il fléchit les genoux, dépose la coupe et salue à genoux. Il prend la coupe et se lève. Le maître d'hôtel lui rend le salut à genoux et reçoit la coupe. Le ministre descend et retourne à sa place.

La coupe est offerte à tous les ministres. Le maître d'hôtel descend avec la coupe vide, et à genoux, la dépose dans une corbeille. Celui qui porte les ordres du prince dit aux ministres de monter. Les ministres montent tous et vont à leurs nattes. S’il y a des ministres d'un grand État étranger, on leur offre à boire avant de l'offrir aux ministres du pays. On le leur offre avec le même cérémonial qu'aux ministres du pays. Leur s nattes sont à l'ouest des degrés orientaux, tournées vers le nord. Elles sont rangées de l'est à l'ouest, le côté oriental est le plus honorable. Il n'y a pas deux nattes l'une sur l'autre.

$\mathbf{O}$ Un petit officier prie de nouveau le prince de désigner des hommes pour porter les coupes. Deux grands préfets sont chargés de cet office, comme précédemment. Le petit officier demande au prince si la coupe sera offerte au prince par tous les deux ou par un seul. Si le prince ordonne que le plus $\bullet_{232}$ 
honorable des deux remplisse seul cet office, tous deux déposent leurs coupes dans des corbeilles. L'un des deux attend au sud des cruches. Le plus respectable, chargé de présenter la coupe au prince, au bas des degrés orientaux, salue deux fois à genoux, inclinant le front jusqu'à terre. Le prince lui rend le salut à genoux. Le grand préfet rince une coupe d'ivoire, monte et la remplit. Il fléchit les genoux et dépose la coupe au sud des conserves de viande du prince. Il descend. Celui qui est debout au sud des cruches et lui saluent tous deux à genoux deux fois, inclinant le front jusqu'à terre, devant le prince qui tient la coupe.

Le prince fait circuler la coupe de nouveau. Il fait offrir à boire au principal invité, au plus respectable, à ceux qu'il veut récompenser. Il fait offrir à boire à tous au haut des degrés occidentaux, comme précédemment. Celui des grands préfets qui reçoit la coupe le dernier descend avec cette coupe et la dépose dans une corbeille.

Le maître d'hôtel rince une coupe et mo nte, pour offrir à boire aux grands préfets au haut des degrés occidentaux. Chacun des grands préfets monte, salue à genoux et reçoit la coupe. Le maître d'hôtel salue à genoux le grand préfet qui a $\bullet_{233}$ reçu et tient la coupe. Le grand préfet fléchit les genoux, dépose la coupe, offre le vin aux esprits, se lève et boit tout le vin. Il ne salue pas après avoir vidé la coupe. Le maître d'hôtel reçoit la coupe. Le grand préfet descend et retourne à sa place.

Un officier sert des conserves de viande au maître d'hôtel, qui est au nord des cruches, le visage tourné vers l'ouest. Avec les conserves de viande il ne lui sert pas de viande de chien sur une petite table. On offre la coupe à tous les grands préfets; puis on leur sert à tous des conserves de viande. Ils sont rangés à la suite du principal invité, de l'est à l'ouest, par ordre de dignité. Si, à cause du nombre, il en est qui aient le visage tourné vers l'est, et soient rangés du nord au sud, les plus honorables sont au nord. Cette cérémonie terminée, celui qui communique les ordres du prince dit aux grands préfets de monter. Les grands préfets montent tous et vont à leurs nattes.

$\mathbf{O}$ On place les nattes des musiciens au haut des degrés occidentaux, un peu à l'est. De petits officiers introduisent les musiciens. Les musiciens sont six chanteurs et quatre joueurs de guitare. (Parmi les six chanteurs on compte le chef et le sous-chef de musique). Le grand chef des serviteurs, sans rien porter, conduit le chef de musique. (Les musiciens sont aveugles). Un chef de serviteurs conduit le sous-chef de musique. $\bullet_{234}$ De petits chefs de serviteurs conduisent les quatre autres cháng køung chanteurs.

Ceux qui conduisent les joueurs de guitare portent sur le bras gauche une guitare, dont la tête est en arrière. De la main gauche ils touchent les cordes à travers l'ouverture percée dans la table d'harmonie. De la main droite ils conduisent les joueurs de guitare. Ensuite ceux qui conduisent les six autres musiciens, les introduisent, sans rien porter. Le second directeur de la musique les suit. Les conducteurs avec les dix musiciens montent par les degrés occidentaux, tournent le visage vers le nord, et se rangent de l'est à l'ouest, 
par ordre de dignité, les plus dignes à l'est. Les conducteurs des joueurs de guitare, à genoux, leur donnent les guitares. Ensuite tous les conducteurs descendent. Le second directeur de la musique se tient debout à l'est des degrés occidentaux. Les musiciens exécutent trois fois le chant Les cerfs brament.

Le maître d'hôtel rince une coupe, monte et remplit la coupe pour offrir à boire aux musiciens. Les musiciens ne se lèvent pas. Les joueurs de guitare sont à gauche. Un seul (le chef des musiciens) salue à genoux et reçoit la coupe. Le maître d'hôtel, $\bullet_{235}$ au haut des degrés occidentaux, le salue à genoux après lui avoir donné la coupe. On sert des conserves de viande à ce musicien. Un homme est chargé de l'aider à offrir aux esprits le vin et la viande. Le musicien, après avoir vidé la coupe, ne salue pas. Le maître d'hôtel reçoit la coupe vide. Tous les autres musiciens reçoivent la coupe sans saluer. Ils fléchissent les genoux, offrent le vin aux esprits, puis ils le boivent. On leur sert à leur tour des conserves de viande. Ils ne les offrent pas aux esprits. Le maître d'hôtel reçoit la coupe, descend, dépose la coupe dans une corbeille, et retourne à sa place.

Le chef et le sous-chef des musiciens, ainsi que les chanteurs, descendent et se tiennent debout au nord des tambours. Tous les autres musiciens se mettent à leur suite. Les flûtes exécutent trois fois le chant Le nouveau palais. (Chant qui n'existe plus). Quand les flûtes ont fini d'exécuter ce chant, le chef de musique, le sous-chef et les chanteurs, à l'est de la créden ce qui est à l'est, le visage tourné vers l'ouest, s'assiéent rangés du nord au sud, par ordre de dignité, les plus dignes au nord.

O L'officier qui communique les ordres du prince, au bas $\bullet_{236}$ des degrés orientaux, demande au prince la permission de nommer un directeur des cérémonies. Le prince le permet. Cet officier nomme alors un directeur des cérémonies. Celui-ci va auprès des cruches, et rince une coupe de corne. Le visage tourné vers le sud, il fléchit les genoux et dépose la coupe au milieu de la cour. Il monte, va à l'est de la colonne orientale, et reçoit les ordres du prince. Au haut des degrés occidentaux, le visage tourné vers le nord, il communique les ordres du prince au principal invité, aux ministres des grands États étrangers, aux ministres du pays et aux grands préfets. Il leur dit :

— Le prince me dit de vous donner du repos.

Ces dignitaires répondent tous :

— Oui ; oserions-nous ne pas (obéir et ne pas) nous reposer?

Le directeur des cérémonies descend par les degrés occidentaux. Le visage tourné vers les sud, il fléchit les genoux, prend une coupe, monte et remplit la coupe à une jarre. Il descend. Le visage tourné vers le midi, il fléchit les genoux et dépose la coupe. Il se lève, tourne à droite, et le visage vers le nord, demeure quelque temps debout. Il fléchit les genoux, prend la coupe et se lève. Il fléchit les genoux, et, sans offrir le vin aux esprits, il le boit entièrement. Il dépose la coupe et se lève. Il salue deux $\bullet_{237}$ fois le prince à 
genoux, inclinant le front jusqu'à terre. Il tourne à gauche. Le visage vers le midi, à genoux, il prend la coupe et la rince. Le visage tourné vers le midi, il reporte la coupe dans l'endroit qui lui est propre. Le visag e tourné vers le nord, il se tient debout.

Le chef des archers va dans la tente, se découvre le bras gauche, met un doigtier au pouce de sa main droite et une manche de cuir sur son bras gauche. Il prend un arc et quatre flèches. Il tient ces quatre flèches des deux mains sur son arc, la pointe sur le bras de l'arc. (Sa main gauche tient le bras de l'arc) ; le pouce de sa main droite est prêt à tirer la corde. Devant les degrés orientaux il dit :

— Le commandant invite à tirer de l'arc.

Ensuite il donne cet avis :

- Les grands préfets seront associés avec les grands préfets. (S’ils sont en nombre impair), un simple officier sera associé avec un grand préfet.

Ensuite il va devant les degrés occidentaux. Le visage tourné vers le nord et regardant à droite, il ordonne aux officiers d'apporter les objets nécessaires pour le tir. Tous ces objets sont apportés. L'arc et les flèches du prince sont placés sur la partie orientale de la plateforme. L'arc et les flèches du principal invité restent au bas de la partie occidentale de la plateforme, ainsi que les récipients des fiches, les fiches, et les cuvettes qu'on place sous les amphores du prince. En temps ordinaire, les archers ne $\bullet_{238}$ tiennent pas dans leur mains leurs arcs et leurs flèches. Ces arcs, ces flèches et les récipients des flèches sont tous sous la tente et attendent.

Le chef des artisans et l'ouvrier qui travaille le bois montent par les degrés septentrionaux. Dans l'intervalle des deux colon nes, ils prennent deux espaces parallèles séparés l'un de l' autre par une distance égale à la longueur d'un arc. Ils les enduisent de couleur rouge ou de couleur noire. Ils les mesurent, et òu les limitent par des lignes, les unes longitudinales, les autres transversales. Le grand chef des archers inspecte leur travail. (Ces deux espaces, appelés $u$, sont ceux dans lesquels les deux archers se tiennent en tirant à la cible). Après avoir délimité ces deux espaces, le chef des artisans et l'ouvrier qui travaille le bois descendent par les degrés septentrionaux. L'in tendant du palais balaie les deux espaces qui ont été délimités, et descend par les degrés septentrionaux.

- Le grand annaliste, à l'ouest de l'endroit où l'on place les récipients des fiches, le visage tourné, vers l'est, attend les ordres des chefs. Le chef des archers, le visage tourné vers l'ouest, proclame cette règle :

- - Le prince, au tir de l'arc, se sert de la grande cible ; les grands préfets, de la cible dont le centre représente différents animaux; les simples officiers, de la cible dont le centre représente un chien de garde. Si un archer se sert d'une cible qui n'est pas la sienne, même quand sa flèche frappe $•{ }_{239}$ le centre, son succès ne compte pas. Celui qui tire de l'arc avec un compagnon d'une dignité supérieure à la sienne tire à la même cible que lui. 
(le principal invité tire à la cible du prince ; un simple officier, à la cible d'un grand préfet, s'il est son com pagnon). Le grand annaliste donne son assentiment.

Ensuite le directeur du tir associe six archers deux à deux. Ces six archers attendent au nord de la tente, le visage tourné vers l'ouest, rangés du nord au sud, par ordre de dignité, les plus dignes au nord. Le directeur du tir dit au premier archer de chaque paire :

- Un tel sera votre compagnon de tir, Monseigneur.

Il dit au second archer :

— Monseigneur, vous tirerez de l'arc avec le seigneur un tel.

Ensuite il dit aux six archers de prendre des arcs et des flèches dans la tente.

Le directeur du tir entre dans la tente, enfonce trois flèches sous sa ceinture et en tient une quatrième des deux mains avec son arc. Il sort de la tente, et, le visage tourné vers l'ouest, salue par une inclination profonde. Vis-à-vis des degrés, le visage tourné vers le nord, il fait une inclination profonde. Arrivé près des degrés, il fait une inclination profonde. Il monte à la plateforme et fait une inclination profonde. En face des deux espaces où les deux archers se tiennent pour lancer leurs flèches, le visage tourné vers le nord, il fait une inclination profonde. Arrivé auprès de ces deux espaces, il fait une inclination profonde. Il s'écarte un peu de l'espace assigné au second archer et invite les archers à tirer de l'arc.

- ${ }_{240}$ Le directeur du tir lance des flèches sur les trois cibles. Il prend quatre flèches. Il tire d'abord sur la cible dont le centre représente un chacal ; puis sur celle dort le centre représente différents animaux. Il tire deux fois sur la grande cible. Quand il a fini de tirer, le visage tourné vers le nord, il fait une inclination profonde. Arrivé aux degrés, il fait une inclination profonde et descend. Il observe les mêmes règles qu'en montant pour tirer de l'arc. Ensuite il va à l'ouest de la plate forme, et prend une nouvelle flèche, qu'il tient des deux mains avec son arc. Puis il prend sa baguette, l'enfonce sous sa ceinture, et, le visage tourné vers l'est, se tient debout au sud-ouest de l'endroit où l'on place les récipients des fiches.

Le commandant en chef ordonne à ceux qui doivent être derrière les cibles (et signaleront les victoires) de prendre leurs guidons et de se placer derrière les cibles. Ces officiers vont auprès des cibles, prennent leurs guidons, se tiennent derrière les cibles et attendent.

Le directeur du tir va à la tente et dit à la première paire d'archers de tirer de l'arc. Ces deux archers sortent de la tente ; le visage tourné vers l'ouest, ils saluent par une inclination profonde, et s'avancent, le premier à gauche du second. Ils marchent $\bullet_{241}$ côte à côte. En face des degrés, le visage tourné vers le nord, ils font une inclination profonde. Arrivés auprès des degrés, ils saluent par une inclination profonde. Le premier des deux archers monte le 
premier les trois degrés. Le second le suit à un degré d’intervalle. Le premier s'avance sur la plateforme, un peu à gauche. Le second s'avance aussi. Le premier salue par une inclination profonde. Tous deux marchent côte à côte.

En face des deux espaces où ils doivent se tenir pour tirer de l'arc, le visage tourné vers le nord, ils saluent tous deux par une inclination profonde. Arrivés près de ces espaces, ils font une inclination profonde. Tous deux posent le pied gauche sur ces espaces. Ils se tournent et regardent le centre de la cible. Chacun d'eux met les deux pieds à côté l'un de l'autre et attend.

Le commandant en chef va à la tente, se découvre le bras gauche, se met un doigtier au pouce de la main droite et une manche de cuir sur le bras gauche. Il prend un arc, dont il tient la corde de la main droite. Il sort de la tente, monte par les degrés occidentaux, va auprès de l'espace assigné au second, archer, et se tient debout entre les deux espaces. Prenant de la main gauche le bras de son arc et de la main droite l'extrémité, $\bullet_{242}$ il agite son arc vers le midi ; il ordonne à ceux qui sont derrière les cibles de s'éloigner des cibles. Ces officiers répondent :

$-N \bullet$, nous obéissons.

Ils crient $n \bullet$ sur la note $k \bullet u n g$, en marchant très vite droit vers l'ouest. Arrivés au sud de la cloison, ils crient $n \bullet$ sur la note $c h \bullet n g$. Arrivés à la cloison, ils cessent de crier.

Celui qui présente le guidon à l'officier chargé de signaler les victoires se retire et se tient debout à l'ouest. L'officier qui signale les victoires se lève, joint les mains devant la poitrine et attend.

Le commandant en chef sort de la tente, passe au sud du second archer, tourne derrière lui, descend par les degrés occidentaux. Ensuite il va à la tente, dépose son arc, ôte son doigtier et sa manche de cuir, couvre son bras gauche et retourne à sa place.

Le directeur du tir s'avance et se croise avec le commandant en chef devant les degrés; il passe à sa gauche et réciproquement. Au bas de la plateforme, à l'est des degrés occidentaux, le visage tourné vers le nord, il donne cet avis au premier archer :

- Évitez de frapper de vos flèches, soit en ligne directe soit de côté, celui qui signale les victoires,) Le premier archer salue par une inclination profonde. Le directeur du tir se retire et retourne à sa place.

- ${ }_{243}$ Ensuite a lieu le tir. Quand le premier archer a lancé une flèche, il en prend une autre et la tient des deux mains avec son arc. Puis le second archer lance une flèche. Tous deux lancent ainsi chacun quatre flèches alternativement. L'officier chargé de signaler les victoires les proclame à genoux. Il lève son guidon en chantant hou• sur la note $k \bullet$ ung. Il le couche en chantant hou ${ }^{\bullet}$ sur la note chøng. On signale les victoires; mais on ne pose pas encore de fiches. Les archers, après avoir lancé leurs flèches, tenant de la main 
droite la corde de l'arc, le visage tourné vers le nord, saluent par une inclination profonde. Ils saluent comme ils l'ont fait en montant pour tirer de l'arc.

Le premier archer descend trois marches. (Dans le palais des princes, les marches étaient au nombre de sept.). Le second archer, un peu à droite le suit. Quand ils arrivent à la marche du milieu (à la quatrième marche), tous deux vont côte à côte, le premier archer à gauche. Ils passent à gauche des deux autres archers qui montent pour tirer de l'arc ; ils se croisent avec eux devant les degrés. Ils les saluent par une inclination profonde et réciproquement. Ils vont à la tente, déposent leurs arcs, ôtent leurs doigtiers et leurs manches de cuir, se couvrent le bras gauche et retournent à leurs places. Les trois premières paires d'ar chers s'acquittent du tir de cette manière,

- ${ }_{244}$ Le directeur du tir enlève sa baguette, et l'appuie à l'ouest des degrés. Il va au bas des degrés orientaux, et le visage tourné vers le nord, il avertit le prince en ces termes :

— Les archers des trois premières paires ont fini de tirer de l'arc.

Il s'en va, enfonce de nouveau sa baguette sous sa ceinture et retourne à sa place.

Le commandant en chef se découvre le bras gauche, se met un doigtier au pouce de la main droite et une manche de cuir sur le bras gauche. Il prend un arc, dont il tient la corde de la main droite. Il sort de la tente, se croise avec le directeur du tir devant les degrés, l'un passant à gauche de l'autre. Il monte par les degrés occidentaux, passe derrière l'espace délimité pour l'archer de droite, et se tient debout entre les deux espaces destinés aux deux archers. Le visage tourné vers le sud-ouest, il fait signe avec son arc et crie de prendre des flèches. Ceux qui se tiennent derrière les cibles lui répondent qu'on va lui obéir, comme précédemment. Ils quittent les cibles, vont prendre leurs guidons, reviennent se placer derrière leurs cibles et attendent.

Le commandant en chef descend par les degrés occidentaux, et, le visage tourné vers le nord, ordonne de placer les récipients $\bullet_{245}$ des flèches. Un chef de petits officiers place ces récipients. Le commandant en chef, le visage tourné vers l'est, fait signe avec son arc et ordonne de tout préparer. Quand les récipients des flèches ont été placés, le commandant en chef va à la tente, dépose son arc, ôte son doigtier et sa manche de cuir et couvre son bras gauche. Il retourne à sa place.

Un petit officier, à genoux, met des flèches dans les récipients, la coche tournée vers le nord. Le commandant en second, à genoux, les compte quatre par quatre. Si elles ne sont pas en nombre suffisant, le commandant en chef de nouveau se découvre le bras gauche, prend son arc, monte et ordonne de prendre des flèches, comme précédemment. Il dit :

- On n’a pas pris assez de flèches. 
On va de nouveau chercher des flèches et on les met dans les récipients. Cela fait, le commandant en chef s'avance, fléchit les genoux, et avec les deux mains, met quatre flèches à gauche pour le premier archer de chaque paire, et quatre flèches à droite pour le second archer. Il se lève et retourne à sa place.

Le directeur du tir va à l'ouest des degrés occidentaux et $\bullet_{246}$ dépose sa baguette contre les degrés. Il monte par les degrés occidentaux. Le visage tourné vers l'est, il demande au prince la permission de commencer le tir. Le prince permet. Le directeur du tir va au haut des degrés occidentaux, et dit au principal invité d'être le compagnon de tir du prince. Il avertit de même et divise par paires les ministres des grands États étrangers et les ministres du pays, au haut des degrés. Quant aux grands préfets, il descend, retourne à sa place, et les avertit ensuite (au bas des degrés).

Le directeur du tir, du haut des degrés occidentaux, le visage tourné vers le nord, dit aux grands préfets :

— Je vous invite à descendre.

Il descend le premier, enfonce sa baguette sous sa ceinture et retourne à sa place. Les grands préfets descendent à sa suite, vont à la tente, et se tiennent debout au sud des trois premières paires d'archers, le visage tourné vers l'ouest, rangés du nord au sud par ordre de dignité.

Le directeur du tir, le visage tourné vers l'est, au nord-est des grands préfets, les associe ensemble par paires. Il dit au premier archer de chaque paire :

— Un tel sera votre compagnon de tir, Seigneur.

Il dit au second archer :

- Seigneur, vous $\bullet_{247}$ tirerez de l'arc avec le seigneur un tel.

Cela fini, il associe deux à deux les autres archers de moindre rang. Ces archers, associés deux à deux, se tiennent debout au sud des grands préfets, le visage tourné vers l'ouest, rangés du nord au sud, par ordre de dignité, les plus dignes au nord. Sil y a un simple officier associé avec un grand préfet, il est le premier archer de la paire.

Le directeur du tir commande à ce compagnon d'un grand préfet en ces termes :

- Seigneur, vous tirerez de l'arc avec le seigneur un tel.

Il avertit le grand préfet en ces termes :

- Un tel sera votre compagnon de tir, Seigneur.

Il commande aux autres archers de rang inférieur dans les mêmes termes qu'il a commandé aux archers des trois premières paires. Les ministres des grands États étrangers et les ministres du pays ne sont pas encore descendus.

Ensuite le directeur du tir ordonne aux six archers des trois premières paires de prendre chacun des flèches une à une alternativement avec son 
compagnon. Ces six archers se découvrent tous le bras gauche, se mettent un doigtier au pouce de la main droite et une manche de cuir sur le bras gauche. Ils prennent chacun un arc, dont ils tiennent la corde de la main droite. Deux archers de la même paire sortent de la tente, et, le visage tourné vers l'ouest, saluent par une inclination profonde. ${ }_{248}$ En face des récipients des flèches, le visage tourné vers le nord, ils saluent par une inclination profonde. Arrivés aux récipients, ils font encore une inclination profonde.

Le premier des deux archers tourne le visage vers l'est, le second vers l'ouest. Le premier des deux archers salue par une inclination profonde et s'avance. Il fléchit les genoux, tient son arc transversalement de la main gauche (le bois en haut, la corde en bas), passe la main droite entre le bois et la corde, et prend une flèche. De la main gauche il tient l'extrémité de cette flèche, ainsi que le bras de son arc, et se lève. Il passe la main droite le long des plumes de la flèche dans le sens des barbes. Puis il tourne à gauche, mais ne fait pas un tour complet. Il tourne le visage et salue par une inclination profonde.

Le second archer s'avance, fléchit les genoux, tient son arc transversalement (de la main gauche, la corde en haut, le bois en bas), passe la main droite au dessus du bois de l'arc (entre le bois et la corde) et prend une flèche. Il la tient de la main gauche, ainsi que le bras de son arc, et se lève. Il passe la main droite le long des plumes de la flèche dans le sens des barbes. Ensuite il tourne à gauche sans faire un tour complet. Le visage changé de direction, il salue par une inclination profonde. Quand les deux archers ont pris leurs flèches une à une $\bullet_{249}$ alternativement, chacun d'eux place ses flèches bien ensemble à côté les unes des autres. Il tient quatre flèches des deux mains, ainsi que son arc. Les deux archers se tournent l'un vers l'autre. Puis, le visage regardant le midi, ils saluent par une inclination profonde.

Ils vont au sud des récipients des flèches. Tous deux tournent à gauche, et, le visage regardant le nord, saluent par une inclination profonde. Ils enfoncent trois flèches sous leurs ceintures, et en tiennent une quatrième des deux mains, ainsi que leurs arcs. Ils font une inclination profonde et tournent à gauche l'un de l'au tre ; le premier se tient à la gauche du second. Les deux archers qui se retirent après avoir tiré de l'arc se croisent avec les deux qui s'avancent pour tirer ; ils passent à gauche les uns des autres. Ils se saluent par une inclination. profonde. Les deux archers de la première paire tournent et se retirent. Ils déposent leurs arcs et leurs flèches dans la tente, ôtent leurs doigtiers et leurs manches de cuir, se couvrent le bras gauche et retournent à leurs places. Les deux archers de la deuxième paire prennent des flèches une à une alternativement, comme les précédents.

Le second archer de la troisième et dernière paire, outre les quatre flèches qu'il prend pour lui-même, prend des flèches qui $\bullet_{250}$ serviront au directeur pour donner le signal du tir. Il les lui donne sous la tente. Les deux archers se couvrent le bras gauche et retournent à leurs places. 
Le directeur du tir ordonne de tirer de l'arc, comme précé demment. Deux archers de la même paire saluent par une inclination profonde, et montent, comme précédemment. Le commandant ordonne de s'éloigner des cibles. Ceux qui se tiennent derrière les cibles répondent oui, comme précédemment. Le commandant descend, dépose son arc et retourne à sa place.

Le directeur du tir tient encore des deux mains une flèche, ainsi que son arc. Il enlève sa baguette, se croise avec le commandant devant les degrés, va au bas des degrés orientaux, et le visage tourné vers le nord, demande au prince la permission de faire poser des fiches, quand les flèches frapperont le but. Le prince permet. Le directeur du tir s'en retourne et enfonce sa baguette sous sa ceinture. Ensuite le directeur du tir ordonne à celui qui posera les fiches de placer le récipient des fiches. Avec son arc il lui marque l'endroit où il faut le placer et (reste debout) le visage tourné vers le nord.

Ce sera le grand annaliste qui posera les fiches. Un chef de petits officiers prend le récipient des fiches; il en tient la tête $\bullet_{251}$ dirigée en avant. Il le dépose à genoux, le visage tourné vers l'est, et se retire. Le grand annaliste met huit fiches dans le récipient. Il dépose les autres fiches transversalement à l'ouest du récipient. Il se lève, joint les mains devant la poitrine et attend.

Le directeur du tir, le visage tourné vers l'ouest, proclame la règle suivante :

- Si une flèche atteint la cible au dessus des cordes qui lient ses extrémités aux poteaux, si elle va butter contre l'angle supérieur de la cible et revient, dans le cas où c'est le prince qui l'a lancée, elle est marquée comme ayant frappé le but; mais non dans le cas où elle a été lancée par un autre. Par exception, dès que la flèche du prince a atteint l'une des trois cibles, elle est toujours marquée comme ayant frappé le but. Le grand annaliste qui posera les fiches communique cette prescription au second annaliste. Le second annaliste la communique à celui qui signalera les victoires.

Ensuite le directeur du tir s'avance. Au bas de la plateforme, le visage tourné vers le nord, il donne, cet avis au premier archer de la paire :

- Toute flèche qui ne perce pas la cible n'ob tient pas de fiche.

Le premier archer salue par une inclination profonde. Le directeur du tir se retire et retourne à sa place. ${ }_{252}$ Celui qui pose les fiches fléchit les genoux, prend les huit fiches qui sont dans le récipient, y met huit autres fiches, se lève tenant dans les mains les huit fiches qu'il a prises dans le récipient, et il attend.

Pour chacune des flèches qui frappent le but, celui qui pose les fiches pose une fiche. Il met à droite les fiches du premier archer de la première paire, et à gauche celles du second archer. S’il y a des fiches restantes (parce que les flèches n'ont pas toutes frappé le but), il les remet à leur place. Il prend de nouveau les huit fiches qui sont dans le récipient, y met huit autres fiches, se 
lève, et tenant dans des mains les huit fiches quil a prises dans le récipient, il attend. Ainsi s'exécute le tir des trois premières paires d'archers.

Le principal invité descend et prend son arc et ses flèches à l'ouest de la plateforme. Les ministres des grands États étrangers et les ministres du pays vont à la tente, et se rangent à la suite des six premiers archers, du sud au nord. Le prince va tirer de l'arc. Le commandant en chef dit à tous les officiers qui se tiennent derrière les cibles de prendre leurs guidons, de se placer derrière leurs cibles et d'attendre. Le commandant en chef retourne à sa place. Des serviteurs balaient le chemin qui $\bullet_{253}$ s'étend depuis chaque cible jusqu'à l'endroit d'où les archers lancent leurs fl èches.

Le directeur du tir enlève sa baguette, et va au bas des degrés orientaux avertir le prince de tirer de l'arc. Le prince y consent. Le directeur du tir va à l'est des degrés occidentaux avertir le principal invité. Ensuite il enfonce sa baguette sous sa ceinture et retourne à sa place. Un sous-directeur du tir prend le doigtier et la manche de cuir du prince sur la crédence orientale. Un autre sous-directeur du tir donne l'arc du prince au directeur en chef, qui l'essuie. Ces officiers attendent avec ces objets sur la plateforme orientale.

Le prince se préparant à tirer de l'arc, le principal invité descend, va à l'ouest de la plateforme, se découvre le bras gauche, met son doigtier au pouce de sa main droite et sa manche de cuir sur le bras gauche, prend son arc enfonce trois flèches sous sa ceinture, et en tient une quatrième des deux mains, ainsi que son arc. Il monte par les degrés occidentaux, arrive le premier et attend le prince au nord de la place d'où le prince doit lancer ses flèches. Il se tient au nord de cette place, à la distance de la longueur d'une flèche, le visage tourné vers l'est, $\bullet_{254}$ debout. Le commandant monte et ordonne de s'éloigner de la cible, comme précédemment. Il tourne à droite et descend. Il dépose son arc et retourne à sa place.

Le prince va à la place où il doit être en tirant de l'arc. Le sous-directeur du tir lui porte son doigtier et sa manche de cuir dans une corbeille. Le directeur en chef, tenant l'arc du prince, le suit avec le sous-directeur jusquà la place d'où le prince doit lancer ses flèches. Le sous-directeur fléchit les genoux et dépose la corbeille au sud de cette place. Ensuite il essuie le doigtier avec un linge, le prend, se lève, aide le prince à mettre le doigtier au pouce de la main droite, et à $k \bullet$ séparer du pouce les trois doigts suivants, en les entourant d'une pièce de cuir rouge. Un chef de petits officiers aide le prince à se découvrir le bras gauche. Le prince conserve sur le bras gauche la manche de sa tunique rouge. (Il met la manche de cuir sur cette manche de tunique). Quand le prince s'est découvert ainsi le bras gauche, le chef de petits officiers se retire, et attend sur la plateforme orientale. Le sous-directeur du tir fléchit de nouveau les genoux, prend la manche de cuir du prince, se lève et aide le prince à la mettre sur le bras gauche. Il se retire ${ }_{255}$ avec la corbeille, la dépose sur la crédence et retourne à sa place.

Le grand directeur du tir avec les manches de sa tunique prend l'arc du prince, et l'essuie en passant ses manches le long des deux courbures de l'arc, 
deux fois en haut, une fois en bas. De la main gauche il prend un bras de l'arc et de la main droite une extrémité, et donne l'arc au prince. Le prince lui -même fait fléchir son arc (pour voir sill a l'élasticité voulue). Le chef des petits officiers essuie des flèches dans un linge et les présente au prince, l'extrémité postérieure dirigée en avant.

Le grand directeur du tir se tient debout derrière le prince et l'avertit de la marche de ses flèches. Quand la flèche du prince tombe trop bas, il lui dit :

— Elle est restée en deçà du but.

Quand elle monte trop haut, il lui dit :

— Elle est montée au dessus du but.

Quand elle passe à droite ou à gauche du but, il lui dit :

— Elle a passé à côté.

Quand le prince a lancé ses flèches, le grand directeur du tir reçoit l'arc du prince. Il attend que le compagnon de tir du prince, le principal invité, ait lancé ses flèches à son tour, et il prend quatre autres flèches pour le prince.

Après que le prince a fini de tirer de l'arc, le chef de petits $\bullet_{256}$ officiers se retire avec son linge et retourne à sa place. Le grand directeur du tir reçoit l'arc du prince. Le sous -directeur du tir reçoit dans sa corbeille le doigtier et la manche de cuir du prince, se retire, dépose la corbeille sur la crédence et retourne à sa place. Le grand directeur du tir se retire, et retourne à la place du maître des cérémonies. Un chef de petits officiers aide le prince à se couvrir le bras gauche.

Le prince tourne. Ensuite le principal invité descend et dépose son arc à l'ouest de la plateforme. Il va reprendre sa place à l'ouest des degrés, le visage tourné vers l'est. Le prince retourne à sa natte.

Le directeur des cérémonies, sur l'ordre du prince, fait monter le principal invité. Le principal invité monte et retourne à sa natte. Ensuite les ministres d'État et les grands préfets continuent le tir commencé par le prince. Les ministres des grands États étrangers et les ministres du pays prennent des arcs et des flèches dans la tente. Ils se découvrent le bras gauche, mettent le doigtier au pouce de la main droite et la manche de cuir sur le bras gauche. Ils prennent leurs arcs, enfoncent trois flèches sous la ceinture, et tiennent une flèche des deux mains, $\bullet_{257}$ ainsi que leurs arcs. Ils sortent de la tente. Le visage, tourné vers l'ouest, ils saluent par une inclination profonde. Ils font les mêmes inclinations profondes que les trois premières paires d'archers. Ils montent et tirent de l'arc. Quand ils ont fini de lancer leurs flèches, ils descendent comme ont fait les six premiers archers. Ils vont à la tente, déposent leurs arcs, ôtent leurs doigtiers et leurs manches de cuir, se couvrent le bras gauche et retournent à leurs places. Tous les autres archers continuent le tir. On pose des fiches pour tous, comme précédemment. 
Le tir terminé, celui qui a posé les fiches, va au bas des degrés orientaux, avec les fiches restantes dans les mains. Le visage tourné vers le nord, il avertit le prince en ces termes :

- Les premiers et les seconds archers de chaque paire ont fini de lancer leurs flèches.

Il retourne à sa place. A genoux il dépose les fiches restantes à l'ouest du récipient. Il se lève, joint les mains devant la poitrine et attend.

Le commandant se découvre le bras gauche, prend son arc, monte et ordonne de prendre des flèches, comme précédemment. Chacun de ceux qui sont chargés de se tenir derrière la cible répond oui, prend son guidon et va se placer derrière sa cible, comme précédemment. Le commandant descend et dépose son arc, $\bullet_{258}$ comme précédemment. Un petit officier met des flèches dans les récipients, comme précédemment. Il lie séparément avec du chiendent toutes les flèches des ministres des grands Etats étrangers, des ministres du pays et des grands préfets, (par respect pour ces dignitaires). Cela fini, le commandant en chef fléchit les genoux, met les deux mains sur les flèches, et allant des unes aux autres, les lie fortement. Il retourne à sa place. Les flèches du principal invité ont données à l'officier chargé des flèches, au bas de la partie occidentale de la plateforme. Le commandant dépose son arc et retourne à sa place. Ensuite les ministres et les grands préfets montent et vont à leurs nattes.

Le directeur du tir va à l'ouest des degrés, dépose son arc, enlève sa baguette et couvre son bras gauche. Il s'avance, passe à l'est du récipient des fiches et reste debout au sud de ce récipient. Le visage tourné vers le nord, il examine les fiches. Celui qui a posé les fiches, le visage tourné vers l'est, à l'ouest du récipient, fléchit les genoux, et compte d'abord les fiches qui sont à sa droite (les fiches obtenues par les seconds archers des différentes paires).

$\mathbf{O}$ Deux fiches font une paire. Celui qui les a posées les $\bullet_{259}$ prend et les met paire par paire dans sa main gauche. Quand il en a dix paires dans sa main gauche, il les dépose en long devant lui. Chaque fois qu'il en dépose dix paires, il les place dans un sens différent des dix paires précédentes. (En long, en travers). Sill reste des paires en sus des dizaines de paires, il les place transversalement auprès des dizaines de paires. Une fiche est une unité. S'il reste une fiche seule en sus des paires, l'officier la place longitudinalement auprès des paires restantes. Il se lève, s'écarte en passant devant les fiches, et va à celles des fiches qui sont à sa gauche (fiches obtenues par les premiers archers des différentes paires). Le visage tourné vers l'est, il fléchit les genoux.

A genoux, il prend à la fois toutes les fiches de gauche et les tient dans sa main gauche. Il les dépose deux à deux. Chaque fois qu’il en a déposé dix paires, il dépose les dix paires suivantes en sens contraire. (En long, en travers). S îl en reste, il les place comme les fiches de droite restantes. Le directeur du tir retourne à sa place. Ensuite celui qui a posé les fiches s'avance 
et prend les fiches du parti vainqueur. Les tenant dans les mains, il va au bas des degrés orientaux, et, le visage tourné vers le nord, il informe le prince.

Si les seconds archers des différentes paires sont victorieux, ${ }_{260}$ il dit :

— Les seconds archers l'ont emporté sur les premiers.

Si les premiers archer; sont victorieux, il dit :

— Les premiers archers ont été plus habiles que le seconds.

Il annonce le nombre de paires de fiches que chacun des deux partis a obtenues. S'il y a de plus une unité, il le dit aussi. Si les deux partis ont obtenu le même nombre de fiches, il prend une fiche de chaque parti, l'une dans une main, l'autre dans l'autre, et d it :

— Les deux partis ont obtenu le même nombre de fiches.

Il tourne et va reprendre sa place. Il fléchit les genoux, prend à fois toutes les fiches, en met huit dans le récipient et dépose les autres à l'ouest du récipient. Il se lève, joint les mains devant la poitrine et attend.

Le directeur du tir ordonne de placer une cuvette. Un officier du maître d'hôtel prend une cuvette, monte par les degrés occidentaux, et, le visage tourné vers le nord, à genoux, place la cuvette à l'ouest de la colonne occidentale. Il descend et retourne à sa place. Un jeune archer du parti vainqueur rince une coupe, monte, remplit la coupe à une jarre, et, le visage tourné vers le sud, à genoux, il dépose sur la cuvette. Il descend et retourne à sa place.

- ${ }_{261}$ Le directeur du tir se découvre le bras gauche, prend son arc, tient une flèche des deux mains. ainsi que son arc, et enfonce sa baguette sous sa ceinture. Le visage tourné vers l'est, à l'ouest des trois premières paires d'archers, il donne ses ordre s à ces six premiers archers et à tous les autres. Tous les vainqueurs, le bras gauche découvert, le doigtier au pouce de la main droite et la manche de cuir sur le bras gauche, tiennent en mains leurs arcs bandés. Ton, les vaincus, le bras gauche couvert, sans doigtier ni manche de cuir, la main gauche en bas et la main droite en haut, tiennent les deux bras de leurs arcs débandés. Le directeur du tir retourne le premier à sa place.

Les six premiers archers, et tous les autres archers montent au haut des degrés occidentaux, et les vaincus boivent une coupe de vin qui est pour eux comme un châtiment). Le sous-directeur du tir les fait monter pour boire le vin du tir, comme il les a fait monter pour tirer de l'arc. Une paire d'archers sort des rangs et salue par une inclination profonde, comme quand elle est montée pour tirer de l'arc. Quand elle arrive aux degrés, le vainqueur monte le premier. Il avance sur la plateforme et $\bullet_{262}$ se tient un peu à droite. Le vaincu s'avance ; le visage tourné vers le nord, à genoux, il prend la coupe qui est sur la cuvette. Il se lève, se retire un peu en arrière, et debout, vide la coupe. Il s'avance, fléchit les genoux et dépose la coupe aup rès de la cuvette. Il se lève et fait une inclination profonde. 
Le vaincu descend le premier. Ces deux archers passent à gauche de ceux qui vont monter, et réciproquement. Ils se croisent avec eux devant les degrés, et se saluent avec eux par une inclination profonde. Ils vont à la tente, déposent leurs arcs, et, le bras gauche couvert, retournent à leurs places. Un chef de serviteurs continue à verser le vin du tir imposé comme châtiment aux vaincus. Chaque fois il prend la coupe, la remplit, et la reporte sur la cuvette. Il se retire en arrière, et attend à l'angle du bâtiment latéral.

Ainsi font les archers qui montent pour boire la coupe des vaincus. Quand les six premiers ont fini, si l'invité principal, l'un des ministres ou l'un des grands préfets est du parti vaincu, il ne descend pas; il ne prend pas son arc ; son compagnon de tir ne monte pas les degrés. Un chef de serviteurs rince une coupe, remplit la coupe et la donne à ce haut dignitaire. Celui-ci reçoit la coupe sur sa natte. Il quitte sa traite, va au haut des $\bullet_{263}$ degrés occidentaux (sans son compagnon de tir), et le visage tourné vers le nord, il boit debout. Après avoir vidé la coupe, il la rend à celui qui la lui a présentée, et retourne à sa natte.

Si l'on offre à boire au prince (parce qu'il est du parti vaincu), son compagnon de tir (le principal invité) descend, rince une coupe de corne, monte, emplit la coupe à une jarre, et descend pour saluer le prince à genoux. Le prince descend une marche. Un chef de petits officiers dit au principal invité de la part du prince de ne pas saluer au bas des degrés. Le principal invité monte, et salue deux fois à genoux, inclinant le front jusqu’à terre. Le prince lui rend deux fois le salut à genoux. Le principal invité, à genoux, offre le vin aux esprits, le boit lui-même entièrement, et salue deux fois à genoux, inclinant le front jusqu'à terre. Le prince lui rend deux fois le salut à genoux.

Le principal invité descend, rince une coupe divoire, monte, remplit la coupe du vin du prince, pour l'o ffrir au prince. Il descend et veut saluer à genoux. Un chef de petits officiers lui dit de ne pas saluer au bas des degrés. L'invité monte, et salue deux fois à genoux, inclinant le front jusqu'à terre. Le prince lui rend $\bullet_{264}$ deux fois le salut à genoux. Le prince vide la coupe. Le principal invité s'avance et reçoit la coupe. Il descend, rince une coupe commune, monte, remplit la coupe à une jarre. Il descend et veut saluer à genoux. Un chef de petits serviteurs lui dit de ne pas le faire. Le principal invité monte, et salue deux fois à genoux, inclinant le front jusqu’à terre. Le prince lui rend deux fois le salut à genoux.

Le principal invité fléchit les genoux, et, sans offrir le vin aux esprits, le boit entièrement. Il descend et dépose la coupe dans une corbeille. Il se tient debout à l'ouest des degrés, le visage tourné vers l'est. Celui qui porte les ordres du prince lui dit de monter. Le principal invité monte et va à sa natte. Si le compagnon de tir d'un ministre d'un grand État étranger, d'un ministre du pays ou d'un grand préfet, n'est pas du parti vainqueur, il tient aussi son arc débandé, monte seul et boit. Ensuite tous les archers du parti vaincu boivent le vin, comme ceux des trois premières paires. Le vin est offert à tous les vaincus sans exception. Ensuite on enlève la cuvette et la coupe. 
$\mathbf{O} \cdot \bullet_{265}$ - Le maître d'hôtel place les amphores dont le vin sera offert aux officiers qui se sont tenus auprès des heòu cibles ou qui ont travaillé à les dresser. Il les place au nord-est de $f^{\bullet} u$ p $\bullet$ l'officier qu i est chargé du soin des animaux sauvages (et qui pendant le tir s'est tenu derrière l'abri fà). Ces amphores sont deux vases $\mathrm{sou}^{\bullet}$ ciselés pleins de vin. Elles regardent l'est ; la plus noble est au sud de l'autre. Sur chacune d'elles on met une cuiller. O n met des cruches au nord-ouest des amphores, et des corbeilles au midi. Les corbeilles sont rangées de l'ouest à l'est ; l'ouest est la place d'honneur. L'une d'elles contient une grande coupe sán. Le commandant en chef rince la coupe. Ensuite il la remplit, et l'offre à l'officier, qui a soin des animaux sauvages. Cet officier, au nord-ouest de la cible, à la distance de trois póu doubles, $(3 \mathrm{~m})$, le visage tourné vers le nord, salue à genoux et reçoit la coupe. Le commandant en chef, le visage tourné vers l'ouest, salue à genoux l'officier qui a reçu la coupe. Il retourne à sa place. Un employé de lintendant de la cuisine sert des conserves de viande au gardien des animaux sauvages. Un jeune archer lui apporte sur une petite table les membres séparés d'un animal.

Des viandes semblables ont été préparées pour ceux qui ont signalé les victoires, ts'ou • séparément de celles préparées $\bullet_{266}$ pour le gardien des animaux sauvages. Chacun de ceux qui ont signalé les victoires va au côté droit de sa cible. Les viandes y sont portées à sa suite. De la main gauche il prend la coupe ; de la main droite il offre les viandes aux esprits. Des deux mains ; il leur offre le vin. Il va au côté gauche de la cible et fait les mêmes offrandes qu'au côté droit. Au milieu, il fait encore la même chose. Après avoir fait ces offrandes, il se place au nord-ouest, du côté gauche de la cible, à trois póu de distance, le visage tourné vers l'est. On lui sert les conserves de viande, et la petite table sur laquelle sont les membres séparés d'un animal. Debout, il vide la coupe.

O Le grand maréchal reçoit la coupe vide, la rince, et offre à boire aux serviteurs, à l'ouvrier qui travaille le bois et à ceux qui ont signalé les victoires, cela avec les cérémonies avec lesquelles le vin a été offert aux officiers employés à la grande cible.

Cela fait, le commandant en chef reçoit la coupe vide et la dépose dans une corbeille. Ceux qui ont signalé les victoires prennent leurs conserves de viande. De jeunes archers prennent les petites tables de ceux qui ont signalé les victoires, et ils les suivent. Ils vont ensemble placer ces mets derrière les abris des cibles, un peu au sud. Le gardien des animaux sauvages retourne $\bullet_{267}$ se placer derrière sa cible et attend.

Le directeur du tir va à l'ouest des degrés et dépose sa baguette. Il va à l'ouest de la plateforme, dépose son arc, ôte son doigtier et sa manche de cuir ; il couvre son bras gauche. Il va auprès des cruches, rince une coupe, monte et remplit la coupe. Il descend, va à la place où est celui qui a posé les fiches, un peu au sud, et lui offre à boire. Il lui fait servir des conserves de viande, et, sur une petite table, les membres séparés d'un animal. Ces mets doivent être offerts aux esprits. 
Celui qui a posé les fiches, à droite des conserves de viande, le visage tourné vers l'est, salue à genoux et reçoit la coupe. Le directeur du tir, le visage tourné vers le nord, le salue après lui avoir donné la coupe. Celui-ci va auprès de ses conserves de viande. Il fléchit les genoux; de la main gauche il prend la coupe, et de la main droite il offre aux esprits les conserves de viande. Il se lève, prend les poumons, et à genoux, les offre aux esprits. Ensuite il leur offre le vin.

Il se lève. A l'ouest du directeur du tir, le visage tourné vers le nord, il boit debout tout le vin de la coupe. Il ne salue pas $\bullet_{268}$ après avoir bu. Le directeur du tir reçoit la coupe vide et la dépose dans une corbeille. Celui qui a posé les fiches se retire un peu à l'ouest de ses conserves de viande et retourne à sa place.

$\mathbf{O}$ Le directeur du tir appuie sa baguette à l'ouest des degrés, va au bas des degrés orientaux, et le visage tourné vers le midi, demande au prince de faire tirer de l'arc, comme précédemment. Il s'en retourne, enfonce sa baguette sous sa ceinture, va à sa tente. Il ordonne aux archers des trois premières paires de se découvrir le bras gauche, de mettre le doigtier au pouce de la main droite et la manche de cuir sur le bras gauche, de prendre leurs arcs, de sortir de la tente en ordre et de prendre des flèches. Le directeur du tir le premier retourne à sa place. Les six archers, deux à deux, prennent des flèches une à une alternativement, comme précédemment. Le sous-directeur du tir veille à qu'ils fassent ainsi, comme précédemment.

Quand les archers des trois premières paires ont pris leurs flèches une à une alternativement, les ministres des grands États étrangers, les ministres du pays, les grands préfets descendent tous et reprennent leurs places précédentes. Ils entrent dans la $\bullet_{269}$ tente avec leurs compagnons de tir. Tous se découvrent le bras gauche, mettent le doigtier au pouce de la main droite et la manche de cuir sur le bras gauche, et prennent leurs arcs. Tous s'avancent. En face des récipients des flèches, ils s'avancent, fléchissent les genoux et enlèvent le lien de chiendent qui tient ensemble leurs flèches. Le premier archer de, chaque paire, le visage tourné vers l'est, le second archer, le visage tourné vers l'ouest, tous deux prennent des flèches une à une alternati vement, comme les archers des trois premières paires.

Si un simple officier est compagnon de tir d'un grand préfet, le simple officier tourne le visage vers l'est et le grand préfet vers l'ouest. Le grand préfet s'avance, fléchit les genoux et enlève le li en qui tient ses flèches unies ensemble. Il se retire et retourne à sa place; Son compagnon de tir salue par une inclination profonde, avance, fléchit les genoux et prend à la fois quatre flèches. Il se lève, passe la main le long des plumes de ses flèches dans le sens des barbes. Il tourne à gauche, sans faire un tour complet. Le visage changé de direction, il fait une inclination profonde.

Le grand préfet s'avance, fléchit les genoux, et prend aussi à la fois quatre flèches, comme son compagnon. Le visage tourné $\bullet_{270}$ vers le nord, il enfonce trois flèches sous sa ceinture, et en tient une des deux mains, ainsi que son arc. 
Il fait une inclination profonde et s'avance. Le grand préfet et son compagnon de tir vont tous deux à la tente, déposent leurs arcs, citent leurs doigtiers et leurs manches de cuir, se couvrent le bras gauche et retournent à leurs places. Les ministres des grands États étrangers et les ministres du pays montent et vont à leurs nattes. Ensuite tous les autres archers, deux à deux, prennent des flèches une à une alternativement, comme les trois premières paires d'archer. Puis ils entrent dans la tente, déposent leurs arcs et leurs flèches, ôtent le poucier et la manche de cuir, se couvrent le bras gauche, et retournent à leurs places.

$\mathbf{O}$ Le directeur du tir, tenant encore une flèche et son arc des deux mains, invite à tirer de l'arc, comme précédemment. Deux archers d'une même paire font une inclination profonde et montent, comme précédemment. Le commandant monte et ordonne de s'éloigner de la cible. Ceux qui se tiennent derrière les cibles répondent oui. Le commandant descend, dépose son arc et retourne à sa place.

Le directeur du tir se croise avec le commandant en passant $\bullet_{271}$ devant les degrés. Il dépose sa baguette au côté occidental des degrés, va au bas des degrés orientaux, et le visage tourné vers le nord, demande au prince la permission de faire entendre la musique. Le prince le permet. Le chef du tir s'en retourne et enfonce sa baguette sous sa ceinture. Le visage tourné vers l'est, il dit au directeur de la musique :

- Le prince ordonne d'exécuter des chants.

Le directeur de la musique répond :

— J'obéis.

Ensuite le directeur du tir va au bas de la plateforme. Le visage tourné vers le nord, il donne au premier archer de chaque paire cet avertissement :

- On ne posera pas de fiche pour une flèche qui n'aura pas été lancée au moment marqué par la musique, (même quand elle aurait frappé le but).

Le premier archer le salue par une inclination profonde. Le directeur du tir se retire et retourne à sa place.

Le directeur de la musique dit au chef de musique :

- Exécutez le chant La tête du chien sauvage. Entre les strophes, que les intervalles soient égaux.

(Ce chant n'existe plus). Le chef de musique, sans se lever, répond oui. Le directeur de la musique retourne à sa place. On exécute le chant La tête $d u$ chien sauvage, pour régler le tir. Quand les trois premières paires d'ar chers ont fini de tirer, le principal invité, à l'endroit marqué $\bullet_{272}$ aux archers pour lancer leurs flèches, attend le prince, comme précédemment. Le prince ne se rend à cet endroit que quand la musique commence à se faire entendre. Un officier lui présente les flèches, la coche en avant. Le prince ne s'astreint pas à 
tirer ses flèches en mesure d'accord avec la musique. Pour le reste, on suit les mêmes règles que précédemment.

Le tir du prince terminé comme précédemment, le principal invité retourne à sa natte. Les ministres des grands États étrangers, les ministres du pays, les grands préfets et tous les autres archers continuent le tir. On pose des fiches comme précédemment. Après avoir tiré, les archers descendent et retournent à leurs places. Celui qui a posé les fiches prend en main les fiches restantes, s'avance, et avertit comme précédemment, que les premiers et les seconds archers de chaque paire ont fini de lancer leurs flèches.

$\mathbf{O}$ Le commandant monte et ordonne de prendre des flèches. Ceux qui se tiennent derrière les cibles répondent oui. Le commandant descend, dépose son arc et retourne à sa place. Un petit officier apporte et dépose des flèches. Le commandant en chef les compte et les divise quatre par quatre, comme précédemment. Le directeur du tir dépose son arc et examine les $\bullet_{273}$ fiches, comme précédemment. Celui qui a posé les fiches annonce, comme précédemment, quel est le parti vainqueur, ou dit que les deux partis ont le même nombre de fiches. Il retourne à sa place,

Le directeur du tir ordonne de placer la cuvette sur laquelle on met la coupe, et de remplir la coupe, comme précédemment. Ensuite il ordonne aux vainqueurs de tenir en mains leurs arcs bandés, et aux vaincus de tenir leurs arcs débandés, et de monter, afin que les vaincus boivent, comme précédemment. Après qu'ils ont bu, on retire en arrière la cuvette et la coupe, comme précédemment.

O De nouveau, le directeur du tir se découvre le bras gauche, met un doigtier au pouce de la main droite et une manche de cuir sur le bras gauche. De la main gauche il tient le bras de son arc; de la main droite il tient la corde, et une flèche, la pointe en avant. Il va à la tente, et ordonne aux archers de prendre des flèches une à une alternativement, comme précédemment. Il retourne à sa place. Les archers des trois premières paires, les ministres des grands États étrangers, les ministres du pays, les grands préfets et tous les autres archers se découvrent le bras gauche, mettent le doigtier au pouce de la main droite et la manche de cuir sur le bras gauche ; deux à deux, ils prennent des flèches une à une alternativement, comme précédemment. ${ }_{274}$ Ils ne tiennent pas une flèche des deux mains, ainsi que leurs arcs ; mais de la main droite ils tiennent la corde de leurs arcs, et une flèche, la pointe en avant, (comme le directeur du tir). Après le tir, ils s'en vont à la tente, donnent tous à un officier les arcs et les flèches, se couvrent le bras gauche et retournent à leurs places.

Les ministres et les grands préfets montent et vont à leurs nattes. Le directeur du tir va à la tente, ôte son doigtier et sa manche de cuir, quitte sa baguette, couvre son bras gauche, et retourne à sa place. Le commandant en chef ordonne de retirer en arrière les récipients des flèches, et de délier une corde à chaque cible. Un chef de petits officiers se retire avec les récipients des flèches. Le charron et le mesureur délient à chaque cible la corde qui 
attache au poteau la partie inférieure du côté gauche. Le commandant en chef ordonne à chaque officier qui signale les victoires de se retirer avec son guidon, ses conserves de viande et sa petite table. Le directeur du tir ordonne à celui qui pose les fiches de se retirer avec les fiches et leur récipient, et d'attendre.

De nouveau, le prince prend et dépose une coupe, pour offrir $\bullet_{275}$ à boire seulement à ceux qu'il veut récompenser, comme sont le principal invité, les hommes les plus honorables. La coupe leur est offerte à tous au haut des degrés occidentaux, comme précédemment. Celui des grands préfets qui reçoit la coupe le dernier, descend avec la coupe vide, la dépose dans une corbeille, et retourne à sa place.

O Le commandant en chef monte par les degrés occidentaux. A l'est de la colonne orientale, le visage tourné vers le nord, il avertit le prince, et lui demande de faire enlever les petites tables. Le prince le permet. Alors le commandant en chef va au haut des degrés occidentaux, et, le visage tourné vers le nord, avertit le principal invité. Le principal invité, le visage tourné vers le nord, prend sa petite table et l'e mporte dehors. Les ministres des grands États étrangers et les ministres du pays prennent leurs petites tables, de la même manière que le principal invité. Ensuite ils les emportent et les donnent à leurs suivants en dehors de la grande porte du gymnase. Les grands préfets descendent et retournent à leurs places. Le chef des jeunes archers enlève la petite table du prince, descend avec elle par les degrés orientaux et la porte à l'est.

$\mathbf{O} \cdot{ }_{276}$ Le principal invité, les ministres des grands États étrangers et les ministres du pays rentrent par la grande porte, et, le visage tourné vers l'est, se rangent du nord au sud, les plus honorables au nord. Le directeur des cérémonies fait monter le principal invité. Le principal invité, les ministres des grands États étrangers, les ministres du pays, les grands préfets citent tous leurs chaussures, montent et vont à leurs nattes. Le prince fait asseoir et reposer à l'aise tous ces dignitaires.

On leur sert toute sorte de friandises. Les grands préfets offrent aux esprits les conservés de viande. Le directeur des cérémonies monte et reçoit les ordres du prince. Il communique ces ordres à tous en ces termes :

- Le prince dit: «Que parmi tous les assistants, il n’y ait personne qui ne boive son soûl. »

Le principal invité, les ministres des grands États étrangers, les ministres du pays, les grands préfets se lèvent tous et répondent :

- Nous obéissons. Oserions-nous (désobéir et) ne pas boire notre soûl ?

Ils retournent tous à leurs places et s'assiéent.

$\mathbf{O}$ Le maître d'hôtel rince une coupe, et la remplit, pour offrir à boire aux simples officiers au haut des degrés occidentaux, Le principal des simples 
officiers monte, salue à genoux $\bullet_{277}$ et reçoit la coupe. Le maître d'hôtel salue à genoux cet officier qui part avec la coupe. L'officier, à genoux, offre le vin aux esprits, et debout, le boit. Il ne salue pas après avoir vidé la coupe. Les autres officiers ne saluent pas; à genoux, ils offrent le vin aux esprits, se lèvent et le boivent debout.

Ensuite on sert des conserves de viande au directeur des cérémonies et au sous-chef des archers, au sud de la coupe. Ces deux officiers ont le visage tourné vers le nord. Le plus honorable est à l'est de l'autre ; c'est le directeur des cérémonies. La coupe est offerte à tous les simples officiers. Après qu'ils ont bu, ils se tiennent debout à l'est, le visage tourné. vers l'ouest, rangés du nord au sud; le nord est le côté le plus honorable. Ensuite on leur sert des conserves de viande.

L'invocateur, l'annaliste, le chef des petits officiers vont aussi à leurs places. On leur sert des conserves de viande, Le maître d'hôtel va à l'amphore des officiers qui vivent à la cour et leur offre à boire. Ces officiers, sans saluer, reçoivent la coupe, offrent le vin aux esprits à genoux et le boivent debout. De maître d'hôtel prend la coupe vide, la dépose dans une corbeille, et retourne à sa place.

O • ${ }_{278}$ Le principal invité descend, et rince une coupe, pour boire luimême, et ensuite offrir à boire au prince une deuxième fois. Il remplit la coupe à une jarre. Il descend pour saluer à genoux. Le prince descend une marche, et envoie un chef de petits officiers dire au principal invité de ne pas saluer au bas des degrés. Celui-ci monte, et salue deux fois à genoux, inclinant le front jusqu’à terre. Le prince lui rend deux saluts à genoux. Le principal invité, à genoux, offre le vin aux esprits, le boit entièrement, et salue deux fois à genoux, inclinant le front jusqu'à terre. Le prince lui rend deux fois le salut à genoux. Le principal invité descend, rince une coupe d'ivoire, monte, remplit la coupe à l'amphore du prince. A genoux, il la dépose au sud des conserves de viande du prince. Il descend pour saluer à genoux. Un chef de petits officiers lui dit que le prince ne le veut pas. Linvité monte et fait ses salutations. Le prince lui rend le salut à genoux. L’invité retourne à sa place.

Le prince à genoux prend la coupe que le principal invité lui a offerte pour la deuxième fois. Il se lève, et offre à boire seulement à ceux qu'il veut récompenser. Ceux qui reçoivent la coupe observent les mêmes règles que celles quils ont observées précédemment en recevant la coupe pour la deuxième fois. $\bullet_{279}$ Le principal invité prend une autre coupe, la rince, monte et remplit la coupe à l'amphore du prince. Il descend, et veut saluer deux fois à genoux, inclinant le front jusqu'à terre. Un chef de petits serviteurs lui dit de ne pas saluer au bas des degrés. Linvité monte et fait ses salutations. Le prince lui rend le salut à genoux. Ensuite le prince va à sa natte, s'assied et fait circuler la coupe. Ceux-là seuls saluent à genoux qui la reçoivent du prince.

Le directeur des cérémonies ordonne d'offrir la coupe à tous les officiers qui l'ont portée aux autres. Celui d'entre eux qui la reçoit le dernier, se lève en la tenant dans les mains, et demande qu'elle soit offerte aux simples officiers 
pour la deuxième fois. Celui des grands préfets qui reçoit la coupe le dernier, se lève en la tenant dans les mains, et va au haut des degrés occidentaux offrir à boire pour la deuxième fois aux simples officiers. Un officier monte. Le grand préfet dépose la coupe et salue à genoux. L'officier rend le salut à genoux. Le grand préfet debout boit tout le vin de la coupe, et ne salue pas. Il remplit la coupe. Le simple officier salue à genoux. et reçoit la coupe. Le grand préfet salue à genoux l'officier qui a reçu la coupe. Tou s les simples officiers sans exception reçoivent la coupe. Ils se versent à boire les uns aux autres.

$\mathbf{O} \cdot{ }_{280} \mathrm{Si}$ le prince ordonne de tirer de l'arc encore une fois, on n'offre pas à boire aux jeunes gens (pour le moment, mais après le tir). Le directeur des cérémonies proclame un nouveau tir, seulement pour ceux qui veulent tirer. Les ministres d'État et les grands préfets descendent tous, et saluent deux fois le prince à genoux, inclinant le front jusqu'à terre. Le prince leur rend le salut à genoux. Toute flèche qui frappe l'une des trois cibles obtient • également une fiche.

Le maître d'hôtel rince une coupe, monte par les degrés occi dentaux, et offre à boire aux jeunes gens au haut des degrés orientaux, avec les mêmes cérémonies qu’il l'a offert aux simples officiers. Il leur offre à boire à tous sans exception. Il descend, rince la coupe. Ensuite il offre à boire aux différents tchéng chefs d'officiers qui sont à droite et à gauche dans la cour, et aux petits officiers de l'intérieur. Il leur offre à boire à tous au haut des degrés orientaux, avec les mêmes cérémonies qu'il l'a offert aux jeunes gens.

Le nombre de coupes qu'on boit n'est pas limité. Il y a un simple officier qui porte la coupe du prince; il y en a un qui présente une coupe ordinaire. Celui qui porte la coupe du prince la remplit et va la présenter au prince. Le prince la reçoit sans ${ }_{281}$ saluer. Celui qui porte la coupe ordinaire la remplit et va trouver le prince. Le prince lui désigne ceux quill veut récompenser. Ceux qu'il récompense se lèvent, reçoivent la coupe, descendent auprès de leurs nattes, déposent la coupe, et saluent deux fois à genoux, inclinant le front jusqu'à terre. Le prince leur rend deux saluts à genoux.

Ceux qui reçoivent la coupe à titre de récompense vont à leurs nattes avec la coupe et fléchissent les genoux. Le prince ne boit que quand ils ont tous bu. L'officier qui porte la coupe du prince la reçoit, la remplit et retourne la déposer devant le prince.

Le premier qui a reçu la coupe ordinaire en récompense la donne à l'officier chargé de la porter. Cet officie r la remplit et la fait circuler. Ceux-là seuls saluent à genoux qui la reçoivent du prince. Le grand préfet qui a reçu la coupe le dernier se lève, et va offrir à boire aux simples officiers pour la seconde fois au haut des degrés occidentaux. Un simple officier monte. Le grand préfet, sans saluer, boit lui-même le premier. Il remplit la coupe. Le simple officier, sans saluer, reçoit la coupe. 
- ${ }_{282}$ Le grand préfet va à sa natte. Les simples officiers se versent tous à boire les uns aux autres de cette manière.

Le prince ordonne d'enlever les couvertures qui sont sur ses amphores. Alors le principal invité, les ministres des grands États étrangers, les ministres du pays, les grands préfets descendent tous. Au bas des degrés occidentaux, le visage tourné vers le nord, rangés de l'est à l'ouest par ordre de dignité, les plus honorables à l'est, ils saluent deux fois à genoux le prince, inclinant le front jusqu'à terre. Le prince leur fait dire par un chef de petits officiers de s'abstenir de le saluer au bas des degrés. Le prince à son tour les salue à genoux. Tous les grands préfets se retirent de côté (comme pour éviter l'honneur que le prince leur fait). Ils montent et retournent à leurs places. Les simples officiers s'offrent tous à boire les uns aux autres, comme précédemment. Le nombre des chants qu'on exécute n'est pas limité.

$\boldsymbol{O}$ Le soir, un des jeunes gens tient un flambeau au haut des degrés orientaux. Le maître d'hôtel en tient un au haut des degrés occidentaux. Le chef des laboureurs tient un grand flambeau dans la cour. Le portier place un flambeau en dehors de la grande porte.

- 283 Le principal invité a bu son soûl. Le visage tourné vers le nord, à genoux, il prend les tranches de viande qu'on lui a servies et descend. On exécute le chant Kai. Le principal invité fait don de ses tranches de viande à ceux qui battent. les cloches dans la cour sous les gouttières près de la grande porte. Ensuite il sort. Les ministres et les grands préfets sortent tous. Le prince ne les salue pas à leur départ. Il rentre dans ses appartements. On exécute le chant Ngâo. 


\title{
CHAPITRE VIII
}

\author{
Ambassades
}

$\mathbf{O} \cdot{ }_{284}$ Le prince délibère avec ses ministres sur l'affaire qui don ne lieu à l'ambassade ou au message. Ensuite il nomme un envoyé ou chef d'ambassade (quil choisit parmi les ministres consultés). Celui qui est nommé chef d'ambassade ou de mis sion (s'avan ce), salue deux fois à genoux, inclinant le front jusqu'à terre, et s'excuse (en disant qu'il n'est pas assez intelligent pour remplir cet office). Le prince n'accepte pas son refus. L'ambassadeur se retire à sa place. Le prince, après avoir délibéré sur l'affaire (qui donne lieu à l'ambassade, (nomme et) avertit celui qui sera la principal compagnon de l'envoyé ; cela de la même manière quỉl a nommé et averti le chef de l'am bassade. Le premier ministre charge le ministre de la guerre de nommer et d'avertir tous les autres compagnons de l'ambas sadeur. Ceux-ci acceptent tous leur nomination, sans opposer d'excuse. Le premier ministre inscrit les présents que l'ambas sade devra emporter. Il charge l'intendant des magasins d'ordon ner à ses subordonnés de fournir tous les objets nécessaires.

$\mathbf{O} \cdot{ }_{285}$ Le soir du jour fixé pour le départ, on va voir les pièces de soie et tous les objets qui seront offerts comme présents. $(S \bullet$ Soir, faire visite le soir, examiner le soir). Le chef d'ambas sade, en habits de cour, à la tête de tous ses compagnons, va voir les présents. L'officier chargé de préparer les logements dresse une tente (sous laquelle on placera les présents, en dehors de la grande porte des appartements particuliers du prince (dans la cour extérieure). Les officiers étalent les présents. Ils tournent vers le nord la tête des peaux (de tigres et de léopards). Ils les rangent de l'ouest à l'est, les plus belles à l'ouest. Sur les peaux qui sont à gauche, ils placent les pièces de soie que l'ambassadeur présentera lui-même au prince étranger en paraissant devant lui. Les chevaux qui seront offerts comme présents ont la tête tournée vers le nord. (Ils sont au sud de la tente). Les présents sont déposés devant la tête des chevaux. L'ambassadeur, le visage tourné vers le nord, (est de bout au sud de la tente). Tous ses compagnons sont debout à sa gauche, rangés de l'est à l'ouest par ordre de dignité, les plus dignes à l'est. Les ministres et les grands préfets sont à l'est de la tente, le visage tourné vers l'ouest, rangés du nord au sud par ordre de dignité, les plus dignes au nord.

Le premier ministre entre et annonce au prince que tout est prêt. Le prince, en habits de cour, sort par la grande porte ${ }_{286}$ lóu mên, et se tient au côté gauche de cette porte, le visage tourné vers le sud. L'annaliste lit la liste de tous les présents. Les officiers les étalent (et les examinent pour s'as surer que rien ne manque). Le premier ministre prend cette liste, et avertit le prince que tout est préparé. Il donne la liste à l'ambassadeur. L'ambassadeur la reço it et 
la donne à son principal compagnon. Le prince salue par une inclination profonde, et rentre dans ses appartements particuliers. Les officiers mettent les présents sur des voitures traînées par des hommes, et les conduisent dans la grande cour du palais. Le principal compagnon de l'ambassadeur examine les présents transportés dans la cour du palais. Il prend la liste qu'il a reçue de l'ambassadeur et s'en va.

O Le lendemain matin (le jour du départ), l'ambassadeur, en habits de cour, dépose des pièces de soie dans celui des temples où est la tablette du père du prince. (L'ambassadeur est appelé chéu tchè envoyé, pøn hôte qui reçoit l'hospitalité. Plus loin, il sera appelé tchòu tsèu maître). Le gardien du temple met une natte et un escabeau dans la salle du temple (pour les mânes du père du prince). L’invo cateur entre le premier. Tchòu, jên L'ambassadeur entre à sa suite. A la droite de l'invocateur, il salue deux fois à genoux. Linvocateur annonce aux mânes le départ de l'ambas sade. De nouveau, l'ambassadeur salue deux fois à genoux. ${ }_{287}$ L'invocateur étale les pièces de soie. Elles ont la longueur réglementaire. Elles sont les unes noirâtres, les autres brunes. Il y a en tout cinq pièces (trois de soie noirâtre, deux de soie brune). (Tchéu, Régler; longueur réglementaire d'une pièce de soie. Cette longueur est de tcháng $p^{\bullet}$ tch'u $3 \mathrm{~m}, 60 \mathrm{~cm}$ ). L’invocateur les dépose auprès de l'escabeau et sort de la salle du temple. L'ambassadeur se tient debout à l'est de la porte de la salle du temple, et l'invocateur à l'ouest de la fenêtre. (Ils attendent l'arrivée des mânes). L'invocateur rentre dans la salle du temple, prend les pièces de soie, descend avec elles, les enroule, les met dans des corbeilles, et les enterre à l'est des degrés occidentaux (en l'honneur des mânes). L'invo cateur étale aussi des pièces de soie dans le chemin (en dehors de la grande porte du temple, et les y enterre en l'honneur des esprits protecteurs des chemins). Ensuite l'ambassadeur reçoit les ordres des mânes (par la bouche de l'invocateur). Le principal compagnon de l'ambassadeur étale et offre aussi des pièces de soie aux mânes du père du prince et aux esprits protecteurs des chemins, de la même manière que l'ambassadeur.

$\mathbf{O}$ Le principal compagnon et tous les autres compagnons de l'ambassadeur l'attendent devant la grande porte de sa mai son. L'ambassadeur arbore un étendard rouge sur sa voiture, et, à la tête de ses compagnons, va à la cour recevoir les ordres du prince. Le prince, en habits de cour, a le visage tourné vers le midi. Les ministres. et les grands préfets, le visage tourné vers l'ouest, sont rangés du nord au sud par ordre de dignité, $\bullet_{288}$ les plus dignes au nord. Le prince dit aux ministres de faire entrer l'ambassadeur. L'ambassadeur entre. Tous ses compa gnons entrent à sa suite, et, le visage tourné vers le nord, se rangent de l'est à l'ouest par ordre de dignité, les plus dignes à l'est. Le prince salue l'ambassadeur par une inclination profon de et le fait avancer près de lui. Le principal compagnon est debout à la gauche de l'ambassadeur, et entend avec lui les ordres du prince.

- Le prévôt des marchands, le visage tourné vers l'ouest, fléchit les genoux, ouvre une cassette, en tire une tablette de jade munie de cordons 
pendants. Sans se lever, il la donne au premier ministre. Le premier ministre prend la tablette et tient les cordons repliés. Placé à la gauche du prince, il donne la tablette à l'ambassadeur. L'ambassadeur reçoit la tablette, le visage tourné du même côté que le premier ministre (tourné vers le nord). Il laisse pendre les cordons (symbole de fidélité), et entend les ordres du prince. L'ambassadeur, le visage tourné du même côté que son principal compagnon, après lui avoir répété les ordres du prince, lui donne la tablette. Le principal compagnon reçoit la tablette, tient les cordons repliés, sort et donne la tablette au prévôt des marchands (qui accompagnera l'ambassade). Il n'est pas suivi des autres compagnons de l'ambassadeur.

- 289 L'ambassadeur reçoit la pièce de jade ronde qu'il offrira au prince étranger sur cinq pièces de soie blanche unie. Il reçoit la tablette oblongue qu'il présentera à la femme du prince étran ger, quand il paraîtra devant elle pour s'acquitter de sa mi ssion; et la tablette de jade rectangulaire qu'il offrira à cette princesse sur cinq pièces de soie, les unes noirâtres les autres brunes, et sur cinq pièces de soie blanche unie. Il les reçoit comme précédemment il a reçu la tablette kou॰i. Ensuite (le même jour) l'ambassadeur se met en marche avec ses compagnons. Il loge dans la campagne non loin de la capitale. Il enlève la bannière qui est arborée sur sa voiture.

S’il doit traverser une contrée étrangère, arrivé aux frontières, il envoie son deuxième compagnon demander au prince la permission de passer sur ses terres. Le compagnon prend cinq pièces de soie blanche, va à la cour du prince étranger et exécute l'ordre reçu. Il dit :

- Je demande la permission de continuer notre voyage.

Il dépose les présents. Un grand préfet du dernier rang prend les présents, entre au palais et informe le prince. Il sort et annonce l'autorisation du prince. Ensuite le prince accepte les présents.

Le prince étranger donne des animaux de boucherie aux voyageurs, plus ou moins à chacun, comme il convient au rang $\bullet_{290}$ de chacun. Il donne au chef d'ambassade un bouf, un agneau et un porc. Il lui fournit, à lui spécialement, du fourrage et des grains. Il donne des animaux de boucherie à tous les compagnons de l'ambassadeur. (Avant que les voyageurs entrent dans le pays), un officier va avec une escorte jusqu'à l'extrémité de la frontière. A la frontière, une convention est jurée. (Les voyageurs promettent de ne commettre aucun dégât dans le pays, ni en allant ni en revenant). L'ambassadeur a le visage tourné vers le midi, et son principal compagnon vers l'ouest. Ses autres compagnons, le visage tourné vers le nord, sont rangés de l'est à l'ouest par ordre de dignité, les plus dignes à l'est. L'annaliste du pays étranger lit la convention. Le ministre de la guerre, le fouet à la main, est debout derrière l'annaliste (comme pour menacer d'un châtiment le voyageur qui enfreindrait la convention).

Avant de franchir la frontière du pays où ils vont en mission, les voyageurs s'exercent avec toute l'application possible (à observer les règles prescrites aux envoyés). 
Ils font un tertre peu élevé (qui simule à leurs yeux la salle d'un temple où sont les tablettes des ancêtres et la salle de réception d'un palais). Au bas ils tracent des dessins qui simulent pour eux les degrés qui servent à monter à la salle. Au nord ils dressent une tente. Ils n'élèvent pas de $k$ ung mur d'enceinte. Ils revêtent leurs habits de cour. Ils ne consti tuent pas de prince et n'offrent pas de pierre préc ieuse. Tous ${ }_{291}$ les compagnons de l'ambassadeur prennent part à cet exercice. Ils ont le visage tourné vers le nord, et sont rangés de l'ouest à l'est par ordre de dignité, les plus dignes à l'ouest. Ils s'exercent à offrir les présents. Les officiers pre nnent les présents qui seront étalés dans la cour du palais du prince. Ils s'exercent de la même manière à offrir les présents avec lesquels il paraîtront devant la princesse, et ceux qu'ils lui donneront ensuite. Ils s'exercent à traiter les affaires publ iques dont ils sont chargés. Ils ne s'exercent pas à traiter les affaires particulières.

L'ambassadeur, arrivé à la frontière du pays où il doit aller, arbore son étendard sur sa voiture. Il jure la promesse de ne commettre aucun dégât. Il avertit le gardien de la barrière. Celui-ci lui demande combien il a d'hommes à sa suite. L'ambas sadeur lui dit le nombre de ses compagnons, c'est-à-dire, des attachés d'ambassade, qui sont trois, cinq ou sept au plus, selon la dignité du prince qui les a envoyés. Le prince envoie un officier lui demander quelle affaire l'amène. Ensuite l'ambassadeur franchit la frontière.

A la frontière, l'ambassadeur enlève son étendard. Ensuite il étale les présents qu'il amène avec lui. Une tente est dressée. L'ambassadeur, en habits de cour, se tient debout à l'est de la tente, le visage tourné vers l'ouest. Ses compagnons ont tous le visage tourné vers le nord, et sont rangés de l'est à l'ouest par ordre de dignité, les plus dignes à l'est. Le prévôt des mar chands, le visage tourné vers le nord, fléchit les genoux, et essuie $\bullet_{292}$ la tablette de jade de forme oblongue. Ensuite il la prend et la montre. Le principal compagnon de l'ambassadeur, le visage tourné vers le nord, l'examine, se retire et retourne à sa place. Le prévôt des marchands enlève la tablette kouøi. (Il ne la range pas avec les autres tablettes, parce qu'elle est plus noble). Les peaux sont étalées, la tête tournée vers le nord. Elles sont rangées de l'ouest à l'est par ordre de beauté, les plus belles à l'ouest.

Le prévôt des marchands essuie aussi les tablettes de jade de forme annulaire, les étale avec les autres présents, les place sur les peaux qui sont à gauche. Le principal compagnon de l'ambassadeur examine ces présents et se retire. Les chevaux qui seront donnés comme présents sont au sud de la tente, la tête tournée vers le nord. Devant leurs têtes on dépose les pièces de soie et les autres présents. On étale de la même manière les pièces de soie que l'ambassadeur offrira à la princesse, quand il paraîtra devant elle, et les présents quill lui offrira en suite.

Le prévôt des marchands avertit le principal compagnon de l'ambassadeur (il lui dit que les présents sont étalés). Le premier compagnon avertit l'ambassadeur. L'officier chargé du transport des présents étale tous les 
présents qui seront offerts en particulier par les membres de l'ambassade. Il en avertit l'ambassadeur.

Quand l'ambassade arrive à la zone de terrain qui s'étend • ${ }_{293}$ jusqu'aux faubourgs de la capitale, les présents sont encore étalés comme précédemment. Quand elle arrive dans l'hôtelle rie où le prince loge ses hôtes à l'entrée de cette zone, les présents sont étalés, comme précédemment, dans le logement assigné au prévôt des marchands.

Quand l'ambassadeur arrive dans cette zone près des faubourgs de la capitale, il arbore son drapeau. Le prince envoie un grand préfet de second rang le prier de dire quel est l'objet de son voyage. Quand le grand préfet est revenu, le prince envoie un ministre d'État, en habits de cour, offrir à l'ambas sadeur cinq pièces de soie unie, et le complimenter sur les fatigues du voyage. Le principal compagnon de l'ambassadeur sort, et prie le ministre de dire ce qu'il désire. Il rentre et avertit l'ambassadeur. L'ambassadeur, par politesse, refuse d'abord l'honneur de cette visite. Ensuite il va au devant du ministre jusque hors de la grande porte de son logement, et le salue deux fois à genoux. Le ministre chargé de le complimenter ne lui rend pas ce salut (parce que le ministre vient au nom du prince). L'ambassadeur salue le ministre par une inclination profonde, et entre le premier. Il recevra les pièces de soie du ministre dans l'intérieur de sa cour. Le ministre, tenant en mains les pièces de soie, entre, et, le visage tourné vers l'est, s'acquitte de la commission quill a reçue de son prince. L'ambas sadeur, le visage tourné vers le nord, écoute les paroles du ministre. Il tourne, se retire un peu en arrière, salue, deux fois $\bullet_{294}$ à genoux, inclinant le front jusqu'à terre, et reçoit les pièces de soie. Le ministre sort du logement de l'ambassadeur (et attend en dehors près de la grande porte). L'ambassadeur donne les pièces de soie à son laò intendant.

Il sort de son logement et va inviter le ministre à rentrer. Le ministre refuse d'abord par politesse. L'ambassadeur le salue par une inclination profonde et entre le premier. Le ministre le suit. Il fait déposer dans la cour (et offre à l'ambassadeur) quatre peaux de cerfs. L'am bassadeur, avec l'honneur dû à un hôte, offre au ministre cinq pièces de soie à fleurs. (L'ambas sadeur est dans son logement; il est comme chez lui. Le ministre est comme son hôte). Le ministre salue deux fois à genoux, inclinant le front jusqu'à terre, et reçoit les pièces de soie. L'ambassadeur salue deux fois à genoux, inclinant le front jusqu'à terre, devant le ministre qui a reçu les pièces de soie. Le ministre salue par une inclination profonde l'officier qui lui rend le service d'emporter les peaux. Ensuite il revient sur ses pas. L'ambassadeur le reconduit jusqu'au sortir de la grande porte, et le salue deux fois à genoux.

$\mathbf{O}$ La princesse envoie un grand préfet de deuxième classe complimenter l'ambassadeur au sujet des fatigues du voyage. Elle l'en voie avec deux corbeilles de bambou de forme carrée, recouvertes de soie noirâtre à l'extérieur et de soie brune à l'in térieur, et munies de couvercles. Ces corbeilles contiennent des $\bullet_{295}$ jujubes cuites et des châtaignes choisies (dépouillées de leur pelure). Le grand préfet se présente en tenant à la fois (les 
jujubes de la main droite et les châtaignes de la main gauche). L'ambassadeur reçoit les jujubes. Le grand préfet, des deux mains, lui présente les châtaignes. L'ambassadeur reçoit les pré sents offerts par le grand préfet de la même manière qu'il a reçu précédemment ceux offerts par le ministre. Il donne à son hôte (au grand préfet) cinq pièces de soie, comme précédemment au ministre. Ensuite le grand préfet chargé de complimenter l'ambassadeur le conduit à la capitale.

Quand l'ambassadeur arrive à la grande porte du palais, le prince dit :

- Le misérable temple où sont les tablettes de mes ancêtres reculés a été balayé pour y recevoir l'ambassadeur.

L'ambassadeur répond :

- Attendons kiøn un peu de temps.

(Il demande du temps pour se laver la tête et tout le corps); ou bien,

- Attendons que le prince hiên ait le loisir de me recevoir.

O Un grand préfet le conduit au logement destiné aux hôtes. Un ministre y va lui parler au nom du prince. L'ambassadeur va au devant du ministre et le salue deux fois à genoux. Le ministre lui exprime les sentiments du prince. L'ambassadeur salue deux fois à genoux, inclinant le front jusqu'à terre. Le ministre se retire. L'ambassadeur le reconduit et le salue deux fois à genoux.

O • ${ }_{296}$ Un intendant, en habits de cour, sert un repas à l'ambas sadeur et aux hommes de sa suite. Il place à l'ouest neuf chau dières contenant un bœuf, un agneau et un porc cuits, et trois chaudières contenant des mets exquis. Il place à l'est sept chau dières contenant un bøuf, un agneau et un porc non cuits. Sur la plateforme devant la salle, il place huit sortes de mets ; près du bâtiment situé à l'ouest de la cour, il place six sortes de mets. En dehors de la grande porte, l'intendant place pour l'am bassadeur vingt voitures de grain battu et vingt voitures de gerbes. Il place deux fois autant de voitures de chauffage et de fourrage que de gerbes; (quarante voitures de chauffage et quarante de fourrage).

Pour le principal compagnon de l'ambassadeur, l'intendant place à l'ouest sept chaudières contenant un bouf, un mouton et un porc cuits ; et trois chaudières contenant des mets exquis. Sur la plateforme devant la salle, il place six sortes de mets. En dehors de la grande porte, il place dix voitures de grain battu, dix de grain en gerbes, vingt de chauffage et vingt de fourrage. A chacun des autres compagnons de l'ambassadeur, l'intendant donne un mouton et un porc.

O Le lendemain matin, un grand préfet de second rang va $\bullet_{297}$ au logement de l'ambassadeur et l'invite à le suivre. L'ambas sadeur, coiffé du bonnet de peau, va remplir la mission dont son prince l'a chargé. Arrivé à la porte du palais, il entre dans une tente. Alors (un officier entre dans le palais, et à la porte du temple, sous une tente), étale les présents portés par l'ambassadeur. 
Un ministre d'État du prince qui reçoit l'ambas sade fait l'office de grand hôtelier un grand préfet fait l'office de deuxième hôtelier ; un simple officier fait l'office de trois ième hôtelier. Le grand hôtelier sort et demande quelle affaire amène l'ambassadeur.

Le prince, coiffé du bonnet de peau, va au devant de l'ambas sadeur jusqu'en deçà de la grande porte du palais (il ne sort pas). Un grand préfet (sort et) introduit l'amba ssadeur.

L'ambassadeur entre et se tient au côté gauche de la grande porte. Le prince le salue deux fois à genoux. L'ambassadeur se retire de côté (comme pour décliner cet honneur. Il ne rend pas ce salut. Le prince lui fait une inclination profonde et entre le premier. A chaque grande porte, à chaque tournant, il le salue par une inclination profonde.

Arrivé à la grande porte du temple où est la tablette de son père, le prince, après une inclination profonde, entre suivi de son hôte. Il se tient debout au milieu de la cour. L'ambassadeur se tient debout $t s i \bullet$ près du bâtiment situé à l'ouest de la grande porte du temple.

Une natte et un escabeau sont préparés pour les mânes. Le ${ }_{298}$ grand hôtelier sort et demande ce que désire l'ambassadeur. Le prévôt des marchands, le visage tourné vers l'est, fléchit les genoux, ouvre sa cassette, prend une tablette de jade de forme oblongue munie de cordons pendants, et sans se lever, la donne au principal compagnon de l'ambassadeur. Celui -ci, sans être revêtu d'une troi sième tunique, replie les cordons de la tablette et la donne à l'ambassadeur. L'ambassadeur, revêtu d'une troi sième tunique, prend la tablette. Le grand hôtelier entre et avertit le prince. Il sort et dit que le prince refuse de recevoir une pierre précieuse. Il introduit l'ambassadeur dans le temple. L'ambassadeur entre et se tient au côté gauche de la grande porte du temple. Les attachés d'ambassade entrent aussi tous, et se tiennent au côté gauche de la porte, le visage tourné vers le nord, rangés de l'ouest à l'est par ordre de dignité, les plus dignes à l'ouest.

Le prince et l'ambassadeur se saluent l'un l'autre par une inclination profonde en trois endroits différents dan la cour. Arrivés aux degrés, trois fois ils veulent se céder le pas l'un à l'aut re. Quand le prince a monté deux marches, l'ambassadeur monte aussi. (Les degrés ont sept marches). L'ambassadeur passe à l'ouest de la colonne occidentale, et reste le visage tourné vers l'est. Le grand hôtelier se retire au milieu de la cour. L'ambassade ur dit ce que son prince lui a ordonné de $\bullet_{299}$ dire. Le prince tourne à gauche ; son visage regarde le nord. Le grand hôtelier s'avance. Le prince, sous la poutrelle qui soutient le bord du toit de la plateforme, salue deux fois à genoux (pour remercier du présent). L'ambassadeur se retire trois. fois en arrière (pour décliner cet honneur). Il a le dos tourné au bâtiment latéral. Le prince, seul à l'écart, revêt une troisième tunique. Il reçoit la tablette de jade au milieu entre le nord et le sud de la plateforme, entre les deux colonnes, plus près de la colonne orientale que de la colonne occidentale. Le grand hôtelier se retire. Le dos tourné au bâtiment situé à l'est de la grande 
porte, il reste debout. L'ambassadeur descend. Ses compagnons sortent dans l'ordre inverse de celui dans lequel ils s ont entrés. (Ceux qui sont entrés les premiers sortent les derniers). L'ambassadeur sort. Le prince, resté seul, donne la tablette de jade à son intendant. Il ôte sa troisième tunique, descend et reste debout.

Le grand hôtelier sort, et demande à l'ambassa deur s’il désire quelque chose. L'ambassadeur ôte sa tunique de dessus, prend cinq pièces de soie et place dessus une tablette de jade de forme ronde, pour les offrir au prince avec d'autres présents. L'hôtelier entre dans le temple et. informe le prince. Il sort et dit que le prince consent à recevoir les présents. Un officier range dans la cour les présents offerts par l'ambassadeur. Il prend les peaux des deux mains, (les pattes de devant de la main droite et les pattes de derrière de la main gauche. Ce sont des peaux de tigres et de léopards). Il met le poil à l'intérieur. Il tient les peaux des deux mains, les deux mains néi tournées l'une vers l'autre. Il entre et range les présents dans la cour.

- ${ }_{300}$ L'ambassadeur entre par le côté gauche de la grande porte. Le prince et lui se font des inclinations profondes, veulent se céder le pas, comme précédemment. Ils montent. L'ambassadeur dit ce que son prince lui a ordonné de dire. On étale les peaux (de manière à laisser voir le poil des pattes). Le prince salue deux fois à genoux et reçoit les pièces de soie. Un de ses officiers reçoit les peaux. Il passe derrière l'ambassadeur et se met à sa droite. L'ambassadeur sort. En sa présence, l'officier du pri nce fléchit les genoux et prend les peaux des deux mains. Le prince, resté seul, donne les pièces de soie à son intendant. Les peaux sont emportées comme elles ont été apportées, la tête tournée à droite. Elles sont portées à l'est.

L'ambassadeur fait visi te à la princesse, portant avec lui une tablette de jade $t c h \bullet n g$. Il lui offre des présents, portant avec lui une tablette $t$ 'ŝung. Les cérémonies sont les mêmes que précédemment dans le palais du prince.

Si plus tard l'ambassadeur veut parler au prince, il porte cinq pièces de soie unie, comme quand il a offert les présents.

O (L'ambassadeur va au palais). L'hôtelier sort et lui demande quelle affaire l'amène. L'ambassadeur répond que les affaires d'État sont terminées. Tenant en mains cinq pièces de soie à fleurs, il demande à faire une visite particulière au $\bullet_{301}$ prince. L'hôtelier entre et informe le prince. Il sort et dit que le prince n'accepte pas cette visite, et demande de traiter l'ambassa deur avec honneur, de lui offrir des présents. L'ambassadeur, par politesse, refuse d'abord cet honneur. Ensuite il cède au désir du prince. L'hôtelier entre et informe le prince.

Un officier de l'intendant enlève l'escabeau qui a été placé pour les mânes et met une autre natte. Le prince sort, va au devant de l'ambassadeur et l'introduit. Ils se font tous deux des inclinations profondes et veulent se céder le pas l'un à l'autre, comme précédemment. Le prince monte, s'écarte et reçoit un escabeau à l'angle du bâtiment latéral. L’intendant, avant de le donner au 
prince, essuie trois fois lintérieur (le côté inférieur) de l'escabeau ; puis le tenant par les deux extrémités, il s'avance et le présente au prince. Le prince, tourné vers le sud-est, essuie trois fois l'extérieur de l'escabeau ; il l'époussette avec sa man che. Il le tient des deux mains par le milieu, des deux côtés, s'avance, et tourné vers l'ouest, il le présente à l'ambassadeur. L'hôtelier se retire. Il se tient le dos tourné au bâtiment situé à l'est de la grande porte. L'ambassadeur offre aux esprits les $\bullet_{302}$ tranches de viande et le hachis. Avec la cuiller il leur offre du vin trois fois.

Les présents destinés à être exposés dans la cour (quatre chevaux) y sont placés. L'ambassadeur quitte sa natte. Le visage tourné vers le nord, il prend ensemble des deux mains la cuiller et la coupe, cháng li les lève ensemble, fléchit les genoux et goûte le vin. Le prince offre à l'ambassadeur cinq pièces de soie unie.

Un grand officier de l'intendant verse du vin non fermenté dans une coupe de corne. Sur la coupe il met une cuiller, dont il tourne le manche en avant. Le prince, à l'écart (à l'angle du bâtiment situé au côté oriental), reçoit la coupe (et va la présenter à l'ambassadeur). L'ambassadeur ne descend pas. Il salue une fois à genoux, s'avance devant sa natte, reçoit la coupe et reprend sa place. Le prince salue à genoux l'ambassadeur qui se retire avec la coupe.

L'officier sert à l'ambassadeur des tranches de viande séchées dans un vase de bambou, et de la viande hachée assaisonnée de saumure dans un vase de bois. L'ambassadeur prend place sur sa natte. Lhôtelier avertit l'ambassadeur que le prince lui apporte l'escabeau. L'ambassadeur s'avance, va au devant du prince. Il reçoit l'escabeau devant sa propre natte. Le visage tourné vers l'est, (l'escabeau dans les mains), il attend que le $\bullet_{303}$ prince le salue. Le prince salue une fois à genoux l'ambassadeur qui a reçu l'escabeau. L'ambassadeur, avec l'escabeau en mains, quitte sa place, et le visage tourné vers le nord, dépose l'esca beau. Il ne descend pas. Au haut des degrés, à son tour il salue deux fois le prince à genoux, inclinant le front jusqu'à terre. L'ambassadeur met la cuiller dans la coupe, et le visage tourné vers le nord, les dépose à l'est des conserves de viande. L'hôtelier s'avance et aide le prince à donner et à recevoir les présents. L'ambassadeur descend les degrés et refuse les présents. Le prince descend une marche, et dit qu'il n'agrée pas ce refus. L'ambassadeur $l \cdot k i \bullet i$ monte les degrés rapidement sans poser successivement les deux pieds sur chaque marche. Il se rend au désir du prince. Il descend pour saluer le prince à genoux en signe de remerciement. Le prince le prie de ne pas saluer au bas des degrés. L'ambass adeur monte, et salue deux fois à genoux, inclinant le front jusqu'à terre.

Il reçoit les présents, près de la colonne orientale, le visage tourné vers le nord. Il se retire, et le visage tourné vers l'est, il attend que le prince le salue à genoux. Le prince le salue une fois à genoux. L'ambassadeur descend les degrés. Le prince le salue deux fois à genoux.

Parmi les quatre chevaux de quadrige qui sont dans la cour pour être donnés à l'ambassadeur, l'ambassadeur prend le che val auxiliaire de gauche. 
Il sort avec ce cheval. (Les trois autres lui sont conduits par des palefreniers). Le premier attaché d'am bassade reçoit les pièces de soie. Les suivants de l'ambassadeur vont prendre les quatre chevaux.

- 304 L'ambassadeur fait au prince une visite particulière, non officielle. Il porte cinq pièces de soie à fleurs. (Il se présente comme le ferait un sujet du prince). Avec l'aide de deux hommes, il conduit quatre chevaux, dont tsôung il tient les huit rênes réunies. Il entre au palais par le côté droit de la grande porte. Le visage tourné vers le nord, il dépose les pièces de soie, et salue deux fois à genoux, inclinant le front jusqu'à terre. Le prince, par la bouche de l'hôtelier, refuse la visite. (Il ne veut pas traiter l'ambassadeur comme son sujet). L'amb assadeur sort du palais. L'hôtelier à genoux prend les pièces de soie et les emporte (pour les rendre à l'ambassadeur). A sa suite, deux officiers conduisent derrière eux et emmènent dehors les quatre chevaux (aussi pour les rendre à l'ambassadeur), L'amba ssadeur, le visage tourné vers l'ouest, est au sud du bâtiment situé à l'est de la grande porte. L'hôtelier l'invite à reprendre ses présents. L'ambassadeur, par politesse, refuse d'abord. Ensuite il se soumet à la volonté du prince.

Quatre hommes conduisent derrière eux les quatre chevaux, se mettent à leur droite, entrent par la grande porte, et mettent les chevaux dans la cour du palais. L'ambassadeur, tenant les pièces de soie, entre par le côté gauche de la grande porte. Tous les attachés d'ambassade entrent aussi par le côté gauche, et là, se rangent de l'ouest à l'est par ordre de dignité, les plus dignes à l'ouest. Le prince et l'ambassadeur se saluent par des $\bullet_{305}$ inclinations profondes, veulent se céder le pas l'un à l'autre, comme précédemment. Ils montent. Le prince, le visage tourné vers le nord, salue l'ambassadeur deux fois à genoux. Celui-ci se retire trois fois en arrière. Il retourne à sa place, tourne le corps, et se tient le dos tourné au bâtiment latéral. Il secoue la poussière qui est sur les pièces de soie, s'avance, et les donne au prince, près de la colonne orientale, le visage tourné vers le nord. Les officiers qui vont recevoir les chevaux passent devant la tête des chevaux, tournent derrière ceux qui les ont amenés, vont à leur droite et prennent les chevaux. Ceux qui ont amené les chevaux, passent devant leurs têtes, vont à l'ouest et sortent.

L'ambassadeur descend, et à l'est des degrés, veut saluer à genoux le prince qui a reçu les pièces de soie. Le prince le prie de ne pas saluer au bas des degrés. L'ambassadeur persiste à vouloir saluer. Le prince descend une marche, et le prie de ne pas saluer au bas des degrés. L'hôtelier dit :

— Notre prince descend à votre suite, Seigneur.

Bien que l'ambassadeur, à genoux, se prépare à saluer, il se lève. Il monte les degrés rapidement, sans mettre les deux pieds l'un après l'autre sur chacun d'eux. Le prince est tourné vers l'ouest. L'ambassadeur, au haut des degrés, le salue deux fois à genoux, inclinant le front jusqu'à terre. Le prince se retire un peu en arrière. L'ambassadeur descend et s'en va. Le prince, resté seul, donne les pièces de soie ${ }_{306}$ au premier ministre. Les chevaux sont emmenés dehors. Le prince descend et se tient debout. 
O L'hôtelier sort et demande aux attachés d'ambassade ce quills désirent. Le premier attaché d'ambassade tient en mains cinq pièces de soie à fleurs de diverses couleurs. Les quatre autres attachés d'ambassade, simples officiers, tiennent en mains chacun une tablette de jade sur cinq pièces de soie à fleurs. Ils demandent à voir le prince. Lhôtelier entre et informe le prince. Il sort et dit que le prince agrée leur visite. Le premier attaché d'ambassade tient en mains des pièces de soie et deux peaux de cerf. Deux hommes l'aident à porter les peaux. Tous les attachés d'ambassade entrent par le côté droit de la grande porte, et là, se rangent de l'est à l'ouest par ordre de dignité, les plus dignes à l'est. Ils déposent les pièces de soie, et saluent tous à genoux, inclinent le front jusqu'à terre. (Les deux aides ont dé posé les peaux et sont sortis).

L'hôtelier les prie de ne pas se présenter devant le prince de la même manière que se présenteraient des sujets de ce prince. Les attachés d'ambassade sortent en ordre inverse (ceux qui sont entrés les premiers sortent les derniers). Lhôtelier prend les pièces de soie du premier attaché d'ambassade. De simples officiers prennent celles des autres attachés. Deux subordonnés du majordome enlèvent les peaux, et suivent ceux qui emportent les pièces de soie. L'hôtelier sort pour prier les attachés ${ }_{307}$ d'ambassade de reprendre tous ces présents. Il dépose les peaux (devant la grande porte), le visage tourné vers le sud. (Il tourne vers le sud la tête des peaux). Les attachés d'ambassade, qui ont apporté les présents, ont le visage tourné vers l'oues t, et sont rangés devant la grande porte du nord au sud par ordre de dignité, les plus dignes au nord. L'hôtelier les prie de reprendre leurs présents. D'abord, par politesse, les attachés d'ambassade refusent. Puis ils se soumettent. Ils s'avancent tous, vont au devant de leurs pièces de soie et les reprennent.

Le premier attaché d'ambassade prend ses pièces de soie, et à la suite des aides qui portent ses peaux, il entre par le côté gauche de la grande porte. Les aides déposent les peaux. Le prince salue deux fois à genoux dans la cour. Les attachés d'ambassade secouent la poussière qui est sur leurs pièces de soie, passent à l'ouest des peaux, et le visage tourné vers le nord, donnent leurs pièces de soie. Ils se retirent et retournent à leurs places. Ils saluent deux fois à genoux, inclinant le front jusqu'à terre, devant le prince qui a reçu les pièces de soie. Ils sortent. Lintendant passe à gauche du prince et fait prendre les pièces de soie. Deux subordonnés du majordome, à genoux, enlèvent les peaux et les emportent à l'est.

L'hôtelier introduit de nouveau les trois simples officiers qui sont attachés d'ambassade (et l'ambassadeur les accompagne). ${ }_{308}$ Ceux-ci entrent par le côté droit de la grande porte, déposent leurs pièces de soie, et saluent deux fois à genoux, inclinant le front jusqu'à terre. L'hôtelier leur dit de ne pas se présenter comme feraient des sujets du prince. Les attachés d'ambassade sortent en ordre inverse. (Ceux qui sont entrés les derniers sortent les premiers.). L'hôtelier pre nd les pièces de soie du chef de l'ambassade. Il les emporte dehors. Avec politesse il le prie de les reprendre. Le chef d'ambassade refuse instamment de les reprendre. 
Le prince à son tour salue les attachés d'ambassade deux fois à genoux. L'hôtelier sort du palais, se tient debout au milieu de l'entrée de la grande porte, et les salue à genoux au nom du prince. Les attachés d'ambassade se retirent de côté, comme pour décliner cet honneur. Trois officiers, rangés de l'est à l'ouest par ordre de dignité, le plus digne à l'est, fléchissent les genoux, prennent les pièces de soie des trois attachés d'ambassade et se lèvent. L'hôtelier s'avance vers le prince. Un subal terne de l'intendant reçoit les pièces de soie de l'ambassadeur au milieu de la cour et va les porter à l'est. Les trois officiers qui portent les pièces de soie des trois attachés d'ambassade le suivent l'un après l'autre par ordre de dignité (et lui donnent les pièces de soie).

L'hôtelier sort et demande au chef d'ambassade s'il désire encore q uelque chose. Celui-ci répond que les affaires sont $\bullet_{309}$ terminées. L'hôtelier entre et informe le prince. Le prince sort et reconduit l'ambassadeur. Arrivé près de la grande porte, il interroge l'ambassadeur sur la santé et la situation du prince qui l'a envoyé. L'ambassadeur répond. Le prince salue deux $\mathrm{f}$ ois à genoux. Le prince interroge l'ambassadeur sur les grands préfets de son pays. L'ambassadeur répond. Le prince le complimente sur les fatigues de son voyage. L'ambassadeur le salue deux fois à genoux, inclinant le front jusqu'à terre. Le prince à son tour le salue à genoux. Le prince complimente les attachés d'ambassade sur les fatigues du voyage. Ceux -ci le saluent deux fois à genou, inclinant le front jusqu'à terre. Le prince à son tour les salue à genoux. L'ambassadeur s'en va. Le prince le salue de ux fois à son départ. L'ambassadeur part vite sans tourner la tête.

O L'ambassadeur demande au prince l'autorisation de traiter avec les grands préfets. Le prince, par politesse, refuse d'abord cet honneur pour ses grands préfets ; puis il accepte. L'ambas sadeur va à son hôtel.

Les ministres d'État et les grands préfets vont à l'hôtel de l'ambassadeur pour le féliciter des fatigues de son voyage. Ils ne paraît pas. (Il ne les reçoit pas, parce que les affaires dont son prince l'a chargé ne sont pas encore terminées). Ces visiteurs, sans entrer, déposent chacun une oie sauvage devant la grande porte de l'ambassadeur, et saluent deux fois à genoux. Le premier attaché d'ambassade reçoit les oies pour son chef. Les $\bullet_{310}$ ministres et les grands préfets vont au logis du premier attaché d'ambassade pour le complimenter sur ses fatigues. Il en est encore de même. (Ils ne sont pas reçus. Ils laissent chacun une oie).

O Le prince envoie un ministre, coiffé du bonnet de peau, offrir à l'ambassadeur des animaux de bouche rie, les uns tués, les autres vivants : cinq boufs, cinq moutons et cinq porcs. Le premier attaché d'ambassade demande au ministre quelle affaire l'amène. L'ambassadeur, en habits de cour, refuse d'abord les présents. (Ensuite il les accepte). Un officie $r$ entre et range les présents. D'abord les mets cuits. Devant les degrés occidentaux, il place neuf chaudières contenant un boaf, un mouton et un porc cuits. En face de ces chaudières, près de l'angle extérieur, il place trois autres chaudières qui 
contiennent du bouillon de bouf, du bouillon de mouton, du bouillon de porc. Il les tourne vers l'est. Il les range du nord au sud. Il place au nord, près de la colonne, la plus distinguée (celle qui contient le bouillon de bouf). Il range les deux autres au midi. Il apporte des poissons, un lièvre séché, et, dans une même chaudière, des intestins et des estomacs, Il ajoute des morceaux de viande pris avec la peau sur le devant du corps du porc. Les poissons sont des poissons frais. Le lièvre séché est de date récente. Auprès des chaudières, il place les leviers qui servent à les $\bullet_{311}$ porter et les couvertures dont on les couvre. Les trois chaudières qui contiennent le bouillon de bøaf, le bouillon de mouton et le bouillon de porc font le pendant des chaudières dans lesquelles est la viande de ces trois animaux.

Les viandes crues sont deux boufs, deux moutons et deux porcs. Il y a sept paires de chaudières. Il n'y a pas de poisson frais, ni de viande nouvellement séchée. Les chaudières sont placées devant les degrés orientaux, tournées vers l'ouest, disposées du sud au nord, sur de ux rangées, comme les chaudières qui contiennent et celles qui accompagnent les viandes cuites.

Sur la plateforme il y a huit vases de bois, placés à l'ouest de la porte de la salle, rangés de l'ouest à l'est, deux à deux, le plus noble des deux à l'est. I 1 y a des poireaux, des légumes conservés dons le vinaigre. Au midi de ces légumes et de ces poireaux, $k^{\prime} \imath^{\bullet}$ sur une seconde ligne, il y a t'àn de la viande hachée, mêlée de sang et conservée dans le sel et le vinaigre; il y a hàt de la viande hachée, mêlée de levain, conservée dans le sel et le vinaigre. A la suite viennent huit vases kоuèi de bois ou d'argile, dont quatre contiennent du millet glutineux et quatre du millet non glutineux. Le millet non glutineux est au sud du millet glutineux. Ces huit vases (sont placés sur deux lignes et) alternent deux à deux.

Viennent ensuite six chaudières. Il y a de la viande de bouf ; il y a du mouton et du porc ; à l'ouest de la viande de boaf, $\bullet_{312}$ au midi du porc, il y a du bouf ; à l'est du bouf il y a du mouton et du porc. Viennent ensuite deux fòu vases contenant du riz et du sorgho. Le sorgho est au nord du riz.

Dans le bâtiment situé au côté occidental, sont placées huit jarres de vin, rangées du nord au sud, les plus nobles au nord. Elles sont rangées par paires, la plus noble des deux au sud de l'autre, (le vin de riz au sud du vin de millet).

Près du bâtiment situé à l'ouest, sont placés six vases de bois. Ils sont rangés au pied du mur occidental, du nord au sud, les plus nobles au nord. Il y a des poireaux, des légumes conservés dans le sel et le vinaigre. A l'est des légumes il y a des viandes hachées conservées dans le sel et le vinaigre. Ces vases forment deux lignes.

Viennent ensuite six vases, dont trois contiennent du millet glutineux, et alternent avec trois autres contenant du millet non glutineux; le millet non glutineux est à l'est du millet glutineux. Puis viennent quatre marmites. Il y a de la viande de bouf. Au sud de la vi ande de bouf, il y a du mouton. A l'est de la viande de mouton, il y a du porc au nord de la viande de porc il y a du boaf. 
Viennent ensuite deux vases contenant du riz et du sorgho. Le sorgho est à l'ouest. Ces deux vases forment la paire. Ils sont $\bullet_{313}$ rangés du sud au nord. Puis viennent six jarres de vin, rangées de l'ouest à l'est, les plus nobles (le vin de riz) à l'ouest. Elles sont rangées deux à deux, l'une à l'est de l'autre.

Des mets sont aussi disposés de la même manière à l'est. Les mets les plus distingués sont au nord-ouest. Les jarres de vin sont rangées de l'ouest à l'est, les plus distinguées à l'est.

Auprès de la colonne du bâtiment latéral, sont rangées, dix par dix, cent jarres, dont cinquante contiennent du vinaigre, et cinquante de la viande hachée conservée dans le sel et le vinaigre. Le vinaigre est à l'est de la viande hachée.

Des animaux de boucherie vivants, à savoir, deux boufs, deux moutons et deux porcs, sont à l'ouest de la grande porte, la tête tournée vers le nord, rangés de l'est à l'ouest, les plus nobles (les baufs) à l'est. A l'ouest d'un bouf, il y a un mouton et un porc. A l'ouest de ce porc, il y a un bouf, un mouton et un porc.

Cent corbeilles de riz et de millet, dont chacune contient la moitié d'un $h \bullet u$ sont au milieu de la cour, rangées dix par dix, du nord au sud, les plus nobles au nord (le riz au nord du millet. $H \bullet u$ : Dix boisseaux). Le millet glutineux, le sorgho et le riz forment chacun deux rangées ; le millet non glutineux forme quatre rangées.

- ${ }_{314}$ En dehors de la grande porte on range trente voitures de grain de riz ou de millet. Chaque voiture en contient 240 teòu boisseaux. (Pìng. 160 boisseaux. Chòu. 16 boisseaux). Ces voitures sont à l'est de la grande porte, sur trois rangées de dix, de l'est à l'o uest; par ordre de distinction, (d'abord le millet glutineux, à l'est; puis le riz; en troisième lieu, le millet non glutineux).

Trente voitures de céréales en gerbes, dont chacune contient trois tóu, en tout 1200 javelles, sont à l'ouest de la grande p orte, rangées de l'ouest à l'est. (Tòu. 400 pìng javelles). Les voitures de chauffage et de fourrage sont deux fois aussi nombreuses que celles de céréales en gerbes (soixante voitures de chauffage et soixante de fourrage. Le timon de ces quatre sortes de voitures est tourné vers le nord).

L'ambassadeur, coiffé du bonnet de peau, va au devant du grand préfet (de première classe ou ministre d'État) jusque hors de la grande porte extérieure de la maison, et salue deux fois à genoux. Le grand préfet ne lui rend pas de salut. Tous deux se saluent l'un l'autre par une inclination profonde et entrent. Quand ils arrivent à la grande porte du temple, l'ambassadeur salue par une inclination profonde et entre seul. Le grand préfet (resté dehors) prend cinq pièces de soie (et entre aussi). L'ambassadeur et le grand préfet, entrés dans la cour du temple, se saluent trois $\bullet_{315}$ fois par une inclination profonde, et marchent kiøi côte à côte. Arrivés aux degrés de la grande salle du temple, ils veulent se céder le pas l'un à l'autre. Le grand préfet le premier monte une 
marche. L'ambassadeur le suit, monte sur la plateforme, et (au haut des degrés) le visage tourné vers le nord, écoute les paroles que le grand préfet lui apporte de la part du prince. Le grand préfet, le visage tourné vers l'est, s'acquitte de sa com mission. L'ambassadeur descend. A l'ouest des degrés, il veut saluer deux fois à genoux inclinant le front jusqu'à terre, pour remercier le prince de ses paroles. Il veut le saluer de la même manière pour le remercier des vivres qu’il a reçus. Le grand préfet le prie de ne pas saluer au bas des degrés. L'ambassadeur monte et accomplit ses salutations. Il reçoit les pièces de soie sur la partie occidentale de la plateforme, au milieu entre le nord et le sud, le visage tourné vers le nord.

Le grand préfet descend et sort du temple. L'ambassadeur descend, donne les pièces de soie à son intendant. Il sort et invite le grand préfet à revenir. Le grand préfet refuse d'abord par politesse ; puis il accepte. L'ambassadeur et le grand préfet entrent, se saluent l'un l'autre en s'inclinant profondément, et veulent se céder le pas l'un à l'autre, comme précédemment. L'ambassadeur monte une marche. Le grand préfet le suit et monte avec lui sur la plateforme.

- 316 Les présents sont exposés dans la cour. Ce sont les quatre chevaux d'un quadrige offerts par l'ambassadeur au grand pré fet. L'ambassadeur descend de la plateforme, et reçoit cinq pièces de soie à fleurs des mains de son intendant. Le grand préfet reste sur la plateforme. (Il ne descend pas). L'ambassadeur (monte et) tient en mains les pièces de soie, le visage tourné vers l'ouest. Le grand préfet a le visage tourné vers l'est. L'ambassadeur lui parle et lui offre les pièces de soie. Le grand préfet répond. Le visage tourné vers le nord, sous la poutrelle qui soutient le bord du toit, il salue deux fois à genoux, inclinant le front jusqu’à terre. Il reçoit les pièces de soie entre les deux colonnes, le visage tourné vers le midi. Il se retire. Tourné vers l'est, il attend debout. L'ambassadeur salue deux fois à genoux, inclinant la tête jusqu'à terre, devant le grand préfet qui se retire avec les pièces de soie. Le grand préfet descend, prend le cheval auxiliaire de gauche du quadrige et l'emmène hors du temple. (Le premier attaché d'ambassade reçoit les pièces de soie. Les hommes de la suite de l'ambassadeur emmènent les qua tre chevaux). L'ambassadeur accompagne le grand préfet jusque hors de la grande porte extérieure de la maison et le salue deux fois à genoux.

Le lendemain, l'ambassadeur va saluer le prince à genoux au palais (à l'extérieur, devant la grande porte. Il n'e ntre pas et ne voit pas le prince). Il le salue deux fois à genoux, inclinant le $\bullet_{317}$ front jusqu'à terre, pour le remercier de lui avoir envoyé des viandes, et deux fois pour le remercier de lui avoir envoyé d'autres provisions de vivres.

O Un grand préfet de dernière classe, envoyé par le prince étale des viandes et d'autres provisions de vivres dans la cour du premier attaché d'ambassade. Il y a trois boufs, trois mou tons et trois porcs. Un bouf, un mouton et un porc cuits sont placés à l'ouest dans sept chaudières avec trois chaudières de ragoûts ; un bœuf, un mouton et un porc non cuits sont placés à l'est dans sept chaudières. Six sortes de mets sont sur la plateforme, et six 
autres près du bâtiment situé au côté occidental de la cour. On prépare au premier attaché d'ambas sade autant de corbeilles de grain et de jarres de vin qu'au chef d'ambassade. Un bouf, un mouton et un porc vivants sont en dehors de la grande porte. (Il y a en tout trois lâ̂).

Il y a autant de voitures de grain battu et autant de voitures de grain en gerbes que de voitures de viande de bouf, de mouton et de p orc. Les voitures de viande sont au nombre de dix. Il y a deux fois autant de voitures de chauffage et deux fois autant. de voitures de fourrage que de voitures de grain en gerbes. Taus les présents qui entrent dans la cour du premier attaché d'ambassade e t tous ceux qui sont étalés pour lui sont disposés comme ceux qui sont offerts au chef d'ambassade. Un grand préfet de dernier ordre, coiffé du bonnet de cuir, va $\bullet_{318}$ avec cinq pièces de soie unie offrir ces présents. Le premier attaché d'ambassade, coif fé du bonnet de cuir, reçoit les présents. Les cérémonies sont les mêmes que pour les présents offerts au chef d'ambassade. Le premier attaché d'ambassade, avec l'urbanité d'un hôte, donne au grand préfet, deux chevaux et cinq pièces de soie à fleurs de diverses couleurs.

Les quatre autres attachés d'ambassade, simples officiers, reçoivent chacun des animaux de boucherie ; à savoir, un bouf, un mouton et un porc vivants, avec cent corbeilles de grain battu. Ces présents sont mis devant la grande porte. (Les animaux de boucherie n'entrent pas dans les cours de ces quatre attachés d'ambassade). Un intendant, en habits de cour, conduit le bouf par la corde derrière lui, et offre ces présents à chacun des quatre attachés d'ambassade. Ceux -ci, en habits de cour, le visage tourné vers le nord, saluent deux fois à genoux, inclinant le front jusqu'à terre, et reçoivent les présents. Eux-mêmes n'en donnent pas.

O Le chef d'ambassade, en habits de cour, fait visite aux ministres. Chaque ministre le reçoit dans celui des bâtiments du temple des ancêtres où est la tablette de son aïeul paternel. Un grand préfet de second rang sert d'intermédiaire ou d'hôtelier. L'hôtelier sort de la résidence du ministre, et demande à l'ambassa deur quelle affaire l'amène. Le grand préf et de premier rang (le ministre d'État), en habits de cour, va au devant de l'ambassadeur jusqu'au dehors de la grande porte extérieure de sa résidence. ${ }_{319}$ Il le salue deux fois à genoux. L'ambassadeur ne lui rend pas ce salut. Tous deux se saluent l'un l'autre par une inclination profonde. Le ministre entre le premier. A chaque porte, à chaque tournant, tous deux se saluent l'un l'autre par une inclination profonde. Quand ils arrivent à la grande porte du temple, le ministre fait une inclination profonde et entre. L'hôtelier prie l'ambassadeur d'exécuter les ordres qu'il a reçus de son prince,

Les présents offerts par l'ambassadeur sont rangés dans la cour. Ce sont quatre peaux de cerfs. L'ambassadeur, tenant en mains cinq pièces de soie unie, entre. Le ministre et lui se saluent trois fois l'un l'autre par une inclination profonde, en trois endroits différents. Ils s'avancent côte à côte. Arrivés aux degrés, ils veulent se céder le pas l'un à l'autre. L'ambassadeur monte une marche. Le ministre le suit et monte avec lui sur la plateforme. Le 
visage tourné vers le nord, il écoute ce que l'ambassa deur lui dit de la part du prince qui l'a envoyé. L'amba ssadeur le lui dit, le visage tourné vers l'est. Le ministre descend ; il veut saluer deux fois à genoux, inclinant le front jusqu'à terre, au bas des degrés occidentaux. L'ambassadeur le prie de ne pas saluer au bas des degrés. Le ministre monte et accomplit ses salutations. Il reçoit les pièces de soie au milieu de la partie occidentale de la plateforme, le visage tourné vers le nord. L'ambassadeur descend et s'en va. Le ministre descend et donne ${ }_{320}$ les pièces de soie à un intendant. Il ne donne pas de présents à l'ambassadeur.

$\mathbf{O}$ (L'ambassadeur fait des visites particulières, en son propre nom, à chacun des ministres. Il se présente à la grande porte). L'hôtelier sort et demande quelle affaire l'amène. L'am bassadeur répond qu'il désire mién faire une visite particulière au ministre. Il apporte des pièces de soie, comme pour faire une visite particulière au prince. Il tient en mains les pièces de soie. Il est suivi des présents qu’il veut exposer dans la cour, (ce sont quatre chevaux). Il veut entrer par le côté droit de la grande porte (comme un inférieur). Le ministre s'y oppose. En conséquence, l'ambassadeur entre par le côté gauche. Ses présents (quatre chevaux) sont placés dans la cour.

L'ambassadeur et le ministre (dans la cour) se saluent l'un l'aut re par une inclination profonde et veulent se céder le pas, comme précédemment, trois fois en trois endroits différents). Le ministre monte une marche. L'ambassadeur le suit. Le minis tre tourne le visage vers l'ouest (comme devant un inférieur). L'ambassadeur lève la tête, (le regarde et refuse cet honneur). Le ministre répond. Le visage tourné vers le nord, sous la poutrelle qui soutient le bord du toit, il salue deux fois à genoux. Il reçoit les pièces de soie entre les deux colonnes, le visage tourné vers le sud. Il se retire en arrière, et reste debout, le visage tourné vers l'ouest. L'ambassadeur, sous $\bullet_{321}$ la poutrelle qui soutient le bord du toit, salue deux fois à genoux, devant le ministre qui a reçu les pièces de soie. Il descend et s'en va. Le ministre descend et donne les pièces de soie à un intendant.

$\mathbf{O}$ (Le premier attaché d'ambassade se présente devant la porte de chacun des ministres successivement). L'hôtelier sort et demande quelle affaire l'amène. Le premier attaché d'ambas sade répond qu'il désire faire une visite particulière au ministre, $t$ ' ' seul sans les autres attachés d'ambassade. Il apporte des pièces de soie, comme pour une visite particulière au prince. Luimême tient en mains les pièces de soie, Deux hommes l'ai dent, et apportent quatre peaux de cerfs (qu'ils mettent dans la cour). Il entre par le côté droit de la grande porte, dépose les pièces de soie, et veut saluer deux fois à genoux. Le ministre le prie d'entrer par le côté gauche. (L'attaché d'ambassade sort). L'hô telier (sort après lui et) lui rend ses pièces de soie. (On lui rend aussi ses peaux).

Le premier attaché d'ambass ade fait mettre ses peaux dans la cour (une seconde fois). Il entre, tenant en mains ses pièces de soie. Le ministre et lui se saluent par des inclinations profondes et demandent de se céder le pas l'un à 
l'autre, comme précé demment. L'attaché d'ambassad e monte les degrés. Le ministre le salue deux fois à genoux et reçoit les pièces de soie. L'attaché d'ambassade descend et veut saluer à genoux. Le ministre descend et s'y oppose. L'attaché d' ambassade monte, salue deux fois à ${ }_{322}$ genoux devant le ministre qui a reçu les pièces de soie. (Il sort).

$\mathbf{O}$ (Les autres attachés d'ambassade font une visite particu lière à chacun des ministres. Ils sont accompagnés par le chef d'ambassade. Ils se présen tent devant la grande porte du ministre). L'hôtelier sort et demande ce quils désirent. Ils répondent quills désirent faire une visite particulière au ministre. Ils tiennent en mains des pièces de soie, comme pour une visite particulière au prince. Ils entrent par le côté droit de la grande porte, déposent les pièces de soie, et saluent tous deux fois à genoux. Le ministre les prie de ne pas entrer par le côté droit de la porte. Les attachés d'ambassade sortent dans l'ordre inverse (ceux qui sont entrés les derniers sortent les premiers). L'hôtelier prend les pièces de soie du chef d'ambassade. Avec politesse il le prie de les reprendre. Le chef d'ambassade refuse. Le ministre, à son tour, salue les visiteurs deux fois à genoux. Lhô telier, ayant en mains les pièces de soie du chef d'ambassade, se tient debout au milieu de l'entrée de la grande porte pour saluer à genoux les attachés d'ambassade, au nom du ministre. Ceux -ci se retirent (pour décliner cet honneur). Un intendant reçoit au milieu de la cour les pièces de soie qui sont entre les mains de l'hôtelier. Trois officiers, à genoux, prennent toutes les autres pièces de soie et suivent l'intendant.

$\mathbf{O}$ (Le chef d'ambassade paraît de nouveau à la porte $d u \cdot{ }_{323}$ ministre). L'hôtelier sort et lui demande quelle affaire l'amène. Le chef d'ambassade (répond que tout est fini et) sort. Le ministre le reconduit jusque hors de la grande porte extérieure, et le salue deux fois à genoux. L'ambassadeur part sans tourner la tête. Lhôtelier se retire. Le ministre le salue à genoux pour le remercier de sa peine.

Les grands préfets de second rang qui dans le passé sont allés en mission auprès du prince de l'ambassadeur reçoivent chacun la visite et les pièces de soie des attachés d'ambassade, Le premier attaché d'amba ssade, en habits de cour, avec ses trois compagnons, fait visite à chacun de ces grands préfets. Le grand préfet reçoit les pièces de soie avec les mêmes cérémonies qu'un ministre. Les attachés d'ambassade lui font visite avec les mêmes cérémonies que le chef d'ambassade fait visite à un ministre.

Si l'un de ces grands préfets (pour une raison ou pour une autre) ne peut pas paraître devant les attachés d'ambassade, le prince charge un autre grand préfet du même grade de remplacer ce grand préfet, et de recevoir les pièces de soie, avec les mêmes cérémonies que le ferait le maître de la maison, c'est à-dire, ce grand préfet. Le remplaçant ne salue pas à genoux.

$\mathbf{O} \cdot{ }_{324}$ Le lendemain au soir, par ordre de la princesse, un grand préfet de second ordre, coiffé du bonnet de cuir, porte des présents à l'ambassadeur, en retour des présents que celui-ci a offerts à la princesse. Sur la plateforme de la 
salle de l'ambas sadeur, il place six vases de bambou contenant des tranches de viande séchée, et six vases de bois contenant de la viande hachée conservée dans le sel et le vinaigre. Il les place à l'est de la porte de la salle, de l'ouest à l'est, les plus nobles (les vases de bois) à l'ouest. Il les range par paires, deux côte à côte, (un vase de conserves au sud d'un vase de tranches de viande), en allant de l'est à l'ouest. Des amphores pleines de vin sont pla cées près du bâtiment situé au côté oriental ; le vin le plus exquis (le vin de riz) est au nord. Elles sont rangées deux à deux, l'une à côté de l'autre, du s ud au nord. Elles contiennent du vin dont la couleur est blanche (vin de riz), du vin de millet à panicules, du vin limpide (vin de sorgho). Il y a deux amphores de chacune de ces trois espèces de vin.

Le grand préfet offre ces présents à l'ambassadeur en tenant dans les mains cinq pièces de soie unie. L'ambassadeur les reçoit avec les mêmes cérémonies qu’il a reçu les viandes. Il don ne à l'envoyé quatre chevaux et cinq pièces de soie à fleurs de diverses couleurs.

La princesse envoie au premier attaché d'ambassade quatre vases de bois contenant de la viande hachée conservée dans une $\bullet_{325}$ saumure, quatre vases de bambou contenant des tranches de viande séchée, et quatre amphores de vin. L'attaché d'ambassade reçoit ces présents avec les mêmes cérémonies que le chef de l'ambassade. Il donne à l'envoyé de ux chevaux et cinq pièces des soie à fleurs de diverses couleurs. Le lendemain, le chef d'ambassade (suivi de ses quatre compagnons) va à la cour, et salue deux fois à genoux, pour remercier la princesse de ses présents.

$\mathbf{O}$ De la part de la princesse, un grand préfet envoie son intendant offrir à l'ambassadeur un boaf, un mouton et un porc vivants, et huit corbeilles de millet. L'ambassadeur va au de vant de l'intendant et le salue deux fois à genoux. Lintendant conduit le bouf par la corde derrière lui , et offre les présents. L'ambassadeur salue deux fois à genoux, inclinant le front jus qu'à terre, et reçoit les présents. L’intendant se retire. L'am bassadeur salue deux fois à genoux l'intendant qui s'en va.

Il en est de même du premier attaché d'ambassade que du chef d'ambassade. Les autres attachés d'ambassade reçoivent chacun de la princesse par l'entremise d'un simple officier un mouton et un porc vivants, et six corbeilles de millet. Toujours un officier conduit le mouton par la corde pour offrir ces présents.

$\mathbf{O}$ Le prince invite l'ambassadeur une fois à un repas, deux fois à un hiàng festin. Les ién banquets où la boisson tient la première place, les si u repas savoureux où l'on mange des oies et des canards sauvages, les présents au ch $\boldsymbol{\imath}$ commencement ${ }_{326}$ de chaque saison, ces faveurs n'ont pas de nombre déterminé. Le lendemain, le chef et les attachés d'ambassade vont ensemble à la cour et saluent le prince à genoux. En outre, le prince invite le premier attaché d'ambassade une fois à un repas, une fois à un festin. (Les autres attachés d'ambassade y assistent). 
Si le prince ne peut pas assister en personne au repas offert au chef ou au premier attaché d'ambassade, il envoie à sa place un grand préfet du même rang que l'invité. Le grand préfet, en habits de cour, préside au repas, offre à l'invité des pièces de soie et ióu l'engage à manger, comme quand le prince offre des viandes. L'invité ne donne pas de présents à l'envoyé. Quand le prince offre un repas, dans lequel il offre des pièces de soie à l'invité en l'engageant à boire une seconde fois, il en est encore de même. (Si le prince n'y assiste pas, l'invité ne donne pas de présents).

$\mathbf{O}$ Chacun des ministres invite l'ambassadeur une fois à un festin, une fois à un repas. Il invite également le premier attaché d'ambassade. à un repas et à un festin. Si un ministre ne peut pas assister en personne au festin, le prince envoie un grand préfet remplacer le ministre, et offrir des pièces de soie à l'invité en l'engageant à boire une seconde fois. Au repas, le grand préfet offre aussi des pièces de soie à l'invité en l'engageant à manger.

Le prince envoie un ministre, coiffé du bonnet de peau, à • ${ }_{327}$ l'hôtel de l'ambassadeur, pour lui rendre les pièces de jade que l'ambassadeur a données. L'ambassadeur, coiffé du bonnet de peau, et vêtu d'une troisième tunique, va au devant du ministre jusque hors de la grande porte extérieure de sa maison. Il ne le salue pas. Il fait entrer le grand préfet (le ministre). Le grand préfet monte par les degrés occidentaux, et sur la plateforme tourne au nord de la colonne. L'ambassadeur dans la cour au nord de la colonne, reçoit le message du prince. Il monte par les degrés occidentaux. Il passe à la gauche du grand préfet, et, le visage tourné vers le midi, reçoit la tablette de jade kouei que l'ambassadeur a donnée au prince. Il se retire, et se tient debout, le dos tourné au bâtiment qui est au côté droit de la salle. Le grand préfet descend au milieu de la cour. L'ambassadeur descend ; il passe au nord de la colonne, et, le visage tourné vers l'est, donne la tablette de jade au premier attaché d'ambassade, à l'est des degrés orientaux.

(Le grand préfet, après être sorti, revient). Le premier attaché d'ambassade sort et lui demande ce qu'il désire. L'ambassadeur va au devant du grand préfet. Celui-ci vient lui rendre la tablette tchøng que l'ambassadeur a donnée à la princesse. Il entre comme précédemment.

(Le grand préfet revient). L'ambassadeur, vêtu d'une tunique $s^{\bullet}$ (sans pardessus $s^{\bullet}$ ), va au devant du grand préfet. Celui-ci ${ }_{328}$ lui fait présent de cinq pièces de gaze de soie. Il lui rend la tablette ronde $p \bullet$, les cinq pièces de soie unie et les quatre peaux que l'ambassadeur lì a offertes au prince. Il les lui rend de la même manière qu'il lui a rendu la tablette de jade de forme oblongue kоиөi. Le grand préfet sort. L'ambas sadeur le reconduit, mais ne le salue pas en le quittant.

$\mathbf{O}$ Le prince va au logis de l'ambassadeur. Celui-ci, par modestie, ne se permet pas de le recevoir. Le premier attaché d'ambassade écoute les paroles du prince (qui lui sont communiquées par l'hôtelier du prince). Le prince a reçu des présents de l'ambassadeur deux fois p’íng et hiàng; la princesse en a reçu aussi deux fois ; les ministres en ont reçu quand il leur a fait visite. Pour 
ces trois raisons, et afin de présenter ses adieux à l'ambassadeur (qui se prépare à s'en retourner dans son pays le lendemain), le prince le salue deux fois à genoux. Le prince se retire. L'ambassadeur le suit, et va au palais pour lui demander ses instructions et le saluer. Le prince décline sa visite et ses salutations. L'ambassadeur se retire.

L'ambassadeur va au palais, et salue trois fois à genoux pour remercier le prince, qui lui a envoyé quatre oiseaux. Il demande les dernières instructions du prince. Ensuite il se met en route. Il loge dans la campagne près de la capitale.

O Le prince envoie un ministre d'État offre à l'ambassadeur des présents semblables à ceux que l'ambassadeur à donnés au ${ }_{329}$ prince dans sa visite particulière. L'ambassadeur les reçoit en dehors de la grande porte, de la même manière qu'il a reçu ceux qui lui ont été offerts à sa première arrivée dans la campagne. Il ne donne aucun présent. Le prince envoie un grand préfet de seconde classe offrir au premier attaché d'ambassade des présents semblables à ceux que celui ci a offerts au prince dans la visite particulière. Le prince envoie un simple officier offrir aux autres attachés d'ambassade des présents semblables à ceux qu'il a reçues d'eux dans leur visite particulière.

Les grands préfets vont en personne offrir à l'ambassadeur des présents semblables à ceux qu'ils ont reçus de lui, dans sa visite particulière. L'ambassadeur ne leur donne aucun présent. Les grands préfets font la même chose pour le premier attaché d'ambassade. Ils envoient un simple officier offrir aux autres attachés d'ambassade des présents semblables à ceux quil ont reçus d'eux dans la visite particulière. Un simple officier ac compagne l'ambassadeur et sa suite jusqu'à la frontière du pays.

L'ambassadeur s'en retourne dans son pays. Arrivé dans la campagne près de la capitale, il envoie un officier demander à son prince la permission d'aller lui rendre compte de sa mission. Il revêt ses habits de cour, et arbore son étendard rouge sur sa voiture. Il offre un sacrifice pour dissiper les influences des mauvais esprits; puis il entre dans la capitale. Ensuite il entre $\bullet_{330}$ au palais du prince. Il étale dans la cour du palais les présents reçus. Il les range de l'ouest à l'est, en commençant par les plus distingués. Il étale les présents, soit officiels soit particuliers, qu'il a reçus lui-même, et les présents officiels que le premier attaché d'ambassade a reçus. Il n'étale pas les présents reçus par les autres attachés d'ambassade. Les rouleaux de cinq pièces de soie unie qui ont été offerts avec les peaux sont étalés dans la cour chacun à gauche des peaux avec lesquelles ils ont été offerts.

Le prince a le visage tourné vers le midi. Un ministre d'État introduit l'ambassadeur. L'ambassadeur, tenant en mains la tablette oblongue kou $i$ avec les cordons pendants, tourne le visage vers le nord. Le premier attaché d'ambassade, tenant en mains la tablette tchøng avec les cordons repliés, est debout à la gauche du chef d'ambassade.

L'ambassadeur rend compte de sa mission en ces termes : 
- Prince, par votre ordre, j'ai été en mission auprès du prince de telle contrée. Le prince de telle contrée a reçu les pièces de soie dans le temple où est la tablette de tel de ses ancêtres, et il a salué deux fois à genoux. Je lui ai offert vos présents. Il a salué deux fois à genoux (et reçu vos présents).

L'intendant, à la gauche du prince, reçoit la tablette oblongue kou $i$ de $\bullet_{331}$ l'ambassadeur. Il reçoit aussi la tablette tchøng du premier attaché d'ambassade. Celui-ci rend compte de sa mission au prince de la même manière que le chef d'ambassade.

L'ambassadeur, tenant en mains les pièces de soie qui lui ont été données par un grand préfet, informe son prince en ces termes :

- Le prince de telle contrée a envoyé tel officier me donner ces présents.

Il remet ces présents à l'intendant du prince. Il avertit le prince et remet à l'intendant de la même manière les pièces de jade quil a reçues sur cinq pièces de soie. Tenant en mains les pièces de soie qu'il a reçues comme présents, il dit au prince en quelles occasions chacun de ces rouleaux de soie lui a été donné. Le prince répond :

- C'est bien. N'êtes -vous pas un excellent ambassadeur?

L'ambassadeur donne les pièces de soie au premier attaché d'ambassade. Il salue deux fois à genoux le prince, inclinant le front jusqu'à terre. Le prince à son tour le salue deux fois à genoux. L'ambas sadeur ne parle pas au prince des présents qui ont été reçus en particulier (non officiellement).

Le prince félicite et console l'ambassadeur des fatigues de son voyage. L'ambassadeur salue deux fois à genoux, inclinant le front jusqu'à terre. Le prince à son tour le salue deux fois à genoux, Si l'ambassadeur a quelque objet à offrir au prince, il dit :

- Cet objet est un présent que m’a donné tel prince.

Le prince en $\bullet_{332}$ fait don à l'ambassadeur, ordinairement, mais pas infailliblement. (Il peut accepter cet objet. Hôu exprime le doute).

Le premier attaché d'ambassade se présente devant son prince, t'ôu les mains vides (sans tenir en mains de pièces de soie), et l'informe des présents officiels qu'il a reçus, de la même manière que l'ambassadeur. Le prince le félicite et le console des fatigues de son voyage. Le premier attaché d'ambassade salue deux fois à genoux, inclinant le front jusqu'à terre. Le prince à son tour le salue à genoux. Il félicite et console de la même manière les autres attachés d'ambassade.

Le prince ordonne à son intendant de donner à l'ambassadeur quelques-unes des pièces de soie que l'ambassadeur a ame nées en voiture avec lui. L'ambassadeur salue deux fois à genoux, inclinant le front jusqu'à terre. Le prince ordonne de donner aux attachés d'ambassade quelques -unes 
des pièces de soie qu'ils ont amenées avec eux. Tous saluent deux fois à genoux, inclinant le front jusqu'à terre. Ensuite ils se retirent. Les attachés d'am bassade conduisent tous le chef d'ambassade jusqu'à la grande porte de sa résidence. En le quittant, ils le saluent par une inclination profonde. Le chef d'ambassade les remercie de leur dérangement en les saluant à genoux.

$\mathbf{O} \cdot{ }_{333}$ Le chef d'ambassade dépose des pièces de soie à l'extérieur devant la grande porte de sa maison (en l'honneur des esprits protecteurs des portes). Ensuite il va au temple où est la tablette de son père défunt, (pour annoncer son retour à son père). Une natte et un escabeau sont placés dans la salle de ce temple (pour les mânes du père). On sert aux mânes des tranches de viande séchées, et de la viande hachée conservée dans une saumure. Une coupe pleine de vin est déposée auprès. Une natte est étendue au haut des degrés orientaux de la salle du temple pour le chef d'ambassade. On lui sert des tranches de viande séchées et de la viande conservée dans la saumure. On lui offre à boire trois fois.

Un homme lève une coupe et la présente à l'ambassadeur. L'ambassadeur la reçoit et offre lui-même à boire à tous ceux qui l'ont suivi dans son voyage. Il leur offre à boire une deuxième fois ; puis il s'en va. Le premier attaché d'ambassade, de retour à sa maison, fait les mêmes choses que les chef d'ambassade. (Il dépose des pièces de soie devant la grande porte, va au temple où est la tablette de son père,...).

O Si l'ambassade apprend la mort du prince auprès duquel elle est envoyée, et qu'elle soit déjà sur le territoire de ce prince, elle continue sa marche vers la capitale. Dans la campagne près des faubourgs, elle ne reçoit pas de félicitations. (Elle s'ac quitte de sa mission auprès du cercueil du prince, non dans le temple des ancêtres), On ne place pas de natte ni d'escabeau ${ }_{334}$ pour les mânes. On ne fait pas à l'ambassadeur tous les hon neurs accoutumés : Celui qui préside aux cérémonies funèbres lui envoie tous les vivres dont il a besoin. L'ambassadeur n'ac cepte que les viandes et les animaux de boucherie vivants. On ne lui offre ni houéi présent, ni tablette de jade; on ne lui fait aucun don à son départ.

Si l'ambassade arrive au temps des cérémonies funèbres après la mort de la femme ou de l'héritier présomptif du prince auquel elle est envoyée, le prince ne la reçoit pas en personne, (parce qu’il préside aux cérémonies funèbres). Il charge un grand préfet de la recevoir dans le temple des ancêtres de ce grand préfet. Pour le reste, on fait comme au temps des funérailles du prince.

Quand l'ambassade arrive au temps des cérémonies funèbres après la mort du prince, de la princesse ou de l'héritier pré somptif, c'est à un grand préfet qu'elle communique les ordres qu'elle a reçus du prince qui l'a envoyée. Ce grand préfet, qui tient la place du chef de l'État, la reçoit vê tu d'une longue tu nique et coiffé d'un bonnet de grosse soie. 
Si l'ambassade est déjà entrée dans le territoire du prince auquel elle est envoyée, quand survient la mort de ce prince, elle continue sa marche. L'officier qui va annoncer cette mort de son prince au prince qui envoie l'ambassade, avant d'arriver à la capitale, pousse des lamentations à la porte de la ruelle, près de l'hôtel qui lui est assigné, et met le plastron de deuil sur sa poitrine dans son hôtel. Il reçoit des vivres (des mets cuits et $\bullet_{335}$ des animaux de boucherie) ; il ne reçoit ni festin ni repas. Arrivé dans la capitale, il sort avec le plastron de deuil sur la poitrine. En présent, il n'accepte que du grain.

De retour chez lui, tenant en mains la tablette oblongue, il rend compte de sa mission auprès du cercueil de son prince. Il monte par les degrés occidentaux. Il n'avance pas sur la plateforme. L'héritier présomptif va occuper la place où il pleure chaque jour son père; il ne pousse pas de lamentations. Le messager rend un compte détaillé de l'exécution des ordres reçus, comme le fait un ambassadeur. L'héritier présomptif et tous ses officiers poussent des lamentations. (Le messager sort). Il rentre avec les compagnons qui l'ont suivi dans son voyage, et tourné vers le nord, il pousse des lamentations. Il sort, se découvre le bras gauche, et lie sa chevelure à la manière des hommes en deuil. Il entre par le côté droit de la grande porte, va occuper sa place pour pleurer le prince défunt, et bondit en signe de douleur.

O Si un ambassadeur, en pays étranger, apprend un deuil de famille (la mort de son père ou de sa mère), il pousse des lamentations dans son hôtel, met le plastron de deuil sur sa poitrine, et demeure chez lui. Il ne reçoit ni festin ni repas. A son retour dans son pays, il fait marcher tous ses compagnons avant lui ; il les suit, le plastron de deuil sur la poitrine.

O Si l'ambassadeur, entré sur le territoire du prince auquel il est envoyé, vient à mourir, ses compagnons continuent leur marche. Le prince de ce pays étranger leur fournit tout ce qui est nécessaire pour les cérémonies funèbres, jusqu'à la mise dans le cercueil. Le premier attaché d'ambassade prend la place de son chef défunt et s'acquitte de sa mission. Le prince auprès duquel il remplit cette mission exprime ses condoléances. Le premier attaché d'ambassade préside aux cérémonies funèbres. Il y emploie toujours les pièces de soie qu'on a coutume d'offrir aux ambassadeurs. Il accepte tous les présents qu'on a coutume d'offrir aux ambassadeurs ; il n'en refuse aucun. Il n'accepte pas de festin ni de repas.

De retour dans son pays, il rend compte à son prince de l'exécution de ses ordres. Le cercueil qui contient le corps du défunt reste en dehors du palais, devant la grande porte. Quand le premier attaché d'ambassade a fini de rendre compte de sa mission, il sort et conduit le cercueil à la maison du défunt. Le prince y va exprimer ses condoléances. Il assiste à toutes les cérémonies qui sont faites alors auprès du cercueil.

Quand un grand préfet, attaché d'ambassade, meurt en pays étranger, les mêmes cérémonies ont lieu. Quand un simple officier, attaché d'ambassade, meurt en pays étranger, on le met dans le cercueil vêtu de ses habits 
ordinaires. Le prince ${ }_{337}$ ne va pas en personne exprimer ses condoléances. (Il envoie un officier).

Si l'ambassadeur meurt à la capitale du pays étranger où il est envoyé, avant de s'être acquitté de sa mission, son corps, après avoir été revêtu et mis dans le cercueil, est transporté promptement au palais du prince, et le premier attaché d'am bassade s'acquitte pour lui de sa mission.

Quand un attaché d'ambassade meurt en pay s étranger, l'ambassadeur à son retour, en allant rendre compte de sa mission à son prince, ne conduit le corps au palais que si c'est le premier attaché d'ambassade. Si un attaché d'ambassade meurt en pays étranger, quand même ce ne serait qu'un simple officier, le chef d'ambassade, après avoir rendu compte de sa mission à son prince, va à la maison du défunt, et assiste à toutes les cérémonies qui se font alors au cercueil. Puis il retourne chez lui.

O Une petite ambassade s'appelle visite. L'envoyé n'off re pas de $p$ • tablette ronde accompagnée de présents. Il offre des présents non officiels; il n'en offre pas à la princesse. Le prince ne fait placer ni escabeau pour les mânes de son aïeul, (il ne le reçoit pas dans le temple des ancêtres). P•u lì Il ne lui offre pas à boire. Il reçoit sa visite particulière dans la cour ; il ne le fait pas monter à la salle. Il ne lui envoie pas de félicitations ${ }_{338}$ dans la campagne près des faubourgs de la capitale. L'envoyé est traité et il agit comme le premier attaché d'ambassade dans une grande ambassade. Il a trois compagnons.

\section{NOTES SUPPLÉMENTAIRES.}

Quand deux princes ont été longtemps sans se voir, sans renouveler les traités, ils s'envoient l'un à l'autre des ambassa deurs. S’il y a une calamité dans le pays de l'ambassad eur, après avoir rempli sa mission principale, il présente un écrit placé sur cinq pièces de soie, pour informer le prince étranger et lui demander du secours. - Si cet écrit contient cent mîng lettres ou plus, il est tracé sur des tablettes de bambou. S'il contient moins de cent lettres, il est tracé sur une planchette. Le prince charge quelqu'un (l'annaliste) de lire cet écrit avec l'ambassadeur dehors, devant la grande porte du temple des ancêtres. Quand l'am bassadeur se prépare à s'en retourner dans son pays, le prince envoie un grand préfet à son logement lui porter une réponse à son écrit, avec les cinq pièces de soie sur lesquelles l'écrit a été présenté. Le lendemain, le prince va lui faire visite à son logis.

$\mathbf{O}$ Après que l'ambassadeur a reçu des provisions pour son voyage, il s'en va. Le prince va voir son intendant (dans le magasin), et lui demande pour combien de mois sont les provisions qu’il a données. Le jour où l'ambassadeur a reçu des $\bullet{ }_{339}$ provisions pour son voyage, il va à la cour avec 
les attachés d'ambassade; il se place avec eux au même endroit qu'auparavant.

Quand l'ambassadeur est sorti du temple où est la tablette du premier des ancêtres du prince, il présente une offrande aux esprits protecteurs des chemins. Il leur offre du vin et des tranches de viande séchées. Ensuite il boit ce vin avec ses compagnons en son particulier.

O Le tablette de jade de forme oblongue que les princes et leurs ambassadeurs tiennent en mains, lorsqu'ils paraissent devant le fils du ciel, a neuf $t$ s'uén $(18 \mathrm{~cm})$ de longueur, ainsi que ses cordons pendants. Le partie supérieure, taillée en pointe, a un ts'uén et demi $(3 \mathrm{~cm})$ de long. Cette tablette a la moitié d'un ts'uén d'épaisseur. Elle a trois ts'uén $(6 \mathrm{~cm})$ de largeur. Ses cordons, au nombre de six, sont de trois couleurs différentes. Deux sont rouges ; deux sont blancs et deux sont de couleur azurée. La tablette qu'un ambassadeur tient en mains lorsqu'il fait vi site à un prince, a huit ts'uén $(16 \mathrm{~cm})$ de long, ainsi que ses quatre cordons pendants, dont deux sont rouges et deux verts. Les cordons sont tous de soie noirâtre doublée de soie brune. (Ils ne diffèrent que par la couleur des pierres de prix dont ils sont ornés). Un ruban, enrichi d'ornements de diverses couleurs, et long de un $t c h ' u(20 \mathrm{~cm})$ sert à suspendre la tablette de jade.

$\mathbf{O}$ Les présents que l'ambassadeur se prépare à offrir aux $\bullet_{340}$ grands préfets qu'il visite (n'entrent pas avec lui dans la capit ale, ils) restent dans la campagne. Ils y sont étalés. Il en est de même des peaux et des chevaux que l'ambassadeur offrira aux grands préfets.

Les expressions dont l'ambassadeur se sert sont variables. Son langage doit être accommodant et aimable. S'il ét ait diffus, il sentirait la rhétorique. S'il était trop concis, il ne serait pas compris. S’il est juste suffisant pour être bien compris, il est parfait. Quand il refuse quelque chose, il dit :

- Cela ne convient pas. Je me permets de refuser.

Quand il répond négativement à une question, il dit :

- Cela ne convient pas. Je me permets de ne pas l'admettre.

O Un ministre d'État, venu en ambassade, est logé chez un grand préfet. Un grand préfet est logé chez un simple officier ; un simple officier est logé chez le prévôt des marchands. L'officier chargé de prendre soin de l'ambassadeur lui fournit pendant trois jours de l'eau pour se laver la chevelure ; pendant cinq jours, il lui fournit de l'eau pour se laver tout le corps. Quand on sert un repas à l'amba ssadeur pøu tchéu sans le lui offrir au nom du prince, il ne salue pas à genoux. Il se lave la chevelure et le corps, et mange.

O Un grand préfet va au devant d'un ministre d'État qui vient en ambassade ; un simple officier va au devant d'un grand préfet. Des envoyés vont au devant de tous les simples officiers. $\bullet_{341}$ Quand l'ambassadeur arrive 
au logis qui lui est préparé, l'officier qui a été au devant de lui le traite d'après les ordres du prince. Quand il va le revoir dans une visite particulière, il tient en mains et offre à l'ambassadeur un présent, (une oie sauvage, s'il est grand préfet, ou un faisan, s'il est simple officier). Quand l'ambassadeur a terminé les affaires publiques dont son prince l'a chargé, il rend la visite à l'officier qui a été au devant de lui. Il tient en mains et lui rend l'oiseau qu'il a reçu de lui.

$\mathbf{O}$ Les quatre sortes de tablettes de jade que les chefs d'États tiennent en mains dans les visites sont à leurs yeux ce quils ont de plus précieux. Les ambassadeurs aussi doivent s'en servir.

$\mathbf{O}$ Le maître des cérémonies du temple des ancêtres fournit les pièces de toile d'une tente (où l'ambassadeur étalera ses présents). Cette tente est dressée en dehors du palais, un peu en arrière de celle du prince.

Le premier attaché d'ambassade prend la tablette de jade. Il la tient comme il tiendrait un objet très lourd. Il la donne au chef d'ambassade. Celui -ci entre à la grande porte du temple des ancêtres du prince et compose son extérieur. En montant à la grande salle, il marche derrière le prince. Pour lui présenter sa tablette de jade, il a soin de marcher vite. Il la lui donne avec empressement, de la même manière que si le prince la disputait à quelqu'un. Il descend de la salle avec respect, de la $\bullet_{342}$ même manière que si le prince le reconduisait. Après que le prince s'en est retourné, il se retire. Arrivé au bas des degrés, sa respiration se détend, comme celle d'un homme qui est à l'aise. Après avoir fait quelques pas, il recommence à marcher vite. Arrivé à la grande porte, il reprend son allure ordinaire.

$\mathbf{O}$ (Quand il va offrir au prince ses présents), il tient en mains sa tablette de jade. Entré à la grande porte du temple, il tient le corps courbé, comme s'il craignait de laisser tomber sa tablette. Quand il offre ses présents, sa respiration se détend ; il a l'air d'un homme qui est tout à fait à son aise. Les attachés d'ambassade, (en entrant dans le temple à la suite de leur chef), le visage tourné vers le nord, marchent avec aisance et dignité. L'ambassadeur, dans les visites particulières faites au prince, a un air accommodant et respectueux. En sortant du temple des ancêtres, il marche avec dignité et lenteur, comme les oies domestiques. L'ambassadeur compose son extérieur avant de se mettre en marche. En entrant à la grande porte, il se montre surtout respectueux. En montant à la salle, il est avant tout attentif.

Les présents que l'ambassadeur fait étaler dans la cour du prince n'y entrent pas tous en même temps. Ceux qui doivent être placés à gauche $\mathrm{y}$ entrent les premiers. Les peaux peuvent kiøn remplacer les chevaux, et les chevaux remplacer les peaux. (Il n'est pas nécessaire d'offrir les deux à la fois. L'ambassadeur peut offrir seulement des chevaux ou seulement des peaux). De tous les présents que l'ambassadeur offre au prince, les chevaux - 343 seuls sortent du palais. (ils sont conduits aux écuries du prince). Tous les autres sont enfermés à l'est dans les magasins du prince. 
Offrir en présent trop de richesses offense la vertu. Offrir des pièces de soie trop belles est contraire aux convenances. Les présents que le prince offre à l'ambassadeur doivent être en rapport avec ceux que l'ambassadeur a offerts.

Quand l'ambassadeur tient en mains et présente une tablette de jade, si elle ne repose pas sur des pièces de soie ou sur des tsaò cordons, il est revêtu de la tunique extérieure $s^{\bullet}$.

L'ambassadeur ne salue pas à genoux pour remercier le prince des présents qu’il reçoit de lui à sa première arrivée dans son hôtel.

Pour offrir du vin non fermenté à l'ambassadeur, on place dans le bâtiment situé au côté oriental de la cour une amphore faite d'argile et de grande dimension. Elle repose sur une cuvette. On lui sert cinq tranches de viande séchées, au-dessus et en travers desquelles est une demi-tranche qu’il offre aux esprits. L'ambassadeur, pour offrir le vin aux esprits, lève deux foi s la coupe. Au commencement il la lève et l'offre une pre mière fois. A la fin, il la lève et l'offre une seconde fois aux esprits. Quand le prince a offert les présents étalés dans la cour, il sort à la suite de l'ambassadeur (qui emmène l'un des quatre chevaux). Trois officiers de l'ambassadeur vont au devant des trois autres chevaux, les prennent et les emmènent.

$\mathbf{O} \cdot{ }_{344}$ Si l'ambassadeur, après une visite particulière faite au prince, lui offre un objet rare ou précieux qui lui appartient, il le lui offre au nom de son prince. (Il se présente à la porte du palais. Lhôtelier sort et lui demande ce qu'il désire). Il rentre et avertit le prince. Il sort de nouveau. (Sur l'ordre du prince), il refuse d'abord le présent par politesse. L'ambassadeur, le visage tourné vers l'est, fléchit les genoux, dépose le présent, et salue deux fois à genoux, inclinant le front jusqu'à terre. L'hôtelier, le visage tourné vers l'est, fléchit les genoux, prend le présent, l'emporte, entre et informe le prince. Il sort de nouveau, et, par pure formalité, prie l'ambassadeur de reprendre son présent. L'ambassadeur s'y refuse fortement. Le prince, à son tour, salue deux fois à genoux pour remercier l'ambassadeur. Lhôtelier se tient debout en dehors du seuil de la porte, pour saluer aussi à genoux au nom du prince. L'ambassadeur s'écarte pour éviter cet honneur. L'hôtelier donne le présent à l'intendant des magasins, au milieu de la cour.

O Si la femme du prince est de la famille et proche parente du prince de l'ambassadeur, l'ambass adeur fait une visite particulière à cette princesse.

O Si le prince (empêché par la maladie ou par une autre cause) ne se présente pas à l'ambassadeur, il envoie un grand préfet (ministre d'État) recevoir les présents. Ce grand préfet, $\bullet_{345}$ au bas des degrés de la salle, entend les paroles de l'ambassa deur qui est au haut des degrés. Il monte par les degrés occidentaux, reçoit les présents, et reste debout adossé contre le bâtiment situé au côté droit de la salle. L'ambassadeur descend; le grand préfet descend aussi. Il n'offre pas de présents à l'ambassadeur. 
O Tous ceux à qui l'ambassadeur (après avoir parlé au prince) offre des présents, vont le féliciter et le remercier de sa venue, (sans retard), sans quitter leurs habits de cour.

O Quand le prince envoie à l'ambassadeur des mets cuits et des viandes, l'ambassadeur offre avant tout le bouillon gras et la viande cuite (aux mânes de son propre père, ou de son aïeul, si son père vit encore). Pour représenter le défunt, il consulte les brins d'achillé e sur le choix de l'un de ses proches parents. Il choisit un parent qui après sa mort aura sa tablette, soit à droite soit à gauche de celle de ce défunt. dans le temple des ancêtres. L'un de ses officiers fait l'office d'invocateur. L'invocateur dit aux m ânes du défunt :

- Un tel, votre petit-fils ou votre fils plein de piété filiale, vous offre d'excellents pré sents, à vous son auguste aïeul appelé de tel fòu nom d'adoles cence, ou son auguste père, Seigneur un tel.

Si le prince envoie un repas à l'ambas sadeur, celui-ci emprunte à un grand préfet les vases dans lesquels il offre les mets aux ${ }_{346}$ mânes. (Il n'ose pas les offrir dans les vases du prince). Il distribue les viandes à ses subordonnés, jusqu'à cheø l'inten dant des écuries et $k i \bullet$ lintendant des voitures.

$\mathbf{O}$ Le jour où l'ambassadeur s'acquitte de sa mission auprès du prince, le prince lui envoie des viandes, les unes cuites, les autres crues. Le lendemain, l'ambassadeur fait visite aux grands préfets. Ce même jour, au soir, la princesse lui envoie des présents. Dix jours après que le prince a envoyé à l'ambas sadeur des viandes, les unes cuites, les autres crues, il lui envoie des grains.

Lintendant de la cuisine commence à lui fournir chaque jour autant de chèng paires d'oiseaux de basse cour (oies domestiques, canards), que de boufs, de moutons et de porcs, les uns cuits, les aut res tués et crus, les autres vivants. (Cinq boufs, cinq moutons et cinq porcs. Cinq paires d'oiseaux). Aux attachés d'ambassade, le prince envoie tous les deux jours deux paires d'oiseaux de basse cour. Chaque fois les officiers qui présentent ces vivres au chef et aux attachés d'ambassade, tiennent en mains une paire d'oiseaux, et déposent le reste devant le chef et les attachés d'ambassade. Chø Au commencement de chaque saison, les mets de la saison sont offerts à l'ambassade de la même manière que les oiseaux de basse cour et les mets exquis préparés sur le feu.

$\mathbf{O}$ Le jour où l'ambassadeur offre ses principaux présents, après avoir reçu lui-même des mets cuits, des viandes crues et des animaux de boucherie, il demande l'autorisation de visiter ${ }_{347}$ le temple des ancêtres (et d'en considérer les beautés). Un officier va au devant de lui, le conduit et l'introduit dans le temple par une porte latérale.

O Chaque fois qu'un officier offre des présents, il est vêtu des habits de cour qui conviennent à son rang. 
O Le prince n'envoie pas de viandes cuites ou crues aux simples officiers attachés d'ambassade. Parce quil ne leur en envoie pas, ces attach és d'ambassade n'offrent pas de présents.

O Un grand préfet, ministre d'État, n'ose pas refuser lui -même les présents de l'ambassadeur. C'est le prince qui prend l'initiative de refuser pour lui.

O Chaque fois que le prince offre un grand repas, toujours aux mets cuits il ajoute des tranches de viande séchées dans un vase de bambou, et de la viande hachée assaisonnée de saumure dans un vase de bois.

Il n'offre pas de grand repas à ceux à qui il n'offre pas de viandes, les unes cuites, les autres crues.

O Chaque fois qu'un grand préfet offre des animaux de boucherie vivants à un chef ou à un premier attaché d'ambas sade, il lui offre dans des corbeilles du millet glutineux, du sorgho et du millet non glutineux, en tout cinquante boisseaux. $\bullet_{348}$ (Il offre deux corbeilles de riz glutineux, deux de sorgho et quatre de millet non glutineux).

O Dès qu'un ambassadeur a terminé les affaires publiques dont il est chargé, il demande au prince qu'il a visité la permis sion de s'en retourner dans son pays. Quand un ambassadeur, un peu avant son retour dans son pays, va au palais saluer à genoux devant la grande porte pour remercier le prince des présents reçus, toujours un officier du prince va recevoir ses remerciements.

O Au banquet, le premier attaché d'ambassade remplace le chef d'ambassade. L'ambassadeur (avec l'agrément du prince, n'y assiste pas) ; afin que les cérémonies soient moins solennelles. L'intendant de la cuisine (et non le prince) offre à boire.

O Quand un ambassadeur arrive en dehors du temps des ambassades réglementaires, le prince lui offre de riches présents; il lui rend les pièces de soie et les joyaux qu'il a reçus de lui. Il lui dit :

- Seigneur, c'est par ordre de votre prince que vous êtes chez moi, pauvre petit prince. Je salue à genoux votre prince pour le remercier d'avoir daigné vous envoyer. Comme prince, je sers les esprits protecteurs du territoire et des grains conjointement avec la princesse ma femme. Je salue à genoux votre prince, et le remercie pour elle des présents quill lui a envoyés. En outre, je vous donne le salut d'adieu. Votre prince m'a gratifié de ses présents. Sa libéralité s'est étendue jusqu'à mes quelques ministres. Je le remercie à genoux pour eux.

- ${ }_{349}$ L'ambassadeur, en quittant la maison où il a reçu l'hospita lité, y laisse quatre peaux et cinq pièces de soie unie, dans la salle, entre les deux colonnes, pour le propriétaire de cette maison. Comme il ne les présente pas au nom de son prince, le propriétaire ne salue pas à genoux. 
$\mathbf{O}$ Quand un grand préfet vient en qualité d'envoyé, s'il ne viole aucune règle, le prince lui offre un grand repas. S'il n'ob serve pas toutes les règles, le prince lui fournit seulement des animaux de boucherie vivants. A un grand repas, l'ambassadeur a pour assesseur le premier attaché d'ambassade. Sill survient un ministre d'une grande principauté, le prince n'invite le pre mier ni à un festin ni à un repas. Il lui envoie des présents.

C'est seulement aux grandes ambassades qu'on place une natte et un escabeau dans le temple pour les mânes du défunt.

Dix boisseaux s'appellent $h \bullet u$. Seize boisseaux s'appellent chòu. Dix chôu s'appellent ping. Deux cent quarante boisseaux (de millet forment la charge d'une voiture). Quatre ping javelles s'appellent kiù. Dix kiù s'appellent $t$ s $u n g$. Dix tsøung, s'ap pellent tóu ou tch'â. Quatre cents javelles font un tóu. 


\section{CHAPITRE IX}

\section{Repas donné par un prince à un grand préfet étranger}

- ${ }_{350}$ Le grand préfet dont il est ici question est un ministre d'État d'un petit prince tsèu ou nân, qui l'a envoyé faire visite ou remplir une petite ambassade. Cependant les règles tracées dans ce chapitre s'appliquent à tous les ambassadeurs de tous les princes.

$\mathbf{O}$ Le prince envoie un grand préfet avertir (et inviter à dîner le grand préfet étranger). Il envoie un grand préfet de même rang. Le premier attaché d'ambassade sort et demande à l'envoyé le sujet de sa venue. Il rentre et avertit l'ambas sadeur. L'ambassadeur refuse trois fois le repas (par la bouche du premier attaché d'ambassade). Il sort, et salue à genoux l'envoyé pour le remercier d'avoir daigné venir. L'envoyé ne lui rend pas le salut, (parce quil n'est que simple envoyé, exécutant l'ordre de son prince). Il invite l'ambassadeur au nom du prince. L'ambassadeur salue deux fois à genoux, inclinant le front jusquà terre (pour remercier le prince. Il accepte $\bullet_{351}$ l'invitation). L'envoyé s'en retourne au palais. L'ambassadeur ne le salue pas au départ. Mais après, il le suit (il va au palais).

L'ambassadeur, en habits de cour, va prendre place en dehors du palais, près de la grande porte, (sous une tente, et il attend), comme font les ambassadeurs.

Les officiers du prince vont prendre leurs places, (et lintendant de la cuisine) dispose tous ses ustensiles (devant la grande porte du temple où est la tablette du père du prince).

Quand le bouillon gras est préparé à point, le chef des laboureurs dispose sept chaudières en face de la grande porte. Il les tourne vers le sud, et les range de l'ouest à l'est, les plus distinguées à l'ouest. Il dépose les leviers avec lesquels on porte ces chaudières et les couvertures qu'on met dessus. Ces couvertures sont faites (de tiges de chiendent) liées ou tressées ensemble.

Des cruches sont placées, comme avant un grand repas. Un petit officier met une cuvette et une aiguière au bas de la partie orientale de la plateforme (pour que le prince se lave les mains). L'intendant dispose une grosse natte de bambou, sur laquelle il ajoute une autre natte et un escabeau pour l'ambas sadeur. On ne place pas d'amphore. Le vin qu'on boira au repas et la boisson de riz attendent dans le bâtiment situé au côté oriental de la salle. Les autres boissons et les mets que l'inten dant fournit sont dans le bâtiment situé au côté oriental de $\bullet{ }_{352}$ la salle. 
O Le prince, vêtu d'habits semblables à ceux de l'ambas sadeur, va au devant de lui jusqu'à la grande porte, mais ne sort pas. Un grand préfet introduit l'ambassadeur. L'ambassadeur entre par le côté gauche de la grande porte. Le prince le salue deux fois à genoux. L'ambassadeur s'écarte, et salue le prince deux fois à genoux, inclinant le front jusqu'à terre. Le prince le salue par une inclination profonde et entre. L'ambassadeur le suit. Arrivé à la grande porte du temple où est la tablette du père du prince, le prince salue par une inclination profonde et entre. L'ambassadeur entre. Le prince et lui sinclinent profondément en trois endroits différents. Arrivés aux degrés, ils demandent trois fois à se céder le pas l'un à l'autre. Après que le prince a monté deux marches, l'ambassadeur monte aussi.

O Les grands préfets du pays se tiennent debout nu sud du bâtiment situé au côté oriental, le visage tourné vers l'ouest, rangés du nord au sud par ordre de dignité, les plus dignes au nord. Les simples officiers se tiennent debout à l'est de la grande porte, le visage tourné vers le nord, rangés de l'ou est à l'est par ordre de dignité, les plus dignes à l'ouest. Les officiers d'un rang peu élevé sont au bas de la partie orientale de la plateforme, le visage tourné vers le sud, rangés de l'ouest à l'est par ordre de dignité, les plus dignes à l'ouest. Les intendants ${ }_{353}$ sont au nord du bâtiment situé au côté oriental, le visage tourné vers l'ouest, rangés du sud au nord par ordre de dignité, les plus dignes au sud. Les officiers subalternes de l'intendant de la princesse sont au nord -est des intendants du prince, le visage tourné vers l'ouest, rangés du sud au nord par ordre de dignité, les plus dignes au sud. Les attachés d'ambassade sont au sud de la grande porte, le visage tourné vers le nord, rangés de l'ouest à l'est par ordre de dignité, les plus dignes à l'oues t.

$\mathbf{O}$ Le prince, arrivé en face de la poutrelle qui soutient le bord du toit, le visage tourné vers le nord, se met en devoir de saluer deux fois à genoux l'ambassadeur. (A peine a-t-il salué une fois que) l'ambassadeur descend. Le prince le salue une deuxième fois à genoux. L'ambassadeur, à l'est des degrés occidentaux, le visage tourné vers le nord, veut à son tour saluer le prince à genoux. Lhôtelier, de la part du prince, le prie de ne pas saluer au bas des degrés, comme un sujet. L'ambassadeur salue n éanmoins à genoux au bas des degrés. Le prince descend une marche, et refuse ces salutations, en disant :

- Moi prince dépourvu de vertu, je vous suis, (je descends à votre suite), Seigneur.

Bien que l'ambassadeur soit à genoux pour saluer de nouveau, il se lève (et ne salue pas). Il monte les degrés sans mettre les deux pieds l'un après l'autre sur chaque marche. (Il monte rapidement pour obéir au prince). Il ne salue pas (parce qu'il a déjà salué au bas des degrés, malgré l'avis du prince.). Le prince lui dit de faire ses salutations. L'ambassadeur, au haut $\bullet_{354}$ des degrés, le visage tourné vers le nord, salue le prince deux fois à genoux, inclinant le front jusqu’à terre. 
Des officiers portent des chaudières. (Chaque chaudière est portée par deux hommes au moyen d'un levier). Ils laissent dehors les couvertu res. Ils entrent par ordre successivement. Ils placent les chaudières dans la cour au sud de la colonne. Ils les tournent vers le sud, et les rangent de l'ouest à l'est, les plus distinguées à l'ouest. Ceux des porteurs qui sont à droite retirent les leviers, et à genoux, les déposent à l'ouest des chaudières. Partant de l'ouest des chaudières, ils s'en vont au midi dans l'ordre le plus commode. (Les derniers venus s'en vont les premiers). Les porteurs qui sont à gauche attendent pour mettre le contenu des chaudières sur les petites tables. Le chef de cuisine entre avec les petites tables et les range au sud des chaudières. Ses aides, le visage tourné vers le sud, mettent des cuillers sur les chaudières, et se retirent.

Les grands préfets, par ordre d'âge, les plus âgés les premiers, se lavent les mains au sud-est des cruches, le visage tourné vers l'ouest. Ils sont rangés du nord au sud par ordre d'âge, les plus âgés au nord. Ils s'avancent par ordre l'un après l'autre, et se lavent les mains. Celui qui se r etire (après s'être lavé les mains) et celui qui s'avance (pour se les laver) se croisent devant les cruches (au sud des cruches). Quand ils ont fini de $\bullet_{355}$ se laver les mains, ils s'avancent par ordre. Le visage tourné vers le sud, avec les cuillers ils retirent le contenu des chaudières (et le donnent aux porteurs des chaudières). Ceux-ci le mettent sur les petites tables, le visage tourné vers l'ouest.

Les poissons et l'animal séché (le cerf) sont cuits. On met sur les petites tables les parties osseuses, les muscles tournés en avant. Sept poissons sont placés longitudinalement sur les petites tables, la tête couchée à droite. (Ces tables sont oblongues. Ceux qui les portent les tiennent ordinairement des deux mains par les deux extrémités). Sept intestins et sept estomacs sont placés sur les mêmes petites tables ; ainsi que sept morceaux de viande choisis qui ont été pris avec la peau sur le devant du corps du porc. Les intestins, les estomacs, les morceaux de viande de porc sont tous placés transversalement sur les petites tables, de sorte que leurs extrémités pendent en dehors. Les grands préfets, après avoir retiré le contenu des chaudières avec les cuillers déposent les cuillers sur les chaudières, s'en vont dans l'ordre contraire de celui dans lequel ils sont venus (les derniers venus s'en vont les premiers), et retournent à leurs places.

O Le prince descend pour se laver les mains. L'ambassadeur descend aussi pour lui faire honneur. Le prince refuse cet honneur. Quand il a fini de se laver les mains, il salue l'ambassadeur une fois par une inclination profonde, l’invite une fois à monter le premier. Le prince monte ; l'ambassadeur monte à sa suite.

- ${ }_{356}$ L'intendant, sortant du bâtiment situé au côté oriental de la salle, donne au prince du vinaigre et de la sauce. Le prince les place devant l'ambassadeur. L'ambassadeur refuse l'honneur d'être servi par le prince en personne. Le visage tourné vers le nord, il fléchit les genoux et change de place le vinaigre et la sauce. Il les met à l'est, à la place qui leur convient. Le 
prince se tient debout dans le bâtiment situé au côté oriental de la plateforme, le visage tourné vers l'ouest. L'ambassadeur se $\mathrm{t}$ ient debout à l'ouest des degrés occidentaux (à la hauteur de la plateforme) ; il s'y tient debout • avec une contenance ferme.

Un intendant apporte du bâtiment situé au côté oriental de la salle et sert à l'ambassadeur six sortes de mets dans six vases de bois. Il les place à l'est de la sauce, de l'ouest à l'est, les plus distingués à l'ouest. Il plac e d'abord les poireaux conservés dans le sel et le vinaigre. A l'est des poireaux, il place de la viande qui a été séchée, hachée, mêlée de sang et conservée dans le sel et le vinaigre, et des racines de joncs. Au sud des racines de joncs, il place de la viande de grand cerf, qui, sans avoir été désossée, a été séchée, hachée et conservée dans le sel et le vinaigre. A l'ouest de cette viande de grand cerf, il place des navets conservés dans le sel et le vinaigre, et de la viande de cerf ordinaire, qui a été préparée comme celle de grand cerf.

Des officiers placent des petites tables au sud des vases de $\bullet_{357}$ bois ; ils les rangent de l'ouest à l'est, les plus distinguées à l'ouest. Sur ces petites tables il y a de la viande de bouf, de la viande de mouton et de la viande de porc. Au sud de la viande de bouf, il y a des poissons. Viennent ensuite la viande séchée, les intestins et les estomacs. Les morceaux de viande de porc sont seuls (à l'est des petites tables).

Les serviteurs du chef de cuisine prennent les cuillers. Les laboureurs prennent les chaudières vides sur leurs épaules. Ces hommes sortent dans l'ordre le plus commode (les derniers venus sortent les premiers). Ils déposent les cuillers et les chaudières à l'endroit où elles sont déposées ordinaireme nt. L'intendant dispose six vases, dont trois contiennent du millet glutineux et trois du millet non glutineux. Il les place à l'ouest des petites tables, deux à deux, du nord-est au sud-ouest, les plus distingués (le millet glutineux) au nord-est. Il place du millet glutineux en face de la petite table sur laquelle est la viande de bouf. A l'ouest du millet glutineux il place du millet non glutineux; au sud du millet non glutineux il place du millet glutineux. Il alterne ainsi jusqu’à la fin.

Le bouillon principal de viande juteuse est sans assaisonnement, (il ne contient ni sel ni légumes). Il est dans un vase d'argile. L'intendant, tenant de le main droite le vase d'argile, et de la main gauche le couvercle de ce vase, entre par la grande porte et monte par les degrés orientaux. Il monte toutes les marches, mais n'avance pas sur la plateforme. Il donne le vase $\bullet_{358}$ au prince ; il descend et sort du temple avec le couvercle. Il rentre et retourne à sa place. Le prince place le vase à l'ouest de la sauce devant l'ambassadeur. L'ambassadeur décline l'hon neur d'être servi par le prince. Il fléchit les genoux et change de place (met à l'est) le vase d'argile.

L'intendant apporte quatre chaudières contenant du bouillon gras mêlé d'assaisonnements. Il les place à l'ouest des vases de bois, les range de l'est à l'ouest, les plus distinguées à l'est. Il place d'abord du bouillon de bouf. A l'ouest du bouillon de bouf, il place le bouillon de mouton. Au sud du 
bouillon de mouton il place le bouillon de porc. A l'est du bouillon de porc, il place du bouillon de boaf.

Le vin qui sert de boisson durant le repas est dans une coupe de corne, qui repose sur une cuvette. Lintendant, tenant la coupe de la main droite et la cuvette de la main gauche, s'a vance et les place à l'est des vases de bois. Le visage tourné vers l'est, il fléchit les genoux, ouvre les vases qui contienne nt le millet, et dépose à l'ouest de chacun d'eux son couvercle tourné à l'envers.

Un aide, le dos tourné au bâtiment situé au côté oriental de la salle, le visage tourné vers le midi, avertit le prince que tout est préparé. Le prince salue deux fois à genoux $\bullet_{359}$ l'ambassadeur, se lève, fait une inclination profonde et invite l'ambas sadeur à manger. L'ambassadeur descend pour saluer au bas des degrés. Le prince s'y oppose. L'ambassadeur monte, et salue deux fois à genoux, inclinant le front jusqu'à terre. Il monte sur sa natte, fléchit les genoux, prend les poireaux conservés dans le sel et le vinaigre, les trempe entièrement dans la saumure de la viande, et les offre aux esprits, entre les deux premiers vases de bois. Des aides, le visage tourné vers l'es t, à genoux, prennent de la main droite tous les vases de millet glutineux, et les passent dans la main gauche. D'autres prennent de la main gauche tous les vases de millet non glutineux et les passent dans la main droite. Il se lèvent, et donnent l'un apr ès l'autre ces vases à l'ambassadeur. L'ambassadeur les offre aux esprits. Les deux poumons de chacun des trois animaux (bouf, mouton, porc) ne sont pas séparés l'un de l'autre par une incision à leur petite extrémité. Les aides (les séparent et) donnent chaque paire de poumons une à une à l'ambassadeur. L'ambassadeur se lève, les reçoit, fléchit les genoux, et les offre aux esprits. Il essuie ses mains. Avec la cuiller il retire ce qui est contenu dans les deux premières chaudières, trempe tout dans la saumure, et l'offre aux esprits dans l'intervalle entre les deux premières chaudières. Il offre aux esprits le vin ordinaire, dans l'intervalle $\bullet_{360}$ entre les deux principaux vases de bois. Il n'offre aux esprits ni les poissons, ni la viande séchée, ni la sauce, ni le bouillon.

L'intendant donne au prince la bouillie de sorgho. Le prince la met à l'ouest du bouillon gras. L'ambassadeur, le visage tourné vers le nord, prie le prince de ne pas le servir lui-même. Il fléchit les genoux, et met la bouillie de sorgho à une autre place (à l'est). Le prince et l'ambassadeur retournent tous deux à leurs premières places, (le prince dans le bâtiment situé au côté oriental de la plateforme, l'ambassadeur à l'ouest des degrés occidentaux). L'intendant apporte la bouillie de riz, et la place à l'ouest de la bouillie de sorgho.

Des officiers apportent et servent différents mets exquis. Entre deux vases contenant les mets exquis, ils placent toujours un t'ái mets composé d'une seule substance excellente, sans mélange ni condiment. (Ici ce mets est un ventre de poisson). Ces vases ont des couvercles. Les officiers les tiennent comme l'intendant tient le bouillon gras, le vase de la main droite, et le couvercle de la main gauche. (Ces vases sont nombreux, plus nombreux que les officiers). Les officiers qui ont apporté les premiers retournent en chercher 
et en apportent d'autres. Ils entrent par la grande porte, et montent par les degrés occidentaux. Le premier de tous monte et place son vase au sud du riz, à l'ouest du millet. Dans l'intervalle (à l'ouest du millet, à $\bullet_{361}$ l'est du mets exquis), un homme peut passer. (L'ambassadeur, en allant et en venant, passe dans cet intervalle).

Sur les côtés de la natte de l'ambassadeur, les mets sont placés sur quatre rangées, du nord-ouest au sud-est, les plus distingués au nord-ouest. Le premier est le bouillon de bouf. A l'est du bouillon de bouf est le bouillon de mouton, le bouillon de porc, et la viande de bouf rôtie. Au sud du rôti de bœuf il y a de la viande hachée conservée dans le sel et le vinaigre. A l'ouest de cette viande hachée il y a de la viande de bouf hachée ou coupée en morceaux, de la viande de bouf hachée et conservée dans le sel et le vinaigre, de la viande de bouf de la chair de poisson hachée et conservée dans le sel et le vinaigre. Au sud du poisson il y a de la viande de mouton rôtie. A l'est de cette viande rôtie il y a de la viande de mouton hachée ou coupée en morceaux, de la viande de mouton hachée conservée dans le sel et le vinaigre, de la viande de porc rôtie. Au sud de la viande de porc rôtie il y a de la viande de porc hachée conservée dans le sel et le vinaigre. A l'ouest de cette viande il y a de la viande de porc hachée ou coupée en morceaux, de la moutarde, de la chair de poisson hachée. Les officiers qui apportent les mets délicats montent tous toutes les marches ; mais ils n'avancent pas tous sur la plateforme. Ils donnent les vases (à celui d'entre eux qui est monté le premier, et qui les place l'un après l'autre). Ils descendent en tenant en mains les couvercles, et sortent. Un aide, le dos tourné au $\bullet_{362}$ bâtiment situé au côté oriental de la salle, avertit le prince que tout est préparé.

$\mathbf{O}$ Un aide (de la part du prince) invite l'ambassadeur à prendre place sur sa natte. L'ambassadeur, à genoux à l'une des extrémités de sa natte, prend le sorgho, puis le riz, et les offre aux esprits. Il les offre dans l'intervalle laissé entre le bouillon et la sauce. Un aide, le visage tourné vers le nord, à genoux, prend un à un tous les mets t'ái distingués qui sont entre les mets exquis, se lève et les donne à l'ambassadeur, un à un. L'ambassadeur les reçoit, et les offre aux esprits, tous ensemble, en une seule fois.

O L'ambassadeur descend, et veut saluer à genoux le prince au bas des degrés, pour le remercier d'avoir fait servir ces mets délicats. Le prince le prie de ne pas saluer au bas des degrés. L'ambassadeur monte, et salue deux fois à genoux, inclinant le front jusqu'à terre. Le prince à son tour le salue deux fois à genoux.

L'ambassadeur, le visage tourné vers le nord, passe entre le vase de sorgho et le vase de bouillon, fléchit les genoux, prend dans le bras gauche le vase de sorgho, prend de la main droite le vase de bouillon et descend. (Il n'ose pas manger et boire au haut des degrés). Le prince le prie de ne pas manger au bas des degrés. L'ambassadeur, le visage tourné vers l'ouest, fléchit $\bullet_{363}$ les genoux et dépose ses deux vases à l'ouest des degrés. Le visage tourné vers l'est, il répond au prince. Le visage tourné vers l'ouest, à genoux, il reprend 
ses deux vases, et monte rapidement les degrés, sans mettre les deux pieds l'un après l'autre sur chaque marche. Le visage tourné vers le nord, il remet les deux vases à leurs premières places. Il descend, et prie le prince de ne pas lui faire l'honneur d'assister à son repas. Le prince y consent. L'ambas sadeur monte. Le prince le salue par une inclination profonde, et se retire dans l'un des deux bâtiments situés aux côtés de la cour. L'officier chargé de traiter avec les hôtes se retire. Le dos tourné au bâtiment situé à l'est de la grande porte, il se tient debout.

L'ambassadeur fléchit les genoux, et enroule la seconde natte qu'on lui a mise sur une première. (Par modestie il n'en veut qu'une. On en avertit le prince). Le prince le laisse faire. L'ambassadeur mange trois fois. Après chaque fois, il boit un peu de bouillon, et mange un peu de viande trempée dans la sauce, (Il mange très peu, Ainsi doit faire un homme distingué). L'intendant prend une coupe pleine d'eau de riz avec sa cuvette, et présente la coupe à l'ambassadeur. L'ambassadeur s'essuie 1 es mains, se lève et reçoit la coupe. Lintendant place la cuvette à l'ouest du vase de riz. Le prince fait étaler dans la cour les présents qu'il destine à l'ambassadeur. (Ce sont des pièces de soie et des peaux). L'ambassadeur, à genoux, offre la boisson aux esprits ; puis il boit, et dépose la coupe sur la cuvette.

- ${ }_{364}$ Le prince reçoit des mains de l’intendant cinq pièces de soie unie, pour les offrir à l'ambassadeur en l'invitant à manger. Tourné vers l'est, il se tient debout. L'ambassadeur quitte sa natte, et se tient le visage tourné vers le nord. L'officier qui traite avec les hôtes s'avance, et offre à l'ambassadeur les présents du prince. L'ambassadeur descend et refuse d'abord les présents. Il monte et se conforme à la volonté du prince, (Il accepte les présents). L'ambassadeur descend pour saluer à genoux. Le prince le prie de ne pas le saluer au bas des degrés. L'ambas sadeur monte, et salue deux fois à genoux, inclinant le front jusqu'à terre. Il reçoit les présents du prince, en face de la colonne orientale, le visage tourné vers le nord. Il se retire, et reste debout à l'ouest de la colonne occidentale, le visage tourné vers l'est. Le prince le salue une fois à genoux. L'ambassadeur descend. Le prince le salue une seconde fois à genoux. Les attachés d'ambassade s'en vont dans l'ordre inverse de celui dans lequel ils sont venus (les derniers venus s'en vont les premiers). L'ambassadeur, le visage tourné vers le nord, salue par une inclination profonde, prend les présents placés dans la cour et sort. Le prince descend et reste debout. Le premier attaché d'ambassade reçoit les pièces de soie de l'ambassadeur. Ses suivants vont prendre les peaux.

O • 365 L'ambassadeur (retourne au temple des ancêtres du prince), entre par le côté gauche de la grande porte. Sous l'extrémité des gouttières, (au sud de la cour), le visage tourné vers le nord, il salue deux fois à genoux, inclinant le front jusqu'à terre, (devant le prince qui est dans la cour). Le prince le prie de ne pas saluer à genoux dans la cour. Le prince et l'ambassadeur se saluent l'un l'autre par une inclina tion profonde en trois endroits de la cour, demandent de se céder le pas l'un à l'autre, et montent comme précédemment. 
L'ambassadeur salue deux fois à genoux, inclinant le front jusqu'à terre. Le prince à son tour le salue deux fois à genoux.

$\mathbf{O}$ L'ambassad eur descend, et, comme précédemment, il prie le prince de se retirer. (Il veut manger de nouveau, mais n'ose pas le faire en présence du prince). L'ambassadeur monte. Le prince le salue par une inclination profonde, et se retire dans l'un des bâtiments situés au côté de la cour. L'ambassadeur, après avoir mangé du houéi fàn millet (trois fois), boit trois fois. Il s'essuie les mains et se lève. Le visage tourné vers le nord, il fléchit les genoux, prend le sorgho et la sauce, et descend. Le visage tourné vers l'ouest, il fléchit les genoux et dépose le sorgho et la sauce à l'ouest des degrés. Le visage tourné vers l'est, il salue deux fois à genoux, inclinant le front jusqu'à terre. Le prince descend et le salue deux fois à genoux.

- ${ }_{366}$ Les attachés d'ambas sade s'en vont dans l'ordre inverse de celui dans lequel ils sont venus. (Les derniers venus s'en vont les premiers). L'ambassadeur s'en va aussi. Le prince le recon duit jusque près de la grande porte, et le salue deux fois à genoux. L'ambassadeur ne tou rne pas la tête. (Il semble ne pas faire attention aux salutations du prince). Un officier recueille les petites tables et la viande des trois animaux (bouf, mouton, porc) qui est dessus. Il envoie les tables et la viande à l'hôtel de l'ambassadeur. Les poissons et la viande séchée n'y figurent pas (ne sont pas envoyés).

O Le lendemain, l'ambassadeur, en habits de cour, va au palais. (Il n'entre pas. En dehors, devant la grande porte), il salue à genoux pour remercier le prince de ses faveurs. Il salue deux fois à genoux, inclinant le front jusqu'à terre, pour remercier le prince de son festin ; puis encore deux fois, pour le remercier des présents d'encouragement qui ont accompagné le festin. Un officier envoyé par le prince va vers lui et entend ses remerciements. (Tout ce qui vient d'être dit concerne un repas offert par un prince à un grand préfet de second rang venu en ambassade).

$\mathbf{O}$ Quand un prince offre un repas à un grand préfet de premier rang (à un ministre d'État), il lui fait servir huit vases de bois contenant de la viande et des légumes, huit vases contenant du millet, six chaudières, neuf petites tables sur lesquelles il y a de la viande. Chacune de ces neuf tables est accompagnée - ${ }_{367}$ de deux autres sur lesquelles il y a des poissons et de la viande séchée. Les poissons, les intestins, les estomacs, les morceaux choisis de viande de porc sont au nombre de neuf ou de onze, si c'est un grand préfet de première classe ; au nombre de sept ou de neuf, si c'est un grand préfet de classe inférieure. Tous les mets délicats sont placés transversalement de l'ouest à l'est. Il n'y en a pas plus de quatre rangées (quel que soit le rang du grand préfet). A un grand préfet de premier rang on sert vingt mets délicats. Outre les mets qu'on sert à un grand préfet de rang inférieur, on lui sert un faisan, un lièvre, une caille, une alouette.

O Si le prince (pour cause de maladie ou pour une autre cause) n'assiste pas lui-même au festin, il se fait remplacer par un grand préfet du même rang 
que l'ambassadeur. Le grand préfet, en habits de cour, offre à l'ambassadeur, au nom du prince, les présents qui accompagnent l’invitation à manger. Les mets qui seront servis dans les vases de bois sont dans des cruches. Ces cruches sont rangées en dehors (au sud) des colonnes, deux à deux, du nord au sud. Le millet et le riz qui seront servis dans les vases de bois ou d'argile sont dans des corbeilles. Ces corbeilles sont rangées à l'intérieur (au nord) des colonnes, au milieu entre les deux colonnes, deux à deux, du sud au nord. Tous les mets délicats sont rangés dans la cour au nord de la colonne. Les présents sont étalés dans la cour $\bullet_{368}$ au sud de la colonne. Les boufs, les moutons, les porcs sont rangés à l'inté rieur près de la grande porte, à l'ouest, de l'est à l'ouest, les animaux les plus nobles (les boufs) à l'est, (puis les moutons, enfin les porcs). L'ambassadeur, en habits de cour, reçoit les présents de la même manière qu'il a reçu le repas. Il ne donne pas de présents. Le lendemain, l'ambassadeur, en habits de cour, va au palais et salue à genoux (devant la grande porte) pour remercier le prince. Un officier envoyé par le prince entend les remerciements de l'ambassadeur.

O Lorsqu'un grand préfet offre un repas à un autre grand préfet, siáng au nom du prince, il va lui-même l'inviter ; (puis, quand tout est prêt) il va l'appeler. Il va recevoir son hôte en dehors de la grande porte, et le salue à genoux pour le remercier de son arrivée. Les salutations à genoux sont les mêmes qu'au festin hiàng. Le maître de la maison (le grand préfet) descend et se lave les mains. Il reçoit des mains de ses officiers la sauce, le bouillon, les présents qui accompagnent le repas, les cinq pièces de soie à fleurs. Pour les recevoir, il descend toujours de la plateforme par les degrés orientaux. (Il ne descend qu'une marche). L'officier qui lui donne un objet ne monte qu'une marche. (Dans la résidence d'un grand préfet, les marches étaient au nombre de trois. L'officier mont ait sur la première marche. Le grand préfet descendait sur la deuxième et recevait l'objet).

- ${ }_{369}$ L'hôte reste au haut des degrés. (Il ne descend pas). Il prend le sorgho et le bouillon et va à l'angle du bâtiment situé au côté occidental de la plateforme. (Il n'ose pas manger à une place honorable). Le maître de la maison lui dit de ne pas agir ainsi. L'hôte reporte ses mets au haut des degrés. Des deux nattes qu'on lui a mises l'une sur l'autre, il enlève et enroule la natte supérieure. Le maître de la maison le prie de ne pas enlever cette seconde natte. L'hôte la replace sur la première. Il ref use les présents. Il descend une marche. Le maître de la maison le suit (et le prie de ne pas descendre). L'hôte reçoit les présents qui accompagnent l'invitation à manger. Il salue deux fois à genoux, inclinant le front jusquà terre. Le maître de la mais on salue son hôte partant avec les présents. Il en est encore de même, (l'hôte à son tour le salue deux fois à genoux, inclinant le front jusqu'à terre).

L'hôte prie le maître de la maison de ne pas assister à son repas. Il descend une marche. Le maître de la maison le suit (et s'en va). Quand l'hôte a fini de manger, il enlève les restes des mets, et les porte à l'extrémité du bâtiment situé au côté occidental de la plateforme. Le visage tourné vers l'est, il salue 
deux fois à genoux, descend et s'en va. Tout le reste se passe comme quand un prince offre à manger à un grand préfet.

$\mathbf{O}$ Si le grand préfet désigné par le prince pour offrir un $\bullet_{370}$ repas à l'ambassadeur n'y peut pas assister en personne, le prince charge un autre grand préfet d'aller en habits de cour offrir ce repas, et donner des présents à l'ambassadeur en l'engageant à manger. L'ambassadeur reçoit les présents sur la plateforme. Lui-même n'en donne pas.

\section{NOTES SUPPLÉMENTAIRES.}

Le prince, après kiái avoir invité l'ambassadeur à dîner (trois jours avant le repas), $p \bullet u$ si• ne l'avertit pas de nouveau (un jour avant le repas). Il l'invite, mais ensuite il ne va pas le presser de venir (il ne va pas le chercher au moment du repas).

$\mathbf{O}$ Le prince ne présente pas à l'ambassadeur l'escabeau contre lequel l'ambassadeur appuie ra le dos étant assis sur sa natte. On n'étend pas de natte au haut des degrés orientaux pour le prince. (Le prince ne s'assied pas). Les mets sont cuits en dehors de la grande porte du temple, à l'est. Lintendant du palais fournit pour l'ambassadeur un e scabeau; une natte de jonc longue de tch'âng 16 tch' $u$ pieds $(3 \mathrm{~m}, 20 \mathrm{~cm})$, bordée de toile noire ; une seconde natte de fin jonc, sîn longue de huit $t c h$ ' $u$ pieds, bordée de soie noirâtre. Il enroule ces deux nattes ensemble, en commençant par celle des extrémités où l'ambassadeur aura les pieds étant assis. La natte de l'intendant général est apportée du bâtiment situé au côté oriental de la $\bullet_{371}$ salle. La voiture de l'ambassadeur reste en dehors du palais, à l'ouest de la grande porte, le timon tourné vers le nord. (Elle attend qu'il sorte du palais).

Aux mets qui sont dans les chaudières on ajoute des légumes. On mêle des feuilles de haricots à la viande de bouf, des laiterons à la viande de mouton, diverses plantes à la viande de porc. Dans tous ces mets il y a des émollients (violettes, hémérocalles,...).

$\mathbf{O}$ Les aides se lavent les mains et montent à la suite des petites tables.

Les vases qui contiennent le riz et les différentes espèces de millet ont chacun un couvercle et une couverture. Les viandes rôties ne sont jamais accompagnées de sauce. (Elles sont assaisonnées de sel).

$\mathbf{O}$ Sur la natte de jonc d'un grand préfet de première classe on place une autre natte de jonc fin. Ces deux nattes sont bordées comme celles d'un grand préfet de classe inférieure.

Quand l'ambassadeur est un ministre d'État, le minist re d'État qui lui porte les paroles du prince reste au bas des degrés. (Il ne monte pas les degrés). L'aide de premier rang qui est à son service est un grand préfet de classe inférieure. 
O - 372 Avec les différents mets délicats servis à un grand préfet de première classe, on lui sert du vin ordinaire et de l'eau de riz. Ces boissons vont bien avec tous les mets délicats. Quand l'ambassadeur salue pour remercier des mets servis ou des présents qui accompagnent le repas, il salue toujours deux fois à genoux, inclinant le front jusqu’à terre. 


\section{CHAPITRE $X$}

\section{Visites des princes à l'empereur}

- ${ }_{373}$ Kin signifie spécialement visite faite à l'empereur par les princes en automne. Ici il signifie visite faite à l'empereur en n'importe quelle saison.

Quand un prince arrive à la zone appelée kín kia $\bullet$ à cinquante lì stades de la capitale de l'empire, le tá hîng jên grand officier des messages de l'empereur lui souhaite la bienvenue. Cet officier porte sur la tête le bonnet de cuir, et tient dans les mains une tablette de jade de forme ronde. Le heôu chèu prince, portant aussi le bonnet de cuir, va au devant de l'envoyé jusqu'en dehors de la grande porte, faite de tentures, de son logement, et le salue deux fois à genoux. L'en voyé ne lui rend pas le salut à genoux, (parce quỉl représente la personne de l'empereur). Ensuite, tenant en mains sa pièce de jade, il s'avance avec le prince. Le prince et l'envoyé se $\bullet_{374}$ saluent l'un l'autre par une inclination profonde trois fois en trois endroits différents. Quand ils arrivent aux degrés par lesquels on monte sur le t'ân tertre élevé dans l'enclos du prince, l'en voyé ne cède pas le pas au prince; il monte le premier sur le tertre, (parce quill représente la personne de l'empereur). Le prince monte, et écoute les paroles que l'envoyé lui apporte de la part de l'empereur. Il descend, et salue deux fois à genoux, inclinant le front jusqu'à terre. Ensuite il monte, et reçoit la tablette de jade de l'envoyé. L'envoyé tourne à gauche et reste debout. Le prince lui rend la tablette de jade. L'envoyé la reçoit. Le prince descend, et salue deux fois à genoux, inclinant le front jusqu'à terre. Alors l'envoyé s'en va.

Le prince l'arrête. (L'assistant du prince invite l'envoyé à revenir). L'envoyé rentre. Le prince et l'envoyé s’invitent l'un l'autre à monter. Le prince monte le premier. Il donne un escabeau à l'envoyé, et le salue à genoux après le lui avoir donné. L'envoyé pl ace l'escabeau sur la natte qui lui est préparée, et rend le salut à genoux. Le prince offre à l'envoyé cinq pièces de soie unie et les quatre chevaux d'un quadrige. L'envoyé salue deux fois à genoux, et accepte ces présents. Le prince salue deux fois à genoux l'envoyé qui a reçu les présents. L'envoyé descend, et s'en va avec le cheval auxiliaire qu'on attelle à gauche du timon. Le ${ }_{375}$ prince l'accompagne jusque hors de la grande porte, et le salue deux fois à genoux. Puis, à sa suite, il va à la capitale.

L'empereur donne au prince un hôtel. Il lui fait dire par son envoyé :

- Mon oncle, vous obéissez fidèlement à l'empereur et vous venez lui faire visite. Je vous donne un hôtel. 
(L'empereur appelle $p \bullet$ fóu les grands princes qui portent le même nom de famille que lui). Le prince salue deux fois à genoux, inclinant le front jusqu'à terre. Il offre à l'envoyé cinq pièces de soie unie et quatre chevaux,

L'empereur envoie un grand préfet avertir le prince et lui dire :

- Tel jour, mon oncle, vous accomplirez la cérémonie tch' $u$ prescrite par les anciens usages, (vous viendrez me faire visite).

Le prince salue deux fois à genoux, inclinant le front jusqu’à terre.

$\mathbf{O}$ (Tous les princes qui vont faire visite à l'empereur, avant de paraître devant lui, prennent logement au palais impérial dans de grandes tentes, devant la grande porte du temple où est le tablette de Ouên ouâng). Les logements des princes qui portent le même nom de famille que l'empereur regardent l'ouest ; ils sont rangés du nord au sud, les plus honorables sont au nord. Les logements des autres princes regardent l'est ; ils sont $\bullet_{376}$ rangés $d u$ nord au sud, les plus honorables sont au nord.

Chaque prince, portant le vêtement et le bonnet de cérémonie, dépose des pièces de soie dans le temple où est la tablette du père de l'empereur. Il monte une voiture noire, qui porte un étendard orné de figures de dragons, et un arc dans un fourreau. Il se rend au palais impérial avec sa tablette de jade munie de cordons pendants. On dispose pour l'empereur, entre la fenêtre et la porte de la salle d'audience, un paravent orné de figures de haches, et deux escabeaux, l'un à gauche, l'autre à droite du paravent.

L'empereur, portant la tunique ornée de figures de dragons et le bonnet de cérémonie, est debout, le dos tourné au paravent orné de figures de haches. Linspecteur des champs reçoit la de mande du prince qui sollicite une audience ; il la transmet à l'empereur. L'empereur répond :

- Moi l'homme unique, je n'ai d'autre désir que celui de féliciter mon oncle, qui est venu en personne me faire visite. Que mon oncle entre ; je le recevrai.

Le prince entre par le côté droit de la grande porte, fléchit les genoux, dépose sa tablette, et salue deux fois à genoux, inclinant le front jusqu'à terre, Un officier chargé par l'empereur $\bullet_{377}$ de traiter avec les étrangers communique au prince les paroles de l'empereur. Le prince, à genoux, prend sa tablette, monte et expose ce qu'il a à dire. L'empereur reçoit la tablette de jade. Le prince descend. A l'est des degrés occidentaux, le visag e tourné vers le nord, il veut saluer deux fois à genoux ; inclinant le front jusqu'à terre. L'officier chargé de traiter avec les hôtes l’invite à monter, en disant :

- Montez.

Le prince monte et fait ses salutations. Ensuite il s'en va.

Trois fois le prince offre des présents à l'empereur. Chaque fois il tient dans les mains une tablette de jade sur cinq pièces de soie. 
Les présents qu'il étale dans la cour du temple sont tous des produits de son pays. Tenant dans les mains cinq pièces de soie unie, il amène un cheval tchou $\bullet$ grand, cháng le plus beau de tous. Il est suivi de neuf autres chevaux. Il les range au milieu de la cour, de l'ouest à l'est par ordre de beauté, le plus beau à l'ouest. Il dépose ses pièces de soie, et salue deux fois à genoux, inclinant le front jusqu'à terre. L'empereur lui fait dire par l'hôtelier :

- Moi l'homme unique, je recevrai en personne les présents.

Le prince monte et parle à l'empereur. (Il monte avec la tablette de jade et les pièces de soie). L'empereur pose la main sur la tablette, (mais ne la prend pas). Le prince descend par $\bullet_{378}$ les degrés occidentaux. Le visage tourné vers l'est, il donne les pièces de soie (et la tablette) à l'intendant de l'empereur. Devant les degrés occidentaux, il salue deux fois à genoux, inclinant le front jusqu'à terre. Il emmène dehors le plus beau des chevaux; il le donne à un officier. Les neuf autres chevaux le suivent. (L'empereur n'accepte pas les chevaux. Le prince les fait reconduire dans son hôtel). La cérémonie est terminée.

Ensuite le prince, à l'est de la grande porte du temple, se dénude le côté droit (comme un homme qui se reconnaît coupable et s'offre à subir, la flagellation). Il entre par le côté droit de la grande porte. Debout, le visage tourné vers le nord, il dit à l'hôtelier qu'il s'offre à être châtié pour ses méfaits. L'hôtelie r avertit l'empereur. L'empereur refuse de châtier le prince. Il lui fait dire :

- Mon oncle, il n'y a rien contre vous. Retournez gouverner en paix nài vos États.

Le prince salue deux fois à genoux, inclinant le front jusqu’à terre.

Le prince sort, passe au sud du petit mur élevé dehors devant la grande porte, (et caché derrière ce mur, se couvre le côté droit). Il retourne à l'ouest de la grande porte ; puis il rentre par le côté gauche de cette porte ; et le visage tourné vers le nord, il se tient debout. L'empereur le félicite et le remercie de ses fatigues. Le prince veut saluer deux fois à genoux, inclinant ${ }_{379}$ le front jusqu'à terre. L'officier chargé de traiter avec les hôtes l’invite à monter, en lui disant :

- Montez.

Le prince monte et accomplit ses salutations. Il descend et s'en va.

L'empereur lui envoie en récompense une voiture et des vêtements de cérémonie. Le prince va recevoir l'envoyé de l'em pereur jusqu'en dehors de la grande porte de son hôtel. Il salue deux fois à genoux. La voiture est d'abord placée dans la cour du prince à l'ouest, l'ouest étant le côté le plus honorable; (le timon est tourné vers le nord). Les quatre chevaux lóu hiá qui traînent la voiture sont (dételés et) iá placés ensuite (à l'est de la voiture). Les riches présents de l'empereur (les belles pièces de soie), en nombre indéterminé, sont placés au sud de la voiture. 
Un ministre d'État de l'empereur, tenant dans les mains la corbeille, qui contient les vêtements donnés par l'empereur, et sur les vêtements, le rescrit de l'empereur, monte par les degrés occidentaux, et tourne le visage vers l'est. Le grand annaliste impérial est à sa droite. Le prince monte sur la plateforme, et le visage tourné vers l'ouest, se tient debout. Le grand annaliste lit le rescrit par lequel l'empereur donne au prince une voiture, des vêtements,...

- ${ }_{380}$ Le prince descend. Entre les deux rangées de degrés, le visage tourné vers le nord, il veut saluer deux fois à genoux, inclinant le front jusqu'à terre. (Le grand annaliste lui dit de ne pas saluer au bas des degrés). Le prince monte et fait ses salutations. Le grand annaliste place le rescrit sur les vêtements dans la corbeille. Le prince reçoit la corbeille. L'envoyé s'en va. Le prince salue son départ deux fois à genoux. Il fait présent de cinq pièces de soie unie et de quatre chevaux à cet envoyé ; ainsi qu'au ministre qui lui a apporté les vêtements donnés par l'empereur. Il offre les mêmes présents au grand annaliste.

O Au chef d'un grand État qui porte le même nom de famille que l'em pereur, l'empereur donne le nom d'oncle paternel qui est l'aîné de ses frères. Au chef d'un grand État qui ne porte pas le même nom de famille que l'empereur, l'empereur donne le nom d'oncle maternel qui est l'aîné de ses frères. Au chef d'un petit État qui porte le même nom de famille que l'em pereur, l'empereur donne le nom d'oncle paternel qui n'est pas l'aîné de ses frères. Au chef d'un petit État qui ne porte pas le même nom de famille que l'empereur, l'empereur donne le nom d'oncle maternel qui n'est pas l'aîné de ses frères.

L'empereur offre au prince un grand repas et des présents. Ensuite le prince s'en retourne dans ses États.

$\mathbf{O}$ - Quand un prince fait visite à l'empereur, un hôtel lui $\bullet_{381}$ est préparé (en dehors de la capitale). Cet hôtel occupe un espace carré qui a trois cents рóu $(360 \mathrm{~m})$ de chaque côté. Il a quatre grandes portes. Le tertre élevé dans l'enclos a douze $\sin (92 \mathrm{tch} \cdot u$ pieds ou $18 \mathrm{~m}, 40 \mathrm{~cm}$ de haut). Sur ce tertre, quatre pieds plus bas que le sommet, (aux quatre points cardinaux), il y a des siáng statues qui représentent les chên mîng intelligences spirituelles (les esprits protecteurs de ciel, de la terre, des points cardinaux).

Ces statues sont de bois. Elles sont carrées et ont quatre pieds $(80 \mathrm{~cm}) \mathrm{de}$ chaque côté. Elles sont peintes de six couleurs différentes. La statue des esprits protecteurs de l'orient est peinte en bleu ; celle des esprits protecteurs $\mathrm{du}$ midi est peinte en rouge; celle des esprits protecteurs de l'occident est peinte en blanc ; celle des esprits protecteurs du septentrion est peinte en noir ; celle des esprits du ciel est de couleur bleu-ciel ; celle des esprits de la terre est jaune. Pour honorer ces six sortes d'esprits, on leur offre six sortes de tablettes. Aux esprits du ciel, on offre une tablette oblongue kouøi de couleur bleu-ciel ; aux esprits de la terre, une tablette ronde $p \bullet$ de couleur jaune ; aux esprits du midi, une tablette tchøng de couleur rouge; aux esprits de l'occident, une tablette hòu de couleur blanche ; aux esprits du septentrion, 
une tablette houâng de couleur noire; aux esprits de l'orient, une tablette kouøi de couleur bleue.

Le premier compagnon de chaque prince prend l'étendard $\bullet_{382}$ de son prince, et l'arbore dans l'hôtel qui lui est préparé. (Les divers hôtels sont rangés de gauche à droite). Le côté gauche est le plus honorable. Tous les princes des cinq rangs kथng heôu p• tsèu nân vont chacun auprès de leurs étendards et se tiennent debout. L'hôtelier leur dit à tous de se mettre sur quatre rangs (les tsèu et les nân sur un seul et même rang). La voiture du fils du ciel est traînée par des loung chevaux qui ont huit pieds $(1 \mathrm{~m}, 60 \mathrm{~cm}) \mathrm{de}$ haut. Elle porte le grand étendard, sur lequel sont représentés le soleil, la lune, et des dragons, dont les uns montent et les autres descendent. L'em pereur sort de la capitale, salue à genoux le soleil en dehors de la grande porte orientale des hôtels préparés dans la campagne pour recevoir les princes. A son retour vers la capitale, il fait des offrandes aux esprits protecteurs du ciel, de la terre et des quatre points cardinaux. (Devant la porte orientale de ces mêmes hôtels), il fait des salutations et des offrandes au soleil devant la porte méridionale ; à la lune et aux esprits des quatre grands cours d'eau, devant la porte septentrionale ; aux esprits des montagnes, des torrents et des collines, devant la porte occidentale. L'empereur brûle sur un bûcher ce qu'il offre au ciel. Il fait des offrandes aux esprits des montagnes et des collines, dans un lieu élevé ; aux torrents, dans un lieu bas. Il enterre ce qu’il offre à la terre.

\section{NOTES SUPPLEMENTAIRES.}

Les escabeaux (ne sont pas disposés des deux côtés du paravent de l'empereur avant son arrivée. Ils) attendent dans le bâtiment situé à l'est de la cour.

Les voitures des p’ién collatéraux ou subordonnés de l'empereur, c. -à-d, les voitures des princes, n'entrent pas dans l'enceinte du palais impérial.

Le tablette de jade de forme oblongue se place sur les tsaò cordons dont elle est ornée.

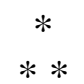




\section{CHAPITRE XI}

\section{Vêtements de deuil}

- 385 ARTICLE I. De ceux qui portent le plastron sans ourlet sur la poitrine, la robe sans ourlet, le bandeau et la ceinture de brins de chanvre femelle, le bâton noir comme le chanvre femelle, la ceinture de brins de chanvre tordus ensemble, le bonnet de toile retenu sur la tête par une corde de brins de chanvre mâle qui tient lien de rubans, les chaussures faites des fibres d'une plante textile appelée kiøn ou kouøn.

Dans les Mémoires (de Tsèu hià, disciple de Confucius) il est dit :

«Que signifie le mot tchàn? Il signifie ne pas ourler. Le chanvre dont on fait le bandeau et la ceinture du grand deuil de trois ans est celui qui porte des fruits (le chanvre femelle). Ce bandeau est de grosseur à remplir la main. La plus grosse extrémité des fibres du chanvre pend au côté gauche de la tête. La ceinture est d'un cinquième moins grosse que le bandeau (pour les hommes, mais non pour les femmes). Le $\bullet{ }_{385}$ bandeau qui va avec le plastron ourlé est de la même grosseur que la ceinture qui va avec le plastron sans ourlet. La ceinture est d'un cinquième moins grosse que le bandeau.

«Le bandeau du deuil de neuf mois est de la même grosseur que la ceinture qui va avec le plastron ourlé. La ceinture est d'un cinquième moins grosse. Le bandeau du deuil de cinq mois est de la même grosseur que la ceinture du deuil de neuf mois. La ceinture est d'un cinquième moins grosse. Le bandeau du deuil de trois mois est de la même grosseur que la ceinture du deuil de cinq mois. La ceinture est d'un cinquième moins grosse.

« Le bâton de couleur noire sur lequel un fils s'appuie à la mort de son père est de bambou. Le bâton taillé sur lequel il s'appuie à la mort de sa mère est d'éléo cocca. (L'extrémité inférieure de ce bâton est taillée à angles droits). La longueur de chacun de ces bâtons est telle qu'il va des pieds au coar de celui qui le porte. Le gros bout est à la partie inférieure. Qu'est-ce qu'un bâton? C'est un insigne de dignité. Celui qui n'est revêtu d'aucune dignité, pourquoi s'appuie-t-il sur un bâton ? Il représente le maître de la maison. (C'est sa dignité). Celui qui n'est pas le chef de la maison, pourquoi porte -t-il un bâton ? C'est $\bullet_{386}$ que la douleur l'affaiblit au point d'avoir besoin de s'appuyer sur un bâton. Pourquoi un fils âgé de moins de quinze ans ne s'appuie-t-il pas sur un bâton ? C'est qu'il ne convient pas qu'il se laisse affaiblir par la douleur au point d'avoir besoin de s'appuyer sur un bâton. Pourquoi une femme ne s'appuie-t-elle pas sur un bâton ? C'est qu'il ne convient pas non plus qu'elle se laisse tant affaiblir par la douleur. 
«La ceinture de brins de chanvre tordus ensemble est comme une ceinture de corde. Au bonnet de deuil les ^ng rubans pendants sont remplacés par des cordes. Ce bonnet tchø est lié autour de la tête par une corde. Sa couture est au côté droit. (Elle paraît au dehors). La chaîne de la toile de ce bonnet est de six fois chøng quatre-vingts fils. Les $p \bullet$ extrémités de la corde qui est liée autour de ce bonnet paraissent au dehors. Pour touán blanchir la toile de ce bonnet, on ne se sert pas de cendre. La chaîne de la toile dont est fait le plastron est de trois fois chøng quatre-vingts fils. Les chaussures de chanvre à présent sont appelées kiøn féi. Les extrémités des brins de chanvre paraissent au dehors, et $n \bullet$ sont tressées ensemble.

Un fils, à la mort de son père, demeure dans une cabane faite de pieux inclinés (en dehors de la grande porte de la maison. Jusqu'à l'enterrement), il couche sur un paillasson, la tête appuyée sur une motte de terre. Il pousse des lamentations le jour et la nuit, sans heures fixes, Il boit, une fois le matin, une fois le soir, une bouillie claire qui contient $\bullet$ une poignée ${ }_{387}$ de riz ou de millet. En se couchant pour dormir, il n'ôte ni son bandeau ni sa ceinture de deuil.

Après les offrandes qui ont lieu à la maison au retour de l'enterrement, il détruit le mur élevé devant sa cabane. Il étaie la poutrelle qui est au bord du toit de cette cabane. Il a une natte pour se coucher. Il mange une nourriture grossière et boit de l'eau. Il pousse des lamentations une fois le matin, une fois le soir; voilà tout. La première année du deuil écoulée, il demeure dans un appartement particulier situé en dehors de ses appartements particuliers ordinaires. Il commence à manger des légumes et des fruits. Il mange des mets communs. Il n'a plus de moment fixe pour pousser des lamentations.

$\mathbf{O}$ Un fils, à la mort de son père, porte le grand deuil. Dans les Mémoires il est dit : "Pourquoi le fils, à la mort de son père, porte-t-il la robe et le plastron sans ourlet ? C'est à cause du très grand respect qu'il doit à son père. » (Les Mémoires cités dans ce chapitre sont attribués à Tsèu hià, disciple de Confucius).

$\mathbf{O}$ Un prince, après la mort du fils du ciel, porte le deuil durant trois ans. Il est dit dans les Mémoires : «Un très grand respect est dû au fils du ciel. »

O Après la mort d'un prince, tous ses officiers portent le deuil durant trois ans. Il est dit dans les Mémoires : «C'est à cause du grand respect quils doivent à leur prince. »

$\mathbf{O} \cdot 388$ - Un père, à la mort du fils aîné de sa femme principale, porte le deuil durant trois ans. Il est dit dans les Mémoires : "Pourquoi trois ans de deuil ? C'est que ce fils était comme la chair et les os des aïeux, et que plus tard, après la mort de son père, la charge importante de garder le temple des ancêtres lui aurait été transmise, s’il avait encore vécu. Un fils qui n’est pas l'aîné de la femme principale ne peut pas porter le deuil durant trois ans à la mort du fils aîné de sa femme principale, parce qu'il n'est pas le successeur de ses ancêtres. 
Celui qui est le successeur d'un homme (qui n'a pas de fils) porte le deuil durant trois ans après la mort de ce père adoptif. Il est dit dans les Mémoires : «Pourquoi garde-t-il le deuil durant trois ans ? Parce qu'il a reçu de son père adoptif la charge importante de garder le temple des ancêtres, il doit après sa mort observer le grand deuil. Que faut-il pour pouvoir devenir le successeur d'un homme qui n'a pas de fils ? Un parent qui est d'une branche de famille issue d'un fils cadet de la femme principale peut être le successeur d'un homme qui n'a pas de fils. (A défaut de ce parent), un autre parent qui est d'une branche de famille issue d'un fils d'une femme de second rang peut être le successeur. Le successeur, à l'égard de l'aïeul, du père, de la mère, de l'épouse, des parents de l'épouse, des frères ${ }_{389}$ et des neveux du parent à qui il succède, doit agir, et à leur mort, doit porter le deuil, comme s'il était le fils de ce parent. »

Une femme porte le deuil durant trois ans après la mort de son mari. Il est dit dans les Mémoires : «.Elle doit un très grand respect à son mari. »

$\mathbf{O}$ Une femme de second rang porte le deuil durant trois ans à la mort de son mari, auquel elle donne le nom de kiøn seigneur. Il est dit dans les Mémoires : «Elle doit un très grand respect à son kiùn. »

O La tsèu fille d'une niù tsèu fille (une petite fille) qui demeure encore dans la maison maternelle, (si elle a passé l'âge de quinze ans), garde le deuil durant trois ans après la mort du père de sa mère.

$\mathbf{O}$ Une femme ou une fille qui est en deuil pour trois ans lie sa chevelure avec une bande de toile, y enfonce un bâtonnet en guise d'épingle de tête, enroule sa chevelure en forme de chignon, et porte le plastron de deuil sur la poitrine durant trois ans. Il est dit dans les Mémoires : «La chaîne de la bande de toile qui lie la chevelure d'une femme en deuil est de six fois chøng quatre-vingts fils. La partie de cette bande de toile qui pend au bas du chignon a six ts'uén pouces de long $(12 \mathrm{~cm})$. Le bâtonnet qui sert d'épingle de tête a un $t c h$ ' $u$ pied de long $(20 \mathrm{~cm})$. En dehors du temps de deuil l'épingle de tête a un pied et deux pouces de long $(24 \mathrm{~cm})$. »

$\mathbf{O} \cdot{ }_{390}$ Une fille qui, après son mariage, retourne et demeure dans la maison paternelle, porte le deuil durant trois ans après la mort de son père.

Les officiers d'un ministre d'État, tous les employés d'un grand préfet, à la mort du ministre ou du grand préfet, portent une ceinture de toile et des chaussures faites de cordes. Il est dit dans les Mémoires: «Le grand intendant, les officiers, les principaux employés et tous les autres employés d'un ministre d'État ou d'un gran d préfet, à la mort de leur maître, si leur maître possédait un fief, prennent le bâton de deuil ; mais ils ne s'en servent pas quand ils vont prendre leurs places et pousser des lamentations. Les officiers qui ont vécu auprès du défunt suivent les mêmes observances que leur nouveau maître (le successeur du défunt). Les chaussures faites de cordes sont à présent nommées chêng féi. » 
ARTICLE II. De ceux qui, durant trois ans, portent le plastron et la robe de grosse toile avec ourlets, le bandeau de brins de chanvre mâle, le bonnet dont les rubans sont de toile, le bâton dont l'extrémité inférieure est taillée à angles droits, la ceinture de toile, les grosses chaussures de paille.

- 391 Il est dit dans les Mémoires : «Que signifie le mot tsø ? Il signifie ourlé. Le chanvre mâle est le chanvre appelé sì. Les racines des brins de chanvre mâle sont au côté droit de la tête, au dessus du bandeau. Le bonnet sur lequel est ce bandeau est le même que celui qu'on porte au commencement du kòu køung deuil de neuf mois. Les grosses chaussures sont faites des fibres de la plante textile appelée pià̀ k'ouái. »

$\mathbf{O}$ Un fils qui n'a plus de père porte le plastron ourlé pendant trois ans après la mort de sa mère.

$\mathbf{O}$ - Un fils, après la mort de celle que son père devenu veuf a épousée en secondes noces, porte le deuil comme pour sa propre mère. Il est dit dans les Mémoires : «Pourquoi un fils porte-t-il le deuil après la mort de sa marâtre comme après la mort de sa propre mère ? La marâtre, étant la compagne du père, est comme la $n$ propre mère du fils. C'est pourquoi un fils qui a de la piété filiale envers son père ne se permet pas de mettre de différence entre sa propre mère et sa marâtre. »

$\mathbf{O}$ Un fils, à la mort de la femme de second rang qui a été sa mère par affection (sa mère adoptive), porte le deuil comme pour sa propre mère. - Il est dit dans les Mémoires: "Qu'appel le-t-on ts'êu mòu ? Les anciens Mémoires donnent la réponse suivante : «Quand une femme de second rang n'a pas d'enfant, ${ }_{392}$ et que le fils d'une autre femme de second rang a perdu sa mère, le père dit à la femme de second rang qui n'a pas d'enfant : "Traitez cet enfant comme votre propre fils. » Il dit à son fils : "Considérez cette femme comme votre propre mère. » En pareil cas, cette femme nourrit et élève le fils jusqu'à ce qu'elle meure, comme si elle était sa propr e mère. Quand elle meurt, le fils porte le deuil pendant trois ans, comme si elle avait été sa propre mère ; cela par respect pour les ordres de son père. » (Tseu hia cite ici des Mémoires antérieurs aux siens).

$\mathbf{O}$ Une mère, à la mort de son fils aîné, porte sur la poitrine le plastron ourlé pendant trois ans, (si elle est la femme principale de son mari). Il est dit dans les Mémoires : «Pourquoi porte-t-elle le deuil pendant trois ans ? Le père ne se permet pas de moins faire (parce que son fils aîné devait être le successeur de ses aïeux). La mère ne se permet pas non plus de moins faire. »

ARTICLE III. De ceux qui portent durant un an le plastron et la robe de grosse toile avec ourlets, le bandeau de chanvre mâle, le bonnet à cordons, de toile, le bâton dont l'extrémité inférieure est taillée à angles droits, la ceinture de toile, les grosses chaussures de chanvre. 
Dans les Mémoires il est dit : «On demande : «Quel bonnet porte-t-on en temps de deuil ? »Il est répondu : «Avec le plastron ourlé et avec la robe du deuil de neuf mois, le plastron prend la toile du bonnet, c.-à-d, la toile qui sert à faire le bonnet avant l'enterrement sert à faire le plastron après l'enterrement. (Durant le deuil d'un an, avant l'enterrement, la chaîne de la toile du plastron comprend 320 fils ; la chaîne de la toile du bonnet est de 560 fils. Après l'enterrement, la chaîne de la toile du plastron est de 560 fils ; la chaîne de la toile du bonnet est de 640 fils. Durant le deuil de neuf mois, avant l'enterrement, la cha îne de la toile qui sert à faire le plastron est de 560 fils; la chaîne de la toile qui sert à faire le bonnet est de 800 fils. Après l'enterrement, la chaîne de la toile qui sert à faire le plastron est de 800 fils ; la chaîne de la toile qui sert à faire le bonnet est de 880 fils).

Durant le $s \bullet u$ mâ deuil de trois mois et le siaò $k \bullet u n g$ deuil de cinq mois, après l'enterrement, une toile de même qualité sert à faire le plastron et le bonnet. La ceinture et la bordure de la robe sont faites de la même toile que le bonnet. (la chaîne de cette toile est de 960 fils pour le deuil de cinq mois, et de 1200 fils pour le deuil de trois mois).

$\mathbf{O}$ Un fils, du vivant de son père, porte le deuil durant un an à la mort de sa mère. Il est dit dans les Mémoires : « Pourquoi porte-t-il le deuil pendant un an seulement ? Il restreint la manifestation de sa douleur. Son père, à qui il doit le plus grand respect, étant encore en vie, il n'ose pas, pour satisfaire ses sentiments particuliers, étendre à sa mère (avoir pour sa $\bullet_{394}$ mère) un respect égal. Mais le père doit attendre trois ans avant de prendre une autre femme, pour montrer quill partage les sentiments de son fils. »

O Le mari porte le deuil de sa femme pendant un an. Il est dit dans les Mémoires : «Pourquoi le mari porte-t-il le deuil de sa femme pendant un an ? C'est que la femme et le mari ne font qu'un. »

$\mathbf{O}$ Le fils d'une femme répudiée porte le deuil de sa mère pendant un an. Il est dit dans les Mémoires : «Le fils d'une femme répudiée porte le deuil de sa mère pendant un an. Mais il ne porte pas le deuil du père ni de la mère de sa mère. On lit dans les anciens Mémoires : «La parenté du fils avec les proches parents de sa mère est rompue; pour lui l'obligation de porter le deuil ne s'étend plus à eux. Mais la parenté du fils avec la mère continue toujours. »

$\mathbf{O}$ Le fils d'une femme répudiée, sỉl a déjà succédé à son père défunt, ne porte pas le deuil de sa mère répudiée. Dans les Mémoires il est dit : « Le fils ne fait qu'un avec son père, pour qui il a un très grand respect. Il n'ose pas porter le deuil d'une personne qui reste sa parente, mais qui n'a plus de parenté avec son père. »

$\mathbf{O} \cdot 395 \cdot$ Si un fils, après la mort de son père, suit sa marâtre dans la maison d'un second mari, il porte le deuil de sa marâtre, par reconnaissance pour les soins qu'elle lui a donnés. Dans les Mé moires il est dit : "Pourquoi porte-t-il 
le deuil pendant un an ? C'est pour témoigner sa reconnaissance pour les soins que sa marâtre lui a donnés jusqu’à la fin. »

ARTICLE IV. De ceux qui ne portent pas le bâton de deuil, et gardent les chaussures de chanvre pendant un an.

$\mathbf{O}$ Un fils qui a déjà succédé à son père défunt garde ainsi le deuil pendant un an à la mort du père et de la mère de son père. Dans les Mémoires il est dit : «Pourquoi garde-t-il le deuil pendant un an ? C'est parce (qu'il tient la place de son père, et) que son père doit le plus grand respect à ceux qui lui ont donné le jour. »

Un neveu porte le deuil durant un an à la mort du chèu fòu frère aîné de son père, et à la mort de la femme de ce frère aîné ; de même, à la mort d'un chø fóu oncle paternel qui n'est pas l'aîné, et à la mort de la femme de cet oncle. Dans les Mémoires il est dit : "Pourquoi un neveu porte-t-il le deuil durant un an à la mort de chacun de ses oncles paternels ? C'est que ses oncles sont comme les membres d'un même corps avec son père, pour qui il a un très grand respect. Cela étant, pourquoi un oncle porte-t-il aussi le deuil durant un an à la mort de chacun ${ }_{396}$ des fils de ses frères ? Ses neveux sont des collatéraux pour qui il a du respect. Par eux-mêmes, ils ne méritent pas un si grand respect. Leur oncle montre ce grand respect envers eux en considération de ses frères dont ils sont les fils. Le père et le fils sont comme un seul et même corps. Le mari et la femme sont aussi comme un seul et même corps. Les frères sont comme un seul et même corps. Le père est comme la tête ; les fils sont comme les pieds. Le mari et la femme sont comme les deux moitiés réunies d'un seul et même corps. Les frères sont comme les bras et les jambes d'un seul et même corps. Ils doivent donc être unis de sentiments, Cela étant, ceux qui peuvent être divisés de sentiments, ce sont les cousins, qui pí vient dans des appartements séparés les uns des autres, et dont chacun $s \bullet u$ doit avoir une affection particulière pour son propre père. Un fils qui n'a pas une affection particulière pour son père n'est pas un véritable fils. • (Quand les frères sont mariés et demeurent dans la maison paternelle, chacun d'eux a des appartements séparés où il habite avec ses propres enfants). Aussi distingue-t-on le bâtiment oriental, le bâtiment occidental, le bâtiment méridional, le bâtiment septentrional. Les appartements sont différents, mais les biens et les revenus restent en commun. - Quand les revenus sont surabondants, le surplus va entre les mains du frère aîné. Quand les revenus de l'un des frères cadets ne suffi sent pas, le frère aîné y pourvoit. Pourquoi un neveu porte-t-il aussi le deuil durant un an, à la mort de la femme du frère aîné de son père, et de la femme de tout autre frère de son $\bullet_{397}$ père ? Il porte ainsi le deuil à cause du nom qu'il donne à la femme d'un oncle paternel. »(Il l'appelle sa mère).

O Le fils aîné de la femme principale d'un grand préfet porte le deuil perdant un an à la mort de sa propre femme. Dans les Mémoires il est dit : «Pourquoi porte-t-il le deuil pendant un an ? C'est que son père ne trouve pas 
dans sa dignité de grand préfet une raison suffisante pour porter le deuil moins d'un an. Il ne se permet pas non plus de le porter moins d'un an. Pourquoi ne prend-il pas le bâton de deuil ? Il ne prend pas le bâton de deuil, parce que son père vit encore. »( $\mathrm{Du}$ vivant de son père, si sa mère venait à mourir, il prendrait le bâton de deuil et garderait le deuil seulement durant un an. Son deuil doit être moindre à la mort de sa femme qu'à la mort de sa mère).

$\mathbf{O}$ Un frère porte le deuil durant un an à la mort d'un frère, soit plus âgé soit moins âgé que lui.

$\mathbf{O}$ Un père porte le deuil durant un an à la mort de l'un de ses fils autre que l'aîné de sa femme principale, (même lorsque le défunt est le fils d'une femme de second rang).

$\mathbf{O}$ Un frère porte le deuil pendant un an à la mort d'un fils de l'un de ses frères, que ce frère soit plus âgé ou moins âgé que lui. Dans les Mémoires il est dit : «Pourquoi porte-t-il le deuil pendant un an ? C'est par reconnaissance pour l'affection que son frère a pour lui. »

$\mathbf{O} \cdot{ }_{398}$ Le fils d'une femme de second rang d'un grand préfet porte le deuil durant un an à la mort d'un fils de la femme principale de ce grand préfet, que le défunt soit plus âgé ou moins âgé que lui. Dans les Mémoires il est dit : «Pourquoi porte-t-il le deuil pendant un an ? Son père ne porte pas le deuil moins d'un an. Il ne se permet pas de le porter no n plus moins d'un an. »

$\mathbf{O}$ Un frère porte le deuil pendant un an à la mort du fils aîné de la femme principale de son frère, si ce frère était l'aîné de la femme principale de son père, le successeur de son père (et s'il est déjà mort). Dans les Mémoires il est dit : «Il ne se permet pas de porter le deuil moins longtemps à la mort du successeur de son père. Si ce frère aîné existe encore, le neveu n'est pas encore le chef de la famille. A la mort de la femme de ce neveu, le deuil dure le même temps qu'à la mort du neveu lui-même. »

Le successeur d'un homme qui n'a pas de fils porte le deuil durant un an à la mort de son propre père et de sa propre mère, par reconnaissance pour leurs bienfaits. Il est dit dans les Mémoires : «Pourquoi porte-t-il le deuil seulement durant un an ? On ne porte pas deux fois le plastron et la tunique sans ourlet du deuil de trois ans. Comment cela ? Celui qui observe les prescriptions du grand deuil à la mort du chef de la famille doit restreindre son deuil à la mort du chef d'u ne ${ }_{399}$ branche de la famille. Le successeur d'un homme qui n'a pas de fils, à qui succède-t-il ? Il succède au chef de la famille. Pourquoi n'agirait il pas comme chef de la famille ? - Le chef de la famille mérite le plus grand respect. Un animal connaît sa mère et ne connaît pas son père. Un sauvage dit: «Que me font à moi mon père et ma mère ? »L'officier d'un canton ou d'une bourgade sait honorer son père défunt. Un grand préfet ou un chef de gymnase sait honorer son aïeul défunt. Le chef d'un État sait étendre son respect jusqu'au premier des ancêtres illustres de sa famille. Le fils du ciel sait étendre son respect jusqu'au premier des ancêtres dont sa famille tire son origine. 
«- Les ancêtres que respecte un homme de haut rang remontent à la haute antiquité. Ceux que respecte un homme d'un rang peu élevé ne remontent pas à une haute antiquité. Le chef de la famille mérite le plus grand respect. Il conserve la race. Il n'est pas permis de ne pas lui donner de successeur. C'est pourquoi, quand il n'a pas de fils, tous les parents se réunissent et lui choisissent pour successeur un rejeton d'une branche de ${ }_{400}$ la famille. Un rejeton de la souche première de la famille ne peut pas être ce successeur. »

O Une niù tsèu fille mariée, qui chøu est sous la dépendance d'un homme, son mari, ainsi que ses tsèu enfants, porte le deuil une seule année, ainsi que ses enfants, à la mort de son père, de sa mère, et de celui de ses frères qui est le successeur de son père. Dans les Mémoires il est dit : "Pourquoi cette femme porte-t-elle le deuil une seule année à la mort de son propre père ? Une femme mariée ne porte pas deux fois la robe et le plastron sans ourlet du deuil de trois ans. Comment cela? Une femme vit successivement sous la dépendance de trois hommes. Elle ne peut pas suivre sa propre volonté. Avant le mariage, elle dépend de son père. Mariée, elle dépend de son mari. Après la mort de son mari, elle dépend de son fils. Le père est pour sa fille comme le ciel. Le mari est pour sa femme comme le ciel.

«Une femme ne porte pas deux fois le plastron et la robe sans ourlet du deuil de trois ans ; c'est comme si l'on disait que le soleil n'a pas deu x cieux. Une femme mariée ne peut pas avoir un égal respect pour deux hommes. (Elle doit montrer plus de $\bullet_{401}$ respect et garder le deuil plus longtemps pour son mari que pour son propre père). Pourquoi une femme mariée porte-t-elle aussi le deuil durant un an à la mort de celui de ses frères qui est le successeur de son père ? Bien qu'une femme mariée ait qui tté la maison paternelle, elle reste toujours la descendante des aïeux de sa famille et des aïeux de la branche de famille. C'est pourquoi elle porte le deuil durant un an. »

$\mathbf{O}$ - Un fils porte le deuil durant un an à la mort du second mari de sa mère, s'il a demeuré chez lui avec sa mère. Dans les Mémoires il est dit : «Pourquoi garde-t-il le deuil durant un an ? Dans les anciens Mémoires il est répondu: «Le mari est mort; la femme n'est pas vieille (elle n'a pas cinquante ans accomplis). Le fils est encore jeune (il a moins de quinze ans). Le fils n'a avec son beau -père, ni avec la famille de son beau-père, chez qui il a suivi sa mère, aucun lien de parenté qui l'oblige à porter le deuil pendant neuf mois. Le beau-père n'a non plus avec l'enfant aucun semblable lien de parenté.

« Le beau-père, avec l'argent de l'enfant, lui élève un temple où il lui fait présenter des offrandes aux parents de l'enfant à chaque saison de l'année. La femme n'ose pas assister à ces offrandes, (parce qu'elle a rompu avec la famille de son fils). $\bullet_{402} \mathrm{Si}$ le beau-père agit ainsi, il remplit bien ses devoirs de beau-père. A sa mort, si le fils demeure encore avec lui, il porte sur la poitrine le plastron ourlé pendant un an (par reconnaissance). S’il ne demeure plus 
avec lui, il porte le plastron ourlé pendant trois mois. Mais il faut qu'il ait demeuré chez son beau-père, avant d'occuper une autre habitation. S'il n'a jamais vécu chez lui, on ne peut pas dire qu'il se soit séparé d'habitation ; » (il ne prend pas le deuil à la mort de son beau-père).

O La femme d'un officier porte le deuil du prince de son mari pendant un an. Il est dit dans les Mémoires : "Pourquoi porte-t-elle le deuil pendant un an ? Elle porte le deuil comme son mari. »

Une tante, une sour, une fille marié e, les enfants d'une fille font comme le mari ou le père de qui ils dépendent. (A la mort d'un neveu, d'un frère, d'un oncle maternel, leur deuil est de neuf mois). Mais si le défunt n'a personne qui s'occupe de lui, la tante et les sours gardent le deuil comme si elles n'é taient pas mariées, durant un an, par reconnaissance pour l'af fection du défunt. Il est dit dans les Mémoires : "Quand le défunt n'a personne qui s'occupe de lui, c'est-à-dire, qui lui présente ces offrandes, pourquoi sa tante et ses sours gardent-elles le deuil durant une année ? C'est parce que personne ne lui ${ }_{403}$ présente d'offrande. » (elles ont compassion de lui).

Un officier porte le deuil pendant un an à la mort du père, de la mère, de la femme, du fils aîné, de l'aïeul et de l'aïeule de son prince. Dans les Mémoires il est dit : "Pourquoi garde-t-il le deuil pendant un an ? C'est pour prendre part au deuil du prince. Le prince, à la mort de son père, de sa mère, de son fils aîné, porte la robe et le plastron sans ourlet. La femme du prince est la petite princesse des sujets. (Les sujets lui donnent ce nom. Ils lui doivent du respect). Si le père du prince est mort avant l'aïeul du prince, le prince a succédé, non à son père, mais à son aïeul. Le prince porte le plastron et la robe sans ourlet à la mort de son aïeul. »

La femme de second rang porte le deuil pendant un an à la mort de la femme principale, sa maîtresse. Il est dit dans les Mémoires : "Pourquoi porte-t-elle le deuil durant un an ? La femme de second rang sert la femme principale comme la femme principale sert le père et la mère de son mari. » (Le deuil doit être le même).

$\mathbf{O}$ Une femme mariée porte le deuil pendant un an à la mort du père et de la mère de son mari. Il est dit dans les Mémoires : "Pourquoi garde-t-elle le deuil pendant un an ? C'est pour prendre part au deuil de son mari. »

$\mathbf{O} \cdot{ }_{404}$ Une femme porte le deuil durant un an à la mort d'un neveu ou d'une nièce de son mari. Dans les Mémoires il est dit : "Pourquoi garde-t-elle le deuil pendant un an ? C'est pour répondre à l'affection des enfants des

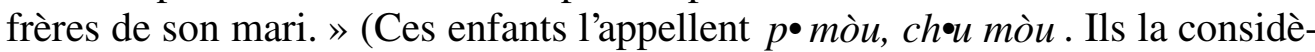
rent comme leur mère. Elle doit les traiter comme ses enfants).

O La femme de second rang d'un prince ou d'un grand pré fet porte le deuil durant un an à la mort de l'un de ses propres enfants. Il est dit dans les Mémoires : «Pourquoi porte-t-elle le deuil durant un an? Une femme de second rang ne peut pas former comme une seule et même personne avec son 
mari. (Elle ne peut pas porter le deuil durant trois ans à la mort de son fils aîné, comme la femme principale. Mais) elle peut porter le deuil durant un an à la mort de ses enfants comme la femme principale à la mort d'un enfant autre que son fils aîné. »

Une fille mariée porte le deuil durant un an à la mort du père et de la mère de son propre père, ainsi que ses enfants. Il est dit dans les Mémoires : «Pourquoi garde-t-elle le deuil durant un an ? Pour le père et pour la mère de son père, elle n'ose pas porter le deuil moins longtemps que si elle vivait encore dans la maison paternelle. »

$\mathbf{O}$ Le fils d'un grand préfet porte le deuil durant un an pour celui de ses oncles qui est le principal héritier de la $\bullet_{405}$ famille, pour la femme de cet oncle, pour ses autres oncles, pour les femmes de ses autres oncles, pour ses enfants, pour ses frères, pour les enfants de ses frères, pour ses tantes paternelles, pour ses propres sours, pour sa fille, pour les enfants de sa fille, sil n'y a personne qui présente des offrandes à leurs mânes. Seulement à la mort de la femme titrée d'un grand préfet, ce n'est pas par commisération, (mais par respect de l'usage), que le fils d'un grand préfet porte toujours le deuil durant un an. (Mîng fóu. Femme à qui le chef de l'État a conféré un titre honorifique).

Il est dit dans les Mémoires : «Le fils d'un grand préfet est lui -même grand préfet. Une tante, une sour, une fille ou une petite fille de ce fils de grand préfet a reçu un titre honorifique, et a été la femme d'un grand préfet. Elle meurt et n'a personne qui s'occupe d'elle. Une femme titrée n'a personne qui présente des offrandes à ses mânes. Pourquoi dit-on que, spécialement dans ce cas, le fils d'un grand préfet ne diminue pas le temps de son deuil ? (Sa dignité n'est pas une raison suffisante pour qu'il porte le deuil moins d'un an).

«Une femme mariée, étant, ainsi que ses enfants, sous la dépendance d'un homme (son mari ou son fils aîné), ne porte le deuil qu'un an à la mort de son propre père et de sa propre mère. (Elle porte le deuil moins longtemps que si elle vivait ${ }_{406}$ dans la maison paternelle). On dit que, par exception, à la mort de la femme titrée d'un grand préfet, son neveu, son frère ou son père, fils de grand préfet et grand préfet lui-même, p^u paò n'usent pas de commisération si elle n'a personne qui lui présente des offrandes. A la mort de ses autres tantes, de ses autres soars, de ses autres filles, il use de commisération. Pourquoi porte-t-il le deuil durant un an à la mort de cette femme titrée ? A la mort d'une personne pour qui le père ne porte pas le deuil moins longtemps, le fils n'ose pas non plus porter le deuil moins longtemps. Pourquoi un grand préfet ne porte-t-il pas le deuil moins longtemps à la mort de la femme d'un autre grand préfet, quand cette femme a reçu un titre honorifique ? C'est parce que le mari de cette femme, étant grand préfet, a tenu un haut rang à la cour, et que cette femme, ayant été la femme d'un grand préfet et ayant été décorée d'un titre honorifique, a tenu un haut rang dans sa maison. » (Un grand préfet ne trouve pas dans sa dignité une raison suffisante pour diminuer son deuil à 
la mort d'une femme titrée. Il ne prolonge pas non plus son deuil, si elle n'a personne qui lui présente des offrandes, parce que son deuil est assez long).

$\mathbf{O}$ Un grand'préfet porte le deuil durant un an à la mort de son aïeul paternel, de son aïeule paternelle, de celui de ses petits-fils qui devait être le principal héritier de la famille, même quand cet aïeul ou ce petit-fils n'a été que simple officier. Il est dit dans les Mémoires : «Pourquoi porte-t-il le deuil durant un an ? Un grand préfet n'ose pas porter le deuil moins longtemps pour le père et la mère de son père, ni pour le principal héritier de ses aïeux. »

$\mathbf{O} \cdot{ }_{407}$ Une femme de second rang, depuis celle d'un prince jus qu'à celle d'un officier inférieur, porte le deuil durant un an à la mort de son propre père et de sa propre mère. Il est dit dans les Mémoires : "Pourquoi garde-t-elle le deuil durant un an? Une femme de second rang ne forme pas comme une seule et même personne avec son mari. Par suite elle est libre de porter le deuil pour ses propres parents plus longtemps que son mari. »

ARTICLE V. De ceux qui, après avoir quitté le plastron et la robe de grosse toile ourlée, et le bandeau de chanvre mâle, ne prennent pas d'autres insignes de deuil.. (Leur deuil est fini au bout de trois mois).

O Un prince qui vit réfugié dans les États d'un autre prince porte ainsi le deuil à la mort de cet autre prince. Il est dit dans les Mémoires : «Qu'appelle-t-on prince réfugié ? C'est un prince qui a perdu ses États. Pourquoi porte-t-il le plastron ourlé durant trois mois à la mort du prince auprès duquel il vit réfugié ? il est dit que c'est pour se conformer à la pratique des sujets du prince défunt. »

O Un mari et sa femme portent le deuil durant trois mois à la mort du chef de la branche de famille, à la mort de la mère ou de la femme du chef de la branche de famille de l'un des deux époux. Il est dit dans les Mémoi res : «Pourquoi les deux époux portent-ils le plastron ourlé durant trois mois ? C'est $\bullet{ }_{408}$ par respect pour les aïeux. Par respect pour les aïeux, ils honorent le chef de la branche de famille. En honorant le chef de la branche de famille, leur intention est de témoigner leur respect envers les aïeux. Si la mère du chef de la branche de famille existe encore, les deux époux ne prennent pas le deuil à la mort de sa femme. »

O Un officier (qui a donné sa démission pour raison de vieillesse ou de santé) porte le plastron ourlé durant trois mois à la mort du prince quil a servi, et à la mort de la mère et de la femme de ce prince. Dans les Mémoires il est dit: "Quel est celui qui porte ainsi le deuil à la mort de son ancien prince ? C'est celui qui a exercé une charge au service de ce prince, et a donné sa démission. Pourquoi porte-t-il le plastron ourlé pendant trois mois ? (A la mort du prince, il garde le deuil trois mois seulement). Il est devenu simple sujet; il agit comme un simple sujet. (A la mort de la mère et de la femme du prince, il témoigne plus de respect et de reconnaissance que les simples sujets, 
parce que) il a appelé ces princesses du beau nom de Ma petite princesse. » (Il leur est plus redevable que les simples sujets).

O Les sujets qui n'ont pas de rang officiel portent le deuil durant trois mois à la mort du prince. (Ils ne portent pas le deuil plus longtemps, même lorsqu'ils exercent une petite charge, comme celle de chef de magasin).

O • ${ }_{409}$ Quand un grand préfet est allé avec sa femme vivre en pays étranger, sa femme (qui demeure avec lui et son fils aîné resté dans son ancien pays) portent le plastron ourlé durant trois mois à la mort de son ancien prince. Il est dit dans les Mémoires : «Pourquoi portent-ils le plastron ourlé durant trois mois ? La femme du grand préfet agit comme les simples sujets du prince. Son fils aîné n'a pas quitté le pays ; (il porte aussi le deuil comme un simple sujet).

$\mathbf{O}$ Un fils, à la mort du second mari de sa mère, porte le plastron ourlé durant trois mois, s'il a cessé d'habiter dans la même maison que lui.

Un arrière-petit-fils porte le plastron ourlé durant trois mois à la mort de son bisaïeul et de sa bisaïeule. Il est dit dans les Mémoires : «Pourquoi porte-t-il le plastron ourlé pendant trois mois ? Un frère porte le deuil de son frère pendant trois mois, (mais ne porte pas le plastron). Un arrière-petit-fils n'ose pas, à la mort de celui à qui il doit le plus grand respect, porter le deuil seulement comme à la mort d'un frère. » (Il y ajoute le plastron).

$\mathbf{O}$ Un grand préfet porte le plastron ourlé durant trois mois à la mort du chef de la branche de famille à laquelle il appartient.

• ${ }_{410}$ Il est dit dans les Mémoires : «Pourquoi porte-t-il le plastron ourlé durant trois mois ? Il n'ose pas (prendre pour motif sa dignité de grand préfet, et) diminuer son deuil à la mort du chef de la branche de famille. »

$\mathbf{O}$ (Un grand préfet, qui, ne pouvant pas faire agréer ses remontrances à son prince, a quitté le service de son prince et est allé demeurer dans la campagne, en attendant une sentence d'exil), porte le plastron ourlé durant trois mois, si, avant la sentence d'exil, ce prince vient à mourir. Il est dit dans les Mémoires : «Pourquoi ce grand préfet, si son prince vient à mourir, porte-t-il le plastron ourlé pendant trois mois ? Quand un grand préfet quitte le service du prince et s'en va, le prince fait balayer et tenir propre le temple des ancêtres de ce grand préfet, (afin que les descendants y présentent des offrandes aux mânes de leurs pères). C'est pourquoi le grand préfet porte le plastron ourlé durant trois mois à la mort de ce prince, comme un simple sujet du prince. De quel grand préfet est-il question ? D'un grand préfet qui a quitté le service de son prince pour de justes raisons (parce que son prince refusait de suivre ses avertissements), et qui n'a pas encore été entièrement rejeté par le prince (puisqu'il n'a pas encore été condamné à l'exil).

$\mathbf{O}$ Un grand préfet porte le plastron ourlé durant trois mois, comme les hommes du commun, à la mort de son bisaïeul et de sa bisaïeule, même quand 
son bisaïeul a été simple officier. Il $\bullet_{411}$ est dit dans les Mémoires : «Pourquoi porte-t-il le plastron ourlé durant trois mois ? Il n'ose pas diminuer son deuil pour ses aïeux à raison de la dignité de grand préfet. » (Il le diminue pour d'autres parents).

Une arrière-petite-fille, mariée ou non mariée, porte, le plastron ourlé durant trois mois, à la mort de son bisaïeul paternel et de sa bisaïeule paternelle. De même ses enfants, si elle est mariée. Il est dit dans les Mémoires : «Une fille mariée, si elle est mariée à un grand préfet, ou une fille non mariée, si elle a atteint sa vingtième année et n'est encore ni mariée ni fiancée ; pourquoi cette fille porte-t-elle le plastron ourlé durant trois mois ? Une fille n'ose pas diminuer son deuil pour ses ascendants. »

ARTICLE VI. De ceux qui portent le plastron et la robe de tá $k^{\bullet} u n g$ grosse toile, le bandeau de chanvre mâle, et $p^{\bullet} u$ cheóu n'en prennent pas d'autres dans le courant du deuil. (Tá køng. Toile portée durant le deuil de sept mois et le deuil de neuf mois).

O Un fils, une fille non mariée, une fille mariée, les enfants de cette fille portent le deuil durant neuf mois à la mort d'un frère ou d'une sœur âgé de seize à dix-neuf ans ou de douze à quinze ans. Il est dit dans les Mémoires : «Pourquoi gardent-ils le deuil durant neuf mois seulement, et non durant un an ? Parce que le défunt n'a pas atteint l'âge parfait. Pourquoi ces frères et ces - ${ }_{412}$ sœurs, après l'enterrement, ne prennent -ils pas pour le bonnet la toile qui sert pour le plastron avant l'enterrement ? Le jøu nombre des insignes de deuil et des jours durant lesquels on les porte ne varie pas avec l'âge de ceux pour lesquels on les porte, quand ils ont atteint l'âge parfait. Il varie à la mort de ceux qui n'ont pas atteint cet âge. Ainsi on ne tord pas ensemble, mais on laisse pendre librement, les extrémités des fibres du bandeau qu'on porte à la mort de ceux qui n'ont pas atteint 1 âge de vingt ans. C'est parce qu'ils n'ont pas atteint l'âge parfait. Un jeune homme qui meurt entre seize et dix -neuf ans s'appelle tcháng chøng. Celui qui meurt entre douze et quinze ans s'appelle tchøung chøng. Un enfant qui meurt entre huit et onze ans s'appelle hiá chøng.

«Un enfant qui meurt avant l'âge de huit ans accomplis est un chøng pour lequel on ne prend pas le deuil. Après la mort des enfants pour lesquels on ne prend pas le deuil, le nombre des jours pendant lesquels on pousse des lamentations varie avec le nombre des mois quils ont vécu. (Autant de mois, autant de jours de lamentations). A la mort de ces enfants pour lesquels le nombre de jours, de lamentations varie avec le nombre des mois de leur vie, on ne porte pas le deuil. Trois $\bullet_{413}$ mois après la naissance d'un enfant, son père lui donne un nom. Si cet enfant meurt, on fait entendre des lamentations. Quand un enfant meurt avant d'avoir reçu un nom, on ne pousse pas de lamentations. »

O A la mort d'un parent âgé de seize à dix -neuf ans ou de huit à onze ans, on porte le deuil durant neuf mois, si c'est le fils ou la fille d'un oncle qui 
n'est pas l'aîné, le fils ou la fille d'une tante ou d'une sour, le fils ou la fille d'un frère, le fils ou la fille d'un frère du mari, le fils o u la fille d'une fille mariée, le petit-fils ou la petite-fille d'une fille mariée, le fils ou la fille d'un petit-fils né de la femme principale. Le fils d'une femme de second rang d'un grand préfet porte le deuil durant neuf mois à la mort d'un fils ou d'une fille, qui est né de la femme principale de son père et qui a vécu de douze à dix-neuf ans.

Un prince porte le deuil durant neuf mois à la mort d'un petit-fils ou d'une petite-fille qui est né d'un fils de sa femme principale, et a vécu de douze à dix-neuf ans. Un grand préfet porte le deuil durant neuf mois à la mort d'un petit-fils ou d'une petite-fille, qui est né d'un fils de sa femme principale et a vécu de douze à dix-neuf ans.

$\mathbf{O} \cdot{ }_{414}$ Un père porte toujours pendant neuf mois le bandeau muni de cordons à la mort d'un fils âgé de seize à dix -neuf ans. Il porte pendant sept mois le bandeau sans cordons à la mort d'un fils âgé de douze à quinze ans.

ARTICLE VII. De ceux qui portent durant trois mois le plastron et la robe de toile grossière appelée tá $k \bullet u n g$, le bandeau de chanvre mâle avec cordon, la ceinture de toile ; qui, au bout de trois mois, prennent le plastron fait de toile appelée sià̀ kथung, et le bandeau fait de fibres de dolic, et qui gardent le deuil en tout neuf mois. Il est dit dans les Mémoires : "La chaîne de la toile de la tunique, pour le deuil de sept mois ou de neuf mois, est de neuf chøng (neuf fois quatre-vingts fils); pour le deuil de cinq mois, elle est de onze chøng (onze fois quatre-vingts fils). »

$\mathbf{O}$ Une tante, une sour, une fille mariée, les enfants de cette fille, vivant sous la dépendance d'un mari ou d'un père, portent le deuil durant neuf mois. Il est dit dans les Mémoires : «Pourquoi ces femmes portent-elles le deuil pendant neuf mois seulement? Elles ont quitté leurs propres familles.

O Les cousins germains portent le deuil durant neuf mois.

$\mathbf{O} \cdot{ }_{415}$ Le successeur d'un parent qui n'avait pas de fils porte le deuil durant neuf mois seulement à la mort de ses propres frères. Il est dit dans les Mémoires : «Pourquoi garde-t-il le deuil seulement durant neuf mois? Devenu successeur d'un père adoptif, (il est censé n'être plus le fils de son propre père) ; il diminue son deuil à la mort de ses propres frères. »

$\mathbf{O}$ Un aïeul porte le deuil durant neuf mois à la mort d'un petit-fils qui est né ou dont le père est né d'une femme de second rang.

$\mathbf{O}$ Le père et la mère portent le deuil durant neuf mois à la mort de la femme du fils aîné de la femme principale. Il est dit dans les Mémoires : «Pourquoi portent-ils le deuil durant neuf mois ? Leur respect pour l'aîné de la femme principale ne leur permet pas de porter le deuil moins longtemps. » 
Une fille mariée, vivant sous la dépendance de son mari, porte le deuil durant neuf mois, ainsi que ses enfants, à la mort de ses propres frères, excepté à la mort du fils aîné de la femme principale.

O Le mari et la femme paó portent le deuil tous deux ensemble durant le même temps (durant neuf mois) à la mort des neveux et des nièces du mari et de la femme. (Paó. Le mari, pour répondre à l'affection de sa femme ; la femme, pour répondre à l'affection de son mari). Il est dit dans les Mémoires : «Qu'appelle-t-on ici neveux et nièces ? Celle que nous appelons $\bullet_{416} k \bullet u$ sour de notre père nous appelle neveux ou nièces. »

O A la mort d'une femme, l'aïeul et l'aïeule du mari, l'aîné des oncles et les autres oncles du mari, ainsi que leurs femmes, portent le deuil durant neuf mois. Il est dit dans les Mémoires : «Pourquoi portent-il le deuil durant neuf mois ? C'est pour s'associer au deuil du mari. Pourquoi les frères du mari ne prennent-ils pas le deuil ? Le mari a des devoirs de père à remplir ; la femme a toujours des devoirs de mère. Le mari a des devoirs de fils; la femme a toujours des devoirs d'épouse. Les femmes des frères puînés sont des épouses. (Chacune d'elles remplit des devoirs envers son mari, mais n'a pas de devoirs à remplir envers les frères de son mari. Ceux-ci ne lui doivent aucune reconnaissance). Seule la femme du frère aîné peut être considérée comme une mère. Aussi le nom que l'usage lui a décerné est un nom honorable. (Elle s'appelle saò. Cette lettre est composée de la lettre seòu, qui signifie vieillard, homme digne de respect). Les frères puînés de son mari ne doivent-ils pas y faire attention, » (et prendre le deuil à sa mort,) ?

$\mathbf{O}$ Un grand préfet porte le deuil durant neuf mois à la mort d'un oncle, soit plus âgé, soit moins âgé que son père, à la mort de la femme d'un oncle ; à la mort d'un fils ; à la mort d'un $\bullet_{417}$ frère, soit plus âgé soit moins âgé que lui ; à la mort du fils d'un frère ; cela, si le défunt est un simple officiel. Il est dit dans les Mémoires : "Pourquoi garde-t-il le deuil pendant neuf mois seulement ? C'est que le défunt lui est inférieu r en dignité. Si la dignité était la même, le grand préfet devrait garder le deuil comme la parenté le demande (durant un an). »

$\mathbf{O}$ Ceux des frères d'un prince qui sont nés de femmes de second rang, ceux des fils d'un grand préfet qui sont nés de femmes de second rang, portent le deuil durant neuf mois seulement à la mort d'une mère, d'une femme ou d'un frère. Il est dit dans les Mémoires : «Pourquoi portent-ils le deuil durant neuf mois seulement? Les fils que le prince leur père, de son vivant, à cause de sa dignité supérieure, a réduits à porter le deuil moins longtemps, ne peuvent pas, quand leur père n'existe plus, garder le deuil plus de neuf mois. Les fils d'une femme de second rang d'un grand préfet, du vivant de leur père, portent le deuil moins longtemps, parce que leur père le porte moins longtemps (à cause de sa dignité). Quand le père ne porte pas le deuil moins longtemps, le fils ne se permet pas de le garder moins longtemps. » (Un grand préfet porte le deuil aussi longtemps que les hommes du commun à la mort 
d'un fils né de sa principale femme, à la mort de la femme de ce fils,... Ses fils l'imitent).

$\mathbf{O} \cdot{ }_{418}$ Toujours un grand préfet porte le deuil durant neuf mois à la mort d'un cousin germain du côté paternel, quand ce cou sin a té grand préfet.

Une femme porte le deuil durant neuf mois à la mort de la femme d'un frère de son mari, et à la mort des enfants de cette femme, si cette femme, si ces enfants vivaient encore sous la dépendance de ce frère.

Une femme de second rang d'un grand préfet porte le deuil durant neuf mois à la mort d'un fils d'une autre femme de second rang de son kiøn mari.

O La fille (d'une femme de second rang d'un grand préfet), qu'elle soit mariée ou non, si elle est à l'âge de se marier, porte le deuil durant neuf mois à la mort de l'un de ses oncles, à la mort de la femme de l'un de ses oncles, à la mort d'un e sour de son père, à la mort de l'une de ses propres søurs. Ses enfants portent aussi le deuil durant neuf mois, si elle est mariée. Il est dit dans les Mémoires : «La fille d'une femme de second rang d'un grand préfet, si elle est mariée à un grand préfet, ou bien, si elle a atteint sa vingtième année, et n'a pas encore contracté mariage ; pourquoi cette fille porte-t-elle le deuil durant neuf mois ? La femme de second rang d'un grand préfet doit porter le deuil à la mort des parents de son mari comme la femme ${ }_{419}$ principale. Ensuite il est dit qu'elle porte le deuil durant neuf mois à la mort d'un de ses oncles paternels, à la mort d'une femme d'un oncle paternel, à la mort d'une tante, à la mort d'une søur. Cela signifie qu'une femme de second rang d'u n grand préfet porte le deuil durant neuf mois à la mort de ses propres parents. »

$\mathbf{O}$ Un grand préfet, la femme, le fils et la fille d'un grand préfet, le frère d'un prince portent le deuil durant neuf mois à la mort d'une tante ou d'une soar, à la mort d'u ne fille mariée, et à la mort d'un enfant de l'une de ces parentes, si cette parente est mariée à un grand préfet. Un prince porte le deuil durant neuf mois à la mort d'un tante, d'une sœur ou d'une fille, à la mort d'un enfant de l'une de ces parentes, si cette parente est mariée au chef d'un État. Il est dit dans les Mémoires : «Pourquoi ce grand préfet, ce prince,.. portent-ils le deuil durant neuf mois ? C'est que la dignité est la même des deux côtés (du côté de la personne défunte et du côté de la personne qui porte le deuil). Quand la dignité est la même, il convient de ne pas diminuer le deuil à la mort des parents. Le fils d'un chef d'État s'appelle fils de prince. (S'il n'est pas le successeur de son père), il ne peut pas élever de temple à son ${ }^{\bullet}{ }_{420}$ père) le prince défunt. Le petit-fils d'un chef d'État s'appelle petit -fils de prince. (S'il n'est pas le successeur de son aïeul), il ne peut pas élever de temple à son aïeul qui était chef d'un État. C'est parce que ce fils ou ce petit-fils est comme le rameau d'un tronc plus noble que lui. Quand l'arrière -petit-fils d'un prince devient chef d'un État autre que celui de son bisaïeul, les successeurs de cet arrière-petit-fils, de génération en génération, l'honorent comme le chef de leur famille ; ils n'honorent pas comme tel le fils 
du prince son père. C'est que cet arrière -petit-fils est comme le rameau d'un tronc moins noble que lui.

«C'est pourquoi celui des membres d'une famille qui le premier devient chef d'État ne commande ni à ses oncles ni à ses frères comme à des sujets. Le fils du fondateur d'un État ne commande pas à ses oncles comme à des sujets, mais il traite ses frères comme des sujets. Le petit fils du fondateur d'un État traite tous ses oncles et tous ses frères comme ses sujets. Pour la même raison, le fils d'un prince ne se permet pas de ne pas porter le deuil à la mort de ceux pour lesquels son père porte le deuil; il ne se permet pas de porter le deuil à la mort de ceux pour lesquels son père ne porte pas le deuil. »

- ${ }_{421}$ ARTICLE VII. Ceux qui portent le plastron et la robe de souéi toile mince et claire, le bandeau et la ceinture de brins de chanvre mâle, et qui déposent ces insignes de deuil après l'ent errement.

Il est dit dans les Mémoires : (Qu'appelle-t-on plastron de souéi ? C'est celui qui est fait d'une toile mince et claire semblable à la toile du deuil de cinq mois.

O Un ministre d'État d'une principauté porte le plastron de toile mince et claire à la mort du fils du ciel. Il est dit dans les Mémoires : «Pourquoi porte-t-il le plastron de toile mince et claire ? C'est parce que, dans les chêu tsi• réunions qui ont eu lieu à la cour impériale aux époques fixées, hién il s'est présenté devant le fils du ciel. »

ARTICLE VIII. Ceux qui portent le plastron et la robe de toile du deuil de cinq mois, la ceinture et le bandeau de brins de chanvre tsaò lavé et nettoyé, et qui gardent ces insignes durant cinq mois.

$\mathbf{O}$ Ce deuil est porté durant cinq mois à la mort d'un enfant qui était âgé de huit à onze ans, et qui était fils ou fille, soit d'un oncle autre que l'aîné de la femme principale, soit d'un petit-fils de l'aîné des oncles nés de la femme principale, soit • ${ }_{422}$ d'un frère. Le fils d'un grand préfet, s'il n'est pas l'aîné de la femme principale, porte le deuil durant cinq mois à la mort d'un enfant qui était âgé de huit à onze ans, et qui était fils ou fille soit d'un frère né de la femme principale du grand préfet, soit d'une tante ou d'une sœur, soit d'une fille, soit d'une petite-fille. Le successeur d'un homme mort sans enfant mâle porte le deuil durant cinq mois à la mort d'un jeune homme qui était âgé de seize à dix-neuf ans, et qui était fils, soit d'un frère, soit d'un cousin germain.

Il est dit dans les Mémoires : «On demandera pourquoi l'on ne parle pas d'un enfant qui meurt âgé de douze à quinze ans. A la mort d'un enfant âgé de douze à quinze ans, on porte le deuil comme s’il était mort âgé de s eize à dix-neuf ans, dans le cas ou l'on devrait porter le deuil durant neuf mois, s'il avait atteint l'âge mûr. On porte le deuil comme s'il était mort âgé de huit à 
onze ans, dans le cas où l'on devrait porter le deuil seulement trois mois, s'il était mort à l'âge mûr. »

$\mathbf{O}$ Une femme porte le deuil durant trois mois à la mort d'un jeune homme qui est âgé de seize à dix-neuf ans, et qui est fils d'un oncle du mari autre que l'aîné de la famille. Elle porte le deuil durant trois mois à la mort d'un enfant qui est âgé de huit à onze ans, et qui est né soit d'un fils de l'un de ses propres frères, soit d'une de ses propres filles, soit d'un fils ou d'une fille d'une de ses propres filles, soit d'un fils d'un fils d'un $\bullet{ }_{423}$ frère de son mari, soit d'une fille de son mari, soit du fils ou d'une fille d'une fille de son mari. Elle porte le deuil durant trois mois à la mort d'un jeune homme qui est âgé de seize à dix -neuf ans, et qui est né soit, de l'un de ses propres neveux, soit d'un petit -fils ou d'une petite-fille dont le père n'est pas l'aîné. Une femme de second rang porte le deuil durant trois mois à la mort d'un jeune homme qui est âgé de seize à dix-neuf ans, et qui est né de la femme principale de son mari.

$\mathbf{O}$ Un grand préfet, le frère d'un prince, le fils d'un grand préfet portent le deuil durant trois mois à la mort d'un jeune homme qui est âgé de seize à dix-neuf ans, et qui est né soit d'un frère, soit d'un fils autre que l'aîné, soit d'une tante ou d'une sœur, soit d'une fille, soit d'un fils ou d'une fille de cette fille.

Une femme de second rang d'un grand préfet porte le deuil durant trois mois à la mort d'un jeune homme qui est âgé de seize à dix -neuf ans et dont le père est un fils du grand préfet autre que l'aîné.

ARTICLE IX. Ceux qui portent le plastron et la robe de toile du deuil de cinq mois, le bandeau et la ceinture de fibres de chanvre mâle, puis le bandeau et la ceinture de fibres de dolic, et qui gardent le deuil durant cinq mois.

$\mathbf{O}$ Les frères de l'aïeul paternel et leurs femmes, les neveux de l'aïeul paternel et leurs femmes portent le deuil durant cinq ${ }_{424}$ mois, les deux époux ensemble, à la mort des parents de l'un ou de l'autre, paó par affection l'un pour l'autre.

$\mathbf{O}$ Les fils des frères de l'aïeul paternel portent le deuil durant cinq mois. De même les filles des oncles paternels. De même, les petits-fils et les petites filles qui vivent sous la dépendance d'un père, d'un mari,...

O Le successeur, d'un parent qui est mort sans laisser de fils, porte le deuil durant cinq mois à la mort de ses propres sours qui vivaient sous la dépendance de leurs maris ou de leurs fils aînés.

$\mathbf{O}$ Un fils porte le deuil durant cinq mois (au lieu de trois mois) à la mort du père et de la mère de sa nièce. Il est dit dans les Mémoires : "Pourquoi porte-t-il le deuil durant cinq mois ? Il augmente le temps du deuil par respect. » (Il les appelle tsòu vénérables). 
O A la mort d'une tante maternelle (soit du mari soit de la femme), le mari et la femme paó se rendent la pareille, c'est-à-dire, portent tous deux le deuil durant cinq mois. Il est dit dans les Mémoires : «Pourquoi gardent-ils le deuil durant cinq mois ? Ils portent le deuil plus longtemps à cause du nom vénérable mòu quills donnent à la tante. A la mort des parents du côté des femmes, généralement le deuil est de trois mois seulement. »

O Un mari et sa femme portent le deuil durant cinq mois à la mort d'une tante ou d'une sour du mari ou de la femme, paó par affection réciproque.

La femme d'un frère puîné et la femme d'un frère plus âgé • ${ }_{425}$ portent le deuil durant cinq mois à la mort l'une de l'autre, paó par affection réciproque. Il est dit dans les Mémoires : «La femme du frère puîné, étant nommée la première, est supposée être la plus âgée des deux. Pourquoi, l'une des deux venant à mourir, l'autre porte-t-elle le deuil durant cinq mois ? Parce qu'elles ont demeuré ensemble dans une même maison, dans la maison du père de leurs maris, il en résulte un lien de parenté qui exige cinq mois de deuil. »

$\mathbf{O}$ Un grand préfet, le fils d'un grand préfet, les frères d'un chef d'État portent le deuil durant cinq mois à la mort d'un cousin germain du côté paternel, d'un petit-fils qui n'est pas le fils de l'aîné. De même à la mort d'une tante, d'une fille et de ses enfants vivant sous la dépendance d'un simple officier leur mari ou leur père.

Une femme de second rang d'un grand préfet porte le deuil durant cinq mois à la mort d'une fille de l'un des fils de ce grand préfet autre que l'aîné de la femme principale, si la défunte vivait sous la dépendance de son mari ou de son fils aîné. De même, à la mort de la femme d'un fi ls de ce grand préfet autre que le fils aîné de la femme principale.

$\mathbf{O}$ Une femme de second rang d'un prince porte le deuil durant cinq mois à la mort du père et de la mère de la mère du prince, pour s'associer au deuil de sa mère. Il est dit dans les Mémoires : $\bullet_{426}$ « Pourquoi garde-t-elle le deuil durant cinq mois ? Du vivant de la mère du prince, elle n'ose pas ne pas porter le deuil comme elle. Quand la mère du prince n'existe plus, elle ne porte pas le deuil. »

$\mathbf{O}$ Un fils ou un petit-fils d'un prince porte le deuil durant cinq mois à la mort d'une femme de second rang qui a été sa mère nourricière. Il est dit dans les Mémoires : «Le fils ou le petit-fils d'un prince est le fils d'un père élevé en dignité. A la mort d'une femme de second, rang de son père, pourquoi garde-t-il le deuil durant cinq mois ? Il augmente la durée de son deuil, parce que cette femme l'a soigné avec l'affection d'une mère. »

ARTICLE X. De ceux qui portent le plastron et la tunique de søu fine toile de chanvre, le bandeau et la ceinture de brins de chanvre, et gardent le deuil durant trois mois. 
Dans les Mémoires il est dit : «(La chaîne de la toile de chanvre dont on fait des vêtements de cour) se compose de quinze écheveaux de 80 fils chacun, en tout 1200 fils). La chaîne de la toile du deuil de trois mois tch'eôu $k$ ı̂ pán se compose d'un nombre d'écheveaux de fils moitié moindre (en tout 600 fils). Le fil est chéu bien travaillé. (Il est semblable à celui dont on fait des vêtements de cour. Il est fin comme le $\bullet_{427} s \bullet u$ fils de soie). Mais la toile n'est pas travaillée (n'est pas lustrée). Cette toile très fine et très claire s'appelle sथ . »

$\mathbf{O}$ On porte le deuil durant trois mois à la mort des parents en ligne collatérale et de leurs femmes, depuis les fils du trisaïeul jusqu'aux petits -fils des arrière-petits-fils du trisaïeul inclusivement (cinq générations).

De même à la mort de la femme, et à la mort d'un fils de douze à quinze ans d'un petit -fils qui n'est pas la fils aîné de la femme principale.

$\mathbf{O}$ Le mari et la femme portent le deuil durant trois mois à la mort d'une tante ou d'une cousine germaine du père du mari ou du la femme, lorsqu'elle vit sous la dépendance de son mari ou de son fils aîné. On porte le deuil durant trois mois à la mort d'un jeune homme qui est âgé de seize à dix neuf ans, et qui est fils d'un cousin germain ou d'un cousin issu de germain du père. De même, à la mort du fils ou du petit-fils d'une fille mariée. De même, à la mort d'un enfant qui est âgé de huit à onze ans, et qui est fils d'un neveu du père.

Une femme porte le deuil durant trois mois à la mort d'un enfant qui est âgé de douze à quinze ans ou de huit à onze ans, et qui est le fils d'un oncle puîné de son mari.

$\mathbf{O} \cdot{ }_{428}$ Le mari et la femme portent tous deux le deuil durant trois mois à la mort d'un jeune homme qui est âgé de seize à dix-neuf ans, et qui est fils d'une tante maternelle du mari ou de la femme.

$\mathbf{O}$ Un fils d'une femme de second rang qui est le successeur de son père (parce que la femme principale de son père n'a pas de fils) porte le deuil durant trois mois à la mort de sa propre mère. Dans les Mémoires il est dit : «Pourquoi porte-t-il le deuil durant trois mois seulement? On lit dans des Mémoires anciens : "Il participe à la dignité de son père (il est censé être le fils aîné de la femme principale de son père). Il n'ose pas porter le deuil à la mort de ses parents particuliers. Alors, pourquoi porte-t-il le deuil durant trois mois ? Lorsqu'il meurt quelqu'un dans la maison, (ne serait-ce qu'un simple officier), à cause de sa mort, les offrandes aux esprits cessent durant trois mois. (Toutes les cérémonies, funèbres ou joyeuses, cessent). C'est pourquoi ce fils peut porter le deuil pendant trois mois. » (Il n'est obligé à assister à aucune cérémonie incompatible avec le deuil).

$\mathbf{O}$ Un simple officier porte le deuil durant trois mois à la mort d'une femme de second rang de son père. Il est dit dans les Mémoires : «Pourquoi porte-t-il le deuil pendant trois mois ? Il porte le deuil à la mort de cette 
femme parce qu'il lui donne le nom de mère. Un grand préfet ou un dignitaire supérieur ${ }_{429}$ à un grand préfet ne porte pas le deuil à la mort d'une femme de second rang de son père. »

$\mathbf{O}$ Un ministre d'État ou u n grand préfet porte le deuil durant trois mois à la mort d'un subalterne qui exerçait une haute charge, ou d'une femme de second rang qui avait autorité sur les autres femmes de son sérail. Dans les Mémoires il est dit : «Pourquoi porte-t-il le deuil durant trois mois ? C'est à cause de la dignité de cet officier ou de cette femme. »

Un homme porte le deuil durant trois mois à la mort de sa nourrice. Dans les Mémoires il est dit : "Pourquoi porte-t-il le deuil durant trois mois ? Il porte le deuil, parce qu'il l'appelle sa mère. »

O On porte le deuil durant trois mois à la mort d'un fils d'un cousin germain. De même à la mort d'un arrière -petit-fils. De même, à la mort d'une tante du père.

$\mathbf{O}$ De même, à la mort d'un fils d'une scur de la mère. Il est dit d ans les Mémoires : «Pourquoi porte-t-on le deuil pendant trois mois ? On porte le deuil, parce qu'un homme appelle du nom de mère la sour de sa propre mère. »

O Un frère porte le deuil durant trois mois à la mort du fils d'une saur. Il est dit dans les Mémoires: Qu'appelle-t-on chøng Nous appelons chøng les enfants de notre sœur. Pour quoi un frère porte-t-il le deuil durant trois mois à la mort des enfants de sa sœur ? C'est par réciprocité. (Les enfants d'une sœur portent le deuil durant trois mois à la mort d'un de leurs oncles maternels).

$\mathbf{O} \cdot{ }_{430}$ Un mari et sa femme portent le deuil durant trois mois à la mort du mari de leur fille. Il est dit dans les Mémoires : «Pourquoi portent-ils le deuil durant trois mois ? C'est un devoir réciproque. » (Le mari de la fille porte le deuil durant trois mois à la mort du père et de la mère de sa femme).

$\mathbf{O}$ Un mari porte le deuil durant trois mois à la mort du père et de la mère de sa femme. Il est dit dans les Mémoires : "Pourquoi porte-t-il le deuil durant trois mois ? C'est pour s'as socier au deuil de sa femme. »

O On porte le deuil durant trois mois à la mort du fils d'une tante paternelle. Il est dit dans les Mémoires : «Pourquoi porte-t-on le deuil durant trois mois ? C'est par réciprocité. » (Le fils d'une tante porte le deuil durant trois mois à la mort du fils de son oncle maternel).

O Un fils porte le deuil durant trois mois à la mort d'un frère de sa mère. Il est dit dans les Mémoires : «Pourquoi porte-t-elle deuil durant trois mois ? C'est pour s'asso cier au deuil de sa mère. »

O Un fils porte le deuil durant trois mois à la mort du fils d'un oncle maternel. Il est dit dans les Mémoires : «Pourquoi porte-t-il le deuil durant trois mois ? C'est pour s'associer au deuil de sa mère. » 
$\mathbf{O} \cdot{ }_{431}$ Une femme porte le deuil durant trois mois à la mort d'un jeune homme qui est âgé de seize à dix-neuf ans, et qui est le fils d'une tante ou d'une sœur de son mari.

$\mathbf{O}$ Une femme porte le deuil durant trois mois à la mort du bisaïeul et de l'aïeul de so $n$ mari, et réciproquement.

$\mathbf{O}$ Un sujet porte le deuil durant trois mois à la mort des frères de la mère de son prince (si la mère vit encore). Il est dit dans les Mémoires : «Pourquoi porte-t-il le deuil durant trois mois ? C'est pour s'associer au deuil d e la mère. »

$\mathbf{O}$ On porte le deuil durant trois mois à la mort d'un jeune homme qui est âgé de seize à dix-neuf ans, et qui est le fils ou le petit-fils d'un cousin germain du côté paternel. Une femme porte le deuil durant trois mois à la mort de la femme d'un cousin germain de son mari.

Il est dit dans les Mémoires: "Pourquoi ce deuil de trois mois? L'habitation dans une même maison a créé un lien de parenté qui exige le deuil de trois mois. Lorsqu'un parent meurt âgé de seize à dix neuf ans ou de douze à quinze ans, le deuil est d'un degré moindre que s'il était mort à l'âge mûr. Lorsqu'il meurt âgé de huit à onze ans, le deuil est de deux degrés $\bullet_{432}$ moindre. Lorsqu'un parent meurt âgé de douze à quinze ans, on porte le deuil comme s'il était mort âgé de seize à dix -neuf ans, dans le cas où l'on aurait porté le plastron ourlé, s’il était mort à l'âge mûr. On porte le deuil comme s'il était mort âgé de huit à onze ans, dans le cas où l'on aurait porté le deuil pendant neuf mois, s'il était mort à l'âge mûr. »

\section{NOTES SUPPLÉMENTAIRES.}

Le fils d'une femme de second rang d'un prince, à la mort de sa propre mère, porte le bonnet de soie cuite, le bandeau et la ceinture de chanvre, la tunique de chanvre avec des bordures rougeâtres. A la mort de sa femme, il porte le bonnet de soie rougeâtre, le bandeau et la ceinture de fibres de dolic, la tunique de chanvre à bordures rougeâtres. Après l'enterrement, il quitte tous ces insignes. Il est dit dans les Mémoires : "Pourquoi ne porte-t-il pas les insignes de l'un des cinq degrés de deuil, et pourquoi ne garde-t-il pas le deuil le temps accoutumé ? A la mort de ceux pour lesquels le prince son père ne porte pas le deuil, le fils n'ose pas porter le deuil. A la mort de ceux pour lesquels le prince porte le deuil, le fils n'ose pas ne pas porter le deuil. »

$\mathbf{O} \cdot \bullet_{433}$ Un grand préfet (à cause de sa dignité), le frère d'un prince (à raison de la dignité de son frère), le fils d'un grand préfet (à cause de la dignité de son père), diminuent leur deuil d'un degré à la mort d'un parent en ligne collatérale. 
O Le successeur d'un parent mort sans enfant mâle diminue son deuil d'un degré à la mort de ses propres parents en ligne collatérale, et réciproquement. Il porte le deuil comme s'il était le fils de celui à qui il succède, à la mort des parents en ligne collatérale de cet homme.

O Quand deux cousins du côté paternel vivent en pays étranger, si l'un d'eux vient à mourir, l'autre augmente son deuil d'un degré. Quand deux cousins n'ont connu ni leurs pères ni leurs mères (parce que leurs parents sont morts ou les ont quittés de bonne heure), si ces deux cousins vivent ou ont vécu dans la même maison, à la mort de l'un d'eux, l'autre augmente son deuil d'un degré.

Dans les Mémoires il est dit : «De quels cousins est-il question ? On lit dans les anciens Mémoires : «Il s'agit de deux cou sins desquels, si l'un vient à mourir dans les circonstances ordinaires, l'autre porte le deuil durant cinq mois au plus. »

$\mathbf{O} \cdot{ }_{434}$ Quand deux amis vivent ensemble en pays étranger, (si l'un deux vient à mourir, et n'a pas de parent qui préside aux cérémonies funèbres, l'autre y préside) ; il se découvre le bras gauche et porte la coiffure de deuil. Après le retour à la maison, cette obligation cesse, (si le défunt a un parent qui préside aux cérémonies funèbres).

O Un ami, à la mort de son ami, porte le bandeau et la ceinture de chanvre, (chaque fois quill entre dans la maison de son ami).

O Quand le maître (ministre d'État ou grand préfet) porte le deuil à la mort d'un parent du côté paternel en ligne collatérale de la même génération que lui, l'intendant porte aussi le deuil, un deuil moindre d'un degré.

O Quand le mari porte le deuil à la mort d'un parent du côté paternel en ligne collatérale de la même génération que lui, la femme porte aussi le deuil, un deuil moindre d'un degré.

O Quand le fils d'une femme de second rang est le succes seur de son père, (parce que la femme principale n'a pas de fils), il ne porte pas le deuil à la mort du père ni de la mère ni d'un frère de sa mère. Quand il n'est pas successeur, il porte le deuil comme les habitants de la contrée à la mort de leurs parents.

O Quand le chef d'une branche de famille est un enfant ou un jeune homme orphelin, et meurt avant l'âge de vingt ans, $\bullet_{435}$ ses proches parents, pendant trois mois, portent, les uns le plastron du deuil de neuf mois, les autres le plastron du deuil de cinq mois. Ses autres parents portent pour lui le deuil un nombre de mois plus ou moins grand selon leur degré de parenté, comme les habitants de la contrée. 
O Quand on déterre un mort et qu'on l'enterre dans un autre endroit, tous ses parents et ses officiers portent les insignes du deuil de trois mois durant trois mois.

O On porte le deuil durant trois mois à la mort d'un jeune homme qui n'a pas encore reçu le bonnet viril, a perdu son père et n'a pas encore dix -neuf ans, seulement dans le cas où il gère déjà les affaires domestiques. Il est dit dans les Mémoires : "S’il ne gère pas les aff aires domestiques, on ne porte pas le deuil durant trois mois. »

Une femme de second rang porte toujours le deuil durant trois mois à la mort de ses propres frères ou cousins, comme les autres habitants de la contrée.

O Lorsqu'un grand préfet, à la mort d' une femme honorée d'un titre, fait une visite de condoléance, il porte un plastron de toile très fine et très lisse. Lorsqu'une femme titrée fait une visite de condoléance à la mort d'un grand préfet, elle porte aussi un plastron de cette toile. Il est dit dans les Mémoires : "Qu'appelle-t-on $s \bullet$ ? C'est une toile de chanvre qui a été tra vaillée, lustrée. La chaîne de la fine toile de chanvre dont on ${ }_{436}$ fait les vêtements de cour se compose de quinze écheveaux de 80 fils chacun, en tout 1200 fils. La chaîne de la toile appelée $s^{\bullet}$ est faite d'un fil semblable ; mais tch'e u kî pán elle se compose d'un nombre d'écheveaux moitié moindre, sept éche veaux et demi, en tout 600 fils. Le fil de cette toile ôu chéu n'est pas travaillé ; mais la toile elle-même est travaillée, lustrée, elle s'appelle $s^{\bullet}$. »

O Une fille mariée qui vit avec ses filles sous la dépendance de son mari, à la mort de son propre père ou de sa propre mère, enroule ses cheveux en forme de chignon, qu'elle fixe au moyen d'une mauvaise épingle qui a une tête. Les filles qui vivent avec elle font de même. Une femme mariée fait aussi de même à la mort du père ou de la mère de son mari. Le temps des pleurs continuels écoulé, la fille mariée et ses filles cassent la tête de leurs belles épingles de tête ordinaire, enveloppent leurs cheveux d'un linge, et les fixent au moyen de leurs belles épingles ordinaires dont la tête est cassée.

Dans les Mémoires il est dit: «Épingle à tête : la mauvaise épingle a une tête. Elle est faite du même bois que les $t c h \bullet$ peignes (bois de coudrier). Une fille mariée, après la mort de son père ou de sa mère, casse la tête de son épingle, c'est-à-dire, la tête de la belle épingle qu'elle porte quand elle n'est pas en deuil. Cette épingle est d'ivoire. Après avoir dit qu' une fille mariée casse la tête de son épingle d'ivoire à la mort de son père et de sa mère, pourquoi n'ajoute-t-on pas qu'une femme mariée $\bullet_{437}$ casse la tête de son épingle d'ivoire à la mort du père ou de la mère de son mari ? Une femme mariée, à la mort du père ou de la mère de son mari, porte la mauvaise épingle de bois jusqu'à la fin du deuil. »

O Une femme de second rang, à la mort de la femme principale ou du fils aîné de la femme principale, lie sa chevelure avec une bande de toile, qu'elle fixe au moyen d'une mauvaise épingle à tête. 
Toujours les bandes de toile dont le plastron est composée sont entaillées, (afin que le plastron prenne bien la forme de la poitrine), et les entailles paraissent au dehors. Les bandes de toile dont la jupe est composée sont aussi entaillées (à l'endroit des reins, afin que la jupe soit étroite à sa partie supé rieure) ; les entailles sont cachées à l'intérieur. Chaque bande de toile a trois entailles. S'il y a des ourlets, les ourlets de la jupe sont cachés à l'inté rieur ; ceux du plastron sont à l'extérieur. La planche qu'on porte sur le dos en temps de deuil, dans sa largeur, dépasse d'un ts'uén $(4 \mathrm{~cm})$ le ch $u$ collet carré qu'on porte sur le cou. Ce collet est large de quatre ts'uén $(8 \mathrm{~cm})$; en avant il descend sur le plastron. Le plastron a six ts'uén $(12 \mathrm{~cm})$ de long ou de haut et quatre ts'uén $(8 \mathrm{~cm})$ de large.

La tunique descend d'un $t c h ' \bullet(20 \mathrm{~cm})$ au dessous de la ceinture. Les jèn pans de la tunique (en forme de queue d'hirondelle) ont deux $t c h$ ' $u$ et cinq ts'uén $\left(50 \bullet_{438} \mathrm{~cm}\right)$ de long. Les manches sont faites chacune d'une pièce de toile prise dans toute sa largeur ( 2 tch'u et 2 ts'uén, $44 \mathrm{~cm})$. Le $\bullet$ corps des manches (le pourtour des manches en leur milieu) est de $44 \mathrm{~cm}$ L'ouverture $k i \bullet$ des manches, à leur extrémité, a un $t c h$ 'u deux ts'uén de pourtour $(24 \mathrm{~cm})$.

O Lorsque, au commencement du deuil, la chaîne de la toile du plastron se compose de trois écheveaux ou de trois écheveaux et demi de 80 fils chacun, la chaîne de la toile du bonnet se compose de six écheveaux. Après l'enterrement, cheóu on prend, pour faire le plastron, une toile semblable à celle qui a servi à faire le bonnet. La chaîne de cette toile se compose de sept écheveaux. Lorsque, au commencement du deuil, la chaîne de la toile du plastron ourlé se compose de quatre écheveaux de 80 fils chacun, la chaîne de la toile du bonnet se compose de sept écheveaux. Après l'enterrement, on prend, pour faire le plastron, une toile semblable à celle qui a servi à faire le bonnet. La chaîne de cette toile se compose de huit écheveaux.

La chaîne de la toile souéi du plastron porté par les grands préfets des princes à la mort du fils du ciel se compose de quatre écheveaux et demi de 80 fils chacun. La chaîne de la toile du bonnet se compose de huit écheveaux.

La chaîne de la toile du deuil de neuf mois se compose de huit ou de neuf écheveaux. La chaîne de la toile du deuil de cinq mois se compose de dix ou de onze écheveaux.

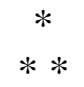




\section{CHAPITRE XII}

\section{Cérémonies funèbres à la mort d'un officier}

O $\cdot_{439} \cdot$ Le mort est dans la salle principale de ses appartements particuliers. On couvre son corps du linceul dans lequel on l'enveloppera, quand on le parera de tous ses vêtements.

O Un homme seul, chargé de rappeler l'âme de l'officier défunt, prend le bonnet de peau couleur tête de moineau et le vêtement correspondant de l'officier, met la jupe sur la tunique, et les porte ensemble sur l'épaule gauche, le collet de la tunique enfoncé sous sa ceinture. Il monte sur le faîte du toit par l'extrémité orientale du pan antérieur (pan méridional) du toit. Au milieu du toit, le visage tourné vers le nord, il rappelle l'âme du défunt en lui montrant les vêtements, et en lui disant : «Un tel, je vous crie de revenir. » Il pousse ce cri trois fois. Il laisse tomber les vêtements du défunt devant (au midi de) la salle. Un autre officier recueille ces vêtements dans une corbeille, et montant par les degrés orientaux, les met sur le corps du défunt. L'officier qui a rappelé l'âme descend du toit par l'extrémité occidentale du pan postérieur (pan septentrional) du toit.

$\mathbf{O} \cdot{ }_{440}$ On met entre les dents du mort une cuiller de corne qui tient les mâchoires ouvertes. On attache les pieds du mort aux pieds d'un escabeau qui ién les tient en repos (et empêche les jambes de se contourner).

On dépose près du défunt des tranches de viande séchées, de la viande hachée et conservée dans le sel et le vinaigre, du vin non fermenté ou du vin fermenté. On monte par les degrés orientaux, et on place ces mets et cette boisson à l'est du cadavre (étendu sur son lit).

O Le corps du mort est placé sur la plateforme au midi de la salle, et entouré de tentures.

O Un envoyé va au palais annoncer au prince la mort de l'officier. Le chef de la maison, c'est-à-dire, le père ou le plus âgé des frères du mort, prescrit à cet envoyé ce quỉl faut dire au prince, et le salue à genoux à son départ.

O S'il vient un étranger (un ami ou un collègue du défunt), le maître de la maison le salue à genoux. L'étranger entre, et se met à genoux à l'est du lit du mort. Tous les maitres de la maison, c'est-à-dire, les frères du défunt, sont (debout) derrière, au nord du lit, le visage tourné vers l'ouest. Les femmes de la maison sont (à genoux), $k i \bullet$ vis-à-vis des hommes, à l'ouest du lit, le visage tourné vers l'est. Tous les autres proches parents, hommes et femmes, sont dans la salle. Les femmes dont la $\bullet_{441}$ parenté est plus éloignée sont dehors, à la porte de la salle, le visage tourné vers le nord. Les hommes qui ne sont pas 
très proches parents sont au bas de la plateforme de la salle, le visage tourné vers le nord.

$\mathbf{O}$ Le prince envoie un officier faire une visite de condoléance. On enlève les tentures qui sont autour du mort. Le chef de la maison va recevoir l'envoyé du prince jusqu'en dehors de la grande porte des appartements particuliers. En voyant l'en voyé, il ne pousse pas de lamentations. Il entre le premier, et se tient au côté droit de la grande porte, le visage tourné vers le nord. L'e nvoyé qui apporte les condoléances du prince, entre, monte par les degrés occidentaux et tourne le visage vers l'est. Le chef de la maison s'avance jusqu'au milieu de la cour, (il ne monte pas). L'envoyé s'acquitte de son message (qui parle au nom du prince). Le chef de la maison pousse des lamentations, salue à genoux en frappant du front la terre, et bondit trois fois en signe de douleur. L'envoyé s'en va. Le chef de la maison le salue à genoux, et l'accompagne jusqu'en dehors de la grande porte extérieu re de le maison.

Le prince envoie un officier offrir des vêtements pour parer le mort. On enlève les tentures qui sont autour du lit du mort. Le chef de la maison reçoit cet envoyé comme précédemment il $\bullet_{442}$ a reçu l'officier qui lui a exprimé les condoléances du prince. L'envoyé, tenant de la main gauche le collet de la tunique offerte par le prince, et de la main droite la ceinture de la jupe, entre, monte et s'acquitte de son message. Le chef de la maison le salue à genoux, comme précédemment il a salué le premier envoyé du prince. L'envoyé entre dans l'endroit où est le mort, et met sur lui les vêtements offerts par le prince. Il s'en va. Le chef de la maison le salue à genoux et l'accompagne, comme précédemment il a salué et accompagné l'autre officier du prince.

Le chef de la maison ne sort que pour recevoir et reconduire les envoyés du prince. (Il ne fait pas cet honneur aux autres étrangers). Il monte et descend par les degrés occidentaux (comme s'il n'était pas le chef de la maison). Il salue à genoux les visiteurs. Si parmi plusieurs visiteurs venus ensemble il y a un grand préfet, il lui fait un salut particulier. (Il salue tous les autres par un salut commun). Il va prendre sa place au bas des degrés occidentaux, et tourne le visage vers l'est. Il ne bondit pas. Quand même le grand préfet ne lui aurait pas dit de ne pas le reconduire, le maître de la maison rentre sans le reconduire.

O Les proches parents envoient des vêtements pour parer le mort. Les envoyés vont étendre ces vêtements dans la salle, sans les présenter au chef de la maison. Les parents plus éloignés $\bullet_{443}$ envoient aussi des vêtements. Les envoyés vont offrir ces vêtements au chef de la maison dans la salle. Le chef de la maison les salue à genoux dans la salle sans quitter sa place. (Il ne sort pas). Il dépose les vêtements à l'est du mort sur le lit. Les amis apportent des vêtements. Ils les présentent eux-mêmes en personne. Le chef de la maison les salue à genoux. Il dépose les vêtements comme précédemment. Au départ des amis, il pousse des lamentations ; il ne bondit pas.

Des officiers chargés d'en lever les vêtements offerts les prennent de la manière qu'on les a présentés, c'est -à-dire, en tenant de la main gauche le 
collet de la tunique, et de la main droite la ceinture de la jupe. Ils les portent dans le bâtiment latéral des appartements particuliers du chef de la maison.

O On écrit le nom de famille et le nom d'enfance de l'officier mort sur la bannière qui lui était propre. S'il n'avait pas de bannière (parce qu'il n'avait aucun rang officiel), on se sert d'une bande de toile noire, longue d'un $t c h$ ' $u$ $(20 \mathrm{~cm})$, à l'extrémité de laquelle est une bande de toile rouge longue de deux tch' $u$, et large de trois ts'uén $(6 \mathrm{~cm})$. Sur la bande rouge on écrit : "Cercueil contenant le corps d'un tel de telle famille. »Cette inscription, fixée au bout d'une hampe de bambou longue de trois $t c h$ ' $u$, est arborée au haut des degrés occidentaux sous le bord du toit.

- ${ }_{444}$ \# Linspecteur des champs creuse une fosse entre les deux rangées de degrés, un peu plus près des degrés occidentaux. Il construit, au bas du mur occidental, un fourneau qui fait face à l'est.

O On lave et on apporte au bas des degrés occidentaux cinq sortes d'objets nouvellement fabriqués : (les cuvettes, des bassins, des cruches, des vases de bois féi sans pied, des chaudières à étages.

$\mathbf{O}$ On étale dans le bâtiment latéral les chéu objets (les vêtements) dont $s^{\bullet}$ on parera le corps du mort. Les collets des tuniques sont tournés vers l'ouest. Les vêtements sont rangés du sud au nord, les plus beaux au sud. $P \bullet u t c h \bullet n g$ Ils sont tous sur une seule et même ligne.

Les vêtements mîng d'une propreté remarquable (qui touc heront le corps du mort) sont de toile. L'épingle de tête qui fixera le chignon du mort est de bois de mûrier. (On choisit le bois de mûrier, parce que les deux lettres [] et [] ont le même son). Elle est longue de quatre $t$ 's'uén (huit $\mathrm{cm}$ ) en son $i \bullet u$ milieu. (Le milieu est étroit et court. Les deux extrémités sont larges).

Le linge de toile qui enveloppera la tête est $f \bullet u$ une pièce de toile houân aussi large que longue. (Il a $40 \mathrm{~cm}$ de long et autant de large. Quand il aura été mis sur la tête du mort), $p \bullet u t s^{\bullet}$ on ne le soulèvera pas (pour mettre des pierres de prix $\bullet_{445}$ dans la bouche). Le voile qui couvrira la figure et le reste de la tête du mort est de soie cuite. Sa largeur est celle d'une pièce de soie. Il a cinq tch'u (un mètre) de long. Son extrémité est $s \bullet$ fendue (elle sera fixée sous le menton).

Pour couvrir les oreilles du mort, on se servira de ouate de soie blanche. Pour couvrir les yeux, on se servira d'un voile noir carré (qui a un tch'u et deux ts'uén $(24 \mathrm{~cm})$ de chaque côté. Sa doublure est rouge. Il est garni de ouate. Il sera fixé sur les yeux au moyen de cordons.

Le coussinet que le mort tiendra dans chaque main est de soie noirâtre, doublé de soie brune. Il a un tch'u deux ts'uén $(24 \mathrm{~cm})$ de long, cinq ts'uén (dix $\mathrm{cm}$ ) de large. En son milieu, il est leôu plus étroit ; il a un ts'uén de moins de chaque côté (il n'a que trois ts'uén de large). Il est garni de ouate. Il sera lié au moyen de cordons. 
Le doigtier d'archer qu'on mettra au pouce de la main droite du mort est fait de tchéng excellent bois d'un jujubier sauvage appelé ouâng $k \bullet$ ou d'un jujubier sauvage appelé $t c h \bullet k \bullet$. Un cordon sert à le fixer. Deux flocons de ouate de soie simulent deux $k \bullet$ doigtiers pour l'index de la main droite. (L'archer por tait un doigtier de cuir à l'index de la main droite).

La partie supérieure tchø du maó sac dans lequel on mettra le corps du mort, est $t c h \bullet$ faite de toile noire ; elle est assez longue pour envelopper le corps depuis la tête jusqu'à l'extrémité des mains. La partie inférieure chái est tch'败 faite $\bullet_{446}$ de toile rouge; elle enveloppera le corps depuis les reins jusqu'à l'extrémité des pieds.

On étale les vêtements qu'un officier porte avec le bonnet de peau couleur tête de moineau ; tchouèn • la tunique bordée ; les vêtements qu'il porte avec le bonnet de cuir ; t'ouán • la longue tunique noirâtre; la ceinture de toile noire ; les kiá genouillères méi de cuir couleur garance ; la tablette de bambou sur laquelle un officier note ce qu'il doit dire et ce quil entend. En été, on étale des chaussures de $k \bullet$ dolic ; en hiver, des chaussures de cuir blanc. Le liseré - cousu entre l'empeigne et la semelle de ces deux espèces de chaussures est noir. Le k’îu ruban cousu à la pointe de la chaussure est bordé. Un cordon sert à lier la chaussure au talon. A la suite de ces objets, on étale ceux qui ont été offerts par les parents et les amis, même les objets qui ne serviront pas la première fois que le corps du mort sera paré.

Trois perles sont dans une corbeille. Un boisseau de riz est contenu dans un panier carré. Trois serviettes, faites de grosse toile de dolic, sont dans une corbeille. L'une servira à essuyer la tête et les deux autres à essuyer le reste du corps, quand le corps aura été lavé. Un peigne est dans une corbeille. Une tunique dont on revêtira le corps après l'avoir lavé est dans une corbeille rectangulaire. Tous ces objets sont placés au pied du bâtiment situé au côté occidental de la plateforme. Ils sont rangés du sud au nord, les plus distingués au sud.

$\mathbf{O} \cdot{ }_{447}$ Le maître d'hôtel tire de l'eau du puits. (Il apporte la cruche plein e d'eau), sans enlever la corde ; il tient la corde repliée. Un invocateur, au bas de la plateforme, le visage tourné vers le sud, lave dans une cuvette du grain de riz ou de millet. Le maître d'hôtel monte tous les degrés ; mais n'avance pas sur la plateforme. Il reçoit l'eau dans laquelle le riz a été lavé, et la fait bouillir sur le fourneau dans une chaudière. Deux chaudières placées l'une sur l'autre. L'eau bout dans la chaudière inférieure. La vapeur fait cuire le riz qui est dans la chaudière supérieure). Linvocateur met le riz dans un vase de bois, et place ce vase au nord des perles. (En été), pour un officier défunt ; le prince donne de la glace. Il convient de la mettre dans un bassin de grandeur moyenne.

Des ouái iú serviteurs de la maison reçoivent l'eau (dans laquelle le riz a été lavé et qui a été chauffée) ; ils l'apportent pour laver la tête du mort. Tous les maîtres de la maison (les frères du mort) sortent, et se tiennent en dehors (au sud) de la porte de la salle, le visage tourné vers le nord. Alors on lave la 
tête du mort ; on peigne sa chevelure; on essuie sa tête avec un linge. On lave le corps du mort; on l'essuie avec un linge. On l'essuie de nouveau en le revêtant de la tunique préparée pour cette circonstance. On jette dans une fosse l'eau qui a servi à laver le corps, (ainsi • ${ }_{448}$ que le peigne, les serviettes, la tunique dont on a fait usage). On coupe les ongles, on coupe la barbe au mort, de la manière quill se les coupait avant sa mort. On lie la chevelure du mort en forme de chignon avec un cordon. On fixe le chignon avec une épingle de tête. On étale une tunique et une jupe mîng d'une très grande propreté.

Les maîtres de la maison rentrent dans la salle et reprennent leurs places. - Un invocateur expert dans les cérémonies de la dynastie des Chang étend des vêtements. Il étend les vêtements avec lesquels le mort présentait des offrandes et la tunique noire. Il les étend ts'éu sur le deuxième lit, (sur lequel le mort sera transporté).

Le chef de la maison sort de la salle. Le visage tourné vers le sud, il se découvre le côté gauche, (il tire le bras gauche hors de sa manche); fait passer la manche gauche sur le devant du corps, et l'enfonce sous la ceinture au côté droit. Il se lave les mains dans un bassin, lave des perles, les prend et entre dans la salle. Un intendant lave une cuiller, l'enfonce toute droite dans le riz, prend le vase de riz et suit les maîtres de la maison. L'invocateur expert dans les cérémonies des Chang, tenant un voile à la main, suit l'intendant et entre. Près de la fenêtre, le visage tourné vers le nord, (au sud du mort), il enlève le coussin qui est sous la tête du mort, met le voile sur le visage du $\bullet_{449}$ mort, enlève la cuiller qui tient les mâchoires ouvertes, reçoit les perles et les dépose à l'ouest du mort. Le chef de la maison passe à l'ouest d es pieds du mort, et se met à genoux sur le lit, le visage tourné vers l'est. L'invocateur reçoit aussi le riz et le dépose au nord des perles. Lintendant le suit; il se tient debout à l'ouest du lit, au côté droit du chef de la maison. Le chef de la mai son, de la main gauche, puise du riz et le met dans la bouche du mort, au côté droit de la bouche ; cela trois fois. Ensuite il met une perle dans la bouche au côté droit. Il fait la même chose au côté gauche et au milieu de la bouche. Ensuite il met du riz dans la bouche jusqu'à ce qu'elle soit bien remplie. Le chef de la maison se couvre le côté, gauche et retourne à sa place (à l'est du mort).

L'invocateur expert dans les cérémonies de la dynastie des Chang couvre le visage, Il met de la ouate sur les oreilles ; il place un voile sur les yeux. Ensuite il met au mort les chaussures. Il lie sur le cou-de-pied les cordons qui sont au talon de la chaussure, et les attache au ruban qui est à la pointe de la chaussure. Ensuite on revêt le mort de trois habillements complets, sans compter la tunique mîng d'une grande propreté (qui est à l'intérieur, sur la peau). On lui met des genouillères, une ceinture. On enfonce sous sa ceinture la tablette sur laquelle un officier écrit des notes. On lui met un doigtier d'ar cher au pouce de la main droite. Ce doigtier est retenu par un cordon, ${ }_{450}$ dont le milieu fait le tour de la fàn base du pouce et dont les deux extrémités sont nouées derrière le poignet. On lui met dans la main un coussinet qu'on attache au poignet. On étend un double sac ; on met le mort dedans. On le 
couvre d'un linceul. - Le voile, la cuiller, les rognures des cheveux et des ongles sont enterrés dans une fosse.

La tablette sur laquelle on inscrira le nom du mort est faite de bois. Elle est taillée et percée de deux trous (afin qu'on puisse y suspendre deux chaudières). \# L'inspecteur des champs la dresse au milieu de la largeur de la cour, au tiers de la longueur de la cour en allant vers le midi.

- Un invocateur expert dans les cérémonies de la dynastie des Hia fait cuire le reste du riz dans deux chaudières au bas du mur occidental. Les couvertures de ces chaudières sont de grosse toile. On kiòu ferme avec soin l'ouverture de ces chaudières. On y lie une bande d'écorce de bambou, au moyen de laquelle on les suspend à la tablette. On couvre cette tablette et ces deux chaudières avec une natte faite de roseau, dont les deux extrémités croisent l'une sur l'autre au nord sur le devant, et dont l'extr émité supérieure est fixée au côté gauche. (Cette natte simule une tunique). En guise de ceinture, houó on applique une bande d'écorce de bambou, qu'on lie par derrière (au midi). Un invocateur prend la bannière sur laquelle sont inscrits le nom de famille et le nom d'enfance du mort, et la dresse près de la tablette.

${ }_{451}$ Le lendemain matin, on étale les tuniques dans le bâtiment latéral ; le collet est tourné au sud ; on les range de l'ouest à l'est ; les plus distinguées sont à l'ouest. Tchøng On en fait plusieurs rangées. On étend des bandes de toile, trois en travers, une en long. Elles sont de la largeur d'une pièce de toile. Elles sont fendues à leur extrémité. On dispose des couvertures de lit faites de toile noire, doublées de toile rouge, sans rubans pendants à la bordure. Ensuite viennent les vêtements qu'un officier revêt pour assister aux offrandes en l'honneur des morts ; puis, des vêtements sàn de toute sorte ; en tout dix-neuf habillements complets. On place à la suite les vêtements, qui ont été offerts par les parents et les amis. Il n'est pas nécessaire de les employer tous. (Pour siaó lién parer le corps la première fois, on n'emploiera que dix-neuf habillements complets),

$\mathrm{Au}$ bas de la partie orientale de la plateforme, on place des tranches de viande séchées, de la viande hachée et conservée dans le sel et le vinaigre, du vin non fermenté du vin fermenté. Les couvertures qu'on mettra sur les vases sont faites de la toile qui sert durant le deuil de neuf mois. Elles sont dans une corbeille, à l'est des mets et des boissons. A l'est des mets et des boissons, on place des bassins, des cuvettes pour se laver les mains, et des serviettes.

Le bandeau de brins de chanvre femelle est de grosseur à ${ }_{452} n g \bullet$ remplir la main fermée. La plus grosse extrémité des brins de chanvre est tournée en bas, sur le côté gauche de la tête. La ceinture de chanvre femelle est moins grosse que le bandeau. Les brins de chanvre ne sont pas tressés ensemble; leurs extrémités sont pendantes. Elle a trois tch' $u(60 \mathrm{~cm})$ de long. Au bandeau de chanvre mâle, la grosse extrémité des brins est tournée en haut, sur le côté droit de la tête. Les extrémités des brins de chanvre de la ceinture ne sont pas tressées ensemble et pendent librement. Tous ces insignes de deuil sont étalés à l'est. Les ceintures des femmes sont faites de brins de chanvre 
mâle qui sont tressés ensemble à leur plus grosse extrémité. Elles sont dans le bâtiment latéral.

Les nattes de lit, les couvertures de lit sans ornements sont étalées au sud de la crédence occidentale. A l'ouest sont les objets nécessaires pour se laver les mains, comme à l'est.

On place une chaudière, devant la grande porte à l'extérieur des appartements particuliers, près du bâtiment qui est au côté oriental de la grande porte, un peu au midi ; on la tourne vers l'ouest. Elle contient les quatre pieds $t$ ' séparés d'un jeune porc, moins les orteils ; deux côtes prises sur le devant du corps, deux côtes prises sur le dos, et les poumons. On dépose le levier qui sert à porter la chaudière et la natte qui sert à la couvrir. On tourne vers l'ouest la plus pe tite extrémité des brins de chiendent dont cette natte est tressée. Une petite table sans ornement est $\bullet_{453}$ placée à l'ouest de la chaudière. A l'ouest il est facile de mettre sur la petite table la viande qui est dans la chaudière. Sur la chaudière est une cuiller renversée, (le côté concave tourné en bas), le manche tourné vers l'est.

Deux officiers, après s'être lavé les mains, se tiennent debout ensemble, le visage tourné vers l'est, au bas des degrés occidentaux. (Ils attendent pour transporter le corps). Dans l'intérieur de la salle, on étend deux nattes l'une sur l'autre, à savoir, une natte de jonc et, par dessus, une natte de bambou. Un invocateur expert dans les cérémonies de la dynastie des Chang étend des bandelettes, une couverture. Sur la couverture il étend différentes tuniques les unes sur les autres, et les vêtements qu'un officier porte en faisant des offrandes aux morts. Il a soin de ne pas tourner à l'envers les vêtements qui servent pour les offrandes aux morts, (cela, par respect pour ces vêtements). Il étend dans le milieu les vêtements les plus distingués. Les deux officiers prennent le corps du mort et le transportent sur les vêtements. Ils retournent à leurs places. On étend la natte du lit entre les deux colonnes de la plateforme. Les nattes sur lesquelles le corps repose directement sont replacées comme auparavant. Il y a un coussin pour soutenir la tête.

Quand le corps est paré, on enlève les rideaux qui le cachaient. Les maîtres de la maison, le visage tourné vers l'ouest, tour à tour appuient la poitrine contre la poitrine $\mathrm{du} \bullet_{454}$ mort, puis bondissent en signe de douleur un nombre de fois indéterminé. Les femmes des maîtres de la maison, le visage tourné vers l'est, appuient aussi la poitrine contre la poitrine du mort (et bond issent) de la même manière. Le chef de la maison enroule sa chevelure en forme de chignon et se découvre le bras gauche. Tous les autres maîtres de la maison, (après avoir enroulé la chevelure en forme de chignon), se couvrent la tête d'un linge dans le bâtiment latéral. Les femmes s'enroulent la chevelure en forme de chignon dans la salle.

Des officiers soulèvent le corps du mort. Les hommes et les femmes le prennent, l'étendent sur la plateforme, le couvrent $h \bullet u$ de la couverture sans ornement. Les hommes et les femmes, rangés comme dans la salle, bondissent un nombre de fois indéterminé. 
Le chef de la maison s'en va, passe devant les pieds du mort, et descend par les degrés occidentaux. Tous les autres maîtres de la maison vont à l'est reprendre leurs places. Les femmes se tiennent au haut des degrés orientaux, le visage tourné vers l'ouest. Le chef de la maison salue à genoux les étrangers. Il fait un salut particulier à chaque grand préfet. Il fait un seul salut commun à tous les simples officiers. Il va à sa place et bondit. Il se couvre le bras gauche et met le bandeau sur sa tête, à l'est du bâtiment situé au côté oriental. Il retourne $\bullet_{455}$ à sa place (au bas des degrés orientaux).

Ensuite on présente des offrandes au mort. Les officiers qui ont porté la chaudière se lavent les mains. Celui qui est à droite, de la main droite prend la cuiller; il tient le côté concave du cuilleron tourné en bas. Celui qui est à gauche, de la main gauche prend la petite table. Il la tient transversalement. (Ces deux hommes prennent la chaudière, le premier de la main gauche, le second de la main droite). Ils entrent; le visage tourné vers l'ouest, ils déposent la chaudière devant les degrés orientaux. Celui qui porte la petite table, la dépose le visage tourné vers le nord. Celui qui est à droite passe la cuiller dans sa main gauche. (De la main droite) il tire le levier qui sert à porter la chaudière et le met dans sa main gauche avec la cuiller. De la main droite, il enlève la natte qui couvre la chaudière, la dépose au nord de la chaudière, et met le levier sur cette natte. Il ne fléchit pas les genoux.

(Avec la cuiller il tire la viande de la chaudière). Celui qui est à gauche, avec la cuiller, met la viande sur la petite table. Il met les deux cuisses aux deux extrémités de la table; puis les deux épaules à côté des cuisses ; puis deux côtes prises sur le devant du corps de l'animal ; puis, au milieu, il place des côtes prises sur le dos de l'animal et les poumons. Il couvre le tout (pour le préserver de la poussière). Il tient en mains la table, l'extrémité inférieure des os dirigée en avant, et il attend.

- ${ }_{456}$ Un invocateur expert dans les cérémonies des Hia se lave les mains, ainsi que ses aides. L'invocateur prend le vin non fermenté et marche le premier. Les aides le suivent, portant le vin fermenté, les tranches de viande séchées, la viande hachée conservée dans le sel et le vinaigre, et la petite table. Linvocateur monte par les degrés orientaux. Les hommes bondissent. L'inspecteur des champs enlève la toile qui couvre la chaudière. Il attend au bas des degrés orientaux.

L'invocateur dépose les offrand es au côté oriental du mort. Les aides qui tiennent en mains les deux sortes de vins sont debout, le visage tourné vers le nord, le plus respectable (le porteur du vin non fermenté) à l'ouest de l'autre. Linvocateur place le vase de bois (et le vase de ba mbou). A l'est de ces vases il place la petite table. Les aides qui ont porté ces deux vases restent debout au nord de la petite table, le plus respectable (celui qui a porté le vase de bois) à l'ouest de l'autre. L'invocateur place les deux sortes de vin $\mathrm{s}$ au sud des vases de bois et de bambou. Linvocateur reçoit des serviettes de toile ; il les étend sur les vases. Il passe derrière les pieds du mort et descend par les degrés occidentaux. Les femmes bondissent. Ceux qui ont aidé à déposer les 
offrandes passent au côté méridional et au côté oriental de la tablette du mort. Les hommes bondissent. Les étrangers s'en vont. Le chef de la maison les salue à $\bullet_{457}$ genoux, et les reconduit jusqu'en dehors de la grande porte du temple. Ensuite les parents et les anis vont les uns après les autres pousser des lamentations auprès du mort, sans observer entre eux aucun ordre de dignité.

S'il est des envoyés étrangers qui viennent offrir des vêtements pour tá lién parer complètement le mort, et veulent parler au chef de la maison au nom de leurs maîtres ; l'officier qui traite avec les hôtes sort et leur demande ce qu'ils désirent. Il rentre et informe le chef de la maison. Celui -ci attend les envoyés étrangers à sa place (il ne sort pas). L'hôtelier sort de nouveau, e t dit aux envoyés étrangers que le chef de la maison les attend. Puis il les introduit. Les envoyés étrangers entrent. Au milieu de la cour, le visage tourné vers le nord, ils s'acquittent de leur commission. Le chef de la maison les salue à genoux, frappant du front la terre. Les étrangers montent par les degrés occidentaux, passent derrière les pieds du mort, et, le visage tourné vers l'ouest, déposent les vêtements sur la plateforme, avec les mêmes cérémonies que précédemment dans la salle, avant que le corps fût paré des premiers vêtements. Ils descendent et s'en vont. Le chef de la maison sort et salue à genoux les partants. (Après que le corps a été paré des premiers vêtements, le chef de la maison ne sort pas encore pour aller au devant des étrangers, mais il sort pour les reconduire).

Les amis vont en personne porter les vêtements quils donnent $\bullet{ }_{458}$ pour parer le mort. Les cérémonies sont les mêmes que précédemment (peu après la mort de l'officier). Ensuite les amis, à l'est des degrés occidentaux, le visage tourné vers le nord, poussent des lamentations et bondissent trois fois. Ils descendent. Le chef de la maison ne bondit pas. Parmi les vêtements offerts il y a des tuniques doublées (non ouatées). Il y a aussi nécessairement les jupes qui leur correspondent. Ceux qui tiennent en mains les tuniques les tiennent comme il a été dit précédemment. Ceux qui les enlèvent les enlèvent aussi comme il a été dit. Ils montent et descendent par les degrés occidentaux. Ils vont à l'est déposer les vêtements.

O Le soir on allume des torches dans la cour. Le lendemain matin, on éteint les torches. On étale dans le bâtiment latéral les tuniques, le collet tourné vers le midi. On les range de l'ouest à l'est, les plus distinguées à l'ouest ; tchøng on les met sur plusieurs lignes, On étend des bandelettes, des linceuls, deux couvertures. On étale les vêtements donnés par le prince, les vêtements avec lesquels un officier assiste aux offrandes présentées aux morts, des vêtements de toute sorte, tous les vêtements qui ont été offerts pour le mort. En tout on lui mettra trente habillements complets, sans compter les linceuls. Il ne sera pas nécessaire de lui mettre tous les habillements qui ont été donnés. (Il suffit d'en employer trente).

Les ustensiles et les comestibles placés au côté oriental sont $\bullet_{459}$ deux jarres d'argile contenant du vin non fermenté et du vin fermenté, une coupe de corne ou en forme de corne, une cuiller de bois; deux vases de bois couverts 
de feutre, et contenant des mauves salées, des racines d'arum, des escargots hachés et conservés dans le sel et le vinaigre ; deux vases de bambou, qui ne sont pas entourés de cordes, sont couverts d'un linge, et contiennent des châtaignes non épluchées et quatre tranches de viande séchées.

La natte sur laquelle on présentera des offrandes au mort est au nord des vases qui contiennent les mets et les boissons. La natte sur laquelle le corps sera paré de tous ses vêtements est à l'est de la première.

On creuse (au haut des degrés occidentaux de la salle du temple) la fosse $i$ dans laquelle le cercueil sera déposé et restera jusqu'à l'enterrement. On laissera à découvert les jèn agrafes qui fixeront le couvercle sur le cercueil.

Le cercueil entre dans la cour du temple où est la tablette de l'aïeul. Le chef de la maison ne pousse pas de lamentations. On monte le cercueil sur la plateforme au moyen d'un chariot muni de quatre petites roues. On laisse le couvercle du cercueil au bas de la plateforme. Au sud de la crédence occidentale, on place des aliments chauffés jusqu'à dessiccation, à savoir, du millet glutineux et du millet non glutineux. Il y a deux corbeilles de chacune de ces deux espèces de millet. Il y a aussi des poissons et un lièvre séché.

- 460 En dehors de la grande porte, on place trois chaudières. On les range du nord au sud, la plus distinguée au nord. Elles contiennent les pattes d'un jeune porc, celle du côté droit et celles du côté gauche (les quatre pattes) $h \bullet$ ensemble. Il y a des poissons, neuf carpes, neuf tortues ; la moitié gauche d'un animal séché. Les os du bassin ne sont pas dans les chaudières. Tout le reste est disposé comme précédemment, quand le corps a été paré de ses premiers vêtements. Des flambeaux attendent à l'est des mets et des boissons.

Un invocateur enlève les mets qui ont été déposés auprès du mort, quand le mort a été paré de ses premiers vêtements. A cet effet, il se lave les mains en dehors de la grande porte du temple. Il entre et monte par les degrés orientaux. Les hommes bondissent. Linvocateur enlève les serviettes qui couvrent les vases. Il les donne aux aides. Il leur dit d'attendre au bas des degrés orientaux. Il enlève les vases. Il prend d'abord les jarres de vin non fermenté et de vin fermenté, et reste debout, le visage tourné vers le nord. Il enlève ensuite les autres vases en commençant par ceux qui ont été rangés les premiers. Il s'en va en passant derrière les pieds du mort. Il descend par les degrés occidentaux. Les femmes bondissent. Il range tous les vases au sud-ouest du bâtiment latéral, en face de l'extrémité $\bullet_{461}$ occidentale de la crête du toit; il les range dans le même ordre que sur la plateforme. Ceux qui portent le vin non fermenté et le vin fermenté sont aux mêmes places que précédemment. Les aides sont au nord des vases de bois, le visage tourné vers le sud, rangés de l'est à l'ouest, les plus respectables à l'est. Ensuite ils vont à l'endroit où sont les nouvelles offrandes.

O On dresse des rideaux sur la plateforme (pour cacher le corps du mort), Les femmes sont à l'ouest du corps du mort, le visage to urné vers l'est. Les maîtres de la maison et les proches parents montent par les degrés 
occidentaux, passent derrière les pieds du mort, et le visage tourné vers l'ouest, se découvrent le bras gauche. Des officiers se lavent les mains, et se tiennent à la même place que précédemment (avant le siâ lién). On étend deux nattes l'une sur l'autre, comme précédemment avant le siaô lién, (sur la plateforme, au haut des degrés orientaux). Un invocateur expert dans les cérémonies de la dynastie des Chang étend des bandelettes, un linceul, une couverture, et des tuniques, dont il place les plus distinguées à l'extérieur, c'est-à-dire, en premier lieu afin qu'elles soient à l'extérieur sur le corps du mort. Il a soin de ne pas tourner à l'envers les vêtements donnés p ar le prince. $\mathrm{Si}$ un grand préfet arrive, l'hôtelier va l'avertir que la cérémonie commence. Des officiers prennent le corps du mort et le changent de place (le mettent sur les vêtements étendus). Ils retournent à leurs places. Les maîtres de la maison bondissent $\bullet_{462}$ un nombre de fois indéterminé.

Quand le corps a été paré de tous ses vêtements, on enlève les rideaux. Les maîtres de la maison appuient la poitrine contre la poitrine du mort, comme précédemment. Les femmes font aussi la même chose. Les maîtres de la maison prennent le corps paré de tous ses vêtements et le mettent dans le cercueil. Ils bondissent comme précédemment. On met le couvercle sur le cercueil. Le chef de la maison descend et salue à genoux le grand préfet qui est arrivé en dernier lieu. Le visage tourné vers le nord, il regarde la fosse, (dans sa douleur il n'en peut dé tacher ses yeux).

Les femmes font aussi la même chose. Tous les maîtres de la maison retournent à leurs places. Les femmes vont à l'est et reprennent leurs places.

On met un réchaud près du cercueil et une corbeille de millet de chaque côté. Puis on enduit de mortier les branchages placés sur le cercueil. On bondit un nombre de fois indéterminé. Quand on a fini d'appliquer le mortier, un invocateur prend la bannière sur laquelle sont inscrits les noms du mort, et la dresse auprès du cercueil. Les maîtres de la maison retournent à leurs places. Ils bondissent et se couvrent le bras gauche.

- 463 Ensuite on dépose les offrandes auprès du mort. Des porteurs de flambeaux montent par les degrés orientaux. L’invocateur prend une serviette, et suivi d'un aide qui porte deux nattes, il va placer les nattes l'une sur l'autre et la serviette (pour les mânes du mort, à l'endroit le plus tranquille) à l'angle sud-ouest de la salle. Il tourne vers l'est le devant des nattes. L'invocateur descend de nouveau, et, avec les aides, prend les boissons et les mets déposés dans le bâtiment oriental. Des officiers se lavent les mains, prennent les chaudières, entrent, tournent les chaudières vers l'ouest; ils les rangent du nord au sud, la plus distinguée au nord, comme précédemment. Ils mettent le contenu des chaudières sur les petites tables. Les poissons sont placés la tête à gauche, la nageoire dorsale en avant, sur trois rangées (de trois chacune). Le quadrupède séché est placé les pattes en avant.

L’invocateur prend la jarre de vin non fermenté, comme pré cédemment. Il est suivi par des aides qui portent la jarre de vin fermenté, les vases de bois, 
les petites tables. Il monte par les degrés orientaux. Les hommes bondissent. Linspecteur des champs enlève les chaudières. (Elles sont vides). Linvocateur et ses aides, tenant en mains les offrandes, passent a u delà de la colonne et entrent dans la salle. Ceux qui portent les jarres de vin ont le visage tourné vers le nord. L'invocateur place le vase de bois. A droite du vase de bois il place les légumes salés. Au sud des légumes salés, il place des châtaignes. A l'est des châtaignes, il place les tranches de viande séchée. Il - 464 place la viande de porc en face du vase de bois ; les poissons à la suite du porc ; le quadrupède séché seul au nord des petites tables ; les jarres de vin non fermenté et de vin fermenté au sud du vase de bambou. Il couvre les offrandes comme précédemment.

Cela fait, ceux qui ont aidé à placer les offrandes s'en vont. Ils se tiennent debout à l'ouest de la porte de la salle, rangés de l'ouest à l'est par ordre de dignité, les plus dignes à l'ouest. L'invocateur ferme ensuite la porte de la salle. Il marche le premier, passe à l'ouest de la colonne et descend par les degrés occidentaux. Les femmes bondissent. Les aides passent au sud de la tablette du mort, et vont à l'est reprendre leurs places. Les hommes bondissent. Les étrangers s'en vont. Les femmes bondissent. Le chef de famille salue à genoux les étrangers, et les accompagne jusque hors de la grande porte du temple.

Il rentre. Avec ses parents, le visage tourné vers le nord, il pousse des lamentations auprès du cercueil. Ses parents s'en vont. Il les salue à genoux, et les accompagne jusque hors de la grande porte du temple. Tous les maîtres de la maison sortent du temple. Les lamentations cessent. Les maitres de la maison ${ }_{465}$ se tiennent tous à l'est, le visage tourné vers l'ouest. On ferme la grande porte du temple. Le chef de la maison salue les maîtres de la maison par une inclination profonde, et va demeurer dans la cabane de deuil.

Si le prince, par une insigne faveur, vient voir parer le corps du mort, il arrive quand les vêtements ont été étendus. Le chef de la maison sort et va au devant de lui jusqu'en dehors de la grande porte extérieure de la maison. Quand il voit la tête des chevaux du prince, il cesse de se lamenter. Il tourne et rentre dans le temple (avant que le prince soit arrivé). A droite de la grande porte du temple, le visage tourné vers le nord, avec tous les maîtres de la maison, il se découvre le bras gauche. Le magicien reste en dehors de la grande porte du temple (et ne remplit aucune fonction). Un invocateur le remplace (et chasse les mauvais esprits).

Deux officiers d'un rang peu élevé, portant des lances, précédent le prince; deux autres le suivent. Le prince offre des légumes aux esprits protecteurs de la grande porte. Il entre. Tous les maîtres de la maison quittent leurs places (par respect pour le prince). Le prince monte par les degrés orientaux et se tourne vers l'ouest. Linvocateur a le dos tourné au mur et le visage tourné vers le midi. Le chef de la maison est au milieu ${ }_{466}$ de la cour. Le prince pousse des lamentations. Le chef de la maison pousse des lamentations, et salue à genoux le prince, frappant du front la terre. Il bondit et 
s'en va. (Il n'ose pas retenir le prince plus longtem ps. Il s'en va comme si le prince allait se retirer de suite).

Le prince lui dit de revenir et de faire la cérémonie (de parer le mort de ses vêtements). Le chef de la maison retourne à sa place. Le prince le fait monter. Le chef de la maison se tient à l'est de la colonne occidentale, le visage tourné vers le nord. Le prince fait monter les ministres de premier et de second rang, et les grands préfets. Ces dignitaires se placent à la suite des maîtres de la maison, les plus dignes à l'est. Ensuite on pare le corps du mort.

La cérémonie terminée, les ministres et les grands préfets descendent • dans l'ordre inverse de l'ordre dans lequel ils ont monté (ceux qui ont monté les premiers descendent les derniers). Ils retournent à leurs places. Le chef de la maison descend et s'en va (pour la même raison que précédemment.) Le prince le rappelle. Le chef de la maison reste dans la cour du temple. Le prince à genoux appuie son cour contre le cour du mort. Le chef de la maison le salue à genoux, frappant du front la terre. Il bondit et s'en va. Le prince le rappelle. Le chef de la $\bullet_{467}$ maison retourne à la place qu'il occupait précédemment. Tous les maîtres de la maison se retirent auprès du mur oriental, et tournent le visage vers le sud. Le prince descend, et tourné vers l'ouest, il invite le chef de la maison à appuyer sa poitrin e contre la poitrine du mort. Le chef de la maison monte par les degrés occidentaux, passe derrière les pieds du mort, tourne le visage vers l'ouest, et appuie sa poitrine contre la poitrine du mort ; mais pas au même endroit que le prince (pas au cour). Il bondit. Les femmes de la maison, le visage tourné vers l'est, appuient la poitrine contre la poitrine du mort aussi, de la même manière.

On prend le mort paré de ses vêtements et on le met dans le cercueil. Puis on place le couvercle sur le cercueil. Le chef de la maison descend et s'en va. Le prince le rappelle. Le chef de la maison rentre au côté gauche de la grande porte; il regarde couvrir le cercueil de branchages et de mortier. Le prince monte les degrés et va à sa place. Tous les maîtres de la maison retournent à leurs places. Quand on a fini de couvrir le cercueil de mortier, le chef de la maison s'en va. Le prince le rappelle et lui dit de déposer des offrandes auprès du cercueil. Le chef de la maison rentre par le côté droit de la grande porte du temple. Alors il dépose des offrandes. Il monte par les degrés occidentaux. Le prince prend ce moment pour bondir. Le chef de la maison bondit ensuite. Quand il a fini de déposer les $\bullet_{468}$ offrandes, il s'en va. Les lamentations cessent. Quand le prince sort de la grande porte du temple, dans le temple les lamentations recommencent. Le chef de la maison ne pousse pas de lamentations. Il se retire. Le prince, les mains posées sur l'appui de sa voiture, le salue par une inclination. Les voitures secondaires du prince sont attelées, et montées par les officiers venus à sa suite. Le chef de la maison pousse des lamentations, salue à genoux et accompagne les partants (jusque hors de la grande porte du temple). Il se couvre le bras gauche, rentre et va à sa place. Tous les maîtres de la maison se couvrent le bras gauche. Ils saluent à genoux les grands préfets (qui sont arrivés en dernier lieu, et ils bondissent. Les 
étrangers s'en vont. Le chef de la maison les salue à genoux et les accompagne.

Trois jours après la mort (le lendemain du jour où le corps a été paré de tous ses vêtements), on se revêt de tous les habits de deuil. Les proches parents (les hommes) s'appuient sur un bâton. Le chef de la maison salue à genoux les envoyés du prince, et les étrangers, qui viennent exprimer leurs condoléances. Il ne salue pas les envoyés qui apportent des présents pour le mort qui est dans le cercueil.

- ${ }_{469}$ Matin et soir, les hommes et les femmes se réunissent et poussent des lamentations, même le jour $k i \bullet t s e ̀ u$, premier jour du cycle, qui est le jour anniversaire de la mort du tyran Tcheóu, et le jour • maò, cinquante-deuxième jour du cycle, qui est le jour anniversaire de la mort du tyran $\mathrm{Ki} \bullet$. (Ces deux jours on s'abstient de toute réjouissance ; mais on peut faire une cérémonie funèbre). Les femmes vont prendre leurs places sur la plateforme. Elles se rangent du sud au nord, les plus respectables au sud; elles poussent des lamentations. Les hommes vont prendre leurs places en dehors de la grande porte du temple. Ils tournent le visage vers l'ouest ; ils se rangent du nord au sud par ordre de dignité, les plus respectables au nord.

Les parents qui ne portent pas le même nom de famille que le défunt sont au sud de ceux qui portent le même nom de famille; ils sont rangés du sud au nord par ordre de dignité. Les étrangers se rangent à leur suite; les uns, du nord au sud par ordre de dignité ; les autres à l'est de la grande porte, le visage tourné vers le nord, de l'ouest à l'est par ordre de dignité ; d'au tres, à l'ouest de la porte, le visage tourné vers le nord, de l'est à l'ouest par ordre de dignité ; d'autres, à l'ouest, le visage tourné vers l'est, du nord au sud par ordre de dignité. Le chef de la maison va à sa place. Il ouvre la grande porte du temple. (Quand il n'y a pas de cérémonie, la porte reste fermée). Les • 470 femmes se frappent la poitrine, sans se lamenter. Le chef de la maison salue à genoux les étrangers; il fait trois saluts de trois côtés différents, (le premier vers l'ouest, le deuxième vers le sud, le troisième vers l'est). Il tourne à droite, rentre dans le temple et pousse des lamentations. Les femmes bondissent. Le chef de la maison se tient au bas de la plateforme, près du bâtiment situé au côté oriental, le visage tourné vers l'ouest. Les pare nts se placent comme ils étaient placés en dehors du temple. Les ministres, les grands préfets sont au sud du chef de la maison. Les ministres du plus haut rang sont à l'est de la grande porte, un peu en avant. Les officiers des contrées étrangères qui ont une dignité supérieure à celle du chef de la maison sont à l'ouest de la grande porte, un peu en avant. Parmi les officiers qui lui sont égaux en dignité, le chef de la maison salue d'abord ceux qui sont venus de pays étrangers. Il salue à leurs places tous ceux qui ont une dignité supérieure à la sienne. (Il les salue un à un).

Les officiers chargés d'enlever les offrandes qui ont été pré sentées au mort, après qu'il a été paré de tous ses vêtements, se lavent les mains en dehors de la grande porte du temple. Précédés par des porteurs de flambeaux, 
ils entrent et montent par les degrés orientaux. Les hommes bondissent. Un invocateur prend la jarre de vin non fermenté et tourne le visage vers le $\bullet_{471}$ nord. Un officier prend la jarre de vin fermenté, et se tient debout à l'est de l'invocateur. D'autres officiers prennent le vase de bois, le vase de bambou, les petites tables. Ils tournent le visage vers le sud, et se rangent de l'ouest à l'est par ordre de dignité. L'invocateur s'en va le premier. Ceux qui ont pris le vin fermenté, le vase de bois, le vase de bambou et les petites tables, s'en vont à sa suite par ordre. Ils descendent par les degrés occidentaux. Les femmes bondissent. On dépose les offrandes au sud-ouest du bâtiment latéral, vis-à-vis de l'extrémité occidentale de la crête du toit. Ceux qui ont porté les jarres de vin ont le visage tourné vers le nord, le plus distingué (celui qui a porté le vin non fermenté) à l'ouest de l'autre. Celui qui a porté le vase de bois le dépose, le visage tourné vers l'ouest, et reste de bout au nord du vase de bois, le visage tourné vers le sud. Ceux qui ont porté le vase de bambou et les petites tables, après les avoir placés, se tiennent debout à l'ouest de celui qui a porté le vase de bois ; ils se rangent de l'est à l'ouest par ordre de dignité. Celui qui a porté la jarre de vin fermenté la dépose et retourne à sa place. Celui qui a porté la jarre de vin non fermenté la dépose à l'ouest de l'autre jarre. Ensuite il part le premier, passe au nord du chef de la maison et va chercher de nouvelles provisions.

Alors on dépose de nouvelles offrandes auprès du cercueil. $\bullet_{472}$ Les officiers montent les degrés, portant du vin non fermenté, du vin fermenté, des tranches de viande séchées et de la viande hachée conservée dans le sel et le vinaigre. Les hommes bondissent. Les porteurs entrent dans la salle du temple, et rangent les offrandes comme précédemment. Ils ne couvrent pas les ustensiles avec des serviettes. Ceux qui ont placé les offrandes s'en vont. Ils se tiennent debout à l'ouest de la porte de la salle, rangés de l'ouest à l'est par ordre de dignité. Ceux qui portent les flambeaux les éteignent et s'en vont. L'invocateur ferme la porte de la salle, et descend le premier par les degrés occidentaux. Les femmes bondissent. Ceux qui ont déposé les offrandes passent au sud de la tablette du mort et vont à l'est. Les hom mes bondissent.

Les étrangers s'en vont. Les femmes bondissent, Le chef de la maison salue à genoux les étrangers et les accompagne. Tous les maîtres de la maison sortent du temple. Les femmes bondissent. Quand les maîtres de la maison sont sortis de la porte du temple, les lamentations cessent. Chacun retourne à sa place (hors du temple). On ferme la grande porte du temple. Quand le chef de la maison a fini de saluer et de reconduire les étrangers, il salue par une inclination profonde tous les maîtres de la maison, et va demeurer dans la cabane de deuil.

Le premier jour du mois lunaire, on présente au mort un jeune ${ }_{473}$ porc seul, des poissons, un quadrupède séché. On dispose trois chaudières, comme précédemment. Les provisions qui attendent à l'est sont aussi disposées de la même manière que précédemment. Il n'y a pas de vase de bambou. Il y a du millet glutineux et du millet non glutineux. Ce millet est dans des vases 
d'argile à couvercle, qu'on met à la place occupée ordinairement par le vase de bambou.

Le chef de la maison salue à genoux les étrangers. On housse des lamentations, comme le matin et le soir. Après qu'on a enlevé toutes les offrandes qui ont été déposées auprès du cercueil précédemment ; les officiers, portant les chaudières, entrent dans le temple et montent les degrés. Tout est disposé de la même manière que précédemment. Après qu'on a tiré la viande des chaudières et qu'on l'a placée sur les petites tables au moyen de cuillers ; les cuillers sont mises sur les chaudières, et les petites tables sont portées à leur place. Ceux qui ont employé les cuillers s'en vont ; le dernier arrivé s'en va le premier. L'inspecteur des champs enlève les chaudières. On apporte successivement et par ordre le vin non fermenté, le vin fermenté, les légumes salés, la viande hachée conservée dans le sel et le vinaigre, le millet glutineux, le millet non glutineux, les petites tables.

On étale toutes ces offrandes dans la salle. Le vase de bois ${ }_{474}$ est déposé et les petites tables sont placées. La chair séchée d'un petit animal, le millet glutineux, le millet non glutineux sont en face de l'endroit où l'on met ordinairement le vase de bambou. Le couvercle des vases de millet est enlevé et placé à l'envers au sud de ces vases. Le vin non fermenté et le vin ferme nté sont à la même place que précédemment. L'invocateur et celui qui a porté le vase de bois couvrent de serviettes les offrandes et s'en vont. Les maîtres de la maison, hommes et femmes, en cette occasion, bondissent, et suivent les mêmes règles que quand ils poussent des lamentations le matin et le soir.

$\mathbf{O}$ Le quinzième jour du mois lunaire, il n'y a pas offrande solennelle de mets. On présente des fruits nouveaux de la saison, de la même manière qu'on présente les offrandes le premier jour du mois lunaire. On enlève les offrandes du premier jour du mois. On enlève d'abord le vin non fermenté et le vin fermenté. Pour le reste, on enlève en premier lieu ce qui a été placé en premier lieu. On laisse ouvert le couvercle des vases de millet. On le tourne vers les pieds de ces vases. On emporte les offrandes dans le même ordre qu'on les a apportées. On les range hors de la salle du temple de la même manière que dans la salle.

O On consulte les sorts au moyen de brins d'achillée sur le lieu de la sépulture. L'o fficier chargé du soin des tombes trace $\bullet_{475}$ le contour du terrain où l'on a intention d'enterrer le mort. On creuse un trou à chacun des quatre angles et l'on jette hors de ce terrain la terre qu'on retire des trous. On creuse un trou au milieu, et l'on jette au sud de ce trou la terre qu'on en retire.

Après les lamentations du matin, les maîtres de la maison vont au lieu projeté. Ils se tiennent au sud de ce terrain, le visage tourné vers le nord. Ils ôtent leurs bandeaux de deuil (parce qu'il s'agit d'une chose de bon augure). L'officier qui d oit formuler la question que le sorcier posera devant les brins d'achillée est au côté droit du chef de la maison. Le sorcier, le visage tourné vers l'est, enlève la partie supérieure de l'étui qui contient les brins d'achillée, et la tient de la même main avec la partie inférieure. Le visage tourné vers le 
sud, il écoute la question à poser devant les brins d'achillée. On lui dit de l'exprimer en ces termes : "Le fils affligé un tel consulte les sorts au moyen des brins d'achillée sur le lieu de sépulture de son père qui a reçu tel nom dans son adolescence. Il forme le projet d'établir ici cette sombre demeure. Sil place la tombe dans ce terrain, dans l'avenir n'arrivera -t-il pas quelque malheur?»

Le sorcier promet d'obéir. Il ne répète pas la question. Il tourne à droite ; le visage regardant le nord, il montre du doigt le milieu du terrain désigné, et manipule les brins d'achillée. • ${ }_{476}$ Celui qui dessine à terre les symboles formés par les brins d'achillée est à sa gauche. Le sorcier, après avoir manipulé les brins d'achillée, (dessine sur une planchette les symboles obtenus) et les montre à celui qui a formulé la question. Celui-ci les reçoit, les regarde et les rend au sorcier. Le sorcier, le visage tourné vers l'est, avec l'aide de liù plusieurs assistants, cherche la signification des symboles.

Quand il l'a devinée, il s'avance, et informe celui qui a for mulé la question et le chef de la maison. Après leur avoir communiqué son interprétation, il ajoute : «La réponse des sorts est favorable. » Le chef de la maison, la tête ceinte du bandeau, pousse des lamentations. Il ne bondit pas. Si la réponse des sorts n'est pas favorable, on les consulte au moyen des brins d'achillée sur le choix d'un autre terrain ; cela, de la même manière que précédemment. Le chef de la maison retourne à la salle du temple. Devant le cercueil (au bas des degrés occidentaux), le visage tourné vers le nord, il pousse des lamentations. Il ne bondit pas.

Quand les charpentiers ont réuni les unes sur les autres (devant la porte du temple) toutes les pièces du cercueil extérieur, en forme de la lettre tsìng, le chef de la maison, le visage tourné vers l'ouest, les salue à genoux en signe de remerciement. Il tourne à gauche autour des pièces du cercueil extérieur, et va - ${ }_{477}$ reprendre sa place. Il pousse des lamentations. Il ne bondit pas. Les femmes poussent des lamentations sur la plateforme de la salle du temple. Les charpentiers présentent au chef de la maison les pièces du bois dont ils fabriqueront les instruments nécessaires. Ils les étalent devant la grande porte du temple où est le mort. Ils les tournent vers l'ouest, et les rangent du nord au sud, les principales pièces au nord. Ils les mettent sur plusieurs lignes. Le chef de la maison examine toutes les pièces. Il pousse des lamentations, comme il l'a fait après avoir vu les pièces de bois du cercueil extérieur. Les charpentiers ont présenté les pièces de bois encore à l'état brut. Ensuite ils les pré senteront de la même manière, quand elles seront parfaitement travaillées.

On consulte les sorts, au moyen de l'écaille de tortue, sur le jour de l'enterrement. Après les lamentations du matin, chacun retourne à sa place hors de la salle du temple. Le sorcier dépose d'abord l'écaille de tortue auprès du bâtiment situé au côté occidental de la grande porte du temple. Il tourne vers le midi la tête de l'écaille. Une natte est étendue. Une torche de bois épineux est placée sur d'autres torches, à l'est de l'écaille de tortue. (La torche de bois épineux servira à griller l'écaille. Les autres serviront à allumer la 
première). Le chef de la parenté préside à cette consultation des sorts. Le maître des cérémonies et lui, en habits de fête, se tiennent debout à l'ouest de la grande porte, le visage tourné vers l'est, le plus digne au sud de l'autre. Trois hommes chargés d’interpréter les signes sont au sud de ces deux chefs ; ils sont rangés du nord au sud $\bullet_{478}$ par ordre de dignité.

Le sorcier, ceux qui portent les torches et celui qui porte la natte sont à l'ouest du bâtiment situé a u côté occidental de la grande porte. On ferme le battant oriental de la porte de ce bâtiment. Les femmes de la maison se tiennent debout à l’intérieur de la cour. La natte est étendue à l'ouest du poteau sur lequel se joignent les deux battants de la porte, en dehors du seuil. Le maître des cérémonies avertit que tout est préparé. Le chef de la maison, le visage tourné vers le nord, ôte son bandeau de deuil et le tient sur le bras gauche. Celui qui préside à la consultation des sorts va se placer à l'est de la porte, le visage tourné vers l'ouest. Le sorcier tient dans les bras l'écaille de tortue et la torche. Il dépose d'abord l'écaille de tortue, dont il tourne la tête vers l'ouest. Ensuite il dépose la torche au nord de l'écaille. (Puis il reprend l'écaille dans les mains). Le maître des cérémonies reçoit l'écaille de tortue des mains du sorcier, et montre la convexité du ventre de l'écaille au chef de la parenté, qui préside à cette divination. Celui-ci reçoit l'écaille, la regarde et la rend au sorcier.

Le maître des cérémonies se tourne, se retire un peu en arrière, et reçoit du chef de la parenté la question à poser devant l'écaille de tortue. La question est celle-ci : «Le fils affligé un tel consulte les sorts au moyen de l'écaille de tortue pour savoir si, lâi jøu mòu tel jour à venir, il convient d'enterrer son père, qui a reçu tel nom dans son adolescence. (Si l'enter rement a lieu en ce jour), les mânes du défunt, k'à̀ montant et kiáng descendant, ne seront-elles pas kín exposées à quelque houéi chagrin ?» Le maître des cérémonies promet d'employer cette formule. Il ne la répète pas. Il se tourne, va à sa natte. Le visage tourné vers l'ouest, il fléchit les genoux, et adresse la question à l'écaille de tortue. Il se lève, donne l'écaille au sorcier et se tient debout, le dos tourné au battant oriental de la porte. Le sorcier, à genoux, opère sur l'écaille de tortue. (Il la couvre d'encre et la soumet au feu). Le maître des cérémonies la reçoit et la montre à celui qui préside. Celui-ci la prend, la regarde et la rend au sorcier. Le maître des cérémonies se retire en arrière et tourne le visage vers l'est. Alors les interprètes des signes formés dans l'encre sur l'écaille de tortue s'appliquent ensemble à en deviner la signification. Cela fini, le maître des cérémonies, tenant encore en mains l'écaille de tortue, informe celui qui préside et le chef de la maison. Il donne cette interprétation : «Tel jour sera un jour heureux.» Il rend l'écaille au sorcier, et avertit les femmes de la maison. Ces femmes poussent des lamentations.

Le maître des cérémonies informe les dignitaires qui sont d'un rang plus élevé que l'officier mort, (les ministres d'État, • ${ }_{480}$ les grands préfets). Il envoie des messagers informer tous les étrangers (les collègues, les amis de l'officier mort, qui ne sont pas présents). Le sorcier enlève l'écaille de tortue. Le maître des cérémonies avertit que la consultation des sorts est terminée. Le 
chef de la maison, la tête ceinte du bandeau de deuil, entre et pousse des lamentations, comme il a fait après avoir consulté les sorts au moyen de brins d'achillée sur le lieu de la sépul ture. Les étrangers s'en vont. Le chef de la maison les salue à genoux et les reconduit.

Si la réponse des sorts n'a pas été favorable, on les consulte au moyen de l'écaille de tortue sur le choix d'un autre jour, de la même manière que précédemment. 


\section{CHAPITRE XIII}

\section{Après les lamentations du soir}

- 481 (Deux jours avant l'enterrement) après les lamentations du soir, le maître des cérémonies demande au chef de la maison quand aura lieu $k \grave{\imath}$ la levée du corps, afin d'avertir les étrangers (les collègues et les amis du mort). Le lendemain on se lève de bonne, heure. On place des cuvettes avec de l'eau pour se laver les mains devant la grande porte, en dehors du temple où est la tablette de l'aïeul du mort. (Le corps est encore dans le nì temple où est la tablette du père du mort. Après qu'il a été levé pour l'enterrement, il est placé dans le temple où est la tablette de son aïeul. Un officier du premier rang a deux temples dans sa résidence. Un officier du deuxième ou du troisième rang n'en a qu'un seul. Le tablette de l'aïeul et celle du père sont dans le même temple). On dispose trois chaudières, comme on l'a fait avant de parer le corps de ses vêtements. Les offrandes sont aussi rangées à l'est de la même manière. Le lit sur lequel le corps $\hat{\imath}$ a été étendu après avoir été paré des premiers vêtements est placé entre les deux rangées de degrés au bas de la plateforme.

O Deux hommes portant des flambeaux attendent à ${ }_{482}$ l'extérieur devant la grande porte du temple où est le cercueil. Les hommes, la chevelure enroulée en forme de tchou $\bullet$ chignon, et les reins ceints d'une ceinture de brins de chanvre dont les extrémités sont libres et pendantes, vont prendre leurs places en dehors du temple, comme précédemment, (quand les lamentations avaient lieu le matin et le soir). Les femmes ne poussent pas de lamentations. Le chef de la maison salue à genoux les étrangers (les collègues et les amis du mort), entre, va à sa place, et se découvre le bras gauche.

Un invocateur expert dans les cérémonies de la dynastie des Chang, la coiffure de deuil sur la tête et le bras gauche découvert, entre dans le temple où est le cercueil. Il porte dans les mains une serviette dont la toile est semblable à celle employée durant le deuil de neuf mois ou de cinq mois, (elle servira à essuyer la poussière, et à chasser les influences néfastes). Il monte par les degrés occidentaux. Il monte tous les degrés, mais n'avance pas sur la plateforme. Il pousse trois fois trois cris (pour éveiller l'attention des mânes du mort). Il annonce trois fois son arrivée au mort. Il lui dit ce pour quoi il vient. Il pousse des lamentations. Les porteurs de flambeaux entrent. Linvocateur descend. Il se croise en chemin au bas des degrés avec un autre invocateur expert dans les cérémonies de la dynastie des Hia. Ce dernier prend la bannière sur laquelle sont inscrits les noms du mort ; il la dresse près de la tablette du mort. Le chef de la maison bondit un nombre de fois illimité. L’invocateur expert dans les cérémonies de la dynastie des Chang essuie le 
cercueil avec son linge (le toile de deuil, et le couvre avec la couverture sur laquelle le mort $i$ a été étendu.

- ${ }_{483}$ Le cercueil est transporté du temple où est la tablette du père du mort dans le temple où est la tablette de son aïeul. Il est transporté sur un chariot. La tablette du mort marche en avant. Les offrandes la suivent. Derrière les offrandes marche un porteur de flambeau. Le cercueil le suit. Derrière le cercueil est un deuxième flambeau. Les maîtres de la maison terminent le convoi funèbre, (les hommes à droite, les femmes à gauche). Le cercueil monte à la plateforme du temple par les degrés occidentaux. Ceux qui portent les offrandes attendent au bas des degrés, le visage tourné vers l'est, rangés du nord au sud, les plus respectables au nord. Les maîtres de la maison montent ensuite. Les femmes de la maison montent et tournent le visage vers l'est. Tous les autres assistants vont se placer au bas des degrés orientaux.

Le cercueil est placé juste au milieu entre le nord et le sud, dans l'intervalle des deux colonnes de la plateforme, (la tête du mort tournée vers le nord). On fait usage du lit sur lequel le mort $\hat{\imath}$ a été étendu. Le chef de la maison, à l'est du cercueil, le visage tourné vers l'ouest, dresse la tablette du mort comme précédemment (quand le mort a été paré de ses vêtements). On monte une natte sur la plateforme ; on l'étend à l'ouest du c ercueil (à la droite du mort). Les offrandes sont rangées dans le même ordre que précédemment (devant la natte). Les vases $\bullet_{484}$ sont couverts d'un linge. On monte et on descend par les degrés occidentaux. Le chef de la maison bondit un nombre de fois illimité. Il descend, salue à genoux les étrangers, va à sa place, bondit et se couvre le bras gauche. Les femmes de la maison et les parentes passent derrière les pieds du mort, (vont à l'est) et tournent le visage vers l'ouest.

On amène (trois) voitures. On les place droit en face de l'extrémité orientale du faîte du toit de la salle, le timon tourné vers le nord. Il fait grand jour; on éteint les flambeaux. Pour enlever les offrandes de la veille, on monte par les degrés orientaux ; on descend par les degrés occidentaux. Alors on dispose des offrandes, (dans le temple où est la tablette de l'aïeul) de la même manière que précédemment (dans le temple où est la tablette du père). Ceux qui les portent montent et descendent par les degrés occidentaux. Le chef de la maison, (pendant qu'on monte et qu'on descend), profite de ce moment pour bondir.

On amène les chevaux, (deux chevaux pour chaque voiture). Leurs colliers portent, à l'endroit du poitrail, un ornement composé de trois rubans de trois couleurs différentes. Ils entrent par la grande porte, la tête tournée vers le

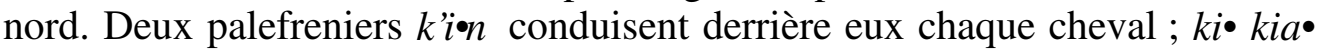
pí celui qui est à droite tient la rêne gauche, et celui qui est à gauche tient la rêne droite. Les conducteurs des voitures, le $\bullet_{485}$ fouet en main, se tiennent debout derrière les chevaux. Le chef de la maison pousse des lamentations et bondit. Les chevaux tournent à droite et s'en vont. Les étrangers s'en vont. Le chef de la maison les reconduit jusque hors de la grande porte du temple. 
Le maître des cérémonies demande au chef de la maison quand tsòu commencera le transport du mort dans le temple de son aïeul. Le chef de la maison répond: « Ce sera quand le soleil aura passé le méridien. » (Après midi) le chef de la maison entre dans le temple où est le cercueil. Il se découvre le bras gauche. Ensuite on charge le cercueil sur un chariot. Le chef de la maison bondit un nombre de fois illimité. Quand le cercueil est sur le chariot, on le lie pour qu'il ne tombe pas. Le chef de la maison se couvre le bras gauche. Il descend. On dépose des offrandes vis-à-vis des liens qui sont à la tête du cercueil.

Un invocateur expert dans les cérémonies de la dynastie des Chang orne le cercueil de tentures sur le chariot. (Il met d'abo rd des ouêi tentures verticales, puis, en dessus, des houøng tentures horizontales). Il établit à la partie supérieure comme une tchêu gouttière faite de bambou. Les tentures sont

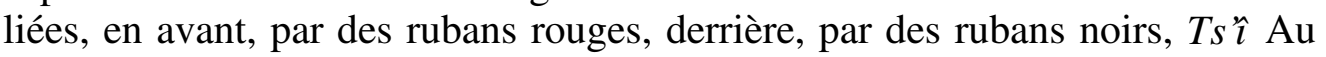
milieu, sur le devant, pendent des bandes de soie de trois couleurs. Ces bandes de soie ne sont pas ornées de perles. Des deux côtés du cercueil, on met des cordes, que des hommes tiendront à la main durant la marche, pour l'em pêcher de tomber du char funèbre. Au chariot on attache des cordes qui serviront à le traîner.

- ${ }_{486}$ A l'ouest des voitures, on étale les ustensiles et les instruments qui seront offerts à l'âme intelligente mîng du mort. Il y a un $t c h \cdot$ cadre de bois (en forme de lit), couvert de nattes placées transversalement. Il y a des pièces de bois qu'on mettra dans la fosse sur le cercueil pour soutenir la terre ; elles sont placées, trois en travers, deux en long. Sur ces pièces de bois on met trois nattes. Par dessus, on met des coussins faits de grosse toile de couleur noire ou ts ïèn foncée. Ils ont les dimensions d'une pièce de toile ordinaire. On les met aussi, deux en long, trois en travers. Les ustensiles et les instruments sont à l'ouest, rangés du sud au nord, les plus honorables au sud; ils sont sur plusieurs lignes. Viennent ensuite des coussins (au nord des ustensiles).

On place deux enveloppes faites de jonc tressé, dans lesquelles on mettra les viandes ; trois corbeilles, dont la première contient du millet glutineux, la deuxième du millet non glutineux, la troisième du blé ; trois cruches, qui contiennent, la première, du vinaigre, la deuxième, de la viande hachée conservée dans le sel et vinaigre, la troisième, (de la cannelle et du gingembre en) petits morceaux, et qui sont couvertes de grosse toile; deux jarres, dont l'une contient du vin no n fermenté et l'autre du vin fermenté, et dont les couvertures sont faites d'une toile semblable à celle des vêtements du deuil de neuf mois ou de cinq mois. Chacun de ces ustensiles est bouché avec un bouchon de bois.

On étale des instruments et des ustensiles d'un usage ordinaire $; \bullet_{487}$ (les arcs, des flèches, une charrue, un soc de charrue, deux vases de bois pour le riz ou le millet, deux grandes tasses pour le bouillon et la sauce, un bassin et une aiguière pour se laver les mains. L'aiguière est dans le bassin, le bec tourné vers le sud. Il n'y a pas d'ustensiles servant à présenter des offrandes 
aux morts. Il convient qu'on étale les ustensiles employés dans les festins et des instruments de musique.

On étale des instruments de guerre: des cuirasses, des casques, des boucliers, des carquois. Un étale des objets employés en temps de repos des chapeaux d'écorce de bambou, de grands éventails.

On enlève les offrandes qui ont été déposées précédemment pour les mânes du mort. Les serviettes, les nattes attendent à l'ouest. Les maître s de la maison, hommes et femmes, profitent de ce moment pour bondir. Les hommes se dénudent le bras gauche. Un invocateur expert dans les cérémonies de la dynastie des Chang se place devant le cercueil pour conduire la marche. Alors tsòu commence (le transport du cercueil). Les maîtres de la maison bondissent. Ils se couvrent le bras gauche. Ils s'avan cent un peu vers le midi et se tiennent vis à vis des liens qui fixent la partie antérieure du cercueil sur le char. Les femmes descendent et vont se placer entre les deux rangées de degrés.

Pour commencer, on tourne le char (du nord vers le midi). ${ }_{488}$ On ne change pas la direction de ustensiles ni des instruments. (ils sont alignés du sud au nord). L'invocateur prend la bannière sur laquelle sont inscrits les noms du mort, et la place sur les coussins. Deux hommes changent la direction de la tablette du mort. (Ils la dirigent vers le nord). Ils tournent à gauche. On étend une natte ; on y place les offrandes pour les mânes du mort, comme précédemment. Pendant ce temps, les maîtres de la maison. bondissent. On amène de nouveaux chevaux, comme précédemment. Les étrangers s'en vont. Le chef de la maison les reconduit. Le maître des cérémonies demande au chef de la maison quand aura lieu l'enterrement. Le chef de la maison rentre dans le temple, et retourne à sa place (non loin du cercueil).

$\mathbf{O}$ Le chef de l'État envoie pour les funérailles cinq pièces de soie noirâtre, cinq pièces de soie brune et deux chevaux. L'officier qui traite avec les hôtes sort et demande à l'envoyé du prince ce qu’il désire. Il rentre et avertit le chef de la maison. Le chef de la maison dépose son bâton, et va au devant de l'envoyé du prince jusqu'au dehors de la grande porte du temple. Il ne pousse pas de lamentations. Il entre le premier et se tient au côté droit de la grande porte, le visage tourné vers le nord. Il se découvre le bras gauche, ainsi que tous les maîtres de la maison. Les deux chevaux entrent et sont placés (dans la cour, au sud de la tablette du mort). L'envoyé du prince prend dans les bras les pièces de soie, passe à l'ouest des chevaux du char funèbre, s'arrête à côté de la barre transversale antérieure du timon du char, et s'acquitte de son message. (Deux barres de bois sont fixées transversalement, l'une à la partie antérieure, ${ }_{489}$ l'autre à la partie postérieure du timon. On y attache les cordes qui servent à traîner le char funèbre). Le chef de la maison pousse des lamentations. Il salue à genoux, frappant du front la terre. Il bondit. L'envoyé dépose les pièces de soie près de la caisse du char funèbre, et s'en va par le côté gauche. Lintendant passe au nord du chef de la maison, prend 
les pièces de soie et les porte à l'est du cercueil. Des officiers prennent les deux chevaux donnés par le prince et les emmènent. Le chef de la maison accompagne l'envoyé du prince hors de la grande porte du temple, et le salue à genoux. Il se couvre le bras gauche, rentre dans le temple, retourne à sa place, et reprend son bâton de deuil.

O Des officiers, envoyés par leurs chefs, viennent offrir des présents pour l'enterrement. L'officier qui traite avec les hôtes leur demande ce qu'ils désirent. Il rentre et informe le chef de la maison. Il sort de nouveau, et dit aux envoyés que le chef de la maison les attend. Les chevaux offerts en présent entrent et sont rangés dans la cour du temple. Les envoyés tiennent dans les mains des pièces de soie. L'officier chargé de traiter avec les hôtes entre le premier (pour montrer le chemin). Les envoyés le suivent, et s'acquittent de leur commission, comme précédemment l'envoyé du prince. Le chef de la maison les salue à genoux, sans quitter sa place. Il ne bondit pas. Les envoyés déposent les pièces de soie, comme précédemment l'envoyé du prince. Les pièces de soie sont emportées et les chevaux emmenés, aussi comme précédemment.

- ${ }_{490}$ (Les envoyés reviennent). Celui qui est chargé de traiter avec les hôtes sort et leur demande ce quils désirent. Il peut se faire que ces étrangers veulent déposer des présents auprès du cercueil. L'officier qui traite avec les hôtes rentre et informe le chef de la maison. Il sort et rentre avec les étrangers. Ceux-ci s'acquittent de leur commission, comme précédemment.

A la mort d'un simple officier, le chef de la maison reçoit des agneaux, de la même manière qu'il reçoit des chevaux. L'officier qui traite avec les hôtes va aussi demander aux envoyés ce quils désirent.

Si un étranger vient offrir de l'argent, des objets de prix, (pour aider à faire des funérailles), l'officier qui traite avec les hôtes entre et informe le chef de la maison. Celui-ci sort, et se tient dehors à gauche de la grande porte du temple, le visage tourné vers l'ouest. L'étranger, le visage tourné vers l'est, s'acquitte de sa commission. Le chef de la maison le salue à genoux. L'étranger, à genoux, dépose son présent. L’inten dant passe au nord du chef de la maison, et le visage tourné vers l'est, enlève le présent. Le chef de la maison retourne à sa place. $\mathrm{Si}$ le • ${ }_{491}$ présent n'est pas dans un récipient, l'envoyé ne le dépose pas ; l'intendant, tourné en face de l'envoyé, reçoit le présent de main à main. Celui qui traite avec les hôtes demande à l'envoyé sỉl a encore quelque chose à dire ou à faire. L'envoyé répo nd que tout est fini. Le chef de la maison le salue à genoux, le reconduit et rentre dans le temple.

Si un étranger se présente pour offrir un don au mort par amitié pour lui, celui qui traite avec les hôtes sort et lui demande ce qu'il désire. Il introd uit l'étranger, comme précédemment il a introduit les autres. L'étranger dépose ses pièces de soie, comme le précédent (au côté gauche de la caisse du char funèbre). S’il offre des vases tsióu parfaitement travaillés, à genoux, il les dépose parmi les vases semblables qui sont rangés en ordre pour le mort. A tous ceux qui ont offert des présents, celui qui traite avec les étrangers ne 
manque pas de demander s'il leur reste autre chose à dire ou à faire. Quand ils ont répondu que tout est fini, le chef de la maison les salue à genoux et les reconduit.

Les parents du mort peuvent déposer leurs présents auprès du cercueil. Les présents offerts par les connaissances du mort n'y sont pas déposés. Les connaissances du mort tséng offrent des présents pour témoigner leur respect, leur amitié envers le mort. Les connaissances des vivants, c'est-à-dire, des maîtres de, la maison, leur offrent des présents pour les fòu aider à faire les frais des obsèques. On inscrit sur des planchettes les noms des $\bullet_{492}$ donateurs et les présents quills ont offerts. On écrit sur chaque planchette neuf lignes, sept lignes, ou cinq lignes, (selon le nombre des présents offerts). On inscrit sur des tablettes de bambou les k'ién objets qui sont offerts pour être enterrés avec le cercueil. Les lamentations se succèdent auprès du cercueil, comme précédemment, (quand le corps a été paré des premiers vêtements). Le soir, on allume des torches dans la cour au côté droit de la grande porte.

Le lendemain matin, on place cinq chaudières hors de la cour près de la grande porte, comme précédemment, quand le corps a été paré de tous ses vêtements. Elles contiennent les mets suivants. (La première contient du mouton, la deuxième du porc, la troisième des poissons, la quatrième la chair d'un quadrupède séchée, la cinquième de la viande fraîche). La première chaudière contient la moitié gauche du corps d'un mouton moins le bassin. Elle contient cinq intestins, cinq estomacs, des poumons séparés l'un de l'autre à leur petite extrémité par une incision. (Les grosses extrémités restent unies ensemble). La deuxième chaudière contient la moitié gauche du corps d'un porc, comme la première celle d'un mouton. Le porc est divisé en plusieurs parties, comme d'ordinaire on divise les jeunes porcs. Il n'y a dans cette chaudière ni intestins ni estomacs. Les poissons, la viande séchée, le quadrupède nouvellement tué sont préparés comme précédemment (comme lorsque le corps du mort a été paré de vêtements. Le quadrupède séché et le quadrupède nouvellement tué sont des lièvres aux obsèques d'un simple officier. On emploie la viande de cerf séchée aux ${ }_{493}$ obsèques d'un grand préfet).

A l'est de la plateforme on place quatre vases de bois. Le premier contient des estomacs de ruminants ; le deuxième, des huîtres hachées conservées dans le sel et le vinaigre; le troisième, des mauves conservées dans le sel et le vinaigre; le quatrième, des escargots hachés et conservés dans le sel et le vinaigre. On place ensuite quatre vases de bambou. Le premier contient des jujubes, le deuxième du grain grillé ou des galettes, le troisième des tranches de viande séchées. Puis viennent deux jarres, dont l'une contient du vin non fermenté, l'autre du vin fermenté. On range ensuite les ustensiles et les instruments. On éteint les torches. Des hommes portant des flambeaux se tiennent des deux côtés du timon du char funèbre le visage tourné vers le nord. Le chef de la maison (sans quitter sa place) salue à genoux les étrangers qui entrent. 
On entre pour enlever les offrandes qui ont été déposées près du cercueil, après que le corps a été paré de vêtements. Les hommes bondissent. On place ces offrandes au nord-ouest du char funèbre. Les femmes bondissent. Ceux qui ont enlevé les offrandes vont à l'est (au bas de la plateforme).

Les chaudières entrent. Alors on dépose les offrandes pour le mort. On range les vases de bois, du sud au nord, les plus $\bullet_{494}$ distingués au sud, sur plusieurs lignes. On place les vases de bambou au sud des escargots conservés dans le sel et le vinaigre. On les range du nord au sud, les plus distingués au nord, sur plusieurs lignes. On place les petites tables deux à deux, sur la même ligne. Celle sur laquelle sera la chair du quadrupède tué depuis peu de temps est seule sans une deuxième qui lui corresponde. Une jarre de vin non fermenté et une jarre de vin fermenté sont placées à l'ouest des vases de bambou, la plus distinguée (la jarre de vin non fermenté) au nord de l'autre. Les officiers qui ont disposé ces offrandes s'en vont. Le chef de la maison profite de ce temps pour bondir.

Linspecteur des champs emporte la tablette du mort. Il sort par le milieu de l'ouverture de la porte. Il dépose la tablette à gauche du chemin. On fait avancer les chevaux. Les chevaux sortent de la cour du temple par le milieu de l'ouver ture de la grande porte. Chaque voiture suit les chevaux qui doivent la traîner. Les voitures sont attelées hors du temple près de la grande porte. Elles sont tournées vers le nord, et attendent, rangées du sud au nord, la plus distinguée au sud.

Des officiers entrent pour enlever les offrandes. Les maîtres de la maison bondissent comme précédemment. On enlève les serviettes qui couvrent les vases. On met dans les enveloppes de jonc la chair des animaux tués. On en retire les tibias. On ne fait pas usage des poissons ni du lièvre séché. On emporte les ustensiles et les instruments. On emporte d'abord les coussins $\bullet_{495}$ et les paquets de viande ; puis les ustensiles et les instruments, par ordre. Les voitures marchent à la suite. Ceux qui ont enlevé les objets exposés s'en vont. On bondit comme précédemment.

Le secrétaire du chef de la maison lui demande la permission de lire la liste des présents qui ont été offerts et ont été inscrits sur des planchettes, avec les noms des donateurs. Un homme prend des bâtonnets et le suit. Tous deux se placent à l'est du cercueil, près des cordes qui lient la partie antérieure de cercueil sur le char funèbre. Ils tournent le visage vers l'ouest. Le secrétaire ne recommande pas de ne pas pousser de lamentations. Ceux qui poussent des lamentations s'avertissent les uns les autres de cesser. Seules les personnes de la maison, hommes et femmes, gémissent encore. Un homme tient un flambeau à la droite du secrétaire, le visage tourné vers le midi. (Le soleil ne brille pas encore ; le lecteur a besoin d'être éclairé). Le secrétaire lit la liste des objets offerts. (Afin d'en savoir le nomb re, quand un objet a été nommé), le compagnon, à genoux, dépose un bâtonnet. La lecture terminée, le secrétaire avertit qu'on peut pousser des lamentations. On éteint le flambeau. Le secrétaire, tenant en mains sa liste, et son compagnon ; tenant en mains ses 
bâtonnets, s'en vont en ordre inverse. (Celui qui porte les bâtonnets, venu le second, s'en va le premier).

- ${ }_{496}$ Le secrétaire du chef de l'État, placé à l'ouest, le visage tourné vers l'est, recommande de cesser les lamentations. Les assistants, même les personnes de la maison, hommes et femmes, cessent tous de se lamenter. Le secrétaire lit la liste des objets qui ont été donnés pour être enterrés avec le cercueil, et été inscrits sur des tablettes de bambou. Sa lecture terminée, il avertit qu'on peut pousser des lamentations. On éteint les flambeaux qui sont des deux côtés du timon du char funèbre. Le secrétaire du prince s'en va.

O Un invocateur expert dans les cérémonies de la dynastie des Chang prend une serviette dont la toile est semblable à celle du deuil de neuf mois ou de cinq mois. Il se met en avant du cercueil, pour diriger la marche. Huit hommes tiennent les cordes des deux côtés. (L'invocateur, avec sa serviette, leur fera signe de prendre garde, quand il y aura des accidents de terrain). Les maîtres de la maison se découvrent le bras gauche. Le cercueil se met en marche. Hommes et femmes bondissent un nombre de fois illimité. Arrivés hors de la maison, devant la grande porte, ils bondissent, puis se couvrent le bras gauche.

Quand le convoi funèbre arrive à la grande porte de la capitale, un intendant envoyé par le prince offre cinq pièces de soie noirâtre et cinq pièces de soie brune. Le chef de la maison quitte son bâton de deuil, ne pousse pas de lamentations, tourne à gauche, et reçoit le message du prince. L'envoyé tourne à droite et s'acquitte de sa commission. Le chef de la maison $\bullet_{497}$ pousse des lamentations, et salue à genoux, frappant du front la terre. L'envoyé monte sur le char funèbre, met les pièces de soie sur le couvercle du cercueil et descend. Le chef de la maison le salue à genoux à son départ, retourne à sa place derrière le cercueil et reprend son bâton. Ensuite la marche continue.

Quand le convoi funèbre arrive auprès de la fosse, on range les objets à l'est et à l'ouest du chemin, du nord au sud, les plus distingués au nord. On met d'abord les coussins dans la fosse. On enlève les cordes qui ont servi à traîner le char funèbre. Le chef de la maison se découvre le bras gauche. Tous les maîtres de la maison, le visage tourné vers l'ouest, sont rangés du nord au sud, par ordre de dignité. Les femmes ont le visage tourné vers l'est. Personne ne pousse de lamentations.

Alors le cercueil est descendu dans la fosse. Le chef de la maison pousse des lamentations, et bondit un nombre de fois illimité. Il se couvre le bras gauche. Il offre au mort cinq pièces de soie noirâtre et cinq pièces de soie brune, tchéu dont chacune a la longueur réglementaire, dix-huit pieds. Il salue à genoux, frappant du front la terre. Il bondit, comme précédemment. Cela fait, il se découvre le bras gauche et salue à genoux les étrangers. La maîtresse de la maison salue aussi à genoux les femmes étrangères. Ils retournent tous deux à leurs places. $\bullet_{498}$ Les hommes et les femmes font trois fois trois bonds 
alternativement. Les hommes se couvrent le bras gauche. Les étrangers s'en vont. Le chef de la maison les salue à genoux à leur départ.

On met les instruments et les ustensiles dans la fosse à côté du cercueil. On les met aux endroits où les ornements du cercueil paraissent. (C'est pour cacher le cercueil). On met à côté du cercueil les enveloppes faites de jonc et pleines de viande, et les corbeilles contenant du millet et du blé. On met par dessus le $t c h \bullet$ cadre de bois en forme de lit; on tourne en bas le plus beau côté de ce cadre. Sur le cadre on met des nattes k'áng destinées à soutenir la terre ; le beau côté est tourné en bas. Sur les nattes on place des pièces de bois, destinées à soutenir la terre. Après qu'on a jeté dans la fosse trois pelletées de terre, le chef de la maison salue à genoux les villageois du canton (pour les remercier d'être venus aider à traîner le cercueil, à le mettre dans la fosse, à l'enterrer). Il retourne à sa place, bondit et se couvre le bras gauche, comme précédemment.

O Au retour de l'enterrement, on pousse des lamentations dans le temple où est la tablette de l'aïeul du mort. - Le chef de la maison entre, monte par les degrés occidentaux et tourne le visage vers l'est. Tous les maîtres de la maison se tiennent au bas de la plateforme, le visage tourné vers l'est, rangés du nord au sud par ordre de dignité, les plus dignes au nord. Les femmes $\bullet_{499}$ entrent. Les hommes bondissent. Les femmes montent par les degrés orientaux. Les femmes de la maison entrent dans la salle, bondissent, sortent de la salle, vont prendre leurs places sur la plateforme. Ensuite elles font trois fois trois bonds alternativement avec les hommes.

Le plus honorable des étrangers présente les condoléances de tous. Il monte par les degrés occidentaux. Il dit : «Que faut-il faire ? » Le chef de la maison le salue à genoux, frappant du front la terre. Cet étranger descend et s'en va. Le chef de la maison l'accompagne jusque hors de la grande porte du temple, et le salue à genoux, frappant du front la terre.

Ensuite tous les assistants vont dans le temple où le mort a été mis dans le cercueil. Ils prennent les places qu'ils ont occupées quand le cercueil a été enlevé et transporté. Les hommes et les femmes font trois fois trois bonds alternativement. Les cousins du mort s'en vont. Le chef de la maison les salue à genoux et les accompagne. Tous les maîtres de la maison sortent du temple. Les lamentations cessent. On ferme la grande porte du temple. Le chef de la maison salue les partants par une inclination. Ensuite il va demeurer dans la cabane funèbre.

Le jour de l'enterrement, les lamentations se font encore le matin et le soir dans le temple. On ne présente pas d'offrandes $\bullet_{500}$ au mort (au moment de ces lamentations). On lui présente des offrandes solennelles trois fois. (La première fois, au retour de l'enterrement, à midi ; les deux autres fois, les jours suivants). Après ces trois offrandes, les lamentations quotidiennes cessent. Le lendemain du jour où elles cessent, on offre des offrandes au mort et à son aïeul dans le temple où est la tablette de son aïeul, qui sera son $p \bullet n$ 
voisin. (Le temple où sera la tablette du nouveau défunt sera à côté du temple où est la tablette de son aïeul).

\section{NOTES SUPPLÉMENTAIRES.}

Un officier, tant qu'il est en bonne santé, demeure dans le principal des appartements particuliers de sa maison; il se couche, la tête tournée vers l'ouest, auprès du mur septentrional. Quand il est malade, si la maladie est grave, il a besoin d'un logement tch $i$ très pur où il n'y a rien de souillé. De même quand il est en convalescence. (Son esprit a besoin de repos). On enlève les guitares et les luths. (Toute musique cesse).

En cas de maladie, $t s^{\bullet}$ grave ou píng légère, on balaie la terre à l'intérieur et à l'extérieur des appartements, (à cause des étrangers qui viennent visiter le malade. Pour la même raison), on enlève les vêlements vieux et sales ; on met des vêtements neufs. (Si le malade ne peut se remuer), quatre hommes sont constamment auprès de lui et le prennent chacun par un $\bullet_{501}$ membre. Hommes et femmes, tous changent de vêtements (pour recevoir les visites). On applique de la ouate de soie à la bouche et aux narines du moribond, et l'on attend pour voir quand la respiration cessera. Il ne convient pas qu'un homme expire entre les mains des femmes, ni une femme entre les mains des hommes. On va adresser des supplications aux esprits protecteurs des cinq parties de la maison, (qui sont les portes intérieures, le foyer, la grande porte, les allées et la cour centrale).

Quand le malade meurt, les maîtres de la maison (les frères) pleurent et gémissent; les cousins poussent des lamentations. On place un bois de lit auprès de la fenêtre. Sur ce lit on met deux nattes : une natte de jonc, et par dessus, une natte de bambou. On met un coussin pour soutenir la tête. On transporte le cadavre sur le lit.

Celui qui est chargé de rappeler l'âme du mort prend les habits de cour du mort. De la main gauche il tient 1a tunique par le collet; de la main droite il tient la jupe par la ceinture. Il invite l'âme à revenir en lui montrant la tunique et la jupe, quil tient toutes deux de la main gauche.

Pour que la bouche du mort reste ouverte, on lui met entre les mâchoires une cheville qui a la forme d'un joug recourbé, et dont les deux extrémi tés paraissent au-dessus de la bouche. Pour que les jambes restent droites, on attache entre les pieds un de ces escabeaux contre lesquels on se repose étant assis. Les pieds de l'escabeau sont tournés vers le midi. Un serviteur ; à genoux, tient cet escabeau (de peur qu'il ne se dérange).

- ${ }_{502}$ Des officiers vont au lit du mort et déposent des offrandes vis-à-vis de la tête de son épaule droite. Ils se servent de vases et d'ustensiles employés en dehors des temps de deuil. Ils mettent une jarre de vin non fermenté et une 
jarre de vin fermenté, ou deux jarres d'une seule de ces deux sortes de vins. Ils ne mettent ni serviette ni cuiller sur les vases.

La mort d'un officier est annoncée au chef de l'État en ces termes :

- Le serviteur du prince, un tel, est mort.

La mort de la mère, de la femme ou du fils aîné d'un officier est annoncée au prince en ces termes :

- Mòu La mère, La femme ou Le fils aîné (un tel) du serviteur du prince, un tel, est mort. » (On ne dit pas le nom des femmes. On dit le nom du fils aîné).

Dans la salle où est le mort, seuls les maîtres de la maison et leurs femmes peuvent s'asseoir. Ceux des cousins et celles des femmes des cousins qui ont un titre honorifique peuvent aussi s'asseoir. (Les autres personnes doivent se tenir debout).

Quand le mort est dans la salle, s’il vient un message du chef de l'Étal, aucun des maîtres de la maison, excepté le chef, ne sort pour recevoir ou reconduire l'envoyé du prince. Les envoyés qui apportent des vêtements pour parer le corps du mort les déposent sur le lit sans se mettre à genoux, (parce que le lit est très haut). Ils parlent au chef de la maison dans la $\bullet_{503}$ salle, à l'ouest de la porte, le visage tourné vers le nord.

Un invocateur expert dans les cérémonies des Hia lave du riz. Il prépare ainsi l'eau de riz avec laquelle on $t s^{\prime}{ }^{\prime} u^{\bullet}$ lavera la chevelure du mort. Quatre serviteurs tiennent une couverture levée au dessus du corps, pour le cacher aux regards, et on le lave. Il ne reste que le bois de lit. (Les nattes ont été enlevées, pour qu'elles ne soient pas mouillées).

Quand la mère d'un officier meurt, les servantes de la maison lavent le corps. Elles lient leurs chevelures en forme de chignon, et n'y mettent pas d'épingle de tête.

On apporte la tunique et la jupe dont on revêtira l'officier. Sa femme apporte la ceinture qui ceindra le milieu du corps.

Quand on a fini de laver le corps, on rapporte les perles dans une corbeille. Elles sont mises dans la bouche du mort, du côté droit et du côté gauche, près des dents canines. Un invocateur expert dans les cérémonies de la dynastie des Hia enlève les restes de bouillie de riz. On couvre les oreilles du mort avec des flocons de ouate de soie.

$\mathrm{Au}$ sud, au bas de la plateforme (entre les deux rangées de degrés), on creuse, du nord au sud, une fosse qui a un $t c^{\prime} u(20 \mathrm{~cm})$ de largeur, deux tch' $\bullet(40 \mathrm{~cm}) \mathrm{de} \bullet_{504}$ longueur, et trois $t c h{ }^{\prime} u$ de profondeur. La terre qu'on en retire est rejetée au midi de la fosse. On bouche avec une motte de terre le • trou par lequel sortira la fumée du fourneau établi dans cette fosse.

La tunique et la jupe dont on revêt le mort sont faites d'une toile semblable à celle dont on fait les tentes. Les manches sont faites chacune 
d'une pièce de toile qui a toutes les dimensions ordinaires. La tunique est assez longue pour descendre jusqu'aux genoux. La jupe n'est pas plissée à l'endroit des reins, ni par devant ni par derrière, (elle est aussi large en haut qu'en bas). Elle est assez longue pour descendre jusque sur les pieds. Les bordures latérales et les bordures mises au bas de la jupe sont rouges. Les bordures du collet et des manches de la tunique sont noires. On met à la main droite du mort une sorte de gant, dont une moitié est appliquée sur la peau de la paume de la main, l'autre moitié est liée au doigt du milieu par un cordon (et couvre le revers de la main). Les deux moitiés sont liées ensemble par un cordon derrière le poignet.

L'inspecteur des champs tasse la terre sur les côtés de la fosse creusée au bas de la plateforme (et y fait un fourneau). Des condamnés bouchent les fosses d'aisance. (Le jour du décès), après que le mort a été vêtu d'une tunique et d'une jupe, le soir on allume des torches dans la cour. Le lendemain matin, on éteint les torches, et on étale les habits qui couvriront le mort.

- ${ }_{505}$ La toile des bandelettes et des linceuls est toujours semblable à celle dont on fait les vêtements de cour.

On place un grand plateau à l'est, au bas de la plateforme, du nord au sud, parallèlement à la crédence. Sur ce plateau on met deux jarres, contenant l'une du vin non fermenté, l'autre du vin fermen té ; le vin fermenté est placé au sud du vin non fermenté. A l'est de ces jarres, on place des corbeilles, du nord au sud. Ces corbeilles contiennent quatre coupes de corne, deux cuillers de bois, et deux cuillers sans ornement. Au nord des deux jarres, on place deux vases de bois à côté l'un de l'autre. On place de même deux vases de bambou. Toujours quand les vases de bambou et les vases de bois ont été remplis, préparés et étalés, on les couvre chacun d'une serviette. En attendant le moment où les coupes seront remplies, une cuiller est sur chacune d'elles, le cuilleron renversé, le manche tourné en avant. Quand on dépose les cuillers, après s'en être servi, on les met dans les coupes.

Jusquà ce que $p$ '• le moment arrive où le corps est paré des premiers vêtements, les offrandes présentées au mort ne sont pas enlevées de la salle. On ne bondit pas d'une manière réglée. Après que chacun a appuyé la poitrine contre la poitrine $\mathrm{du} \bullet_{506}$ mort, le chef de la maison se découvre le bras gauche, enroule sa chevelure en forme de chignon, et tord les extrémités pendantes des brins de chanvre de sa ceinture. Tous les autres maîtres de la maison portent une ceinture de toile.

Le corps est paré de tous ses vêtements au haut des degrés orientaux. Les grands préfets montent par les degrés occidentaux. Ils se tiennent sur la plateforme à l'est de ces degrés, le visage tourné vers le nord, rangés de l'est à l'ouest par ordre de dignité. Après avoir appuyé la poitrine cont re la poitrine du mort, ils descendent dans l'ordre inverse de celui dans lequel ils ont monté. (Ceux qui ont monté les derniers descendent les premiers). Ils retournent à leurs places dans la cour. Les offrandes sont couvertes de serviettes. Ceux qui 
portent des flambeaux les éteignent et s'en vont. Ils descendent par les degrés orientaux, passent au nord du chef de la maison et vont à l'est.

Après que le corps a été mis dans le cercueil, le chef de la maison se coupe la mèche de cheveux qui pend du côté gauche de sa tête et qui lui rappelle ses devoirs envers son père. Trois jours après, il tord ensemble les extrémités pendantes des brins de chanvre de sa ceinture. La chaîne de la toile de son bonnet se compose de six fois quatre-vingts fils ou 480 fils. Les $p \bullet$ coutures de son bonnet paraissent au dehors. Une corde est liée autour des bords de ce bonnet, et ses extrémités pendantes $\bullet_{507}$ tiennent lieu de rubans. Il est aplati. La chaîne de la toile du plastron se compose de trois fois quatre-vingts fils. Les extrémités des brins de chanvre dont les chaussures sont faites, sont liées ensemble à l'extérieur. La plus grosse extrémité du bâton de deuil est l'extrémité inférieure. Qu’il soit de bambou ou d'éléococca, c'est la même chose. (L'extrémité inférieure est t oujours la plus grosse).

Un fils, en temps de deuil, demeure dans une cabane inclinée, dressée en dehors de la grande porte de la maison. Il couche sur un paillasson, la tête appuyée sur une motte de terre. Il n'ôte ni son bandeau ni sa ceinture (ni le jour ni la nuit). Il pousse des lamentations à n’importe quel moment de la journée. Il ne parle que de choses concernant les funérailles. Il mange le matin une poignée de riz mise en bouillie claire, et une poignée le soir. Il ne mange ni légumes ni fruits.

Le chef de la maison monte une mauvaise voiture; une peau de chien blanc couvre l'appui sur lequel il pose les mains. Cette voiture est couverte de nattes de jonc. Le conducteur emploie une tige de jonc en guise de fouet. Dans cette voiture, le carquois et le fourreau d'arc sont de peau de chien. Le cercle fixé dans le moyeu de chaque roue est de bois (au lieu d'être de fer). La corde dont on s'aide pour monter dans cette voiture est un vulgaire cordeau, ainsi que les guides des chevaux. Le mors des brides est de bois. Le poil des chevaux n'est pas lisse. $\bullet_{508}$ La voiture de la maîtresse de la maison est comme celle de son mari. Les tentures qui couvrent les côtés de cette voiture de la femme sont de grosse toile. Le carquois et le fourreau d'arc qui sont dans la seconde voiture, soit du chef de la maison soit de sa femme, sont $c h \bullet$ bordés de peau de chien blanc. Pour le reste, cette seconde voiture est comme celle que monte le maître de la maison ou sa femme.

$\mathbf{O}$ Le premier jour du mois, un jeune serviteur prend un balai, tourne en bas la tête du balai (avec la main droite); puis il le tient de la main gauche. A la suite de ceux qui vont enlever les offrandes présentées au mort, il entre dans la salle. Le moment venu de déposer de nouvelles offrandes, il enlève la natte et balaie la salle. Il réunit les balayures à l'angle sud -est de la salle. Il étend la natte comme elle était précédemment. Après que de nouvelles offrandes ont été déposées, celui qui a balayé la salle prend son balai, tient le manche tourné en bas et la tête du balai tournée vers sa poitrine. A la suite des porteurs de flambeaux, il va à l'est. 
On présente au mort, comme précédemment avant le décès, les iáng mets dont un fils nourrit. ses parents ién dans les appartements particuliers, les kouéi mets qui sont servis aux trois repas de chaque jour, les si $\bullet$ friandises de la saison, $t$ ' $n g$ mथ l'eau chaude dont on se lave le corps et la chevelure. Le premier du mois, si l'on sert au mort de nouveaux mets, $\bullet_{509}$ c'est dans la salle d'audience des appartements particuliers. Les mets servis aux trois repas de chaque jour n'y paraissent pas.

O Avant de consulter les sorts au moyen de brins d'achillée sur le lieu de la sépulture, l'officier chargé du soin des tombes trace un plan sur le terrain projeté. Après avoir consulté les sorts au moyen d'une carapace de tort ue sur le jour de l'enterrement, si la réponse a été favorable, le maître des cérémonies (après avoir informé le chef de la maison), annonce à la femme du chef de la maison que la réponse a été favorable. Cette femme pousse des lamentations. Toutes les autres femmes se lamentent. La femme du chef de la maison monte sur la plateforme de la salle. Toutes les lamentations cessent.

Le matin du jour où le cercueil doit être enlevé pour être transporté dans le temple de l'aïeul, les hommes et les femmes s'abstien nent de pousser des lamentations. Le lit sur lequel le mort a été étendu et le char funèbre sont placés à l'est des degrés occidentaux, dans le temple où est la tablette du père du mort.

Le temple où est la tablette du père est celui des deux temples dans lequel on place des offrandes. On dépose ces offrandes, comme lorsque le corps a été paré des premiers vêtements. Ensuite on lève le cercueil. Il est tourné vers le - 510 temple où est la tablette du père. La tablette du nouveau défunt reste à l'ouest de la grande porte, le côté principal tourné vers l'est. Le cercueil entre. Il monte par les degrés occidentaux ; il est placé juste entre les deux colonnes de la plateforme.

Ceux qui portent les offrandes s'arrêtent au bas des degrés occidentaux, le visage tourné vers l'est, rangés du nord au sud par ordre de dignité. Le chef de la maison monte, et se tient à l'est du cercueil, le visage tourné vers l'ouest. Tous les maîtres de la maison (montent et) vont à l'est occuper leurs places. Les femmes montent à leur suite, et tournent le visage vers l'est. Ceux qui portent les offrandes montent, et déposent les offrandes à l'ouest du cercueil. Ils montent et descendent par les degrés occidentaux. Le chef de la maison, pendant qu'on dispose les offrandes, bondit.

Celui des deux porteurs de flambeaux qui est entré devant le cercueil monte sur la plateforme, et se place au sud de la colonne orientale, le visage tourné vers l'ouest. Celui qui est entré derrière le cercueil se tient à l'est des degrés occidentaux, le visage tourné vers le nord; il reste au bas de la plateforme. Le chef de la maison descend et va à sa place. Des officiers enlèvent les offrandes; puis ils en déposent d'autres. Ils montent $\bullet_{511}$ et descendent par les degrés occidentaux. Le chef de la maison bondit, comme précédemment. 
Un invocateur et des aides prennent les offrandes; ils descendent suivis de ceux qui portent les serviettes. Le cercueil les suit. Les assistants, rangés par ordre, suivent le cercueil. Ils vont tous au temple où est la tablette de l'aïeul.

$\mathbf{O}$ (Trois voitures du défunt) transportent des vêtements à la sépulture. D’abord, la chéng $k i \bullet$ voiture qu’il montait ordinai rement. La barre d'appui placée sur le devant, le bouclier et le carquois placés dans l'intérieur de cette voiture, tout est couvert de peau du cerf à court poil. Les laisses des chevaux sont de cuir. Cette voiture porte un étendard rouge. A l'intérieur on met le bonnet de cuir du défunt et les vêtements qui accompagnent ordinairement ce bonnet. Les rubans des brides et les rênes ornées de perles pendent sous le joug qui est sur le cou des chevaux. (Les palefreniers, en entrant dans la cour, conduisent les chevaux derrière eux par une laisse. Les rênes reposent sur le dos des chevaux). La voiture de voyage du défunt porte des habits de cour. Sa kaò voiture de chasse porte un manteau et un chapeau de jonc ou d'écorce de bambou.

O Avant de mettre le cercueil sur le char funèbre, un invocateur et des aides prennent les offrandes déposées près du cercueil. Puis ils se tiennent à l'ouest de la porte de la salle, le visage tourné vers le sud, rangés de l'est à l'ouest par ordre $\bullet_{512}$ de dignité. Avant qu'on ait fini de lier le cercueil sur le char, ils descendent et déposent les offrandes sur une natte à l'ouest du cercueil. Ils couvrent de serviettes les offrandes. Ensuite on dresse autour du cercueil des tentures qui simulent des murs.

Les pièces de bois qui seront placées sur le cercueil dans la fosse pour soutenir la terre sont taillées. Les coussins qu'on mettra dans la fosse sous le cercueil sont bourrés de fleurs de chiendent; ils contiennent des substances calmantes (gingembre,..), et des fleurs de marais (orchis, iris,...). Les enveloppes faites de roseau ont trois tch'eu $(60 \mathrm{~cm})$ de long, et sont toutes tressées de la même manière. Il y a trois baquets faits de jonc. Les grains qu'ils contiennent (millet, blé) $i \bullet$ ont été trempés dans l'eau bouillante.

$\mathbf{O} \mathrm{Au}$ commencement, quand on tourne les voitures, personne ne change de place. Quatre hommes, dont deux de chaque côté, tiennent les cordes du cercueil.

La couleur, la qualité des pièces de soie offertes par les étrangers ne sont fixées par aucune règle.

On ne fait jamais frire dans la graisse les grains grillés ou les galettes. (Ils auraient une odeur désagréable).

En chemin, on n'arrête le cercueil que pour recevoir un message du chef de l'État. On ne l'arrête pour aucune $\bullet_{513}$ autre cause.

- Quand les voitures qui précèdent le cercueil arrivent près de la fosse, elles se mettent au côté gauche du chemin, et s'arrêtent, tournées vers le nord, rangées de l'est à l'ouest, les plus nobles à l'est. Quand le cercueil est arrivé près de la fosse (et a été enlevé du char funèbre), lièn on prend tous les 
vêtements qui sont dans les voitures de transport, et on les met sur le char funèbre. Après que le cercueil a été mis dans la fosse (et couvert d'un peu de terre), on s'en retourne. On ne presse pas la marche des chevaux.

Si le chef de l'État vient voir parer le corps, et s'en va avant qu'on ait déposé les offrandes, il se retire quand le couvercle a été mis sur le cercueil. Sil ne v oit pas parer le corps, il arrive après que le cercueil a été couvert, et reste jusqu'à la fin de la cérémonie, (jusqu'à ce que les offrandes aient été déposées). Quand le cercueil a été disposé convenablement entre les deux colonnes de la plateforme, les étrangers s'en vont. Ensuite les ouvriers amènent le char funèbre entre les deux rangées de degré. Les offrandes que l'invocateur dépose au commencement, quand on tourne le char funèbre, sont placées par lui au sud du chef de la maison, près de la barre transversale fixée à la partie antérieure du timon. Elles sont rangées du nord au sud; le nord est le côté le plus honorable. Des serviettes les couvrent.

L'arc et les flèches sont récemment et grossièrement façonnés. (On n'en fait aucun usage). Les extrémités de l'arc sont garnies ${ }_{514}$ d'os ou de corne. On peut le bander aussi, comme les arcs ordinaires. Une armature de bambou est liée au bois de l'arc, pour l'empêcher de se déformer, quand il est débandé. On met du cuir aux endroits où la corde est liée au bois de l'arc, et à l'endroit où la flèche glisse sur le bois de l'arc. L'arc a un fourreau. Il y a quatre flèches, dont le bois est muni de plumes et dont la pointe est d'os. Les plumes touàn ouéi sont courtes. Il y a quatre flèches semblables à celles tchéu faites pour l'exercice du tir. Les deux extrémités de ces flèches sont également lourdes. Les plumes sont aussi courtes. (L'extrémité antérieure d'une flèche ordinaire doit être plus lourde que l'extrémité postérieure). 


\section{CHAPITRE XIV}

\section{Offrandes présentées au retour de l'enterrement d'un simple officier}

- ${ }_{515}$ On offre un porc et du millet. On fait cuire $t c h \bullet$ la moitié du porc hors du temple, à droite de la grande porte, sur un fourneau tourné vers l'est. Les fourneaux sur lesquels on fait cuire les poissons et le lièvre séché viennent ensuite. Le plus noble des deux (celui sur lequel on fait cuire les poissons) est au nord de l'autre. Les fourneaux sur lesquels on fait cuire les deux sortes de millets sont auprès du mur oriental et regardent l'oues t.

On place des cruches vides au sud-ouest des degrés occidentaux. On met des vases pleins d'eau à l'ouest des cruches, et des corbeilles à l'est des cruches. On place des amphores dans la salle auprès du mur septentrional, visà-vis de la porte. Ce sont deux jarres, qui contiennent, l'une du vin non fermenté, l'autre du vin fermenté. Le vin fermenté est à l'est du ${ }_{516}$ vin non fermenté. Ces jarres n'ont pas de support. Elles sont couvertes de serviettes de fine toile de dolic. Une cuiller est sur chacune d'elles, le manche tourné vers le sud. Un escabeau sans ornement et une natte de roseau sont au bas du bâtiment occidental (pour les mânes du mort).

La paille qu'on mettra sous les offrandes est du chiendent haché, dont les brins sont longs de cinq ts'uén (un décimètre), liés ensemble et contenus dans des corbeilles. Cette paille est placée à l'ouest sur la crédence.

On place à l'est de la colonne occidentale deux vases de bois, contenant, l'un des légumes salés et conservés dans le vinaigre, l'autre de 1 a viande haché et conservée dans le sel et le vinaigre. On place la viande hachée à l'ouest des légumes. Vient ensuite un vase contenant un ragoût. Viennent ensuite deux vases de bois et quatre vases de bambou, contenant ts'ôung hién des mets qui seront servis après le vin. Ils sont rangés du nord au sud ; le nord est la place la plus honorable.

Deux vases, contenant, l'un du millet glutineux, l'autre du millet non glutineux, sont placés entre les deux rangées de degrés, le premier à l'ouest du second ; ils reposent sur une natte de roseau. Des aiguières pleines d'eau, pour se laver les mains, sont placées au milieu de bassins, le bec tourné vers le midi, au sud des degrés occidentaux. A l'est des aiguières $\bullet_{517}$ sont des serviettes dans des corbeilles.

On place trois chaudières en dehors du temple, à droite de la grande porte ; on les tourne vers le nord; on les range du nord au sud, par ordre de dignité. On dépose les leviers qui servent à les porter et les serviettes qui servent à les couvrir. On place des cuillers et des petites tables à l'ouest du bâtiment situé 
au côté occidental de la grande porte. A l'intérieur de ce bâti ment, on place des mets exquis, les viandes rôties sur des petites tables; on les met au sud pour plus de commodité.

Les maîtres de la maison et leurs cousins, vêtus comme pour l'enterrement, les étrangers et les officiers de service, vêtus comme pour une visite de condoléance, vont tous se placer en dehors de la grande porte, comme pour les lamentations du matin et du soir. Les femmes de la maison et les cousines, en habits de deuil, vont se placer sur la plateforme, aussi comme pour les lamentations.

Un invocateur, coiffé du bonnet de deuil, et portant le bandeau et la ceinture de toile de dolic tsaò blanchie, étend au milieu de la salle une natte, qu'il tourne vers l'est. A droite il place un escabeau. Puis il descend et sort. Avec le maître des cérémonies, il va prendre sa place à l'ouest de la grande porte. Tous deux tournent le visage vers l'est, le plus digne au sud de l'autre . Le maître des cérémonies avertit le chef de la maison que les officiers ont tout préparé, et le prie de saluer à genoux les étrangers, comme avant les lamentations. Le chef de la maison entre dans le temple et pousse des lamentations. Les femmes se lamentent. Le chef de la maison va prendre sa place sur la plateforme. Tous les maîtres de la maison, les cousins, les étrangers vont à l'ouest occuper les places qu'ils prennent au retour des lamentations.

L'invocateur entre par le côté gauche de la grande porte du temple, et tourne le visage vers le nord. Le maître des cérémonies se tient devant les degrés occidentaux, le visage tourné vers le nord. Linvocateur se lave les mains, monte, prend la paille sur laquelle les offrandes seront placées, descend, lave la paille. Il monte, entre, dépose la paille à l'est de l'escabeau sur la natte; il l'étend de l'est à l'ouest. Il descend, lave une coupe et monte. Les lamentations cessent.

Le chef de la maison, appuyé sur le bâton de deuil, entre dans le temple. L’inv ocateur le suit, et se place à sa gauche, le visage tourné vers l'ouest. Les aides servent des légumes salés ${ }_{519}$ et de la viande hachée et conservée dans le sel et le vinaigre. Ils placent la viande au nord des légumes.

Les servants de table et les officiers de service se lavent les mains et vont chercher les chaudières. (Un servant et un officier portent chaque chaudière). Le plus digne des deux (l'officier) marche à la gauche du servant. Les chaudières entrent, et sont placées devant les degrés occidentaux, tournées vers l'est, rangées du nord au sud, la plus distinguée au nord. Les cuillers et les petites tables viennent ensuite et sont rangées auprès des chaudières. Celui qui est à gauche (l'officier) enlève le levier, la couverture et la cuiller. Le servant de table, aidé de l'officier qui s'est placé aussi à droite de la chaudière, retire la viande de la chaudière et la met sur la petite table. Cela fini, ceux qui ont apporté les cuillers s'en vont dans l'ordre inverse de celui dans lequel ils sont venus. (Le dernier arrivé s'en va le premier). Ils retournent à leurs places (parmi les étrangers). 
Les petites tables entrent dans la salle, et sont placées à l'est des vases de bois. Les poissons sont placés à la suite des petites tables ; puis le lièvre séché est placé seul. Au sud des petites tables, un aide place deux vases dont l'un contient du millet glutineux et l'autre du millet non glutineux. Il place le millet non glutineux à l'est du millet ${ }_{520}$ glutineux. Au sud des vases de bois, on place un vase qui contient du bouillon aux herbes. Les servants de table sortent et restent debout à l'ouest de la porte de la salle. Des aides enlèvent les chaudières.

Un invocateur verse du vin non fermenté dans une coupe, et dit aux servants de table d'ouvrir le couvercle des vases de bois qui contiennent le millet. Les servants de table disent oui, enlèvent les couvercles, les renversent et les déposent au sud des vases. Ils retournent à leur place (à l'ouest de la porte de la salle). L'invocateur dépose la coupe au sud du vase de bouillon, et retourne à sa place (à gauche du chef de la maison).

Le chef de la maison salue l'invocateur deux fois à genoux, inclinant la tête jusqu'à terre. L'invocateur invite les mânes du mort à un repas. Il ordonne aux servants de table de leur offrir des mets. Les servants de table disent oui. Ils relèvent la manche gauche de la tunique et se découvrent le bras gauche. Ils prennent les deux sortes de millets, et les offrent à l'âme du mort sur la paille de chiendent, à trois reprises. Ils prennent les morceaux de viande de porc et les offrent de la même manière à trois reprises. L'invocateur prend la coupe qu'il a déposée, et l'offre aussi de la même manière. Il n'a pas épuisé tout le vin des amphores. Il • ajoute, c-à-d, il verse de nouveau, ${ }_{521}$ du vin dans la coupe, et retourne la déposer pour l'âme du mort. Le chef de la maison le salue deux fois à genoux, inclinant la tête jusqu'à terre. Après que l'invocateur tcheóu a offert le repas au mort au nom du chef de la maison, et promis à celui-ci beaucoup de prospérité au nom du mort, le chef de la maison le salue à genoux comme précédemment, pousse des gémissements, s'en va et retourne à sa place.

L’invocateur va au devant de celui qui a été choisi pour représenter la personne du mort. Un homme, portant sur la poitrine le plastron et sur la tête le bandeau de deuil, et tenant dans les mains une corbeille, suit le représentant du mort, en poussant des lamentations. Quand le représentant du mort entre à la grande porte du temple, les hommes bondissent. Puis les femmes bondissent. On verse de l'eau au représentant du mort, et il se lave les mains. Le maître des cérémonies lui présente un essuie-main.

Quand le représentant du mort arrive aux degrés de la salle, l'invocateur l'invite à monter. Le représentant du mort monte. Le maître des cérémonies engage les assistants à bondir, comme ils l'ont fait précédemment. Quand le représentant du mort entre à la porte de la salle, on bondit comme précédemment. Les lamentations cessent. Les femmes entrent dans le bâtiment latéral. Le chef de la maison et l'invocateur saluent à genoux le représentant du mort, et t'ouò l'invitent à s'asseoir $\bullet_{522}$ tranquillement. Le représentant du mort les salue à genoux et s'assied. Un suivant place une 
corbeille à la gauche du représentant du mort, sur une natte, et reste debout au nord de la natte. Le représentant du mort prend chaque offrande (de la main droite), puis la tient de la main gauche. (De la main droite) il prend les légumes salés, les trempe dans la saumure de la viande hachée, et les offre au mort entre les vases de bois. L'invocateur dit au servant de table de prendre les offrandes une à une, de les touó tenir en bas (au lieu de les kiù lever, et de les donner au représentant du mort). Le servant de table prend les deux sortes de millet, et les poumons, qui doivent être offerts aux mânes, et les donne au représentant du mort. Celui-ci les offre aux mânes. Il leur offre les mets qui ont été déposés. L'invocateur tcheóu adresse la parole au mort au nom du chef de la maison, et promet au chef de la maison une grande prospérité au nom du mort. Le chef de la maison le salue à genoux, comme précédemment. Le représentant du mort goûte le vin non fermenté et dépose la coupe.

Le servant de table lève les poumons et les côtes du dos du porc; il les donne au représentant du mort. Celui-ci les reçoit, les secoue, les offre au mort, les goûte, et les tient de la main gauche. Linvocateur dit au servant de placer près $\mathrm{du} \bullet_{523}$ représentant du mort le vase qui contient le millet glutineux. Le servant prend ce vase et le place sur la natte du représentant du mort. Le représentant du mort offre au mort le bouillon aux herbes et le goûte. Le bouillon principal, composé de viande juteuse, entre par la grande porte du temple, et est placé au sud du bouillon aux herbes. Quatre vases contenant de la viande coupée eu petits morceaux sont placés à gauche (au sud) du bouillon principal.

Après que le représentant du mort a mangé du millet trois fois, le reste est jeté dans des corbeilles. D’abord, après qu'il a mangé trois fois du riz, le servant de table lève et lui présente l'épine dorsale du porc. Le représentant du mort la reçoit, la secoue et goûte la viande. Puis le servant la met dans une corbeille. Le représentant du mort mange de nouveau du millet. Le servant lève et lui présente la partie supérieure d'un membre antérieur. Le représentant du mort l'offre au mort, comme précédemment. Le servant lève et lui présente du poisson et du lièvre séché. (Le représentant du mort n'en agrée pas l'odeur ; il ne les reçoit pas). Le servant les met dans une corbeille. Le représentant du mort mange du millet encore trois fois. Le servant lève et lui présente une épaule. Le représentant des mânes l'offre aux mânes comme les pièces $\bullet_{524}$ précédentes. Le servant enlève les petites tables sur lesquelles sont les poissons et le lièvre séché, et les dépose à l'écart.

Quand le représentant du mort a fini de manger, le servant reçoit les poumons et l'épine dorsale, et les met dans une corbeille. Il reporte le millet glutineux, et le replace comme auparavant.

Le chef de la maison lave une coupe féi sans pied, et y verse du vin, pour que le représentant du mort se rince la bouche. Celui-ci le salue à genoux et reçoit la coupe. Le chef de la maison, le visage tourné vers le nord, lui rend le salut à genoux. Le représentant du mort offre le vin au mort et le goûte. 
Le plus respectable des étrangers prend ensuite le foie et le met sur une petite table, dans le sens de la longueur. A droite de la table, il met du sel. Le représentant du mort prend la coupe de la main gauche. Il prend le foie de la main droite, le plonge dans le sel, le secoue, l'offre au mort, le goûte et le place sur la petite table. L'étranger descend, reporte la petite table dans le bâtiment situé au côté occidental de la grande porte et retourne à sa place. Quand le représentant du mort a fini de boire, l'invocateur reçoit la coupe. $P \bullet u$ siáng tsi $\bullet$ il n'avertit pas le chef de la maison de le saluer. Néanmoins, $\bullet_{525}$ le chef de la maison le salue à genoux. Le représentant du mort lui rend le salut.

L'invocateur verse du vin dans une coupe et le donne au re présentant du mort. Celui-ci l'offre au chef de la maison pour lui rendre la pareille. Le chef de la maison le salue à genoux et reçoit la coupe. Le représentant du mort lui rend le salut. Le chef de la maison, à genoux, offre le vin au mort. Quand il a fini de boire, il salue à genoux. Le représentant du mort lui rend le salut.

Une natte est étendue pour l'invocateur ; elle regarde le midi. Le chef de la maison offre à boire à l'invocateur. L'invocateur salue à genoux, (se lève), fléchit de nouveau les genoux et reçoit la coupe. Le chef de la maison lui rend le salut. On sert -à l'in vocateur des légumes salés, et de la viande hachée conservée dans le sel et le vinaigre. On lui apporte une petite table. L'in vocateur prend la coupe de la main gauche et offre au mort les mets présentés. Il dépose la coupe. Il se lève, prend les poumons, à genoux les offre au mort et les goûte. Il se lève et replace les poumons sur la petite table. Il offre le vin au mort et le goûte.

${ }_{526}$ Le foie arrive ensuite. L'invocateur prend le l'oie, le plonge dans le sel, le secoue, l'offre au mort, le goûte et le replace sur la petite table. Après avoir bu le vin, il salue à genou. Le chef de la maison lui rend le salut. L’invocateur fléchit les genoux et rend la coupe au chef de la maison.

Le chef de la maison verse du vin dans une coupe. Il offre à boire à chaque servant. Le servant, le visage tourné vers le nord, salue à genoux, se relève, fléchit les genoux et reçoit la coupe. Le chef de la maison lui rend le salut. Le servant offre le vin au mort. Après l'avoir bu, il salue à genoux. Le chef de la maison lui rend le salut. Il reçoit la coupe, s'en va et met la coupe dans une corbeille. Il monte sur la plateforme et retourne à sa place.

$\mathbf{O}$ La maîtresse de la maison rince une coupe à pied dans le bâtiment latéral, y verse du vin, et offre à boire une seconde fois au représentant du mort, comme le chef de la maison le lui a offert une première fois. Elle revient, et apporte elle-même deux vases de bambou contenant des jujubes et des châtaignes. Elle les place au sud des couvercles des vases de millet; elle met les jujubes à l'ouest des châtaignes. Le représentant du mort offre au mort les jujubes et les châtaignes. Il lui offre le vin, comme ${ }_{527}$ précédemment. Le plus respectable des étrangers apporte ensuite de la viande rôtie, comme le chef de la maison l'a fait précé demment. Le représentant du mort offre au mort cette viande, et vide la coupe, comme précédemment. 
$\mathbf{O}$ La maîtresse de la maison verse du vin dais une coupe, et offre à boire à l'invocateur. Le plus honorable des étrangers lui apporte ensuite des vases de bambou et de la viande rôtie. La maîtresse de la maison offre à boire à chacun des servants, comme elle l'a fait aux précédents. Elle prend ensuite la coupe vide et la porte dans le bâtiment latéral. Le plus honorable des étrangers rince une coupe dont le pied porte un - bel ornement, et offre du vin pour la troisième fois (au nom de la maîtresse de la maison). Le vin est accompagné de viande rôtie. Le tout, comme précédemment.

Les femmes retournent à leur place (sur la plateforme). L’in vocateur sort de la salle. Le visage tourné vers l'ouest, il an nonce au chef de la maison que la lì réfection est terminée. Le chef de la maison pousse des lamentations. Tous les assistants, hommes et femmes, poussent des lamentations. Les suivants prennent en mains les corbeilles. Les assistants se lamentent comme précédemment. Le représentant du mort, précédé de l'invocateur, sort de la salle. Les assistants bondissent comme précédemment à son entrée. Le représentant du mort descend $\bullet_{528}$ de la plateforme. Les assistants bondissent comme précédemment. Le représentant du mort sort de la grande porte $\mathrm{du}$ temple. Les assistants bondissent encore de même.

L'invocateur (avec des aides) retourne dans la salle, enlève les offrandes, et les place à l'angle nord-ouest, dans le même ordre qu'auparavant. Il met l'escabeau au sud des offrandes. Pour le cacher aux regards, il met des nattes. Il enlève les nattes sur lesquelles les offrandes ont été déposées dans la salle, et les porte dans le bâtiment latéral. Il prend lui même sa petite table et l'emporte dehors. Un aide ferme la fenêtre et la porte de la salle.

Le chef de la maison descend. Les étrangers sortent du temple. Le chef de la maison sort de la grande porte du temple. Les lamentations cessent. Tous les assistants retournent à leurs places hors du temple). Le maître des cérémonies, avertit que la cérémonie est terminée. Les étrangers s'en vont. Le chef de la maison les accompagne jusque hors de la grande porte de la maison, et les salue à genoux, frappant du front la terre.

\section{NOTES SUPPLEMENTAIRES.}

Après les offrandes qui ont lieu au retour de l'enterrement et les deux jours suivants à midi, celui qui est en deuil pour ${ }_{529}$ trois ans se lave le corps, mais il ne se peigne pas encore les cheveux. On place au dehors de la grande porte du temple, à droite du bâtiment postérieur, les deux animaux offerts au mort (le chèu porc et le $s \bullet$ lièvre séché). On tourne leurs têtes vers le nord. On met le plus distingué (le porc) à l'ouest du lièvre. A midi a lieu la cérémonie. Le porc est tué à l'ouest de la grande porte du temple. Le chef de la maison n'est pas présent (quand on le tue, ni) quand on le dépèce. 
Quand le bouillon gras est chauffé, on monte à la salle les parties suivantes prises sur le côté gauche du porc : l'épaule, la partie inférieure et la partie supérieure du membre antérieur, la partie inférieure et la partie supérieure du membre postérieur, une côte du dos, une côte du devant du corps, trois morceaux de viande prises avec la peau sur le devant du corps et destinés à être offerts aux mânes, la chair du côté gauche du cou. Il y a de plus des poumons séparés l'un de l'autre par une incision à leur petite extrémité, et des poumons destinés à être offerts aux mânes. Toutes ces pièces sont dans la première et la principale chaudière.

On monte à la salle des tortues, des carpes, en tout neuf poissons. Ils sont mis dans la chaudière du milieu. On monte à la salle la moitié gauche d'un lièvre séché, moins les os du bassin. Elle est mise dans la dernière chaudière. On range ces $\bullet_{530}$ trois chaudières par ordre; on dépose auprès de chacune d'elles son levier et sa couverture. Encore (comme au commencement du deuil), on place en avant sur les petites tables l'extrémité inférieure des os des quadrupèdes et l'épine dorsale des poissons.

Sur la petite table de l'invocateur, on place un os du bassin, un morceau de viande du cou, une côte du dos, une côte du devant du corps, des poumons séparés l'un de l'autre à leur petite extrémité par une incision. On met cette table entre les deux rangées de degrés, à l'est des vases de millet.

O Quand on verse de l'eau sur les mains du représentant des mânes pour qu'il se les lave, celui qui tie nt la cuvette a le visage tourné vers l'ouest ; celui qui tient l'aiguière a le visage tourné vers l'est. Celui qui tient l'essuie -main est au nord du représentant des mânes, le visage tourné vers l'est. Le maître des cérémonies présente l'essuie -main, le visage tourné vers le sud.

Quand le chef de la maison est dans la salle du temple, si le maître des cérémonies y monte pour lui annoncer quelque chose, il se tient à la porte hors de la salle, le visage tourné vers le nord. Quand les servants de table n'on t rien à faire, ils sortent de la salle, et se tiennent entre la porte et la fenêtre, le dos tourné à la salle, le visage tourné au sud.

$\mathbf{O}$ Les herbes qu'on met dans le ragoût du vase sont des $\bullet_{531}$ laiterons appelées ouèi. Pour édulcorer ce ragoût, en été, on se sert de mauves; en hiver, on se sert d'hémérocalles. Près de ce vase est une cuiller, dans les vases de bois il y a des mauves et des légumes salés. A l'ouest de ces légumes salés, il y a des escargots, et de la viande conservée dans le sel et le vinaigre. Dans les vases cuites et des châtaignes choisies ou épluchées.

Quand le représentant du mort entre dans le temple, l’invocateur le suit. Le représentant du mort s'assied dans la salle sans ôter ses chaussures. Quand le représentant du mort se lève (pour sortir de la salle), l'invocateur le précède. (Arrivé à la porte de la salle, l'invocateur arrête et) se tourne vers lui. Puis il se retourne et sort de la porte de la salle. (Au haut des degrés), il se tourne encore vers le représentant du mort. Il se retourne et passe auprès du chef de la maison. Il se tourne de nouveau vers le représentant du mort. Il se retourne et 
descend les degrés. Il se tourne de nouveau vers le représentant du mort. Après avoir descendu les degrés (et s'être tourné vers le re présentant du mort), il se retourne. Arrivé à la grande porte du temple, il se tourne encore vers le représentant du mort, comme au sortir de la porte de la salle.

Quand le représentant du mort est sorti du temple, $\bullet_{532}$ l'invocateur y rentre par le côté gauche de la grande parte ; le visage tourné vers le nord, il reprend sa place. Ensuite le maître des cérémonies avertit le chef de la maison de descendre. Les vêtements du représentant du mort sont semblables aux vêtements de première classe que portait le $t s \bullet$ mort, quand il assistait à un sacrifice à la cour. Un homme mort est représenté par un homme. Une femme morte est représentée par une femme. On choisit toujours une femme qui porte un nom de famille différent de celui de la défunte, et qui n'est pas de basse condition. (Au contraire, le représentant d'un homme mort porte le même nom de famille que lui. C'est un de ses petits -fils, ou, à défaut de petit-fils, un autre parent).

$\mathbf{O}$ Quand personne ne représente le mort, les cérémonies, les offrandes, les aliments sont les mêmes que lorsqu'il y a un représentant. (Mais il y a les différences suivantes). Après le repas, les offrandes sont déposées sur une couche de paille, et l'invocateur adresse la parole au mort et parle au nom du mort. Le servant ne présente pas les offrandes tournées en bas. On ne sert pas de bouillon principal contenant de la viande juteuse. On ne sert pas de viande hachée ou coupée en morceaux, après avoir offert le vin. Le chef de la maison sort de la salle, pousse des lamentations et retourne à sa place.

L'invocateur ferme la fenêtre et la porte de la salle du temple. Il retourne à sa place à l'ouest de la grande porte. Les hommes ${ }_{533}$ et les femmes font trois fois trois bonds alternativement. Tout cela, pendant que le représentant du mort mange.

L'invoca teur monte. Les lamentations cessent. L'invocateur crie trois fois (comme pour avertir le mort). Il ouvre la porte de la salle. Le chef de la maison entre dans la salle. L’invoca teur le suit et ouvre la iòu hiáng fenêtre, comme précédemment. Le chef de la maison sort de la salle et retourne à sa place. Quand les mets ont été enlevés, l'invoca teur et les servants descendent et retournent à leurs places. Le maître des cérémonies avertit le chef de la maison de descendre, comme précédemment.

La première fois que les offrandes appelées iú sont présentées au mort, c'est un jour du cycle qui est d'ordre pair, (le jour de l'enterrement à midi). Linvocateur dit au mort :

- Votre fils affligé, un tel, dans sa douleur, déploie son dévouement. Il se lève tôt et se couche tard. Il n'a pas de repos. Il se permet de prendre une victime pure, un animal à crinière raide (un porc) : du ( chòu millet) hiøng odoriférant et $h \bullet$ glutineux ; des mets excellents (tsiù hái des légumes salés, de la viande séchée et conservée dans le sel et le vinaigre); des mets universellement 
estimés et bien conditionnés, du millet glutineux et du millet non glutineux tsí une boisson ming récemment préparée (de l'eau pure nouvellement tirée du puits, ou, selon une autre interprétation, du vin non fermenté); et che $u$ du vin fermenté de couleur blanche. Dans son affliction, $\bullet_{534} k i \bullet$ chéu il présente ces offrandes à tous ses ancêtres. Allez au temple où est la tablette de votre aïeul un tel, et rassasiez-vous.

Les offrandes appelées $i \hat{u}$ sont présentées au mort une deuxième fois (un autre jour) de la même manière que la première fois. Linvocateur dit :

- Dans son affliction, il vous présente les offrandes $i \hat{u}$.

Les offrandes appelées î̂ sont présentées au mort une troisième fois, quand on a cessé de pleurer régulièrement chaque jour le matin et le soir. Elles sont présentées de la même manière que la première fois, avec cette différence qu'on choisit un jour du cycle qui est d'ordre impair. Linvocateur dit :

- Dans son affliction, il vous présente des offrandes parfaites.

O Après avoir offert le vin trois fois, on n'enlève pas encore les mets. Alors on tsièn offre le vin au représentant du mort comme à un homme qui part pour un voyage. Deux amphores sont placées en dehors à droite de la grande porte du temple, un peu au sud. Celle des deux qui contient l'eau est placée à l'ouest de celle qui contient le vin. Sur chacune d'elles est u ne cuiller dont le manche est tourné vers le nord. Des cuvettes sont placées au sud-est des amphores ; des aiguières, à l'est des cuvettes ; des corbeilles, à l'ouest. On apporte des vases de bambou, des vases de bois, quatre tranches de viande séchée. Dans le bâtiment situé au côté occidental de la grande porte, il y a $\bullet_{535}$ de la viande séchée, un porc découpé eu plusieurs parties et placé sur une petite table, deux tranches régulières de viande séchée, la moitié d'une troisième tranche placée en long (placée en travers sur les deux autres tranches) et destinée à être offerte aux mânes.

Quand le représentant du mort quitte la salle du temple, on porte à sa suite son escabeau, et à la suite, sa natte. Arrivé hors du temple, il se tient au côté droit de la grande porte, le visage tourné vers le sud. Sa natte est étendue au nord-ouest des amphores, tournée vers l'est ; son escabeau est placé au sud de sa natte. Les étrangers sortent du temple, et retournent à leurs places (près de la grande porte du temple). Le chef de la maison sort du temple, et va se placer à l'est de la grande porte, un peu au sud. Les femmes sortent, et vont se placer au nord du chef de la maison, tournées comme lui vers l'ouest. Elles ne cessent pas leurs lamentations. Le représentant du mort va s'asseoir sur sa natte.

Seul le chef de la maison ne pousse pas de lamentations. Il rince une coupe sans pied, y verse du vin et l'offre au repré sentant du mort. Celui-ci salue à genoux et reçoit la coupe. Le maître de la maison salue à genoux le représentant du mort $\bullet_{536}$ qui a reçu la coupe. Il pousse des lamentations et retourne à sa place. On sert au représentant du mort des tranches de viande 
séchée, de la viande hachée et conservée dans le sel et le vinaigre. A l'est de ces viandes on place une petite table. La plus grosse extrémité des tranches de viande est tournée vers le sud. Le représentant du mort, tenant la coupe de la main gauche, prend de la main droite une tranche de viande, la trempe dans la saumure de la viande hachée et l'offre au mort. Le servant de table présente au représentant du mort la viande séchée pour qu’il la goûte. Le représentant du mort la reçoit, la secoue, l'offre au mort, la goûte et la rend au servant (qui la dépose sur la petite table). Il offre le vin au mort. Après l'avoir bu, il dé pose la coupe au sud. Le chef de la maison et ses parents bondissent. Les femmes les imitent.

La maîtresse de la maison rince une coupe munie d'un pied, et offre à boire au représentant du mort pour la seconde fois, comme le chef de la maison pour la première fois. Aucun mets n'est servi après le vin. On bondit comme précédemment. Le plus respectable des étrangers rince une coupe • dont le pied est paré d'un bel ornement. Il offre à boire au représentant du mort pour la troisième fois, comme la maîtresse de la maison pour la (deuxième fois. On bondit comme précédemment. Le servant prend la petite table et met la viande dans une corbeille.

- 537 Le représentant du mort se lève. Un de ses suivants prend la corbeille, et le suit en poussant des lamentations. Linvocateur marche en avant. Hommes et femmes, tous suivent le représentant du mort, en poussant des lamentations. Arrivés près de la grande porte du temple, dans la cour, ils bondissent comme précédemment. Quand le représentant du mort sort de la grande porte du temple, les lamentations cessent. Les étrangers s'en vont. Le chef de la maison les accompagne, et les salue à genoux, frappant du front la terre (dehors, devant la grande porte du temple). La maîtresse de la maison salue aussi à genoux les femmes étrangères.

Les hommes ôtent leurs bandeaux et leurs ceintures de deuil hors de la grande porte du temple. Des parents entrent et enlèvent ce qui a été servi. Le chef de la maison n'y est pas présent. Les femmes ôtent leurs bandeaux de deuil ; elles n'ôtent pas leurs ceintures.

Quand il n'y a pas de représentant du mort, on n'offre pas tsién le vin du départ. Néanmoins, quand on sort du temple, on place hors du temple un escabeau et une natte, comme il a été dit précédemment. (C'est pour le mort). Les hommes et les femmes font trois fois trois bonds alternativement. Puis les lamentations cessent. Le maître des cérémonies avertit que la cérémonie est terminée. Les étrangers s'en vont.

$\mathbf{O}$ Trois jours après la mort, le corps est paré de ses vêtements. Trois mois après la mort, il est mis en terre. Après l'enterrement, on cesse de pleurer chaque jour matin et soir. (Le jour où les pleurs réguliers cessent), au point du jour, des offrandes sont déposées pour le mort et pour son aieul dans le temple où est la tablette de l'aïeul. Ensuite l'invocateur dit à l'aïeul : 
— Le fils affligé, un tel, lâi jøu mòu aujourd'hui tel jour, montera à votre temple, et vous présentera des offrandes, à vous son aïeul un tel, et à son père. Il espère que ces offrandes vous seront agréables.

Si c'est une fille qui est morte, (des offrandes lui sont offertes, à elle et à la mère de son père); l'invocateur dit :

- A vous, son aïeule une telle.

Si c'est une femme mariée qui est morte, l'invocateur dit :

- A la femme de votre petit-fils, et à vous, une telle, qui êtes la belle-mère de la belle-mère de cette femme.

Le reste de la formule de l'invocateur est le même pour tous les morts.

En offrant les mets au représentant du mort, l’invocateur dit :

- Le fils affligé un tel kouøi s'est purifié, et dans sa douleur, il présente ces offrandes. Veuillez les avoir pour agréables.

Le lendemain du jour où les lamentations quotidiennes ont cessé, on renouvelle ces offrandes au mort et à son aïeul, dont les tablettes seront $p \bullet n$ voisines. Ensuite, celui qui est en deuil $\bullet_{539}$ pour trois ans se lave la chevelure et tout le corps ; il se peigne ; il se taille les ongles ; il arrange ses cheveux.

Sur les petites tables sur lesquelles sont les parties séparées de l'animal, les morceaux de viande pris avec la peau sur le devant du corps tiennent une place spéciale. (Ils sont très estimés). On prend teòu • la chair du cou. Pour le reste, ces petites tables sont préparées comme quand on offre un porc au mort ou à son représentant.

Ensuite on emploie un nouveau représentant du mort, (sur le choix duquel on consulte les sorts au moyen de brins d'a chillée). L'invocateur dit :

- Le fils plein de piété filiale $\mathrm{N}$, dans sa piété filiale, montre son dévouement. Il se lève tôt, se repose tard. Il est attentif et animé d'une crainte respectueuse. Il ne se livre pas à la paresse ; il ne donne pas de repos à son corps. Il présente des offrandes ìn régulièrement coupées, à savoir, des pòu tranches de viande séchée. Il présente des mets excellents, p'ôu tchaó des mets universellement estimés et bien préparés, à savoir, du chòu millet glutineux et du $t s^{\bullet}$ millet non glutineux ; p'òu tsién un mets qui est universellement présenté, à savoir, hîng $k \bullet n g$ du bouillon gras mêlé d'herbes dans un vase ; du vin fermenté de couleur blanche. Il vient à vous son aïeul N. Il monte à votre temple, et vous présente des offrandes, à vous et à votre petit-fils N. Puissent ces offrandes vous être agréables !»

- ${ }_{540}$ Après la première année du deuil, on présente les offrandes appelées sià̀ siâng offrandes quelque peu de bon augure, offrandes qui ressemblent un peu à celles qu'on présente en temps ordinaire, quand on n'est pas en deuil. L'invocateur dit : (Il offre ces offrandes ordinaires. » La deuxième année du 
deuil écoulée, on présente les offrandes appelées tá siâng tout à fait de bon augure. L'invocateur dit :

- Il présente ces offrandes de bon augure.

Après un mois d'intervalle, c'est -à-dire, un mois après, ou, selon une autre interprétation, quinze jours après, on présente les offrandes appelées t'àn . Durant ce mois (après les offrandes t'àn, le deuil étant terminé), quand on présente des offrandes $k \bullet$ qui sont de celles qu'on présente régulièrement en dehors des temps de deuil, on n'associe pas encore l'aïeule à l'aïeul et au petit-fils. 


\section{CHAPITRE XV}

\section{Offrandes d'une seule victime}

• 541 - (Avant d'offrir un porc aux mânes d'un simple officier), on ne délibère pas en conseil sur le choix du jour de cette offrande. (Mais on consulte les sorts à ce sujet). Quand vient le jour de consulter les sorts sur ce sujet au moyen de brins d'achillée, le chef de la maison, portant le bonnet et la tunique de couleur noirâtre, va prendre sa place en dehors de la grande porte du temple, et tient le visage tourné vers l'ouest. Les tsèu síng fils des fils (les petits-fils) du chef de la maison, ses frères et ses cousins, vêtus comme lui, se tiennent au sud de sa personne, le visage tourné vers l'ouest, rangés du nord au sud par ordre de dignité ou d'âge. Le maître des cérémonies et tous les aides, vêtus comme les cousins, le visage tourné vers l'est, sont rangés du nord au sud par ordre de dignité ou d'âge.

Une natte est étendue à l'entrée de la grande porte du temple, à l'ouest du poteau dressé au milieu de la porte, en dehors du seuil. Le devin prend des brins d'achillée dans le bâtiment $\bullet_{542}$ situé à l'ouest de la brande porte. Les tenant dans les mains, le visage tourné vers l'est, il reçoit les ordres du chef de la maison (la question qu'il adressera aux sorts). L'intendant passe à gauche du chef de la maison, et transmet ses ordres au devin. Il lui donne cette formule : «Le petit-fils plein de piété filiale N. interroge les sorts pour savoir si tel jour à venir sera favorable. Il les consulte sur telle offrande. (Le nom de cette offrande est exprimé). Il la présentera dans le temple où est la tablette de son aïeul, le seigneur N.. Il espère qu'elle sera agréable aux mânes. »

Le devin promet d'obéir. Il tourne, va à sa natte, et le visage regardant l'ouest, il fléchit les genoux. Celui qui dessinera a terre les symboles obtenus est à la gauche du devin. Quand le devin a fini de manipuler les brins d'achillée, son compagnon écrit sur des planchettes les signes obtenus. Le devin prend les planchettes et les montre au chef de la maison. Le chef de la maison les reçoit, les regarde et les rend au devin. Le devin se tourne vers l'est. Les plus respectables des assistants interprètent les symboles. Quand ils ont fini, ils font connaître leur interprétation au chef de la maison, en disant :

— La réponse des sorts est favorable.

Si la réponse des sorts n'a pas été favorable, on propose un autre jour plus éloigné, et on consulte les sorts $\bullet_{543}$ sur le choix de ce jour, comme

précédemment. Le maître des cérémonies avertit, que la consultation est terminée.

- Trois jours avant le jour déterminé, au matin, on consulte les sorts au moyen de brins d'achillée sur le choix du repré sentant du mort, de la même 
manière qu'on les a consultés sur le choix du jour. Le chef de la maison prescrit au devin cette formule :

- Le petit-fils plein de piété filiale, un tel, a consulté au sujet de telle offrande. Il viendra la présenter au temple de son aïeul, le seigneur un tel. Il consulte les sorts au moyen des brins d'achillée pour savoir s'il convient d'employer un tel, fils d'un tel, comme représentant du défunt. Il espère que cette offrande sera agréable aux mânes.

O Ensuite le chef de la maison va avertir et inviter celui qui est désigné pour représenter le défunt. Il se tient debout en dehors de la grande porte extérieure de la résidence de ce seigneur. Les petits-fils, les frères, les cousins du chef de la maison (l'accompagnent et) se tiennent debout derrière lui, le visage tourné vers le nord, rangés de l'est à l'ouest par ordre d'âge ou de dignité. Le futur représentant du mort, vêtu comme le chef de la maison, sort et se tient au côté gauche de la grande porte, le visage tourné vers l'ouest. Le chef de la maison et ses compagnons changent de position pí par respect pour le ${ }_{544}$ représentant du mort, se tournent tous (vers lui) vers l'est, et se rangent du nord au sud par ordre de dignité.

Le chef de la maison salue deux fois à genoux. Le représentant du mort lui rend ce salut. Le maître des cérémonies, au nom du chef de la maison, dicte à l'invocateur une formule semblable à celle que l’intendant a dictée au devin. Il y ajoute :

— Le devin a consulté les sorts pour savoir s’il convient, Seigneur, que vous représentiez la personne de N. qui est défunt. Les interprètes ont dit que la réponse était favorable. Je me permets de vous avertir et de vous inviter.

L'invocateur promet d'obéir. Il s'acquitte de sa commission. L'invité accepte l'honneur de repré senter la personne du défunt. Le chef de la maison le salue deux fois à genoux, inclinant la tête jusqu'à terre. Le représentant du défunt rentre dans ses appartements (il ne reconduit pas son visiteur). Le chef de la maison se retire.

O Le chef de la maison va avertir et inviter l'étranger qui fera l'office de principal invité, Celui-ci, vêtu comme le chef de la maison, sort de sa résidence, se place à gauche de la grande porte, et le visage tourné vers l'ouest, salue deux fois à genoux. Son visiteur, le visage tourné vers l'est, lui rend ce double salut. Le maître des cérémonies, au nom du chef de la maison, dit à l'invité :

- Un tel présentera des offrandes, comme il est d'usage à $\bullet_{545}$ chaque saison de l'année. Monseigneur, il se permet de vous inviter à y présider.

L’invité répond :

— Moi un tel, oserais-je ne pas obéir avec respect? 
Le chef de la maison le salue deux fois à genoux. L'invité lui rend ce salut. Le chef de la maison se retire. L'invité le salue à genoux et le reconduit.

O Le lendemain du jour de cette invitation, au soir, des chaudières sont étalées en dehors de la grande porte du temple. Elles sont tournées vers le nord, et rangées du nord au sud, la plus noble au nord. Chacune d'elles a une couverture. Un grand plateau est au sud des chaudières. Au sud il sera facile de le prendre. Sur ce plateau est un quadrupède (un lièvre séché), la tête tournée vers l'est. Un animal (un porc vivant, les pattes liées) est à l'ouest du plateau, la tête au nord, les pieds à l'est. Des cuvettes sont placées au sud -est des degrés orientaux. Des jarres et des supports sont dans le bâtiment situé au côté oriental de la plateforme. Des vases de bois, des vases de bambou et d'autres vases appelés hîng sont dans le bâtiment situé au côté oriental de la salle. Ils sont rangés du sud au nord, les plus nobles au sud. On met un escabeau, une natte, et deux vases contenant des ragoûts sur la partie occidentale de la plateforme.

Le chef de la maison, ses fils, ses petits-fils, ses frères et ses $\bullet_{546}$ cousins vont prendre leurs places à l'est de la grande porte du temple, comme précédemment (quand on a consulté les sorts). Le principal invité et tous les autres étrangers vont se placer à l'ouest de la grande porte, le visage tourné vers l'est, rangés du nord au sud par ordre de dignité. Le maître des cérémonies et l'invocateur se tiennent debout au nord-ouest du principal invité, le visage tourné vers l'est, le plus digne au sud de l'autre.

Le chef de la maison salue deux fois à genoux. Le principal invité lui rend deux fois ce salut. Le chef de la maison salue à genoux trois fois en commun tous les autres étrangers. Ceux-ci à leur tour le saluent chacun deux fois. Le chef de la maison salue par une inclination profonde et entre à la grande porte du temple. Ses proches parents le suivent. Ils sont suivis par le principal invité et par tous les autres étrangers. Ils vont tous se ranger au bas de la plateforme, dans le même ordre qu'ils étaient rangés hors du temple.

Le maître des cérémonies monte par les degrés occidentaux, examine les jarres qui ont été rincées, examine les vases de bois et de bambou, s'en retourne, descend, et le visage tourné vers le nord-est, avertit que les vases sont rincés et préparés. Le principal invité sort du temple; le chef de la maison sort aussi. Ils retournent tous deux aux places qu'ils occupaient en $\bullet_{547}$ dehors du temple.

Le maître des cérémonies examine le porc, et annonce au chef de la maison que cet animal est bien gras. Lintendant fait remuer le porc. (Il lui donne un coup de fouet, pour entendre son cri et s'assurer par son cri quil n'est pas malade). Le maître des cérémonies lève par la queue le quadrupède (le lièvre séché), et dit que l'animal a été bien préparé. Il lève la couverture des chaudières, et dit que les chaudières sont très propres. Il demande à quel moment aura lieu la présentation des offrandes. Le chef de la maison lui répond : 
— Quand le bouillon gras aura été bien chauffé.

(le lendemain, de très bon matin). Le maître des cérémonies avertit les assistants que tout est fini pour le moment. Les étrangers s'en vont. Le chef de la maison les salue à genoux et les reconduit.

O Le lendemain on se lève de bonne heure. Le chef de la maison, vêtu comme précédemment, se tient debout hors du temple, à l'est de la grande porte, le visage tourné vers le sud, et regarde tuer l'unique victime qui sera immolée (le porc). La maîtresse de la maison va voir cuire le millet sur le fourneau, au bas de la partie occidentale de la plateforme. On fait cuire les viandes en dehors de la grande porte du temple, à l'est. Les fourneaux font face à l'ouest. Ils sont rangés du nord au sud, le plus noble au nord.

- 548 Quand le bouillon gras a été chauffé à point, on remplit de viande les chaudières, et on le place en dehors de la grande porte du temple, comme précédemment. Les amphores sont à l'est de la porte de la salle. Le vin noirâtre (l'eau pure) est à l'ouest du vin fermenté. On remplit les vases de bois, les vases de bambou, les vases appelés hîng, et on les étale dans le bâtiment situé au côté de la salle, comme précédemment. Les petites tables destinées aux aides sont placées entre les deux rangées de degrés, sur deux lignes allant du nord au sud, les plus nobles au nord. On remplit deux vases de millet, et on les place à la partie occidentale de la plateforme, sur des roseau fins. Une natte et un escabeau sont placés sur la partie occidentale de la plateforme, comme précédemment.

Le représentant du mort se lave les mains. L'eau de l'aiguière est versée sur ses mains et tombe dans une cruche. Une serviette dans une corbeille est à l'intérieur du temple à droite de la grande porte. L'escabeau et la natte que l'invocateur prépare pour les mânes sont au milieu de la salle, et regardent l'est.

La maîtresse de la maison, ayant la chevelure enveloppée d'une bande de soie et fixée avec une épingle de tête, et portant $\bullet_{549}$ une tunique sia $\bullet$ de soie noire, se tient debout dans le bâtiment latéral, le visage tourné vers le sud. Le chef de la maison, le principal invité, tous les parents, tous les aides vont prendre leurs places dehors auprès de la grande porte du temple, comme précédemment. Le maître des cérémonies avertit le chef de la maison que les officiers out tout préparé. Le chef de la maison salue à genoux le principal invité, comme précédemment. Il sincline profondément, entre dans le temple, et va prendre sa place, comme précédemment. Les servants de table, le visage tourné vers le nord, sont debout au milieu de la cour.

$\mathbf{O}$ Le chef de la maison et linvocateur montent les degrés. Linvocateur entre le premier dans la salle du temple. Le chef de la maison le suit, et se tient debout, le visage tourné vers l'ouest, dans la salle près de la porte. La maîtresse de la maison se lave les mains dans le bâtiment latéral. Elle apporte deux vases de bois, contenant des mauves salées, et des escargots hachés conservés dans le sel et le vinaigre. Elle place au nord les escargots. Le maître 
des cérémonies envoie les servants de table et les aides se laver les mains, et leur dit d'aller dehors.

Le chef de la maison descend. Le principal invité et lui se lavent les mains et sortent. Le chef de la maison, à droite, et un servant de table, à gauche, portent la chaudière qui contient le porc. Le plus respectable des étrangers, à droite, et un $\bullet_{549}$ aide, à gauche, portent la chaudière qui contient les poissons et le lièvre séché. (La troisième chaudière est portée par le principal invité et un aide). On ôte les couvertures des chaudières. Le maître des cérémonies, tenant en mains une grande fourchette de bois, entre le premier dans le temple, Il se tient devant les degrés orientaux, le visage tourné vers le sud.

Les chaudières sont placées, tournées vers le sud. Celui des deux porteurs de chaque chaudière qui est à droite (le chef de la maison, le plus respectable des étrangers) retire le levier, et le dépose au nord de la chaudière. Les aides placent les petites tables. Sur chacune d'elles ils mettent une cuiller. Alors avec la cuiller, celui des deux porteurs qui est à droite retire la viande qui est dans la chaudière; (celui qui est à gauche la met sur la petite table). Le servant de table met sur la petite table le cour et la langue de porc (pour le représentant du mort.). Il la couvre d'une serviette, et la place sur la plate-forme à l'ouest des degrés orientaux. Quand la viande a été placée sur les petites tables, les cuillers sont mises sur les chaudières.

Le chef de la maison monte les degrés, entre dans la salle et reprend sa place. Un homme entre après lui avec une petite table. Il la place à l'est du vase de bois. Il place les poissons à ${ }_{551}$ la suite, à l'est de la petite table, et un lièvre séché seul au nord de la petite table. La maîtresse de la maison place au sud de la petite table du représentant du mort deux vases, dont l'un contient du millet glutineux, et l'autre du millet non glutineux ; elle place le plus noble de ces deux vases (le millet glutineux) à l'ouest de l'autre. Au sud du vase de bois, elle place et range du sud au nord deux vases contenant du bouillon gras maó mêlé d'herbes.

L’invocateur rince une coupe, la remplit, et la dépose. Il la dépose au s ud des vases de bouillon (devant le représentant du mort). Ensuite il ordonne aux servants d'ouvrir les couvercles des vases de millet. Les servants enlèvent les couvercles, les renversent et les mettent au sud des vases de millet. Ils s'en vont, et se tiennent debout à l'ouest, le visage tourné vers le sud. Le chef de la maison salue deux fois à genoux le représentant du mort, inclinant la tête jusqu'à terre. L'invocateur est à la gauche du chef de la maison. Quand l'invocateur a fini de réciter sa formule, le chef de la maison salue deux fois à genoux l'invocateur, inclinant la tête jusqu'à terre.

L'invocateur va recevoir le représentant du mort en dehors de la grande porte du temple. Le chef de la maison descend les degrés, et reste debout à l'est des deg rés orientaux. Le représentant du mort entre par le côté gauche de la grande porte, et, le visage tourné vers le nord, se lave les mains. Le ${ }_{552}$ maître des cérémonies lui présente un essuie-main. Quand le représentant du mort arrive auprès des degrés, l'i nvocateur l’invite à monter. Le représentant 
du mort monte et entre dans la salle. L’invocateur le précède et le chef de la maison le suit.

O Le représentant du mort va s'asseoir sur sa natte. Le chef de la maison le salue à genoux, quand il le voit assis commodément. Le représentant du mort lui rend son salut. Les servants tiennent en mains les offrandes. L'invocateur prie le représentant du mort de les avoir pour agréables. Le chef de la maison salue à genoux l'invocateur, comme précédemment. Linvocateur recommande aux servants de touó ou houéi tenir les offrandes bas (de ne pas les lever en les donnant au représentant du mort. D'après les meilleurs commentateurs, au lieu de touó, il faut lire cheóu donner). Le représentant du mort, tenant la coupe de la main gauche, prend les légumes salés de la main droite, les plonge dans la saumure de la viande hachée, et les offre au mort entre les vases de bois.

Les servants prennent le millet glutineux, le millet non glutineux, les poumons qui doivent être offerts aux mânes ; il les donnent au représentant du mort. Le représentant du mort les offre au mort. Il lui offre le vin ; il goûte le vin et dit qu’il est excellent. Le chef de la maison le salue à genoux. Le ${ }_{553}$ représentant du mort dépose la coupe et rend le salut. Il offre au mort le bouillon gras mêlé d'herbes, le goûte et dit qu'il est excellent. Le chef de la maison le salue à genoux. Le représentant du mort lui rend le salut.

L'invocateur ordonne èul d'approcher du représentant du mort les vases de millet. Les servants approchent le millet glutineux et le millet non glutineux sur la natte du représentant du mort. Au nord de la viande hachée conservée dans le sel et le vinaigre, ils placent le bouillon principal composé de viande juteuse. Ils lèvent les poumons et une côte du dos; ils les donnent au représentant du mort. Celui-ci reçoit les poumons, les secoue, les offre au mort, le goûte et les tient de la main gauche. Puis il mange. Il mange la côtelette que le servant a levée et lui a présentée. Le chef de la maison place au nord du lièvre séché la petite table, sur laquelle sort le coar et la langue du porc.

Après avoir mangé trois fois, le représentant du mort dit qu’il est rassasié. L'invocateur l'engage à manger encore. Le chef de la maison le sa lue à genoux. Le servant lève une côte prise sur le devant du corps du porc. Le représentant du mort la reçoit, la secoue, l'offre au mort et la goûte. Le servant la reçoit, et la dépose sur la petite table avec le coar et la langue du porc. Le servant lève une côte prise sur le devant du corps du lièvre séché ; il lève un poisson. La même cérémonie recommence. Le représentant du mort met dans le vase de légumes les poumons et la côtelette qu'on lui a présentés. Les servants lui apportent quatre $\bullet_{554}$ vases de bois contenant des mets chóu ordinaires. Ils les rangent à sa gauche, du sud au nord, les plus distingués au sud. L'un de ces vases contient de la viande hachée conservée dans le sel et le vinaigre.

De nouveau, après avoir mangé trois fois, le représentant du mort dit qu'il est rassasié. L’invocateur l'engage à manger encore, comme précédemment. 
Les servants lèvent et présentent la partie inférieure d'un membre postérieur du porc, la partie inférieure d'un membre postérieur du lièvre séché, et un poisson, comme précédemment.

De nouveau, après avoir goûté de trois mets, le représentant du mort dit qu'il est rassasié. L'invocateur l'invite à manger encore, comme précédemment. Les servants lèvent et donnent au représentant du mort une épaule du porc, une épaule du lièvre séché, et un poisson, comme précédemment. Ensuite ils mettent les restes sur la petite table sur laquelle sont le cour et la langue du porc. Sur les petites tables vides, ils placent (et servent au représentant des mânes) trois sortes de mets (des côtelettes de porc et de lièvre séché, et des poissons). Ils prennent les restes des poumons et de la côtelette du dos du porc qu'il ont levés et donnés au représentant des mânes ; ils les mettent sur la petite table sur laquelle sont le coaur et la langue du porc. Ils reportent les deux sortes de millet à la place ordinaire des millets.

$\mathbf{O} \cdot{ }_{555}$ Le chef de la maison rince une coupe de corne ou une coupe faite en forme de corne. Il monte les degrés, verse du vin dans la coupe, et la présente au représentant du mort, pour qu'il se rince la bouche. Le représentant du mort le salue à genoux et reçoit la coupe. Le chef de la maison le salue ensuite à genoux. Le représentant du mort offre le vin au mort et le goûte. Le plus respectable des étrangers lui offre ensuite le foie du porc. Le représentant du mort, tenant la coupe de la main gauche, prend le foie de la main droite, le plonge dans le sel, le secoue, l'offre au mort, le goûte, et le met dans le vase de bois qui contient les légumes salés. Il vide la coupe. L'invocateur reçoit cette coupe, et dit au chef de la maison :

- Saluez celui qui a bu la coupe. L'auguste représentant des mânes a vidé la coupe.

Le chef de la maison le salue à genoux. Le représentant du mort lui rend ce salut.

L'invocateur verse du vin dans une coupe, et donne la coupe au représentant du mort. Celui-ci la reçoit, et offre à boire à son tour au chef de la maison. Le chef de la maison salue à genoux et reçoit la coupe. Le représentant des mânes le salue ensuite à genoux. Le chef de la maison se retire à sa place. Les servants lui présentent, sans les lever, les mets qui doivent être offerts au mort. Le chef de la maison fléchit les genoux, et ${ }_{556}$ tenant la coupe de la main gauche, il reçoit de la main droite les mets qu'il doit offrir au mort. Il les lui offre. Il lui offre le vin. Après avoir goûté le vin, il s'avance, pour entendre les souhaits de prospérité qui lui sont adressés par l'invocateur.

Le servant met en boulette le riz glutineux, et le donne à l'invocateur. L'invocateur le présente au représentant du mort. Le représentant du mort le reçoit, le met dans le vase de bois qui contient les légumes salés, et tenant en mains ce vase, il exprime lui-même au chef de la maison des souhaits de prospérité. Le chef de la maison tient la coupe de la main gauche. Il (la dépose et) 
salue deux fois à genoux, inclinant la tête jusqu'à terre. Il reçoit le vase de bois et reprend sa place. Il chøu prend dans ses bras sur sa poitrine le vase de bois, le met dans la manche gauche de sa tunique et l'y retient avec le petit doigt. Il vide la coupe, et salue à genoux. Le représentant du mort lui rend le salut. Le chef de la maison sort de la salle. Il va dans le bâtiment latéral sié verser le $c h \bullet$ millet. L'invocateur le reçoit dans un vase de bambou.

On prépare pour l'invocateur une natte, qu'on tourne vers le sud. Le chef de la maison verse du vin dans une coupe $\bullet_{557}$ et le présente à l'invocateur. L'invocateur salue à genoux et reçoit la coupe. Le chef de la maison le salue ensuite à genoux. (La maîtresse de la maison) sert à l'invocateur des légumes salés, de la viande hachée conservée dans le sel et le vinaigre. Un servant place devant lui une petite table. Linvocateur tient la coupe de la main gauche. Il (la dépose et) offre au mort le contenu des vases de bois (les légumes et la viande hachée). Il se lève, prend les poumons, fléchit les genoux, offre les poumons au mort, et les goûte. Il se lève et met les poumons sur la petite table. Il fléchit les genoux, offre le vin au mort et le goûte. On lui offre ensuite le foie du porc. L'invocateur tient la coupe de la main gauche. Il prend le foie de la main droite, le plonge dans le sel, le secoue et l'offre au mort. Il le goûte et le met sur la petite table. Il vide la coupe et salue à genoux. Le chef de la maison lui rend le salut, et reçoit la coupe.

Le chef de la maison remplit la coupe, et l'offre à chaque servant. Le servant, le visage tourné vers le nord, salue à genoux et reçoit la coupe. Le chef de la maison le salue ensuite à genoux. Le servant, à genoux, offre le vin au mort. Il vide la coupe et salue à genoux. Le chef de la maison lui rend le salut. Il reçoit la coupe, descend les degrés, reporte la coupe dans sa corbeille, monte les degrés, entre dans la salle et retourne à sa place.

- ${ }_{558}$ La maîtresse de la maison rince une coupe dans le bâtiment latéral, y verse du vin, et, la deuxième fois, offre à boire au représentant du mort. (Le chef de la maison lui a offert à boire une première fois). Le représentant du mort la salue à genoux et reçoit la coupe. La maîtresse de la maison, le visage tourné vers le nord, salue ensuite à genoux. La femme du maître des cérémonies prend deux vases de bambou (contenant des jujubes et des châtaignes). Devant la porte de la salle elle se tient à genoux. La maîtresse de la maison reçoit ces deux vases, et les place au sud des deux vases de millet. L'invocateur donne les vases de bambou au représentant du mort, pour quil offre au mort les jujubes et les châtaignes. Le représentant du mort les reçoit et les offre au mort. Il lui offre le vin, et il le goûte.

Le plus respectable des frères ou des cousins du chef de la maison sert ensuite de la viande rôtie. Le représentant du mort la reçoit, la secoue, l'offre au mort, la goûte et la tend à celui qui la lui a servie. Celui qui l'a servie la reçoit, la met sur la petite table sur laquelle sont le cour et la langue du porc, et il sort de la salle. Le représentant du mort vide la coupe. Lin vocateur la reçoit, et, comme précédemment, avertit le chef de la maison de saluer à genoux le représentant du mort qui a vidé la coupe. 
Le représentant du mort, à son tour, offre à boire à la $\bullet_{559}$ maîtresse de la maison, comme il a offert à boire au chef de la maison. La maîtresse de la maison va dans le bâtiment latéral, et tourne le visage vers le sud. Les servants lui donnent les offrandes, sans les lever. La maîtresse de la maison tient la coupe de la main gauche. Elle pose la main droite sur les mets présentés et les offre au mort. Elle lui offre le vin et le goûte. Elle entre dans la salle et vide la coupe, de la même manière que le chef de la maison.

La maîtresse de la maison offre à boire à l'invocateur ; puis elle lui sert ou fait servir des vases de bambou, de la viande rôtie, de la même manière que précédemment l'in vocateur. Elle fait le même honneur aux servants. Enfin elle prend la coupe et entre dans le bâtiment latéral.

$\mathbf{O}$ Le principal invité offre à boire la troisième fois, comme le chef de la maison la première fois, et la maîtresse de la maison la deuxième fois. Ensuite il offre également de la viande rôtie. La coupe est mise au repos.

$\mathbf{O}$ Une natte est placée dans la salle près de la porte (pour le chef de la maison). La maîtresse de la maison rince une coupe, y verse du vin et la présente au chef de la maison. Celui-ci la salue à genoux dans la salle et reçoit la coupe. La maîtresse de la maison le salue à genoux après qu'il a reçu la coupe. ${ }_{560}$ La femme du maître des cérémonies l'aide, elle lui apporte des vases de bois dans la salle, comme précédemment. La maîtresse de la maison les reçoit. Elle place deux vases de bois et deux vases de bambou. Les petites tables arrivent et sont placées. Le chef de la maison tient la coupe de la main gauche. Il offre au mort les mets présentés. Le maître des cérémonies apporte les autres mets qui doivent être offerts au mort. Le chef de la maison dépose la coupe et se lève. Il prend les poumons, fléchit les genoux, sépare les poumons l'un de l'autre à leur petite extrémité, les goûte, se lève et met les poumons sur la petite table. Il fléchit les genoux, s'essuie les mains, offre le vin au mort et le goûte.

Vient ensuite le foie. Le chef de la maison tient la coupe de la main gauche. Il prend le foie, le trempe dans le sel, fléchit les genoux, secoue le foie, l'offre au mort et le goûte. Le maître des cérémonies reçoit le foie et le met sur la petite table. La viande rôtie est l'objet de semblable cérémonie. Le chef de la maison se lève, se met à genoux à l'extrémité de sa natte, vide la coupe et salue sa femme à genoux. La maîtresse de la maison lui rend le salut.

Elle reçoit la coupe, y verse du vin, $t s^{\bullet}$ pour boire à son $\bullet_{561}$ tour. Elle tient la coupe de la main gauche. Elle (la dépose, et) salue son mari à genoux. Son mari lui rend le salut. Elle fléchit les genoux, offre le vin au mort, se lève et boit debout. Après avoir vidé la coupe, elle salue à genoux. Le chef de la maison lui rend le salut. Elle sort de la salle et retourne dans le bâtiment latéral.

$\mathbf{O}$ Le chef de la maison descend les degrés, rince une coupe, la remplit, et la présente à la maîtresse de la maison. Elle est sur sa natte dans le bâtiment latéral, tournée vers le midi. Elle salue à genoux et reçoit la coupe. Le chef de 
la maison, le visage tourné vers l'ouest, lui rend le salut. La femme du maître des cérémonies apporte à la maîtresse de la maison des vases de bois ; elle lui fait servir une petite table. Ensuite elle lui offre à boire. Tout cela, comme précédemment pour le chef de la maison. Le chef de la maison prend une autre coupe, y verse du vin et boit lui-même à son tour. Après avoir vidé la coupe, il descend les degrés et met la coupe dans une corbeille. Il entre dans la salle et retourne à sa place.

$\mathbf{O}$ Le vin est offert une troisième fois (par le principal invité) ; ensuite la coupe est mise au repos. Après que le représentant du mort a vidé la coupe, le principal invité présente à boire à son tour à ceux qui lui ont offert à boire.. Il verse du vin $\bullet_{562}$ dans une coupe, et offre à boire à l'invocateur, ainsi qu'aux servants. Il rince la coupe, y verse du vin, et la présente au chef de la maison et à la maîtresse de la maison. On leur sert ensuite de la viande rôtie. Le tout, comme précédemment. Le principal invité prend une autre coupe, et offre à boire à son tour au chef de la maison. Cela fait, il retourne à sa place.

$\mathbf{O}$ Le chef de la maison descend par les degrés orientaux. Le visage tourné vers l'ouest, il salue à genoux le principal invité. Le tout, comme précédemment. Il se prépare à rincer une coupe. Le principal invité le prie de ne pas rincer la coupe lui-même. Quand la coupe a été rincée, le chef de la maison le salue par une inclination profonde, l'invite à monter le premier, et monte avec lui. Il verse du vin dans la coupe ; au haut des degrés occidentaux, il offre à boire au principal invité. L'invité, le visage tourné vers le nord, salue à genoux et reçoit la coupe. Le chef de la maison, à sa droite, lui rend le salut. On sert à l'invité des tranches de viande séchées, de la viande hachée conservée dans le sel et le vinaigre. On place près de lui une petite table sur laquelle sont des morceaux de porc.

Le principal invité tient la coupe de la main gauche. Il offre au mort la viande hachée contenue dans le vase de bois. Il dépose la coupe et se lève. Il prend les poumons, fléchit les genoux, sépare les poumons l'un de l'autre à leur petite extrémité, ${ }_{563}$ les offre au mort et les goûte. Il se lève, met les poumons sur la petite table, fléchit les genoux, s'essuie les mains, offre le vin au mort. Après avoir vidé la coupe, il salue à genoux. Le chef de la maison lui rend le salut. Il reçoit la coupe, et y verse du vin pour boire lui-même après avoir offert à boire à son hôte. Il dépose la coupe et salue à genoux. Le principal invité lui rend le salut. Le chef de la maison fléchit les genoux et offre le vin au mort. Après avoir vidé la coupe, il salue à genoux. Le principal invité lui rend le salut.

L'invité salue le chef de la maison par une inclination profonde, prend les offrandes et descend les degrés. Le visage tourné vers l'ouest, il dépose les offrandes à sa propre place. Sa place est comme précédemment (au bas des degrés occidentaux). Les viandes et la petite table sont ensuite placées près de lui.

Tous les étrangers montent les degrés tour à tour. Chacun d'eux salue à genoux, reçoit la coupe, fléchit les genoux, offre le vin au mort, se lève et boit 
debout. Des viandes et une petite table lui sont ensuite servies à sa place. Les étrangers ont tous cet honneur. Le chef de la maison rend le salut à chacun d'eux. Il descend ensuite les degrés et met la coupe dans une corbeille.

O Deux amphores sont placées à l'est des degrés orientaux Sur chacune est une cuiller, le manche tourné vers le sud. Deux $\bullet_{564}$ autres amphores sont placées à l'ouest des degrés occidentaux, de la même manière. Le chef de la maison rince une coupe, y verse du vin de l'amphore de l'ouest. Devant les degrés occidentaux, le visage tourné vers le nord, il offre à boire une seconde fois au principal invité. Celui-ci se tient à sa gauche. Le chef de la maison dépose la coupe et salue à genoux. Le principal invité lui rend le salut. Le chef de la maison fléchit les genoux et offre le vin au mort. Il vide la coupe (il boit lui-même le vin, pour donner l'exemple à son hôte et l'encourager à boire en suite). Il salue à genoux le principal invité. Celui-ci lui rend le salut.

Le chef de la maison s'en va pour rincer la coupe. Le principal invité le prie de ne pas la rincer. Le chef de la maison lui répond. Après que la coupe a été rincée, il y verse du vin, et tourne le visage vers l'ouest. Le principal invité, le visage tourné vers le nord, le salue à genoux. Le chef de la maison dépose la coupe au nord des viandes servies à l'invité. L'invité fléchit les genoux, prend la coupe, se tourne vers l'est et salue à genoux. Le chef de la maison lui rend le salut. L'invité dépose la coupe au sud des viandes servies, incline le corps profondément et retourne à sa place (à l'ouest des viandes).

$\mathbf{O}$ Le chef de la maison rince une coupe, et offre à boire au plus respectable de ses parents, au haut des degrés orientaux, de la même manière qu'il a offert à bo ire au principal invité. ${ }_{565}$ Il rince une coupe, et offre à boire à tous ses parents, comme il l'a offert à tous les étrangers.

Le chef de la maison rince une coupe, et offre à boire à toutes les femmes de ses parent, dans le bâtiment latéral, avec les mêmes cérémonies. Le visage tourné vers l'ouest, il leur rend le salut à genoux.

Il prend une autre coupe, et l'emplit pour boire lui -même à son tour Après avoir vidé la coupe, il descend les degrés, met la coupe dans une corbeille, entre dans la salle et retourne à sa place.

Le plus respectable des parents du chef de la maison rince une coupe, et le vin est offert une fois de plus, avec les mêmes cérémonies que précédemment. Il n'est pas offert aux servants de table ni aux aides d'un rang inférieur. Ce parent, après avoir rincé la coupe, la présente au chef de la maison et à la maîtresse de la maison, comme précédemment. Après que la coupe a été offerte, on ne sert aucun mets. Le plus respectable des étrangers (rince une coupe), et le vin est offert une fois de plus, comme précédemment. Ensuite la coupe est mise au repos.

$\mathbf{O} \cdot{ }_{566}$ Le futur successeur du chef de la maison va présenter une coupe au représentant du mort et la dépose devant lui, (afin que le représentant du mort lui offre à boire dans cette coupe à lui-même, et boive ensuite). Pour cela, 
après s'être lavé les main s, il entre dans la salle, et le visage tourné vers le nord, il salue deux fois à genoux le représentant du mort, inclinant la tête jusqu'à terre. Le représentant du mort prend la coupe déposée devant lui, et la présente au futur successeur. Celui-ci la reçoit, retourne à sa place, offre le vin au mort et le goûte. Le représentant du mort prend le foie. Le futur successeur, qui a donné la coupe au représentant du mort et l'a déposée devant lui, tient cette coupe de la main gauche. Il (la dépose et) salue deux fois à genoux, inclinant la tête jusqu'à terre. Il s'avance, reçoit le foie et retourne à sa place. Il fléchit les genoux et mange le foie. Il vide la coupe et salue à genoux. Chaque fois qu'il salue à genoux, le représentant du mort lui rend son salut .

Le futur successeur, qui a pris la coupe et l'a déposée devant le représentant du mort, rince cette coupe, y verse du vin et entre dans la salle. Le représentant du mort le salue à genoux et reçoit la coupe. Le futur successeur lui rend le salut. Le représentant du mort offre le vin au mort, le goûte et dépose la coupe. Le futur successeur sort de la salle et retourne à sa place.

Le plus jeune ou l'un des plus jeunes des frères ou des cousins $\bullet{ }_{567}$ rince une coupe, y verse du vin à l'amphore placée à l'es t. Devant les degrés orientaux, le visage tourné vers le nord, il lève et présente la coupe au plus respectable des frères ou des cousins. Les cérémonies sont les mêmes que quand le chef de la maison offre à boire la seconde fois au principal invité.

$\mathbf{O}$ Le maître des cérémonies avertit les assistants d'offrir au mort la viande placée sur les petites tables. Alors on leur sert différents mets.

$\mathbf{O}$ Le principal invité, à genoux, prend une coupe. Devant les degrés orientaux, le visage tourné vers le nord, il offre à boire une deuxième fois au plus respectable des parents, frère ou cousin, qui se tient à sa droite. Il dépose la coupe et salue à genoux. Le parent lui rend son salut. L'invité debout boit le vin (pour donner l'exemple au parent). Il verse du vin dans la coupe à l'amphore placée pour lui. Le visage tourné vers l'est, il se tient debout. Le parent le salue à genoux et reçoit la coupe. L'invité, tourné vers le nord, lui rend le salut. Il incline le corps profondément et retourne à sa place.

Le plus respectable des parents est au bas des degrés occidentaux, le visage tourné vers le nord. Le plus respectable des étrangers passe à sa gauche, pour recevoir de lui la coupe qui. sera offerte à tous les assistants ; cela, comme précédemment. $\bullet_{568}$ Le plus respectable des parents vide la coupe, la remplit à son amphore, et se tient debout, le visage tourné vers le nord. Celui qui reçoit de lui la coupe le salue à genoux avant de la recevoir. Le plus respectable des parents, le visage tourné vers le nord, lui rend le salut, et, après une inclination profonde, retourne à sa place. Tous les étrangers et tous les parents, sans exception, passant l'un devant l'autre, s'offrent à boire chacun à son voisin. (La coupe circule de main en main, de l'est à l'ouest). Tout cela, comme précédemment. 
Le plus respectable des étrangers offre le vin une fois de plus. Il fait circuler la coupe, qui a été mise au repos. Il emploie les mêmes cérémonies que précédemment le plus respectable des parents.

$\mathbf{O}$ Le plus respectable des parents offre à boire une deuxième fois à tous les étrangers, sans exception, comme le principal invité a offert à boire une deuxième fois à tous les parents. Celui qui reçoit la coupe le dernier la met dans une corbeille.

Le plus jeune des étrangers et le plus jeune des parents rincent chacun une coupe, et y versent du vin, chacun à son amphore. Au milieu de la cour, ils ont le visage tourné vers le nord, le plus digne à l'ouest de l'autre. Chacun d'eux lève sa $\bullet_{569}$ coupe et l'offre au plus vénérable des siens. Il dépose sa coupe et salue à genoux. Les deux vénérables rendent le salut. Les deux jeunes gens qui présentent les coupes offrent le vin au mort, le goûtent et saluent à genoux. Les deux vénérables leur rendent le salut.

Les deux jeunes gens rincent les coupes, et y versent du vin, chacun à son amphore. Ils retournent à leurs places précédentes. Les deux vénérables saluent à genoux. Les deux jeunes gens déposent les coupes à droite des mets servis aux deux vénérables. Les deux vénérables prennent les coupes et se lèvent. Les deux jeunes gens retournent à leurs places, et rendent le salut. Les deux vénérables déposent chaque coupe à sa place. Chacun d'eux salue par une inclination profonde le jeune homme qui lui a offert la coupe. Les deux jeunes gens retournent à leurs places. Tous les assistants boivent un nombre de coupes qui n'est pas limité.

O Un lí échanson rince une coupe sans ornement, et l'offre au représentant $\mathrm{du}$ mort. Celui-ci à son tour offre à boire aux principaux assistants jusqu'à l'invocateur inclusivement, avec les mêmes cérémonies que précédemment. L’invocateur descend ${ }_{570}$ et met la coupe dans une corbeille.

$\mathbf{O}$ Le chef de la maison sort de la salle, et se tient debout près de la porte de la salle, le visage tourné vers l'ouest. L'invo cateur, le visage tourné vers l'ouest, avertit que les mets sont préparés. Le représentant du mort se lève pour s'en aller. Linvocateur le précède. Le chef de la maison descend les degrés. L’invocateur retourne sur ses pas, rentre dans la salle avec le chef de la maison. Ils reprennent tous deux leurs places. Linvocateur dit au servant d'enlever la petite table du repré sentant du mort. La petite table est emportée hors du temple. On emporte les différents mets qui ont été servis au représentant du mort, et on les place auprès du bâtiment situé au côté occidental de la salle.

O Deux nattes sont étendues l'une vis -à-vis de l'autre. Les servants de table distribuent en deux parts les vases de millet et les vases de bouillon qui ont été servis au représentant des mânes. (Ils en mettent une moitié sur chaque natte). Le maître des cérémonies envoie le futur successeur du chef de la maison et le plus respectable des frères ou des cousins se laver les mains, et se tenir debout au bas des degrés occidentaux, le visage tourné vers l'est, le plus 
digne au nord de l'autre. L'invocateur les $•{ }_{571}$ invite à goûter les mets des restes du représentant du mort). Le futur successeur, invité à tsiún manger les restes, répond oui. Il monte les degrés, entre dans la salle et tourne le visage vers l'est. Le plus respectable des parents est vis-à-vis de lui. Tous deux s'assiéent. Les servants de table lèvent et présentent à chacun d'eux un morceau de viande pris avec la peau sur la partie antérieure du corps du porc.

Le chef de la maison, le visage tourné vers l'ouest, les salue deux fois à genoux. Linvocateur leur dit :

- En mangeant les restes du représentant du défunt, ayez un désir.

(le désir d’imiter les vertus du défunt). Ces deux hommes invités à manger les restes, déposent sur leurs petites tables la viande qu'on leur a présentée, et répondent oui. Tous deux rendent le salut. Cette cérémonie et cet avis ont lieu trois fois. Les deux invités prennent la viande qu'on leur présente et l'offrent aux mânes. Ils mangent du millet, et offrent aux mânes la viande qu'on leur présente. Ils mangent encore du millet, et offrent aux mânes le ragoût. Ils mangent la viande qui leur est présentée.

Quand ils ont fini de manger, le chef de la maison descend les degrés pour rincer une coupe, Lintendant lui présente une coupe. Le chef de la maison monte les degrés, verse du vin dans la coupe, et l'offre au plus respectable des deux hommes $\bullet_{572}$ qui ont mangé les restes, afin qu'il se rince la bouche. Celui-ci salue à genoux et reçoit la coupe. Le chef de la maison lui rend le salut. Ensuite il offre à boire au second des deux hommes qui ont mangé les restes. La cérémonie est la même que la précédente. Le chef de la maison les salue tous deux à genoux.

\section{L’invocateur leur dit :}

- Rincez-vous la bouche, (et à l'exemple de votre parent défunt) iòu iù ayez de bonnes relations avec tous vos parents.

Cette cérémonie est semblable à la précédente. Ces deux hommes tiennent en mains leurs coupes. Ils (les déposent et) saluent à genoux le chef de la maison. Ils offrent le vin aux mânes, le boivent et saluent à genoux. Le chef de la maison leur rend le salut. Ces deux hommes descendent les degrés et mettent leurs coupes dans les corbeilles.

Le plus respectable des deux rince une coupe, monte les degrés, verse du vin dans la coupe, et à son tour offre à boire au chef de la maison. Le chef de la maison salue à genoux et reçoit la coupe. Celui qui la lui a offerte retourne à sa place, fléchit les genoux et rend le salut. Le chef de la maison fléchit les genoux, offre le vin aux mânes, le boit et salue à genoux. Le plus respectable de ceux qui ont mangé les restes lui rend le salut, reçoit la coupe, descend les degrés et met la coupe dans une corbeille. Le chef de la maison sort de la salle, et reste $\bullet_{573}$ debout à la porte de la salle, le visage tourné vers l'ouest.

O Linvocateur fait enlever la petite table, le vase de bois et le vase de bambou qui sont au haut des degrés orientaux (et ont été servis au chef de la 
maison). Il les fait mettre au pied du bâtiment situé au côté oriental de la plateforme. Il prend sa petite table, l'emporte et se tient à l'ouest de la porte de la salle, le visage tourné vers l'est. La femme du maître des céré monies enlève le vase de bois et le vase de bambou de l'invo cateur, et les porte dans le bâtiment situé à côté de la salle. Elle enlève la petite table et les vases qui ont été servis à la maîtresse de la maison.

Les servants de table enlèvent les vases de viande, la petite table et les vases de millet du représentant des mânes ; ils les mettent à l'angle nord-ouest de la salle. Ils placent l'escabeau au sud. Pour en cacher la vue, ils se servent d'une natte. Ils mettent une amphore dans la salle. Ils ferment la fenêtre et la porte de la salle, et descendent les degrés. L'invocateur annonc e que le repas est fini. Il descend les degrés et sort du temple. Le chef de la maison descend aussi et retourne à sa place. Le maître des cérémonies avertit que la cérémonie est terminée. Le principal invité s'en va. Le chef de la maison • 574 l'accompagne jusqu'en dehors de la grande porte du temple, et le salue deux fois à genoux, Le servant enlève la petite table du chef de la maison. Chacun des assistants (à l'exception du principal invité), au bas de la plateforme, prend sa petite table et l'em porte hors du temple.

\section{NOTES SUPPLÉMENTAIRES.}

Quand on offre la viande d'un seul animal, c'est -à-dire, d'un porc, ce qui a lieu après la mort d'un simple officier, tous les principaux officiers portent les vêtements de cour, le bonnet noirâtre, la ceinture noire et les genouillères noires. Seuls le représentant des mânes, l'invocateur et les servants portent une tunique noirâtre, et une jupe soit noirâtre soit jaune, soit de n'importe quelle couleur. Leurs genouillères sont toujours de cuir de couleur tête de moineau.

On place des cuvettes du sud au nord, dans le sens de la largeur de la plateforme, et de l'est à l'ouest, à l'angle oriental du faîte de la salle. Des aiguières sont placées à l'est des cuvet tes. Des corbeilles sont à l'ouest des cuvettes. Elles sont tournées vers le sud pour plus de commodité. Elles contiennent deux coupes appelées $t s i \bullet$, deux coupes appelées $k \bullet$, quatre coupes appelées tchéu, une coupe appelée ki•, une coupe appelée sán.

- ${ }_{575}$ Des jarres, avec leurs plateaux et leurs supports, sont déposées dans le bâtiment situé à l'est de la plateforme. Elles sont au sud pour plus de commodité. Elles ont chacune un couvercle, qui est déposé au sud. Quand il fait grand jour, tous ces objets sont placés. On couvre les jarres avec des serviettes de grosse toile de dolic. Quand le représentant des mânes va prendre sa place dans la salle, ces deux jarres sont emportées (et placées près de lui). On met une cuiller sur chacune d'elles. 
Les couvertures placées sur les vases de bambou sont de grosse toile de dolic, doublée de toile brune. Ces vases contiennent des jujubes cuites et des châtaignes de choix. Les plantes potagères mêlées au bouillon gras dans les vases sont des laiterons ou des plantes appelées ouêi. Pour édulcorer le bouillon, on y mêle des mauves en été et des hémérocalles en hiver. Les cuillers sont faites de coar de jujubier sauvage. Elles sont sculptées.

On fait cuire le porc en dehors de la grande porte du temple, au sud-est. On fait cuire les poissons et le lièvre séché au sud du porc. Les deux fourneaux sont tournés vers l'ouest. On fait cuire le millet au pied du mur situé au côté occidental de la plateforme.

On retranche les deux extrémités du cour et de la langue ${ }_{576}$

qu'on sert sur la $k \hat{\imath}$ petite table. On fait sur les deux une incision en forme de croix. Ils sont et on les prend dans la chaudière qui contient la viande de porc. Après avoir déposé le coar sur la petite table, on met la langue debout. (On les place dans le sens de la largeur de la table et) chø on les présente en avant à celui à qui on les sert.

Les mets qui sont servis au principal invité et au plus vénérable des parents viennent du bâtiment situé au côté oriental de la salle. Les mets qui sont servis aux autres convives sont préparés à la partie orientale de la plateforme.

Quand le représentant des mânes se lave les mains, un seul homme l'aide pour chaque chose. Celui qui tient la cuvette a le visage tourné vers l'est. Celui qui tient l'aiguière a le visage tourné vers l'ouest ; il verse l'eau sur les mains. Celui (qui tient la serviette est au nord de celui qui tient l'aiguière. Le maître des cérémonies, le visage tourné vers l'est, prend la serviette, la secoue trois fois, et, le visage tourné vers le sud, la donne au représentant des mânes. Quand Celui-ci a fini de s'essuyer les mains, celui qui a apporté la serviette la reprend.

Quand le représentant des mânes entre dans la salle, le chef de la maison et le principal invité quittent leurs places, (par respect). De même, quand il sort.

Le futur successeur du chef de la maison apporte une coupe $\bullet_{577}$ et la dépose devant le représentant des mânes. Les servants placent après de lui des vases de bois et du sel.

Quand les servants ont quelque chose à faire, ils se tiennent dehors à la porte de la salle, le visage tourné vers le sud. Quand ils n'ont rien à faire, ils restent dans la cour, le visage tourné vers le nord. Chaque fois que l'invocateur appelle un servant, le servant répond :

- A vos ordres.

Quand on offre à boire, et quand tous les convives boivent à la ronde, le maître des cérémonies est rangé parmi les étrangers d'après son âge. Quand on boit à la ronde, les servants de table sont rangés parmi les parents d'après leur âge. 
Deux amphores sont placées dans le bâtiment latéral, au bas du mur occidental, la plus noble (celle qui contient l'eau) au sud de l'autre. Les femmes étrangères se tiennent debout au nord des amphores, le visage tourné vers l'est, rangées du sud au nord par ordre de dignité. Les parentes sont sur la plate forme septentrionale, le visage tourné vers l'est, rangées du nord au sud par ordre de dignité. La maîtresse de la maison, les étrangères et les parentes boivent aussi à la ronde, comme les hommes, le visage tourné vers l'ouest.

- ${ }_{578}$ Les parentes qui aident à servir les mets tiennent les vases dans les mains, à genoux en dehors de la porte de la salle, et les donnent à la maîtresse de la maison.

Quand le représentant des mânes a fini de manger, il offre le millet et la viande cuite au dieu du foyer. Le principal invité suit le représentant des mânes. (Il le reconduit jusqu'à la grande porte du temple). La petite table du représentant des mânes est emportée hors du temple. Le principal invité retourne à sa place dans le temple.

Sur les petites tables du représentant des mânes on place les parties suivantes du côté droit du porc: l'épaule, la partie inférieure et la partie supérieure du membre antérieur, la partie supérieure et la partie inférieure du membre postérieur, deux côtes droites et une côte transversale prises sur le dos, deux longues côtes et une côte courte prises sur le devant du corps, trois morceaux de viande pris avec la peau sur le devant du corps, deux paires de poumons séparés l'un de l'autre à leur petite extrémité, trois paires de poumons dont on a retranché les petites extrémités. On y met quinze poissons, et les mêmes parties osseuses du lièvre séché que celles du porc.

Sur la petite table de l'invocateur on sert la hanche, une tranche de viande séchée, deux $\bullet_{579}$ côtes prises sur le dos, deux côtes prises sur la partie antérieure du corps, un morceau de viande pris avec la peau sur la partie antérieure du corps, deux poumons séparés l'un de l'autre à leur petite extrémité.

Sur la petite table du chef de la maison, on place la partie inférieure du membre antérieur, deux côtes droites et une côte transversale prises sur le dos, deux longues côtes et une côte courte prises sur le devant du corps, un morceau de viande pris avec la peau sur le devant du corps, deux poumons séparés l'un de l'autre à leur petite extrémité. Sur la petite table de la maîtresse de la maison, on place la moitié de la partie inférieure d'un membre postérieur. Les autres mets sont les mêmes que ceux qui sont sur la petite table du chef de la maison.

Sur les petites tables des servants, on met la moitié de la partie inférieure d'un membre postérieur, une côte prise sur le dos, une côte prise sur le devant du corps, un morceau de viande pris avec la peau sur le devant du corps, deux poumons séparés l'un de l'autre à leur plus petite extrémité. Sur la petite table du principal invité est la partie inférieure du membre postérieur gauche. L'un des quatre membres (on ne dit pas lequel) est coupé en deux parties. Une partie est mise sur la petite table du plus respectable des parents, et l'autre sur 
celle du maître des cérémonies. De plus, on leur sert les mêmes mets qu'aux servants de table. Quant à la foule des étrangers, des parents, des femmes étrangères et des parentes, ainsi qu'aux officiers publics ou privés du prince, sil y en a, on sert à $\bullet_{580}$ chacun un ragoût composé de viande et de légumes, de la viande, un morceau de viande pris avec la peau sur la partie antérieure du corps du porc, deux poumons séparés l'un de l'autre à leur petite extrémité.

Les officiers publics du prince sont placés à l'ouest de la grande porte, le visage tourné vers le nord, rangés de l'est à l'ouest par ordre de dignité. Ils reçoivent la coupe après la foule des étrangers. Les officiers privés sont placés à l'est de la grande porte, le visage tourné vers le nord ; ils sont rangés de l'ouest à l'est par ordre de dignité. Ils reçoivent la coupe après la foule des parents. Ils montent les degrés pour aller recevoir la coupe ; ils les descendent pour boire le vin. 


\section{CHAPITRE XVI}

\section{Offrandes d'un agneau et d'u n porc}

- ${ }_{581}$ Laô Étable ou enclos pour les animaux domestiques. Chaò laô Un agneau et un porc ; T'ái lâo Un bøaf, un agneau et un porc. Un ministre d'État ou un grand préfet im mole un agneau et un porc.

O Le jour doit être l'un des jours du cycle désignés par la lettre tøng ou la lettre kì. Onze jours avant celui où l'on se propose de faire l'offrande, on consulte les sorts au moyen de brins d'achillée sur le choix du jour. Le devin manipule les brins d'achillée en dehors de la grande porte du temple dans lequel est la tablette de l'aïeul du chef de la maison. Le chef de la maison, en habits de cour, le visage tourné vers l'ouest, se tient à l'est de la grande porte. L'annaliste, en habits de cour, tenant de la main gauche l'étui qui contient les bries d'achillée, enlève de la main droite la partie supérieure de cet étui et la passe dans la main gauche. Tenant ainsi à la fois de la main gauche les deux parties de l'étui, le visage tourné vers l'est, il reçoit les ordres du chef de la maison.

Le chef de la maison lui dit d'employer la formule suivante :

« ${ }_{582}$ Le petit-fils un tel, plein de piété filiale, se propose de prendre le prochain jour tøng hái pour présenter les offrandes annuelles à son auguste aïeul un tel, qui est le premier de plusieurs frères, et p'éi conjointement à telle fi épouse de son aïeul, laquelle porte tel nom de famille. Il espère que les mânes auront ces offrandes pour agréables. » (Le maitre de la maison doit être désigné par son nom d'enfance. L'aïeul doit être désigné par son tséu nom reçu dans l'adolescence. S’il a reçu un chéu nom posthume, il doit être désigné par son nom posthume. S'il n'est pas le premier d'entre plusieurs frères, mais le deuxième, le troisième, le quatrième,... la lettre [] est remplacée par l'une des lettres tchóung, chøu, kí. On peut choisir un jour désigné par la lettre tøng ou désigné par la lettre kì, suivie de n’importe laquelle des douze lettres horaires. Par conséquent la désignation du jour est variable ; ce n'est pas nécessairement hái).

L'annaliste répond :

- J'obéis.

Le visage tourné vers l'ouest, debout à l'ouest de la grande porte, il enlève la partie inférieure de son étui. Tenant de la main gauche les brins d'achillée, et de la main droite les deux parties de l'étui, il frappe coutre les brins d'achillée (pour éveiller l'attention des esprits qui président aux sorts). Ensuite, répétant la formule reçue, il dit : 
- Nous avons recours à vous, Esprits sublimes qui répondez aux questions au moyen des brins d'achillée, suivant des règles constantes. Le petit-fils affectueux un tel se propose de prendre le prochain jour tøng hái pour présenter les offrandes annuelles à son auguste aïeul un tel, qui est le premier de plusieurs frères, et $\bullet_{583}$ conjointement à telle épouse de son aïeul, laquelle porte tel nom de famille. Il espère que ses offrandes seront agréables à leurs mânes. »

Alors l'annaliste dépose l'étui, et debout, manipule les brins d'achillée. Un homme, à genoux, à sa gauche avec un bâton, dessine par terre au fur et à mesure les symboles donnés par les brins d'achillée. La manipulation terminée, cet homme transcrit les symboles sur des planchettes, les montre au chef de la maison, et se retire. (Aidé de plusieurs autres), il cherche la signification des symboles.

Si la réponse des sorts est favorable, l'annaliste renferme les brins d'achillée dans leur étui. Tenant à la fois les brins d'achillée et les symboles, il informe le chef de la maison que les interprètes des symboles ont trouvé la réponse des sorts favorable. Ensuite l'annaliste avertit les offic iers de préparer les objets nécessaires. Il recommande au maître des cérémonies de faire balayer la terre et laver les vases. Il dit à l'intendant de préparer les vins. Ensuite il se retire. Si la réponse des sorts n'a pas été favorable, on choisit un jour plus éloigné, et de nouveau on consulte les sorts comme précédemment.

$\mathbf{O}$ Le chef de la maison avertit les officiers une seconde fois. $\bullet_{584}$ (Il leur rappelle le jour choisi pour les offrandes). Un jour avant de les avertir pour la seconde fois, il avertit une seconde fois celui qui sera le représentant des mânes. - Le matin, au lever du jour, (on ignore quel jour), il consulte les sorts sur le choix du représentant des mânes, de la même manière qu'il les a consultés sur le choix du jour. L'annaliste dit :

- Le fils respectueux N. se propose de prendre le prochain jour tøng hái pour présenter des offrandes annuelles à son vénérable aïeul N., le premier d'entre plusieurs frères, et conjointe ment, à telle femme de son aïeul, laquelle porte tel nom de famille. Pour représenter les mânes, il se propose d'employer N., fils de N., Il espère que ses offrandes seront agréables aux mânes.

L'annaliste manipule les brins d'achillée ; on les écrit, on les interprète, comme précédemment.

Si la réponse des sorts est favorable, le chef de la maison avertit de nouveau le futur représentant des mânes. Il l'avertit par l'intermédiaire de l'invocateur. (Il va avec l'invocateur à la maison du représentant des mânes, et reste devant la grande porte). Il salue deux fois à genoux, inclinant la tête jusqu'à terre. L'invocateur entre et avertit le futur représentant des mânes en ces termes :

- Le petit-fils respectueux N. se propose de prendre le prochain jour désigné par les lettres tøng hái pour présenter les offrandes 
annuelles à son auguste aïeul N., qui est $\bullet_{585}$ l'aîné d'entre plusieurs frères, et conjointement à telle femme de son aïeul, laquelle porte tel nom de famille. Il se permet de vous en informer de nouveau.

L'invité salue à genoux et promet de représenter les mânes. Le chef de la maison le salue de nouveau deux fois à genoux, inclinant la tête jusqu'à terre, et se retire. L'invité l'accompagne et le salue par une inclination profonde ; il ne le salue pas à genoux (à cause de sa dignité de représentant des mânes). Si la réponse des sorts n'a pas été favorable sur le choix du représentant des mânes, on les consulte ensuite de nouveau sur le choix d'un autre représentant.

Le chef de la maison, après avoir averti pour la deuxième fois le futur représentant des mânes, retourne à sa maison, et, devant la grande porte du temple, fixe et annonce l'heure des offrandes. Il se tient à l'est de la grande porte du temple, le visage tourné vers le sud. Le maître des cérémonies, en habits de cour, le visage tourné vers le nord, lui dit :

- Je vous prie de déterminer l'heure des offrandes.

Le chef de la maison répond :

- Ce sera à l'heure que vous voudrez, Seigneur.

Le maître des cérémonies reprend :

— Le matin, au lever du soleil, on présentera les offrandes.

Le chef de la maison répond oui. Ensuite on se retire.

$\mathrm{Au}$ lever du soleil, le chef de la maison, en habits de cour, ${ }_{586}$ va prendre sa place en dehors de la grande porte du temple, à l'est, le visage tourné vers le sud. L'intendant et le maître des cérémonies ont le visage tourné vers l'ouest, le plus digne au nord de l'autre. Les victimes (un agneau et un porc) ont la tête tournée vers le nord ; la plus noble des deux (l'agneau) est à l'est de l'autre. Le commandant égorge l'agneau. Un chef d'of ficiers assomme le porc. Le maître des cérémonies annonce que l'immolation des victimes est terminée. Alors on se retire.

Le chef de cuisine fait laver les chaudières, les cuillers, les petites tables, près des fourneaux où l'on fait cuire les viandes. Ces fourneaux sont au sud-est de la grande porte, rangés du nord au sud par ordre de dignité. Lintendant des greniers fait laver les chaudières tséng, les chaudières ièn, les cuillers, ainsi que les vases pour le millet. Il les fait laver auprès des fourneaux préparés pour faire cuire les grains. Ces fourneaux sont au nord de ceux sur lesquels on fait cuire les viandes. L'inten dant des appartements fait laver les vases de bois, les vases de bambou, les cuillers, les trois sortes de coupes.

Les escabeaux, les cuvettes, les corbeilles sont au bas de la plateforme orientale. Les cuillers, les différentes coupes sont dans les corbeilles. Quand on a fini de laver, on porte les vases ${ }_{587}$ de bois, les vases de bambou et les corbeilles dans le bâtiment latéral; on les range à l'ouest. On place les 
cuvettes au sud-est des degrés orientaux, vis-à-vis de l'extrémité orientale de la crête du toit de la salle.

Lorsque le bouillon gras est préparé à point, le chef de cuisine apporte cinq chaudières vides. Il en place trois à l'ouest de la marmite dans laquelle l'agneau a été cuit, et deux à l'ouest de la marmite dans laquelle le porc a été cuit.

Le commandant retire d'une marmite et met dans une chaudière (pour le représentant des mânes) le côté droit du corps de l'agneau, moins la hanche. Il y met l'épaule, la partie inférieure et la partie supérieure du membre antérieur, la partie supérieure et la partie inférieure du membre postérieur ; une côte droite, une côte raide et une côte transversale prises toutes trois sur le dos de l'animal, une côte courte, une côte droite et une fausse côte prises toutes trois sur le devant du corps de l'agneau. Il met ces parties osseuses deux à deux. Il y ajoute trois intestins, trois estomacs, deux poumons qui seront levés et présentés au représentant des mânes, trois paires de poumons qui seront offerts aux mânes. Toutes les pièces susdites sont mises dans une seule et même chaudière.

$\bullet_{588}$ Un chef d'officiers retire d'une marmite et met dans une chaudière le côté droit du corps du porc, à l'exception de la hanche. Il y met l'épaule, la partie inférieure et la partie supérieure du membre antérieur, la partie supérieure et la partie inférieure du membre postérieur ; une côte droite, une côte raide et une côte transversale prises toutes trois sur le dos du porc ; une côte courte, une côte droite et une côte flottante prises toutes trois sur le devant du corps. Il place ces parties osseuses deux à deux. Il y ajoute deux poumons qui seront levés et donnés au représentant des mânes, et trois paires de poumons qui seront offerts aux mânes. Il met toutes les pièces susdites dans une seule et même chaudière.

Le chef de cuisine choisit neuf morceaux pris avec leur peau sur le devant du corps du porc, et les met dans une autre chaudière. Un chef d'officiers retire aussi des marmites et met dans les chaudières les poissons et la viande séchée. Il met dans une chaudière les poissons au nombre de quinze. Il met dans une autre chaudière la viande séchée, (qui est en un seul morceau. Comme viande séchée, on emploie la viande de grand cerf.

Quand on a fini de mettre les viandes dans les chaudières, on enfile un levier dans les oreilles de chacune d'elles, et on la couvre d'un linge. Ensuite on emporte ces chaudières. On les $\bullet_{589}$ place en dehors de la grande porte du temple, à l'est, tournées vers le nord, rangées du nord au sud, la plus noble au nord. Les deux amphores de l'intendant du palais sont entre le bâtiment latéral et la porte de la salle, sur un même plateau. Elles sont toutes deux recouvertes d'un linge. L'une d'elles contient de l'eau.

L'intendant du palais place des jarres pleines d'eau à l'est des cruches ; il y met des cuillers. Il place des corbeilles à l'ouest des cruches ; il les range du nord au sud. Il transporte les vases de bois et les vases de bambou dans le bâtiment latéral, et les tourne vers le sud, de la même manière que les comes- 
tibles. Il met dans ces vases les comestibles quils doivent contenir. Un invocateur de second rang place un bassin, une aiguière, une corbeille contenant une serviette, à l'est des degrés occidentaux.

O Le chef de la maison, en habits de cour, va prendre sa place à l'est des degrés orientaux, le visage tourné vers l'ouest. L’intendant du palais étend une natte à l'angle sud-ouest de la salle (pour les mânes). L'invocateur place un escabeau sur cette natte, au côté droit (au côté méridional).

- ${ }_{590}$ Le chef de la maison sort du temple et va au devant des chaudières. On enlève les serviettes qui les couvrent. Des officiers, après s'être lavé les mains, portent les chaudières. Le chef de la maison entre le premier. L'intendant du palais prend deux cuillers dans les corbeilles, les lave, et les tenant toutes deux dans les mains, monte les degrés. Il enlève les couvertures placées sur les deux amphores, et les dépose sur le plateau. Il met une cuiller sur chacune des deux amphores, le cuilleron renversé et le manche tourné vers le midi.

Les chaudières entrent par ordre dans la cour du temple. Le chef de cuisine prend une cuiller et suit. Le second chef de cuisine prend quatre cuillers et suit le premier chef. Un chef d'officiers prend à la fois deux petites tables et marche à leur suite. Deux aides du chef des officiers prennent chacun deux petites tables, pour siáng aider leur maître, et avec elles, ils entrent après lui.

Les chaudières sont rangées à l'est, en face du bâtiment latéral. Leur côté méridional est à l'ouest des cruches. Elles regardent toutes l'ouest. Elles sont rangées du nord au sud, la plus noble au nord. La moins noble est celle qui contient les ${ }_{591}$ morceaux de viande pris avec la peau sur le devant du corps du porc. Sur chaque chaudière est une cuiller, le manche tourné vers l'est. Toutes les petites tables sont rangées à l'ouest des chaudières, de l'est à l'ouest, les moins nobles à l'oue st. Celles sur lesquelles sont le cour et la langue de l'agneau et du porc sont au nord de celle sur laquelle sont les autres parties de l'agneau. Elles sont aussi rangées de l'est à l'ouest.

Plusieurs invités (deux servants de table et trois chefs d'offi ciers), envoyés par le maître des cérémonies, vont auprès du chef de la maison. Ils se lavent tous les mains au dessus des cruches. Les plus respectables portent des cuillers. Le cháng lí premier des servants de table enlève des chaudières et place sur les petites tables la chair de l'agneau et la chair du porc. Il met le cour et la langue de chacun de ces deux animaux sur une petite table appelée $k \hat{\imath}$ ou kín. Il racle, il aplanit le côté inférieur du cœur. Il fait une incision en forme de croix sur le côté supérieur. $O \bullet m \bullet$. Il ne le divise pas. Il le place sur la petite table, la plus petite extrémité tournée en haut. Il retranche toujours les deux extrémités de la langue. Il fait aussi une incision en forme de croix sur le côté supérieur, sans la diviser. Il la place sur la petite table droit devant soi, dans le sens ${ }_{592}$ de la largeur de la table. Tout cela, comme précédemment, quand on a mis le cour et la langue sur le feu du fourneau. Le servant de table transporte à l'ouest des degrés orientaux les petites tables s ur lesquelles sont 
les cours et les langues. Il tourne l'extrémité vers l'ouest. Ensuite il retourne à sa place.

Le premier des deux servants de table retire de la chaudière et place sur les petites tables le côté droit du corps de l'agneau, moins la hanch e. Il y place l'épaule, la partie inférieure et la partie supérieure du membre antérieur, la partie supérieure et la partie inférieure du membre postérieur, une côte droite, une côte raide et une côte transversale prises toutes trois sur le dos de l'agneau, une côte courte, une côte droite et une fausse côte prises toutes trois sur le devant du corps de l'agneau. Il place ces parties osseuses deux à deux.

Il y ajoute trois intestins et trois estomacs, qui occupent toute la longueur de la petite table ; une paire de poumons qui ont toute leur longueur et seront offerts à leur destinataire, trois paires de poumons qui seront offerts aux mânes. Sur tous les poumons on fait une incision en forme de croix. L'épaule, la partie inférieure et la partie supérieure du membre antérieur, la partie supérieure et la partie inférieure du membre postérieur occupent les deux extrémités de la petite table. Les côtes sont $\bullet_{593}$ au milieu. L'épaule est à l'extrémité antérieure.

Le second servant de table enlève de la chaudière et met sur une petite table la chair du porc, de la même manière que le premier servant l'a fait pour la chair de l'agneau. Il n'y met ni intestins ni estomac. De tous les membres qu'il met sur la petite table, il place en avant l'extrémité inférieure.

Trois chefs d'officiers retirent des chaudières et mettent sur de petites tables les poissons, la viande séchée, les morceaux de viande pris avec leur peau sur le devant du corps du porc. Les poissons sont des carpes. Il y en a quinze. On les place dans le sens de la longueur de la petite table, la tête tournée à droite, le ventre tourné en avant. Un morceau de viande séchée est placé sur une petite table, aussi le ventre tourné en avant, l'épaule tournée en haut. Neuf morceaux pris avec leur peau sur le devant du corps du porc sont placés dans le sens de la largeur de la petite table, la peau tournée de la même manière.

$\mathbf{O}$ Quand les viandes ont été placées sur les petites tables, l'invocateur se lave les mains auprès des cruches, et monte par les degrés occidentaux. Le chef de la maison se lave les mains, et monte par les degrés orientaux. Linvocateur entre le premier dans la salle, et se tient le visage tourné vers le midi. Le chef ${ }_{594}$ de la maison le suit, et se tient dans la salle près de la porte, le visage tourné vers l'ouest.

La maîtresse de la maison, parée de cheveux étrangers et vêtue d'une tunique à larges manches, sort du bâtiment situé au côté oriental de la salle. Elle apporte des poireaux salés, de la viande qui a été séchée, hachée, mêlée de sang et conservée dans le sel et le vinaigre, de la viande qui a été battue, séchée, hachée, mêlée de levain, et conservée dans le sel et le vinaigre. Elle fléchit les genoux, et dépose ces friandises devant la natte préparée pour les mânes. Une aide de la maîtresse de la maison, parée aussi de cheveux 
étrangers et vêtue d'une tunique à larges manches, apporte des mauves salées, des escargot hachés et conservés dans le sel et le vinaigre. Elle donne ces comestibles à la maîtresse de la maison. Celle-ci les reçoit à genoux sans se lever. Elle place ces mets deux à deux à l'est. Elle les range du sud au nord. Elle place les poireaux salés au sud des mauves salées. Elle se lève et rentre dans le bâtiment latéral.

Le premier servant de table prend la petite table sur laquelle est la chair de l'agneau ; le second prend la petite table sur laquelle est la chair du porc ; trois chefs d'officiers prennent les ${ }_{595}$ trois petites tables sur lesquelles sont les poissons, la chair du quadrupède séché, les morceaux de viande pris avec leur peau sur le devant du corps du porc. Ces cinq hommes montent par ordre, l'un après l'autre, par les degrés occidentaux, se suivent, entrent dans la salle et rangent leurs petites tables. Ils placent l'agneau à l'est des vases de bois ; ensuite le porc au nord de l'agneau ; les poissons à l'est de l'agneau ; la viande séchée à l'est du porc; les morceaux de viande de porc seuls à l'extrémité septentrionale des petites tables.

La maîtresse de la maison sort du bâtiment situé à l'est de la salle. Elle tient dans les mains un vase doré, muni d'un cou vercle, contenant du millet glutineux. A genoux, elle le dépose au sud de la petite table sur laquelle est la chair de l'agneau. Une aide tient dans les mains un vase contenant du millet non glutineux; elle le donne à la maîtresse de la maison. Celle-ci se lève, reçoit le vase, et à genoux, le place au sud de la petite table sur laquelle sont les poissons. Elle se lève de nouveau, reçoit des mains d'une aide un vase contenant du millet glutineux, et à genoux, le dépose au sud du millet non glutineux. Elle se lève de nouveau, reçoit des mains d'une aide un vase contenant du millet non glutineux, et à genoux, le place au sud du millet glutineux. Elle tourne vers le sud la tête de tous ces $\bullet_{596}$ vases de millet. Elle se lève, et rentre dans le bâtiment latéral.

$\mathbf{O}:-$ Un invocateur verse du vin dans une coupe, et la dépose pour l'offrir aux mânes. Ensuite il ordonne à un servant de table d'ouvrir les couvercles des vases de millet. Le servant ouvre et enlève les couvercles des vases qui contiennent les deux sortes de millet; il les dépose tch'ôung deux à deux au sud de ces vases. Le chef de la maison, le visage tourné vers l'ouest, a l'in vocateur à sa gauche. Il salue deux fois à genoux, inclinant la tête jusqu'à terre.

L’invocateur, s'adressant aux mânes, leur dit :

- Le petit-fils respectueux N. se permet de prendre un animal au poil moelleux (un agneau), un animal au crin raide (un porc), des comestibles excellents (des légumes salés et de la viande hachée conservée dans le sel et le vinaigre), des grains qui en tous lieux sont la récompense de la concorde (du millet glutineux et du millet non glutineux). Il se permet de les présenter comme offrandes annuelles à son auguste aïeul N., qui est l'aîné de plusieurs frères, 
et conjointement à telle épouse de son aïeul, qui porte tel nom de famille. Il espère que ces offrandes leur seront agréables.

Le chef de la maison salue de nouveau deux fois à genoux, inclinant la tête jusqu'à terre.

O Linvocateur sort de la salle, et va au devant du $\bullet_{597}$ représentant des mânes jusqu'en dehors de la grande porte du temple. Le chef de la maison descend les degrés, et se tient debout à l'est des degrés orientaux, le visage tourné vers l'ouest. Linvo cateur entre le premier par le côté droit de la grande porte du temple. Le représentant des mânes entre par le côté gauche.

Le maître des cérémonies, le visage tourné vers l'est, tient une cuvette dans les mains, dans la partie méridionale de la cour. Un second maître des cérémonies, à l'est du premier, le visage tourné vers l'ouest, tient une aiguière pleine d'eau. Un troisième maître des cérémonies, au nord du premier, le visage tourné vers le sud, tient un essuie-main dans une corbeille, Celui qui tient l'aiguière verse de l'eau, et le représentant des mânes se lave les mains au dessus de la cuvette. Quand il a fini de se laver les mains, celui qui tient la corbeille, fléchit les genoux, dépose la corbeille et prend l'essuie-main. Il se lève, secoue trois fois l'essuie-main et la donne au représentant des mânes. Il fléchit les genoux, reprend la corbeille, se lève et reçoit l'essuie-main du représentant des mânes.

L'invocateur invite le représentant des mânes à monter. Celui-ci monte par les degrés occidentaux et entre dans la salle. L'invocateur le suit. Le chef de la maison monte par les degrés orientaux. Linvocateur entre avant lui dans la salle. Le chef ${ }_{598}$ de la maison le suit.

Le représentant des mânes monte sur sa natte. Linvocateur et le chef de la maison, le visage tourné vers l'ouest, sont de bout dans la salle près de la porte ; l'invocateur est à la gauche du chef de la maison. Ils saluent tous deux à genoux le représentant des mânes, et l'invitent à s'asseoir commodément. Le représentant des mânes ne dit rien. Il rend le salut à genoux; puis il s'assied. L'invocateur retourne à sa place, et tient le visage tourné vers le sud.

Le représentant des mânes prend les poireaux salés, les trempe dans la saumure de chacun des trois vases de bois, et les offre aux mânes entre les offrandes contenues dans ces vases. Le premier servant de table prend du millet glutineux et du millet non glutineux dans les quatre vases. Le deuxième servant prend sur les petites tables et donne au premier servant des poumons d'agneau et des poumons de porc qui ont été incisés. Le premier servant donne au représentant des mânes ces poumons et le millet glutineux. Le représentant des mânes reçoit et offre ensemble aux mânes les poumons et le millet, au milieu des offrandes contenues dans les vases de bois.

- ${ }_{599}$ Le premier servant de table lève et donne au représentant des mânes les poumons, et les côtes droites prises sur le milieu du dos de l'agneau et $\mathrm{du}$ porc. Il èul approche sur la natte, au côté droit du représentant des mânes, le premier vase de millet glutineux. Le chef de la maison porte lui-même au 
représentant des mânes la petite table sur laquelle sont le cour et la langue du l'agneau et du porc. Il monte par les degrés orientaux et place cette table au nord des morceaux de viande pris sur le devant du corps du porc.

Le premier servant apporte deux chaudières au représentant des mânes. Il prend lui-même dans le bâtiment latéral une chaudière contenant de la viande d'agneau, et à genoux, la place au sud des poireaux salés. Le deuxième servant prend aussi dans le bâtiment latéral une chaudière qui contient de la viande de porc, et marche à la suite du premier servant. Le premier servant reçoit cette deuxième chaudière, et fléchissant les genoux, la place au sud de la première. Chacune de ces chaudières contient des herbes. Chacune a une cuiller.

Le représentant des mânes tch'• avec les cuillers retire le bouillon des chaudières, Il offre aux mânes le bouillon d'agneau. ${ }_{600}$ Ensuite il leur offre le bouillon de porc. Il goûte le bouillon d'agneau. Il mange les viandes qui lui ont été présentées, (les poumons et les côtelettes). Il mange trois fois du millet glutineux. Le premier servant lève et lui présente les côtes prises sur le devant du corps de l'agneau et du porc. Le représentant des mânes les reçoit, les secoue, les offre aux mânes et les goûte. Le servant les reprend et les met sur les petites tables où sont les cours et les langues.

Le premier servant apporte deux vases d'argile contenant, l'un, de la viande d'agneau hachée ou coupée en petits morceaux, l'autre, de la viande de porc semblablement préparée. Il apporte aussi un vase d'argile contenant de la viande hachée conservée dans le sel et le vinaigre. Il place ces vases d'argile au nord des vases de bois qui contiennent des conserves de viande. Le représentant des mânes mange de nouveau. Il mange de la viande hachée. Le premier servant lève et lui offre un poisson. Le représentant des mânes reçoit le poisson, le secoue, l'offre aux mânes et le goûte. Le servant reprend le poisson, et le met en travers sur la petite table sur laquelle sont le cour et la langue.

Le représentant des mânes mange de nouveau. Le premier servant lève et lui offre l'épaule droite du quadrupède séché. Le représentant des mânes la reçoit, la secoue, l'offre aux mânes et la goûte. Le premier servant la reprend et la met sur la petite table sur laquelle sont le coar et la langue.

• ${ }_{601}$ Le représentant des mânes mange de nouveau. Le premier servant lève et lui sert la partie inférieure d'un membre posté rieur de l'agneau et du porc. Les cérémonies sont les mêmes que précédemment.

Le représentant des mânes se dit rassasié. L’invocateu r, le visage tourné vers l'ouest, au côté méridional du chef de la maison, seul, l'engage à manger encore. Sans le saluer, il l'invite en ces termes :

- L'auguste représentant des mânes n'est pas repu. Je l'invite à manger encore.

Le représentant des mânes mange de nouveau. Le premier servant lève et lui présente l'épaule de l'a gneau et l'épaule du porc. Le représentant des 
mânes les reçoit, les secoue, les offre aux mânes et les goûte. Le servant les reprend et les met sur la petite table sur laquelle sont le coar et la langue.

Le représentant des mânes ne mange plus. Il dit qu'il est rassasié. L'invocateur, le visage tourné vers l'ouest, est au côté méridional du chef de la maison. Le chef de la maison, sans rien dire, salue à genoux le représentant des mânes pour l'engager à manger. Celui -ci mange encore trois fois. Le premier servant reçoit des mains du représentant des mânes les poumons et les côtelettes du milieu du dos de l'agneau et $\bullet_{602}$ du porc, et les met sur la petite table avec le cour et la langue.

$\mathbf{O}$ Le chef de la maison descend et rince une coupe. Il monte; le visage tourné vers le nord, il verse du vin dans la coupe, et l'offre au représentant des mânes pour qu'il se rince la bouche. Celui-ci salue à genoux et reçoit la coupe. Le chef de la maison salue à genoux le représentant des mânes qui a bien voulu recevoir la coupe. Le représentant des mânes offre le vin aux mânes et le goûte.

Le plus respectable des étrangers lui apporte le foie de l'agneau et le foie du porc sur une petite table, Il présente la petite table dans le sens de la longueur. Il présente aussi les foies dans le sens de la longueur, la plus petite extrémité en avant. Il met du sel à droite. Le représentant des mânes, tenant la coupe de la main gauche, prend les deux foies ensemble de la main droite, et les trempe dans le sel qui est sur la petite table. Il les secoue, les offre aux mânes, les goûte, et les met dans le vase de bois qui contient les légumes salés. Il vide la coupe (boit tout le vin). Le chef de la maison le salue à genoux. Le représentant des mânes donne sa coupe à l'invocateur, et rend le salut à genoux au chef de la maison.

- ${ }_{603}$ L'invocateur verse du vin dans la coupe et la donne au représentant des mânes. Celui-ci la reçoit, et offre à boire à son tour au chef de la maison. Le chef de la maison salue à genoux et reçoit la coupe. Le représentant des mânes lui rend le salut. Le chef de la maison, le visage tourné vers l'ouest, dépose la coupe, et de nouveau salue à genoux. Le premier servant prend quatre vases contenant du millet glutineux et du millet non glutineux. Le second servant prend des poumons d'agneau et des poumons de porc qui ont été incisés. Il les donne au premier servant. Le premier servant donne le millet et les poumons, sans les lever, au chef de la maison, afin quil les offre aux mânes. Le chef de la maison, tenant la coupe de la main gauche, reçoit de la main droite ce que le servant lui donne. A genoux, il l'offre aux mânes. Il leur offre aussi le vin. Sans se lever, il goûte le vin.

L'invocateur et les deux servants sortent de la salle, et se lavent les mains auprès des cruches. Ils rentrent dans la salle. Les deux servants prennent du millet glutineux chacun dans un vase. Le premier servant prend à la fois ces deux portions de millet, et en fait une boulette, qu'il donne au représentant des mânes. Celui-ci, tenant en main la boulette de millet, parle à ${ }_{604}$ l'invocateur au nom des mânes. - Quand il a fini de parler à l'invocateur, l'invocateur, après l'avoir entendu, tourne le visage vers le nord -est, à l'ouest de la porte de 
la salle, et transmet au chef de la maison, les paroles, les promesses de prospérité des mânes.

Il lui dit :

- L'auguste représentant des mânes m'ordonne, à moi officier invocateur, de vous promettre de la part des mânes des faveurs nombreuses et sans fin, à vous petit-fils respectueux. Approchezvous, petit-fils respectueux. Les mânes vous feront recevoir les bienfaits du ciel. Ils rendront fructueux vos travaux dans les champs. Ils vous obtiendront une longue vieillesse, dix mille années de vie. Ils vous continueront leurs faveurs sans interruption.

Le chef de la maison fléchit les genoux, dépose la coupe et se lève. Il salue deux fois à genoux, inclinant la tête jusqu'à terre. Il se lève, reçoit la boulette de millet glutineux, fléchit les genoux, secoue la boulette, l'offre aux mânes et la goûte. Il chø la presse sur sa poitrine, la met dans sa manche gauche, et l'y retient avec son petit doigt. Tenant la coupe, il se lève. il fléchit le genoux et vide la coupe. Tenant la coupe, il se ${ }_{605}$ lève. Fléchissant les genoux, il la dépose et salue à genoux. Le représentant des mânes lui rend le salut à genoux, Le chef de la maison prend la coupe, se lève et sort de la salle. Linten dant reçoit dans un vase de bambou la boulette de millet glutineux, $c h \bullet$ pronostic de bonnes récoltes. Le chef de la maison la goûte de nouveau et la remet dans le vase de bambou.

$\mathbf{O}$ Le chef de la maison offre à boire à l'invocateur, dont la natte est tournée vers le sud. L'invocateur salue à genoux sur sa natte. (Il se lève), fléchit les genoux et reçoit la coupe. Le chef de la maison, le visage tourné vers l'ouest, lui rend le salut à genoux. On apporte à l'invocateur deux vases de bois, dont l'un contient des légumes salés (des mauves), et l'autre de la chair d'escargots conservée dans le sel et le vinaigre.

Un servant place devant l'invocateur une petite table sur laquelle sont les parties suivantes d'un agneau et d'un porc : les os du bassin, une côtelette prise au bas du dos, une courte côte prise sur le devant du corps, un intestin, un estomac. Sur la petite table il y a aussi trois morceaux de viande pris avec la peau sur le devant du corps du porc, un poisson placé transversalement, deux os du bassin attenant à l'extrémité de l'épine dorsale du quadrupède séché. Linvocateur prend les légumes $\bullet_{606}$ salés, les trempe dans la saumure de la chair d'escargots, les offre aux mânes dans l'intervalle laissé entre les vases de bois. Il leur offre ce qui est sur la petite table. Il leur offre le vin, et le goûte. Arrivent ensuite le foie de l'agneau et le foie du porc. (Il faut lire lâ̂ $k \bullet n)$. Linvocateur prend les foies, les trempe dans le sel, les secoue, les offre aux mânes et les goûte. Sans se lever, il les met sur la petite table. Il vide la coupe et se lève.

$\mathbf{O}$ Le chef de la maison verse du vin dans une coupe et offre à boire au premier servant. Le premier servant, dans la salle près de la porte, à l'est de la fenêtre, le visage tourné vers le nord, salue à genoux. A genoux, il reçoit la 
coupe. Le chef de la maison, le visage tourné vers l'ouest, lui rend le salut à genoux. Le servant offre le vin aux mânes, le boit et salue à genoux. A genoux, il rend la coupe au chef de la maison et se lève. Une petite table est placée pour lui entre les deux rangées de degrés. Sur cette petite table sont des membres divisés de l'agneau et du porc, et un morceau de viande pris avec sa peau sur le devant du corps du porc.

Le chef de la maison offre aussi à boire au second servant, de la même manière. Une petite table est aussi placée pour le second servant entre les deux rangées de degrés, à l'est de celle $\bullet_{607}$ du premier servant. Sur cette petite table sont aussi les membres divisés de l'agneau et du porc, et un morceau de viande pris avec sa peau sur le devant du corps du porc.

O Un aide du maître des cérémonies prend une coupe dans une corbeille, monte les degrés, et donne la coupe à une aide de la maîtresse de la maison entre la porte de la salle et le bâtiment latéral. Cette femme reçoit la coupe et la donne à la maîtresse de la maison. La maîtresse de la maison rince la coupe dans le bâtiment latéral, sort, verse du vin dans la coupe, entre dans la salle ; le visage tourné vers l'ouest, elle salue à genoux le repré sentant des mânes et lui offre à boire. Celui-ci salue à genoux et reçoit la coupe. La maîtresse de la maison, au nord du chef de la maison, le visage tourné vers l'ouest, salue à genoux le représentant des mânes qui a reçu la coupe. Le représentant des mânes offre le vin aux mânes et vide la coupe. La maîtresse de la maison le salue à genoux. L'invocateur reçoit la coupe du représentant des mânes. Celui-ci rend le salut à genoux à la maîtresse de la maison.

L'invocateur prend une autre coupe, la rince, y verse du vin, et la donne au représentant des mânes. (Celui-ci la présente à la maîtresse de la maison). La maîtresse de la maison le salue $\bullet_{608}$ à genoux et reçoit la coupe. Le représentant des mânes lui rend le salut à genoux. Le premier servant de table apporte du millet glutineux qui doit être offert aux mânes. La maîtresse de la maison, le visage tourné vers l'ouest, au nord du chef de la maison, reçoit cette offrande et la présente aux mânes. Elle leur présente le millet avec les mêmes cérémonies que le maître de la maison le leur a présenté. L'invocateur ne lui exprime pas de promesses de félicité. Elle vide la coupe et salue à genoux. Le représentant des mânes lui rend le salut à genoux.

La maîtresse de la maison sort de la salle avec la coupe. Une aide reçoit cette coupe. Elle prend une autre coupe dans une corbeille, et la donne à lai maîtresse de la maison dans le bâtiment latéral. La maîtresse de la maison rince la coupe, y verse du vin et offre à boire à l'invocateur. Linvocateur salue à genoux, (se lève), fléchit les genoux et reçoit la coupe. La maîtresse de la maison, au nord du chef de la maison, rend le salut à genoux. L'invoca teur vide la coupe, et sans se lever, à genoux, rend la coupe à la maîtresse de la maison.

La maîtresse de la maison reçoit la coupe, y verse du vin, et offre à boire au premier servant dans la salle près de la porte. ${ }_{609}$ Le servant, le visage tourné vers le nord, salue à genoux, (se lève), fléchit les genoux et reçoit la 
coupe. La maîtresse de la maison, le visage tourné vers l'ouest, lui rend le salut à genoux. Le servant offre le vin aux esprits et le boit. A genoux, il rend la coupe à la maîtresse de la maison. Celle-ci offre à boire au second servant, de la même manière qu'au premier servant. Ensuite elle reçoit la coupe et rentre dans le bâtiment latéral.

$\mathbf{O}$ Le plus respectable des étrangers rince une coupe et offre à boire au représentant des mânes. Le représentant des mânes salue à genoux et reçoit la coupe. L'étranger, dans la salle à l'ouest de la porte, le visage tourné vers le nord, salue à genoux le représentant des mânes qui a reçu la coupe. Le représentant des mânes offre le vin aux mânes et le boit tout entier. L'é tranger le salue à genoux. Linvocateur reçoit la coupe du représentant des mânes. Celui-ci rend le salut à genoux à l'étranger.

L'invocateur verse du vin dans la coupe, et la donne au représent ant des mânes. (Celui-ci offre à boire à l'étranger). L'é tranger salue à genoux et reçoit la coupe. Le représentant des mânes salue à genoux l'étranger qui a reçu la coupe. L'étranger, à genoux, dépose la coupe, (se lève), puis salue à genoux. Il reprend la coupe et se lève. Il fléchit les genoux, offre le vin aux mânes et le boit. Après avoir vidé la coupe, la tenant dans ${ }^{\circ}{ }_{610}$ la main, il se lève. Il fléchit les genoux, dépose la coupe et salue à genoux. Le représentant des mânes lui rend le salut à genoux.

L'étranger verse du vin dans la coupe et offre à boire à l'in vocateur. Linvocateur le salue à genoux. (Il se lève), fléchit les genoux et reçoit la coupe. L'étranger, le visage tourné vers le nord, rend le salut à genoux. L'invocateur offre le vin aux mânes et le goûte. Il dépose la coupe sur le devant de sa natte.

$\mathbf{O}$ Le chef de la maison sort de la salle, et se tient debout au haut des degrés orientaux, le visage tourné vers l'ouest. L'invocateur sort aussi, et se tient debout au haut des degrés occidentaux, le visage tourné vers l'est. Il avertit le chef de la maison en ces termes :

— Les offrandes sont terminées.

L'invo cateur entre dans la salle. Le représentant des mânes se lève. Le chef de la maison descend, et se tient debout à l'est des degrés orientaux, le visage tourné vers l'ouest. L'invocateur marche en avant ; le représentant des mânes le suit. Tous deux sortent du temple.

O Linvocateur revient; il reprend sa place dans la salle du temple. Le chef de la maison rentre aussi dans la salle et retourne à sa place, L'invocateur dit aux servants d'enlever les ${ }_{611}$ petites tables sur lesquelles sont le cour et la langue de l'agneau et du porc. Les servants descendent avec les tables, et les mettent au bas de la plateforme, au sud des degrés orientaux.

Le maître du palais dispose quatre nattes, deux à deux, pour les quatre hommes qui mangeront les restes du représentant des mânes. Le premier servant se lave les mains et monte les degrés. Le second servant se place 
devant lui. Les deux étrangers les plus respectables complètent le nombre des quatre qui mangeront les restes. Un chef d'officier présente un vase de millet glutineux au premier servant, et un autre au second servant. Il place ces vases à la droite des servants, sur leurs nattes. Il apporte et place du millet glutineux aux deux extrémités de la petite table sur laquelle est la chair de l'agneau. Ce millet est pour les deux étrangers, qui hià forment la deuxième paire de ceux qui mangent les restes avec eux.

Le chef des officiers lève et présente à chacun des quatre un morceau de viande pris avec la peau sur le devant du corps du porc. Ceux qui mangent les restes offrent tous aux mânes le millet glutineux ; puis le morceau de viande de porc qui leur a été présenté. Le chef de la maison, le visage tourné vers l'ouest, salue à genoux trois fois en commun ceux qui mangent $\bullet_{612}$ les restes. Ceux-ci déposent les morceaux de viande de porc sur les petites tables, et à leur tour saluent tous à genoux le chef de la maison. Puis ils reprennent les morceaux de viande de porc.

Le chef des officiers apporte aux deux servants qui mangent les restes un vase à couvercle contenant une sauce ou un ragoût ; il apporte un autre vase semblable aux deux étrangers qui forment la deuxième paire de ceux qui mangent les restes. Il apporte aussi aux deux étrangers deux vases de bois contenant de la viande juteuse. Les deux servants et les deux étrangers mangent tous. Ils mangent la viande de porc. Quand ils ont fini de manger, le chef de la maison rince une coupe, monte les degrés, verse du vin dans la coupe, et la donne au premier des quatre qui mangent les restes, c'est-à-dire, au premier servant de table. Des aides rincent trois coupes et y versent du vin. Le chef de la maison reçoit ces trois coupes dans la salle près de la porte, et les donne aux trois autres qui mangent les restes. Ainsi chacun des quatre a sa coupe. Chacun d'eux reçoit sa coupe sans saluer. Le chef de la maison, le visage tourné vers l'ouest, les salue à genoux trois fois en commun. Tous quatre ${ }_{613}$ déposent leurs coupes, saluent à genoux à leur tour le chef de la maison. Ils offrent tous le vin aux mânes, le boivent, déposent leurs coupes et saluent à genoux. Le chef de la maison à son tour les salue à genoux une seule fois en commun. Trois d'en tre eux se lèvent et sortent de la salle.

Le premier d'entre eux, c'est -à-dire, le premier servant de table, demeure dans la salle. Le chef de la maison reçoit la coupe de ce servant, et y verse du vin, pour boire lui-même à son tour, dans la salle près de la porte, le visage tourné vers l'ouest. Il fléchit les genoux, dépose la coupe, et salue à genoux. Le premier servant lui rend le salut à genoux. Le chef de la maison fléchit les genoux, offre le vin aux mânes et le goûte.

Le premier servant (sans l’inte rmédiaire de l'invocateur) exprime luimême des promesses de bonheur en ces termes :

- Le chef de la maison, en récompense de ses offrandes, recevra les faveurs du ciel. Il aura une vie longue. Il conservera et affermira sa famille et sa maison. 
Le chef de la maison se lève, fléchit les genoux, dépose la coupe et salue à genoux. Il prend la coupe, se lève, fléchit les genoux, boit tout le vin et salue à genoux. Le premier servant lui rend le salut à genoux, se lève et sort de la salle. Le chef de la maison l'accompagne.

- ${ }_{614}$ Le premier servant retourne à sa place parmi les étrangers, et le chef de la maison retourne à la sienne dans la salle. 


\section{CHAPITRE XVII}

\section{Le maître de cérémonie enlève les offrandes}

$\mathbf{O} \cdot{ }_{615}$ Le maitre des cérémonies enlève les comestibles qui sont dans la salle du temple. Il fait balayer la plateforme qui est devant la salle. Le maitre du palais accommode le vin, réchauffe les mets qui ont été servis sur les petites tables du représentant des mânes. Quand il les a réchauffés, il met la chair de l'agneau, du porc et des poissons dans trois chaudières. Il ne prend pas de viande séchée, ni de morceaux de viande coupée avec la peau sur le devant du corps du porc. Alors il dispose les leviers et les couvertures des chaudières. Il range les chaudières en dehors de la grande porte du temple, comme précédemment.

Ensuite il délibère avec le plus respectable des invités sur le choix de celui qui tiendra compagnie au représentant des mânes. Ce compagnon doit être choisi parmi les étrangers qui portent un nom de famille différent de celui du chef de la maison. Le maître des cérémonies avertit dans le temple celui qui a été choisi pour être ce compagnon. Celui-ci sort et attend ${ }_{616}$ en dehors de la grande porte du temple.

O Le maître du palais étend une natte pour le représentant des mânes hors de la salle, à l'ouest de la porte ; il la tourne vers le midi. Il étend une autre natte pour le compagnon du représentant des mânes auprès du bâtiment situé à l'ouest de la plateforme ; il la tourne vers l'est.

O Le représentant des mânes et son compagnon, le visage tourné vers le nord, sont en dehors de la grande porte du temple, le plus respectable des deux au côté occidental de l'autre. Le chef de la maison sort et va au devant du représentant des mânes. Il prend pour intermédiaire le maître des cérémonies. Il salue à genoux le représentant des mânes, qui lui rend le salut. Il salue aussi à genoux le compagnon, qui lui rend également le salut. Le chef de la maison fait une inclination profonde, et entre le premier par le côté droit de la grande porte. Le représentant des mânes entre par le côté gauche de la grande porte. Son compagnon le suit, et entre aussi par le côté gauche.

(En trois endroits différents), le chef de la maison les salue par une inclination profonde, et veut leur céder le pas. Il marche en avant et monte par les degrés orientaux. Le représentant des mânes et son compagnon montent par les degrés occidentaux, $\bullet_{617}$ et se tiennent à l'ouest de la colonne occidentale, le visage tourné vers le nord, le plus respectable des deux à l'est de l'autre. Le chef de la maison, à l'est de la colonne orientale, le visage tourné vers le nord, salue à genoux l'arrivée du repré sentant des mânes. Celui- 
ci lui rend le salut à genoux. Le chef de la maison salue aussi à genoux le compagnon. Le compagnon lui rend le salut.

O Ensuite on porte les chaudières. Le commandant (avec un aide) porte celle qui contient la viande d'agneau. Les chefs d'offi ciers portent celle qui contient la viande de porc, et celle qui contient les poissons. Ces porteurs entrent dans le temple, avec ces chaudières, et les rangent comme précédemment (au bas des degrés orientaux). Le chef de cuisine, tenant une cuiller, les suit. A sa suite marche un aide du chef de cuisine, tenant en main deux cuillers ; après lui, un chef d'officiers, portant à la fois deux petites tables; enfin un aide du chef des officiers, portant aussi à la fois deux petites tables. Une cuiller est mise sur chaque chaudière, le manche tourné vers l'est. Deux petites tables sont placées à l'ouest de la chaudière qui contient la viande d'agneau ; elles sont placées en longueur de l'ouest à l'est. Les deux autres petites tables sont placées à l'ouest des deux $\bullet{ }_{618}$ autres chaudières aussi de l'ouest à l'est dans le sens de la longueur.

Un cuisinier porte à la fois deux petites tables, et les range à l'ouest de la petite table sur laquelle est la viande d'agneau. Il les met à côté l'une de l'autre, de l'ouest à l'est dans le sens de la longueur. Sur chacune des deux petites tables il met une cuiller sculptée, tournée à l'envers, placée dans le sens de la longueur de la petite table, le manche tourné vers l'ouest.

$\mathbf{O}$ Le chef de la maison descend, pour recevoir de lintendant un escabeau (et le donner au représentant des mânes). Le représentant des mânes et son compagnon descendent aussi pour lui faire honneur. Le chef de la maison refuse cet honneur. Le représentant des mânes lui répond. L’intendant donne l'escabeau. Le chef de la maison le prend des deux mains, le tient transversalement, et salue par une inclination profonde le représentant des mânes. Le chef de la maison monte les degrés. Le représentant des mânes et son compagnon aussi. Tous trois retournent à leurs places

Le chef de la maison, le visage tourné vers l'ouest, tient l'escabeau de la main gauche, droit devant lui. De la manche droite de sa tunique, qu'il pousse en avant et retire en arrière, il essuie l'escabeau trois fois. Il le pren d des deux mains dans le ${ }_{619}$ sens de la largeur, et le présente au représentant des mânes devant la natte de celui-ci.

Le représentant des mânes s'avance et reçoit l'escabeau entre les deux mains tournées l'une vers l'autre. Le chef de la maison se retire. Le représentant des mânes tourne l'escabeau droit devant lui dans le sens de la longueur, et tient de la main droite l'extrémité extérieure. Le visage tourné vers le nord, il le dépose sur sa natte, à gauche, du sud au nord dans le sens de la longueur. Il ne fléchit pas les genoux pour le déposer. Le chef de la maison, à l'est de la colonne orientale, le visage tourné vers le nord, salue à genoux. Le représentant des mânes retourne à sa place. Son compagnon et lui, le visage tourné vers le nord, rendent le salut au chef de la maison. 
O Le chef de la maison descend pour rincer une coupe. Le représentant des mânes descend avec son compagnon, et le prie de ne pas rincer de coupe pour lui. Le chef de la maison lui répond. Quand la coupe a été rincée, il monte les degrés. Le représentant des mânes monte aussi avec son compagnon. A l'ouest de la colonne occidentale, le visage tourné vers le nord, il salue à genoux le chef de la maison pour le remercier d'avoir rincé ou fait rincer la coupe. Le chef de la maison, à l'est de ${ }_{620}$ la colonne orientale, le visage tourné vers le nord, dépose la coupe, et rend le salut à genoux.

Il descend pour se laver les mains. Le représentant des mânes descend aussi avec son compagnon. Le chef de la maison le prie de ne pas lui faire l'honneur de descendre. Le repré sentant des mânes lui répond. Le chef de la maison, après s'être lavé les mains, salue par une inclination profonde et monte les degrés. Le représentant des mânes et son compagnon montent aussi. Le chef de la maison, à genoux, prend la coupe. Il y verse du vin, et offre à boire au représentant des mânes. Celui-ci, le visage tourné vers le nord, salue à genoux et reçoit la coupe. Le chef de la maison, à l'est de la colonne orientale, le visage tourné vers le nord, salue à genoux le représentant des mânes qui tient la coupe dans la main.

O La maîtresse de la maison sort du bâtiment situé au côté oriental, et apporte des poireaux salés, de la viande hachée conservée dans le sel et le vinaigre. A genoux, elle les dépose devant la natte du représentant des mânes. Elle place les poireaux salés à l'ouest. Une aide de la maîtresse de la maison apporte des racines de jonc salées, de la viande hachée et conservée dans le sel et le vinaigre. Elle les donne à la maitresse de la maison. Celle-ci, sans se lever (restant à genou), reçoit ces deux mets, ${ }_{621}$ et les place vis-à-vis l'un de l'autre au sud. Elle place les racines de jonc à l'est du hachis.

Elle se lève, et prend des vases de bambou dans le bâtiment latéral ; ils contiennent du grain de blé cuit dans l'eau, du grain de chanvre cuit dans l'eau. A genoux, elle les place à l'ouest des vases de bois. Elle les range en dehors (loin des hîng vases qui contiennent des ragoûts). Elle met le grain de blé à l'est du grain de chanvre. Un e aide apporte, et donne à la maîtresse de la maison $\mathrm{p}^{\bullet}$ du riz cuit dans l'eau, h• du millet glu tineux cuit dans l'eau. La maitresse de la maison, sans se lever, les reçoit et les place au sud des vases de bambou servis précédemment. Elle met le riz à l'ouest du millet. Elle se lève et se retire dans le bâtiment latéral.

O Alors on met la viande sur les petites tables. Un maréchal avec une cuiller tire de la chaudière la viande de l'agneau ; un second maréchal la met sur les petites tables. Il met sur une première petite table les parties suivantes du côté droit de l'agneau : l'épaule, la partie inférieure du membre antérieur, la partie supérieure et la partie inférieure du membre postérieur, la partie supérieure du membre antérieur, une côte droite, une côte raide et une côte transversale prises toutes trois sur le dos, une côte courte, une côte régulière et une fausse côte prises toutes trois sur le devant du corps. Il y ajoute un 
intestin, un ${ }_{622}$ estomac, des poumons destinés à être offerts aux mânes. Il met toutes ces pièces sur une seule petite table.

Sur la petite table placée au sud, il met la viande d'agneau ; à savoir, la viande juteuse, un morceau de la partie supérieure du membre antérieur, une côte régulière prise sur le dos, une côte régulière prise sur le devant du corps, un intestin, un estomac, des poumons qui seront goûtés.

Un chef d'officiers avec une cuiller tire de la chaudière la viande du porc. Un autre chef d'officiers la met sur les petites tables. Il met aussi sur une première petite table les parties suivantes du côté droit du porc : l'épaule, la partie inférieure du membre antérieur, la partie supérieure et la partie inférieure du membre postérieur, la partie supérieure du membre antérieur ; une côte droite, une côte raide et une côte transversale prises toutes trois sur le dos de l'a nimal ; une côte courte, une côte droite et une fausse côte prises toutes trois sur le devant du corps de l'animal. Il y ajoute cinq morceaux de viande pris avec la peau sur le devant du corps du porc, et des poumons préparés pour être goûtés.

On met sur une petite table pour le compagnon du représentant des mânes les parties suivantes du côté gauche de l'agneau : l'épaule, la partie supérieure du membre postérieur, ${ }_{623}$ une côte droite prise sur le dos de l'animal, une côte prise sur le devant du corps. Ou y ajoute un intestin, un estomac, des poumons incisés. On met ces pièces sur une seule table. Sur une petite table pour le compagnon du représentant des mânes, on met les parties suivantes du côté gauche du porc : un morceau de l'épaule, une côte droite prise sur le dos de l'animal, une côte prise sur le devant du corps. On y ajoute trois morceaux de viande pris avec la peau sur le devant du corps, et des poumons incisés.

$\mathrm{Au}$ haut des degrés orientaux, pour le chef de la maison, on met sur une petite table deux poumons d'agneau, deux poumons préparés pour être offerts aux mânes. On lui met sur une deuxième petite table la viande juteuse de l'agneau, la partie inférieure d'un membre antérieur, une côte prise sur le dos de l'agneau, une côte prise sur le devant du corps, trois morceaux de viande pris avec la peau sur le devant du corps, un intestin, un estomac, des poumons préparés pour être goûtés. On lui met sur une troisième petite table de la viande de porc ; à savoir, la partie inférieure d'un membre ant érieur, une côte prise sur le dos de l'animal, une côte prise sur le devant du corps, trois morceaux de viande pris avec la peau sur le devant du corps, des poumons qui doivent être goûtés.

Pour la maîtresse de la maison, on met sur une petite table ${ }_{624}$ les parties suivantes du côté gauche d'un agneau : la partie supérieure du membre antérieur, une côte prise sur le dos de l'agneau, une côte prise sur le devant du corps. On y ajoute un intestin, un estomac, un morceau de viande pris avec la peau sur le devant du corps, des poumons destinés à être goûtés.

Un chef d'officiers avec une cuiller enlève les poissons de la chaudière. Un autre chef d'officiers les met sur les petites tables. Sur la petite table du 
représentant des mânes il met cinq poissons ; il les place transversalement. Il met un poisson sur la petite table du compagnon du représentant des mânes, et un autre sur la petite table du chef de la maison; il les place aussi transversalement. Il met en dessus le ventre des poissons; le ventre sera offert aux mânes.

O Quand les viandes et les poissons sont sur les petites tables, le plus respectable des étrangers place près du représentant des mânes, au sud des vases de bois, la petite table sur laquelle est la viande d'agneau. Il descend les degrés. Le représentant des mânes monte sur sa natte par le côté occidental, et fléchit les genoux. Tenant la coupe de la main gauche, il prend de la main droite les poireaux salés, les trempe dans la saumure des trois vases de bois, et les offre aux mânes dans l'intervalle laissé entre ces vases. Le représentant des mânes prend le grain de blé et le grain de chanvre. Un aide de l'intendant prend le ${ }_{625}$ grain de riz et de grain de millet glutineux, et les donne au représentant des mânes. Celui-ci offre tous ces grains aux mânes au milieu des offrandes contenues dans les vases de bois.

Un cuisinier donne une cuiller sculptée et une petite table à celui des étrangers qui est le deuxième parmi les plus respectables. Cet étranger les reçoit à l'ouest de la chaudière. Il tient de la main gauche la petite table par son extrémité gauche ; il la tient droit devant lui dans le sens de la longueur. Il tourne en bas le revers de la main droite, trend le manche de la cuiller, et la place sur la petite table dans le sens de la longueur. Il les reçoit ainsi des mains du cuisinier, le visage tourné vers l'est, à l'ouest de la chaudière qui contient la viande d'agnea u. Le maréchal, à l'est de cette chaudière, prend des deux mains le manche de la longue cuiller appelée $t^{\prime} i a^{\bullet}$, puise la sauce contenue dans la chaudière et la verse dans la cuiller sculptée ; cela, trois fois.

Le représentant des mânes se lève. Tenant la coupe de la main gauche, il prend les poumons de la main droite, et à genoux, les offre aux mânes. Il leur offre le vin. Il se lève, et tient la coupe de la main gauche. Le deuxième des plus respectables ${ }_{626}$ d'entre les étrangers prend la petite table, et la cuiller qui contient le jus de viande. Il les tient dirigées droit devant lui dans le sens de la longueur. Il monte et présente la cuiller au représentant des mânes. Celui-ci tourne en bas le revers de la main, et prend le manche de la cuiller. Il fléchit les genoux, offre aux mânes le jus de viande et le goûte. Il se lève, tourne en bas la paume de la main et présente la cuiller à l'étranger. L'étranger tourne aussi en bas la paume de la main, reçoit la cuiller, la place sur la petite table dans le sens de la longueur, et descend les degrés avec cette petite table.

Le représentant des mânes, à l'extrémité de sa natte, fléchit les genoux et goûte le vin. Il se lève, fléchit les genoux, dépose la coupe, salue à genoux et loue la bonté du vin. Il prend la coupe et se lève. Le chef de la maison, le visage tourné vers le nord, à l'est de la colonne orientale, lui rend le salut à genoux.

Le maréchal apporte de la viande juteuse d'agneau. Il tient la petite table dirigée droit devant lui dans le sens de la longueur. Le représentant des mânes 
fléchit les genoux et dépose la coupe. Il se lève, prend les poumons, fléchit les genoux, sépare les poumons à leur petite extrémité, les offre aux mânes et les goûte. Il se lève et remet les poumons sur la petite table. Le maréchal dépose cette table dans le sens de la longueur au sud $\bullet_{627}$ de celle sur laquelle est le jus de viande d'agneau. Il met les poumons sur celle-ci. Cela fait, il prend par les côtés la table vide et descend avec elle.

Le représentant des mânes fléchit les genoux, prend la coupe et se lève. Le deuxième des étrangers les plus respectables lui apporte de la viande d'agneau rôtie. Il tient la petite table dirigée en long devant lui. Un morceau de viande rôtie est placé sur la petite table dans le sens de la longueur. A droite il y a du sel. Le représentant des mânes, tenant la coupe de la main gauche, reçoit la viande rôtie, la trempe dans le sel, fléchit les genoux, secoue le morceau de viande, l'offre aux mânes et le goûte. Il se lève, et met la viande rôtie sur la petite table avec les autres parties de l'agneau. L'étranger prend la petite table, et la tenant dirigée en long devant lui, descend avec elle.

Le représentant des mânes quitte sa natte. Le visage tourné vers le nord, à l'ouest de la colonne occidentale, il fléchit les genoux et vide la coupe. Tenant la coupe, il se lève, fléchit les genoux, dépose la coupe et salue à genoux. Il prend la coupe et se lève. Le chef de la maison, le visage tourné vers le nord, à l'est de la colonne orientale, rend le salut à genoux. Il reçoit $\bullet_{628}$ la coupe. Le représentant des mânes monte sur sa natte et se tient à l'extrémité de cette natte.

O Le chef de la maison verse du vin dans une coupe, et l'offre au compagnon du représentant des mânes. Ce compagnon, à l'ouest de la colonne occidentale, le visage tourné vers le nord, salue à genoux et reçoit la coupe. Le chef de la maison, à sa droite, le visage tourné vers le nord, lui rend le salut à genoux. La maîtresse de la maison apporte des poireaux salés, de la viande hachée conservée dans le sel et le vinaigre. Elle fléchit les genoux et dépose ces comestibles devant la natte du compagnon du représentant des mânes. Elle met la viande hachée au sud des poireaux. Des femmes qui aident la maîtresse de la maison, lui donnent deux vases de bambou, dont l'un contient du grain de blé cuit, et l'autre du grain de chanvre cuit. La maîtresse de la maison les reçoit sans se lever. Elle place le grain de blé au sud de la viande hachée et le grain de chanvre à l'est du grain de blé. Ensuite elle entre dans le b âtiment latéral.

Le compagnon du représentant des mânes monte sur sa natte par le côté septentrional., Le maréchal prend par les deux ${ }_{629}$ extrémités une petite table sur laquelle est de la viande d'agneau, et monte les degrés. Il place la petite table à l'est des vases de bois. Le compagnon du représentant des mânes fléchit les genoux. Tenant la coupe de la main gauche, il prend les légumes salés de la main droite, les trempe dans la saumure de la viande hachée, les offre aux mânes entre les vases de bois. Ensuite il prend le grain de blé et le grain de chanvre, et les offre ensemble aux mânes, au milieu des offrandes contenues dans les vases de bois. Il se lève. Tenant la coupe de la main 
gauche, il prend les poumons de la main droite, et à genoux, les offre aux mânes. Il offre le vin aux mânes. Il se lève, tenant la coupe de la main gauche.

Le deuxième des étrangers les plus respectables lui apporte de la viande d'agneau rôtie, de la même manière qu'il en a servi au représentant des mânes. Le compagnon quitte sa natte par le côté septentrional. Le visage tourné vers le nord, à l'ouest des degrés occidentaux, il fléchit les genoux et vide la coupe, Tenant en main la coupe, il se lève. Il fléchit les genoux, dépose la coupe et salue à genoux. Le chef de la maison lui rend le salut à genoux.

O Le représentant des mânes reçoit la coupe des mains de ${ }_{630}$ son compagnon; il descend pour la rincer (et offrir à boire au chef de la maison). Son compagnon descend aussi et se tient debout à l'ouest des degrés occidentaux, le visage tourné vers l'est. Le chef de la maison descend par les degrés orientaux, et prie le représentant des mânes de ne pas rincer la coupe. Celui-ci fléchit les genoux et dépose la coupe dans une corbeille. Il se lève et répond au chef de la maison. Après que la coupe a été rincée par un aide, le chef de la maison monte les degrés. Le représentant des mânes monte par les degrés occidentaux. Le chef de la maison le salue à genoux, pour le remercier d'avoir fait rincer la coupe. Le représentant des mânes, le visage tourné vers le nord, à l'ouest de la colonne occidentale, fléchit les geno ux, dépose la coupe et rend le salut à genoux.

Il descend pour se laver les mains. Le chef de la maison descend aussi pour lui faire honneur. Le représentant des mânes le prie de ne pas lui faire cet honneur. Le chef de la maison lui répond. Quand le représentant des mânes a fini de se laver les mains, le chef de la maison monte les degrés. Le représentant des mânes monte aussi, fléchit les genoux, prend la coupe et y verse du vin. Le maître du palais étend une natte près du bâtiment situé à l'est de la plateforme; il la tourne vers l'ouest. Le chef de la maison, à l'est de la colonne orientale, le visage tourné vers le nord, salue à genoux et reçoit la coupe. Le ${ }_{631}$ représentant des mânes, à l'ouest de la colonne occidentale, le visage tourné vers le nord, lui rend le salut à genoux.

La maîtresse de la maison apporte des poireaux salés, de la viande hachée conservée dans le sel et le vinaigre. A genoux, elle dépose ces mets devant la natte du chef de la maison. Elle place des légumes salés au nord de la viande. Deux femmes qui l'aident lui présentent deux vases de bambou, dont l'un contient du grain de blé cuit, et l'autre du grain de chanvre cuit. La maîtresse de la maison les reçoit sans se lever; elle place le grain de blé au nord-est des légumes salés, et le grain de chanvre à l'ouest du grain de blé. Le chef de la maison monte sur sa natte par le côté septentrional. La maîtresse de la maison entre dans le bâtiment situé à côté de la salle.

Le plus vénérable des étrangers place à l'ouest des vases de b ois une petite table sur laquelle est de la viande d'agneau. Le chef de la maison fléchit les genoux, et tenant la coupe de la main gauche, il offre aux mânes le contenu des vases de bois et des vases de bambou, comme le compagnon du représentant des mânes l'a offert. Il se lève. Tenant la coupe de la main 
gauche, il prend les poumons de la main droite, et à genoux, les offre aux mânes. Il offre le vin aux mânes et se lève. Le deuxième des étrangers les plus vénérables lui présente du jus de $\bullet_{632}$ viande dans une cuiller, comme le représentant des mânes l'a fait. Le chef de la maison, à genoux à l'extrémité de sa natte, goûte le vin. Tenant la coupe dans la main, il se lève.

Le commandant lui apporte de la viande juteuse d'agneau, sur une petite table quil tient dirigée droit devant lui dans le sens de la longueur. Le chef de la maison fléchit les genoux et dépose la coupe à sa gauche. Il se lève, reçoit les poumons, fléchit les genoux, sépare les extrémités des poumons, les offre aux mânes et les goûte. Il se lève et remet les poumons sur la petite table sur laquelle est la viande. Le commandant dépose dans le sens de la longueur la petite table sur laquelle est le jus de viande à l'ouest de celle sur laquelle est la viande d'agneau ; puis il met sur cette dernière le jus de viande. Cela fait, il prend par les deux côtés la petite table qui est vide, et il descend avec elle.

Le chef de la maison fléchit les genoux, prend la coupe et se lève. Le deuxième des étrangers les plus respectables lui sert de la viande rôtie. Le maître de la maison la reçoit de la même manière que le représentant des mânes. Il quitte sa natte par le côté septentrional. Le visage tourné vers le nord, au haut des ${ }_{633}$ degrés orientaux, il fléchit les genoux et vide la coupe. Tenant en main la coupe, il se lève, Il fléchit les genoux, dépose la coupe et salue à genoux. Tenant en main la coupe, il se lève. Le représentant des mânes, à l'ouest de la colonne occidentale, lui rend le salut à genoux. Le chef de la maison fléchit les genoux et dépose la coupe au sud du bâtiment situé à l'est de la plateforme.

Le compagnon du représentant des mânes monte les degrés. Le représentant des mânes et son compagnon, tous deux le visage tourné vers le nord, se tiennent à l'ouest de la colonne occidentale. Le chef de la maison, le visage tourné vers le nord à l'est de la colonne orientale, les salue deux fois à genoux. Il dit quîl est rassasié de vin. (C'est son propre vin. Il veut faire entendre que ce vin n'est pas de bonne qualité, et qu'il ne désire pa s en boire davantage). Le représentant des mânes et son compagnon, à leur tour, le saluent deux fois à genoux. Le chef de la maison, le représentant des mânes et son compagnon montent tous trois les degrés et vont à leurs nattes.

$\mathbf{O}$ Le majordome prend une coupe dans une corbeille, et la donne à une aide, à l'est du bâtiment latéral ; l'aide la donne à la maîtresse de la maison. La maîtresse de la maison rince la $\bullet_{634}$ coupe dans le bâtiment latéral, sort et remplit la coupe. Au sud de l'amphore, le visage to urné vers le nord, elle salue à genoux le représentant des mânes et lui offre la coupe. Celui-ci la salue à genoux sur sa natte et reçoit la coupe. La maîtresse de la maison, le visage tourné vers l'ouest, au nord de la natte du chef de la maison, salue à genoux le représentant des mânes, après lui avoir donné la coupe. Elle entre dans le bâtiment latéral, prend un vase contenant de la viande d'agneau, fléchit les genoux, et dépose ce vase à l'ouest des poireaux salés. Une aide de la maîtresse de la maison la suit, tenant dans les mains un vase contenant de la 
viande de porc. La maîtresse de la maison, sans se lever, reçoit ce vase, et le place à l'ouest de celui qui contient la viande d'agneau. Elle se lève et entre dans le bâtiment latéral.

Elle prend un gâteau de riz, des tranches de viande aromatisées et séchées, et sort avec ces comestibles. A genoux, elle les dépose. Elle place le gâteau de riz à l'ouest du grain de chanvre, et les tranches de viande séchées à l'ouest du grain de riz. Elle se lève, et se tient debout au nord de la natte du maître de la maison, le visage tourné vers l'ouest. Le représentant des mânes fléchit les genoux. Tenant la coupe de la main gauche, il offre aux mânes le gâteau de riz et les $\bullet_{635}$ tranches de viande séchées, tout ensemble, au milieu des offrandes contenues dans les vases de bois.

Avec la cuiller placée sur le vase qui contient le ragoût de viande d'agneau, il puise ce ragoût ; ensuite il puise le ragoût de viande de porc. Il offre ces ragoûts aux mânes au milieu des offrandes contenues dans les vases de bois. Il offre le vin aux mânes. Le deuxième des étrangers les plus vénérables lui sert du jus de viande de porc dans une cuiller, de la même manière qu'il lui a servi du jus de viande d'agneau. Le représentant des mâ nes fléchit les genoux et goûte le vin. Prenant la coupe de la main gauche, il goûte le ragoût de viande d'agneau qui est dans le premier vase. Il se lève tenant la coupe en main. Il fléchit les genoux, dépose la coupe et salue à genoux. La maîtresse de la maison lui rend le salut à genoux. Le représentant des mânes prend la coupe et se lève.

Un chef d'officiers lui sert de la viande de porc. Le repré sentant des mânes fléchit les genoux, dépose la coupe, se lève, et reçoit la viande de porc de la même manière qu'il a reçu le jus de viande d'agneau. Il fléchit les genoux, prend la coupe et se lève. Le deuxième des étrangers les plus respectables lui sert de la viande de porc rôtie. Le représentant des mânes, tenant la ${ }_{636}$ coupe de la main gauche, prend la viande de porc rôtie de la même manière quil a pris la viande d'agneau rôtie. Il fléchit les genoux, vide la coupe et salue à genoux. La maîtresse de la maison lui rend le salut à genoux et reçoit la coupe.

O La maîtresse de la maison verse du vin dans une coupe, et offre à boire au compagnon du représentant des mânes. Celui-ci salue à genoux et reçoit la coupe. La maîtresse de la maison, au nord du chef de la maison. le visage tourné vers l'ouest, lui rend le salut à genoux. Elle lui sert un gâteau de riz et des tranches de viande séchées. A genoux, elle dépose le gâteau de riz au sud du grain de blé cuit, et les tranches de viande au sud du grain de chanvre cuit. Le compagnon du représentant des mânes fléchit les genoux. Tenant la coupe de la main gauche, il prend le gâteau de riz et les tranches de viande. Il les offre ensemble aux mânes au milieu des offrandes contenues dans les vases de bois.

Un chef d'officiers, tenant par les deux côtés une petite table sur laquelle est de la viande de porc, monte les degrés. Le compagnon du représentant des mânes se lève, prend les poumons, fléchit les genoux et offre aux mânes les 
poumons. Le chef d'officiers dépose la petite table sur laquelle est la viande de porc, dans le sens de la longueur, à l'est de la petite t able sur laquelle est la viande d'agneau. Il met la viande de $\bullet_{637}$ porc sur cette dernière table. Cela terminé, il prend la petite table vide par les deux côtés et descend avec elle. Le compagnon du représentant des mânes se lève.

Le deuxième des étrangers les plus respectables lui sert de la viande de porc rôtie. Le compagnon du représentant des mânes la reçoit de la même manière que le représentant des mânes. Il fléchit les genoux, vide la coupe et salue à genoux. La maîtresse de la maison lui rend le salut à genoux et reçoit la coupe.

O La maîtresse de la maison verse du vin dans une coupe, et donne la coupe au chef de la maison. Celui-ci, sur sa natte, salue à genoux et reçoit la coupe. La maîtresse de la maison, le visage tourné vers le nord, au haut des degrés orientaux, rend le salut à genoux. Elle place devant le chef de la maison des ragoûts de viande dans deux vases, un gâteau de riz et des tranches de viande séchées, de la même manière que pour le représentant des mânes. Le chef de la maison offre aux mânes le gâteau de riz et les tranches de viande tout ensemble. Il leur offre les ragoûts ; il leur offre le vin. Il reçoit du jus de viande de porc dans une cuiller. Il fléchit les genoux et goûte le vin. Le tout, comme le représentant des mânes. Il goûte les ragoûts. ${ }_{638} \mathrm{Il}$ ne salue pas. Il reçoit de la viande de porc cuite dans l'eau et de la viande de porc rôtie, aussi comme le représentant des mânes. Il fléchit les genoux, vide la coupe et salue à genoux. La maîtresse de la maison, le visage tourné vers le nord, lui rend le salut à genoux et reçoit la coupe.

$\mathbf{O}$ Le représentant des mânes quitte sa natte, reçoit la coupe que lui donne la maîtresse de la maison, et descend les degrés. Le chef de la maison descend. Le compagnon du représentant des mânes descend aussi. La maîtresse de la maison entre dans le bâtiment latéral. Le chef de la maison se tient debout au nord-est des cruches, le visage tourné vers l'ouest. Le compa gnon du représentant des mânes, le visage tourné vers l'est, est au sud-ouest des degrés occidentaux. Le représentant des mânes prend une autre coupe dans une corbeille, se lave les mains et rince cette autre coupe.

Le chef de la maison salue par une inclination profonde le représentant des mânes et son compagnon. Il monte les degrés. Le représentant des mânes monte par les degrés occidentaux. Son compagnon le suit. Le chef de la maison, le visage tourné vers le nord, se tient debout à l'est de la colonne orientale. Le compagnon du représentant des mânes se tient debout à l'ouest de la colonne occidentale, le visage tourné vers le nord.

• ${ }_{639}$ Le représentant des mânes verse du vin dans une coupe. La maîtresse de la maison sort du bâtiment latéral. Le visage tourné vers l'ouest, elle salue à genoux et reçoit la coupe. Le représentant des mânes, le visage tourné vers le nord, à l'est de son compagnon, rend le salut à genoux. La maîtresse de la maison rentre dans le bâtiment latéral. Le majordome dispose une natte dans 
le bâtiment latéral ; il la tourne vers le midi. La maîtresse de la maison se tient debout à l'ouest de cette natte.

Une aide apporte des poireaux salés, de la viande hachée conservée dans le sel et le vinaigre. A genoux, elle les dépose devant la natte de la maîtresse de la maison, les légumes salés à l'ouest de la viande. Une deuxième aide (la femme du maître des cérémonies) apporte du grain de blé cuit et du grain de chanvre cuit, les donne à la première aide. Celle-ci les reçoit sans se lever. Elle place le grain de blé à l'ouest des légumes salés, et le grain de chanvre au sud du grain de blé.

La maîtresse de la maison monte sur sa natte. Le commandant place au sud des vases de bois une petite table sur laquelle est de la viande d'agneau. La maîtresse de la maison fléchit les genoux. Tenant la coupe de la main gauche, elle prend les $\bullet_{640}$ légumes salés de la main droite, les trempe dans la saumure de la viande hachée, et les offre aux mânes entre les vases de bois. Elle prend aussi le grain de blé et le grain de chanvre, et les offre ensemble aux mânes au milieu des offrandes contenues dans les vases de bois. Elle dépose la coupe et se lève. Elle prend les poumons, fléchit les genoux, sépare les deux extrémités des poumons, les offre aux mânes et les goûte. Elle se lève et met les poumons sur la petite table. Elle fléchit les genoux, s'essuie les mains, offre le vin aux mânes et le goûte.

Le deuxième des étrangers les plus vénérables lui sert de la viande d'agneau rôtie. Elle se lève, et reçoit la viande rôtie, de la même manière que le maître de la maison l'a reçue. Tenant en main la coupe, elle sort du bâtiment latéral. Le visage tourné vers l'ouest, au nord de la natte du chef de la maison, debout, elle vide la coupe. Tenant la coupe en main, elle salue à genoux. Le représentant des mânes, à l'ouest de la colonne occidentale, le visage tourné vers le nord, lui rend le salut à genoux. La maîtresse de la maison rentre dans le bâtiment latéral. Le représentant des mânes, le chef de la maison et le compagnon du représentant des mânes retournent à leurs nattes.

$\mathbf{O} \cdot{ }_{641}$ Le plus vénérable des étrangers rince une coupe et monte les degrés. Il verse du vin dans la coupe et l'offre au représentant des mânes. Celui-ci le salue à genoux et reçoit la coupe. L'étranger, à l'ouest de la colonne occidentale, le visage tourné vers le nord, le salue à genoux après lui avoir donné la coupe. Le représentant des mânes dépose la coupe à l'ouest des mets qui lui ont été servis. L'étranger descend.

$\mathbf{O}$ Le chef de la maison descend pour rincer une coupe. Le représentant des mânes et son compagnon descendent aussi. Le chef de la maison dépose la coupe dans une corbeille et réclame contre cet honneur. Le représentant des mânes lui répond. Quand la coupe a été rincée, le chef de la maison salue par une inclination profonde. Le représentant des mânes monte les degrés. Son compagnon ne monte pas. Le chef de la maison emplit la coupe, pour offrir à boire de nouveau au représentant des mânes. A l'est de la colonne orientale, le visage tourné vers le nord, il fléchit les genoux, dépose la coupe, et salue à genoux. Le représentant des mânes, à l'ouest de la colonne occidentale, le 
visage tourné vers le nord, lui rend le salut à genoux. Le chef de la maison fléchit les genoux, offre le vin aux mânes, puis il le boit (pour donner l'exemple). Après av oir vidé la coupe, il salue à genoux. Le représentant des mânes lui rend le salut à genoux.

- ${ }_{642}$ Le chef de la maison descend pour rincer la coupe. Le représentant des mânes descend aussi, et le prie de ne pas rincer la coupe. Le chef de la maison dépose la coupe dans une corbeille et répond. Quand la coupe a été rincée, le chef de la maison monte les degrés. Le représentant des mânes monte aussi. Le chef de la maison emplit la coupe. Le représentant des mânes le salue à genoux et reçoit la coupe. Le chef de la maison retourne à sa place et rend le salut à genoux. Le représentant des mânes, le visage tourné vers le nord, fléchit les genoux et dépose la coupe à gauche des mets qui lui ont été servis, Le représentant des mânes, son compagnon et le maître de la maison montent tous trois sur leurs nattes.

Ensuite viennent des mets exquis, L'intendant prend des mets exquis préparés dans le bâtiment latéral, et les sert au représentant des mânes, à son compagnon, au chef de la maison, à la maîtresse de la maison. Il les place à leur côté droit. Un chef d'officiers sert différents mets ordinaires au représentant des mânes, à son compagnon, au chef de la maison, à la maîtresse de la maison. Il les place à leur côté gauche.

$\mathbf{O}$ Le chef de la maison descend les degrés. Le visage ${ }_{643}$ tourné vers le midi, il salue à genoux la foule des étrangers, à l'est de la grande porte. Il les salue en commun trois fois. Les étrangers, à l'est de la grande porte, le visage tourné vers le nord, à leur tour le saluent tous à genoux une fois. Le chef de la maison prend une coupe pour la rincer. Le plus vénérable des étrangers le prie de ne pas rincer la coupe. Le chef de la maison dépose la coupe dans une corbeille, se lève et répond. Quand la coupe a été rincée, le chef de la maison monte les degrés, verse du vin dans la coupe, et l'offre à cet étranger au haut des degrés occidentaux. Le plus vénérable des étrangers monte les degrés, salue à genoux et reçoit la coupe. Le chef de la maison, à son côté droit, le visage tourné vers le nord, lui rend le salut à genoux.

L’intendant, sortant du bâtiment latéral, apporte à cet étranger des tranches de viande séchées, et de la viande hachée conservée dans le sel et le vinaigre ; il met la viande hachée à l'ouest des tranches de viande. Un chef d' officier place une petite table au nord des vases de bois. Sur cette petite table il y a la partie inférieure d'un membre postérieur d'un agneau, un intestin, un estomac, des poumons incisés, un morceau de viande pris avec la peau sur le devant du corps. L'étranger $\bullet{ }_{644}$ fléchit les genoux. Tenant la coupe de la main gauche, il prend de la main droite une tranche de viande séchée, la trempe dans la saumure de la viande hachée et l'offre aux mânes. Tenant la coupe dans la main, il se lève. Il prend les poumons, fléchit les genoux et offre les poumons aux mânes. Il leur offre le vin; puis il le boit. Après avoir vidé la coupe, la tenant en main, il se lève. Il fléchit les genoux, dépose la coupe et salue à 
genoux. Il prend la coupe et se lève. Le chef de la maison lui rend le salut à genoux et reçoit la coupe.

L'étranger, à genoux, prend la tranche de viande séchée et les poumons qu'il a offerts aux mânes, et il descend les degrés. Le visage tourné vers l'ouest, à genoux, il dépose ces offrandes au sud-ouest des degrés occidentaux. L'intendant le suit, portant les tranches de viande séchées et la viande hachée conservée dans le sel et le vinaigre ; il place ces mets à l'est des offrandes. Un chef d'officiers prend la petite table, et marchant à sa suite, la place à l'est des tranches de viande séchées et de la viande hachée.

Le plus respectable de la foule des étrangers monte les degrés, salue à genoux et reçoit la coupe. Le chef de la maison lui rend le salut à genoux. L'étranger fléchit les genoux et offre ${ }_{645}$ le vin aux mânes. Il se lève et debout boit le vin. Après avoir vidé la coupe, il ne salue pas à genoux pour remercier celui qui la lui a présentée. Le maître de la maison, aidé par l'inten dant, verse du vin dans une coupe, et offre à boire à chacun des étrangers. Tous les étrangers reçoivent la coupe. Le maître de la maison leur sert des tranches de viande séchées, de la viande hachée conservée dans le sel et le vinaigre, et de la viande mise sur de petites tables. Il leur sert ces mets à leurs places. Ces étrangers sont rangés à la suite du plus respectable d'entre eux, du sud au nord ; ils ont tous le visage tourné vers l'est. On sert sur les petites tables les parties osseuses de l'agneau, par respect.

O Ensuite on fait monter le plus respectable des étrangers. Le chef de la maison verse du vin dans une coupe, pour boire à son tour en présence de cet étranger, au haut des degrés occidentaux, le visage tourné vers le nord. L'étranger est à sa gauche. Le chef de la maison fléchit les genoux, dépose la coupe et salue à genoux. Il prend la coupe et se lève. L'étranger lui rend le salut à genoux. Le chef de la maison fléchit les genoux, offre la vin aux mânes et le boit. Après avoir vidé la coupe, il se lève avec la coupe dans la main. Il fléchit les genoux, dépose la coupe et salue à genoux. L'étranger lui rend le salut à genoux puis descend les degrés.

O Lintendant rince une coupe et monte les degrés, Le chef $\bullet{ }_{646}$ de la maison reçoit cette coupe, y verse du vin, descend les degrés, et offre à boire une deuxième fois au plus respectable des étrangers, au sud des degrés occidentaux, le visage tourné vers le nord. Cet étranger est à sa gauche. Le chef de la maison fléchit les genoux, dépose la coupe et salue à genoux. L'étranger lui rend le salut à genoux. Le chef de la maison fléchit les genoux, offre le vin aux mânes, puis le boit. Après avoir vidé la coupe, il salue à genoux. L'étranger lui rend le salut à genoux ?

$\mathbf{O}$ Le chef de la maison veut rincer une coupe. L'étranger le prie de ne pas la rincer. Le chef de la maison, à genoux, la dépose dans une corbeille et répond. Après que la coupe a été rincée par un aide, le chef de la maison monte les degrés, verse du vin dans la coupe, descend et retourne à sa place. L'étranger salue à genoux et reçoit la coupe. Le chef de la maison salue à 
genoux son départ avec la coupe. L'étranger, le visage tourné vers l'ouest, fléchit les genoux, et dépose la coupe à gauche des tranches de viande séchées et de la viande hachée conservée dans le sel et le vinaigre

$\mathbf{O}$ Le chef de la maison rince une coupe, monte les degrés, verse du vin dans la coupe, et offre à boire à tous les membres de sa famille, au haut des degrés orientaux. Le plus respectable de ses parents monte les degrés, salue à genoux et reçoit ${ }_{647}$ la coupe. Le chef de la maison, à sa droite, lui rend le salut à genoux. Ce parent fléchit les genoux, offre le vin aux mânes, se lève et boit debout. Il ne salue pas à genoux après avoir bu. La même cérémonie a lieu ensuite pour chacun des autres parents sans exception.

Tous sans exception, ils reçoivent la coupe. Ils sont placés à l'est des cruches, le visage tourné vers l'est ; rangés du nord au sud par ordre d'âge ou de dignité. Par ordre, l'un après l'autre, ils montent les degrés et reçoivent la coupe. On sert de la viande sur une petite table à chacun d'eux à sa place. Aux plus âgés d'entre eux, on sert sur une petite table les membres séparés d'un porc, une côte prise sur le devant du corps de l'animal, un morceau de viande pris avec la peau sur le devant du corps. Les parents sont tous traités avec honneur, chacun selon leur dignité.

$\mathbf{O}$ Le chef de la maison rince unie coupe, et offre à boire aux femmes étrangères dans le bâtiment latéral. Chacune d'elle, le visage tourné vers le sud, salue à genoux et reçoit la coupe. Le chef de la maison, le visage tourné vers le sud, à la droite de l'étrangère, lui rend le salut à genoux. L'étrangère fléchit les genoux, offre le vin aux mânes, se lève et boit debout. Elle ne salue pas après avoir bu. Cette même cérémonie se répète pour chacune d'elles sans exception. On sert aussi à chacune de la viande sur une petite table.

$\mathbf{O} \cdot{ }_{648}$ Le chef de la maison descend, rince une coupe, et offre à boire aux officiers de sa maison, au haut des degrés orientaux. Le plus respectable de ces officiers salue à genoux au bas des degrés, monte et reçoit la coupe. Le chef de la maison lui rend le salut à genoux. Cet officier descend, fléchit les genoux, offre le vin aux mânes, se lève et boit debout. Il ne salue pas après avoir bu. Tous les autres officiers reçoivent la coupe de la même manière. Pour verser le vin dans la coupe, le chef de la maison est aidé par son intendant. Il ne rend pas le salut à la foule de ses officiers. (Il ne le rend qu'au plus respectable d'entre eux). Ces officiers se placent au sud des parents du chef de la maison. Ils se rangent comme eux du nord au sud, par ordre de dignité. On sert aussi à chacun de la viande sur une petite table. Le chef de la maison retourne à sa natte au haut des degrés orientaux.

O Le plus respectable des étrangers offre à boire au représentant des mânes pour la troisième fois. Un chef d'officie rs lui sert des poissons dans une sauce. Il monte les degrés, tenant dans les mains les poissons placés droit devant lui sur une petite table. Le représentant des mânes prend le ventre des poissons qui a été coupé pour être offert aux mânes. Il le leur offre. Il leur offre le vin et vide la coupe. 
- ${ }_{649}$ Le chef d'officiers place la petite table sur laquelle sont les poissons au sud de celle sur laquelle est la viande d'agneau; chø il la place longitudinalement, côté contre côté. Il met les poissons transversalement sur la petite table sur laquelle est la viande d'agneau. Puis il descend avec la table vide, en la tenant par les deux côtés. Le représentant des mânes dépose la coupe et salue à genoux. Celui qui lui a offert la coupe pour la troisième fois, le visage tourné vers le nord, lui rend le salut à genoux, et reçoit la coupe.

O Le plus respectable des étrangers verse du vin et offre à boire pour la troisième fois au compagnon du représentant des mânes. Le compagnon le salue à genoux et reçoit la coupe. Celui qui lui offre à boire pour la troisième fois, le visage tourné vers le nord, lui rend le salut à genoux. Le commandant lui sert des poissons dans la sauce, comme on en a servi au représentant des mânes. Le compagnon vide la coupe et salue à genoux. Celui qui lui a offert la coupe pour la troisième fois lui rend le salut à genoux et reçoit la coupe.

O Le plus respectable des étrangers verse du vin dans une coupe, et le présente au chef de la maison. Celui-ci salue à genoux et reçoit la coupe. Celui qui lui a offert la coupe pour la troisième fois, à lest de la colonne orientale, le visage tourné vers le nord, lui rend le salut à genoux. Un chef d'officiers lui ${ }_{650}$ sert un poisson dans une sauce, comme au représentant des mânes. Le chef de la maison vide la coupe et salue à genoux, Celui qui lui a offert la coupe pour la troisième fois lui rend le salut à genoux et reçoit la coupe.

O Le représentant des mânes quitte sa natte, reçoit la coupe de l'étranger qui lui a offert à boire pour la troisième fois, et $\mathrm{y}$ verse du vin, pour lui offrir à boire à son tour. Cet étranger, à l'ouest de la colonne occidentale, le visage tourné vers le nord, salue à genoux avant de recevoir la coupe. Le représentant des mânes, à son côté droit, lui donne la coupe, monte sur sa propre natte, le visage tourné vers le sud, rend le salut à genoux. L'étranger fléchit les genoux, offre le vin aux mânes, puis le boit. Après avoir vidé la coupe, il salue à genoux. Le représentant des mânes lui rend le salut à genoux. L'étranger prend la coupe, descend et la met dans une corbeille.

O Deux hommes rincent des coupes, montent les degrés et versent du vin dans ces coupes. A l'ouest de la colonne occiden tale, le visage tourné vers le nord, le plus respectable à l'est de l'autre, ils fléc hissent les genoux, déposent leurs coupes, saluent à genoux, prennent leurs coupes et se lèvent. Le représentant ${ }_{651}$ des mânes et son compagnon leur rendent le salut à genoux. Ces deux hommes fléchissent les genoux, offrent le vin aux mânes, puis ils le boivent. Après avoir vidé leurs coupes, tenant ces coupes en mains, ils se lèvent. Ils fléchissent les genoux, déposent les coupes et saluent à genoux. Le représentant des mânes et son compagnon leur rendent le salut à genoux. Ces deux hommes descendent les degrés.

Ils rincent leurs coupes, montent les degrés, versent du vin dans leurs coupes et retournent à leurs places. Le représentant des mânes et son compagnon saluent à genoux et reçoivent les coupes. Ceux qui leur ont 
présenté les coupes saluent ensuite ces deux dignitaires. Le compagnon dépose sa coupe à son côté droit, (il ne boit pas).

Ensuite le représentant des mânes prend la coupe et se lève. Le visage tourné vers le nord, au haut des degrés orientaux, il offre à boire une seconde fois au chef de la maison, qui est à sa droite. Il fléchit les genoux, dépose la coupe et salue a genoux. Le chef de la maison lui rend le salut à genoux. Le représentant des mânes n'offre pas le vin aux mânes. Il se lève et boit debout. Il vide la coupe, et ne salue pas après l'avoir vidée. Il verse du vin dans la coupe, et va au haut des degrés orientaux offrir à boire une seconde fois au chef de la maison. Le chef de la maison salue à genoux et reçoit la coupe. Le • ${ }_{652}$ représentant des mânes salue ensuite à genoux. Il retourne à sa natte.

Le chef de la maison offre à boire de nouveau au compagnon du représentant des mânes, à l'ouest de la colonne occidentale. Il a ce compagnon à sa gauche. Il fléchit les genoux, dépose la coupe et salue à genoux. Il prend la coupe et se lève. Le compagnon lui rend le salut à genoux. Le chef de la maison n'offre pas le vin aux mânes ; il se lève et boit debout. Après avoir vidé la coupe, il ne salue pas celui qui la lui a offerte. Il verse du vin dans la coupe, (la présente au compagnon) et retourne à sa place. Le compagnon salue à genoux et reçoit la coupe. Le chef de la maison accompagne d'un salut la réception de la coupe.

Ensuite il fait monter le plus respectable des étrangers. Le compagnon du représentant des mânes offre à boire de nouveau à cet étranger, comme le chef de la maison le lui a offert à lui-même. Ensuite la coupe est offerte à la foule des étrangers, puis à tous les parents du chef de la maison, de la même manière. (Chacun d'eux présente la coupe au suivant). Ils boivent tous au haut des degrés occidentaux.

Ensuite la coupe est offerte aux officiers particuliers du chef de la maison. Chacun d'eux, après avoir salué au bas des degrés $\bullet{ }_{653}$ celui qui a reçu la coupe avant lui, monte les degrés, reçoit la coupe, descend les degrés, et boit au bas des degrés. Chacun d'eux après avoir vidé la coupe, monte les degrés, verse du vin dans la coupe, (la présente au suivant) et retourne à sa place. Ils s'offrent ainsi à boire tous mutuellement. Celui qui boit le dernier met la coupe dans une corbeille.

O Ensuite on sert différents mets aux étrangers, aux parents du chef de la maison, aux femmes étrangères, aux officiers particuliers, au chef de la maison.

$\mathbf{O}$ Le plus jeune des parents du chef de la maison offre à boire au plus âgé des parents. Il rince une coupe, monte les degrés, verse du vin dans la coupe, descend, et le visage tourné vers le nord, se tient debout au sud des degrés orientaux. Le plus âgé des parents est à sa gauche. Le jeune parent fléchit les genoux, dépose la coupe et salue à genoux. Il prend la coupe et se lève. Le plus âgé des parents lui rend le salut à genoux. Le jeune parent fléchit les genoux, offre le vin aux mânes, puis le boit. Après avoir vidé la coupe, la 
tenant dans la main, il se lève. Il fléchit les genoux, dépose la coupe et salue à genoux. Il prend la coupe et se lève. Le plus âgé des parents lui rend le salut à genoux. Le jeune parent rince la coupe, monte les degrés, verse du vin dans la coupe et descend. Le plus âgé des ${ }_{654}$ parents salue à genoux, reçoit la coupe à sa place. Celui qui lui a présenté la coupe, le visage tourné vers l'est, lui rend le salut à genoux. La coupe est mise au repos.

O Le deuxième des plus respectables des étrangers offre à boire au représentant des mânes comme précédemment. On ne lui sert pas de jus de viande. La coupe continue à être présentée. Un des étrangers offre la coupe au représentant des mânes, comme précédemment. Ensuite on offre encore à boire à tous ceux qui lui sont d'un rang inférieur, jusqu'aux officiers parti culiers de la maison. Les étrangers et les parents se croisent. Ils s'offrent à boire mutuellement, tous, les uns aux autres. Ensuite viennent les officiers particuliers du chef de la maison. Le nombre de fois que la coupe est offerte n'est pas limité.

Le représentant des mânes s'en va. Son compagnon le suit. Le chef de la maison les accompagne jusqu'au dehors de la grande porte du temple. Il salue à genoux le représentant des mânes. Celui-ci ne tourne pas la tête et ne le regarde pas. Le chef de la maison salue à genoux le compagnon du représentant des mânes et le plus respectable des étrangers. Il en est encore de même (ces deux personnages ne tournent pas même la tête). Tous les autres étrangers les suivent. Un chef d'officiers envoie chez le représentant des mânes et chez son compagnon les petites $\bullet_{655}$ tables et les viandes qui leur ont été servies. Le chef de la maison se retire dans ses appartements. Le maître des cérémonies enlève tous les comestibles. Si le chef de la maison (est un grand préfet du dernier rang et) traite le représentant des mânes avec moins d'honneur, l'invocateur sert de compagnon à celui -ci ; les cérémonies restent encore les mêmes.

O Le représentant des mânes mange. On met sur de petites tables les parties suivantes d'un agneau et d'un porc : la partie supérieure et la partie inférieure d'un membre antérieur, la partie supérieure d'un membre postérieur, une côte raide et une côte transversale prises sur le dos, une côte courte et une fausse côte prises sur le devant du corps. On lui sert sept poissons. On lui sert un lièvre séché entier, moins la hanche.

Quand les petites tables ont été préparées, on offre au représentant des mânes une épaule de l'agneau et une épaule du porc. Le représentant des mânes les reçoit, les secoue, les offre aux mânes et les goûte. Le servant de table les reçoit, et les dépose sur les petites tables sur lesquelles sont le cœur et la langue. Le servant prend une petite table au bas de la plateforme, et la porte dans la salle. Il la place à l'est de celle sur laquelle est la viande d'agneau. Il prend (quatre des) poissons et (cinq des) morceaux de viande séchée qui sont sur l'une des petites tables. ${ }_{656}$ Il laisse sur la petite table trois poissons. Il prend les autres pièces, c'est-à-dire, quatre poissons et cinq morceaux de viande séchée, les met ensemble sur la petite table qu'il a apportée, et les 
emporte dehors. Les poissons et les morceaux de viande séchée qui seront servis à l'invocateur et au chef de la maison seront pris sur cette petite table.

Le représentant des mânes ne mange plus. Il dit qu'il est rassasié. Le chef de la maison le salue à genoux pour l'engager à manger ; il ne lui parle pas. Le représentant des mânes mange encore trois fois. Le servant reçoit des poumons et les côtes de l'agneau et du porc) qui ont été servis au représentant des mânes. Il les reçoit avec tout l'honneur qu'on rend à un hôte.

Le chef de la maison rince une coupe, y verse du vin, et l'offre au représentant des mânes, afin que celui-ci boive pour se rincer la bouche. Un étranger sert le foie des deux animaux au représentant des mânes, avec tout l'honneur qu'on rend à un hôte. Quand le représentant des mânes a vidé la coupe, le chef de la maison le salue à genoux. L'invocateur reçoit la coupe du représentant des mânes. Celui-ci rend le salut à genoux.

Linvocateu r verse du vin dans une coupe, et donne cette coupe au représentant des mânes. Celui-ci prend la coupe et offre à boire à son tour au chef de la maison; cela aussi avec $\bullet_{657}$ tout 1 'honneur qu'on fait à un hôte. Le chef de la maison donne les offrandes au représentant des mânes, sans les lever. Le représentant des mânes lui promet les faveurs du ciel, aussi avec l'honneur qu'on fait à un hôte, Le chef de la maison offre à boire à l'invocateur et aux deux servants de table, à leurs places. Il leur présente de la viande sur de petites tables, avec l'honneur qu'on fait à des hôtes.

La maîtresse de la maison rince une coupe et offre à boire au représentant des mânes, aussi avec 1 honneur qu'on fait à un hôte. Elle retourne dans le bâtiment latéral, et prend des vases de bambou qui contiennent des jujubes et des galettes faites de grain grillé. Tenant ces vases dans les mains, elle fléchit les genoux. Elle place les jujubes au sud du millet non glutineux, et les galettes au sud des jujubes. Une aide apporte des châtaignes et des tranches de viande séchées. La maîtresse de la maison, sans se lever, les reçoit, et place les châtaignes à l'est des galettes, et les tranches de viande à l'est des jujubes. Elle se lève et retourne à sa place. Le représentant des mânes, tenant la coupe de la main gauche, prend les jujubes et les galettes. L'invocateur prend les châtaignes et les tranches de viande, et les donne au représentant des mânes. Celui-ci offre ensemble tous ces comestibles aux mânes au milieu des offrandes $\bullet{ }_{658}$ contenues dans les vases de bois. Il leur offre le vin et le goûte.

Le deuxième des étrangers les plus respectables lui sert sur de petites tables de la viande rôtie d'agneau et de porc. A droite il met du sel. Le représentant des mânes prend les deux sortes de viande rôtie, les trempe dans le sel, les secoue, les offre aux mânes et les goûte. L'invocateur les reçoit, et les met sur les petites tables sur lesquelles sont le cour et la langue. Après que le représentant des mânes a vidé la coupe, la maîtresse de la maison le salue à genoux. Linvocateur reçoit la coupe du représentant des mânes. Celui -ci rend le salut à genoux.

L'invocateur prend une autre coupe, la rince, y verse du vin et la donne au représentant des mânes. Celui-ci la reçoit, et offre à boire à son tour à la 
maîtresse de la maison. La maîtresse de la maison, au nord du chef de la maison, salue à genoux et reçoit la coupe. Le représentant des mânes lui rend le salut à genoux. La maîtresse de la maison retourne à sa place, et salue de nouveau à genoux. Le premier servant de table lui présente les offrandes sans les lever. Elle est traitée avec tout l'honneur qu'on fait à un hôte. Après avoir vidé la coupe, elle salue à genoux. Le représentant des mânes lui rend le salut à genoux.

$\mathbf{O} \cdot{ }_{659}$ La maîtresse de la maison offre à boire à l'invocateur. Elle lui verse du vin avec tout l'honneur qu'on rend à un hôte. Linvocateur la salue à genoux. A genoux, il reçoit la coupe. La maîtresse de la maison, au nord du chef de la maison, lui rend le salut à genoux. Lintendant sert à l'invocateur des jujubes et des galettes. Il fléchit les genoux, et place les jujubes à l'ouest des légumes salés, et les galettes au sud des jujubes. L'invocateur, tenant la coupe de la main gauche, prend les jujubes et les galettes. Il les offre aux mânes au milieu des offrandes contenues dans les vases de bois. Il offre le vin aux mânes et le goûte. Le deuxième des plus respectables d'entre les étrangers lui sert de la viande rôtie, comme au représentant des mânes. L’invocateur vide la coupe. La maîtresse de la maison reçoit la coupe, y verse du vin, et offre à boire aux dieux servants, avec tout l'honneur qu'on rend aux hôtes. Ensuite elle reçoit la coupe, et l'emporte dans le bâtiment latéral.

$\mathbf{O}$ Le plus respectable des étrangers rince une coupe, et offre à boire au représentant des mânes. Celui-ci le salue à genoux et reçoit la coupe. L'étranger, à l'ouest de la porte de la salle, le visage tourné vers le nord, rend le salut à genoux. La coupe est mise au repos.

$\mathbf{O} \cdot{ }_{660}$ La maîtresse de la maison rince une coupe dans le bâtiment latéral, $\mathrm{y}$ verse du vin et la présente au chef de la maison. Celui-ci la salue à genoux et reçoit la coupe. La maîtresse de la maison, à l'ouest de la porte de la salle, le visage tourné vers le nord, le salue à genoux après lui avoir donné la coupe. Le majordome dispose une natte pour le chef de la maison. La maîtresse de la maison lui sert des poireaux salés, et de la viande hachée conservée dans le sel et le vinaigre. Elle fléchit les genoux, et place ces comestibles devant la natte du chef de la maison. Elle met les légumes salés au nord de la viande. Une aide apporte ensuite des jujubes et des galettes. La maîtresse de la maison, sans se lever, les reçoit ; elle place les jujubes au nord des légumes salés, et les galettes à l'ouest des jujubes.

Les servants placent devant la natte du chef de la maison des petites tables sur lesquelles sont la partie inférieure d'un membre intérieur, une côte prise sur le dos, une côte prise sur le devant du corps et les poumons d'un agneau et d'un porc, trois mor ceaux de viande pris avec la peau sur le devant du corps du porc, un poisson, la partie inférieure d'un membre antérieur d'un quadrupède séché. Le chef de la maison, tenant la coupe de la main gauche, prend de la main droite les légumes salés, les trempe dans la saumure de la viande, et les offre aux mânes entre les vases de bois. 
• ${ }_{661}$ Ensuite il offre aux mânes le contenu des vases de bambou. Il dépose la coupe, se lève, prend les poumons de l'agneau et du porc, fléchit les genoux, sépare les petites extrémités des poumons, les offre aux mânes et les goûte. Il se lève, met les poumons sur les petites tables, fléchit les genoux, s'essuie les mains, et offre le vin aux mânes. Tenant la coupe, il se lève. Il fléchit les genoux, vide la coupe, et salue à genoux.

La maîtresse de la maison lui rend le salut à genoux. Elle reçoit la coupe, et y verse du vin, pour boire à son tour. Dans l'intérieur de la salle, près de la porte, le visage tourné vers le nord, elle salue à genoux. Le chef de la maison lui rend le salut à genoux. Elle vide la coupe et salue à genoux. Le chef de la maison lui rend le salut à genoux. La maîtresse de la maison entre avec la coupe dans le bâtiment latéral.

O Le représentant des mânes remet en circulation la coupe qui a été mise au repos. Il offre le vin aux mânes et vide la coupe. L'étranger qui lui a offert la coupe le salue à genoux. L'invocateur remplit la coupe. Le représentant des mânes rend le salut à genoux. L'invocateur verse du vin dans la coupe et la donne au représentant des mânes, (Celui-ci l'offre à l'étranger). L'étranger salue à genoux et reçoit la coupe. Le représentant des mânes le salue ensuite à genoux. L'étranger fléchit les ${ }_{662}$ genoux ; il offre le vin aux mânes, puis il le boit. Après avoir vidé la coupe, il salue à genoux. Le représentant des mânes lui rend le salut à genoux.

$\mathbf{O}$ Le plus respectable des étrangers offre à boire à l'invo cateur et aux deux servants de table.

Le plus respectable des étrangers rince une coupe et l'offre au chef de la maison. Celui-ci, devant sa natte, salue à genoux et reçoit la coupe. L'étranger, le visage tourné ve rs le nord, lui rend le salut à genoux. Le chef de la maison fléchit les genoux, offre le vin aux mânes, puis le boit. Après avoir vidé la coupe, il salue à genoux. L'étranger lui rend le salut à genoux et reçoit la coupe.

$\mathbf{O}$ Le plus respectable des étrangers verse du vin dans une coupe, et offre cette coupe à la maîtresse de la maison. La maîtresse de la maison est sur la partie septentrionale de la plateforme. Le majordome a disposé pour elle une natte, dont il a tourné le devant vers l'est. La maîtresse de la maison, au nord de cette natte, le visage tourné vers l'est, salue à genoux et reçoit la coupe. L'étranger, le visage tourné vers l'ouest, lui rend le salut à genoux.

Une aide lui sert des poireaux salés, de la viande hachée ${ }_{663}$ conservée dans le sel et le vinaigre. Elle place les légumes salés au sud de la viande. Une deuxième aide apporte des jujubes et des galettes ; elle les donne à la première aide. La première, sans se lever, les reçoit. Elle place les jujubes au sud des légumes salés et les galettes à l'est des jujubes.

Un servant de table place des petites tables à l'est des vases de bois. Sur ces tables sont la partie supérieure d'un membre intérieur d'un agneau, une 
partie d'un membre d'un porc, une côte prise sur le dos et une côte prise sur le devant du corps d'un agneau, les poumons d'un porc pour les offrir aux mânes, un morceau de viande pris avec la peau sur le devant du corps du porc, un poisson, la partie supérieure d'un membre anté rieur d'un quadrupède séché. La maîtresse de la maison monte sur sa natte et fléchit les genoux. Tenant la coupe de la main gauche, elle prend de la main droite les légumes salés, les plonge dans la saumure de la viande et les offre aux mânes. Elle leur offre le contenu des vases de bambou. Elle dépose la coupe, se lève, prend les poumons, fléchit les genoux, sépare les poumons à leur petite extrémité, les offre aux mânes et les goûte. Elle se lève, met les poumons sur une petite table, fléchit les genoux, s'essuie les mains et offre le vin aux mânes. Elle prend la coupe et se lève. Debout, au nord de sa natte, le visage tourné vers l'est, elle vide la coupe et salue à genoux. L'étranger lui rend le salut à genoux et reçoit la coupe.

$\mathbf{O} \cdot{ }_{664}$ L'étranger prend une autre toute dans une corbeille, la rince et y verse du vin, pour boire lui-même à son tour en présence du chef de la maison. A l'ouest de la porte de la salle, le visage tourné vers le nord, il salue à genoux. Le chef de la maison lui rend le salut à genoux. L'étranger vide la coupe et salue à genoux. Le chef de la maison lui rend le salut à genoux. L'étranger descend les degrés avec la coupe et la met dans la corbeille.

O Ensuite on sert des mets exquis. L’intendant sert des mets préparés dans le bâtiment latéral, et un chef d'officiers sert différents autres mets, au représentant des mânes, à l’invocateur, au chef de la maison et à la maîtresse de la maison. Les mets préparés dans le bâtiment latéral sont placés à droite ; les autres mets sont placés à gauche.

$\mathbf{O}$ Le chef de la maison descend les degrés, salue à genoux la foule des étrangers, rince une coupe et leur offre à boire. Il leur fait servir de la viande sur de petites tables. Ces étrangers soit rangés par ordre à leurs places. Le chef de la maison leur offre à boire une deuxième fois, et il boit lui-même à son tour. Il les traite avec tout l'honneur qu'on rend aux hôtes.

Le chef de la maison rince une coupe, et offre à boire à ses $\bullet_{665}$ parents, aux femmes étrangères et à ses officiers particuliers, avec tout l'honneur qu'on rend à des hôtes. Ils se rangent à leurs places. On leur sert de la viande sur de petites tables, avec tout l'honneur qu'on rend à des hôtes. Cela fini, on sert des mets exquis aux étrangers, aux parents, aux femmes étrangères, aux officiers particuliers, à tous sans exception.

$\mathbf{O}$ Le plus respectable des étrangers offre à boire au représentant des mânes. Celui-ci lui offre à boire à son tour. Cet étranger offre à boire à l'invocateur. Il présente la coupe (au maître et à la maîtresse de la maison), qui à leur tour lui offrent à boire à lui-même. Il descend les degrés avec la coupe et la met dans la corbeille. Les étrangers et les parents se croisent; ils s'offrent à boire mutuellement, un à un. Le nombre des coupes qu'ils boivent n'est pas limité. Un servant rince une coupe et offre à boire au représentant 
des mânes. Le représentant des mânes boit à son tour. Le servant offre à boire à l’invocateur. L’invocateur reçoit la coupe, offre le vin aux mânes, le goûte et dépose la coupe.

O Le chef de la maison sort de la salle, et se tient debout au haut des degrés orientaux, le visage tourné vers l'ouest. L'invo cateur sort aussi, et se tient debout au haut des degrés occidentaux, le visage tourné vers l'est. Il dit au chef de la maison :

- ${ }_{666}$ Le service des mets et du vin est terminé,

c'est-à-dire, il ne reste plus autre chose à servir, le repas est terminé. Linvocateur entre dans la salle. Le chef de la maison descend les degrés, et se tient debout à l'est des degrés orientaux, le visage tourné vers l'oues t. Le représentant des mânes se lève. L'invocateur marche en avant. Le représentant des mânes le suit. Il sortent tous deux par la grande porte du temple.

Linvocateur retourne dans le temple et reprend sa place dans la salle. Il ordonne aux servants d'enl ever les petites tables du représentant des mânes. Les servants emportent ces petites tables hors de la grande porte du temple. Un officier les reçoit et les envoie à la résidence du représentant des mânes. On enlève aussi les petites tables qui ont été servies au chef de la maison.

O Ensuite on mange les restes, comme on le fait pour honorer les hôtes. Après que les restes ont été mangés, l'officier en chef ordonne d'enlever les mets, de les placer à l'angle nord-ouest de la salle, et de les tourner vers le sud, dans l'ordre dans lequel ils ont été servis. A droite on place les escabeaux; on les cache avec les nattes. On apporte une amphore dans la salle. Le majordome balaie la terre, et présente des offrandes ${ }_{667}$ aux mânes.

O Le chef de la maison sort de la salle, et se tient debout au haut des degrés orientaux, le visage tourné vers l'ouest. Linvocateur prend et emporte hors de la salle sa propre petite table. Il se tient debout au haut des degrés occidentaux, le visage tourné vers l'est. Le majordome ferme la fenêtre et la porte de la salle. L'invocateur avertit le chef de la maison que le service des mets et du vin est terminé. Il prend la petite table de l'invocateur et l'emporte hors de la grande porte du temple. Un officier la reçoit et l'envoie à la maison de l'invocateur. Tous les étrangers s'en vont. Le chef de la maison les salue à genoux, et les accompagne jusqu'au dehors de la grande porte du temple. Ensuite il rentre dans le temple. Les femmes enlèvent les mets (qui ont été servis à linvocate ur et les petites tables qui ont été servies dans le bâtiment latéral). Elles enlèvent les mets qui sont déposés dans la salle (à l'angle nord-ouest). 
I. Bonnet viril - II. Mariage - III. Visite - IV. Banquet - V. Tir de l'arc - VI. Banquet à la cour - VII. Grand tir de l'arc - VIII. Ambassades - IX. Repas donné à un grand préfet étranger - X. Visite à l'empereur XI. Vêtements de deuil - XII. Cérémonies à la mort d'un officier - XIII. Après les lamentations du soir Offrandes : XIV. Au retour de l'enterrement $-X V$. Une seule victime - XVI. Un agneau et un porc - XVII. Le maître de cérémonie 
Nom du document : i_li.doc

Dossier :

C:\CSS\Envoi021204\classiques

Modèle :

C:IWINDOWS $\backslash$ Application

DatalMicrosoft $\backslash$ Modèles\Normal.dot

Titre :

I-li, Cérémonial

Sujet :

série Chine

Auteur :

divers

Mots clés :

Chine antique, Chine classique, ethnologie de la Chine, mythologie chinoise, civilisation chinoise, religion chinoise, ancient China, anthropologie de la Chine, confucianisme, rites chinois, rituels chinois, cérémonial chinois, culte des ancêtres, prise d

Commentaires : iences_sociales/index.html

http://www.uqac.uquebec.ca/zone30/Classiques_des_sc

Date de création : $\quad$ 02/09/04 13:54

$\mathrm{N}^{\circ}$ de révision : $\quad 27$

Dernier enregistr. le : 04/12/04 12:30

Dernier enregistrement par : Pierre Palpant

Temps total d' édition52 Minutes

Dernière impression sur : $\quad$ 05/12/04 11:08

Tel qu' à la dernière impression

Nombre de pages : $\quad 309$

Nombre de mots : 129281 (approx.)

Nombre de caractères : 736903 (approx.) 